


\section{.}




C., Plinius Secundus

NATURAL HISTORY

\author{
OF \\ P L I N Y.
}

TRANSLATED,

WITH COPIOUS NOTES AND ILLUSTRATIONS

BY THE IATE

JOHN BOSTOCK, M.D., F.R.S.,

AND

H. T. RILEY, EsQ., B.A.,

LATE SCHOLAR OF CLARE HALL, CAMBRIDGE,

LONDON :

HENRY G. BOHN, YORK STREET, COVENT GARDEN. MDCCCLV. 
QH
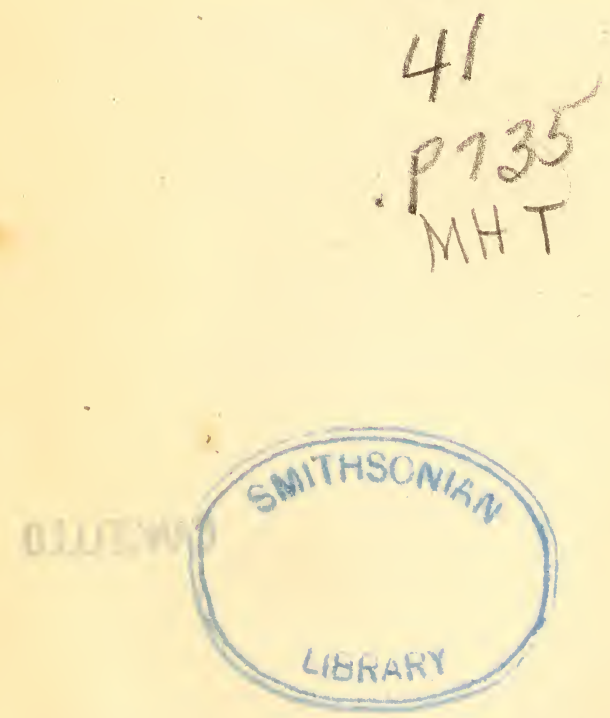


\section{5}

\section{CONTENTS.}

OF THE THIRD VOLUME.

\section{BOOK XI.}

THE VARIOUS KINDS OF INSECTS.

Chap.

1. The extreme smallness of insects .... Page

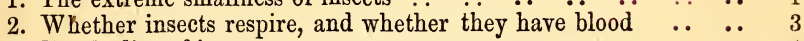

3. The bodies of insects $\ldots \begin{array}{llllllllll} & \ldots & \ldots & \ldots & \ldots & \ldots & \ldots & \ldots & \ldots & 4\end{array}$

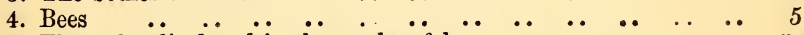

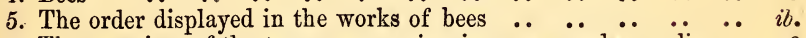

6. The meaning of the terms commosis, pissoceros, and propolis .. 6

7. The meaning of erithace, sandaraca, or cerinthos $\quad \ldots \quad \ldots \quad \ldots 7$

8. What flowers are used by the bees in their work $\quad \ldots \quad \ldots \quad \ldots \quad i b$.

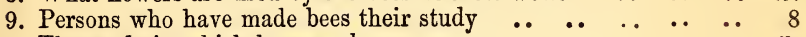

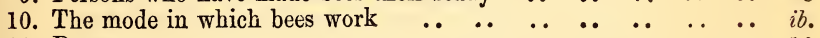

11. Drones ..

12. The qualities of honey $\ldots \begin{array}{llllllllll}\ldots & \ldots & \ldots & \ldots & \ldots & \ldots & \ldots & \ldots & \ldots & 11\end{array}$

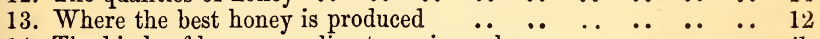

14. The kinds of honey peculiar to various places $\quad \ldots \quad \ldots \quad \ldots \quad \ldots \quad i b$.

15. How honey is tested. Ericæum. Tetralix, or sisirum .. .. 14

16. The reproduction of bees $\ldots \begin{array}{lllllllll} & \ldots & \ldots & \ldots & \ldots & \ldots & \ldots & \ldots & 16\end{array}$

17. The mode of government of the bees $\quad \ldots \begin{array}{llllllll} & \ldots & \ldots & \ldots & \ldots & \ldots & 18\end{array}$

18. Happy omens sometimes afforded by a swarm of bees $\ldots . \quad \ldots \quad 19$

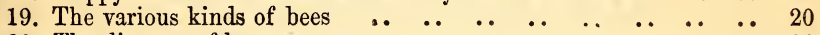

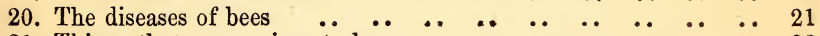

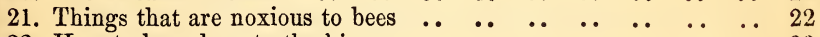

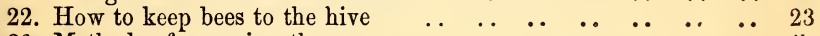

23. Methods of renewing the swarm $\ldots \begin{array}{lllllllll} & \ldots & \ldots & \ldots & \ldots & \ldots & \ldots & i b .\end{array}$

24. Wasps and hornets: animals which appropriate what belongs to

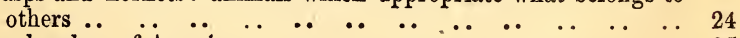

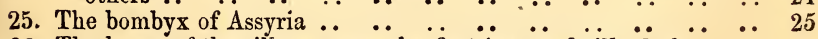

26. The larvæ of the silk-worm-who first invented silk cloths $\quad \ldots \quad i b$.

27. The silk-worm of Cos-how the Coan vestments are made $\quad . .26$

28. Spiders; the kinds that make webs; the materials used by them. in so doing 
Chap.

29. The generation of spiders Page

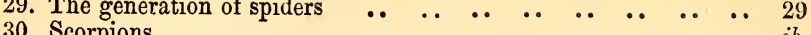

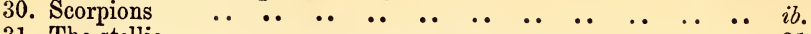

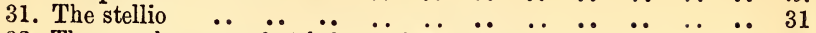

32. The grasshopper: that it has neither mouth nor outlet for food $i b$.

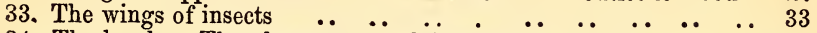

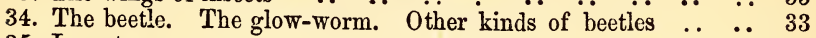

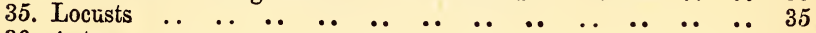

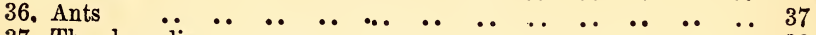

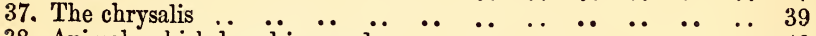

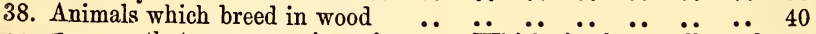

39. Insects that are parasites of man. Which is the smallest of

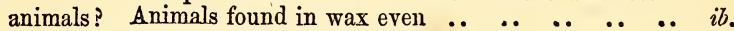

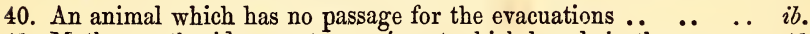

41. Moths, cantharides, gnats-an insect which breeds in the snow.. 41

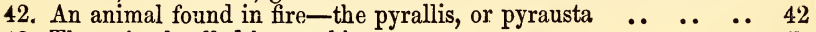

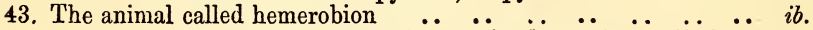

44. The nature and characteristics of all animals considered limb by

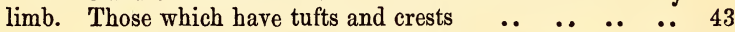

45. The various kinds of horns. Animals in which they are moveable 44

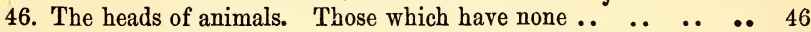

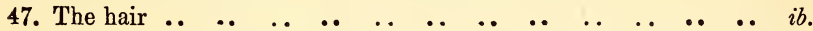

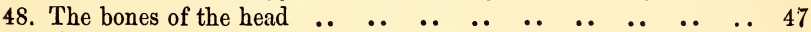

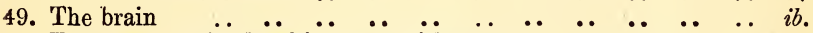

50. The ears. Animals which hear without ears or apertures .. $\quad . .448$

51. The face, the forehead, and the eye-brows $\ldots$..

52. The eyes-animals which have no eyes, or have only one eye $\ldots i b$.

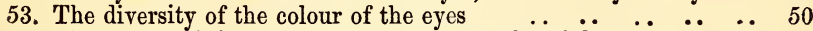

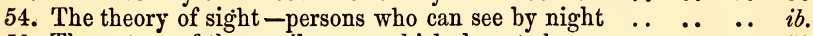

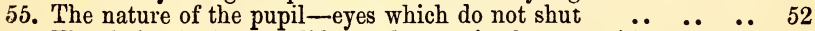

56. The hair of the eye-lids; what animals are without them. Animals which can see on one side only ..

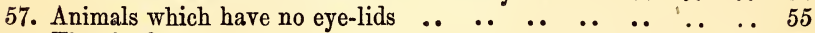

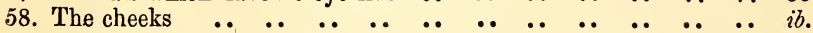

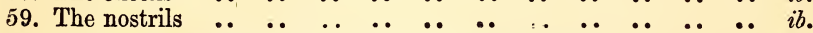

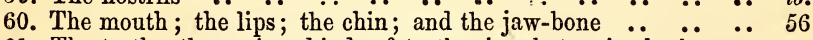

61. The teeth; the various kinds of teeth; in what animals they are not on both sides of the mouth: animals which have hollow teeth

62. The teeth of serpents; their poison. A bird which has teeth ..

63. Wonderful circumstances connected with the teeth .. ... ..

64. How an estimate is formed of the age of animals from their teeth

65. The tongue; animals which have no tongue. The noise made by frogs. The palate

66. The tonsils; the uvula; the epiglossis; the tracheal artery; the gullet

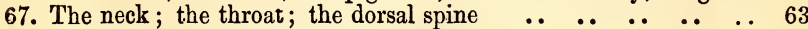

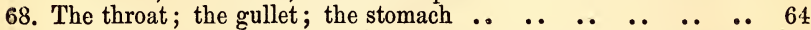

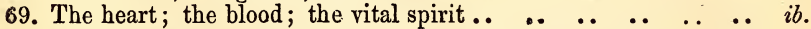

70. Those animals which have the largest heart, and those which have the smallest. What animals have two hearts ... ..

71 . When the custom was first adopted of examining the heart in

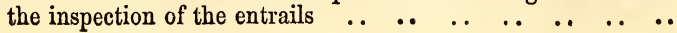


Chap.

72. The lungs : in what animals they are the largest, and in what the smallest. Animals which have nothing but lungs in the interior of the body. Causes which produce extraordinary

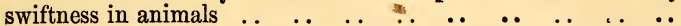

73. The liver; in what animals, and in what part there are two livers found

74. The gall; where situate, and $\ddot{i n}$ what animals it $\ddot{\text { is double. Ani- }}$ mals which have no gall, and others in which it is not situate in the liver

75. The properties of the gall $\quad \begin{array}{lllllllll} & \ldots & \ldots & \ldots & \ldots & \ldots & \ldots & \ldots & \ldots\end{array}$

76. In what animals the liver increases and decreases with the moon. Observations on the aruspices relative thereto, and remarkable prodigies

77. The diaphragm. The nature of laughte $\quad \begin{array}{lllll} & \cdots & \cdots & \cdots & \cdots\end{array}$ 78. The belly : animals which have no belly. "Which $\ddot{\text { are the only }}$ animals that vomit $\ldots \begin{array}{llllllllll} & \ldots & \ldots & \ldots & \ldots & \ldots & \ldots & \ldots & \ldots & 71\end{array}$

79. The small guts, the front intestines, the anus, the colon. The causes of the insatiate voracity of certain animals .. $\quad . \quad \ldots i b$.

80. The omentum : the spleen; animals which are without it .. 73

81. The kidneys : animals which have four kidneys. Animals which

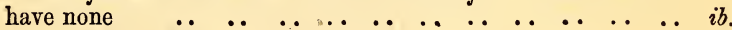

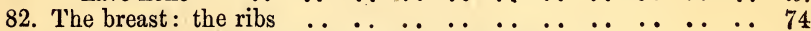

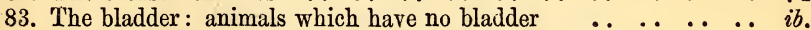

84. The womb: the womb of the sow : the teats $\ldots . . . .75$

85. Animals which have suet: animais which do not grow fat $\ldots i b$.

86. The marrow : animals which have no marrow $\ldots . . . . .76$

87. Bones and fish-bones: animals which have neither. Cartilages 77

88. The nerves : animals which have none $\ldots \ldots \ldots \ldots \ldots$. . . . $\quad$ ib.

89. The arteries; the veins : animals without arteries or veins. The

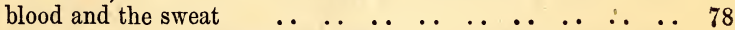

90. Animals, the blood of which coagulates with the greatest rapidity : other animals, the blood of which does not coagulate. Animals which have the thickest blood: those the blood of which is the thinnest : animals which have no blood ......... . .

91. Animals which are without blood at certain periods of the year.. 79

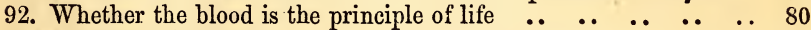

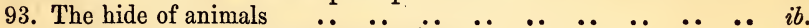

94. The hair and the covering of the skin $\ldots \begin{array}{llllllll} & . . & \ldots & \ldots & \ldots & \ldots & \ldots & 81\end{array}$

95. The paps : birds which have paps. Remarkable facts connected

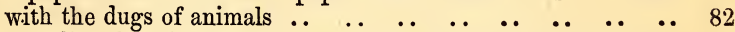

96. The milk: the biestings. Cheese: of what milk cheese cannot be made. Rennet; the various kinds of aliment in milk .. 83

97. Various kinds of cheese $\ldots \begin{array}{llllllllll} & \ldots & \ldots & \ldots & \ldots & \ldots & \ldots & \ldots & \ldots & 85\end{array}$

98. Differences of the members of man from those of other animals.. 86

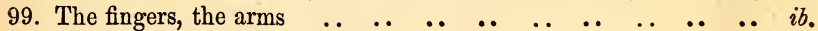

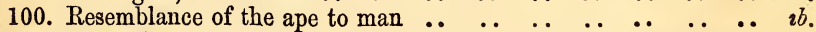

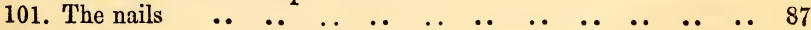

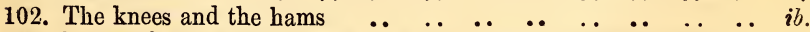

103. Parts of the human body to which certain religious ideas are

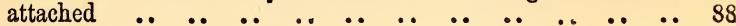


Chap.

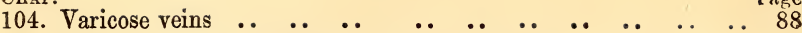

105. The gait, the feet, the legs $\ldots \begin{array}{lllllllll} & \ldots & \ldots & \ldots & \ldots & \ldots & \ldots & \ldots & 89\end{array}$

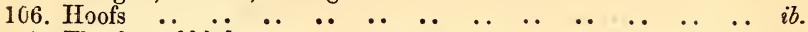

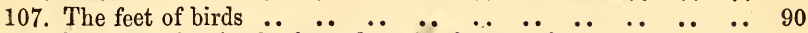

108. The feet of animals, from those having two feet to those with a

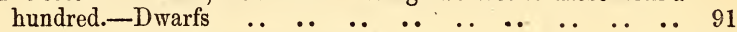

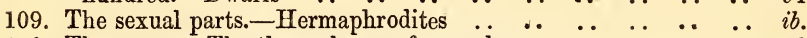

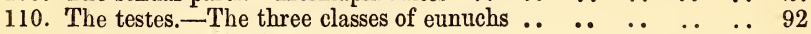

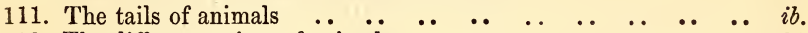

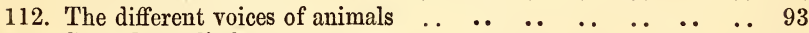

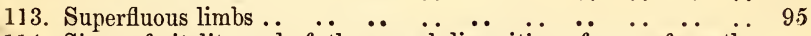

114. Signs of vitality and of the moral disposition of man, from the

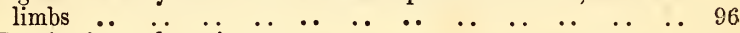

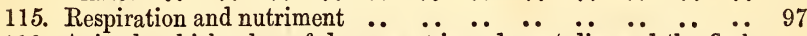

116. Animals which when fed upon poison do not $\ddot{d i e}$, and the fiesh of which is poisonous...

117. Reasons for indigestion. Remedies for crudity .. $\ldots \ldots \ldots \ldots$.. $\quad \ldots$.

118. From what causes corpulence arises; how it may be reduced ... ib.

119. What things, by merely tasting of them, allay hunger and thirst 99

\section{BOOK XII.}

THE NATURAL HISTORY OF TREES.

1. The honourable place occupied by trees in the system of nature 101

2. The early history of tiees $\ldots$.

3. Exotic trees. When the plane-tree first appeared in Italy, and

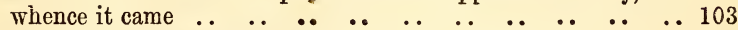

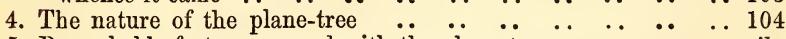

5. Remarkable facts connected with the plane-tree $\quad \ldots \quad$..

6. The chamæplatanus. Who was the first to clip green shrubs .. 106

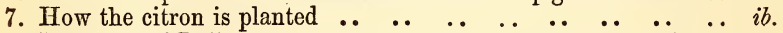

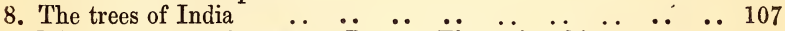

9. When ebony was first seen at Rome. The various kinds of ebony 109

10. The Indian thorn ..

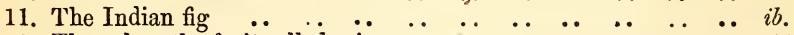

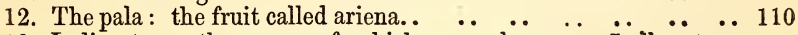

13. Indian trees, the names of which are unknown. Indian trees whicb bear flax ..

14. The pepper-tree.-The various kinds of pepper-bregma-zin-

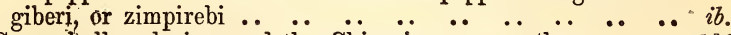

15. Caryophyllon, lycion, and the Chironian pyxacanthus $\ldots . \quad \ldots \quad 113$

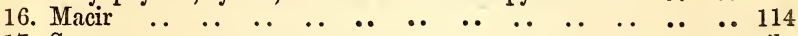

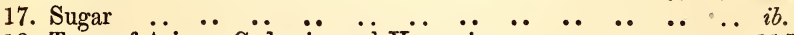

18. Trees of Ariana, Gedrosia, and Hyrcania

19. Trees of Bactriana, bdellium, or brochon, otherwise malacha, or maldacon, scordastum. Adulterations used in all spices and aromatics; the various tests of them and their respective values $2 b$.

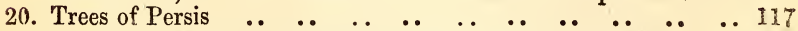

21. Trees of the islands of the Persian Sea. The cotton tree.. .. 
Cháp.

Treese

22. The tree called cyna. Trees from which fabrics for clothing are made in the east ..

23. A country where the trees never lose their leaves $\quad \ldots \quad \ldots \quad \ldots i b$.

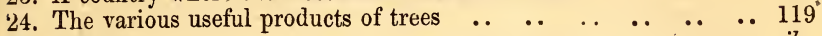

25. Costus. ..

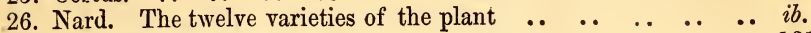

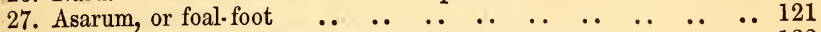

28. Amomum.-Amomis $\ldots$..

29. Cardamomum $\quad \ldots$.

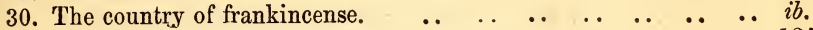

31. Thetrees which bear frankincense

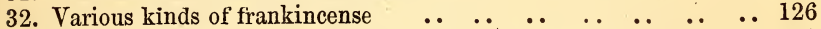

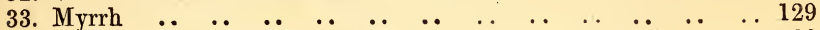

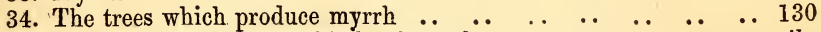

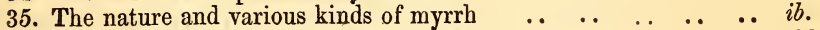

36. Mastich

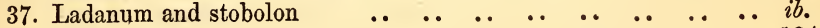

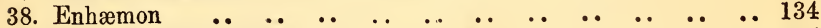

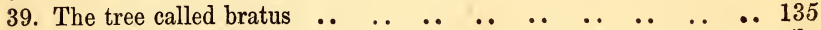

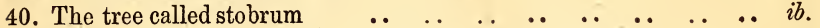

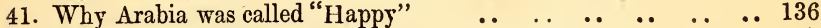

42. Cinnamomum. Xylocinnamum $\ldots$..

43. Cassia $\quad$..

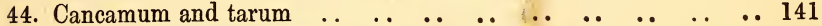

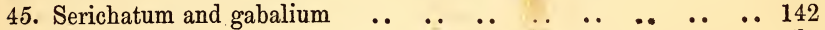

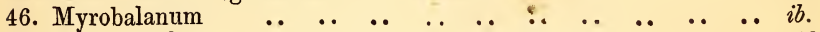

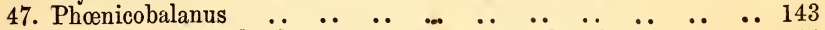

48. The sweet-scented calamus; the sweet-scented rush .. $\quad . . \quad \ldots 144$

49. Hammoniacum $\quad \ldots \quad$..

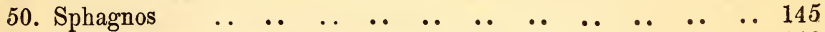

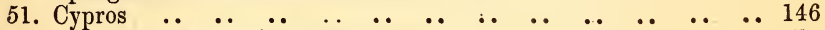

52. Aspalathos, or erysisceptrum ..

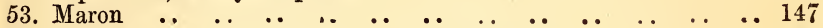

54. Balsamum; opobalsamum; and xylobalsamum .. $\ldots \ldots \ldots$.. $i b$.

55. Storax

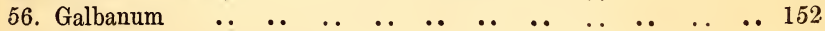

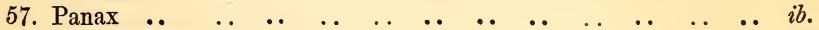

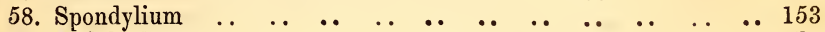

59. Malobathrum ..

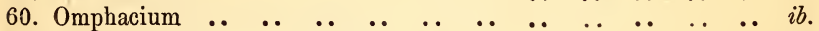

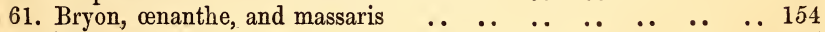

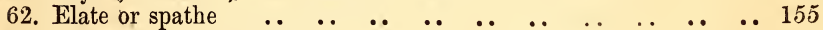

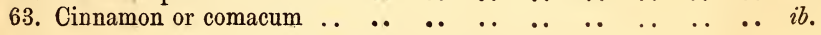

\section{BOOK XIII.}

THE NATURAL HISTORY OF EXOTIC TREES, AND AN ACCOUNT OF UNGUENTS.

1. Unguents-at what period they were first introduced _. . 159

2. The various kinds of unguents - twelve principal compositions .. 160 
ChaP.

3. Diapasma, magma ; the mode of testing unguents $\ldots$.. $\quad \ldots 166$

4. The excesses to which luxury has run in unguents $\quad . . \quad \ldots \quad \ldots 167$

5. When unguents were first used by the Romans $\quad \ldots \quad \ldots \quad \ldots \quad \ldots 168$

6. The palm-tree

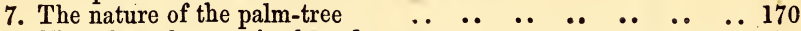

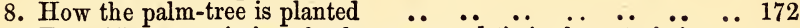

9. The different varieties of palm-trees, and their characteristics .. 173

10. The trees of Syria: the pistacia, the cottana, the damascena, and

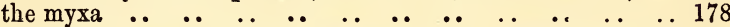

11. The cedar. Trees which have on them the fruit of three years at once $\ldots \begin{array}{lllllllllllllll} & \ldots & \ldots & \ldots & \ldots & \ldots & \ldots & \ldots & \ldots & \ldots & \ldots & \ldots & i b\end{array}$

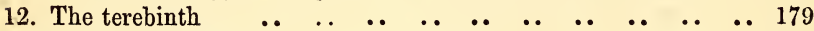

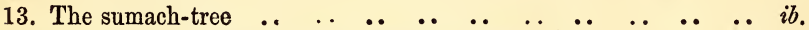

14. The trees of Egypt. The fig-tree of Alexandria.. . . .. . . 180

15. The fig-tree of Cyprus ..

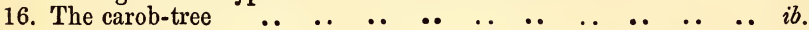

17. The Persian tree. In what trees the fruits germinate the one

18. The cucus below the other

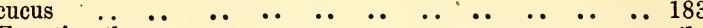

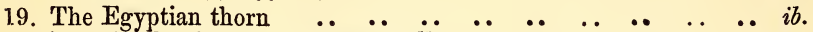

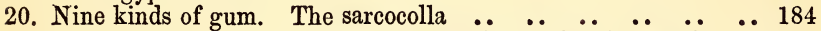

21. The papyrus: the use of paper : when it was first invented .. 185

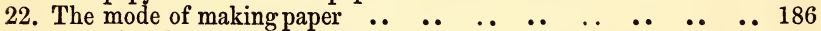

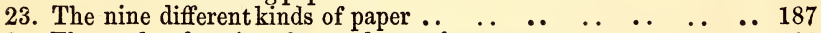

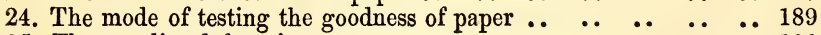

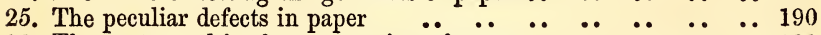

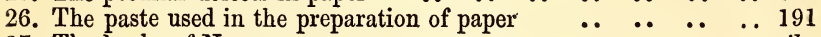

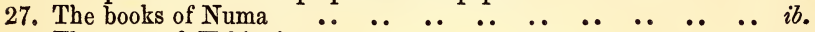

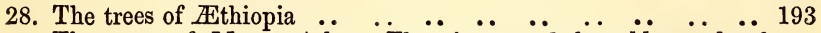

29. The trees of Mount Atlas. The citrus, and the tables made of

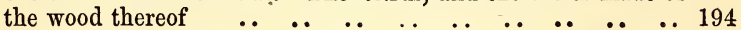

30. The points that are desirable or otherwise in these tables .. .. 195

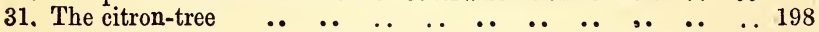

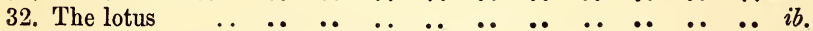

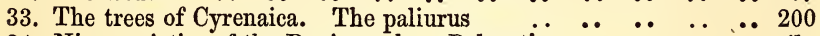

34. Nine varieties of the Punic apple. Balaustium $\ldots \ldots . . \quad \ldots i b$.

35. The trees of Asia and Greece; the epipactis, the erica, the

Cnidian grain or thymelæa, pyrosachne, cnestron, or cneoron.. 201

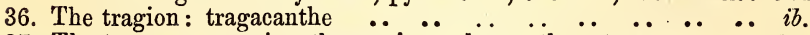

37. The tragos or scorpio; the myrica or brya; the ostrys $\quad \ldots \quad \ldots 202$

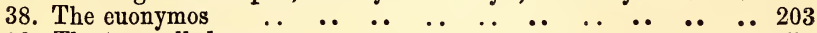

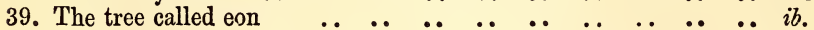

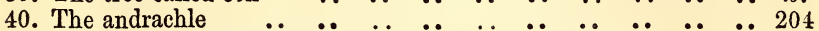

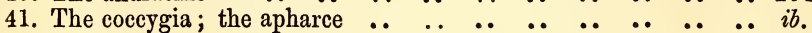

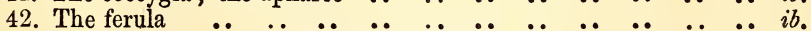

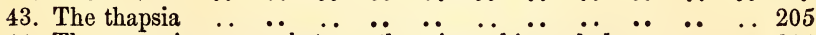

44. The capparis or cynosbaton, otherwise ophiostaphyle .. . . . 206

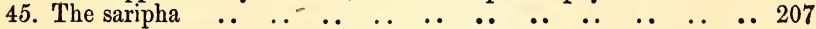

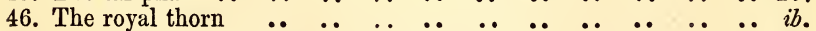

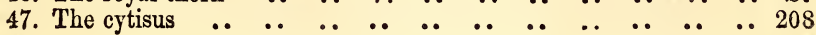


Crap. Page

48. The trees and shrubs of the Mediterranean. The phycos, prason, $\begin{array}{lllllllllllllll}\text { or zoster } & \ldots & \ldots & \ldots & \ldots & \ldots & \ldots & \ldots & \ldots & \ldots & \ldots & \ldots & 209\end{array}$

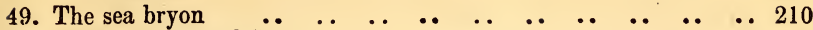

50. Plants of the Red Sea

51. Plants of the Indian Sea $\quad \begin{array}{lllllllll} & \ldots & \ldots & \ldots & \ldots & \ldots & \ldots & \ldots & i b .\end{array}$

52. The plants of the Troglodytic Sea ; the hair of Isis : the Charitoblepharon.

\section{BOOK XIV.}

THE NATURAL HISTORY OF THE FRUIT-TREES.

1 and 2. The nature of the vine. Its mode of fructification .. .. 215

3. The nature of the grape, and the cultivation of the vine $\ldots \quad \ldots 218$

4. Ninety-one varieties of the vine $\begin{array}{lllllllll} & \ldots & \ldots & \ldots & \ldots & \ldots & \ldots & 222\end{array}$

5. Remarkable facts connected with the culture of the vine $\quad \ldots \quad \ldots 233$

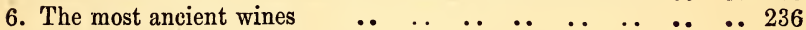

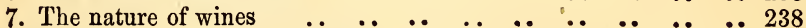

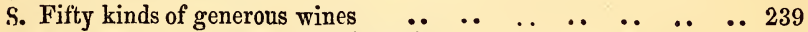

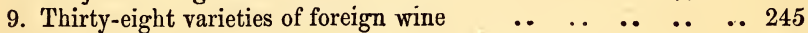

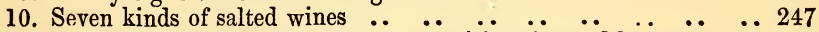

11. Eighteen varieties of sweet wine. Raisin-wine and hepsema .. 248

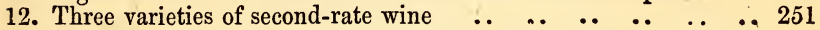

13. At what period generous wines were first commonly made in Italy .

14. The inspection of wine ordered by King Romulus $\ldots \quad \ldots \quad$.. 252

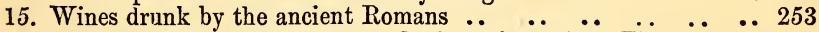

16. Some remarkable facts connected with wine-lofts. The Opimian

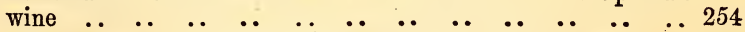

17. At what period four kinds of wine were first served at table $\ldots$ ib.

18. The uses of the wild vine. What juices are naturally the coldest

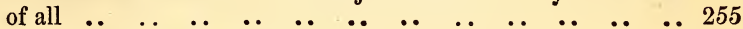

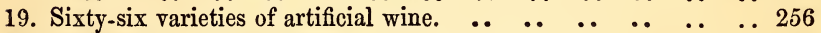

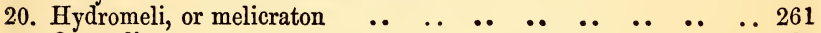

21. Oxymeli ..

22. Twelve kinds of wine with miraculous properties $\quad \ldots \quad$.. $\quad$. 262

23. What wines it is not lawful to use in the sacred rites .. $\quad . . \quad$.. 263

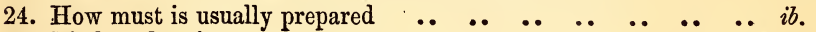

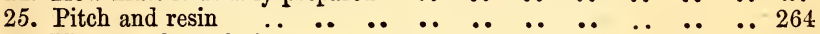

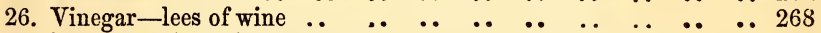

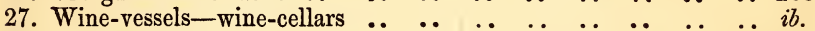

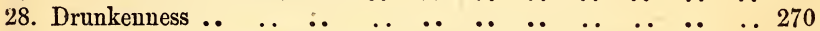

29. Liquors with the strength of wine made from water and corn .. 274

\section{BOOK XV.}

\section{THE NATURAL HISTORY OF THE FRUIT-TREES.}

1. The olive.-How long it existed in Greece only.-At what period it was first introduced into. Italy, Spain, and Africa .. . . . 277

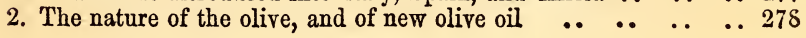


CHAp,

3. Olive oil : the countries in which it is produced, and its various $\begin{array}{lllllllllllll}\text { qualities } & \ldots & \ldots & \ldots & \ldots & \ldots & \ldots & \ldots & \ldots & \ldots & \ldots & \ldots & 279\end{array}$

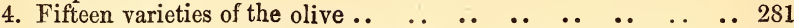

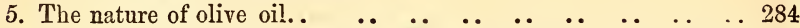

6. The culture of the olive: its mode of preservation. The method of making olive oil $\ldots \begin{array}{llllllllllll} & \ldots & \ldots & \ldots & \ldots & \ldots & \ldots & \ldots & \ldots & 285\end{array}$

7. Forty-eight varieties of artificial oils. The cicus-tree or croton, or sili, or sesamum

8. Amurca

9. The various kinds of fruit-trees and their natures. Four varieties

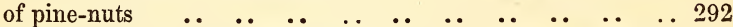

10. The quince. Four kinds of cydonia, and four varieties of the $\begin{array}{lllllllllllll}\text { struthea } & \ldots & \ldots & \ldots & \ldots & \ldots & \ldots & \ldots & \ldots & \ldots & \ldots & \ldots & i b .\end{array}$

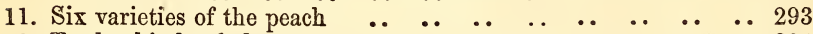

12. Twelve kinds of plums $\quad$.. $\quad$..

13. The peach $\quad$.

14. Thirty different kinds of pomes. At what period foreign fruits were first introduced into Italy, and whence .. $\quad . . \quad \ldots \quad$. . 297

15. The fruits that have been most recently introduced .. $\quad . \quad \ldots i b$.

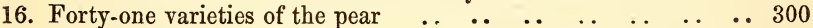

17. Various methods of grafting trees. Expiations for lightning ... 302

18. The mode of keeping various fruits and grapes .. $\quad$.. $\quad . \quad$. 303

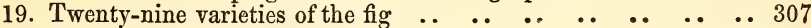

20. Historical anecdotes connected with the fig .. $\quad . . \quad \ldots \quad$.. $\quad . \quad 309$

21. Caprification ..

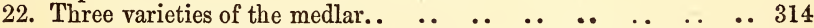

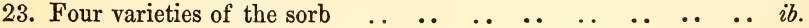

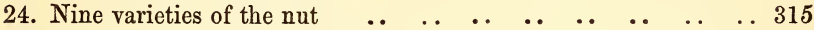

25. Eighteen varieties of the chesnut ..

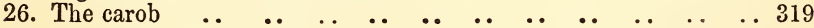

27. The fleshy fruits. The mulberry.. $\quad \ldots \quad \ldots \quad \ldots \quad \ldots \quad \ldots \quad \ldots i b$.

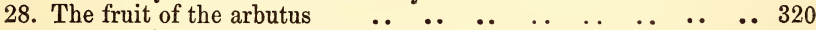

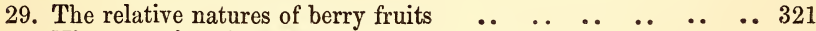

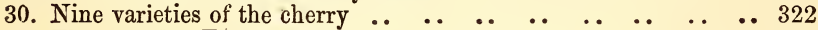

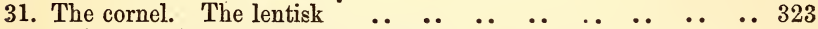

32. Thirteen different flavours of juices $\quad \begin{array}{ccccccc} & \ldots & \ldots & \ldots & \ldots & \ldots & i b\end{array}$

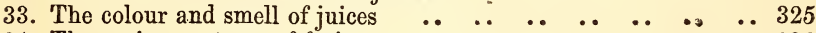

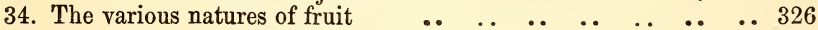

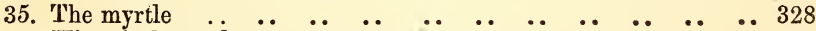

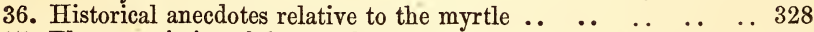

37. Eleven varieties of the myrtle $\quad \begin{array}{llllllll} & \text {. . } & \ldots & \ldots & \ldots & \ldots & \ldots & 330\end{array}$

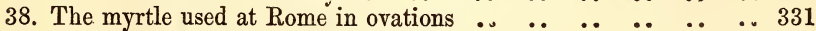

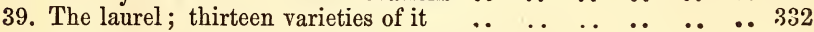

40. Historical anecdotes connected with the laurel $\quad \ldots \quad$..

\section{BOOK XVI.}

THE NATURAL HISTORY OF THE FOREST TREES.

1. Countries that have no trees.

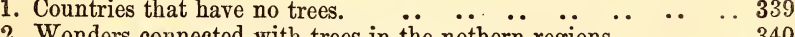


Chap. Page

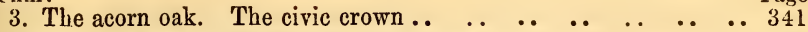

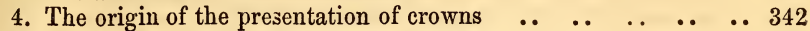

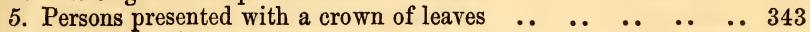

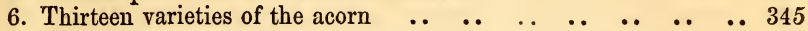

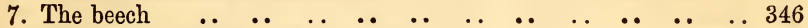

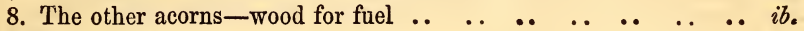

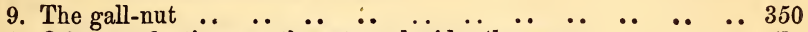

10. Other productions on these trees besides the acorn $\quad \ldots \quad \ldots \quad \ldots i b$.

11. Cachrys

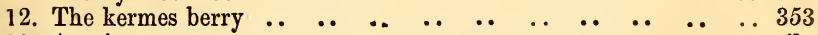

13. Agaric $\ldots{ }_{1}$.

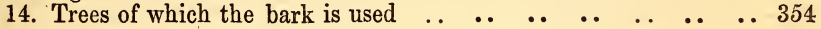

15. Shingles $\ldots \begin{array}{lllllllllllll} & \ldots & \ldots & \ldots & \ldots & \ldots & \ldots & \ldots & \ldots & \ldots & \ldots & \ldots & 355\end{array}$

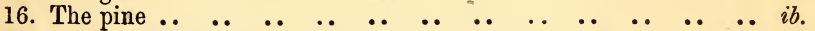

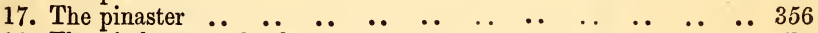

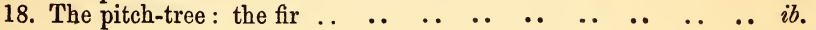

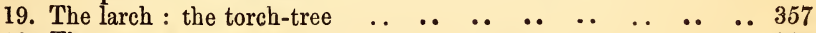

20. The yew ..

21. Methods of making tar-how cedrium is made $\ldots \quad \ldots \quad \ldots \quad \ldots 361$

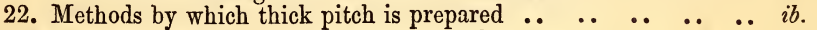

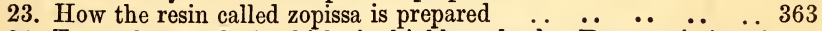

24. Trees the wood of which is highly valued. Four varieties of

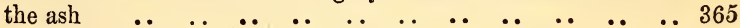

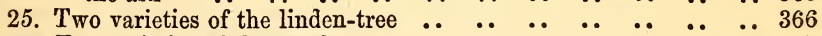

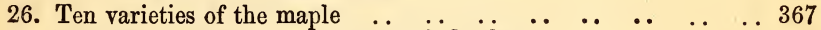

27. Bruscum : molluscum; the staphylodendron $\quad \ldots \quad \ldots \quad \ldots \quad . .368$

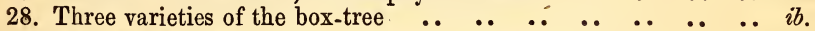

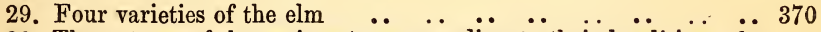

30. The natures of the various trees according to their localities : the mountain trees, and the trees of the plain $\quad . . \quad \ldots \quad \ldots \quad \ldots i b$.

31. Trees which grow on a dry soil : those which are found in wet localities : those which are found in both indifferently .. .. 372

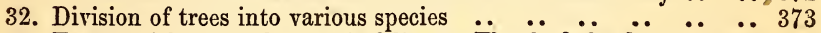

33. Trees which do not lose their foliage. The rhododendron. Trees which do not lose the whole of their foliage. Places in which there are no trees

34. The nature of the leaves which wither and fall \begin{tabular}{llllll} 
& $\ldots$ & $\ldots$ & $\ldots$ & $\ldots$ & $i b$ \\
\hline
\end{tabular}

35. Trees which have leaves of various colours; trees with leaves of various shapes. Three varieties of the poplar $\ldots \quad \ldots \quad \ldots 375$

36. Leaves which turn round every year $\quad \ldots \begin{array}{lllllll} & \ldots & \ldots & \ldots & \ldots & \ldots & 376\end{array}$

37. The care bestowed on the leaves of the palm, and the uses to

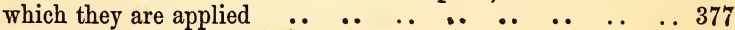

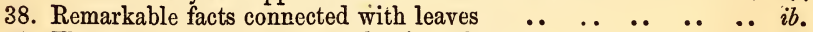

39. The natural order of the production of plants $\quad \ldots \quad$. .

40. Trees which never blossom. The juniper .. $\quad \ldots \quad \ldots \quad \ldots \quad \ldots 380$

41. The fecundation of trees. Germination : the appearance of the fruit 381

42. In what order the trees blossom $\quad \begin{array}{llllllll} & \ldots & \ldots & \ldots & \ldots & \ldots & \ldots & 383\end{array}$

43. At what period each tree bears fruit. The cornel ...

44. Trees which bear the whole year. Trees which have on them

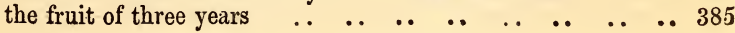


Chap.

45. Trees which bear no fruit: trees looked upon as ill-omened . 385

46. Trees which lose their fruit or flowers most readily $\quad . \quad \ldots \quad . \quad 386$

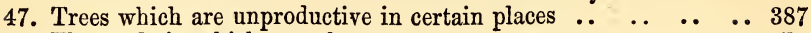

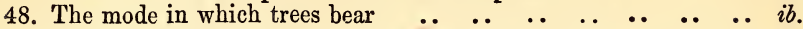

49. Trees in which the fruit appears before the leaves $\ldots \ldots \ldots, \ldots i b$.

50. Trees which bear two crops in a year. Trees which bear three crops ..

51. Which trees become ol $\ddot{d}$ with the greatest rapidity, and which most slowly

52. Trees which bear various products. Cratægum ..

53. Differences in trees in respect of the trunks and branches ..

54. The branches of trees $\ldots$..

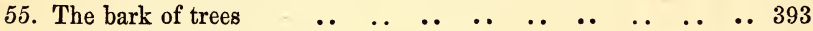

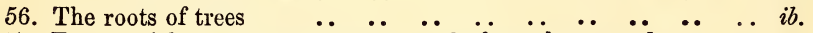

57. Trees which have grown spontaneously from the ground .. . . 394

58. How trees grow spontaneously-diversities in their nature, the same trees not growing everywhere ..

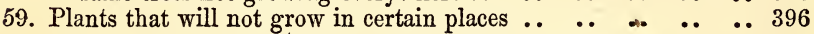

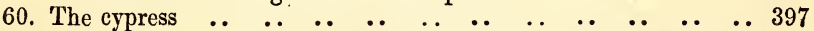

61. That the earth often bears productions which it has never borne before

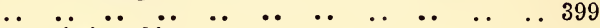

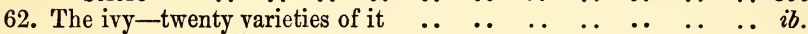

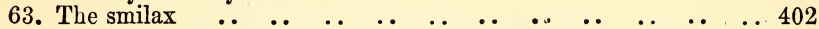

64. Water plants : the rush : twenty-eight varieties of the reed .. 403

65. Reeds used for arrows, and for the purpose of writing .. .. 404

66. Flute reeds : the reed of Orchomenus; reeds used for fowling

and fishing $\ldots \begin{array}{lllllllllllll} & \ldots & \ldots & \ldots & \ldots & \ldots & \ldots & \ldots & \ldots & \ldots & . & 405\end{array}$

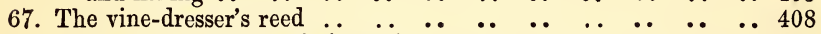

68. The willow : eight varieties of it ..

69. Trees, in addition to the willow, which are of use in making

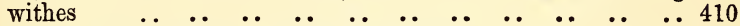

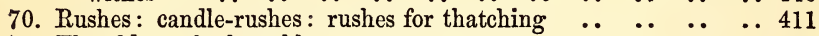

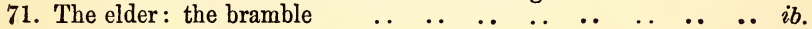

72. The juices of trees ..

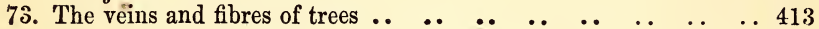

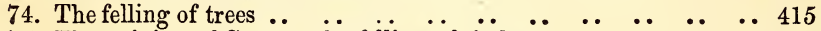

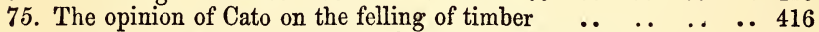

76. The size of trees : the nature of wood : the sappinus .. $\quad \ldots \quad . .417$

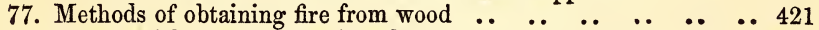

78. Trees which are proof against decay : trees which never split .. 422

79. Historical facts connected with the durability of wood .. .. 423

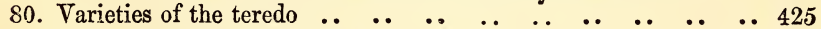

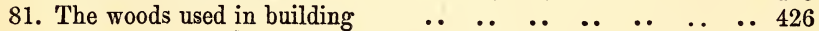

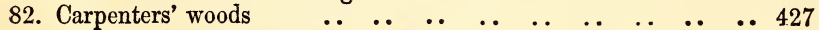

83. Woods united with glue $\begin{array}{llllllllll} & \ldots & \ldots & \ldots & \ldots & \ldots & \ldots & \ldots & \ldots & 4 \\ & & \ldots & \ldots & \ldots & \ldots & \ldots & i b\end{array}$

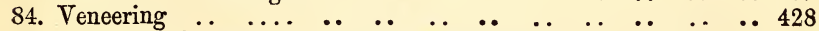

85. The age of trees. $\ddot{A}$ tree that was planted by the first $\ddot{\text { Scipio }}$

Africanus. A tree at Rome five hundred years old .. .. 429

86. Trees as old as the City ..

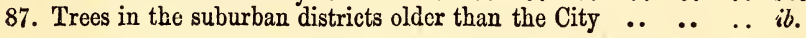


CIIAP.

88. Trees planted by Agamemnon the first year of the Trojan war: other trees which date from the time that the place was called

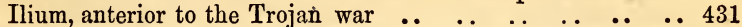
89. Trees planted at Argos by Hercules : others planted by Apollo. A tree more ancient than Athens itself $\quad \ldots \quad \ldots \quad \ldots \quad \ldots \quad \ldots i b$.

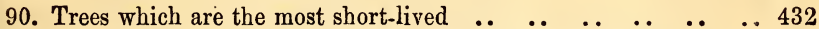
91. Trees which have been rendered famous by remarkahle events .. ib. 92. Plants which have no peculiar spot for their growth: others that grow upon trees, and will not grow in the ground. Nine varieties of them: cadytas, polypodion, phaulias, hippophæston 433

93. Three varieties of mistletoe. The nature of mistletoe and similar $\begin{array}{lllllllllllllll}\text { plants } & . & \ldots & \ldots & \ldots & \ldots & \ldots & \ldots & \ldots & \ldots & \ldots & \ldots & \ldots & 434\end{array}$

94. The method of making birdlime

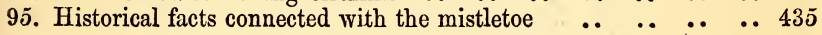

\section{BOOK XVII.}

THE NATURAL HISTORY OF THE CULTIVATED TREES.

1. Trees which have been sold at enormous prices $\quad \ldots \quad \ldots \quad \ldots \quad \ldots 438$

2. The influence of weather upon trees: what is the proper situation

for the vine..

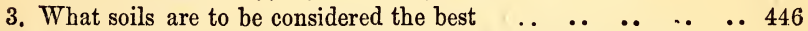

4. The eight kinds of earth boasted of by the Gauls and Greeks .. 452

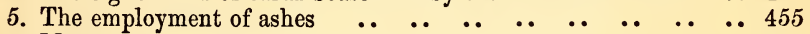

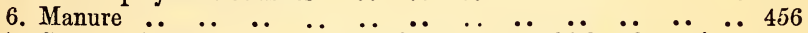

7. Crops which tend to improve the land: crops which exhaust it.. 459

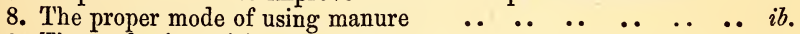

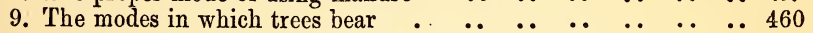

10. Plants which are propagated by seed $\quad \ldots \begin{array}{lllllll} & \ldots & \ldots & \ldots & \ldots & \ldots & i b\end{array}$

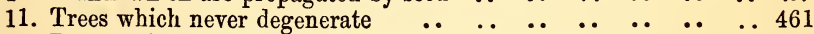

12. Propagation by suckers ..

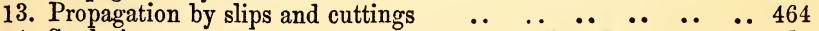

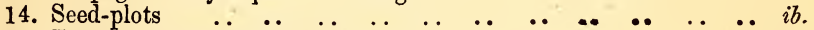

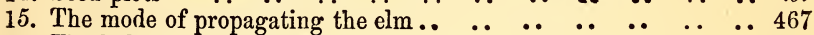

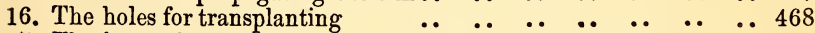

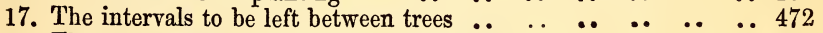

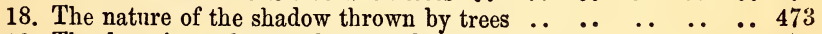

19. The droppings of water from the leaves..

20. Trees which grow but slowly : those which grow with rapidity .. 475

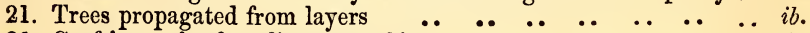

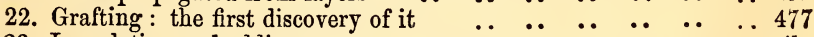

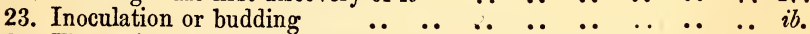

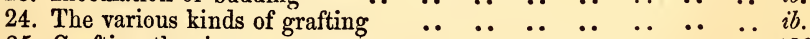

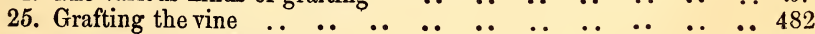

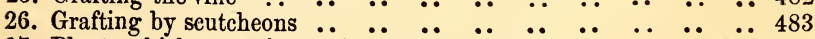

27. Plants which grow from a branch ..

28. Trees which grow from cuttings : the mode of planting them $\ldots 486$

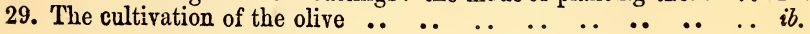


Chap. Page

30. Transplanting operations as distributed throughout the various

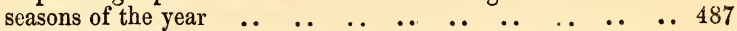

31. The cleaning and baring of the roots, and moulding them .. $\quad . .491$

32. Willow-beds

33. Reed-beds..

34. Other plants that are cut for poles and stakes $\quad \ldots \quad \ldots l$.

35. The culture of the vine and the various shrubs which support it .. 495

36 . How grapes are protected from the ravages of insects $\ldots$.. 517

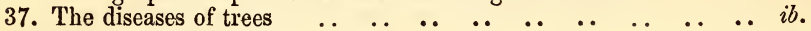

38. Prodigies connected with trees

39. Treatment of the diseases of trees ..

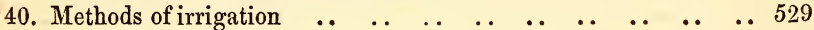

41. Remarkable facts connected with irrigation $\ldots \begin{array}{llllll}. & \ldots & \ldots & \ldots & \ldots & i b\end{array}$

42. Incisions made in trees..$\quad$..

43. Other remedies for the diseases of trees..

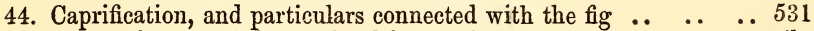

45. Errors that may be committed in pruning $\quad \ldots \begin{array}{llllll} & . & \ldots & \ldots & \ldots & i b\end{array}$

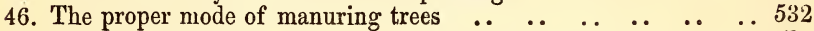

47. Medicaments for trees 


\section{GREEK AND ROMAN MONEY, WEIGHTS, AND MEASURES MENTIONED BY PLINY.}

Acetabulum. $\mathrm{R} \quad \ldots \quad \ldots \quad \ldots \frac{1}{8}$ of a Sextarius, .1238 pint.

Actus. $\mathrm{R} \quad \ldots \quad \ldots \quad \ldots \quad \ldots \quad \ldots \quad \ldots 120$ Pedes or Roman feet.

Amphora. $\mathrm{R} \quad \ldots \quad \ldots \quad \ldots \quad \ldots \quad \ldots 48$ Sextarii, 5 gall. 7.577 pints.

As, $\mathbf{R} \quad \ldots \quad \ldots \quad \ldots \quad \ldots \quad \ldots \quad \ldots 2 \frac{1}{8}$ farthings. Copper.

As. $\mathrm{R}$ [weight] $\quad \ldots \quad$... $\quad$...See " Libra."

Concha, Smaller, G and R ...0412 pint.

Concha, Larger, $G$ and $R \quad \ldots \cdot 1238$ pint.

Congius. $\mathrm{R} \quad \ldots \quad \ldots \quad \ldots \quad \ldots 5.947 \mathrm{l}$ pints.

Cubitus. G $\quad \ldots \quad \ldots \quad \ldots \quad \ldots 1$ foot 6.2016 inches.

$\begin{array}{llllll}\text { Cubitus. } R & \ldots & \ldots & \ldots & \ldots 1 \text { foot } 5.4744 \text { inches. }\end{array}$

$\begin{array}{llllll}\text { Culeus. } & R & \ldots & \ldots & \ldots & \ldots 20 \text { Amphoræ, } 118 \text { gall. } 7.546 \text { pints. }\end{array}$

Cyathus. G and R $\quad \ldots \quad$.. $\quad \ldots \frac{1}{12}$ of a Sextarius, 0825 pint.

Denarius. $R \quad \ldots \quad \ldots \quad \ldots \quad \ldots 16$ Asses, $8 \frac{1}{2}$ pence. Silver.

Denarius. R. [weight] $\ldots . . .552 .5$ to 60 grains.

Digitus, or Finger. R. . . $\quad \ldots \frac{1}{16}$ of a Pes, .7281 inch.

$\begin{array}{llllll}\text { Drackma. } G & \ldots & \ldots & \ldots & \ldots & 63 \text { grains. }\end{array}$

Hemina. $\mathbf{R} \quad \ldots \quad \ldots \quad \ldots \quad \ldots$...

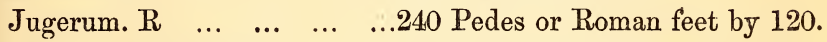

Libra, or Pound. R. $\quad \ldots \quad \ldots 11 \frac{3}{4}$ ounces 60.45 grains, avoird.

Mina.* $\mathrm{G} \quad \ldots \quad \ldots \quad \ldots \quad \ldots 15$ ounces 83.75 grains, avoird.

Modius. R. [dry measure] $\quad \ldots \frac{1}{3}$ of an Amphora, 1 gall. 7.8576

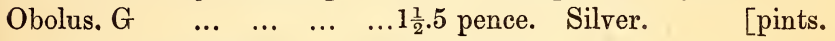
Obolus. G. [weight] $\quad \ldots \quad$...10.5 grains.

Palmus, or Handbreadth. $R$...2.9214 inches.

Passus, or Pace. $\uparrow \mathrm{R} \quad$... ...5 Roman feet, $4 \mathrm{ft} .10 .248$ inches.

* In B. xii. c. 32-it is supposed by some that it is the Roman Libra that is meant, under the name of "Mina," as containing eighty-four Denarii. If so, it must be the old Roman Libra, as it is more generally thought that the Libra of Pliny's time contained ninety-six Denarii, of sixty grains, within a fraction.

† One thousand Paces made a Roman "Mille Passuum," or Mile, 1618 yards English. 
Pes, or Foot. R $\quad \ldots \quad \ldots \quad$...12 Unciæ, 11.6496 inches.

Pollex, or Thumb. R ... ...See "Uncia" [lineal measure].

Quadrans. $\mathrm{R} \quad \ldots \quad \ldots \quad \ldots \quad \ldots \quad \ldots 53,125$ farthing. Copper.

Quadrans. R [weight] $\quad \ldots \quad \ldots 3$ Unciæ, $2 \frac{3}{4}$ ounces 97.21 grs.

Quadrantal. $\mathbf{R} \quad \ldots \quad \ldots \quad$...See "Amphora."

Quartarius. $R \quad \ldots \quad \ldots \quad \ldots \quad \ldots \frac{1}{4}$ of a Sextarius, .2477 pint.

Quinarius. $R \quad \ldots \quad \ldots \quad \ldots \quad \ldots \frac{1}{2}$ of a Denarius.

Scripulum, or Scruple. $\mathrm{R} \quad \ldots \frac{1}{2}$ of an Uncia, 18.06 grains.

Semisextarius. $\mathbf{R} \quad \ldots \quad \ldots \quad \ldots \frac{1}{2}$ of a Sextarius.

$\begin{array}{llllll}\text { Sestertius. } \mathbf{R} & \ldots & \ldots & \ldots & \ldots & \ldots \frac{1}{4} \text { of a Denarius. Brass or Silver. }\end{array}$

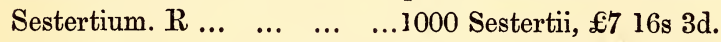

Sextarius. $\mathrm{R} \quad \ldots \quad \ldots \quad \ldots \quad \ldots \quad \ldots \frac{1}{6}$ of a Congius, .9911 pint.

Spithama, or Span. G $\quad \ldots \quad \ldots 9.1008$ inches.

Stadium. $G$ and $R \quad \ldots \quad \ldots \quad \ldots \frac{1}{8}$ of a Roman mile, 606 feet 9 in.

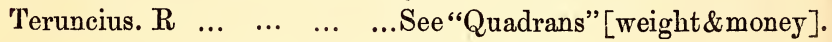

Ulna, or Ell. $\mathrm{R} \quad \ldots \quad \ldots \quad \ldots 6$ feet, 81 inch.

Uncia, or Inch. $R \quad \ldots \quad \ldots \quad \ldots \frac{1}{12}$ of a Pes, .9708 inch.

Uncia, or Ounce. R... ... $\quad \ldots \frac{1}{12}$ of a Libra. 433.666 grs.

Urna. R. ... $\quad \ldots \quad \ldots \quad \ldots \quad \ldots \quad \ldots \frac{1}{2}$ of an Amphora.

Victoriatus. R ... $\quad \ldots \quad$... $\quad$...See "Quinarius."

The Schœnus, an Egyptian and Persian lineal measure, varied considerably ; being sometimes thirty, and sometimes forty Stadia. See B. v. c. 11, B. vi. c. 30, and B. xii. c. 30.

The Attic Talent, as a weight, was equal to $561 \mathrm{tb}$. $15 \frac{1}{4} \mathrm{oz}$. 100.32 grains. The Commercial Talent was $8517.2 \frac{1}{2}$ oz. 70.7 grs. The Silver Attic, or Great Talent, was in value $£ 343$ 15s. or, according to Pollux, $£ 406$ 5s. The Gold, or Sicilian Talent, was equal in weight to six Attic Drachmæ, or about $\frac{3}{4}$ oz. and 71 grs. The Egyptian Talent, as a measure of weight, was equal to about twice the Attic Talent. 


\section{NATURAL HISTORY OF PLINY.}

\section{BOOK XI.}

\section{THE VARIOUS KINDS OF INSECTS.}

\section{CHAP. 1. (1.)-THE EXTREME SMALLNESS OF INSECTS.}

W $\mathrm{E}$ shall now proceed to a description of the insects, a subject replete with endless difficulties $;^{1}$ for, in fact, there are some authors who have maintained that they do not respire, and that they are destitute of blood. The insects are numerous, and form many species, and their mode of life is like that of the terrestrial animals and the birds. Some of them are furnished with wings, bees for instance; others are divided into those kinds which have wings, and those which are without them, such as ants ; while others, again, are destitute of both wings and feet. All these animals have been very properly called "insects," ${ }^{2}$ from the incisures or divisions which separate the body, sometimes at the neck, and sometimes at the corselet, and so divide it into members or segments, only united to each other by a slender tube. In some insects, however, this division is not complete, as it is surrounded by wrinkled folds; and thus the flexible vertebræ of the creature, whether situate at the abdomen, or whether only at the upper part of the body, are protected by layers, overlapping each other; indeed, in no one of her works has Nature more fully displayed her exhaustless ingenuity.

(2.) In large animals, on the other hand, or, at all events,

1 "Immense subtilitatis." As Cuvier remarks, the ancients have committed more errors in reference to the insects, than to any other portion of the animal world. The discovery of the microscope has served more than anything to correct these erroneous notions.

2 "Insecta," "articulated."

VOL. III. 
in the very largest among them, she found her task easy and her materials ready and pliable; but in these minute creatures, so nearly akin as they are to non-entity, how surpassing the intelligence, how vast the resources, and how ineffable the perfection which she has displayed. Where is it that she has united so many senses as in the gnat?-not to speak of creatures that might be mentioned of still smaller size-Where, I say, has she found room to place in it the organs of sight? Where has she centred the sense of taste? Where has she inserted the power of smell? And where, too, has she implanted that sharp shrill voice of the creature, so utterly disproportioned to the smallness of its body? With what astonishing subtlety has she united the wings to the trunk, elongated the joints of the legs, framed that long, craving concavity for a belly, and then inflamed the animal with an insatiate thirst for blood, that of man more especially! What ingenuity has she displayed in providing it with a sting, ${ }^{3}$ so well adapted for piercing the skin! And then too, just as though she had had the most extensive field for the exercise of her skill, although the weapon is so minute that it can hardly be seen, she has formed it with a twofold mechanism, providing it with a point for the purpose of piercing, and at the same moment making it hollow, to adapt it for suction.

What teeth, too, has she inserted in the teredo, ${ }^{4}$ to adapt it for piercing oak even with a sound which fully attests their destructive power! while at the same time she has made wood its principal nutriment. We give all our admiration to the shoulders of the elephant as it supports the turret, to the stalwart neck of the bull, and the might with which it hurls aloft whatever comes in its way, to the onslaught of the tiger, or to the mane of the lion; while, at the same time, Nature is nowhere to be seen to greater perfection than in the very smallest of her works. For this reason then, I must beg of my readers, notwithstanding the contempt they feel for many of these objects, not to feel a similar disdain for the information I am about to give relative thereto, seeing that, in the

3 The trunk of the gnat, Cuvier says, contains five silken and pointed threads, which together have the effect of a sting.

4. The Teredo navalis of Linnæus, not an insect, but one of the mollusks. This is the same creature that is mentioned in B. xvi. c. 80 ; but that spoken of in B. viii. c. 74 , must have been a land insect.

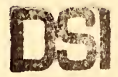


study of Nature, there are none of her works that are unworthy of our consideration.

\section{CHAP. 2. (3.)-WHETHER INSECTS RESPIRE, AND WHETHER THEY HAVE BLOOD.}

Many authors deny that insects respire, ${ }^{5}$ and make the assertion upon the ground, that in their viscera there is no respiratory organ to be found. On this ground, they assert that insects have the same kind of life as plants and trees, there being a very great difference between respiring and merely having life. On similar grounds also, they assert that insects have no blood, a thing which cannot exist, they say, in any animal that is destitute of heart and liver; just as, according to them, those creatures cannot breathe which have no lungs. Upon these points, however, a vast number of questions will naturally arise; for the same writers do not hesitate to deny that these creatures are destitute also of voice, ${ }^{6}$ and this, notwithstanding the humming of bees, the chirping of grasshoppers, and the sounds emitted by numerous other insects which will be considered in their respective places. For my part, whenever I have considered the subject, I have ever felt persuaded that there is nothing impossible to Nature, nor do I see why creatures should be less able to live and yet not inhale, than to respire without being possessed of viscera, a doctrine which I have already maintained, when speaking ${ }^{7}$ of the marine animals; and that, notwithstanding the density and the vast depth of the water which would appear to impede all breathing. But what person could very easily believe that there can be any creatures that fly to and fro, and live in the very midst of the element of respiration, while, at the same time, they themselves are devoid of that respiration; that they can be possessed of the requisite instincts for nourishment, generation, working, and making provision even for time to come, in the enjoyment too (although, certainly, they are not possessed of the organs which act, as it were, as the receptacles

5 They respire by orifices in the sides of the body, known to naturalists as stigmata. The whole body, Cuvier says, forms, in a measure, a system of lungs.

6 Cuvier remarks that the various noises made by insects are in reality not the voice, as they are not produced by air passing through a larynx.

7 B. ix. c. 6 . 
of those senses) of the powers of hearing, smelling, and tasting, as well as those other precious gifts of Nature, address, courage, and skilfulness? That these creatures have no blood ${ }^{8}$ I am ready to admit, just as all the terrestrial animals are not possessed of it ; but then, they have something similar, by way of equivalent. Just as in the sea, the sæpia ${ }^{9}$ has a black liquid in place of blood, and the various kinds of purples, those juices which we use for the purposes of dyeing; so, too, is every insect possessed of its own vital humour, which, whatever it is, is blood to it. While I leave it to others to form what opinion they please on this subject, it is my purpose to set forth the operations of Nature in the clearest possible light, and not to enter upon the discussion of points that are replete with doubt.

\section{CHAP. 3. (4.)-THE BODIES OF INSECTS.}

Insects, so far as I find myself able to ascertain, seem to have neither sinews ${ }^{10}$ bones, spines, cartilages, fat, nor flesh ; nor yet so much as a frail shell, like some of the marine animals, nor even anything that can with any propriety be termed skin ; but they have a body which is of a kind of intermediate nature between all these, of an arid substance, softer than muscle, and in other respects of a nature that may, in strictness, be rather pronounced yielding, ${ }^{11}$ than hard. Such, then, is all that they are, and nothing more ${ }^{12}$ in the inside of their bodies there is nothing, except in some few, which have an intestine arranged in folds. Hence it is, that even when cut asunder, they are remarkable for their tenacity of life, and the palpitations which are to be seen in each of their parts. For every portion of them is possessed of its own vital principle, which is centred in no limb in particular, but

8 Cuvier remarks, that they have a nourishing fluid, which is of a white colour, and acts in place of blood.

9 The dye of seepia, Cuvier remarks, is notblood, nor does it act as such, being an excrementitious liquid. It has in addition a bluish, transparent, blood. The same also with the juices of the purple.

10 "Nervos." Cuvier says that all insects have a brain, a sort of spinal marrow, and nerves.

11 "Tutius."

12 Insects have no fat, Cuvier says, except when in the chrysalis state; but they have a fibrous flesh of a whitish colour. They have also viscera, trachea, nerves, and a most complicated organization. 
in every part of the body; least of all, however, in the head, which alone is subject to no movements unless torn off together with the corselet. No kind of animal has more feet than the insects have, and those among them which have the most, live the longest when cut asunder, as we see in the case of the scolopendra. They have eyes, and the senses as well of touch and taste; some of them have also the sense of smelling, and some few that of hearing.

\section{CHAP. 4. (5.) - BEES.}

But among them all, the first rank, and our especial admiration, ought, in justice, to be accorded to bees, which alone, of all the insects, have been created for the benefit of man. They extract honey and collect it, a juicy substance remarkable for its extreme sweetness, lightness, and wholesomeness. They form their combs and collect wax, an article that is useful for a thousand purposes of life; they are patient of fatigue, toil at their labours, form themselves into political communities, hold. councils together in private, elect chiefs in common, and, a thing that is the most remarkable of all, have their own code of morals. In addition to this, being as they are, neither tame nor wild, so all-powerful is Nature, that, from a creature so minute as to be nothing more hardly than the shadow of an animal, she has created a marvel beyond all comparison. What muscular power, what exertion of strength are we to put in comparison with such vast energy and such industry as theirs? What display of human genius, in a word, shall we compare with the reasoning powers manifested by them? In this they have, at all events, the advantage of us-they know of nothing but what is for the common benefit of all. Away, then, with all questions whether they respire or no, and let us be ready to agree on the question of their blood; and yet, how little of it can possibly exist in bodies so minute as theirs.-And now let us form some idea of the instinct they display.

\section{CHAP. 5. (6.) - THE ORDER DISPLAYED IN THE WORKS OF BEES.}

Bees keep within the hive during the winter-for whence are they to derive the strength requisite to withstand frosts and snows, and the northern blasts? The same, in fact, is done by all insects, but not to so late a period; as those 
which conceal themselves in the walls of our houses, are much sooner sensible of the returning warmth. With reference to bees, either seasons and climates have considerably changed, or else former writers have been greatly mistaken. They retire for the winter at the setting of the Vergiliæ, and remain shut up till after the rising of that constellation, and not till only the beginning of spring, as some authors have stated; nor, indeed, does any one in Italy ever think of then opening the hives. They do not come forth to ply their labours until the bean blossoms; and then not a day do they lose in inactivity, while the weather is favourable for their pursuits.

First of all, they set about constructing their combs, and forming the wax, or, in other words, making their dwellings and cells; after this they produce their young, and then make honey and wax from flowers, and extract bee-glue ${ }^{12}$ from the tears of those trees which distil glutinous substances, the juices, gums, and resins, namely, of the willow, the elm, and the reed. With these substances, as well as others of a more bitter nature, they first line the whole inside of the hive, as a sort of protection against the greedy propensities of other small insects, as they are well aware that they are about to form that which will prove an object of attraction to them. Having done this, they employ similar substances in narrowing the entrance to the hive, if otherwise too wide.

\section{CHAP. 6. (5.)-THE MEANING OF THE TERMS COMMOSIS, PISSO- CEROS, AND PROPOLIS.}

The persons who understand this subject, call the substance which forms the first foundation of their combs, commosis, ${ }^{13}$ the next, pissoceros, ${ }^{14}$ and the third propolis $;{ }^{15}$ which last is placed between the other layers and the wax, and is remarkable for its utility in medicine. ${ }^{16}$ The commosis forms the first crust or layer, and has a bitter taste; and upon it is laid the pissoceros, a kind of thin wax, which acts as a sort of varnish. The propolis is produced from the sweet gum of the vine or

12 "Melligo." For further information on this subject consult Bevan on the Honey Bee.

13 Or "conusis," "gummy matter."

14 Pitch-wax.

${ }^{15}$ A kind of bee-glue; the origin of the name does not seem to be known. Reaumur says that they are all different varieties of bee-glue.

16 See B. xxii. c. 50. 
the poplar, and is of a denser consistency, the juices of flowers being added to it. Still, however, it cannot be properly termed wax, but rather the foundation of the honey-combs; by means of it all inlets are stopped up, which might, otherwise, serve for the admission of cold or other injurious influences; it has also a strong odour, so much so, indeed, that many people use it instead of galbanum.

\section{CHAP. 7.-THE MEANING OF ERITHACE, SANDARACA, OR CERINTHOS.}

In addition to this, the bees form collections of erithace or bee-bread, which some persons call "sandaraca," 17 and others "cerinthos." This is to serve as the food of the bees while they are at work, and is often found stowed away in the cavities of the cells, being of a bitter flavour also. It is produced from the spring dews and the gummy juices of trees, being less abundant while the south-west wind is blowing, and blackened by the prevalence of a south wind. On the other hand, again, it is of a reddish colour and becomes improved by the north-east wind; it is found in the greatest abundance upon the nut trees in Greece. Menecrates says, that it is a flower, which gives indications of the nature of the coming harvest; but no one says so, with the exception of him.

CHAP. 8. (8.) - WHAT FLOWERS ARE USED BY THE BEES IN THEIR WORK.

Bees form wax ${ }^{18}$ from the blossoms of all trees and plants, with the sole exception of the rumex ${ }^{19}$ and the echinopodes, ${ }^{20}$ both being kinds of herbs. It is by mistake, however, that spartum is excepted $;^{21}$ for many varieties of honey that come from Spain, and have been made in the plantations of it, have a strong taste of that plant. I am of opinion, also, that it is without any sufficient reason that the olive has been excepted, seeing that it is a well-known fact, that where olives are in the greatest abundance, the swarms of bees are the most numerous. Bees are not injurious to fruit of any kind ; they will

17 Different combinations of the pollen of flowers, on which bees feed.

18 It is formed from the honey that the bee has digested.

19 Sorrel, or monk's rhubarb.

20 A kind of broom.

21 Spanish broom, the Stipa tenacissima of Linnæus. Ropes were made of it. See B. xix. c. 7 . 
never settle on a dead flower, much less a dead carcase. They pursue their labours within three-score paces of their hives; and when the flowers in their vicinity are exhausted, they send out scouts from time to time, to discover places for forage at a greater distance. When overtaken by night in their expeditions, they watch till the morning, lying on their backs, in order to protect their wings from the action of the dew.

\section{CHAP. 9. (9.)-PERSONS who HAVE MADE BEES THEIr STUDY.}

It is not surprising that there have been persons who have made bees their exclusive study; Aristomachus of Soli, for instance, who for a period of fifty-eight years did nothing else; Philiscus of Thasos, also, surnamed Agrius, ${ }^{22}$ who passed his life in desert spots, tending swarms of bees. Both of these have written works on this subject.

\section{CHAP. 10. (10.) - THE MODE IN WHICH BEES WORK.}

The manner in which bees carry on their work is as follows. In the day time a guard is stationed at the entrance of the hive, like the sentries in a camp. At night they take their rest until the morning, when one of them awakes the rest with a humming noise, repeated twice or thrice, just as though it were sounding a trumpet. They then take their flight in a body, if the day is likely to turn out fine ; for they have the gift of foreknowing wind and rain, and in such case will keep close within their dwellings. On the other hand, when the weather is fine-and this, too, they have the power of foreknowing - the swarm issues forth, and at once applies itself to its work, some loading their legs from the flowers, while others fill their mouths with water, and charge the downy surface of their bodies with drops of liquid. Those among them that are young ${ }^{23}$ go forth to their labours, and collect the materials already mentioned, while those that are more aged stay within the hives and work. The bees whose business it is to carry the flowers, with their fore feet load their thighs, which Nature has made rough for the purpose, and with their trunks load

22 Or, the "wild man."

23 Huber has discovered that there are two kinds of bees of neutral sex, or, as he calls them, unprolific females, the workers, which go out, and the nurses, which are smaller, and stay in the hive to tend the larvæ. 
their fore feet: bending beneath their load, they then return to the hive, where there are three or four bees ready to receive them and aid in discharging their burdens. For, within the hive as well, they have their allotted duties to perform: some are engaged in building, others in smoothing, the combs, while others again are occupied in passing on the materials, and others in preparing food ${ }^{24}$ from the provision which has been brought; that there may be no unequal division, either in their labour, their food, or the distribution of their time, they do not even feed separately.

Commencing at the raulted roof of the hive, they begin the construction of their cells, and, just as we do in the manufacture of a web, they construct their cells from top to bottom, taking care to leare two passages around each compartment, for the entrance of some and the exit of others. The combs, which are fastened to the hire in the upper part, and in a slight degree also at the sides, adhere to each other, and are thus suspended altogether. They do not touch the floor of the hive, and are either angular or round, according to its shape; sometimes, in fact, they are both angular and round at once, when two swarms are living in unison, but hare dissimilar modes of operation. They prop up the combs that are likely to fall, by means of arched pillars, at interrals springing from the floor, so as to leave them a passage for the purpose of effecting repairs. The first three ranks of their cells are generally left empty when constructed, that there may be nothing exposed to view which may invite theft; and it is the last ones, more especially, that are filled with honcy: hence it is that the combs are always taken out at the back of the hive.

The bees that are employed in carrying look out for a favourable breeze, and if a gale should happen to spring up, they poise themselves in the air with little stones, by way of ballast; some writers, indeed, say that they place them upon their shoulders. When the wind is contrary, they fly close to the ground, taking care, however, to keep clear of the brambles. It is wonderful what strict watch is kept upon their work : all instances of idleness are carefully remarked, the offenders are

24 From the honey found in the corollæ of flowers. This, after being prepared in the first stomach of the bee, is deposited in the cell which is formed for its reception. 
chastised, and on a repetition of the fault, punished with death. Their sense of cleanliness, too, is quite extraordinary ; everything is removed that might be in the way, and no filth is allowed to remain in the midst of their work. The ordure even of those that are at work within, that they may not have to retire to any distance, is all collected in one spot, and on stormy days, when they are obliged to cease their ordinary labours, they employ themselves in carrying it out. When it grows towards evening, the buzzing in the hive becomes gradually less and less, until at last one of their number is to be seen flying about the hive with the same loud humming noise with which they were aroused in the morning, thereby giving the signal, as it were, to retire to rest: in this, too, they imitate the usage of the camp. The moment the signal is heard, all is silent.

(11.) They first construct the dwellings of the commonalty, and then those of the king-bee. If they have reason to expect an abundant ${ }^{25}$ season, they add abodes also for the drones: these are cells of a smaller size, though the drones themselves are larger than the bees.

\section{CHAP. 11.-DRONES.}

The drones have no sting, ${ }^{26}$ and would seem to be a kind of imperfect bee, formed the very last of all ; the expiring effort, as it were, of worn-out and exhausted old age, a late and tardy offspring, and doomed, in a measure, to be the slaves of the genuine bees. Hence it is that the bees exercise over them a rigorous authority, compel them to take the foremost rank in their labours, and if they show any sluggishness, punish them ${ }^{27}$ without mercy. And not only in their labours do the drones give them their assistance, but in the propagation of their species as well, the very multitude of them contributing greatly to the warmth of the hive. At all events, it is a well-known fact, that the greater ${ }^{28}$ the multitude of the drones, the more

${ }^{25}$ Cuvier says that the three kinds of cells are absolutely necessary, and that they do not depend on the greater or less abundance. The king of the ancients is what we know as the queen bee, which is impregnated by the drones or males.

${ }^{26}$ This is the fact, but not so their imperfect state.

27. They do not work, but merely impregnate the queen; after which they are driven from the hive, and perish of cold and starvation.

${ }_{28}$ It appears, as Cuvier says, that the ancients had some notion that the swarm was multiplied by the aid of the drones. 
numerous is sure to be the progeny of the swarm. When the honey is beginning to come to malurity, the bees drive away the drones, and setting upon each in great numbers, put them all to death. It is only in the spring that the drones are ever to be seen. If you deprive a drone of its wings, and then replace it in the hive, it will pull off the wings of the other drones.

\section{CHAP. 12,-THE QUALITIES OF HONEY.}

In the lower part of the hive they construct for their future sovereign a palatial abode,,$^{29}$ spacious and grand, separated from the rest, and surmounted by a sort of dome: if this prominence should happen to be flattened, all hopes of progeny are lost. All the cells are hexagonal, each foot ${ }^{30}$ having formed its own side. No part of this work, however, is done at any stated time, as the bees seize every opportunity for the performance of their task when the days are fine; in one or two days, at most, they fill their cells with honey.

(12.) This substance is engendered from the air, ${ }^{31}$ mostly at the rising of the constellations, and more especially when Sirius is shining; never, however, before the rising of the Vergiliæ, and then just before day-break. Hence it is, that at early dawn the leaves of the trees are found covered with a kind of honey-like dew, and those who go into the open air at an early hour in the morning, find their clothes covered, and their hair matted, with a sort of unctuous liquid. Whether it is that this liquid is the sweat of the heavens, or whether a saliva emanating from the stars, or a juice exuding from the air while purifying itself, would that it had been, when it comes to us, pure, limpid, and genuine, as it was, when first it took its downward descent. But as it is, falling from so vast a height, attracting corruption in its passage, and tainted by the exhalations of the earth as it meets them, sucked, too, as it is from off the trees and the herbage of the fields, and accumulated in the stomachs of the bees-for they cast it up

${ }^{29}$ Cuvier says that the cell for the future queen is different from the others, and much larger. The bees also supply the queen larva much more abundantly with food, and of more delicate quality.

so Cuvier says that this coincidence with the number of the legs is quite, accidental, as it is with the mouth that the animal constructs the cell.

31 The basis of it is really derived from the calix or corolla of flowers. 
again through the mouth-deteriorated besides by the juices of flowers, and then steeped within the hives and subjected to such repeated changes-still, in spite of all this, it affords us by its flavour a most exquisite pleasure, the result, no doubt, of its æthereal nature and origin.

CHAP. 13. (13.) - WHERE THE BEST HONEY IS PRODUCED.

The honey is always best in those countries where it is to be found deposited in the calix of the most exquisite flowers, such, for instance, as the districts of Hymettus and Hybla, in Attica and Sicily respectively, and after them the island of Calydna. ${ }^{32}$ At first, honey is thin, like water, after which it effervesces for some days, and purifies itself like must. On the twentieth day it begins to thicken, and soon after becomes covered with a thin membrane, which gradually increases through the scum which is thrown up by the heat. The honey of the very finest flavour, and the least tainted by the leares of trees, is that gathered from the foliage of the oak and the linden, and from reeds.

CHAP. 14. (14.) -THE KINDS OF HONEY PECULIAR TO VARIOUS PLACES.

The peculiar excellence of honey depends, as already stated, ${ }^{33}$ on the country in which it is produced; the modes, too, of estimating its quality are numerous. In some countries we find the honey-comb remarkable for the goodness of the wax, as in Sicily, for instance, and the country of the Peligni ; in other places the honey itself is found in greater abundance, as in Crete, Cyprus, and Africa ; and in others, again, the comb is remarkable for its size; the northern climates, for instance, for in Germany a comb has been known to be as much as eight feet in length, and quite black on the concave surface.

But whatever the country in which it may happen to have been produced, there are three different kinds of honey.-Spring honey ${ }^{34}$ is that made in a comb which has been constructed of flowers, from which circumstance it has received the name of anthinum. There are some persons who say that this should not be touched, because the more abundant the nutriment, the

32 See B. iv. c. 24.

${ }^{34}$ Or "Flower-honey."

33 In the last Chapter. 
stronger will be the coming swarm; while others, again, leave less of this honey than of any other for the bees, on the ground that there is sure to be a vast abundance at the rising of the greater constellations, as well as at the summer solstice, when the thyme and the vine begin to blossom, for then they are sure to find abundant materials for their cells.

In taking the combs the greatest care is always requisite, for when they are stinted for food the bees become desperate, and either pine to death, or else wing their flight to other places : but on the other hand, over-abundance will entail idleness, and then they will feed upon the honey, and not the bee-bread. Hence it is that the most careful breeders take care to leave the bees a fifteenth part of this gathering. There is a certain day for beginning the honey-gathering, fixed, as it were, by a law of Nature, if men would only understand or observe it, being the thirtieth day after the bees have swarmed and come forth. This gathering mostly takes place before the end of May.

The second kind of honey is "summer honey," which, from the circumstance of its being produced at the most farourable season, has received the Greek name of horaion;35 it is generally made during the next thirty days after the solstice, while Sirius is shining in all its brilliancy. Nature has revealed in this substance most remarkable properties to mortals, were it not that the fraudulent propensities of man are apt to falsify and corrupt everything. For, after the rising of each constellation, and those of the highest rank more particularly, or after the appearance of the rainbow, if a shower does not ensue, but the dew becomes warmed by the sun's rays, a medicament, and not real honey, is produced; a gift sent from heaven for the cure of diseases of the eyes, uleers, and maladies of the internal viscera. If this is taken at the rising of Sirius, and the rising of Venus, Jupiter, or Mercury should happen to fall on the same day, as often is the case, the sweetness of this substance, and the virtue which it possesses of restoring men to life, are not inferior to those attributed to the nectar of the gods. 
CHAP. 15. (15.)-HOW HONEY IS TESTED. ERIC.EUMI. TETRAIIX, OR SISIRUM.

The crop of honey is most abundant if gathered at full moon, and it is richest when the weather is fine. In all honey, that which flows of itself, like must or oil, has received from us the name of acetum..$^{36}$ The summer honey is the most esteemed of all, from the fact of its being made when the weather is driest: it is looked upon as the most serviceable when made from thyme $;^{37}$ it is then of a golden colour, and of a most delicious flavour. The honey that we see formed in the calix of flowers is of a rich and unctuous nature ; that which is made from rosemary is thick, while that which is candied is little esteemed. Thyme honey does not coagulate, and on being touched will draw out into thin viscous threads, a thing which is the principal proof of its heaviness. When honey shows no tenacity, and the drops immediately part from one another, it is looked upon as a sign of its worthlessness. The other proofs of its goodness are the fine aroma of its smell, its being of a sweetness that closely borders on the sour, ${ }^{38}$ and being glutinous and pellucid.

Cassius Dionysius is of opinion that in the summer gathering the tenth part of the honey ought to be left for the bees if the hives should happen to be well filled, and even if not, still in the same proportion; while, on the other hand, if there is but little in them, he recommends that it should not be touched at all. The people of Attica have fixed the period for commencing this gathering at the first ripening of the wild fig; others $^{39}$ have made it the day that is sacred to Vulcan. ${ }^{40}$

(16.) The third kind of honey, which is the least esteemed of all, is the wild honey, known by the name of ericaum. ${ }^{41}$ It is collected by the bees after the first showers of autumn, when the heather ${ }^{42}$ alone is blooming in the woods, from which circumstance it derives its sandy appearance. It is mostly pro-

36 "Vinegar" is the ordinary meaning.

37 Sillig remarks that the whole of this passage is corrupt.

${ }^{38}$ Hence, perhaps, its name of "acetum."

39 The people of Italy.

40 The 10th of the calends of September, or 23rd August.

41 Or "heath-honey." In the north of England the lives are purposely taken to the moors.

42 "Erice," "heather," seems to be a preferable reading to "myrice," " tamarisk," which is adopted by Sillig. 
duced at the rising of Arcturus, beginning at the day ${ }^{43}$ before the ides of September. Some persons delay the gathering of the summer honey until the rising of Arcturus, because from then till the autumnal equinox there are fourteen days left, and it is from the equinox till the setting of the Vergiliæ, a period of forty-eight days, that the heather is in the greatest abundance. The Athenians call this plant by the name of tetralix, ${ }^{41}$ and the Eubœans sisirum, and they look upon it as affording great pleasure to the bees to browse upon, probably because there are no other flowers for them to resort to. This gathering terminates at the end of the vintage and the setting of the Vergiliæ, mostly about the ides of November. ${ }^{45}$ Experience teaches us that we ought to leave for the bees twothirds of this crop, and always that part of the combs as well, which contains the bee-bread.

From the winter solstice to the rising of Arcturus the bees are buried in sleep for sixty days, and live without any nourishment. Between the rising of Arcturus and the vernal equinox, they awake in the warmer climates, but even then they still keep within the hives, and have recourse to the provisions kept in reserve for this period. In Italy, however, they do this immediately after the rising of the Vergilia, up to which period they are asleep. Some persons, when they take the honey, weigh the hive and all, and remove just as much as they leave : a due sense of equity should always be stringently observed in dealing with them, and it is generally stated that if imposed upon in this division, the swarm will die of grief. It is particularly recommended also that the person who takes the honey should be well washed and clean : bees have a particular aversion, too, to a thief and a menstruous woman. When the honey is taken, it is the best plan to drive away the bees by means of smoke, lest they should become irritated, or else devour the honey themselves. By often applying smoke, too, they are aroused from their idleness to work; but if they have not duly incubated in the comb, it is apt to become of a livid colour. On the other hand, if they are smoked too often, they will become tainted; the honey, too, a substance which turns sour at the very slightest contact with dew, will very

4312 th September.

44 "Tetralicem" seems preferable to "tamaricem."

45 13th Norember. 
quickly receive injury from the taint thus contracted: hence it is that among the various kinds of honey which are preserved, there is one which is known by the name of acapnon. ${ }^{46}$

\section{CHAP. 16. - THE REPRODUCTION OF BEES.}

How bees generate their young has been a subject of great and subtle research among the learned; seeing that no one has ever witnessed ${ }^{47}$ any sexual intereourse among these insects. Many persons have expressed an opinion that they must be produced from flowers, aptly and artistically arranged by Nature; while others, again, suppose that they are produced from an intercourse with the one which is to be found in every swarm, and is usually called the king. This one, they say, is the only male ${ }^{48}$ in the hive, and is endowed with such extraordinary proportions, that it may not become exhausted in the performance of its duties. Hence it is, that no offspring can be produced without it, all the other bees being females ${ }^{49}$ and attending it in its capacity of a male, and not as their leader. This opinion, however, which is otherwise not improbable, is sufficiently refuted by the generation of the drones. For on what grounds could it possibly happen that the same intercourse should produce an offspring part of which. is perfect, and part in an imperfect state? The first surmise which I have mentioned would appear, indeed, to be much nearer the truth, were it not the case that here another difficulty meets us-the circumstance that sometimes, at the extremity of the combs, there are produced bees of a larger size, which put the others to flight. This noxious bee bears the name of cestrus, ${ }^{50}$ and how is it possible that it should ever be produced, if it is the fact that the bees themselves form their progeny? 51

A fact, however, that is well ascertained, is, that bees sit, ${ }^{2}$ like the domestic fowl, that which is hatched by them at

\&6 "Unsmoked" honey.

47 It takes place while they are on the wing.

48 The only prolific female, in reality.

49 Some unprolific females and some nuales, in reality.

50 Cuvier thinks that either hornets, or else the drones, must be alluded to. Virgil, Georg. B. iv. l. 197, et seq., is one of those who think that bees are produced from flowers.

51 I. e. from flowers.

52 They arrange the eggs in the cells, but they cannot be said to sit. 
first having the appearance of a white maggot, and lying across and adhering so tenaciously to the wax as to seem to be part of it. The king, however, from the earliest moment, is of the colour of honey, just as though he were made of the choicest flowers, nor has he at any time the form of a grub, but from the very first is provided with wings. ${ }^{53}$ The rest of the bees, as soon as they begin to assume a shape, have the name of nympha, ${ }^{54}$ while the drones are called sirenes, or cephenes. If a person takes off the head of either kind before the wings are formed, the rest of the body is considered a most choice morsel by the parents. In process of time the parent bees instil nutriment into them, and sit upon them, making on this occasion a loud humming noise, for the purpose, it is generally supposed, of generating that warmth which is so requisite for hatching the young. At length the membrane in which each of them is enveloped, as though it lay in an egg, bursts asunder, and the whole swarm comes to light.

This circumstance was witnessed at the suburban retreat of a man of consular dignity near Rome, whose hives were made of transparent lantern horn : the young were found to be developed in the space of forty-five days. In some combs, there is found what is known by the name of "nail" wax; ; $^{55}$ it is bitter and hard, and is only met with when the bees have failed to hatch their young, either from disease or a natural sterility, it is the abortion, in fact, of the bees. The young ones, the moment they are hatched, commence working with their parents, as though in a course of training, and the newly-born king is accompanied by a multitude of his own age.

'That the supply may not run short, each swarm rears several kings; but afterwards, when this progeny begins to arrive at a mature age, with one accord ${ }^{56}$ they put to death the inferior ones, lest they should create discord in the swarm. ${ }^{57}$ There are two sorts of king bees; those of a reddish colour are better than the black and mottled ones. The kings have

53 This is not the fact. The queen bee commences as a larva, and that the larva of a working bee, Cuvier says, which, placed in a larger cell, and nurtured in a different manner, developes its sex and becomes the queen of the new swarm.

54 They are then in the chrysalis state.

55 "Clavus."

${ }^{56}$ It is the first hatched queen that puts the others to death.

57 In consequence, really, of their pregnancy.

VOL. III. 
always a peculiar form of their own, and are double the size of any of the rest; their wings are shorter ${ }^{58}$ than those of the others, their legs are straight, their walk more upright, and they have a white spot on the forehead, which bears some resemblance to a diadem : they differ, too, very much from the rest of the community, in their bright and shining appearance.

\section{ChaP. 17. (17.) -THE MODE OF GOVERNMENT OF THE BEES.}

Let a man employ himself, forsooth, in the enquiry whether there has been only one Hercules, how many fathers Liber there have been, and all the other questions which are buried deep in the mould of antiquity! Here behold a tiny object, one to be met with at most of our country retreats, and numbers of which are always at hand, and yet, after all, it is not agreed among authors whether or not the king ${ }^{59}$ is the only one among them that is provided with no sting, and is possessed of no other arms than those afforded him by his majestic office, or whether Nature has granted him a sting, and has only denied him the power of making use of it; it being a well-known fact, that the ruling bee never does use a sting. The obedience which his subjects manifest in his presence is quite surprising. When he goes forth, the whole swarm attends him, throngs about him, surrounds him, protects him, and will not allow him to be seen. At other times, when the swarm is at work within, the king is seen to visit the works, and appears to be giving his encouragement, being hinself the only one that is exempt from work: around him are certain other bees which act as body-guards and lictors, the careful guardians of his authority. The king never quits the hive except when the swarm is about to depart; a thing which may be known a long time beforehand, as for some days a peculiar buzzing noise is to be heard within, which denotes that the bees are waiting for a favourable day, and making all due preparations for their departure. On such an occasion, if care is taken to deprive the king of one of his wings, the swarm will not fly away. When they are on the wing, every one is anxious to be near him, and takes a pleasure in being seen in the performance of its duty. When he is weary, they support him on their shoulders ; and

58 The greater size of the abdomen makes the wings look shorter.

${ }^{50}$ The queen has a sting, like the working bees, but uses it less frequently. 
when he is quite tired, they carry him outright. If one of them falls in the rear from weariness, or happens to go astray, it is able to follow the others by the aid of its acuteness of smell. Wherever the king bee happens to settle, that becomes the encampment of all.

CHAP. 18.-HAPPY OMENS SOMETIMES AFFORDED BY A SWARM OF BEES.

And then, too, it is that they afford presages both of private and public interest, clustering, as they do, like a bunch of grapes, upon houses or temples ; presages, in fact, that are often accounted for by great events. Bees settled upon the lips of Plato when still an infant even, announcing thereby the sweetness of that persuasive eloquence for which he was so noted. Bees settled, too, in the camp of the chieftain Drusus when he gained the brilliant victory at Arbalo $;^{60}$ a proof, indeed, that the conjectures of soothsayers are not by any means infallible, seeing that they are of opinion that this is always of evil augury. When their leader is withheld from them, the swarm can always be detained; and when lost, it will disperse and take its departure to find other kings. Without a king, in fact, they cannot exist, and it is with the greatest reluctance that they put them to death when there are several; they prefer, too, to destroy the cells of the young ones, if they find reason to despair of providing food; in such case they then expel the drones. And yet, with regard to the last, I find that some doubts are entertained; and that there are some authors who are of opinion that they form a peculiar species, like that bee, the very largest among them all, which is known by the name of the "thief," it is distinguished by its black colour and the largeness of its body. It is a well-known fact, however, that the bees are in the habit of killing the drones. These last have no king of their own; but how it is that they are produced without a sting, is a matter still undetermined.

In a wet spring the young swarms are more numerous; in a dry one the honey is most abundant. If food happens to

${ }^{60}$ A place in Germany, where Drusus, the brother of Tiberius, gained a victory over the Germans : the locality is unknown.

61 "Fur." A variety, probably, of the drone. 
fail the inhabitants of any particular hive, the swarm makes a concerted attack upon a neighbouring one, with the view of plundering it. The swarm that is thus attacked, at once ranges itself in battle array, and if the bee-keeper should happen to be present, that side which perceives itself favoured by him will refrain from attacking him. They often fight, too, for other reasons as well, and the two generals are to be seen drawing up their ranks in battle array against their opponents. The dispute generally arises in culling from the flowers, when each, the moment that it is in danger, summons its companions to its aid. The battle, however, is immediately put an end to by throwing dust ${ }^{62}$ among them, or raising a smoke; and if milk or honey mixed with water is placed before them, they'speedily become reconciled.

\section{CHAP. 19. (18.) -THE VARIOUS KINDS OF BEES.}

There are field bees also, and wild bees, ungainly in appearance, and much more irascible than the others, but remarkable for their laboriousness and the excellence of their work. Of domestic bees there are two sorts; the best are those with short bodies, speckled all over, and of a compact round shape. Those that are long, and resemble the wasp in appearance, are an inferior kind; and of these last, the very worst of all are those which have the body covered with hair. In Pontus there is a kind of white bee, which makes honey twice a month. On the banks of the river Thermodon there are two kinds found, one of which makes honey in the trees, the other under ground: they form a triple row of combs, and produce honey in the greatest abundance.

Nature has provided bees with a sting, which is inserted in the abdomen of the insect. There are some who think that at the first blow which they inflict with this weapon they will instantly die, ${ }^{63}$ while others, again, are of opinion that such is not the case, unless the animal drives it so deep as to cause a portion of the intestines to follow; and they assert, also, that after they have thus lost their sting they become drones, ${ }^{64}$

62 So Virgil says-

"Hæc certamina tanta

Pulveris exigui jactu compressa quiescent."-Georg. iv. 87.

${ }^{63}$ If it is left in the wound, the insect dies, being torn asunder.

${ }^{64}$ Of course this is fabulous, as the drones are males. 


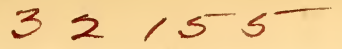

Chap. 20.]

THE DISEASES OF BEES.

and make no honey, being thus castrated, so to say, and equally incapable of inflicting injury, and of making themselves useful by their labours. We have instances stated of horses being killed by bees.

They have a great aversion to bad smells, and fly away from them; a dislike which extends to artificial perfumes even. Hence it is that they will attack persons who smell of unguents. They themselves, also, are exposed to the attacks of wasps and hornets, which belong to the same class, but are of a degenerate ${ }^{65}$ nature; these wage continual warfare against them, as also does a species of gnat, which is known by the name of " mulio;" 66 swallows, too, and various other birds prey upon them. Frogs lie in wait for them when in quest of water, which, in fact, is their principal occupation at the time they are rearing their young. And it is not only the frog that frequents ponds and streams that is thus injurious to them, but the bramble-frog as well, which will come to the hives even in search of them, and, crawling up to the entrance, breathe through the apertures; upon hearing which, a bee flies to the spot, and is snapped up in an instant. It is generally stated that frogs are proof against the sting of the bee. Sheep, too, are peculiarly dangerous to them, as they have the greatest difficulty in extricating themselves from the fleece. The smell of crabs, ${ }^{67}$ if they happen to be cooked in their vicinity, is fatal to them.

\section{CHAP. 20.-THE DISEASES OF BEES.}

Bees are also by nature liable to certain diseases of their own. The sign that they are diseased, is a kind of torpid, moping sadness : on such occasions, they are to be seen bringing out those that are sick before the hives, and placing them in the warm sun, while others, again, are providing them with food. Those that are dead they carry away from the hive, and attend the bodies, paying their last duties, as it were, in funeral procession. If the king should happen to be carried off by the pestilence, the swarm remains plunged in grief' and listless inactivity ; it collects no more food, and ceases to issue

${ }_{65}$ Though belonging to the same class, they are not of degenerate kinds.

66 The "mule-gnat."

67 See Virgil, Georg. B. iv. 1. 27. 
forth from its abode; the only thing that it does is to gather around the body, and to emit a melancholy humming noise. Upon such occasions, the usual plan is to disperse the swarm and take away the body; for otherwise they would continue listlessly gazing upon it, and so prolong their grief. Indeed, if due care is not taken to come to their aid, they will die of hunger. It is from their cheerfulness, in fact, and their bright and sleek appearance that we usually form an estimate as to their health.

(19) There are certain maladies, also, which affect their productions; when they do not fill their combs, the disease under which they are labouring is known by the name of claros, ${ }^{68}$ and if they fail to rear their young, they are suffering from the effects of that known as blapsigonia. ${ }^{69}$

\section{CHAP. 21.-THINGS THAT ARE NOXIOUS TO BEES.}

Echo, or the noise made by the reverberation of the air, is also injurious to bees, as it dismays them by its redoubled sounds; fogs, also, are noxious to them. Spiders, too, are especially hostile to bees; when they have gone so far as to build their webs within the hive, the death of the whole swarm is the result. The common and ignoble moth, ${ }^{70}$ too, that is to be seen fluttering about a burning candle, is deadly to them, and that in more ways than one. It devours the wax, and leaves its ordure behind it, from which the maggot known to us as the "teredo" is produced; besides which, wherever it goes, it drops the down from off its wings, and thereby thickens the threads of the cobwebs. The teredo is also engendered in the wood of the hive, and then it proves especially destructive to the wax. Rees are the victims, also, of their own greediness, for when they glut themselves overmuch with the juices of the flowers, in the spring season more particularly, they are troubled with flux and looseness. Olive oil is fatal ${ }^{71}$ to not only bees, but all other insects as well, and more especially if they are placed

${ }_{68}$ The reading seems doubtful, and the meaning is probably unknown.

69 "Injury of the young."

70 There are two kinds of hive-moth-the Phalæna tinea mellanella of Linnæus, and the Phalæna tortrix cereana. It deposits its larva in holes which it makes in the wax.

${ }^{71}$ In consequence of closing the stigmata, and so impeding their respiration. The same result, no doubt, is produced by the honey when smeared over their bodies. 
in the sun, after the head has been immersed in it. Sometimes, too, they themselves are the cause of their own destruction; as, for instance, when they see preparations being made for taking their honey, and immediately fall to devouring it with the greatest avidity. In other respects they are remarkable for their abstemiousness, and they will expel those that are inclined to be prodigal and voracious, no less than those that are sluggish' and idle. 'Their own honey even may be productive of injury to them; for if they are smeared with it on the fore-part of the body, it is fatal to them. Such are the enemies, so numerous are the accidents-and how small a portion of them have I here enumerated !- to which a creature that proves so bountiful to us is exposed. In the appropriate place ${ }^{72}$ we will treat of the proper remedies; for the present the nature of them is our subject.

\section{CHAP. 22. (20.) - HOW tO KEFP BEES TO THE HIVE.}

The clapping of the hands and the tinkling of brass afford bees great delight, and it is by these means that they are brought together; a strong proof, in fact, that they are possessed of the sense of hearing. When their work is completed, their offspring brought forth, and all their duties fulfilled, they still have certain formal exercises to perform, ranging abroad throughout the country, and soaring aloft in the air, wheeling round and round as they fly, and then, when the hour for taking their food has come, returning home. The extreme period of their life, supposing that they escape accident and the attacks of their enemies, is only seven years; a hive, it is said, never lasts more than ten. ${ }^{73}$ There are some persons, who think that, when dead, if they are preserved in the house throughout the winter, and then exposed to the warmth of the spring sun, and kept hot all day in the ashes of fig-tree wood, they will come to life again.

\section{CHAP. 23.- METHODS OF RENEWING THE SWARM.}

These persons say also, that if the swarm is entirely lost, it may be replaced by the aid of the belly ${ }^{74}$ of an ox newly killed,

72 B. xxi. c. 42.

73 Cuvier says that a hive has been known to last more than thirty years: but it is doubtful if bees ever live so long as ten, or, except the queen, little more than one.

${ }^{74}$ Though Virgil tells the same story, in B. iv. of the Georgics, in relation to the shepherd Aristæus, all this is entirely fabulous. 
covered over with dung. Virgil also says $\mathrm{s}^{75}$ that this may be done with the body of a young bull, in the same way that the carcase of the horse produces wasps and hornets, and that of the ass beetles, Nature herself effecting these changes of one substance into another. But in all these last, sexual intercourse is to be perceived as well, though the characteristics of the offspring are pretty much the same as those of the bee.

\section{CHAP. 24. (21.)-WASPS AND HORNETS : ANIMALS WHICH APPRO- PRIATE WHAT BELONGS TO OTHERS.}

Wasps build their nests of mud in lofty places, ${ }^{76}$ and make wax therein: hornets, on the other hand, build in holes or under ground. With these two kinds the cells are also hexagonal, but, in other respects, though made of the bark of trees, they strongly resemble the substance of a spider's web. Their young also are found at irregular intervals, and are of unshapely appearance; while one is able to fly, another is still a mere pupa, and a third only in the maggot state. It is in the autumn, too, and not in the spring, that all their young are produced; and they grow during the full moon more particularly. The wasp which is known as the ichneumon, ${ }^{77}$ a smaller kind than the others, kills one kind of spider in particular, known as the phalangium; after which it carries the body to its nest, covers it over with a sort of gluey substance, and then sits and hatches from it its young. ${ }^{78}$ In addition to this, they are all of them carnivorous, while on the other hand bees will touch no animal substance whatever. Wasps more particularly pursue the larger flies, and after catching them cut off the head and carry away the remaining portion of the body.

Wild hornets live in the holes of trees, and in winter, like other insects, keep themselves concealed; their life does not exceed two years in length. It is not unfrequently that their sting is productive of an attack of fever, and there are authors who say that thrice nine stings will suffice to kill a man. Of

75 Georg. B. iv. 1. 284, et seq.

76 Under roofs, and sometimes in the ground : hornets build in the hollows of trees.

77 Called "Sphæx" by Linnæus.

78 The true version is, that after killing the insect they bury it with their eggs as food for their future young. 
the other hornets, which seem not to be so noxious, there are two kinds; the working ones, which are smaller in size and die in the winter; and the parent hornets, which live two years; these last, indeed, are quite harmless. ${ }^{79}$ In spring they build their nests, which have generally four entrances, and here it is that the working hornets are produced: after these have been hatched they form other nests of larger size, in which to bring forth the parents of the future generation. From this time the working hornets begin to follow their vocation, and apply themselves to supplying the others with food. The parent hornets are of larger size than the others, and it is very doubtful whether they have a sting, as it is never to be seen protruded. These races, too, have their drones. Some persons are of opinion that all these insects lose their stings in the winter. Neither hornets nor wasps have a king, nor do they ever congregate in swarms; but their numbers are recruited by fresh offspring from time to time.

\section{CHAP. 25. (22.) 一THE BOMBYX OF ASSYRIA.}

A fourth class of this kind ${ }^{80}$ of insect is the bombyx, ${ }^{81}$ which is a native of Assyria, and is of larger size than any of those which have been previously mentioned. They construct their nests of a kind of mud which has the appearance of salt, and then fasten them to a stone, where they become so hard, that it is scarcely possible to penetrate them with a dart even. In these nests they make wax, in larger quantities than bees, and the grub which they then produce is larger.

CHAP. 26. -THE LARVE OF THE SILK-WORM-WHO FIRST INVENTED SILK CLOTHS.

There is another class also of these insects produced in quite a different manner. These last spring from a grub of larger size, with two horns of very peculiar appearance. The larva then becomes a caterpillar, after which it assumes the state in which it is known as bombylis, then that called necydalus, and after that, in six months, it becomes a silk-worm. ${ }^{82}$

79 Cuvier says that it is the males, and not the females, that have no sting.

80 What modern naturalists call the "Hymenoptera."

81 Some kind of wasp, or, as Cuvier says, probably the mason bee.

82 Called "bombyx" also; though, as Cuvier remarks, of a kind altogether different from the preceding one. 
These insects weave webs similar to those of the spider, the material of which is used for making the more costly and luxurious garments of females, known as "bombycina." Pamphile, a woman of $\operatorname{Cos}^{83}$ the daughter of Platea, was the first ${ }^{84}$ person who discovered the art of unravelling these webs and spinning a tissue therefrom; indeed, she ought not to be deprived of the glory of having discovered the art of making vestments which, while they cover a woman, at the same moment reveal her naked charms.

\section{CHAP. 27. (23.) -THE SILK-WORM OF COS-HOW THE COAN VESTMENTS ARE MADE.}

The silk-worm, too, is said to be a native of the isle of Cos, where the vapours of the earth give new life to the flowers of the cypress, the terebinth, the ash, and the oak which have been beaten down by the showers. At first they assume the appearance of small butterflies with naked bodies, but soon ifter, being unable to endure the cold, they throw out bristly hairs, and assume quite a thick coat against the winter, $b$, rubbing off the down that covers the leaves, by the aid of the roughness of their feet. This they compress into balls by carding it with their claws, and then draw it out and hang it between the branches of the trees, making it fine by combing it out as it were : last of all, they take and roll it round their body, thus forming a nest in which they are enveloped. It is in this state that they are taken; after which they are placed in earthen vessels in a warm place, and fed upon bran. A peculiar sort of down soon shoots forth upon the body, on being clothed with which they are sent to work upon another task. The cocoons ${ }^{85}$ which they have begun to form are rendered soft and pliable by the aid of water, and are then drawn out into threads by means of a spindle made of a reed. Nor, in fact, have the men even felt ashamed to make us $^{86}$ of garments formed of this material, in consequence of

83 The first kinds of silk dresses worn by the Roman ladies were from this island, and, as Pliny says, were known by the name of Coce vestes. These dresses were so fine as to be transparent, and were sometimes dyed purple, and enriched with stripes of gold. They probably had their name from the early reputation which Cos acquired by its manufactures of silk.

${ }_{34}$ This account is derived from Aristotle, Hist. Anim. B. v. c. 19.

85 "Lanificia."

86 Early in the reign of Tiberius, as we learn from Tacitus, the senate 
their extreme lightness in summer : for, so greatly have manners degenerated in our day, that, so far from wearing a cuirass, a garment even is found to be too heavy. The produce of the Assyrian silk-worm, however, we have till now left to the women only.

CHAP. 28. (24.)—SPIDERS; THE KINDS THAT MAKE WEBS; THE MATERIALS USED BY THEM IN SO DOLNG.

It is by no means an absurdity to append to the silk-worm an account of the spider, a creature which is worthy of our especial admiration. There are numerous kinds of spiders, however, which it will not be necessary here to mention, from the fact of their being so well known. Those that bear the name of phalangium are of small size, with bodies spotted and running to a point ; their bite is renomous, and they leap as they move from place to place. Another kind, again, is black, and the fore-legs are remarkable for their length. They have all of them three joints in the legs. The smaller kind of wolf-spider ${ }^{87}$ does not make a web, but the larger ones make their holes in the earth, and spread their nets at the narrow entrance thereof. A third kind, again, is remarkable for the skill which it displays in its operations. These spin a large web, and the abdomen suffices to supply the material for so extensive a work, whether it is that, at stated periods the excrements are largely secreted in the abdomen, as Democritus thinks, or that the creature has in itself a certain faculty of secreting ${ }^{88}$ a peculiar sort of woolly substance. How steadily does it work with its claws, how beautifully rounded and how equal are the threads as it forms its web, while it employs the weight of its body as an equipoise! It begins at the middle to weave its web, and then extends it by adding the threads in rings around, like a warp upon the woof: forming the meshes at equal intervals, but continually enlarging them as the web increases in breadth, it finally unites them all by an indissoluble knot. With what wondrous art does it conceal the snares that lie in wait for its prey in its checkered nettings! How little, too, would it seem that there is any such trap laid in the compactness of

enacted "ne vestis Serica viros fædaret"- " That men should not defile themselves by wearing garments of silk," Ann. B. ii. c. 33 .

87 The Aranea lupus of Linnæus.

83 As Cuvier observes, he has here guessed at the truth. 
its web and the tenacious texture of the woof, which would appear of itself to be finished and arranged by the exercise of the very highest art! How loose, too, is the body of the web as it yields to the blasts, and how readily does it catch all objects which come in its way! You would fancy that it had left, quite exhausted, the thrums of the upper portion of its net unfinished where they are spread across; it is with the greatest difficulty that they are to be perceived, and yet the moment that an object touches them, like the lines of the hunter's net, they throw it into the body of the web. With what architectural skill, too, is its hole arched over, and how well defended by a nap of extra thickness against the cold! How carefully, too, it retires into a corner, and appears intent upon anything but what it really is, all the while that it is so carefully shut up from view, that it is impossible to perceive whether there is anything within or not! And then too, how extraordinary the strength of the web! When is the wind ever known to break it, or what accumulation of dust is able to weigh it down?

The spider often spreads its web right across between two trees, when plying its art and learning how to spin ; and then, as to its length, the thread extends from the very top of the tree to the ground, while the insect springs up again in an instant from the earth, and travels aloft by the very self-same thread, thus mounting at the same moment and spinning its threads. When its prey falls into its net, how on the alert it is, and with what readiness it runs to seize it! Even though it should be adhering to the very edge of its web, the insect always runs instantly to the middle, as it is by these means that it can most effectually shake the web, and so successfully entangle its prey. When the web is torn, the spider immediately sets about repairing it, and that so neatly, that nothing like patching can ever be seen. The spider lies in wait even for the young of the lizard, and after enveloping the head of the animal, bites its lips; a sight by no means unworthy of the amphitheatre itself, when it is one's good fortune to witness it. Presages also are drawn from the spider; for when a river is about to swell, it will suspend its web higher than usual. In calm weather these insects do not spin, but when it is cloudy they do, and hence it is, that a great number of cobwebs is a sure sign of showery weather. It is 
generally supposed that it is the female spider that spins, and the male that lies in wait for prey, thus making an equal division of their duties.

\section{CHAP. 29.-THE GENERATION OF SPIDERS.}

Spiders couple ${ }^{89}$ backwards, and produce maggots like eggs; for I ought not to defer making some mention of this subject, seeing, in fact, that of most insects there is hardly anything else to be said. All these eggs they lay in their webs, but scattered about, as they leap from place to place while laying them. The phalangium is the only spider that lays a considerable number of them, in a hole; and as soon as ever the progeny is hatched it devours its mother, and very often the male parent as well, for that, too, aids in the process of incubation. These last produce as many as three hundred eggs, the others a smaller number. Spiders take three days to hatch their eggs. They come to their full growth in twenty-eight days.

\section{CHAP. 30. (25.)-SCORPIONS.}

In a similar manner to the spider, the land scorpion also produces maggots ${ }^{90}$ similar to eggs, and dies in a similar manner. This animal is a dangerous scourge, and has a venom like that of the serpent; with the exception that its effects are far more $e^{91}$ painful, as the person who is stung will linger for three days before death ensues. The sting is invariably fatal to virgins, and nearly always so to matrons. It is so to men also, in the morning, when the animal has issued from its hole in a fasting state, and has not yet happened to discharge its poison by any accidental stroke. The tail is always ready to strike, and ceases not for an instant to menace, so that no opportunity may possibly be missed. The animal strikes too with a sidelong blow, or else by turning the tail

89 They copulate in a manner dissimilar to that of any other insectsthe male fecundates the female by the aid of feelers, which he introduces into the vulva of the female situate beneath the anterior part of the abdomen.

90. Cuvier remarks, that the scorpion is viviparous; but the young are white when born, and wrapped up in an oval mass, for which reason they may easily be taken for maggots or grubs.

${ }^{91}$ This must be understood of the scorpion of Egypt, Libya, and Syria. The sting of that of the south of Europe is not generally dangerous. 
upwards. Apollodorus informs us, that the poison which they secrete is of a white colour, and he has divided them into nine classes, distinguished mostly by their colours-to very little purpose, however, for it is impossible to understand which among these it is that he has pronounced to be the least dangerous. He says, also, that some of them have a double sting, and that the males-for he asserts that they are engendered by the union of the sexes - are the most dangerous. These may easily be known, he says, by their slender form and greater length. He states, also, that they all of them have venom in the middle of the day, when they have been warmed by the heat of the sun, as, also, when they are thirsty-their thirst, indeed, can never be quenched. It is an ascertained fact, that those which have seven joints in the tail are the most ${ }^{92}$ deadly; the greater part, however, have but six.

For this pest of Africa, the southern winds have provided means of flight as well, for as the breeze bears them along, they extend their arms and ply them like so many oars in their flight; the same Apollodorus, however, asserts that there are some which really have wings. ${ }^{93}$ The Psylli, who for their own profit have been in the habit of importing the poisons of other lands among us, and have thus filled Italy with the pests which belong to other regions, have made attempts to import the flying scorpion as well, but it has been found that it cannot live further north than the latitude of Sicily. However, they ${ }^{94}$ are sometimes to be seen in Italy, but are quite harmless there; they are found, also, in many other places, the vicinity of Pharos, in Egypt, for instance. In Seythia, the scorpion is able to kill the swine even with its sting, an animal which, in general, is proof against poisons of this kind in a remarkable degree. When stung, those swine which are black die more speedily than others, and more particularly if they happen to throw themselves into the water. When a person has been stung, it is generally supposed that he may be cured by drinking the ashes of the scorpion ${ }^{95}$ mixed with wine. It

92 Cuvier seems to regard this as fanciful : he says that the instances of seven joints are but rarely to be met with.

93 There are no winged scorpions. Cuvier thinks that he may possibly allude to the panorpis, or scorpion-fly, the abdomen of which terminates in a forceps, which resembles the tail of the scorpion.

94 Probably the panorpis.

95 See B. Xxix. c. 29. 
is the belief also that there is nothing more baneful to the scorpion and the stellio, ${ }^{93}$ than to dip them in oil. This last animal is also dangerous to all other creatures, except those which, like itself, are destitute of blood : in figure it strongly resembles the common lizard. For the most part, also, the scorpion does no injury to any animal which is bloodless. Some writers, too, are of opinion that the scorpion devours its offspring, and that the one among the joung which is the most adroit avails itself of its sole mode of escape, by placing itself on the back of the mother, and thus finding a place where it is in safety from the tail and the sting. The one that thus escapes, they say, becomes the avenger of the rest, and at last, taking advantage of its elevated position, puts its parents to death. 'The scorpion produces eleven at a birth.

$$
\text { CHAP. 31. (26.)-THE STELLIO. }
$$

The stellio ${ }^{97}$ has in some measure the same nature as the chameleon, as it lives upon nothing but dew, and such spiders ${ }^{58}$ as it may happen to find.

CHAP. 32.-THE GRASSHOPPER : THAT IT HAS NEITHER MOUTH NOR OUTLET FOR FOOD.

The cicada ${ }^{99}$ also lives in a similar manner, and is divided into two kinds. The smaller kind are born the first and die the last, and are without a voice. The others are of the flying kind, and have a note; there are two sorts, those known as acheta, and the smaller ones called tettigonia: these last have the loudest voice. In both of these last-mentioned kinds, it is the male that sings, while the female is silent. There are nations in the east that feed upon these insects, the Parthians

96 The starred or spotted lizard.

97 'The stellio of the Romans is the "ascalabos" or "ascalabotes" of the Greeks, the lizard into which Ascalabus was changed by Ceres: see Ovid, Met. B. v. 1. 450, et seq. Pliny also mentions this in B. xxix. c. 4, though he speaks of some difference in their appearance. It is a species of gecko, the tarentola of Italy, the tarente of Provence, and the geckotta, probably, of Lacepède. The gecko, Cuvier says, is not venomous; but it causes small blisters to rise on the skin when it walks over it, the result, probably, of the extreme sharpness of its nails.

${ }_{98}$ See c. 28 of this Book, and B. viii. c. 95 ; B. xxx. c. 27.

${ }^{99}$ A general name for the grasshopper. Cuvier remarks, that Pliny is less clear on this subject than Aristotle, the author from whom he has borrowed. 
even, wealthy and affluent as they are. They prefer the male before it has had sexual intercourse, and the female after; and they take $e^{1}$ their eggs, which are white. They engender with the belly upwards. Upon the back they have a sharp-edged instrument, ${ }^{2}$ by means of which they excavate a hole to breed in, in the ground. The young is, at first, a small maggot in appearance, after which the larva assumes the form in which it is known as the tettigometra. ${ }^{3}$ It bursts its shell about the time of the summer solstice, and then takes to flight, which always happens in the night. The insect, at first, is black and hard.

This is the only living creature that has no mouth; though it has something instead which bears a strong resemblance to the tongues of those insects which carry a sting in the mouth : this organ is situate in the breast ${ }^{4}$ of the animal, and is employed by it in sucking up the dew. The corselet itself forms a kind of pipe; and it is by means of this that the achetæ utter their note, as already mentioned. Beyond this, they have no viscera in the abdomen. When surprised, they spring upwards, and eject a kind of liquid, which, indeed, is our only proof that they live upon dew. This, also, is the only animal that has no outlet for the evacuations of the body. Their powers of sight are so bad, that if a person contracts his finger, and then suddenly extends it close to them, they will come upon it just as though it were a leaf. Some authors divide these animals into two kinds, the "surcularia," which is the largest, and the "frumentaria," by many known as the " avenaria ;" this last makes its appearance just as the corn is turning dry in the ear.

(27.) The grasshopper is not a native of countries thatare bare of trees-hence it is that there are none in the vicinity of the city of Cyrene-nor, in fact, is it produced in champaign coun-

1 "Correptis" seems a preferable reading to "conrupti," that adopted by Sillig.

2 The female has this, and employs it for piercing dead branches in which to deposit its eggs.

3 "The " mother of the grasshopper."

4 The trunk of the grasshopper, Cuvier says, is situate so low down, that it seems to be attached to the breast. With it the insect extracts the juices of leaves and stalks.
5 Or "twig-grasshopper."
7 Or " oat-grasshopper."
' Or " corn-grasshopper." 
tries, or in cool and shady thickets. They will take to some places much more readily than others. In the district of Miletus they are only to be found in some few spots; and in Cephallenia, there is a river which runs through the country, on one side of which they are not to be found, while on the other they exist in vast numbers. In the territory of Rhegium, again, none of the grasshoppers have any note, while beyond the river, in the territory of Locri, ${ }^{8}$ they sing aloud. Their wings are formed similarly to those of bees, but are larger, in proportion to the body.

\section{CHAP. 33. (28.) - THE WINGS OF INSECTS. ${ }^{9}$}

There are some insects which have two wings, flies, for instance; others, again, have four, like the bee. The wings of the grasshopper are membranous. Those insects which are armed with a sting in the abdomen, have four wings. None of those which have a sting in the mouth, have more than two wings. The former have received the sting for the purpose of defending themselves, the latter for the supplying of their wants. If pulled from off the body, the wings of an insect will not grow again; no insect which has a sting in. serted in its body, has two wings only.

CHAP. 34. -THE BEETLE. THE GLOW-WORM. OTHER KINDS OF BEETLES.

Some insects, for the preservation of their wings, are covered with a crust,${ }^{10}$ the beetle, for instance, the wing of which is peculiarly fine and frail. To these insects a sting has been denied by Nature; but in one large kind ${ }^{11}$ we find horns of a remarkable length, two-pronged at the extremities, and forming pincers, which the animal closes when it is its intention to

8 The river Cæcina. See B. iii. c. 15. This river is by Strabo, B. vi. c. 260, called the Alex. Elian has the story that the Locrian grasshoppers become silent in the territory of Rhegium, and those of Rhegium in the territory of Locri, thereby implying that they each have a note in its own respective country.

9 Cuvier says that the observations in this Chapter, derived from Aristotle, are remarkable for their exactness, and show that that philosopher had studied insects with the greatest attention.

$10 \mathrm{Or}$ sheath ; the Coleoptera of the naturalists.

11 The flying stag-beetle, the Lucanus cervus of Linnæus.

VOL. III. 
bite. These beetles are suspended from the neck of infants by way of remedy against certain maladies: Nigidius calls them "lucani." There is another kind ${ }^{12}$ of beetle, again, which, as it goes backwards with its feet, rolls the dung into large pellets, and then deposits in them the maggots which form its young, as in a sort of nest, to protect them against the rigours of winter. Some, again, fly with a loud buzzing or a drony noise, while others ${ }^{13}$ burrow numerous holes in the hearths and out in the fields, and their shrill chirrup is to be heard at night.

The glow-worm, by the aid of the colour of its sides ${ }^{14}$ and haunches, sends forth at night a light which resembles that of fire; being resplendent, at one moment, as it expands its wings, ${ }^{15}$ and then thrown into the shade the instant it has. shut them. These insects are never to be seen before the grass of the pastures has come to maturity, nor yet after the hay has been cut. On the other hand, it is the nature of the black beetle $^{16}$ to seek dark corners, and to avoid the light: it is mostly found in baths, being produced from the humid vapours which arise therefrom. There are some beetles also, belonging to the same species, of a golden colour and very large size, which burrow ${ }^{17}$ in dry ground, and construct small combs of a porous nature, and very like sponge; these they fill with a poisonous kind of honey. In Thrace, near Olynthus, there is a small locality, the only one in which this animal cannot exist; from which circumstance it has received the name of "Cantharolethus." 18

The wings of all insects are formed without ${ }^{19}$ any division in

12 The dung-beetle, the Scarabæus pilularius of Linnæus.

13 Various kinds of crickets.

14 Cuvier says that it is on the two sides of the abdomen that the male carries its light, while the whole posterior part of the female is shining.

15 In the glow-worm of France, the Lampyris noctiluca of Linnæus, the female is without wings, while the male gives but little light. In that of Italy, the Lampyris Italica, both sexes are winged.

16 "Blattæ." See B. xxix. c. 39, where three kinds are specified.

17 This beetle appears to be unknown. Cuvier suggests that the Scarabæus nasicornis of Linnæus, which haunts dead bark, or the Scarabæus auratus may be the insect referred to.

18 "Fatal to the beetle."

19 Cuvier remarks that this assertion, borrcwed from Aristotle, is incor-. rect. The wings of many of the Coleoptera are articulated in the middle, and so double, one part on the other, to enter the sheath. 
them, and they none of them have a tail, ${ }^{20}$ with the exception of the scorpion; this, too, is the only one among them that has arms, ${ }^{21}$ together with a sting in the tail. As to the rest of the insects, some of them have the sting in the mouth, the gad-fly for instance, or the "tabanus," as some persons choose to call it: the same is the case, too, with the gnat and some kinds of flies. All these insects have their stings situate in the mouth instead ${ }^{22}$ of a tongue; but in some the sting is not pointed, being formed not for pricking, but for the purpose of suction: this is the case more especially with flies, in which it is clear that the tongue ${ }^{23}$ is nothing more than a tube. These insects, too, have no teeth. Others, again, have little horns protruding in front of the eyes, but without any power in them; the butterfly, for instance. Some insects are destitute of wings, such as the scolopendra, for instance. ${ }^{2 t}$

\section{CHAP. 35.-LOCUSTS.}

Those insects which have feet, move sideways. Some of them have the hind feet longer than the fore ones, and curving outwards, the locust, for example.

(29.) These creatures lay their eggs in large masses, in the autumn, thrusting the end of the tail into holes which they form in the ground. These eggs remain underground throughout the winter, and in the ensuing year, at the close of spring, small locusts issue from them, of a black colour, and crawling along without legs $\mathrm{s}^{25}$ and wings. Hence it is that a wet spring destroys their eggs, while, if it is dry, they multiply in great abundance. Some persons maintain that they breed twice a year, and die the same number of times; that they bring forth at the rising ${ }^{26}$ of the Vergiliæ, and die at the rising of the Dog-star, ${ }^{27}$ after which others spring up in

${ }^{20}$ Cuvier remarks; that the panorpis has a tail very like that of the scorpion; and that the ephemera, the ichneumons and others, have tails also. Aristotle, in the corresponding place, only says that the insects do not use the tail to direct their flight.

21 These are merely the feelers of the jaws.

22 Not instead of, but in addition to, the tongue, by the aid of which they suck.

${ }_{22}$ Evidently meaning the trunk.

24 See B. xxix. c. 39.

25 It is not true that the young locusts are destitute of feet.

267 th May.

27 18th July. 
their places: according to some, it is at the setting ${ }^{28}$ of Arcturus that the second litter is produced. That the mothers die the moment they have brought forth, is a well-known fact, for a little worm immediately grows about the throat, which chokes them: at the same time, too, the males perish as well. This insect, which thus dies through a cause apparently so trifling, is able to kill a serpent by itself, when it pleases, by seizing its jaws with its teeth..$^{29}$ Locusts are only produced in champaign places, that are full of chinks and crannies. In India, it is said that they attain the length of three ${ }^{30}$ feet, and that the people dry the legs and thighs, and use them for saws. There is another mode, also, in which these creatures perish; the winds carry them off in vast swarms, upon which they fall into the sea or standing waters, and not, as the ancients supposed, because their wings have been drenched by the dampness of the night. The same authors have also stated, that they are unable to fly during the night, in consequence of the cold, being ignorant of the fact, that they travel over lengthened tracts of sea for many days together, a thing the more to be wondered at, as they have to endure hunger all the time as well, for this it is which causes them to be thus seeking pastures in other lands. This is looked upon as a plague $e^{31}$ inflicted by the anger of the gods ; for as they fly they appear to be larger than they really are, while they make such a loud noise with their wings, that they might be readily supposed to be winged creatures of quite another species. Their numbers, too, are so vast, that they quite darken the sun; while the people below are anxiously following them with the eye, to see if they are about to make a descent, and so cover their lands. After all, they have the requisite energies for their flight; and, as though it had been but a trifling matter to pass over the seas, they cross immense tracts of country, and cover them in clouds which bode destruction to the harvests. Scorching numerous objects by their very contact, they eat away everything with their teeth, the very doors of the houses even.

28 11th May.

${ }^{29}$ Cuvier treats this story as purely imaginary.

${ }^{30}$ Cuvier says that some have been known nearly a foot long, but not more.

31 He alludes to the ravages committed by the swarms of the migratory locust, Grillus migratorius of Linnæus. 
Those from Africa are the ones which chiefly devastate Italy ; and more than once the Roman people have been obliged to have recourse to the Sibylline Books, to learn what remedies to employ under their existing apprehensions of impending famine. In the territory of Cyrenaica ${ }^{32}$ there is a law, which even compels the people to make war, three times a year, against the locusts, first, by crushing their eggs, next by killing the young, and last of all by killing those of full growth; and he who fails to do so, incurs the penalty of being treated as a deserter. In the island of Lemnos also, there is a certain measure fixed by law, which each individual is bound to fill with locusts which he has killed, and then bring it to the magistrates. It is for this reason, too, that they pay such respect to the jack-daw, which flies to meet the locusts, and kills them in great numbers. In Syria, also, the people are placed under martial law, and compelled to kill them: in so many countries does this dreadful pest prevail. The Parthians look upon them as a choice food, ${ }^{33}$ and the grasshopper as well. The voice of the locust appears to proceed from the back part of the head. It is generally believed that in this place, where the shoulders join on to the body, they have, as it were, a kind of teeth, and that it is by grinding these against each other that they produce the harsh noise which they make. It is more especially about the two equinoxes that they are to be heard, in the same way that we hear the chirrup of the grasshopper about the summer solstice. The coupling of locusts is similar to that of all other insects that couple, the female supporting the male, and turning back the extremity of the tail towards him; it is only after a considerable time that they separate. In all these kinds of insects the male is of smaller size than the female.

CHAP. 36. (30.)-ANTS.

The greater part of the insects produce a maggot. Ants also produce one in spring, which is similar to an egg, ${ }^{34}$ and they

33 Julius Obsequens speaks of a pestilence there, created by the dead bodies of the locusts, which caused the death of 8000 persons.

33 See also B. vi. c. 35.

34 What are commonly called ants' eggs, are in reality their larvæ and nymphæ. Enveloped in a sort of tunic, these last, Cuvier says, are like grains of corn, and from this probably has arisen the story that they lay 
work in common, like bees; but whereas the last make theirfood, the former only store ${ }^{35}$ it away. If a person only compares the burdens which the ants carry with the size of their bodies, he must confess that there is no animal which, in proportion, is possessed of a greater degree of strength. These burdens they carry with the mouth, but when it is too large to admit of that, they turn their backs to it, and push it onwards with their feet, while they use their utmost energies with their shoulders. These insects, also, have a political community among themselves, and are possessed of both memory and foresight. They gnaw each grain before they lay it by, for fear lest it should shoot while under ground; those grains, again, which are too large for admission, they divide at the entrance of their holes; and those which have become soaked by the rain, they bring out and dry. ${ }^{36}$ They work, too, by night, during the full moon; but when there is no moon, they cease working. And then, too, in their labours, what ardour they display, what wondrous carefulness! Because they collect their stores from different quarters, in ignorance of the proceedings of one another, they have certain days set apart for holding a kind of market, on which they meet together and take stock. ${ }^{37}$ What vast throngs are then to be seen hurrying together, what anxious enquiries appear to be made, and what earnest parleys $\mathrm{s}^{38}$ are going on among them as they meet! We see even the very stones worn away by their footsteps, and roads beaten down by being the scene of their labours. Let no one be in doubt, then, how much assiduity and application, even in the very humblest of objects, can upon every occasion effect! Ants are the only living beings, besides man, that bestow burial on the dead. In Sicily there are no winged ants to be found.

(31.) The horns of an Indian ant, suspended in the temple

up grains against the winter, a period through which in reality they do not eat.

\$5 They stow away bits of meat and detached portions of fruit, to nourish their larvæ with their juices.

${ }^{36}$ It is in reality their larvæ that they thus bring out to dry. The working ants, or neutrals, are the ones on which these labours devolve: the males and females are winged, the working ants are without wings.

37 "Ad recognitionem mutuam."

38 Some modern writers express an opinion that when they meet, they converse and encourage one another by the medium of touch and smell. 
of Hercules, at Erythræ, ${ }^{39}$ have been looked upon as quite miraculous for their size. This ant excavates gold from holes, in a country in the north of India, the inhabitants of which are known as the Dardx. It has the colour of a cat, and is in size as large as an Egyptian wolf. ${ }^{40}$ This gold, which it extracts in the winter, is taken by the Indians during the heats of summer, while the ants are compelled, by the excessive warmth, to hide themselves in their holes. Still, however, on being aroused by catching the scent of the Indians, they sally forth, and frequently tear them to pieces, though provided with the swiftest camels for the purpose of flight; so great is their fleetness, combined with their ferocity and their passion for gold!

\section{CHAP. 37. (32.)-THE CHRTSALIS.}

Many insects, however, are engendered in a different manner; and some more especially from dew. This dew settles upon the radish ${ }^{41}$ leaf in the early days of spring; but when it has been thickened by the action of the sun, it becomes reduced to the size of a grain of millet. From this a small grub afterwards arisess, which, at the end of three days, becomes transformed into a caterpillar. For sereral successive days it still increases in size, but remains motionless, and covered with a hard husk. It moves only when touched, and is covered with a web like that of the spider. In this state it is called a chrysalis, but after the husk is broken, it flies forth in the shape of a butterfiy.

39 See B. v. c. 31.

40 M. de Veltheim thinks that by this is really meant the Canis corsac, the small fox of India, but that by some mistake it was represented by travellers as an ant. It is not improbable, Cuvier says, that some quadruped, in making holes in the ground, may have occasionally thrown up some grains of the precious metal. The story is derived from the narratives of Clearchus and Megasthenes. Another interpretation of this story has also been suggested. We find from some remarks of Mr. Wilson, in the Transactions of the Asiatic Society, on the Miahabharata, a Sanscrit poem, that various tribes on the mountains Meru and Mandara (supposed to lie between Hindostan and Tihet) used to sell grains of gold, which they called paippilaka, or " ant-gold," which, they said, was thrown up by ants, in Sanscrit called pippilaka. In travelling westward, this story, in itself, no doubt, untrue, may very probably have been magnified to its present dimensions.

${ }_{41}$ Cuvier observes, that this is a very correct account of the cabbage or radish butterfly, the Papilio brassicæ or Papilio raphani, of Linnæus. 
CHAP. 38. (33.)-ANIMALS WHICH BREED IN WOOD.

In the same manner, also, some animals are generated in the earth from rain, and some, again, in wood. And not only wood-worms ${ }^{42}$ are produced in wood, but gad-flies also and other insects issue from it, whenever there is an excess of moisture; just as in man, tape-worms ${ }^{43}$ are sometimes found, as much as three hundred feet or more in length.

CHAP. 39.-INSECTS THAT ARE PARASITES OF MAN. WHICH IS THE SMALLEST OF ANIMALS? ANIMALS FOUND IN WAX EVEN.

Then, too, in dead carrion there are certain animals produced, and in the hair, too, of living men. It was through such vermin as this that the Dictator Sylla, ${ }^{44}$ and Alcman, one of the most famous of the Grecian poets, met their deaths. These insects infest birds too, and are apt to kill the pheasant, unless it takes care to bathe itself in the dust. Of the animals that are covered with hair, it is supposed that the ass and the sheep are the only ones that are exempt from these vermin. They are produced, also, in certain kinds of cloth, and more particularly those made of the wool of sheep which have been killed by the wolf. I find it stated, also, by authors, that some kinds of water ${ }^{45}$ which we use for bathing are more productive of these parasites than others. Even wax is found to produce mites, which are supposed to be the very smallest of all living creatures. Other insects, again, are engendered from filth, acted upon by the rays of the sun-these fleas are called "petauristæ," in their hind legs. Others, again, are produced with wings, from the moist dust that is found lying in holes and corners.

CHAP. 40. (34.) -AN ANIMAL WHICH HAS NO PASSAGE FOR THE EVACUATIONS.

There is an animal, ${ }^{47}$ also, that is generated in the summer,

42 Cossi. See B. xrii. c. 37.

43 Tæniæ.

${ }_{44} \mathrm{He}$ alludes to the Morbus pediculosus.

45 Aristotle says, in the corresponding passage, Hist. Anim. B. v. c. 26, that the animals which are affected by lice, are more particularly exposed to them when they change the water in which they wash.

46 Or "leapers."

$47 \mathrm{He}$ alludes to dog-ticks and ox-ticks, the Acarus ricinus of Linnæus, and the Acarus reduvius of Schrank. 
which has its head always buried deep in the skin [of a beast], and so, living on its blood, swells to a large size. This is the only living creature that has no outlet ${ }^{48}$ for its food; hence, when it has overgorged itself, it bursts asunder, and thus its very aliment is made the cause of its death. This insect never breeds on beasts of burden, but is very commonly seen on oxen, and sometimes on dogs, which, indeed, are subject to every species of vermin. With sheep and goats, it is the only parasite. The thirst, too, for blood displayed by leeches, which we find in marshy waters, is no less singular; for these will thrust the entire head into the flesh in quest of it. There is a winged insect ${ }^{49}$ which peculiarly infests dogs, and more especially attacks them with its sting about the ears, where they are unable to defend themselves with their teeth.

\section{CHAP. 41. (35.) - MOTHS, CANTHARIDES, GNATS-AN INSECT} THAT BREEDS IN THE SNOW.

Dust, too, is productive of worms $\mathrm{s}^{50}$ in wools and cloths, and this more especially if a spider should happen to be enclosed in them : for, being sensible of thirst, it sucks up all the moisture, and thereby increases the dryness of the material. These will breed in paper also. There is one kind which carries with it its husk, in the same manner as the snail, only that the feet are to be seen. If deprived of it, it does not survive; and when it is fully developed, the insect becomes a chrysalis. The wild fig-tree produces gnats, ${ }^{51}$ known as "ficarii ;" and the little grubs of the fig-tree, the pear-tree, the pine, the wild rose, and the common rose produce cantharides, ${ }^{52}$ when fully developed. These insects, which are venomous, carry with them their antidote; for their wings are useful in drink

48 In c. 32 he has said the same of the grasshopper, in relation to its ${ }_{49} \mathrm{~A}$ variety of the Cynips of Linnæus, which in vast numbers will sometimes adhere to the ears of dogs.

50 These are really the larvæ of night-moths. His account here is purely imaginary.

51 He speaks of the Cynips psenes of Linnæus, which breeds on the blossom of the fig-tree, and aids in its fecundation. See B. xv. c. 21.

${ }_{52} \mathrm{He}$ alludes to various coleopterous insects, which are not included among the Cantharides of the modern naturalists. They are first an egg, then a larva, then a nympha, and then the insect fully developed. 
medicine, ${ }^{53}$ while the rest of the body is deadly. Again, liquids turned sour will produce other kinds of gnats, and white grubs are to be found in snow that has lain long on the ground, while those that lie above are of a reddish ${ }^{51}$ colourindeed, the snow itself becomes red after it has lain some time on the ground. These grubs are covered with a sort of hair, are of a rather large size, and in a state of torpor.

CHAP. 42. (36.) - AN ANIMAL FOUND IN FIRE-THE PYRALLIS OR PYRAUSTA.

That element, also, which is so destructive to matter, produces certain animals; for in the copper-smelting furnaces of Cyprus, in the very midst of the fire, there is to be seen flying about a four-footed animal with wings, the size of a large fly: this creature is called the "pyrallis," and by some the "pyrausta." So long as it remains in the fire it will live, but if it comes out and flies a little distance from it, it will instantly die.

\section{CHAP. 43.-THE ANIMAL CALLED HEMEROBION.}

The Hypanis, a river of Pontus, brings down in its waters, about the time of the summer solstice, small membranous particles, like a grape-stone in appearance ; from which there issues an animal ${ }^{55}$ with four legs and with wings, similar to the one just mentioned. It does not, however, live more than a single day, from which circumstance it has obtained the name of " hemerobion." 56 The life of other insects of a similar nature is regulated from its beginning to its end by multiples of seven. Thrice seven days is the duration of the life of the gnat and of the maggot, while those that are viviparous live four times seven days, and their various changes and transformations take place in periods of three or four days. The other insects of this kind that are winged, generally die in the

53 See B. xxix. c. 30.

54 The redness sometimes observed on the snow of the Alps and the Pyrenees, is supposed by De Lamarck to be produced by animalculæ: other naturalists, bcwever, suppose it to arise from vegetable or mineral causes.

${ }^{55}$ Cuvier thinks that he alludes to a variety of the ephemera or the phryganea of Linnæus, the case-wing flies, many of which are particularly short-lived. These are by no means peculiar to the river Bog or Hypanis.

5o "Living for a day." 
autumn, the gad-fly becoming quite blind ${ }^{57}$ even before it dies. Flies which have been drowned in water, if they are covered with ashes, ${ }^{58}$ will return to life.

CHAP. 44. (37.) - THE NATURE AND CHARACTERISTICS OF ALI, ANIMALS CONSIDERED LIMB BY LIMB. THOSE WHICH HAVE TUFTS AND CRESTS.

In addition to what is already stated, we will add an account of every part of the body of an animal, taken limb by limb.

All those which have blood, have a head as well. A small number of animals, and those only among the birds, have tufis of various kinds upon the head. The phœnix ${ }^{59}$ has a long row of feathers on it, from the middle of which arises another row ; peacocks have a hairy tuft, resembling a bushy shrub; the stymphalis ${ }^{60}$ has a sort of pointed crest, and the pheasant, again, small horns. Added to these, there is the lark; a little bird, which, from the appearance of its tuft, was formerly called "galerita," but has since received the Gallic name of " alauda,"61 a name which it has transferred to one of our legions. ${ }^{62}$ We have already made mention, also, of one bird ${ }^{63}$ to which Nature has given a crest, which it can fold or unfold at pleasure: the birds of the coot kind ${ }^{64}$ have also received from her a crest, which takes its rise at the beak, and runs along the middle of the head; while the pie of Mars, and the Balearic crane, are furnished with pointed tufts. But the most remarkable feature of all, is the crest which we see attached to the heads of our domestic fowls, substantial and indented like a saw; we cannot, in fact, strictly call it flesh, nor can we pronounce it to be cartilage or a callosity, but must admit that it is something of a nature peculiar to itself. As to the crests of dragons, there is no one to be found who ever saw one.

57 They only appear to be so, from the peculiar streaks on the eyes. Linnæus has hence called one variety, the Tabanus cæcutiens.

${ }^{58}$ Or with pounded chalk or whitening. Flian adds, "if they are placed in the sun," which appears necessary for the full success of the experiment. Life appears to be suspended in such cases for a period of surprising length.

59 Probably the golden pheasant, as already mentioned.

60 Some kind of heron or crane, Cuvier thinks.

61 The Alauda cristata of Linnæus, so called from "galera," a pointed cap like a helmet.

62 The fifth legion. $\quad 63$ The hoopoe, B. x. c. 44.

64 Savigny and Cuvier take this to be the Ardea virgo of Linnæus, a native of Numidia. 
CHAP. 45. -THE VARIOUS KINDS OF HORNS. ANIMALS IN WHICH THEY ARE MOVEABLE.

Horns, too, of various forms have been granted to many animals of the aquatic, marine, and reptile kind, but those which are more properly understood under that name belong to the quadrupeds only; for I look upon the tales of Actæon and of Cippus even, in Latin story, as nothing more nor less than fables. ${ }^{65}$ And, indeed, in no department of her works has Nature displayed a greater capriciousness. In providing animals with these weapons, she has made merry at their expense ; for some she has spread them out in branches, the stag, for instance; to others she has given them in a more simple form, as in the "subulo," so called from the resemblance of its horns to a " subula," others, again, she has flattened them in the shape of a man's hand, with the fingers extended, from which circumstance the animal has received the name of "platyceros." 67 To the roebuck she has given branching horns, but small, and has made them so as not to fall off and be cast each year; while to the ram she has given them of a contorted and spiral form, as though she were providing it with a cæstus for offence. The horns of the bull, again, are upright and threatening. In this last kind, the females, too, are provided with them, while in most it is only the males. The chamois has them, curving backwards; while in the fallow deer ${ }^{68}$ they bend forward. The strepsiceros, ${ }^{69}$ which in Africa bears the name of addax, has horns erect and spiral, grooved and tapering to a sharp point, so much so, that you would almost take them to be the sides of a lyre. ${ }^{69 *}$ In the oxen of Phrygia, the horns are moveable, ${ }^{70}$

${ }^{65}$ The suddenness of their appearance, no doubt, was fabulous; but we have well-authenticated cases in recent times of substances growing on the human head, to all appearance resembling horns, and arising from a disordered secretion of the hair. Witness the case of Mary Davies, a socalled horn from whose head is preserved in the Ashmolean Museum at Oxford. The story of Genucius Cippus, the Roman prætor, is told by Ovid, Met. B. xv. 1. 565, et seq.

66 A spitter, or second year stag, according to Cuvier.

67 "Broad-horned." The Cervus dama of Linnæus.

$6 s$ "Dama." The Antelope redunca of Linnæus, Cuvier thinks.

69 No doubt a kind of antelope.

60* "Lyras" seems preferable to "liras."

70 There are several varieties of oxen, in which the horns adhere to the skin, and not to the cranium. 
like the ears; and among the cattle of the Troglodytæ, they are pointed downwards to the ground, for which reason it is that they are obliged to feed with the head on one side. Other animals, again, have a single horn, and that situate in the middle of the head, or else on the nose, as already stated. $^{71}$

Then, again, in some animals the horns are adapted for butting, and in others for goring; with some they are curved inwards, with others outwards, and with others, again, they are fitted for tossing: all which objects are effected in various ways, the horns either lying backwards, turning from, or else towards each other, and in all cases running to a sharp point. In one kind, also, the horns are used for the purpose of scratching the body, instead of hands.

In snails the horns are fleshy, and are thus adapted for the purpose of feeling the way, which is also the case with the cerastes ${ }^{72}$ some reptiles, again, have only one horn, though the snail has always two, suited for protruding and withdrawing. The barbarous nations of the north drink from the horns of the urus, ${ }^{73}$ a pair of which will hold a couple of urnæ: ${ }^{74}$ other tribes, again, point their spears with them. With us they are cut into laminæ, upon which they become transparent; indeed, the rays of a light placed within them may be seen to a much. greater distance than without. They are used also for various appliances. of luxury, either coloured or varnished, or else for those kinds of paintings which are known as " cestrota," 75 or horn-pictures. The horns of all animals are hollow within, it being only at the tip that they are solid: the only exception is the stag, the horn of which is solid throughout, and is cast every year. When the hoofs of oxen are worn to the quick, the husbandmen have a method of curing them, by anointing the horns of the animal with grease. The substance of the horns is so ductile, that even while upon the body of the living animal, they can be bent by being steeped in boiling wax, and if they are split down when they are first shooting, they may be twisted different ways, and so appear to be

71 B. viii.cc. $29-31$.

72 The Coluber cerastes of Linnæus. See B. viii. c. 35.

73 The drinking-horns of our Saxon ancestors are well known to the antiquarian.

74 The "urna" was half an "amphora," or nearly three gallons.

75 See B. Xzxv, c. 41 . 
four in number upon one head. In females the horns are generally thinner than in the males, as is the case, also, with most kinds of wool-bearing animals.

No individuals, however, among sheep, or hinds, nor yet any that have the feet divided into toes, or that have solid hoofs, are furnished with horns; with the sole exception of the Indian ass, ${ }^{76}$ which is armed with a single horn. To the beasts that are cloven-footed Nature has granted two horns, but to those that have fore-teeth in the upper jaw, she has given none. Those persons who entertain the notion that the substance of these teeth is expended in the formation of the horns, are easily to be refuted, if we only consider the case of the hind, which has no more teeth than the male, and yet is without horns altogether. In the stag the horn is only imbedded in the skin, but in the other ${ }^{77}$ animals it adheres to the bone.

CIIAP. 46.-THE HEADS OF ANTMALS. THOSE WHTCH HAVE NONF.

The head of the fish is very large in proportion to the rest of the body, probably, to facilitate its diving under water. Animals of the oyster and the sponge kind have no head, which is the case, also, with most of the other kinds, whose only sense is that of touch. Some, again, have the head blended with the body, the crab, for instance.

\section{CHAP. 47.-THE HAIR.}

Of all animals man has the longest hair upon the head; which is the case more especially with those nations where the men and women in common leave the hair to grow, and do not cut it. Indeed, it is from this fact, that the inhabitants of the Alps have obtained from us the name of "Capillati,"? as also those of Gallia, "Comata." 79 There is, however, a great difference in this respect according to the various countries. In the island of Myconus ${ }^{80}$ the people are born without hair, just as at Caunus the inhabitants are afflicted with the spleen

76 The rhinoceros. See B. viii. c. 39 .

77 He surely must except the Phrygian oxen with the moveable horns, which he has previously mentioned.

78 Or "long-haired." See B. iii. c. 7.

79 See B. iv. c. 31 .

80 See B. iv. c. 22. 
from their birth. ${ }^{81}$ There are some animals, also, that are naturally bald, such as the ostrich, for instance, and the aquatic raven, which last has thence derived its Greek ${ }^{82}$ name. It is but rarely that the hair falls off in women, and in eunuchs such is never known to be the case; nor yet does any person lose it before having known sexual intercourse. ${ }^{83}$ The hair does not fall off below the brain, nor yet beneath the crown of the head, or around the ears and the temples. Man is the only animal that becomes bald, with the exception, of course, of such animals as are naturally so. Man and the horse are the only creatures whose hair turns grey; but with man this is always the case, first in the fore-part of the head, and then in the hinder part.

\section{CHAP. 48. -THE BONES OF THE HEAD.}

Some few persons only are double-crowned. The bones of the head are flat, thin, devoid of marrow, and united with sutures indented like a comb. When broken asunder they cannot be united, but the extraction of a small portion is not necessarily fatal; as a fleshy cicatrix forms, and so makes good the loss. We have already mentioned, in their respective ${ }^{84}$ places, that the skull of the bear is the weakest of all, and that of the parrot the hardest.

\section{CHAP. 49. - THE BRAIN.}

The brain exists in all animals which have blood, and in those sea animals as well, which we have already mentioned as mollusks, although they are destitute of blood, the polypus, for instance. Man, however, has, in proportion to his body, the most voluminous brain of all. This, too, is the most humid, and the coldest of all the viscera, and is enveloped above and below with two membranous integuments, for either of which to be broken is fatal. In addition to these facts, we may remark that the brain is larger in men than in

81 See B. v. c. 29.

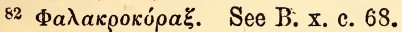

83 He borrows this from Aristotle.

84 B. viii. c. 54 , and B. x. c. 58 . The skull of the bear is not thinner or weaker than that of other animals of its own size; but the skull of the parrot, in proportion to those of other birds, is remarkably hard. 
women. In man the brain is destitute of blood and veins, and in other animals it has no fat. Those who are well informed on the subject, tell us that the brain is quite a different substance from the marrow, seeing that on being boiled it only becomes harder. In the very middle of the brain of every animal there are small bones found. Man is the only animal in which it is known to palpitate ${ }^{85}$ during infancy; and it does not gain its proper consistency until after the child has made its first attempt to speak. The brain is the most elevated of all the viscera, and the nearest to the roof of the head; it is equally devoid of flesh, blood, and excretions. The senses hold this organ as their citadel; it is in this that are centred all the veins which spring from the heart; it is here that they terminate; this is the very culminating point of all, the regulator of the understanding. With all animals it is advanced to the fore-part of the head, from the fact that the senses have a tendency to the direction in which we look. From the brain proceeds sleep, and its return it is that causes the head to nod. Those creatures, in fact, which have no brain, never sleep. It is said that stags ${ }^{86}$ have in the head certain small maggots, twenty in number: they are situate in the empty space that lies beneath the tongue, and around the joints by which the head is united to the body.

\section{CHAP. 50.-THE EAIS. ANIMALS WHICH HEAR WITHOUT EARS OR APERTURES.}

Man is the only animal the ears of which are immoveable. It is from the natural flaccidity of the ear, that the surname of Flaccus is derived. There is no part of the body that creates a more enormous expense for our women, in the pearls which are suspended from them. In the East, too, it is thought highly becoming for the men, even, to wear gold rings in their ears. Some animals have large, and others small ears. The stag alone has them cut and divided, as it were; in the field-mouse they have a velvet surface. All the animals that are viviparous have ears of some kind or other, with the sole exception of the sea-calf, the dolphin, the fishes

85 See B. vii. c. 1 .

${ }^{86}$ Cuvier says that these are the larvæ of the œstrus, which are deposited on the lips of quadrupeds, and so make their way to various cavities. 
which we have mentioned ${ }^{87}$ as cartilaginous, and the viper. These animals have only cavities instead of ears, with the exeeption of the cartilaginous fishes and the dolphin, which last, however, it is quite clear possesses the sense of hearing, for it is charmed by singing, and is often taken while enraptured with the melody: how it is that it does hear, is quite marvellous. These animals, too, have not the slightest trace of olfactory organs, and yet they have a most acute sense of smell.

Among the winged animals, only the horned owl and the longeared owl have feathers which project like ears, the rest having only eavities for the purpose of hearing; the same is the case, also, with the scaly animals and the serpents. Among horses and beasts of burden of all kinds, it is the ears which indicate the natural feelings; when the animal is weary, they are drooping and flaccid; when it is startled, they quiver to and fro; when it is enraged, they are pricked up ; and when it is ailing, they are pendant.

CHAP. 51.-THE FACE, THE FOREHEAD, AND THE EYE-BROWS.

Man is the only creature that has a face, the other animals having only a muzzle or a beak. Other animals have a forehead as well, but it is only on the forehead of man that is depicted sorrow, gladness, compassion, or severity. It is the forehead that is the index of the mind. Man has eyebrows, also, which move together or alternately ; these, too, serve in some measure as indications of the feelings. Do we deny or do we assent, it is the eyebrows, mostly, that indicate our intentions. Feelings of pride may be generated elsewhere, but it is here that they have their principal abode; it is in the heart that they take their rise, but it is to the eyebrows that they mount, and here they take up their position. In no part of the body could they meet with a spot more lofty and more precipitous, in which to establish themselves free from all control.

CHAP. 52.-THE EYES - ANIMALS WHICH HAVE NO EYES, OR HAVE ONLY ONE EYE.

Below the forehead are the eyes, which form the most precious portion of the human body, and which, by the enjoyment

87 B. ix. c. 40.

TOL. III. 
of the blessings of sight, distinguish life from death. Eyes, however, have not been granted to all animals; oysters have none, but, with reference to some of the shell-fish, the question is still doubtful; for if we move the fingers before a scallop half open, it will immediately close its shell, apparently from seeing them, while the solen ${ }^{88}$ will start away from an iron instrument when placed near it. Among quadrupeds the mole ${ }^{89}$ has no sight, though it has something that bears a resemblance to eyes, if we remove the membrane that is extended in front of them. Among birds also, it is said that a species of heron, which is known as the "leucus," 90 is wanting of one eye: a bird of most excellent augury, when it flies towards the south or north, for it is said that it portends thereby that there is about to be an end of perils and alarms. Nigidius says also, that neither locusts nor grasshoppers have eyes. In snails, ${ }^{91}$ the two small horns with which they feel their way, perform the duties of eyes. Neither the mawworm ${ }^{92}$ nor any other kind of worm has eyes.

CHAP. 53.-THE DIVERSITY OF THE COLOUR OF THE EYES.

The eyes vary in colour in the human race only; in all other animals they are of one uniform colour peculiar to the kind, though there are some horses that have eyes of an azure colour. But in man the varieties and diversities are most numerous; the eyes being either large, of middling size, remarkably small, or remarkably prominent. These last are generally supposed to be very weak, while those which are deep-seated are considered the best, as is the case also with those which in colour resemble the eyes of the goat.

CHAP. 54. -THE THEORY OF SIGHT-PERSONS WHO CAN SEE BY
NIGHT.

In addition to this, there are some persons who can see to a

88 Or razor-sheath. See B. x. c. 88 .

89 Aristotle was of this opinion, but Galen maintained that the mole can see. Its eye is extremely small, and hard on the surface.

90 Or "white" heron. As Cuvier remarks, this is probably a mere augur's fable.

${ }_{91}$ It is almost needless to remark, that both snails, as well as locusts and grasshoppers, have eyes.

22 Lumbricus. 
very great distance, while there are others, again, who can only distinguish objects when brought quite close to them. The vision of many stands in need of the rays of the sun; such persons cannot see on a cloudy day, nor yet after the sun has set. Others, again, have bad sight in the day-time, but a sight superior to that of others by night. Of persons having double pupils, or the evil eye, we have already spoken ${ }^{93}$ at sufficient length. Blue ${ }^{94}$ eyes are the best for seeing in the dark.

It is said that Tiberius Cæsar, like no other human being, was so endowed by Nature, that on awaking in the night ${ }^{95}$ he could for a few moments distinguish objects just as well as in the clearest daylight, but that by degrees he would find his sight again enveloped in darkness. The late Emperor Augustus had azure eyes like those of some horses, the white being larger than with other men; he used to be very angry if a person stared intently at them for this peculiarity. Claudius Cæsar had at the corners of the eyes a white fleshy substance, covered with veins, which would occasionally become suffused with blood; with the Emperor Caius ${ }^{96}$ they had a fixcd, steady gaze, while Nero could see nothing distinctly without winking, and having it brought close to his eyes. The Emperor Caius had twenty pairs of gladiators in his training.school, and of all these there were only two who did not wink the eyes when a menacing gesture was made close to them: hence it was that these men were invincible. So difficult a matter is it for a man to keep his eyes from winking: indeed, to wink is so natural to many, that they cannot desist from it; such persons we generally look upon as the most timid.

No persons have the eye all of one colour; that of the middle of the eye is always different from the white which surrounds it. In all animals there is no part in the whole body that is a stronger exponent of the feelings, and in man more especially, for it is from the expression of the eye that we detect clemency, moderation, compassion, hatred, love, sadness, and joy. From the eyes, too, the various characters of persons are judged of, according as they are ferocious, me-

93 B. vii. c. 2.

94 "6 Cæsii."

95 The same has been said also of Cardan, the elder Scaliger, Theodore Beza, the French physician Mairan, aud the republican Camille Desmoulins. s6 Caligula. 
nacing, sparkling, sedate, leering, askance, downcast, or languishing. Beyond a doubt it is in the eyes that the mind has its abode: sometimes the look is ardent, sometimes fixed and steady, at other times the eyes are humid, and at others, again, half closed. From these it is that the tears of pity flow, and when we kiss them we seem to be touching the very soul. It is the eyes that weep, and from them proceed those streams that moisten our cheeks as they trickle down. And what is this liquid that is always so ready and in such abundance in our moments of grief, and where is it kept in reserve at other times? It is by the aid of the mind that we see, by the aid of the mind that we enjoy perception; while the eyes, like so many vessels, as it were, receive its visual faculties and transmit them. Hence it is that profound thought renders a man blind for the time, the powers of sight being withdrawn from external objects and thrown inward: so, too, in epilepsy, the mind is covered with darkness, while the eyes, though open, are able to see nothing. In addition to this, it is the fact that hares, as well as many human beings, can sleep with the eyes open, a thing which the Greeks express by the term

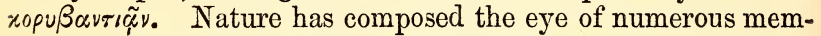
branes of remarkable thinness, covering them with a thick coat to ensure their protection against heat and cold. This coat she purifies from time to time by the lachrymal humours, and she has made the surface lubricous and slippery, to protect the eye against the effects of a sudden shock.

CHAP. 55.-THE NATURE OF THE PUPIL-EYES WHICH DO NOT SHUT.

In the midst of the cornea of the eye Nature has formed a window in the pupil, the small dimensions of which do not permit the sight to wander at hazard and with uncertainty, but direct it as straight as though it were through a tube, and at the same time ensure its avoidance of all shocks communicated by foreign bodies. The pupils are surrounded by a black circle in some persons, while it is of a yellowish cast with others, and azure again with others. By this happy combination the light is received by the eye upon the white that lies around the pupil, and its reflection being thus tempered, it fails to impede or confuse the sight by its harshness. So complete a mirror, too, does the eye form, that the pupil, 
small as it is, is able to reflect the entire image of a man. This ${ }^{97}$ is the reason why most birds, when held in the nand of a person, will more particularly peck at his eyes ; for seeing their own likeness reflected in the pupils, they are attracted to it by what seem to be the objects of their natural affection.

It is only some few beasts of burden that are subject to maladies of the cyes towards the increase of the moon: but it is man alone that is rescued from blindness by the discharge of the humours ${ }^{98}$ that have caused it. Many persons have had their sight restored after being blind for twenty years; while others, again, have been denied this blessing from their very birth, without there being any blemish in the eyes. Many persons, again, have suddenly lost their sight from no apparent cause, and without any preceding injury. The most learned authors say that there are veins which communicate from the eye to the brain, but I am inclined to think that the communication is with the stomach; for it is quite certain that a person never loses the eye without feeling sickness at the stomach. It is an important and sacred duty, of high sanction among the Romans, to close ${ }^{99}$ the eyes of the dead, and then again to open them when the body is laid on the funeral pile, the usage having taken its rise in the notion of its being improper that the eyes of the dead should be beheld by man, while it is an equally great offence to hide them from the view of heaven. Man is the only living creature the eyes of which are subject to deformities, from which, in fact, arose the family names of "Strabo" and "Pætus." ${ }_{2}$ The ancients used to call a man who was born with only one eye, "cocles," and "ocella," a person whose eyes were remarkably small. "Luscinus" was the surname given to one who happened to have lost one eye by an accident.

The eyes of animals that see at night in the dark, cats, for instance, are shining and radiant, so much so, that it is impossible to look upon them; those of the she-goat, too, and the wolf are resplendent, and emit a light like fire. The eyes of the sea-calf and the hyæna change successively to a thousand

97 Hardouin with justice doubts the soundness of this alleged reason.

$98 \mathrm{He}$ alludes, probably, to some method of curing cataract; perhaps somewhat similar to that mentioned by him in B. xx. c. 20 .

${ }_{99}$ This was done by the nearest relatives. This usage still prevails in this country, the eyelids being pressed down with pieces of gold or silver.
1 Or "squint-eyed."
2 Or " cock-eyed." 
colours; and the eyes, when dried, of most of the fishes will give out light in the dark, just in the same way as the trunk of the oak when it has become rotten with extreme old age. We have already mentioned ${ }^{3}$ the fact, that animals which turn, not the eyes but the head, for the purpose of looking round, are never known to wink. It is said, ${ }^{4}$ too, that the chameleon is able to roll the eye-balls completely round. Crabs look sideways, and have the eyes enclosed beneath a thin crust. Those of craw-fish and shrimps are very hard and prominent, and lie in a great measure beneath a defence of a similar nature. Those animals, however, the eyes of which are hard, have worse sight than those of which the eyes are formed of a humid substance. It is said that if the eyes are taken away from the young of serpents and of the swallow, ${ }^{5}$ they will grow again. In all insects and in animals covered with a shell, the eyes move just in the same way as the ears of quadrupeds do; those among them which have a brittle ${ }^{6}$ covering have the eyes hard. All animals of this nature, as well as fishes and insects, are destitute of eye-lids, and their eyes have no covering; but in all there is a membrane that is transparent like glass, spread over them.

CHAP. 56.-THE HAIR OF THE EYE-LIDS; WHAT ANIMALS ARE WITHOUT THEM. ANIMALS WHICH CAN SEE ON ONE SIDE ONLY.

Man has lashes on the eye-lids on either side; and women even make it their daily care to stain them $;^{7}$ so ardent are they in the pursuit of beauty, that they must even colour their very eyes. It was with another view, however, that Nature had provided the hair of the eyelids-they were to have acted, so to say, as a kind of rampart for the protection of the sight, and as an advanced bulwark against the approach of insects or other objects which might accidentally come in their way. It is not without some reason that it is said that the eyelashes ${ }^{8}$ fall off with those persons who are too much given to venereal pleasures. Of the other animals, the only ones that have eyelashes are those that have hair on the rest of the body as well; but the quadrupeds have them on the upper
3 B. viii. c. 45.
5 See B. xxv. c. 50.
4 B. viii. c. 51.
${ }^{6}$ Or crustaceous covering.
$7 \mathrm{Kohl}$ is still used in the east for the same purpose.
8 Aristotle says so, Hist. Anim. B. iii. c. 10. 
eyelid only, and the birds on the lower one: the same is the case also with those which have a soft skin, such as the serpent, and those among the quadrupeds that are oviparous, the lizard, for instance. The ostrich is the only one among the birds that, like man, has eyelashes on either side.

\section{CHAP. 57.-ANIMALS WHICH HAVE NO EYELIDS.}

All birds, however, have not eyelids: hence it is, that those which are viviparous have no nictation of the eye. The heavier kinds of birds shut the eye by means of the lower eyelid, and they wink by drawing forward a membrane which lies in the corner of the eye. Pigeons, and other birds of a similar nature, shut the two eyelids; but the quadrupeds which are oviparous, such, for instance, as the tortoise and the crocodile, have only the lower eyelid moveable, and never wink, in consequence of the hardness of the eye. "The edge of the upper eyelid was by the ancients called "cilium," from which comes our word "supercilia." If the eyelid happens to be severed by a wound it will not reunite, ${ }^{10}$ which is the case also with some few other parts of the human body.

\section{CHAP. 58. - THE CHEEKS.}

Below the eyes are the cheeks, a feature which is found in man only. From the ancients they received the name of "genæ," and by the laws of the Twelve Tables, women were forbidden to tear them. ${ }^{11}$ The cheeks are the seat of bashfulness; it is on them more particularly that blushes are to be seen.

\section{CHAP. 59.-THE NOSTRILS.}

Within the cheeks is the mouth, which gives such strong indications of the feelings of joyousness and laughter; and above it, but in man only, is the nose, which modern notions have stamped as the exponent of sarcasm and ridicule. ${ }^{12}$ In no other animal but man, is the nose thus prominent; birds, serpents, and fishes, have no nostrils, but apertures only for the purpose of smell. It is from the peculiarity of the nose

9 "The eyebrows."

10 This is not the fact.

11 With their nails when mourning for the dead.

12 Hence the word "nasutus," a sneering, captious, or sarcastic man. 
that are derived the surnames of "Simus" 13 and "Silo." Children born in the seventh month often have the ears and the nostrils imperforate.

CHAP, 60.-THE MOUTH; THE LIPS; THE CHIN; AND THE JAW-BONE.

It is from the "Iabia," or lips, that the Brocchi ${ }^{14}$ have received the surname of Labeo. All animals that are viviparous have a mouth that is either well-formed, or harshly defined, as the case may be. Instead of lips and mouth, the birds have a beak that is horny and sharp at the end. With birds that live by rapine, the beak is hooked inwards, but with those which gather and peck only, it is straight: those animals, again, which root up grass or puddle in the mud, have the muzzle broad, like swine. The beasts of burden employ the mouth in place of hands in gathering their food, while those which live by rapine and slaughter have it wider than the rest. No animal, with the exception of man, has either chin or cheek-bones. The crocodile is the only animal that has the upper jaw-bone ${ }^{15}$ moveable; among the land quadrupeds it is the same as with other animals, except that they can move it obliquely.

CHAP. 61.-THE TEETH ; THE VARIOUS KINDS OF TEETH ; IN WHAT

ANIMALS THEY ARE NOT ON BOTH SIDES OF THE MOUTH : ANIMALS WHICH. HAVE HOLLOW TEETH.

Teeth are arranged in three different ways, serrated, in one continuous row, or else protruding from the mouth. When serrated they unite together, just like those of a comb, in order that they may not be worn by rubbing against one another, as in serpents, fishes, and $\operatorname{dogs},{ }^{16}$ for instance. In some creatures they are set in one continuous row, man and the horse, for instance; while in the wild boar, the elephant, and the hippopotamus, they protrude from the mouth. ${ }^{17}$ Among those set in one continuous row, the teeth which divide the food are broad and sharp, while those which grind it are double; the teeth which lie between the incisive and the molar teeth, are those known as the canine or dog-teeth; these

13 " Flat-nosed," and " snub-nosed,"

14 A Roman family - the reading of this word seems doubtful.

15 In reality, the under one only.

$16 \mathrm{He}$ is incorrect in speaking of dogs as having serrated teeth.

27 In the dugong also, babiroussa, muntjac, and others. 
are by far the largest in those animals which have serrated teeth. Those animals which have continuous rows of teeth, have them either situate on both sides of the mouth, as in the horse, or else have no fore-teeth in the upper part of the mouth, as is the case with oxen, sheep, and all the animals that ruminate. The she-goat has no upper teeth, except the two front ones. No animals which have serrated teeth, have them protruding ${ }^{18}$ from the mouth; among these, too, the females rarely have them; and to those that do have them, they are of no ${ }^{19}$ use : hence it is, that while the boar strikes, the sow bites. No animal with horns has projecting teeth; and all such teeth are holiow, while in other animals the teeth are solid. All ${ }^{20}$ fish have the teeth serrated, with the exception of the scarus, ${ }^{21}$ this being the only one among the aquatic animals that has them level ${ }^{22}$ at the edges. In addition to this, there are many fishes that have teeth upon the tongue and over the whole of the mouth, in order that, by the multitude of the bites which they inflict, they may soften those articles of food which they could not possibly manage by tearing. Many animals, also, have teeth in the palate, and even in the tail ; ${ }^{23}$ in addition to which, some have them inclining to the interior of the mouth, that the food may not fall out, the animal itself having no other means of retaining it there.

\section{CHAP. 62.-THE TEETH OF SERPENTS; THEIR POISON. A BIRD}

WHICH HAS TEETH.

The asp also, and other serpents, have similar teeth ; but in the upper jaw, on the right and left, they have two of extreme length, which are perforated with a small tube in the interior,

18 The morse and the dugong are instances to the contrary.

19 The females of the elephant, morse, dugong, chevrotin, and muntjac have them, and they are equally as useful as with the male, only, perhaps, not so strong.

${ }_{20}$ This is incorrect, unless he merely means ranged in one continuous line; and even then he is in error.

${ }^{21}$ See B. ix. c. 29. This is called the parrot-fish, from the resemblance of its upper and lower jaws to the beak of a parrot.

${ }^{22}$ They present this appearance from being worn away at the surface.

${ }^{23}$ Rondelet would read "gula," the throat. This, though repudiated by Hardouin, is approved of by Cuvier, who justly looks upon the ordinary reading as an absurdity. Many fish, he says, and more especially the osseous ones, have teeth in the pharynx. 
just like the sting of the scorpion, and it is through these that they eject their venom. The writers who have made the most diligent enquiries on the subject, inform us that this venom is nothing but the gall of the serpent, and that it is conveyed to the mouth by certain veins which run beneath the spine; indeed, there are some who state that there is only one poisonfang, and that being barbed at the end, it is bent backwards when the animal has inflicted a bite. Other writers, however, affirm that on such an occasion the fang falls out, as it is very easily displaced, but that it soon grows ${ }^{2 t}$ again; this tooth, they say, is thus wanting in the serpents which we see handled about by persons. ${ }^{25}$ It is also stated that this fang exists in the tail of the scorpion, and that most of these animals have no less than three. The teeth of the viper are concealed in the gums : the animal, being provided with a similar venom, exercises the pressure of its fangs for the purpose of instilling the poison in its bite.

No winged creatures have teeth, with the sole exception of the bat. The camel is the only one among the animals without horns, that has no fore-teeth ${ }^{26}$ in the upper jaw. None of the horned animals have serrated ${ }^{27}$ teeth. Snails, too, have teeth; a proof of which are the vetches which we find gnawed away by snails of the very smallest size. To assert that among marine animals, those that have shells, and those that are cartilaginous have fore-teeth, and that the sea-urchin has five teeth, I am very much surprised how such a notion could have possibly ${ }^{28}$ arisen. With insects the sting supplies the place of teeth; the ape has teeth just like those in man. ${ }^{29}$ The elephant

24 There is always one fang, at least, ready to supply the place of the one in front, if lost by any accident.

${ }^{25}$ Like the jugglers of the East at the present day. But it is very doubtful whether the poison fang is in all instances previously extracted from the serpents which they handle.

${ }_{26}$ But the camel, as well as the lama, has an incisive bone, provided with an incisive tooth on each side, and has canine and molar teeth as well.

27 If by this term he means teeth separated from each other, the assertion is incorrect, as in these animals we find the molars separated from the lower incisives by a very considerable space.

${ }^{28}$ Cuvier says, as far as the sea-urchin is concerned, very simply, and merely by looking at it, as its five teeth are very apparent.

${ }_{29}$ 'The incisors are in number, and very nearly in appearance, like those of man. The canines are different in shiape, though similar in number. What he says about the elephant, is peculiar to that of India. 
has in the interior of the mouth fourteen teeth, adapted for chewing, in addition to those which protrude; in the male these are curved inwards, but in the female they are straight, and project outwards. The sea-mouse, ${ }^{30}$ a fish which goes before the balæna, has no teeth at all, but in place of them, the interior of the mouth is lined with bristles, as well as the tongue and palate. Among the smaller land quadrupeds, the two fore-teeth in each jaw are the longest.

\section{CHAP. 63.-WONDERFUL CIRCUMSTANCES CONNECTED WITH THE}

\section{TEETH.}

The other animals are born with ${ }^{31}$ teeth, whereas man has them only at the seventh ${ }^{32}$ month after his birth. While other ${ }^{33}$ animals keep their teeth to the time of their death, man, the lion, the beasts of burden, the dog, and the ruminating animals, all change them; the lion and the dog, however, change none ${ }^{34}$ but the canine teeth. The canine tooth of the wolf, on the right side, is held in high esteem as an amulet. ${ }^{35}$ There is no animal that changes the maxillary teeth, which stand beyond the canine teeth. With man, the last teeth, which are known as the "genuini," or cheek teeth, ${ }^{36}$ come about the twentieth year, and with many men, and females as well, so late even as the eightieth ; but this only in the case of those who have not had them in their youth. It is a well-known fact, that the teeth are sometimes shed in old age, and replaced by others. Mucianus has stated that he, himself, saw one Zocles, a native of Samothrace, who had a new set of teeth - when he was past his one hundred and fourth year. In addition to these facts, in man males have more teeth than females, ${ }^{37}$ which is the case also in sheep, goats, and swine.

30 See B. ix. c. 88.

31 Very few other animals are born with teeth, in their natural state. Apes, dogs, and cats are not born with teeth.

32 From the fourth to the eighth month in reality, during which the four central incisors appear.

${ }^{23}$ The only ones that do not change are those which have three molars on each side of the jaw.

34 This is erroneous: they change the incisors and molars as well.

35 See B. xxviii, c. 78.

36 By us known as the "wisdom" teeth.

${ }^{37}$ This is not the fact: they have usually the same number, but there are exceptions on both sides. The same is also the case with sheep, goats, and swine. 
Timarchus, the son of Nicocles the Paphian, had a double ${ }^{38}$ row of teeth in his jaws: the same person had a brother also who never changed his front teeth, and, consequently, wore them to the very stumps. There is an instance, also, of a man having a tooth growing in the palate. ${ }^{39}$ The canine teeth, ${ }^{40}$ when lost by any accident, are never known to come again. While in all other animals the teeth grow of a tawny colour with old age, with the horse, and him only, they become whiter the older he grows.

\section{CHAP. 64.-HOW AN ESTIMATE IS FORMED OF THE AGE OF ANIMALS FROM. THEIR TEETH.}

The age, in beasts of burden, ${ }^{41}$ is indicated by the teeth. In the horse they are forty in number. At thirty months it loses the two fore-teeth in either jaw, and in the following year the same number next to them, at the time that the eye-teeth ${ }^{42}$ come. At the beginning of the fifth year the animal loses two teeth, which grow again in the sixth, and in the seventh it has all its teeth, those which have replaced the others, and those which have never been changed. If a horse is gelded ${ }^{43}$ before it changes its teeth, it never sheds them. In a similar manner, also, the ass loses four of its teeth in the thirtieth month, and the others from six months to six months. If a she-ass happens not to have foaled before the last of these teeth are shed, it is sure to be barren. ${ }^{44}$ Oxen change their teeth at two years old: with swine they are never changed. ${ }^{45}$ When these several indications of age have been lost in horses and other beasts of burden, the age is ascertained by the projecting of the teeth, the greyness of the hair in the eyebrows, and the hollow pits that form around them; at this period the animal is supposed to be about sixteen ${ }^{46}$ years old. In the human

38 This is not very uncommon.

39 Not at all an uncommon occurrence.

40 Of the second set.

lied upon.

41 It is only in the horse and the ass that these indications can be re-

43 'This has no such effect.

44 The contrary is the case: it will be more prolific.

45 Swine change them just the same as other animals.

46 By certain appearances in the incisors, the age of a horse up to its twenty-fourth year, or even beyond, may be judged of : the other signs cannot be so positively relied upon. 
teeth there is a certain venom; for if they are placed uncorered before a mirror, they will tarnish its brightness, and they will kill young pigeons while yet unfledged. The other particulars relative to the teeth have been already ${ }^{47}$ mentioned under the head of the generation of man. When teething first commences, the bodies of infants are subject to certain maladies. Those animals which have serrated teeth inflict the most dangerous bites. ${ }^{48}$

CHAP. 65.-THE TONGUE; ANIMALS WhICH HAVE NO tongue. The noIse Made by frogs. the palate.

The tongue is not similarly formed in all animals. Serpents have a very thin tongue, and three-forked, ${ }^{49}$ which they vibrate to and fro: it is of a black colour, and when drawn from out of the mouth, of extraordinary length. The tongue of the lizard is two-forked, and covered with hair. ${ }^{50}$ That of the sea-calf also is twofold, ${ }^{51}$ but with the serpents it is of the thinness of a hair; the other animals employ it to lick the parts around the mouth. Fishes have nearly the whole of the tongue adhering to the palate, while in the crocodile the whole of it does adhere thereto : but in the aquatic animals the palate, which is fleshy, performs the duty of the tongue as the organ of taste. In lions, pards, and all the animals of that class, and in cats as well, the tongue is covered with asperities, ${ }^{52}$ which overlap each other, and bear a strong resemblance to a rasp. Such being its formation, if the animal licks a man's skin, it will wear it away by making it thinner and thinner; for which reason it is that the saliva of even a perfectly tame animal, being thus introduced to the close vicinity of the blood, is apt bo bring on madness. Of the tongue of the purple we have made mention ${ }^{53}$ already. With the frog the end of the tongue adheres to the mouth, while the inner part is disjoined from the sides of the gullet; and it is by this means that the males give utterance to their croaking, at the season at which

47 B. viii. c. 15.

48 "Sævissima dentibus," seems to be a preferable reading to "særissime dentiunt."

${ }_{50} \mathrm{It}$ is not covered with hair.

51 It is not bifurcate.

52 These are horny, conical papillæ, the summits of which point backwards. 49 Only two-forked in reality.

53 See B. ix. c. 60. 
they are known as ololygones. ${ }^{54}$ This happens at stated periods of the year, at which the males invite the females for the purposes of propagation: letting down the lower lip to the surface of the water, they receive a small portion of it in the mouth, and then, by quavering with the tongue, make a gurgling noise, from which the croaking is produced which we hear. In making this noise, the folds of the mouth, becoming distended, are quite transparent, and the eyes start from the head and burn again with the effort. Those insects which have a sting in the lower part of the body, have teeth, and a tongue as well; with bees it is of considerable length, and in the grasshopper it is very prominent. Those insects which have a fistulous sting in the mouth, have neither tongue nor teeth; while others, again, have a tongue in the interior of the mouth, the ant, for instance. In the elephant the tongue is remarkably broad; and while with all other animals, each according to its kind, it is always perfectly at liberty, with man, and him alone, it is often found so strongly tied down by certain veins, that it becomes necessary to cut them. We find it stated that the pontiff Metellus had a tongue so ill adapted for articulation, that he is generally supposed to have voluntarily submitted to torture for many months, while preparing to pronounce the speech which he was about to make on the dedication of the temple of Opifera. ${ }^{55}$ In most persons the tongue is able to articulate with distinctness at about the seventh year; and many know how to employ it with such remarkable skill, as to be able to imitate the voices of various birds and other animals with the greatest exactness. The other animals have the sense of taste centred in the fore-part of the tongue; but in man it is situate in the palate as well.

Chap. 66. -The tONSILS; THE UVA; THE EPIGLOSSIS; THE ARTEKY ; THE GULLET.

In man there are tonsils at the root of the tongue; these in swine are called the glandules. The uvula, ${ }^{56}$ which is suspended between them at the extremity of the palate, is found only in man. Beneath this lies a smaller tongue, known by the

54 "Criers."

55 One of the titles of the goddess Fortuna.

56 " Uva," or "grape." 
name of "epiglossis," 57 but it is wanting in animals that are. oviparous. Placed as it is between two passages, the functions of the epiglottis are of a twofold nature. The one of these passages that lies more inward is called the [tracheal] artery, and leads to the lungs and the heart: the epiglottis covers it during the action of eating, that the drink or food may not go the wrong way, and so be productive of suffering, as it is by this passage that the breath and the voice are conveyed. The other or exterior passage is called the "gula," ${ }_{58}$ and it is by this passage that the victuals and drink pass: this leads to the belly, while the former one communicates with the chest. ${ }^{59}$ The epiglottis covers the pharynx, in its turn, when only the breath or the voice is passing, in order that the victuals may not inopportunely pass upwards, and so disturb the breathing or articulation. The tracheal artery is composed of cartilage and flesh, while the gullet is formed of a sinewy substance united with flesh.

\section{CHAP. 67.-THE NECK; THE THROAT; THE DOLSAL SPINE.}

The neck is found to exist in no animal but those which have both these passages. All the others which have the gullet only, have nothing but a gorge or throat. In those which have a neck, it is formed of several rounded vertebræ, and is flexible, and joined together by distinct articulations, to allow of the animal turning round the head to look. The lion, the wolf, and the hyæna are the only animals in which it is fcrmed of a single ${ }^{60}$ rigid bone. The neck is annexed to the spine, and the spine to the loins. The vertebral column is of a bony substance, but rounded, and pierced within, to afford a passage for the marrow to descend from the brain. It is generally concluded that the marrow is of the same nature as the brain, from the fact that if the membrane of exceeding thinness which covers it is pierced, death immediately ensues. ${ }^{61}$ Those animals which have long legs have a long throat as well,

5i More generally "epiglottis." It is found in some few reptiles. This passage is omitted by Sillig.

58 Gullet, or pharynx.

59 Stomachum.

${ }^{60}$ All these animals, on the contrary, have seven vertebre.

${ }^{61}$ This is not the fact. The spinal marrow, even, may be wounded, vithout death being the immediate result. 
which is the case also with aquatic birds, although they have short legs, as well as with those which have hooked talons.

CHAP. 68. -THE THROAT; THE GULLET; THE STOMACH.

Man oily, and the swine, are subject to swellings in the throat, which are mostly caused by the noxious quality of the water ${ }^{62}$ which they drink. The upper part of the gullet is called the fauces, the lower the stomach. ${ }^{63}$ By this name is understood a fleshy concavity, situate behind the tracheal artery, and joining the vertebral column; it extends in length and breadth like a sort of chasm..$^{6 t}$ Those animals which have no gullet have no stomach either, nor yet any neck or throat, fishes, for example; and in all these the mouth communicates immedi- ately with the belly. The sea-tortoise ${ }^{65}$ has neither tongue nor teeth; it can break anything, however, with the sharp edge of its muzzle. After the tracheal artery there is the œsophagus, which is indented with hard asperities resembling bramble-thorns, for the purpose of levigating the food, the incisions ${ }^{66}$ gradually becoming smaller as they approach the belly. The roughness at the very extremity of this organ strongly rescmbles that of a blacksmith's file

CHAP. 69.-THE HEART; THE BLOOD; THE VITAL SPIRIT.

In all other. animals but man the heart is situate in the middle of the breast; in man alone it is placed just below the pap on the left-hand side, the smaller end terminating in a point, and bearing outward. It is among the fish only that this point is turned towards the mouth. It is asserted that the heart is the first among the viscera that is formed in the foetus, then the brain, and last of all, the eyes : it is said, too, that the eyes are the first organs that die, and the heart the very last of all. The heart also is the principal seat of the heat of the body; it is constantly palpitating, and moves as though it were one animal enclosed within another. It is also enve-

62 Snow-water, we know, is apt to produce goitre.

63 "Stomachus." More properly, the œsophagus, or ventricle.

${ }^{54}$ Lacunæ modo.

65 Or turtle. It has a tongue, and though it has no teeth, the jaws are edged with a horny substance like the bills of birds.

66 "Crenis" is read for "renis :" otherwise the passage is unintelligible: it is still most probably in a corrupt state. 
loped in a membrane equally supple and strong, and is protected by the bulwarks formed by the ribs and the bone of the kreast, as being the primary source and origin of life. It contains within itself the primary receptacles for the spirit and the blood, in its sinuous cavity, which in the larger animals is threefold, ${ }^{67}$ and in all twofold at least: here it is that the $\operatorname{mind}^{68}$ has its abode. From this source proceed two large veins, which branch into the fore-part and the back of the body, and which, spreading out in a series of branches, convey the vital blood by other smaller veins over all parts of the body. This is the only one $e^{69}$ among the viscera that is not affected by maladies, nor is it subject to the ordinary penalties of human life; but when injured, it produces instant death. While all the other viscera are injured, vitality may still remain in the heart.

CHAP. 70.-THOSE aNIMALS WHICH HAVE THE LARGEST HeART, AND THOSE WHICH HAVE THE SMALLEST. WHAT ANIMALS HAVE TWO HEARTS.

Those animals are looked upon as stupid and lumpish which have a hard, rigid heart, while those in which it is small are courageous, and those are timid which have it very large. The heart is the largest, in proportion to the body, in the mouse, the hare, the ass, the stag, the panther, the weasel, the hyæna, and all the animals, in fact, which are timid, or dangerous only from the effects of fear. In Paphlagonia the partridge has a double heart. In the heart of the horse and the ox there are bones sometimes found. It is said that the heart increases every year in man, and that two drachmæ in weight are added ${ }^{70}$ yearly up to the fiftieth year, after which period it decreases yearly in a similar ratio; and that it is for this reason that men do not live beyond their hundredth year, the heart then failing them : this is the notion entertained by the Egyptians, whose custom it is to embalm the bodies of the

67 Among all the mammiferæ and the birds, the heart has four cavities, two on each side.

68 Mens.

69 This is a mistake. The heart is subject to disease, equally with other parts of the body.

${ }^{70}$ In spite of what Schenkius says in confirmation of Pliny, this is very doubtful. Of course it must increase from childhood, but the increase surely does not continue till the fiftieth year.

VOL. III. 
dead, and so preserve them. It is said that men have been born with the heart covered with hair, and that such persons are excelled by none in valour and energy; such, for instance, as Aristomenes, ${ }^{71}$ the Messenian, who slew three hundred Lacedæmonians. Being covered with wounds, and taken prisoner, he, on one occasion, made his escape by a narrow hole which he discovered ${ }^{72}$ in the stone quarry where he was imprisoned, while in pursuit of a fox which had found that mode of exit. Being again taken prisoner, while his guards were fast asleep he rolled himself towards a fire close by, and, at the expense of his body, burnt off the cords by which he was bound. On being taken a third time, the Lacedæmonians opened his breast while he was still alive, and his heart was found covered with hair.

\section{CHAP. 71.-WHEN THE CUSTOM WAS FIRST ADOPTED OF EXAMINING}

THE HEART IN THE INSPECTION OF THE ENTRAILS.

On an examination of the entrails, to find a certain fatty part on the top of the heart, is looked upon as a fortunate presage. Still, however the heart has not always been considered as forming a part of the entrails for this purpose. It was under Lucius Postumius Albinus, the King of the Sacrifices, ${ }^{73}$ and after the 126th Olympiad, when King Pyrrhus had quitted Italy, that the aruspices began to examine the heart, as part of the consecrated entrails. The first day that the Dictator Cæsar appeared in public, clothed in purple, and sitting on a seat of gold, the heart was twice found wanting ${ }^{74}$ when he sacrificed. From this circumstance has risen a great question among those who discuss matters connected with divination-whether it was possible for the victim to have lived without that organ, or whether it had lost it at the very moment ${ }^{\text {ij }}$ of its death. It is asserted that the heart cannot be

71 See an account of him in the Messeniaca of Pausanias.

72 In this part of the story may have originated that of the escape of Sindbad the Sailor, when buried in the vault with the body of his wife.See the "Arabian Nights."

73 " Rex Sacrorum." This was a priest elected from the patricians, on whom the priestly duties devolved, which had been originally performed by the kings of Rome. He ranked above the Pontifex Maximus, but was possessed of little or no political influence.

${ }_{74}$ No doubt there was trickery in this.

75 By supernatural agency. 
burnt of those persons who die of the cardiac disease; and the same is said of those who die by poison. At all events, there is still in existence an oration pronounced by Vitellius, ${ }^{76}$ in which he accuses Piso of this crime, and employs this alleged fact as one of his proofs, openly asserting that the heart of Germanicus Cæsar could not be burnt at the funeral pile, in consequence of his having been poisoned. On the other hand, the peculiar nature ${ }^{77}$ of the disease under which Germanicus was labouring, was alleged in Piso's defence.

CHAP. 72.-THE LUNGS: IN WHAT ANIMALS THEY ARE THE LARGEST, AND IN WHAT THE SMALLEST. ANIMALS WHICH HAVE NOTHING BUT LUNGS IN THE INTERIOR OF THE BODY. CACSES WHICH PRODUCE EXTRAORDINARY sWIFTNESS IN ANIMALS.

Beneath the heart are the lungs, the laboratory in which the respiration is prepared. The use of these, is to draw in the air and then expel it; for which purpose their substance is of a spongy nature, and filled with cavernous holes. Some few among the aquatic animals have lungs, as we have already stated $;^{78}$ and among the rest of those which are oviparous, they are small, of a fungous nature, and containing no blood; hence it is, that these animals do not experience thirst. It is for the same reason also, that frogs and seals are able to remain so long under water. The tortoise, too, although it has lungs of remarkable size, and extending throughout the whole of the shell, is also equally destitute of blood. The smaller the lungs are in proportion to the body, the greater is the swiftness of the animal. It is in the chameleon that the lungs are the largest in proportion to the body; in which, in fact, it has no other viscera at all..$^{79}$

CHAP. 73. -THE LIVER: IN WHAT ANIMALS, AND IN WHAT PART THERE ARE TWO LIVERS FOUND.

The liver is on the right side: in this part is situate what has been called the "head of the entrails," and it is subject

76 This was P. Vitellius, who served under Germanicus in Germany. He was one of the accusers of $\mathrm{Cn}$. Piso, who was charged with having poisoned Germanicus.

77 The cardiac disease, as alleged.

${ }^{79}$ But see B. viii. c. 51, and B. xxviii. c. 29.

78 B. ix. c. 6. 
to considerable variations. No liver ${ }^{80}$ at all was found in a victim which was sacrificed by M. Marcellus, about the period when he was killed in battle against Hannibal; while in a victim which was slain on the following day, a double liver was found. It was wanting, also, in a victim sacrificed by $\mathrm{C}$. Marius, at Utica, and in one which was offered by the Emperor. Caius $^{81}$ upon the calends of January, ${ }^{81^{*}}$ on the occasion of his entering the year of the consulship in which he was slain: the same thing happened, also, to his successor, Claudius, in the month in which he was cut off ${ }^{82}$ by poison. When the late Emperor Augustus was sacrificing at Spoletum, upon the first day of his entering on the imperial dignity, in six different victims the liver was found rolled over within itself, from the very lowest lobe; and the answer that was given by the diviners was to the effect that, in the course of the year, he would gain a twofold sway. It is of evil omen to find an incision in the head of the entrails, except on occasions of disquietude and alarm; for then it is significant of cutting all cares, and so putting an end to them. The hares that are found in the vicinity of Briletum ${ }^{83}$ and Tharne, and in the Chersonnesus on the Propontis, have a double liver; but, what is very singular, if they are removed to another place, they will lose one of them.

CHAP. 74.-THE GALL; WHERE SITUATE, AND IN WHAT ANIMALS IT IS DOUBLE. ANIMALS WHICH HAVE NO GALL, AND OTHERS IN WHICH IT IS NOT SITUATE IN THE LIVER.

In the liver is the gall, which, however, does not exist in every animal. At Chalcis, in Eubœa, none of the cattle have it, while in the cattle of the Isle of Naxos, it is of extraordinary size, and double, so that to a stranger either of these facts would appear as good as a prodigy. The horse, the mule, the ass, the stag, the roe-buck, the wild boar, the camel, and the dolphin have no gall, but some kinds of rats and mice have it.

so Plutarch says that it was the "caput," or "head" of the liver that was wanting. M. Marcellus was slain while reconnoitring the Carthaginian camp by night.

${ }_{81}$ Caligula.

82 Cy lis

By his niece and wife, Agrippina, the mother of Nero.

s. See B. iv. c. 11. Tharne does not seem to be known. Of course, this story about the hares is fabulous. 
Some few men are without it, and such persons enjoy robust health and a long life. There are some authors who say that the gall exists in the horse, not in the liver, but in the paunch, and that in the stag it is situate either in the tail or the intestines; and that hence it is, that those parts are so bitter that dogs will not touch them. The gall, in fact, is nothing else but the worst parts of the blood purged off, and for this reason it is that it is so bitter: at all events, it is a well-known fact, that no animal has a liver unless it has blood as well. The liver receives the blood from the heart, to which it is united, and then disperses it in the veins.

\section{ChaP. 75.-THE PROPERTIES OF THE GaLL.}

When the gall is black, it is productive of madness in man, and if it is wholly expelled death will ensue. Hence it is, too, that the word "bile" has been employed by us to characterize a harsh, embittered disposition; so powerful are the effects of this secretion, when it extends its influence to the mind. In addition to this, when it is dispersed over the whole of the body, it deprives the eyes, even, of their natural colour; and when ejected, will tarnish copper vessels even, rendering everything black with which it comes in contact; so that no one ought to be surprised that it is the gall which constitutes the venom of serpents. Those animals of Pontus which feed on wormwood have no gall: in the raven, the quail, and the pheasant, the gall-bladder is united to the renal parts, and, on one side only, to the intestines. In many animals, again, it is united only to the intestines, the pigeon, the hawk, and the murena, for example. In some few birds it is situate in the liver; but it is in serpents and fishes that it is the largest in proportion. With the greater part of birds, it extends all along throughout the intestines, as in the hawk and the kite. In some other birds, also, it is situate in the breast as well : the gall, too, of the sea-calf is celebrated for its application to many purposes. From the gall of the bull a colour is extracted like that of gold. The aruspices have consecrated the gall to Neptune and the influence of water. The Emperor Augustus found a double gall in a victim which he was sacrificing on the day of his victory at Actium. 
CHAP. 76.- -IN WHAT ANIMALS THE LIVER INCREASES AND DECREASES WITH THE MOON. OBSERVATIONS OF THE ARUSPICES RELATIVE THERETO, AND REMARKABLE PRODIGIES.

It is said, that in the small liver of the mouse the number of lobes corresponds to the day of the moon, and that they are found to be just as many in number as she is days old; in addition to which, it is said that it increases at the winter solstice. In the rabbits of Bætica, the liver is always found to have a double lobe. Ants will not touch one lobe of the liver of the bramble-frog, in consequence of its poisonous nature, it is generally thought. The liver is remarkable for its powers of preservation, and sieges have afforded us remarkable instances of its being kept so long as a hundred years. ${ }^{84}$

\section{CHAP. 77. -THE DIAPHRAGM. THE NATURE OF LAUGHTER.}

The entrails of serpents and lizards are of remarkable length. It is related that-a most fortunate omen-Cæcina of Volaterræ beheld two dragons arising from the entrails of the victim; and this will not be at all incredible, if we are ready to believe that while King Pyrrhus was sacrificing, the day upon which he died, the heads of the victims, on being cut off, crawled along the ground and licked up their own blood. In man, the entrails are separated from the lower part of the viscera by a certain membrane, which is called the "præcordia," 85 because it is extended in front of the heart ; the Greeks have given it the name of "phrenes." All the principal viscera have been enclosed by Nature, in her prudentforesight, in their own peculiar membranes, just like so many sheaths, in fact. With reference to the diaphragm, there was a peculiar reason for this wise provision of Nature, its proximity to the guts, and the chances that the food might possibly intercept the respiration. It is to this organ that is attributed quick and ready wit, and hence it is that it has no fleshy parts, but is composed of tine sinews and membranes. This part is also the chief seat of gaiety of mind, a fact which is more particularly proved by the titillation of the arm-holes, to which the midriff extends;

${ }^{81}$ There must be some corrupt reading here; for, as Sillig remarks, who ever heard of a siege which lasted a hundred years ?

85 Or diaphragm ; from "præ," "before," and "cor," the " heart." 
indeed, in no part of the body is the skin more fine; for this reason it is, also, that we experience such peculiar pleasure in scratching the parts in its vicinity. Hence it is, that in battles and gladiatorial combats, many persons have been known to be pierced through the midriff, and to die in the act of laughing. ${ }^{86}$

\section{CHAP. 78. -THE BELLY: ANIMALS WHICH HAVE NO BELLY. WHICH ARE THE ONLY ANIMALS THAT VOMIT.}

In those animals which have a stomach, below the diaphragm the belly is situate. In other animals it is single, but in those which ruminate it is double; in those, again, which are destitute of blood, there is no belly, for the intestinal canal commences in some of them at the mouth, and returns to that part, as is the case with the sæpia and the polypus. In man it is connected with the extremity of the stomach, and the same with the dog. These are the only creatures that have the belly more narrow at the lower part; hence it is, too, that they are the only ones that vomit, for on the belly being filled, the narrowness at its extremity precludes the food from passing; a thing that cannot possibly be the case with the animals in which the belly is more capacious at the extremity, and so leaves a free passage for the food to the lower parts of the body.

CHAP. 79. -THE SMALL GUTS, THE FRONT INTESTINES, THE ANUS, THE COLON. THE CAUSES OF THE INSATIATE VORACITY OF CERTAIN ANIMALS.

After the belly we find in man and the sheep the "lactes,":87 the place of which in other animals is occupied by the " hillæ:"88 it is through these organs that the food passes. We then find the larger intestines, which communicate with the anus, and which in man consist of extremely sinuous folds. Those animals which have the longest intestinal canal, are the most voracious; and those which have the belly the most loaded with fat, are the least intelligent. There are some birds, also, which have two receptacles; the one of which is the crop, in which they stow away the food which

86 With Sardonic laughter, as Hardouin remarks.

${ }^{87}$ Or small guts. 88 Or front intestines. 
they have just swallowed, while the other is the belly, into which they discharge the food when it is duly prepared and digested; this is the case with the domestic fowl, the ring-dove, the pigeon, and the partridge. The other birds are in general destitute of crop, but then they have a more capacious gorge, the jackdaw, the raven, and the crow, for instance: some, again, are constituted in neither manner, but have the belly close to the gorge, those, for instance, which have the neck very long and narrow, such as the porphyrio. ${ }^{89}$

In the solid-hoofed animals the belly is rough and hard, while in some land animals it is provided with rough asperities like teeth, ${ }^{90}$ and in others, again, it has a reticulated surface like that of a file. Those animals which have not the teeth on both sides, and do not ruminate, digest the food in the belly, from whence it descends to the lower intestines. There is an organ in all animals attached in the middle to the navel, and in man similar in its lower part to that of the swine, the name given thereto by the Greeks being "colon," a part of the body which is subject to excruciating pains. ${ }^{91}$ In dogs this gut is extremely contracted, for which reason it is that they are unable to ease it, except by great efforts, and not without considerable suffering. Those animals with which the food passes at once from the belly through the straight intestine, are of insatiate appetite, as, for instance, the hind-wolf, ${ }^{92}$ and among birds the diver. The elephant has four ${ }^{93}$ bellies; the rest of its intestines are similar to those of the swine, and the lings are four times as large as those of the ox. The belly in birds is fleshy, and formed of a callous substance. In that of young swallows there are found little white or pink pebbles, known by the name of " chelidonii," and said to be employed in magical incantations. In the second belly of the heifer there is a black tufa found, round like a ball, ${ }^{9 t}$ and of no weight to speak of: this, it is generally thought, is singu-

89 The coot, probably.

$90 \mathrm{He}$ alludes to the papillæ of the mucous gland.

91 The colic.

92 "Lupus cervarius." Probably the lynx.

93 The belly of the elephant presents five transversal folds.

91 See B. xxviii. c. 77. This substance, known by the name of egagropile, consists of the hair which the animal has swallowed when licking itself. It assumes a round form, in consequence of the action of the intestines. 
larly efficacious in laborious deliveries, if it happens not to have touched the ground.

CHAP. 80. -THE OMENTUM : THE SPLEEN; ANIMALS WHICH ARE WITHOUT IT.

The belly and the intestines are covered with a caul known as the "omentum," consisting of a fatty, thin membrane; except in the case of those animals which are oviparous. To this membrane is attached the spleen, which lies on the left side, and opposite the liver : sometimes, indeed, it changes place with the liver, but such a case is looked upon as nothing less than a prodigy. Some persons imagine that a spleen of extremely diminutive size exists in the oviparous animals, as also in serpents; at all events, it is to be detected in the tortoise, the crocodile, the lizard, and the frog; though it is equally certain that it does not exist in the bird known as the " ægocephalos," ${ }^{95}$ nor yet in those animals which are destitute of blood. The spleen sometimes offers a peculiar impediment in running, for which reason the region of the spleen is cauterize $d^{96}$ in runners who are troubled with pains there. It is said also, that if the spleen is removed ${ }^{97}$ by an incision, animals may survive. There are some persons who think that with the spleen man loses the power of laughing, and that excessive laughter is caused by the overgrowth of it. There is a territory of Asia, known as Scepsis, ${ }^{98}$ in which it is said that the spleen of the cattle is remarkably small, and that from thence it is that remedies for diseases of the spleen have been introduced.

CHAP. 81.-THE KIDNEYS: ANIMALS WHICH HAVE FOUR KIDNEYs. ANIMALS WHICH HAVE NONE.

About Briletum and Tharne ${ }^{98 *}$ the stags have four kidneys: while, on the other hand, those animals which have wings and scales have ${ }^{99}$ none. The kidneys adhere to the upper part of

95 Perhaps the godwit, or stone-plover, the Scolopax ægocephala of Linnæus.

96 See also B. xxvi. c. 83 .

97 This may be done with safety in dogs or other animals.

38 See B. v. c. 32 . $95^{*}$ See p. 68.

99 This is not the case. Birds have kidneys, but of an irregular form. 
the loins. Among all animals, the kidney on the right side is more elevated than the other, less fat, and drier. In both kidneys there is a certain streak of fat running from the middle, with the sole exception of those of the sea-calf. It is above the kidneys, also, that animals are fattest, and the accumulation of fat about them is often the cause of death in sheep. Small stones are sometimes found in the kidneys. All quadrupeds that are viviparous have kidneys, but of those which are oviparous the tortoise is the only one that has them; an animal which has all the other viscera, but, like man, has the kidneys composed, to all appearance, of several kidneys, similar to those of the ox.

\section{CHAP. 82. -THE BREAST: THE RIBS.}

Nature has placed the breast, or, in other words, certain bones, around the diaphragm and the organs of life, but not around the belly, for the expansion of which it was necessary that room should be left. Indeed, there is no animal that has any bones around the belly. Man is the only creature that has a broad breast; in all others it is of a carinated shape, in birds more particularly, and most of all, the aquatic birds. The ribs of man are only eight in number; swine have ten, the horned animals thirteen, and serpents thirty.

CHAF. 83. - THE BLADDER : ANIMALS WHICH HAVE NO BLADDER.

Below the paunch, on the anterior side, lies the bladder, which is never found in any oviparous animal, with the exception of the tortoise, nor yet in any animal that has not lungs with blood, or in any one that is destitute of feet. Between it and the paunch are certain arteries, which extend to the pubes, and are known as the "ilia." In the bladder of the wolf there is found a small stone, which is called "syrites ;" and in the bladders of some persons calculi are sometimes found, which produce most excruciating pains; small hairs, like bristles, are also occasionally found in the bladder. This organ consists of a membrane, which, when once wounded, does not $^{1}$ cicatrize, just like those in which the brain and the heart are enveloped : there are many kinds of membranes, in fact.

1 This is a mistake. It does cicatrize. 
Chap. 84.-THE WOMB : THE WOMB OF tHe SOW: THE TEATS.

Women have all the same organs, except that adjoining to the bladder there is one like a small sac, ${ }^{2}$ from which circumstance it is calied the "uterus." Another name for this part is "loci ;" but in other animals it is known by the name of "vulva." With the viper and other animals whick generate their young within themselves, the womb is double; while with those which are oviparous, it is attached to the diaphragm. In woman it has two concavities, one on either side: when the matrix becomes displaced, it is productive of fatal effects, by causing suffocation. ${ }^{4}$ It is asserted that the cow, when pregnant, carries her young only in the right concavity of the womb, and that this is the case even when she produces twins. The womb of the sow is considered better eating if she has slipped her young, than if she has duly brought forth: in the former case it is known by the name of "ejectitia," in the latter it is called "porcaria." The womb of a sow that has farrowed only once is the most esteemed, and that of those which have ceased farrowing, the least. After farrowing, unless the animal is killed the same day, the womb is of a livid colour, and lean. This part, howerer, is not esteemed in a young sow, except just after the first farrowing : indeed, it is much more highly valued in an animal of a more mature age, so long as it is not past breeding, or has been killed two days before farrowing, or two days after, or upon the day on which it has miscarried. The next best after that of a sow that has miscarried, is that of one that has been killed the day after farrowing: indeed, the paps of this last, if the young have not begun to suck, are excellent eating, while those of an animal that has miscarried are very inferior. The ancients called this part by the name of " abdomen," before it grew hard, and were not in the habit of killing swine while in a state of pregnancy.

CHAP. 85.-ANIMALS WHICH HAVE SUET: ANIMALS WHICH DO NOT GROW FAT.

Those among the horned animals which have teeth in one 2 Or bag.

3 "The (principal) place."

4 Ajasson renders this passage: "The effects are fatal when this organ, becoming displaced, absorbs the air." The text is probably corrupt. 
jaw only, and pastern bones on the feet, produce tallow or suet. Those, on the other hand, which are cloven-footed, or have the feet divided into toes, and are without horns, have simple fat only. This fat becomes hard, and when quite cold turns brittle, and is always found at the extremity of the flesh; while, on the other hand, the fat which lies between the skin and the flesh forms a kind of liquid juice. Some animals naturally do not become fat, such as the hare and the partridge, for instance. All fat animals, male as well as female, are mostly barren; and those which are remarkably fat become old the soonest. All animals have a certain degree of fatness in the eyes. The fat in all animals is devoid of sensation, having neither arteries nor veins. With the greater part of animals, fatness is productive of insensibility; so much so, indeed, that it has been said, that living swine have been gnawed even by mice. ${ }^{5}$ It has been even asserted that the fat was drawn off from the body of a son of L. Apronius, a man of consular rank, and that he was thus relieved of a burden which precluded him from moving.

CHAP. 86.-THE MARROW : aNIMALS WHICH HAVE NO MARROW.

The marrow seems also to be formed of a similar material; in the young it is of a reddish colour, but it is white in the aged. It is only founci in those bones which are hollow, and not in the tibiæ of horses or dogs ; for which reason it is, that when the tibia is broken, the bone will not reunite, a process which is effected ${ }^{6}$ by the flow of the marrow. The marrow is of a greasy nature in those animals which have fat, and suetty in those with horns. It is full of nerves, and is found only in the vertebral column ${ }^{7}$ in those animals which have no bones, fishes, for instance. The bear has no marrow; and the lion has a little only in some few bones of the thighs and the brachia, which are of such extraordinary hardness that sparks may be emitted therefrom, as though from a flint-stone.

5 Varro, De Re Rust. B. ii. c. 4, says that he saw an instance of this in Arcadia.

6 This is not the case.

7 There is no similarity whatever between the spinal marrow and that which is found in the otber bones. 


\section{CHAP. 87.-BONES AND FISH-BONES: aNIMALS WHICH HAVE NEITHER. CARTHLAGES.}

The bones are hard, also, in those animals ${ }^{8}$ which do not grow fat; those of the ass are used by musicians for making flutes. Dolphins have bones, and not ordinary fish-bones; for they are viviparous. Serpents, on the other hand, have bones like those of fish. Among aquatic animals, the mollusks have no bones, but the body is surrounded with circles of flesh, as in the sæpia and the cuttle-fish, for instance; insects, also, are said to be equally destitute of bones. Among aquatic animals, those which are cartilaginous have marrow in the vertebral column; the sea-calf has cartilages, and no bones. The ears also, and the nostrils in all animals, when remarkably prominent, are made flexible by a remarkable provision of Nature, in order that they may not be broken. When cartilage is once broken, it will not unite; nor will bone, when cut, grow again, except in beasts of burden, between the hoof and the pastern.

Man increases in height till his twenty-first year, after which he fills out; but it is more particularly when he first arrives at the age of puberty that he seems to have untied a sort of knot in his existence, and this especially when he has been overtaken by illness.

CHAP. 88.-THE NERVE: ANIMALS WHICH HAVE NONE.

The nerves ${ }^{9}$ take their rise at the heart, and even surround it in the ox; they have the same nature and principle as the marrow. In all animals they are fastened to the lubricous surface of the bones, and so serve to fasten those knots in the body which are known as articulations or joints, sometimes lying between them, sometimes surrounding them, and sometimes running from one to another; in one place they are long and round, and in another broad, according as the necessity of each case may demand. When cut, they will not

8 The hare and the partridge, for instance.

9 There is considerable doubt what the ancients exactly meant by the "nervi ;" and whether, in fact, they had any definite idea of "nerves," in our acceptation of the word. Pliny here expresses the opinions entertained by Aristotle. "Tendons," or "sinews," would almost appear to be the proper translation of the word. 
reunite, and if wounded, it is wonderful what excruciating pain they cause ; though, if completely cut asunder, they are productive of none whatever. Some animals are destitute of nerves, fish, for instance, the bodies of which are united by arteries, though even these are not to be found in the mollusks. Wherever there are nerves found, it is the inner ones that contract the limb, and the outer ones that extend it.

Among the nerves lie concealed the arteries, which are so many passages for the spirit; and upon these float the veins, as conduits for the blood. The pulsation of the arteries is more especially perceptible on the surface of the limbs, and afford indications of nearly every disease, being either stationary, quickened, or retarded, conformably to certain measures and metrical laws, which depend on the age of the patient, and which have been described with remarkable skill by Herophilus, who has been looked upon as a prophet in the wondrous art of medicine. These indications, however, have been hitherto neglected, in consequence of their remarkable subtilty and minuteness, though, at the same time, it is by the observation of the pulse, as being fast or slow, that the health of the body, as regulating life, is ascertained.

\section{CHAP. 89.-THE ARTERIES; THE VEINS: aNIMALS WITHOUT} ARTERIES OR VEINS. THE BLOOD AND THE SWEAT.

The arteries are destitute of sensation, for they are devoid of blood. They do not, all of them, however, contain the vital spirit, and when one of them has been cut, it is only that part of the body that is reduced to a torpid state. Birds have neither veins nor arteries, which is the case also with serpents, tortoises, and lizards ; and they have but a very small proportion of blood. The reins, which are dispersed beneath the whole skin in filaments of extreme thinness, terminate with such remarkable fineness, that the blood is able to penetrate no further, or, indeed, anything else, except an extremely subtle humour which oozes forth from the skin in innumerable small drops, and is known to us as "sweat." The knot, and place of union of the veins, is the navel.

CHAP. 90. (38.) - ANIMALS, THE BLOOD OF WHICH COAGULATES

WITH THE GREATEST RAPIDITY: OTHER ANIMALS, THE BLOOD OF WHICH DOES NOT COAGULATE. ANIMALS WHICH HAVE THE 
THICKEST BLOOD: THOSE THF BLOOD OF WHICH IS THE THINNEST : ANIMALS WHICH HAVE NO BLOOD.

Those animals in which the blood is more abundant and of an unctuous nature, are irascible; it is darker in males than in females, and in the young than in the aged: the blood of the lower extremities is the thickest. There is great vitality, too, in the blood, and when it is discharged from the body, it carries the life with it: it is not sensible, however, of touch. Those animals in which the blood is the thickest are the most courageous, and those in which it is the thinnest the most intelligent; while those, again, which have little or no blood are the most timorous of all. The blood of the bull coagulates and hardens the most speedily of all, and hence it is so particularly deadly ${ }^{10}$ when drunk. On the other hand, the blood of the wild boar, the stag, the roe-buck, and oxen of all kinds, does not coagulate. Blood is of the richest quality in the ass, and the poorest in man. Those animals which have more than four feet have no blood. In animals which are very fat, the blood is less abundant than in others, being soaked up by the fat. Man is the only creature from which the blood flows at the nostrils; some persons bleed at one nostril only, some at both, while others again void blood by the lower ${ }^{11}$ parts. Many persons discharge blood from the mouth at stated periods, such, for instance, as Macrinus Viscus, lately, a man of prætorian dignity, and Volusius Saturninus, ${ }^{12}$ the Prefect of the City, who every year did the same, and yet lived to beyond ninety. The blood is the only substance in the body that is sensible of any temporary increase, for a larger quantity will come from the victims if they happen to have drunk just before they are sacrificed.

Chap. 91.-ANIMALS WHICH ARE WITHOdT BLOOD AT CERTAIN PERIODS OF THE YEAR.

Those animals which conceal themselves ${ }^{13}$ at certain periods of the year, as already mentioned, have no blood at those times, with the exception, indeed, of some very small drops about the

10 See B. xxviii. c. 41.

11 In allusion, probably, to hæmorrhoids, or piles.

12 See B. vii. c. 12.

13 Bears, dormice, serpents, \&c. 
heart. A marvellous dispensation of Nature! and very similar to that witnessed in man, where the blood is sensible of various modifications from the slightest causes ; for not only, similarly to the bile, does it rush upwards to the face, but it serves also to indicate the various tendencies of the mind, by depicting shame, anger, and fear, in many ways, either by the paleness of the features or their unusual redness; as, in fact, the redness of anger and the blush of modesty are quite different things. It is a well-known fact, that when a man is in fear, the blood takes to flight and disappears, and that many persons have been pierced through the body without losing one drop of blood; a thing, however, which is only the case with man. But as to those animals which we have already mentioned as changing ${ }^{14}$ colour, they derive that colour from the reflection ${ }^{15}$ of $0^{t}$ ther objects; while, on the other hand, man is the only one that has the elements which cause these changes centred in himself. All diseases, as well as death, tend to absorb the blood.

वBAP. 92. (39.)-THETHER THE BLOOD IS THE PRINCIPLE OP LIFE.

There are some persons who are of opinion that the fineness of the wit does not depend úpon the thinness of the blood, but that animals are more or less stupid in proportion to the skin or other coverings of the body, as the oyster and the tortoise, for instance: that the hide of the ox and the bristles of the hog, in fact, offer a resistance to the fine and penetrating powers of the air, and leave no passage for its transmission in a pure and liquid state. The same, they say, is the case, too, with men, when the skin is very thick or callous, and so excludes the air: Just as if, indeed, the crocodile was not equally remarkable for the hardness of its skin and its extreme cunning.

\section{CHAP. 93. - THE HIDE OF ANIMALS.}

The hide, too, of the hippopotamus is so thick, that lances, ${ }^{16}$ even, are turned from it, and yet this animal has the intelligence to administer certain medicaments to itself. The hide, too, of

14 The polypus and the chameleon.

15 See B. viii. co. 51, 52.

16 Walking-sticks are still made of it. 
the elephant makes bucklers that are quite impenetrable, and yet to it is ascribed a degree of intelligence superior to that of any quadruped. The skin itself is entirely devoid of sensation, and more particularly that of the head; wherever it is found alone, and unaccompanied with flesh, if wounded, it will not unite, as in the cheek and on the eyelid, ${ }^{18}$ for instance.

\section{CHAP. 94. - THE HAIR AND THE COVERING OF THE SKIN.}

Those animals which are viviparous, have hair ; those which are oviparous, have feathers, scales, or a shell, like the tortoise; or else a purple skin, like the serpent. The lower part of all feathers is hollow ; if cut, they will not grow again, but if pulled out, they will shoot afresh. Insects fly by the aid of a frail membrane; the wings of the fish ${ }^{19}$ called the "swallow" are moistened in the sea, while those of the bat which frequents our houses are dry; the wings of this last animal have certain articulations as well. The hairs that issue from a thick skin are rough, while those on females are of a finer quality. Those found on the horse's mane are more abundant, which is the case also with the shoulders of the lion. The dasypus has hair in the inside of the mouth even and under the feet, two features which Trogus has also attributed to the hare; from which the same author concludes that hairy men are the most prone to lust. The most hairy of all animals is the hare. Man is the only creature that has hair as the mark of puberty; and a person who is devoid of this, whether male or female, is sure to be sterile. The hair of man is partly born with him, and in part produced after his birth. The last kind of hair will not grow upon eunuchs, though that which has been born with them does not fall off; which is the case also with women, in a great degree. Still however, there have been women known to be afflicted with falling off of the hair, just as some are to be seen with a fine down on the face, after the cessation of the menstrual discharge. In some men the hair that mostly shoots forth after birth will not grow spontaneously. The hair of quadrupeds comes off every year, , and

18 As already mentioned, this is not the fact.

19 See B. ix. c. 43. 
grows again. That of the head in man grows the fastest, and next to it the hair of the beard. When cut, the hairs shoot, not from the place where they have been cut, as is the case with grass, but at the root. The hair grows quickly in certain diseases, phthisis more particularly; it grows also with rapidity in old age, and on the body after death. In persons of a libidinous tendency the hair that is produced at birth falls off more speedily, while that which is afterwards produced grows with the greatest rapidity. In quadrupeds, the hair grows thicker in old age; but on those with wool, it becomes thinner. Those quadrupeds which have thick hair on the back, have the belly quite smooth. From the hides of oxen, and that of the bull more especially, glue is extracted by boiling.

CHAP. 95.-THE PAPS: BIRDS THAT HAVE PAPS. RFAIARKABLE FACTS CONNECTED WITH THE DUGS OF ANIMALS.

Man is the only male among animals that has nipples, all the rest having mere marks only in place of them. Among female animals even, the only ones that have mammæ on the breast are those which can nurture their young. No oviparous animal has mammæ, and those only have milk that are viviparous ; the bat being the only winged animal that has it. As for the stories that they tell, about the screech-owl ejecting milk from its teats upon the lips of infants, I look upon it as utterly fabulous : from ancient times the name "strix," ${ }^{20} \mathrm{I}$ am aware, has been employed in maledictions, but I do not think it is well ascertained what bird is really meant by that name.

(40.) The female ass is troubled with pains in the teats after it has foaled, and it is for that reason that at the end of six months it weans its young; while the mare suckles its young for nearly the whole year. The solid-hoofed animals do not bear more than two young ones at a time: they all of them have two paps, and nowhere but between the hind legs. Animals with cloven feet and with horns, such as the cow, for instance, have four paps, similarly situate, sheep and goats two.

20 . It is not improbable that, under this name, some kind of large vampire bat was meant; but, as Pliny says, it is impossible to arrive at any certain knowledge on the subject. 'The best account given of the strix is that in Ovid's Fasti, B. vi. The name was given opprobiously to supposed witches, the "foul and midnight hags" of Shakspeare. 
Those which produce a more numerous progeny, and those which have toes on the feet, have a greater number of paps distributed in a double row all along the belly, such as the sow, for instance; the better sorts have twelve, the more common ones two less: the same is the case also with the female of the dog. Other animals, again, have four paps situate in the middle of the belly, as the female panther; others, again, two only, as the lioness. The female elephant has two only, - situate between the shoulders, and those not in the breast, but without it, and hidden in the arm-pits : none of the animals which have toes have the paps between the hind legs. 'The sow presents the first teat to the first-born in each farrow, the first teat being the one that is situate nearest to the throat. Each pig, too, knows its own teat, according to the order in which it was born, and draws its nourishment from that and no other : if its own suckling, too, should happen to be withdrawn from iny one of them, the pap will immediately dry up, and shrink ack within the belly: if there should be only one pig left of all the farrow, that pap alone which has been assigned for its nutriment when born, will continue to hang down for the purpose of giving suck. The she-bear has four mamme, the dolphin only two, at the bottom of the belly; they are not easily visible, and have a somewhat oblique direction: this is the only animal which gives suck while in motion. The balæna and sea-calf also suckle their young by teats.

CHAP. 96. (41.)—THE MILK : the BIfSTINGS. CHEESE; OF WHAT MILK CHEESE CANNOT BE MADE. RENNET; THE VARIOUS KINDS OF ALIMENT IN MILK.

The milk that is secreted in a woman before her seventh month is useless ; but after that month, so long as the fotus is healthy, the milk is wholesome: many women, indeed, are so full of milk, that it will flow not only from the mammæ, but exudes at the arm-pits even. ${ }^{21}$ Camels continue in milk until they are pregnant again. Their milk, mixed in the proportion of one part to three of water, is considered a very pleasant beverage. The cow has no milk before it has calved, and that which immediately follows upon its bringing forth is known as the "colostra:" 22 if water is not mixed with it, it will

${ }^{21}$ This assertion is borrowed from Aristotle, Hist. Anim. B. vii. e. 14. 22 Or biestings. 
coagulate, and assume the hardness of pumice. She-asses, as socn as they are pregnant, have milk in their udders; when the pasturage is rich, it is fatal to their young to taste the mother's milk the first two days after birth; the kind of malady by which they are attacked is known by the name of "colostration." Cheese cannot be made from the milk of animals which have teeth on either jaw, from the circumstance that their milk does not coagulate. The thinnest milk of all is that of the camel, and next to it that of the mare. The milk of the she-ass is the richest of all, so much so, indeed, that it is often used instead of rennet. Asses' milk is also thought to be very efficacious in whitening the skin of females : at all events, Poppæa, ${ }^{23}$ the wife of Domitius Nero, used always to have with her five hundred asses with foal, and used to bathe the whole of her body in their milk, thinking that it also conferred additional suppleness on the skin. All milk. thickens by the action of fire, and becomes serous when exposed to cold. The milk of the cow produces more cheese than that of the goat: when equal in quantity, it will produce nearly twice the weight. The milk of animals which have more than four mammæ does not produce cheese; and that is the best which is made of the milk of those that have but two. The rennet of the fawn, the hare, and the kid is the most esteemed, but the best of all is that of the dasypus : this last acts as a specific for diarrhœa, that animal being the only one with teeth in both jaws, the rennet of which has that property. It is a remarkable circumstance, that the barbarous nations which subsist on milk have been for so many ages either ignorant of the merits of cheese, or else have totally disregarded it; and yet they understand how to thicken milk and form therefrom an acrid kind of liquid with a pleasant flavour, as well as a rich butter : this last is the foam ${ }^{24}$ of milk, and is of a thicker consistency than the part which is known as the "serum." $25 \mathrm{We}$ ought not to omit that butter has certain of the properties of oil, and that it is used for an ointment among all barbarous nations, and among ourselves as well, for infants.

${ }^{23}$ See B. xxyiii. c. 12. Poppæa Sabina, first the mistress, then the wife, of the Emperor Nero.

24 "Spuma." He calls it so, because it floats on the surface. See B. xxviii. c. 35 . The "acor," or acrid liquid, which he speaks of, is, no doubt, butter-milk. 25 Or whey. 
CHAP. 97. (42.)-VARIOUS KINDS OF CHEESE.

The kinds of cheese that are most esteemed at Rome, where the various good things of all nations are to be judged of by comparison, are those which come from the provinces of $\mathrm{Ne}$ mausus ${ }^{26}$ and more especially the villages there of Lesura and Gabalis ; ${ }^{27}$ but its excellence is only very short-lived, and it must be eaten while it is fresh. The pastures of the Alps recommend themselves by two sorts of cheese; the Dalmatic Alps send us the Docleatian ${ }^{28}$ cheese, and the Centronian ${ }^{29}$ Alps the Vatusican. The kinds produced in the Apennines are more numerous ; from Liguria we have the cheese of Ceba, ${ }^{30}$ which is mostly made from the milk of sheep; from Umbria we have that of Asina, and from the frontiers of Etruria and Liguria those of Luna, remarkable for their vast size, a single cheese weighing as much as a thousand pounds. Nearer the City, again, we have the cheese of Vestinum, the best of this kind being that which comes from the territory of Ceditium. ${ }^{31}$ Goats also produce a cheese which has been of late held in the highest esteem, its flavour being heightened by smoking it. The cheese of this kind which is made at Rome is considered preferable to any other; for that which is made in Gaul has a strong taste, like that of medicine. Of the cheeses that are made bejond sea, that of Bithynia ${ }^{32}$ is usually considered the first in quality. That salt exists in pasturelands is pretty evident, from the fact that all cheese as it grows old contracts a saltish flavour, even where it does not appear to any great extent $;^{33}$ while at the same time it is equally well known that cheese soaked in a mixture of thyme and vinegar will regain its original fresh flavour. It is said that Zoroaster lived thirty years in the wilderness upon cheese, prepared in such a peculiar manner, that he was insensible to the advances of old age.

${ }^{26}$ Nismes, in France. Hardouin speaks of goats'-milk cheeses made in its neighbourhood, and known as fromages de Baux.

27 Probably the modern Losere and Gevaudan. See B. iv. c. 19.

28 For the Docleatæ, see B. iii. c. 26.

${ }^{29}$ For the Centrones, see B. iii. c. 24 . He perhaps refers to the modern fromage de Passi.

30 The modern Marquisat de Cive, which still produces excellent cheese.

31 See B. xiv. c. 8.

32 And more especially at Salona in Bithynia.

33 "Etiam ubi non videtur major." This is probably corrupt. 
CHAP. 98. (43.)-DIFEERENCES OF THE MEMBERS OF MAN FROM THOSE OF OTHER ANIMALS.

Of all the terrestrial animals, man is the only biped: he is also the only one that has a throat, and shoulders, or " humeri," parts in other animals known by the name of " armi." Man, too, is the only animal that has the "ulna," or elbow. Those animals which are provided with hands, have flesh orily on the interior of them, the outer part consisting of sinews and skin.

\section{CHAP. 99.-THE FINGERS, THE AlMS.}

Some persons have six fingers on the hands. We read that C. Horatius, a man of patrician rank, had two daughters, who for this reason had the name of "Sedigitæ;" and we find mention made of Volcatius Sedigitus, ${ }^{34}$ as a famous poet. The fingers of man have three joints, the thumb only two, it bending in an opposite direction to all the other fingers. Viewed by itself, the movement of the thumb has a sidelong direction, and it is much thicker than the rest of the fingers. The little finger is equal in length to the thumb, and two others are also equal in length, the middle finger being the longest of all. Those quadrupeds which live by rapine have five toes on the fore feet, and four on the hinder ones. The lion, the wolf, and the dog, with some few others, have five claws on the nind feet, one of which hangs down near the joint of the leg. The other animals, also, which are of smaller size, have five toes. The two arms are not always equal in length : it is a well-known fact, that, in the school of gladiators belonging to Caius Cæsar, ${ }^{35}$ the Thracian Studiosus had the right arm longer than the left. Some animals also use their forepaws to perform the duties of hands, and employ them in conveying food to the mouth as they sit, the squirrel, for instance.

CIIA. 100. (44.)-RESEMBLANCE OF THE APE TO MAN.

As to the various kinds of apes, they offer a perfect resem-

st He wrote a poem, in which the principal Latin dramatists are enumerated, in the order of merit. A. Gellius, B. xv. c. 24, has prescrved a portion of it.

${ }^{35}$ Germanicus. 
blance to man in the face, the nostrils, the ears, and the eyelids; being the only quadrupeds, in fact, that have eyelushes on the lower eyelid. They have mammæ also on the breast, arms and legs, which bend in opposite directions, and nails upon the hands and fingers, the middle finger being the longest. They differ somewhat from man in the feet; which, like the hands, are of remarkable length, and have a print similar to that of the palm of our hand. They hare a thumb also, and articulations similar to those in man. The males differ from man in the sexual parts only, while all the internal visceri exactly resemble those of man.

\section{CHAP. 101. (45.)--THE NAILS.}

It is generally supposed tirat the nails are the terminations of the sinews. All animals which have fingers have nails as well. In the ape they are long and overlapping, ${ }^{36}$ like a tile, while in man they are broad: they will grow even after death. In the beasts of prey they are hooked, while in others, such as the dog, for instance, they are straight, with the exception, indeed, of the one which is attached to the leg in most of them. All the animals which have feet [and not hoofs], have toes as well, except the elephant; he, also, would appear to have toes, five in number, but rudely developed, undivided, and hardly distinct from one another, bearing a nearer resemblance, in fact, to hoofs than to claws. In the elephant the fore-feet are the largest, and in the hind-feet there are short joints. This animal is able, also, to bend the hams inward like a man, while in all the others the joints of the linder legs bend in a contrary direction to those of the fore ones. Those animals which are riviparous bend the fore-leg forward, while the joint of the hind-leg is directed backward.

\section{CHAP. 102.-THE KNEES AND THE HAMS.}

In man the knee and the elbow bend contrary ways; the same is the case, too, with the bear and the ape, and it is for this reason that they are not so swift of foot as other animals. Those quadrupeds which are oviparous, such as the crocodile and the lizard, bend the knee of the fore-leg back-

${ }^{36}$ This seems to be the meaning of "imbricatus." 
wards, and that of the hind-leg forwards; their thighs are placed on them obliquely, in a similar manner to a man's thumb; which is the case also with the multipede insects, the hind-legs only excepted of such as leap. Birds, like quadrupeds, have the joints of the wings bending forwards, but those of the legs backwards.

\section{CHAP. 103.-PARTS OF THE HUMAN BODY TO WHICH CERTAIN RELIGIOUS IDEAS ARE ATTACHED.}

In accordance with the usages of various nations, certain religious ideas have been attached to the knees. It is the knees that suppliants clasp, and it is to these that they extend their hands ; it is the knees that they worship like so many altars, as it were; perhaps, because in them is centred the vital strength. For in the joint of either knee, the right as well as the left, there is on the fore-side of each a certain empty space, which bears a strong resemblance to a mouth, and through which, like the throat, if it is once pierced, the rital powers escape. ${ }^{37}$ There are also certain religious ideas attached to other parts of the body, as is testified in raising the back of the right hand to the lips, and extending it as a token of good faith. It was the custom of the ancient Greeks, when in the act of supplication, to touch the chin. The seat of the memory lies in the lower part of the ear, which we touch when we summon a witness to depose upon memory to an arrest..$^{38}$ The seat, too, of Nemesis ${ }^{39}$ lies behind the right ear, a goddess which has never yet found a Latin name, no, not in the Capitol even. It is to this part that we apply the finger next the little finger, after touching the mouth with it, when we silently ask pardon of the gods for having let slip an indiscreet word.

\section{CHAP. 104.- - VARICOSE VEINS.}

Men only, in general, have varicose veins in the legs, women but very rarely. We are informed by Oppius, that

${ }^{37}$ Though wounds in the knee are highly dangerous, death does not necessarily ensue.

38 Of another person, who had thus forfeited his bail. It was the custom to touch the ear of the attesting witness.

${ }^{39}$ The goddess of retribution. See B. xxviii. c. 5, where he makes further mention of her statue in the Capitol. 
C. Marius, who was seven times consul, was the only man ever known to be able to have them extracted in a standing position.

\section{CHAP. 105.-THE GAIT, THE FEET, THE LEGS.}

All animals take a right-hand direction when they first begin to walk, and lie down on the left side. While the other animals walk just as it may happen, the lion only and the camel walk foot by foot, or in such a way that the left foot never passes the right, but always comes behind it. Men have the largest feet; in every kind of animal the female has the smallest. Man only $y^{40}$ has calves, and flesh upon the legs: we find it stated by authors, however, that there was once an Egyptian who had no calves on his legs. All men, too, with some few exceptions, have a sole to the foot. It is from these exceptional cases that persons have obtained the names of Plancus, ${ }^{41}$ Plautus, Pansa, and Scaurus; just as, from the malformation of thè legs, we find persons called Varus, ${ }^{42}$ Vacia, and Vatinius, all which blemishes are to be seen in quadrupeds also. Animals which have no horns have a solid hoof, from which circumstance it is used by them as a weapon of offence, in place of horns; such animals as these are also destitute of pastern bones, but those which have cloven hoofs have them; while those, again, which have toes have none, nor are they ever found in the fore-feet of animals. The camel has pastern bones like those of the ox, but somewhat smaller, the feet being cloven, with a slight line of division, and having a fleshy sole, like that of the bear: hence it is, that in a long journey, the animal becomes fatigued, and the foot cracks, if it is not shod.

$$
\text { cHaP. 106. (46.)-HoOFs. }
$$

The horn of the hoof grows again in no animals except beasts of burden. The swine in some places in Illyricum have solid hoofs. Nearly all the horned animals are clovenfooted, no animal having solid hoofs and two horns. The Indian ass is only a one-horned animal, and the oryx is both

40 The frog is, in some measure, an exception.

41 Or "flat-foot," "splay-foot," "large-foot," and "club-footed."

42 Words meaning "knock-kneed," "bow-legged," and "wry-legged." 
one-horned and cloven-footed. The Indian ass ${ }^{43}$ is the only solid-hoofed animal that has pastern-bones. As to swine, they are looked upon as a sort of mongrel race, with a mixture of both kinds, and hence it is that their ankle-bones are so misshapen. Those authors who have imagined that man has similar pastern-bones, are easily to be confuted. The lynx is the only one among the animals that have the feet divided into toes, that has anything bearing a resemblance to a pastern-bone; while with the lion it is more crooked still. The great pastern-bone is straight, and situate in the joints of the foot; it projects outwards in a convex protuberance, and is held fast in its vertebration by certain ligaments.

\section{CHAP. 107. (47.) - THE FEET OF BIRDS.}

Among birds, some have the feet divided into toes, while others, again, are broad and flatfooted-in others, which partake of the intermediate nature of both, the toes are divided, with a wide space between them. All birds, however, have four toes-three in front, and one on the heel; this last, however, is wanting in some that have long legs. The iyn ${ }^{44}$ is the only bird that has two toes on each side of the leg. This bird also protrudes a long tongue similar to that of the serpent, and it can turn the neck quite round and look backwards; it has great talons, too, like those of the jackdaw. Some of the heavier birds have spurs also upon the legs; but none of those have them which have crooked talons as well. The long-footed birds, as they fly, extend the legs towards the tail, while those that have short legs hold them contracted close to. the middle of the body. Those authors who deny that there is any bird without feet, assert that those even which are called apodes, ${ }^{45}$ are not without them, as also the oce, and the drepanis, ${ }^{46}$ which last is a bird but very rarely seen. Serpents, too, have been seen with feet like those of the goose.

${ }^{43}$ The rhinoceros.

44 Or wryneck.

45 See B. x. c. 5.

46 Supposed to be the Hirundo apus of Linnæus. Of the "oce" nothing is known; indeed, the reading is very doubtful. 
ChaP. 108. (48.)-THE FEeT OF ANIMALS, FROM THCSE HAVING TWO FEET TO THOSE WITH A HUNDRED.-DWARF

Among insects, those which have hard eyes have the forefeet long, in order that from time to time they may rub the eyes with their feet, as we frequently see done by flies. The insects which have long hind-feet are able to leap, the locust, for instance. All these insects have six feet: and some of the spiders have two very long feet in addition. They have, all of them, three joints. We have already ${ }^{47}$ stated that marine insects have eight feet, such as the polypus, the sæpia, the cuttle-fish, and the crab, animals which move their arms in a contrary direction to their feet, which last they move around as well as obliquely : they are the only animals the feet of which have a rounded form. Other insects have two feet to regulate their movements; in the crab, and in that only, these duties are performed by four. The land animals which exceed this number of feet, as most of the worms, ${ }^{48}$ never have fewer than twelve feet, and some, indeed, as many as a hundred. The number of feet is never uneven in any animal. Among the solid-hoofed animals, the legs are of their proper length from the moment of their birth, after which they may with more propriety be said to extend themselves than to increase in growth : hence it is, that in infancy they are able to scratch their ears with the hind feet, a thing which, when they grow older, they are not able to do, because their increase of grow th affects only the superficies of the body. It is for the same reason also, that they are only able to graze at first by bending the knees, until such time as the neck has attained its proper length.

(49.) There are dwarfs to be found among all animals, and among birds even.

CHAP. 109. -THE SEXUAL PARTS. - HERM.APHRODITES.

We have already spoken sufficiently $y^{49}$ at length of those animals, the males of which have the sexual parts behind. In the wolf, the fox, the weasel, and the ferret, these parts are bony; and it is the genitals of the last-mentioned animal

47 B. ix. c. 44.

48 He evidently means insects of the centipede class. See B. xxix. c. 39.

${ }^{49}$ B. x. c. 83. 
that supply the principal remedies for calculus in the human bladder. It is said also that the genitals of the bear are turned into a horny substance the moment it dies. Among the peoples of the East the very best bow-strings are those which are made of the member of the camel. These parts also, among different nations, are made the object of certain usages ${ }^{50}$ and religious observances ; and the Galli, ${ }^{51}$ the priests of the Mother of the gods, are in the habit of castrating themselves, without any dangerous results. On the other hand, there is in some few women a monstrous resemblance to the male conformation, while hermaphrodites appear to partake of the nature of both. Instances of this last conformation were seen in quadrupeds in Nero's reign, and for the first time, I imagine ; for he ostentatiously paraded hermaphrodite horses yoked to his car, which had been found in the territory of the Treviri, in Gaul; as if, indeed, it was so remarkably fine a sight to behold the ruler of the earth seated in a chariot drawn by monstrosities!

\section{CHAP. 110.-THE TESTES-THE THREE CLASSES OF IUNUCHS.}

In sheep and cattle the testes hang down to the legs, while in the boar they are knit up close to the body. In the dolphin they are very long, and are concealed in the lower part of the belly. In the elephant, also, they are quite concealed. In oviparous animals they adhere to the interior of the loins: these animals are the most speedy in the venereal congress. Fishes and serpents have no testes, but in place of them they have two veins, which run from the renal region to the genitals. The bird known as the "buteo," 51 has three testes. Man is the only creature in which the testes are ever broken, either accidentally or by some natural malady; those who are thus afflicted form a third class of half men, in addition to hermaphrodites and eunuchs. In all species of animals the male is more courageous than the female, with the exception of the panther and the bear.

\section{CHAP. 111. (50.) - THE talls OF aNIMALS.}

Nearly all the animals, both viviparous as well as oviparous,

${ }^{50}$ Such as circumcision among the Jews.

${ }^{51}$ See B. $x x x v$. c. 46.

${ }^{51}$ Probably the buzzard; from this story also called the "triorchis." 
with the exception of man and the ape, have tails in proportion to the necessities of the body. In animals with bristles the tail is bare, as in the boar, for instance. In those that are shaggy, it is small, such as the bear; while in those animals that have long hair, the tail is long also, the horse, for instance. The tail of a lizard or serpent, if cut off, will grow again. The tail governs the movements of the fish like a rudder, and turning from side to side, to the right or to the left, impels it onwards, acting in some degree like an oar. A double tail is sometimes found in lizards. In oxen, the stalk of the tail is of remarkable length, and is covered with rough hair at the extremity. In the ass, too, it is longer than in the horse, but in beasts of burden it is covered with bristly hairs. The tail of the lion, at the extremity, is like that of the $\mathrm{ox}$ and the field-mouse; but this is not the case with the panther. In the fox and the wolf it is covered with long hair, as in sheep, in which it is longer also. In swine, the tail is curled; among dogs, those that are mongrels carry it close beneath the belly.

CHAP. 112. (51.) - THE DIFFERENT vOICES OF ANIMALS.

Aristotle $^{52}$ is of opinion that no animal has a voice which does not respire, and that hence it is that there is no voice in insects, but only a noise, through the circulation of the air in the interior, and its resounding, by reason of its compression. Some insects, again, he says, emit a sort of humming noise, such as the bee, for instance; others a shrill, long-drawn note, like the grasshopper, the two cavities beneath the thorax receiving the air, which, meeting a moveable membrane within, emits a sound by the attrition.-Also that flies, bees, and other insects of that nature, are only heard while they are flying, and cease to be heard the moment they settle, and that the sound which they emit proceeds from the friction and the air within them, and not from any act of respiration. At all events, it is generally believed that the locust emits a sound by rubbing together the wings and thighs, and that among: the aquatic animals the scallop makes a certain noise as it flies. ${ }^{53}$ Mollusks, however, and the testaceous animals have no voice and emit no sounds. As for the other fishes, although

52 Hist. Anim. B. iv. c. 9.

53 See B. ix. c. 52. 
they are destitute of lungs and the tracheal artery, they are not entirely without the power of emitting certain sounds : it is only a mere joke to say that the noise which they make is produced by grating their teeth together. The fish, too, that is found in the river Acheloüs, and is known as the boar-fish, ${ }^{54}$ makes a grunting noise, as do some others which we have previously ${ }^{55}$ mentioned. The oviparous animals hiss: in the serpent this hissing is prolonged, in the tortoise it is short and abrupt. Frogs make a peculiar noise of their own, as already stated $;^{56}$ unless, indeed, this, too, is to be looked upon as a matter of doubt; but their noise originates in the mouth, and not in the thorax. Still, however, in reference to this subject, the nature of the various localities exercises a very considerable influence, for in Macedonia, it is said, the frogs are dumb, and the same in reference to the wild boars there. Among birds, the smaller ones chirp and twitter the most, and more especially about the time of pairing. Others, again, exercise their voice while fighting, the quail, for instance; others before they begin to fight, such as the partridge; and others when they have gained the victory, the dunghill cock, for instance. The males in these species have a peculiar note of their own, while in others, the nightingale for example, the male has the same note as the female.

Some birds sing all the year round, others only at certain times of the year, as we have already mentioned when speaking of them individually. The elephant produces a noise similar to that of sneezing, by the aid of the mouth, and independently of the nostrils; but by means of the nostrils it emits a sound similar to the hoarse braying of a trumpet. It is only in the bovine race that the voice of the female is the deepest, it being in all other kinds of animals more shrill than that of the male; it is the same also with the male of the human race when castrated. The infant at its birth is never heard to utter a cry before it has entirely left the uterus: it begins to speak at the end of the first year. A son of Crœesus, ${ }^{57}$ however, spoke when only six months old, and, while yet wielding the child's rattle, afforded portentous omens, for

54 "Aper."

55 B. ix. c. 7.

56 Sce c. 65 of the present Book.

57 Not the dumb son mentioned by Herodotus, who saved his father's life at the taking of Sardes. 
it was at the same period that his father's empire fell. Those children which begin to speak the soonest, begin to walk the latest. The human voice acquires additional strength at the fourteenth year; but in old age it becomes more shrill again, and there is no living creature in which it is subject to more frequent changes.

In addition to the preceding, there are still some singular circumstances that deserve to be mentioned with reference to the voice. If saw-dust or sand is thrown down in the orchestra of a theatre, or if the walls around are left in a rough state, or empty casks are placed there, the voice is absorbed; while, on the other hand, if the wall is quite straight, or if built in a concave form, the voice will move along it, and will convey words spoken in the slightest whisper from one end $^{58}$ to the other, if there is no inequality in the surface to impede its progress. The voice, in man, contributes in a great degree to form his physiognomy, for we form a knowledge of a man before we see him by hearing his voice, just as well ${ }^{59}$ as if we had seen him with our eyes. There are as many kinds of voices, too, as there are individuals in existence, and each man has his own peculiar voice, just as much as his own peculiar physiognomy. Hence it is, that arises that vast diversity of nations and languages throughout the whole earth : in this, too, originate the many tunes, measures, and inflexions that exist. But, before all other things, it is the voice that serves to express our sentiments, ${ }^{60}$ a power that distinguishes us from the beasts; just as, in the same way, the various shades and differences in language that exist among men have created an equally marked difference between us and the brutes.

\section{CHAP. 113. (52.) - SUPERFLUOUS LIMBS.}

Supernumerary limbs, when they grow on animals, are of no use, which is the case also with the sixth finger, when it grows on man. It was thought proper in Egypt to rear a human monster, that had two additional eyes in the back part of the head; it could not see with them, however.

${ }^{58}$ Like the whispering gallery of St. Paul's Cathedral. Pliny.

59 "Non aliter quam oculis." On this, few will be found to agree with

60 And not to "conceal" them, according to the opinion of some modern politicians. 


\section{CHAP. 114.-SIGNS OF VITALITY AND OF THE MORAL DISPOSITION OF MAN, FROM THE LIMBS.}

I am greatly surprised that Aristotle has not only believed, but has even committed it to writing, that there are in the human body certain prognostics of the duration of life. Although I am quite convinced of the utter futility of these. remarks, and am of opinion that they ought not to be published without hesitation, for fear lest each person might be anxiously looking out for these prognostics in his own person, I shall still make some slight mention of the subject, seeing that so learned a man as Aristotle did not treat it with contempt. He has set down the following as indications of a short life-few teeth, very long fingers, a leaden colour, and numerous broken lines in the palm of the hand. On the other hand, he looks upon the following as prognostics of a long life-stooping in the shoulders, one or two long unbroken lines in the hand, a greater number than two-and-thirty teeth, and large ears. He does not, I imagine, require that all these symptoms should unite in one person, but looks upon them as individually significant: in my opinion, however, they are utterly frivolous, all of them, although they obtain currency among the vulgar. Our own writer, Trogus, has in a similar manner set down the physiognomy as indicative of the moral disposition; one of the very gravest of the Roman authors, whose own ${ }^{61}$ words I will here subjoin :-

"Where the forehead is broad, it is significant of a dull and sluggish understanding beneath; and where it is small, it indicates an unsteady disposition. A rounded forehead denotes an irascible temper, it seeming as though the swelling anger had left its traces there. Where the eye-brows are extended in one straight line, they denote effeminacy in the owner, and when they are bent downwards towards the nose, an austere disposition. On the other hand, when the eye-brows are bent towards the temples, they are indicative of a sarcastic disposition; but when they lie very low, they denote malice and envy. Long eyes are significant of a spiteful, malicious nature; and where the corners of the eyes next the nose are fleshy, it is a sign also of a wicked disposition. If the white of the eye is large, it bears tokens of impudence, while those who are incessantly closing the eyelids are inconstant. Largeness" of

${ }^{61}$ But they are borrowed from Aristotle, Hist. Anim. B. i. c. 9. 
the ears is a sign of loquacity and foolishness." Thus much of what Trogus says.

CHAP. 115. (53.)-RESPIRATION AND NUTRIMENT.

The breath of the lion is fetid, and that of the bear quite pestilential; indeed, no beast will touch anything with which its breath has come in contact, and substances which it has breathed upon will become putrid sooner than others. It is in man only that Nature has willed that the breath should become tainted in several ways, either through faultiness in the victuals or the teeth, or else, as is more generally the case, through extreme old age. Our breath in itself was insensible to all pain, utterly devoid as it was of all powers of touch and feeling, without which there can be no sensation; ever renewed, it was always fortheoming, destined to be the last adjunct that shall leave the body, and the only one to remain when all is gone beside; it drew, in fine, its origin from heaven. In spite of all this, however, certain penalties were discovered to be inflicted upon it, so that the very substance by the aid of which we live might become a torment to us in life. This inconvenience is more particularly experienced among the Parthians, from their youth upwards, on account of the indiscriminate use of food among them; and, indeed, their very excess in wine causes their breath to be fetid. The grandees, however, of that nation have a remedy for bad breath in the pips of the Assyrian citron, ${ }^{62}$ which they mix with their food, and the aroma of which is particularly agreeable. The breath of the elephant will attract serpents from their holes, while that of the stag scorches them. We have already made mention ${ }^{63}$ of certain races of men who could by suction extract from the body the venom of serpents; and swine will even eat serpents, ${ }^{64}$ which to other animals are poisonous. All those creatures which we have spoken of as insects, can be killed by merely sprinkling them with oil. ${ }^{65}$ Vultures, which are put to flight by unguents, are attracted by other odours: the beetle, too, is attracted by the rose. The scorpion puts to death certain serpents. The Scythians dip their arrows in the poison of

62 See B. xii. c. 7.

${ }^{64}$ See B. xxix. c. 23.

63 B. vii. c. 2.

${ }^{65}$ See c. 21 of the present Book.

voL. III. 
serpents and human blood: against this frightful composition there is no remedy, for with the slightest touch it is productive of instant death.

CHAP. 116. - ANIMALS WHICH WHEN FED UPON POISON DO

NOT DIE, AND THE FIESH OF WHICH IS POISONOUS.

The animals which feed upon poison have been already ${ }^{65}$ mentioned. Some of them, which are harmless of themselves, become noxious if fed upon venomous substances. The wild boar of Pamphylia and the mountainous parts of Cilicia, after having devoured a salamander, will become poisonous to those who eat its flesh; and yet the danger is quite imperceptible by reason of any peculiarity in the smell and taste. The salamander, too, will poison either water or wine, in which it happens to be drowned; and what is more, if it has only drunk thereof, the liquid becomes poisonous. The same is the case, too, with the frog known to us as the bramble-frog. So numerous are the snares that are laid in wait for life! Wasps greedily devour the flesh of the serpent, a nutriment which renders their stings fatal; so vast is the difference to be found between one kind of food and another. In the country, too, of the Ichthyophagi, ${ }^{67}$ as we learn from Theophrastus, the oxen are fed upon fish, but only when alive.

CHAP. 117.-REASONS FOR INDIGESTION. REMEDIES FOR CRUDITY.

The most wholesome nutriment for man is plain food. An accumulation of flavours is injurious, and still more so, if heightened by sauces. All acrid elements are difficult of digestion, and the same is the case if food is devoured greedily, or in too large quantities. Food is also less easily digested in summer than in winter, and in old age than in youth. The vomits which man has invented, by way of remedy for this evil, render the boady more cold, and are more particularly injurious to the eyes and teeth.

CHAP. 118. -FROM WHAT CAUSES CORPULENCE ARISES; HOW IT MAY BE REDUCED.

Digestion during sleep is more productive of corpulence than strength. Hence it is, that it is preferable for athletes to ${ }^{66}$ B. ix. c. 33 . 67 Or Fish-eaters. 
quicken digestion by walking. Watching, at night more especially, promotes digestion of the food.

(54.) The size of the body is increased by eating sweet and fatty substances, as well as by drinking, while, on the other hand, it is diminished by eating dry, acrid, or cold substances, and by abstaining from drink. Some animals of Africa, as well as sheep, drink but once every four days. Abstinence from food for seven days, even, is not of necessity fatal to man ; and it is a well-known fact, that many persons have not died till after an abstinence of eleven days. Man is the only animal that is ever attacked with an insatiate ${ }^{68}$ craving for food.

\section{CHAP. 119.-WHAT THINGS, BY MERELY TASTING OF THEM,} ALLAY HUNGER AND THIRST.

On the other hand, there are some substances which, tasted in small quantities only, appease hunger and thirst, and keep up the strength, such as butter, for instance, cheese made of mares' milk, and liquorice. But the most pernicious thing of all, and in every station of life, is excess, and more especially excess in food; in fact, it is the most prudent plan to retrench everything that may be possibly productive of injury. Let us, however, now pass on to the other branches of Nature.

SUMmaRY.-Remarkable facts, narratives, and observations, two thousand, two hundred, and seventy.

Roman aUTHORS QUOTED.-M. Varro, ${ }^{69}$ Hyginus, ${ }^{70}$ Scrofa, ${ }^{71}$ Saserna ${ }^{72}$ Celsus Cornelius, ${ }^{73}$ Emilius Macer,${ }^{74}$ Virgil, ${ }^{75}$ Columella, ${ }^{76}$ Julius Aquila ${ }^{77}$ who wrote on the Tuscan art of Divination, Tarquitius ${ }^{78}$ who wrote on the same subject, Umbricius Melior ${ }^{79}$ who wrote on the same subject, Cato the Censor, ${ }^{80}$ Domitius Calvinus, ${ }^{81}$ Trogus, ${ }^{82}$ Melissus, ${ }^{83}$ Fabianus, ${ }^{84}$ Mucianus, ${ }^{85}$ Nigidius, ${ }^{86}$ Manilius, ${ }^{87}$ Oppius. ${ }^{88}$

\section{Or bulimia.}

${ }^{69}$ See end of B. ii.

$71 \mathrm{C}$. Tremellius Scrofa, a friend of M. Varro, and one of the early writers. on agriculture.

${ }^{73}$ See end of B. vii.

75 See end of B. vii.

77 See end of B. ii.

79 See end of B. $x$.

81 Nothing seems to be known of this writer.

82 See end of $\mathrm{B}$. vii.

84 See end of B. ii.

${ }^{86}$ See end of B. vi.

88 C. Oppius, one of the most intimate friends of Julius Cæsar, for whom.
72 See end of $B . x$.

${ }^{71}$ See end of B. ix.

76 See end of $B$. viii.

80 See end of B. iii.

83 See end of B. vii.

85 See end of B. ii.

87 See end of B. $x$.
78 See end of B. ii. 
Foreign authors quoted.-Aristotle, ${ }^{89}$ Democritus, ${ }^{90}$ Neoptolemus $^{91}$ who wrote the Meliturgica, Aristomachus ${ }^{22}$ who wrote on the same subject, Philistus ${ }^{93}$ who wrote on the same subject, Nicander, ${ }^{94}$ Menecrates, ${ }^{95}$ Dionysius ${ }^{96}$ who translated Mago, Empedocles, ${ }^{97}$ Callimachus, ${ }^{98}$ King Attalus, ${ }^{99}$ Apollodorus ${ }^{1}$ who wrote on venomous animals, Hippocrates, ${ }^{2}$ Herophilus, ${ }^{3}$ Erasistratus, ${ }^{4}$ Asclepiades, ${ }^{5}$ Themison, ${ }^{6}$ Posidonius? the Stoic, Menander ${ }^{8}$ of Priene and Menander ${ }^{9}$ of Heraclea, Euphronius ${ }^{10}$ of Athens, Theophrastus, ${ }^{11}$ Hesiod, ${ }^{12}$ King Philometor. ${ }^{13}$

with Balbus, he acted in Spain. Of his numerous biographical and historical works, none have survived to our time.

.39 See end of B. ii.

${ }^{0} 0$ See end of B. ii.

91 Probably Neoptolemus of Paros, who wrote a book of Epigrams, a treatise on Languages, and other works.

${ }^{92}$ Of Soli, an observer of the habits of bees. His portrait is said still to exist, on a cornelian, attentively observing a swarm of bees. He wrote upon bees, honey, and the art of mixing wines.

93 Probably a different writer from the one mentioned at the end of B. viii.; nothing seems to be known of him. $\quad{ }_{91}$ See end of B. viii.

${ }_{95}$ See end of B. viii. $\quad 96$ See end of B. $\mathrm{x}$.

97 A philosopher of Agrigentum, and disciple of Pythagoras. $\mathrm{He}$ is said to have perished in the crater of Mount Etna. He wrote numerous works, of which only some fragments exist.

${ }_{98}$ See end of B. iv.

${ }^{99}$ Apparently the same as the King Philometor, mentioned below. See end of $\mathbf{B}$. viii.

1 Of this writer nothing seems to be known.

2 See end of B. vii.

${ }^{3}$ Of Chalcedon, one of the most famous physicians of antiquity. $\mathrm{He}$ was physician to Phalaris, the tyrant of Sicily, and is said to have dissected criminals alive. He was the first that paid particular attention to the nervous system.

4 A native of Iulis, in Cos, or else Ceos, grandson of Aristotle, and disciple of Theophrastus. He acquired great reputation as a physician, at the court of Seleucus Nicator, king of Syria, where he discovered the supposed disease of Prince Antiochus, who had fallen in love with his stepmother, Stratonice. Of his numerous medical works, only the titles and a few fragments exist.

5 See end of B. vii.

${ }^{6}$ A physician of Laodicæa, founder of the school of the Methodici. He was a pupil of Asclepiades, and died about B.c. 43. Of his medical works only a few fragments survive.

8 See end of $\mathrm{B}$. viii.

${ }^{10}$ See end of B. viii.

12 See end of B. vii.

7 See end of B. ii.

9 See end of B. viii.

11 See end of B. iii.

13 See King Attalus, above. 


\title{
BOOK XII.
}

\author{
THE NATURAL HISTORY OF TREES.
}

CHAP. 1. THE HONOURABLE PLACE OCCUPIED BY TREES IN THE SYSTEM OF NATURE.

Such, then, is the history, according to their various species and their peculiar conformations, of all the animals within the compass of our knowledge. It now remains for us to speak of the vegetable productions of the earth, which are equally far from being destitute of a vital spirit, ${ }^{1}$ (for, indeed, nothing can live without it), that we may then proceed to describe the minerals extracted from it, and so none of the works of Nature may be passed by in silence. Long, indeed, were these last bounties of hers concealed beneath the ground, the trees and forests being regarded as the most valuable benefits conferred by $\mathrm{Na}$ ture upon mankind. It was from the forest that man drew his first aliment, by the leaves of the trees was his cave rendered more habitable, and by their bark was his clothing supplied; even at this very day, ${ }^{2}$ there are nations that live under similar circumstances to these. Still more and more, then, must we be struck with wonder and admiration, that from a primæval state such as this, we should now be cleaving the mountains for their marbles, visiting the Seres ${ }^{3}$ to obtain our clothing, seeking the pearl in the depths of the Red Sea, and the emerald in the very bowels of the earth. For our adornment with these precious stones it is that we have devised those wounds which we make in our ears; because, forsooth, it was deemed not enough to carry them on our hands, our necks, and our hair, if we did not insert them in our very flesh as well. It will be only proper, then, to follow the order of human inventions, and to speak of the trees before treating of

1 "Animâ." The notion that plants are possessed of a soul or spirit, is derived from the Greek philosophers, who attributed to them intellect also, and sense.

2 Vitruvius mentions the people of Gaul, Hispania, Lusitania, and Aquitania, as living in his day in dwellings covered with oak shingles, or with straw.

3 See B. vi. c. 20 , and B. xi. c. 26 . 
other subjects; thus may we trace up to their very origin the manners and usages of the present day.

CHAP. 2. (1.)-THE EARLY HISTORY OF TREES.

The trees formed the first temples of the gods, and even at the present day, the country people, preserving in all their simplicity their ancient rites, consecrate the finest among their trees to some divinity ; indeed, we feel ourselves inspired to adoration, not less by the sacred groves and their very stillness, than by the statues of the gods, resplendent as they are with gold and ivory. Each kind of tree remains immutably consecrated to its own peculiar divinity, the beech ${ }^{5}$ to Jupiter, ${ }^{6}$ the laurel to Apollo, the olive to Minerva, the myrtle to Venus, and the poplar to Hercules : besides which, it is our belief that the Sylvans, the Fauns, and various kinds of goddess Nymphs, have the tutelage of the woods, and we look upon those deities as especially appointed to preside over them by the will of heaven. In more recent times, it was the trees that by their juices, more soothing even than corn, first mollified the natural asperity of man; and it is from these that we now derive the oil of the olive that renders the limbs so supple, the draught of wine that so efficiently recruits the strength, and the numerous delicacies which spring up spontaneously at the various seasons of the year, and load our tables with their viands-tables to replenish which, we engage in combat with wild beasts, and seek for the fishes which have fattened upon the dead corpse of the shipwrecked mariner-indeed, it is only at the second ${ }^{7}$ course, after all, that the produce of the trees appears.

But, in addition to this, the trees have a thousand other uses, all of which are indispensable to the full enjoyment of

4 Desfontaines remarks, that we may still trace vestiges of this custom in the fine trees that grow near church porches, and in church-yards. Of course, his remark will apply to France more particularly.

5 It is doubtful whether the æesculus of the Romans was the same as the bay-oak, the holm-oak, or the beech. See B. xvi. c. 4.

${ }_{6}^{6}$ See further on this subject in Phædrus's Fables, B. iii. f. 17.

7 Reckoning the promulsis, antecæna, or gustatio, not as a course, but only a prelude, the bellaria, or dessert, at the Roman banquets, formed the second course, or mensa. It consisted of fruits uncooked, sweetmeats, and pastry. 
life. It is by the aid of the tree that we plough the deep, and bring near to us far distant lands ; it is by the aid of the tree, too, that we construct our edifices. The statues, even, of the deities were formed of the wood of trees, in the days when no value had been set as yet on the dead carcase ${ }^{8}$ of a wild beast, and when, luxury not yet deriving its sanction from the gods themselves, we had not to behold, resplendent with the same ivory, the heads of the divinities ${ }^{\theta}$ and the feet of our tables. It is related that the Gauls, separated from us as they were by the Alps, which then formed an almost insurmountable bulwark, had, as their chief motive for invading Italy, its dried figs, its grapes, its oil, and its wine, samples ${ }^{10}$ of which had been brought back to them by Helico, a citizen of the Helvetii, who had been staying at Rome, to practise there as an artizan. We may offer some excuse, then, for them, when we know that they came in quest of these various productions, though at the price even of war.

CHAP. 3.-EXOTIC TREES. WHEN THE PLANE-TREE FIRST APPEARED IN ITALY, AND WHENCE IT CAME.

But who is there that will not, with good reason, be surprised to learn that a tree has been introduced among us from a foreign clime for nothing but its shade? I mean the plane, ${ }^{11}$ which was first brought across the Ionian Sea to the Isle ${ }^{12}$ of Diomedes, there to be planted at his tomb, and was afterwards imported thence into Sicily, being one of the very first exotic trees that were introduced into Italy. At the present day, however, it has penetrated as far as the country of the Morini, and occupies even a tributary ${ }^{13}$ soil; in return for which

8 He alludes to the pursuit of the elephant, for the purpose of obtaining ivory, which was extensively used in his day, in making the statues of the divinities.

9 A sarcastic antithesis. And yet Dalechamps would read "hominum" instead of "numinum"!

10 Præmissa. The exact meaning of this word does not appear. Though all the IMSS. agree in it, it is probably a corrupt reading. Plutarch, in his Life of Camillus, says that the wine of Italy was first introduced in Gaul by Aruns, the Etruscan.

11 The Platanus orientalis of Linnæus. It received its name from the Greek $\pi \lambda$ áros, " breadth," by reason of its wide-spreading branches.

${ }_{12}$ For further mention of this island, now Tremiti, see B. iii. c. 30 .

13 He alludes, probably, to the "vectigal solarium," a sort of ground- 
those nations have to pay a tax for the enjoyment of its shade. Dionysius the Elder, one of the tyrants of Sicily, had planetrees conveyed to the city of Rhegium, where they were looked upon as the great marvel of his palace, which was afterwards converted into a gymnasium. These trees did not, however, in that locality, attain any very great height. I find it also stated by some authors, that there were some other instances, in those days even, of plane-trees being found in Italy, and I find some mentioned by name as existing in Spain. ${ }^{14}$

\section{CHAP. 4.-THE NATURE OF THE PLANE-TREE.}

This circumstance took place about the time of the capture of the City of Rome; and to such high honour, in the course of time, did the plane-tree attain, that it was nurtured by pouring wine upon it, it being found that the roots were greatly strengthened by doing ${ }^{15}$ so. Thus have we taught the very trees, even, to be wine-bibbers!

\section{CHAP. 5.-REMARKABLE FACTS CONNECTED WITH THE PLANE-TREE,}

The first plane-trees that were spoken of in terms of high admiration were those which adorned the walks of the Academy ${ }^{16}$ at Athens- [in one of which], the roots extended a distance of thirty-three cubits, and spread far beyond its branches. At the present day, there is a very famous plane in Lycia, situate in close proximity to a fountain of the most refreshing coolness; standing near the road, with the cavity in its rent which the tributary nations paid to the Roman treasury. Virgil and Homer speak of the shade of the plane-tree, as a pleasant resort for festive parties.

${ }^{14}$ It is not improbable that Pliny, in copying from Theophrastus, has here committed an error. That author, B. ix. c. 7, says : $\dot{\varepsilon} \nu \mu \dot{\varepsilon} \nu \gamma \dot{\alpha} \rho \tau \tilde{\varphi}$

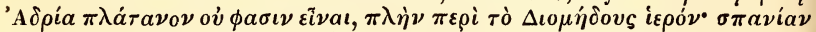

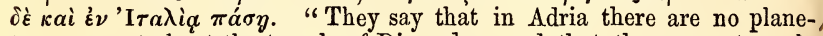
trees, except about the temple of Diomedes: and that they are extremely rare in Italy." Pliny, probably, when his secretary was reading to him,

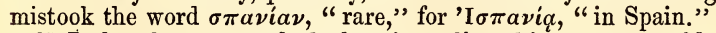

${ }^{15}$ It has been remarked that, in reality, this process would only tend to impede its growth. Macrobius tells us, that Hortensius was guilty of this singular folly.

${ }^{16}$ Situate near the sea-shore. It was here that Plato taught. See B. xxxi. c. 3 . 
interior, it forms a species of house eighty-one feet in width. Its summit, too, presents the foliage of a grove, while it shields itself with huge branches, each of which would equal an ordinary tree in size, as it throws its lengthened shade across the fields. In addition to this, that nothing may be wanting to its exact resemblance to a grotto, there is a circle of seats within, formed of stone, intermingled with pumice overgrown with moss. This tree was looked upon as so worthy of remark, that Licinius Mucianus, who was three times consul, and recently the legatus of that province, thought it a circumstance deserving of transmission even to posterity, that he, together with eighteen persons of his retinue, had sat down to a banquet in the interior of it. Its leaves afforded material for their couches in the greatest abundance, while he himself, sheltered from every gust of wind, and trying in vain to hear the pattering of the rain on the leaves, took his meal there, and enjoyed himself more than he would have done amid the resplendence of marble, a multiplicity of paintings, and beneath a cieling refulgent with gold.

Another curious instance, again, was that afforded in the reign of the Emperor Caius. ${ }^{17}$ That prince was so struck with admiration on seeing a plane in the territory of Veliternum, which presented floor after floor, like those of the several stories of a house, by means of broad benches loosely laid from branch to branch, that he held a banquet in it-himself adding ${ }^{18}$ very materially to the shade it threw-the triclinium being formed for the reception of fifteen guests and the necessary attendants: to this singular dining-room he gave the name of his "nest."

At Gortyna, in the Isle of Crete, there is, in the vicinity of a fountain there, a single plane-tree, which has been long celebrated in the recoràs of both the Greek and the Latin language: it never loses ${ }^{19}$ its leaves, and from an early period one of the fabulous legends of Greece has been attached to it, to the effect that it was beneath this tree that Jupiter lay with Europa; just as if there had not been another tree of a similar nature

${ }_{17}$ Caligula.

18 It is supposed that he here alludes sarcastically to the extreme corpulence of Caligula.

19 M. Feé, the learned editor of the botanical books in Ajasson's translation, remarks, that this cannot have been the Platanus of the botanists, and that there is no tree of Europe, which does not lose its leaves, that at all resembles it. 
in the island of Cyprus. Slips of the tree at Gortyna-so fond is man by nature of novelty-were at an early period planted at different places in Crete, and reproduced the natural imperfections of the tree $;^{20}$ though, indeed, there is no higher recommendation in the plane than the fact that in summer it protects us from the rays of the sun, while in winter it admits them. In later times, during the reign of the Emperor Claudius, a Thessalian eunuch, the freedman of Marcellus Aserninus, ${ }^{21}$ who, however, from motives of ambition had enrolled himself in the number of the freedmen of the emperor, and had acquired very considerable wealth, introduced this plane into Italy, in order to beautify his country-seat: so that he may not inappropriately be styled a second Dionysius. These monstrosities of other lands are still to be seen in Italy, independently of those which that country has herself devised.

\section{CHaP. 6. (2.) 一 THE CHaM TO CLIP GREEN SHRUBS.}

For we find in Italy some plane-trees, which are known as chamæplatani, ${ }^{22}$ in consequence of their stunted growth; for we have discovered the art of causing abortion in trees even, and hence, even in the vegetable world we shall have occasion to make mention of dwarfs, an unprepossessing subject in every case. This result is obtained in trees, by a peculiar method adopted in planting and lopping them. C. Matius, ${ }^{23}$ a member of the Equestrian order, and a friend of the late Emperor Augustus, invented the art of clipping arbours, within the last eighty years.

\section{CHAP. 7. (3.) - HOW THE CITRON IS PLANTED.}

The cherry and the peach, and all those trees which have either Greek or foreign names, are exotics : those, however, of

20 The tendency, namely, to lose their leaves.

${ }^{21}$ Grandson of Asinius Pollio. Tacitus tells us, that he was one of those whom Piso requested to undertake his defence, when charged with having poisoned Germanicus; but he declined the office.

22 Or "ground plane-trees." It is by no means uncommon to see dwarf varieties of the larger trees, which are thus reduced to the dimensions of mere shrubs.

23 C. Matius Calvena, the friend of Julius and Augustus Cæsar, as also of Cicero. He is supposed to have translated the Iliad into Latin verse, and to have written a work on cookery. 
this number, which have begun to be naturalized among us, will be treated of when I come to speak of the fruit-trees in general. For the present, I shall only make mention of the really exotic trees, beginning with the one that is applied to the most salutary uses. The citron tree, called the Assyrian, and by some the Median apple, is an antidote against poisons. ${ }^{2 t}$ The leaf is similar to that of the arbute, except that it has small prickles ${ }^{25}$ running across it. As to the fruit, it is never eaten ${ }^{26}$ but it is remarkable for its extremely powerful smell, which is the case, also, with the leaves; indeed, the odour is so strong, that it will penetrate clothes, when they are once impregnated with it, and hence it is very useful in repelling the attacks of noxious insects. The tree bears fruit at all seasons of the year; while some is falling off, other fruit is ripening, and other, again, just bursting into birth. Various nations have attempted to naturalize this tree among them, for the sake of its medical properties, by planting it in pots of clay, with holes drilled in them, for the purpose of introducing the air to the roots; and I would here remark, once for all, that it is as well to remember that the best plan is to pack all slips of trees that have to be carried to any distance, as close together as they can possibly be placed. It has been found, however, that this tree will grow nowhere ${ }^{27}$ except in Media or Persia. It is this fruit, the pips of which, as we have already mentioned, ${ }^{28}$ the Parthian grandees employ in seasoning their ragouts, as being peculiarly conducive to the sweetening of the breath. We find no other tree very highly commended that is produced in Media.

\section{CHAP. 8. (4.) 一THE TREES OF INDIA.}

In describing the country of the Seres, we hare already

${ }^{24}$ See B. xxiii. c. 55. Fée remarks, that the ancients confounded the citron with the orange-tree.

${ }^{25}$ Fée remarks, that this is not the case. The arbute is described in B. xv. c. 28.

${ }^{26}$ In the time of Plutarch, it had begun to be somewhat more used. It makes one of the very finest preserves.

${ }^{27}$ At the present day, it is cultivated all over India, in China, South America, and the southern parts of Europe. Fée says, that they grow even in the open air in the gardens of Malmaison.

${ }^{28}$ B. xi. c. 115. Virgil says the same, Georg. B. ii. 1l. 134, 135. Theophrastus seems to say, that it was the outer rind that was so used. 
made mention ${ }^{29}$ of the wool-bearing trees which it produces; and we have, likewise, touched ${ }^{30}$ upon the extraordinary magnitude of the trees of India. Virgil ${ }^{31}$ has spoken in glowing terms of the ebony-tree, one of those which are peculiar to India, and he further informs us, that it will grow in no other country. Herodotus, however, has preferred to ascribe $^{32}$ it to Athiopia; and states that the people of that country were in the habit of paying to the kings of Persia, every third year, by way of tribute, ${ }^{32 *}$ one hundred billets of ebony-wood, together with a certain quantity of gold and ivory. Nor ought we here to omit the fact, inasmuch as the same author has stated to that effect, that the Ethiopians were also in the habit of paying, by way of tribute, twenty large elephants' teeth. So high was the esteem in which ivory was held in the year from the building of our city, 310 : for it was at that period ${ }^{33}$ that this author was compiling his History at Thurii, in Italy; which is all the more remarkable, from the implicit confidence we place in him, when he says ${ }^{31}$ that up to that time, no native of Asia or Greece, to his knowledge at least, had ever beheld the river Padus. The plan of Athiopia, which, as we have already mentioned, ${ }^{35}$ was recently laid before the Emperor Nero, informs us, that this tree is very uncommon in the country that lies between Syene, the extreme boundary of the empire, and Meroë, a distance of eight hundred and ninety-six miles; and that, in fact, the only kind of tree that is to be found there, is the palm. It was, probably, for this reason, that ebony held the third place in the tribute that was thus imposed.

29 See B. vi. c. 20.

30 See B. vii. c. 2 . The tree to which he alludes is unknown.

31 Georg. B. ii. 11. 116, 117.

32 B. iii. c. 97 . There is little doubt that, under the general name of " ebony," the wood of many kinds of trees was, and is still, imported into the western world, so that both Herodotus and Virgil may have been correct in representing ebony as the product of both India and Ethiopia.

32* Herodotus says two hundred.

33 In Italy, whither he had retired from the hostile attacks of his fellowcitizens. It is supposed by Le Vayer and others, that Pliny is wrong in his assertion, that Herodotus wrote to this effect while at Thurii ; though Dr. Schmitz is inclined to be of opinion that he is right in his statement.

$3 \pm$ B. iii. c. 115 .

35 B. vi. c. 35 . 
CHAP. 9. -WHEN EBONY WAS FIRST SEEN AT ROME. THE VARIOUS KINDS OF EBONY.

Pompeius Magnus displayed ebony on the occasion of his triumph over Mithridates. Fabianus declares, that this wood will give out no flame ; it burns, however, with a very agreeable smell. There are two kinds ${ }^{36}$ of ebony; the rarest kind is the best, and is produced from a tree that is singularly free from knots. The wood is black and shining, and pleasing to the eye, without any adventitious aid from art. The other kind of ebony is the produce of a shrub which resembles the cytisus, and is to be found scattered over the whole of India.

\section{CHAP. 10. (5.)-THE INDIAN THORN.}

There is in India, also, a kind of thorn ${ }^{37}$ very similar to ebony, though it may be distinguished from it, by the aid of a lantern even; for, on the application of flame, it will instantly run across the tree. We will now proceed to describe those trees which were the admiration of Alexander the Great in his victorious career, when that part of the world was first revealed by his arms.

\section{CHAP. 11.-THE INDIAN FIG.}

The Indian fig ${ }^{38}$ bears but a small fruit. Always growing spontaneously, it spreads far and wide with its vast branches, the ends of which bend downwards into the ground to such a degree, that they take fresh root in the course of a year, and thus form a new plantation around the parent stock, traced in a circular form, just as though it had been the work of the ornamental gardener. Within the bowers thus formed, the shepherds take up their abode in the summer, the space occupied by them being, at once, overshadowed and protected by

${ }^{36}$ Fée remarks, that the words of Pliny do not afford us any means of judging precisely what tree it was that he understood by the name of ebony. He borrows his account mainly from 'Theophrastus.

37 It is not known to what tree he alludes.

${ }^{38}$ This account of the Ficus Indica, or religiosa, known to us as the banian-tree, is borrowed entirely from Theophrastus. Fée remarks, however, that he is wrong in some of his statements, for that the leaves are not crescent-shaped, but oblong and pointed, and that the fruit has not a pleasant flavour, and is only eaten by the birds. 
the bulwark which the tree thus throws around; a most graceful sight, whether we stand beneath and look upwards, or whether we view its arcaded foliage from a distance. The higher branches, however, shoot upwards to a very considerable height, and, by their number, form quite a grove, springing aloft from the vast trunk of the parent tree, which overspreads, very frequently, a space of sixty paces in extent, while the shade that is thrown by it will cover as much as a couple of stadia. The broad leaves of the tree have just the shape of an Amazonian buckler; and hence it is that the fruit, from being quite covered by the leaves, is greatly impeded in its growth. The fruit, indeed, of this tree is but scanty, and never exceeds a bean in size; being ripened, however, by the rays of the sun, as these penetrate the leaves, the figs are remarkable for their singular lusciousness, and are quite worthy of the marvellous tree by which they are produced. These fig-trees are found, more particularly, in the vicinity of the river Acesines. ${ }^{39}$

\section{CHAP. 12. (6.)-The PALA: THE FRUIT CALLEd ARIENA.}

There is another tree ${ }^{40}$ in India, of still larger size, and even more remarkable for the size and sweetness of its fruit, upon which the sages ${ }^{41}$ of India live. The leaf of this tree resembles, in shape, the wing of a bird, being three cubits in length, and two in breadth. It puts forth its fruit from the bark, a fruit remarkable for the sweetness of its juice, a single one containing sufficient to satisfy four persons. The name of this tree is "pala," and of the fruit, "ariena." They are found in the greatest abundance in the country of the Sydraci, ${ }^{42}$ a territory which forms the extreme limit of the expedition of Alexander.

There is another ${ }^{43}$ tree, also, very similar to this, but bearing a still sweeter fruit, though very apt to cause derangement of

39 See B. vi. c. 23.

40 Sprengel and Bauhin are of opinion that the banana is the tree meant here; Dodonæus thinks that it is the pomegranate. Thevet says that the pala is the paquovera of India, the fruit of which is called pacona. The account is borrowed from Theophrastus.

41 The Gymnosophists, or Brahmins.

42 Called Syndraci in B. vi. c. 25.

43 It is not improbable that the Tamarindus Indica of Linnæus is the tree here alluded to: though M. Fée combats that opinion. 
the bowels. Alexander issued strict orders, forbidding any one in the expedition to touch this fruit.

CHAP. 13. - INDIAN TREes, THE NAMES OF WHICH ARE UNKNOWN. INDIAN TREES WHICH BEAR FLAX.

The Macedonians ${ }^{44}$ have made mention of various other kinds of trees, the greater part of which, however, are without names. There is one which resembles the terebinth ${ }^{45}$ in every respect, except the fruit, which is very similar to the almond, though less in size, and remarkable for its extreme sweetness. This tree was met with in Bactria, and some persons looked upon it as a variety of the terebinth, rather than as bearing a strong resemblance to it. As to the tree from which they manufacture a kind of linen ${ }^{46}$ cloth, in leaf it resembles the mulberry-tree, while the calix of the fruit is similar to the dog-rose. ${ }^{47}$ This tree is reared in the plains, and there is no sight throughout the cultivated parts of the country that is more enchanting than the plantations of it.

\section{CHAP. 14. (7.)-THE PEPPER-TREE. -THE VARIOUS KINDS OF} PEPPER-BREGMA-ZINGIBERI, OR ZIMPIBERI.

The olive-tree ${ }^{48}$ of India is unproductive, with the sole exception of the wild olive. In every part we meet with trees that bear pepper, ${ }^{49}$ very similar in appearance to our junipers,

44 See Theophrastus, B. iv. c. 5 .

45 Dalechamps and Desfontaines are of opinion, that the pistachio, or Pistacia terebinthus of Linnæus, is here alluded to; but Fée considers that there are no indications to lead to such a conclusion.

${ }_{46}$ It is not improbable that he may here allude to the cotton-tree, of which further mention is made in c. xxi. of the present Book.

${ }^{47}$ Fée is of opinion that Cynorrhodon here means, not the dog-rose, but the gall which is formed on the tree by the sting of the Cynips bedeguar.

${ }_{48}$ Fée expresses himself at a loss to conjecture what trees are here meant by Pliny.

${ }^{49}$ Fée remarks, that there are many inaccuracies in the account here given by Pliny of the pepper-tree, and that it does not bear any resemblance to the juniper-tree. The grains, he says, grow in clusters, and not in a husk or pod; and he remarks, that the long pepper and the black pepper, of which the white is only a variety divested of the outer coat, are distinct spezies. He also observes, that the real long pepper, the Piper longum of Linnæus, was not known to the ancients. 
although, indeed, it has been alleged by some authors that they oniy grow on the slopes of Caucasus which lie exposed to the sun. The seeds, however, differ from those of the juniper, in being enclosed in small pods similar to those which we see in the kidney-bean. These pods are picked before they open, and when dried in the sun, make what we call "long pepper." But if allowed to ripen, they will open gradually, and when arrived at maturity, discover the white pepper; if left exposed to the heat of the sun, this becomes wrinkled, and changes its colour. Even these productions, however, are subject to their own peculiar infirmities, and are apt to become blasted by the inclemency of the weather; in which case the seeds are found to be rotten, and mere husks. These abortive seeds are known by the name of " bregma," a word which in the Indian language signifies "dead." Of all the various kinds of pepper, this is the most pungent, as well as the very lightest, and is remarkable for the extreme paleness of its colour. That which is black is of a more agreeable flavour; but the white pepper is of a milder quality than either.

The root of this tree is not, as many persons have imagined, the same as the substance known as zimpiberi, or, as some call it, zingiberi, or ginger, although it is very like it in taste.' For ginger, in fact, grows in Arabia and in Troglodytica, in various cultivated spots, being a small plant ${ }^{50}$ with a white root. This plant is apt to decay very speedily, although it is of intense pungency; the price at which it sells is six denarii per pound. Long pepper is very easily adulterated with Alexandrian mustard; its price is fifteen denarii per pound, while that of white pepper is seven, and of black, four. It is quite surprising that the use of pepper has come so much into fashion, seeing that in other substances which we use, it is sometimes their sweetness, and sometimes their appearance that has attracted our notice; whereas, pepper has nothing in it that can plead as a recommendation to either fruit or berry, its only desirable quality being a certain pungency; and yet it is for this that we import it all the way from India! Who was the first to make trial of it as an article of food? and who, I wonder, was the man that was not content to prepare himself

50 Fée remarks, that this is not a correct description of ginger, the Amomum zingiber of Linnæus. Dioscorides was one of those who thought that ginger was the root of the pepper-tree. 
by hunger only for the satisfying of a greedy appetite? Both pepper and ginger grow wild in their respective countries, and yet here we buy them by weight-just as if they were so much gold or silver. Italy, ${ }^{51}$ too, now possesses a species of pepper-tree, somewhat larger than the myrtle, and not very unlike it. The bitterness of the grains is similar to that which we may reasonably suppose to exist in the Indian pepper when newly gathered; but it is wanting in that mature flavour which the Indian grain acquires by exposure in the sun, and, consequently, bears no resemblance to it, either in colour or the wrinkled appearance of the seeds. Pepper is adulterated with juniper berries, which have the property, to a marvellous degree, of assuming the pungency of pepper. In reference to its weight, there are also several methods of adulterating it.

\section{CHAP. 15. - CARYOPHYLLON, LYCION, AND THE CHIRONIAN PYXACANTHUS.}

There is, also, in India another grain which bears a considerable resemblance to pepper, but is longer and more brittle; it is known by the name of caryophyllon. ${ }^{52}$ It is said that this grain is produced in a sacred grove in India; with us it is imported for its aromatic perfume. The same country produces, also, a thorny shrub, with grains which bear a resemblance to pepper, and are of a remarkably bitter taste. The leaves of this shrub are small, like those of the cyprus ; ${ }^{53}$ the branches are three cubits in length, the bark pallid, and the roots wide-spreading and woody, and of a colour resembling that of boxwood. By boiling this root with the seed in a copper vessel, the medicament is prepared which is known by the name of lycion. ${ }^{54}$ This thorny shrub grows, also, on

${ }^{51} \mathrm{It}$ is very doubtful what tree is here alluded to by Pliny, though certain that it is not one of the pepper-trees. Sprengel takes it to be the Daphne Thymelæa.

${ }_{52}$ It has been suggested that under this name the clove is meant, though Fée and Desfontaines express a contrary opinion. Sprengel thinks that it is the Vitex trifolia of Linnæus, and Bauhin suggests the cubeb, the Piper cubeba of Linnæus. Fée thinks it may have possibly been the Myrtus caryophyllata of Ceylon, the fruit of which corresponds to the description here given by Pliny.

53 See c. 52 of the present Book.

${ }^{54}$ Or "Lycium." It is impossible to say with exactness what the medical liquid called "Lycion" was. Catechu, an extract from the tan of the acacia, has been suggested; though the fruit of that tree does not answer the present description.

VOL. III. 
Mount Pelion; ${ }^{55}$ this last kind is much used for the purpose of adulterating the medicament above mentioned. The root of the asphodel, ox.gall, wormwood, sumach, and the amurca of olive oil, are also employed for a similar purpose. The best lycion for medicinal purposes, is that which has a froth on its surface; the Indians send it to us in leather bottles, made of the skin of the camel or the rhinoceros. The shrub itself is known by some persons in Greece under the name of the Chironian pyxacanthus. ${ }^{56}$

\section{CHAP. 16. (8.)-MACIR.}

Macir, ${ }^{57}$ too, is a vegetable substance that is brought from India, being a red bark that grows upon a large root, and bears the name of the tree that produces it; what the nature of this tree is, $\mathrm{I}$ have not been able to ascertain. A decoction of this bark, mixed with honey, is greatly employed in medicine, as a specific for dysentery.

\section{CHAP. 17. - SUGAR.}

Arabia, too, produces sugar ; ${ }^{58}$ but that of India is the most esteemed. This substance is a kind of honey, which collects

${ }^{55}$ Fée suggests that this may possibly be the Lycium Europæum of Linnæus, a shrub not uncommonly found in the south of Europe.

${ }^{56}$ The Rhamnus Lycioides of Linnæus, known to us as buckthorn. The berries of many varieties of the Rhamnus are violent purgatives.

57 What he means under this head is not known. Fée speaks of a tree which the Brahmins call macre, and which the Portuguese ealled arvore de las camaras, arvore sancto, arvore de sancto Thome, but of which they have given no further particulars. Acosta, Clusius, and Bauhin have also professed to give accounts of it, but they do not lead to its identification. De Jussieu thinks that either the Soulamea, the Rex amaroris of Rumphius, or else the Polycardia of Commerson is meant. It seems by no means impossible that mace, the covering of the nutmeg, is the substance alluded to, an opinion that is supported by Gerard and Desfontaines.

58 "Saccharon." Fée suggests that Pliny alludes to a peculiar kind of crystallized sugar, that is found in the bamboo cane, though, at the same time, he thinks it not improbable that he may have heard of the genuine sugar-cane; as Strabo, B. xv., speaks of a honey found in India, prepared without the aid of bees, and Lucan has the line-

"Quique bibunt tenerâ dulces ab arundine succos,"

evidently referring to a sugar in the form of a syrup, and not of erystal, like that of the Bambos arundinacea. It is by no means improbable, that Pliny, or rather Dioscorides, from whom he copies, confuses the two kinds of sugar; as it is well known that the Saccharum officinarum, or sugarcane, has been cultivated from a very early period in Arabia Felix. 
in reeds, white, like gum, and brittle to the teeth. The larger pieces are about the size of a filbert; it is only employed, however, in medicine.

\section{CHAP. 18:-TREES OF ARIANA, GEDROSIA, AND HYRCANIA.}

On the frontiers of India is a country called Ariana, which produces a thorny shrub, ${ }^{59}$ rendered precious by the tears which it distils. It bears some resemblance to myrrh, but is very difficult of access, by reason of the thorns with which it is armed. Here, too, a poisonous shrub is found, with a root like the radish, ${ }^{60}$ and leaves like those of the laurel, By its powerful odour it attracts horses, and was very nearly depriving Alexander of all his cavalry upon his first arrival there, an accident which also happened in Gedrosia. A thorny shrub ${ }^{61}$ has been also spokein of as a native of the same country, with leaves like those of the laurel, the juice of which, if sprinkled upon the eyes, is productive of blindness in all animals. Another plant is also mentioned, with a most remarkable odour, and full of diminutive serpents, ${ }^{62}$ the sting of which is sure to cause instant death. Onesicritus states, that in the vallies of Hyrcania, there is a tree resembling the fig, and known as the occhus, ${ }^{63}$ from which a honey distits for two hours every morning.

CHAP. 19. (9.) 一 TREes OF BACTRIANA, BDELLIUM, OR BROCHON, OTHERWISE MALACHA, OR MALDACON, SCORDASTUM. ADULTER-

59 It is unknown what plant is here alluded to by Pliny, but Sprengel suggests that it is the Acacia latronum.

${ }_{60}$ From the description, this would appear to be a sort of poisonous horse-radish.

61 There is a tree in India, as we are informed by Fée, which is known as the Excæcaria Agallochum, the juice of which is remarkably acrid. Sailors, on striking it with a hatchet, and causing the juice to spirt into their eyes, have been in danger of losing their sight. It is possible that this may be the tree here alluded to by Pliny.

${ }_{62}$ He borrows the account of this marvellous shrub from Theophrastus. No such plant is likely to have ever existed; though small, and even large, snakes may occasionally take refuge among shrubs and hollow trees.

63 There is little doubt that the Hedysarum Alhagi of Linnæus is here meant, from which a kind of honey or manna flows, known as "Eastern" manna, or tereniabin. It is not so high as the fig-tree, and is found in Khorasan, Syria, Mesopotamia, and elsewhere. The manna distils principally in the morning. 
ATIONS USED IN ALL SPICES AND AROMATICS; THE VARIOUS TESTS OF THEM AND THEIR RESPECTIVE VALUES.

In the vicinity, too, of India, is Bactriana, in which region we find bdellium, ${ }^{64}$ that is so highly esteemed. This tree is of a black colour, and about the size of the olive; it has leaves like those of the robur, and bears a fruit similar to that of the wild fig, and in nature resembling a kind of gum. This fruit is by some persons called brochon, by others malacha, and by others, again, maldacon. When of a black colour, and rolled up in cakes, it bears the name of hadrobolon. This substance ought to be transparent and the colour of wax, odoriferous, unctuous when subjected to friction, and bitter to the taste, though without the slightest acidity. When used for sacred purposes, it is steeped in wine, upon which it emits a still more powerful odour. The tree is a native of both India and Arabia, as well as Media and Babylon; some persons give to the bdellium that is imported by way of Media, the name of peraticum. ${ }^{65}$ This last is remarkable for its brittleness, while, at the same tiree, it is harder and more bitter than the other kinds; that of India, on the other hand, is moister, and gummy. This last sort is adulterated by means of almonds, while the various other kinds are falsified with the bark of scordastum, that being the name of a tre $2^{66}$ the gum of which strongly resembles bdellium. These aduiterations, however, are to be detected - and let it suffice to mention it here, in relation to all other perfumes as well-by the smell, the colour, the weight, the taste, and the action of fire. The bdellium of Bactriana is shining and dry, and covered with numerous white spots resembling the finger-nails; besides which, it should be of a certain weight, heavier or lighter than which it ought not to be. The price of bdellium, in its pure state, is three denarii per pound.

6t Fée remarks, that it is singular that a resinous gum, such as bdellium, should have been used in commerce for now two thousand years, and yet its origin remain unknown. Kæmpfer and Rumphus are of opinion, that the tree which produces it is the one known to naturalists as the Borassus flabelliformis of Linnæus, or the Lontarus of others. It is imported into Europe from Arabia and India, and is often found mixed with gum Arabic.

65 Пв from which it was brought.

66 The modern name of this tree is unknown. 
CHAP. 20.-TREES OF PERSIS.

Adjoining the countries which we have previously mentioned is Persis, lying along the shores of the Red Sea, which, when describing ${ }^{67}$ it, we have mentioned as the Persian Sea, the tides of which penetrate far into the land. The trees in these regions are of a marvellous nature; for, corroded by the action of the salt, and bearing a considerable resemblance to vegetable substances that have been thrown up and abandoned by the tide, they are seen to embrace the arid sands of the seeshore with their naked roots, just like so many polypi. When the tide rises, buffeted by the waves, there they stand, fixed and immoveable; nay, more, at high water they are completely covered; a fact which proves to conviction, that they derive their nutriment from the salt contained in the water. The size of these trees is quite marvellous; in appearance they strongly resemble the arbute; the fruit, which on the outside is very similar to the almond, has a spiral kernel within. ${ }^{68}$

CHAP. 21. (10.)-TREes of the ISLANDS OF the PERSIAN SEa. THE COTTON TREE.

In the same gulf, there is the island of Tylos, ${ }^{69}$ covered witi a forest ${ }^{70}$ on the side which looks towards the East, where it is washed also by the sea at high tides. Each of the trees is in size as large as the fig; the blossoms are of an indescribable sweetness, and the fruit is similar in shape to a lupine, but so rough and prickly, that it is never touched by any animal. On a more elevated plateau of the same island, we find trees that bear wool, but of a different nature from those of the Seres $;^{71}$ as in these trees the leaves produce nothing at all, and, indeed, might very readily be taken for those of the vine,

67 B. vi. c. 28.

68 It is supposed that the Rhizophora Mangle of Linnæus is the tree that is here described. It grows on all the coasts of India, from Siam to the entrance of the Persian Gulf. It takes root on spots which have heen inundated by the sea, and its boughs bend downwards, and taking root in the earth, advance gradually towards the sea. The leaf and fruit have the characteristics of those of the arbute and almond as here mentioned.

69 B. vi. c. 32 .

${ }^{70}$ Fée suggests that some kind of mangrove is probably alluded to, of the kind known as avicennia, or bruguiera.

71 See B. vi. c. 20. 
were it not that they are of smaller size. They bear a kind of gourd, about the size of a quince ; ${ }^{72}$ which, when arrived at maturity, bursts asunder and discloses a ball of down, from which a costly kind of linen cloth is made.

(11.) This tree is known by the name of gossypinus: ${ }^{73}$ the smaller island of Tylos, which is ten miles distant from the larger one, produces it in even greater abundance.

\section{CHAP. 22.-THE TREE CALLED CYNA. TREES FROM WHIOH FABRICS FOR CLOTHING ARE MADE IN THE EAST.}

Juba states, that about a certain shrub there grows a woolly down, from which a fabric is manufactured, preferable even to those of India. He adds, too, that certain trees of Arabia, from which vestments are made, are called cynæ, and that they have a leaf similar to that of the palm. Thus do their very trees afford clothing for the people of India. In the islands of Tylos, there is also another tree, with a blossom like the white violet $^{74}$ in appearance, though four times as large, but it is destitute of smell, a very remarkable fact in these climates.

CHAP. 23.-A COUNTRY WHERE THE TREES NEVER LOSE THEIR

\section{LEAVES.}

There is also another tree similar to the preceding one, but with a thicker foliage, and a blossom like the rose. This flower shuts $^{75}$ at night, and, beginning to open towards sun-rise, appears in full blow by mid-day; the natives are in the habit of saying that in this way it goes to sleep. The same island bears also the palm, the olive, the vine, and the fig, with various other kinds of fruit. None of the trees in this island lose their leaves $;^{76}$ it is abundantly watered by cool streams, and receives the benefit of rain.

72 "Cotonei." To this resemblance of its fruit to the quince, the cottontree, which is here alluded to, not improbably owes its modern name.

${ }_{73}$ The cotton-tree, or Gossypium arboreum of Linnæus. It is worthy of remark, that Pliny copies here almost literally from Theophrastus. According to Philostratus, the byssus, or fine tissues worn by the Egyptian priests, were made of cotton.

7t The Malthiola incana.

75 Fée suggests that this may be a Magnolia; but, as he remarks, most plants open and shut at certain hours; consequently, this cannot be regarded as any peculiar characteristic, sufficient to lead with certainty to its identification.

${ }_{76}$ Theophrastus, from whom our author is copying, says that this is the case only with the fig-tree there. 


\section{CHAP. 24.-THE VARIOUS USEFUL PRODUCTS OF TREES.}

Arabia, which is in the vicinity of these islands, requires that we should make some distinction in its vegetable products, seeing that here the various parts of trees which are employed for useful purposes are the root, the branches, the bark, the juices, the gum, the wood, the shoots, the blossoms, the leaves, and the fruit.

\section{CHAP. 25. (12.)-Costus.}

A root and a leaf, however, are the productions which are held in the very highest estimation in India. The root is that of the costus; ${ }^{77}$ it has a burning taste in the mouth, and a most exquisite odour; in other respects, the branches are good for nothing. In the island of Patale, ${ }^{78}$ situate at the very mouth of the river Indus, there are two kinds of costus found, the black and the white; the last is considered the best. The price of it is five denarii per pound.

CHAP. 26. -NARD. THE TWELVE VARIETIES OF THE PLANT.

Of the leaf, which is that of the nard, ${ }^{79}$ it is only right to speak somewhat more at length, as it holds the principal place among our unguents. The nard is a shrub with a heavy, thick root, but short, black, brittle, and yet unctuous as well;

77 According to most commentators, this is the Costus Arabicus of Linnæus. Dioscorides mentions three varieties of costus : the Arabian, which is of the best quality, and is white and odoriferous; the Indian, which is black and smooth; and the Syrian, which is of the colour of wax, dusky, and strong smelling. Fée, however, doubts whether the modern costus is the same thing as that of the ancients; for, as he says, although it has a sweet odour, it does not deserve the appellation of a "precious aromatic," which we find constantly given to it by the ancients.

78 See B. vi. c. 23.

79 It is probable that the nard of the ancients, from which they extracted the famous nard-oil, was not the same plant which we know as the Indian nard, or Andropogon nardus of Linnæus. Indeed, it has been pretty conclusively established by Sir William Jones, in his "Asiatic Researches," that the Valeriana Jatamansi is the plant from which they obtained the oil. Among the Hindoos, it is known as djatâmansi, and by the Arabs under the name of sombul, or "spike," from the fact of the base being surrounded with ears or spikes, whence, probably, the Roman appellation. This species of valerian grows in the more distant and mountainous parts of India, Bootan and Nepaul, for instance. 
it has a musty smell, too, very much like that of the cyperus, with a sharp, acrid taste, the leaves being small, and growing in tufts. The heads of the nard spread out into ears; hence it is that nard is so famous for its two-fold production, the spike or ear, and the leaf. There is another kind, again, that grows on the banks of the Ganges, but is altogether condemned, as being good for nothing; it bears the name of ozænitis, ${ }^{80}$ and emits a fetid odour. Nard is adulterated with a sort of plant called pseudo-nard, ${ }^{81}$ which is found growing everywhere, and is known by its thick, broad leaf, and its sickly colour, which inclines to white. It is sophisticated, also, by being mixed with the root of the genuine nard, which adds very considerably to its weight. Gum is also used for the same purpose, antimony, and cyperus; or, at least, the outer coat of the cyperus. Its genuineness is tested by its lightness, the redness of its colour, its sweet smell, and the taste more particularly, which parches the mouth, and leaves a pleasant flavour behind it; the price of spikenard is one hundred denarii per pound.

Leaf ${ }^{82}$ nard varies in price according to the size; for that which is known by the name of hadrosphærum, consisting of the larger leaves, sells at forty denarii per pound; when the leaves are smaller, it is called mesosphærum, and is sold at sixty. But that which is considered the most valuable of all, is known as microsphærum, and consists of the very smallest of the leaves; it sells at seventy-five denarii per pound. All these varieties of nard have an agreeable odour, but it is most powerful when fresh. If the nard is old when gathered, that which is of a black colour is considered the best.

In our part of the world, the Syrian ${ }^{83}$ nard is held in the

80 From the Greek, "̌aıva, " a putrid sore." Fée suggests that this may have been the Nardus hadrosphærum of the moderns.

81 Fée supposes that this is not lavender, as some have thought, but the Allium victorialis of modern naturalists, which is still mixed with the nard from the Andropogon. He doubts the possibility of its having been adulterated with substances of such a different nature as those mentioned here by Pliny.

82 Fée is of opinion, that the Greek writers, from whom Pliny copied this passage, intended to speak of the ears of nard, or spikenard.

.83 According to Dioscorides, this appellation only means such nard as is cultivated in certain mountains of India which look toward Syria, and which, according to that author, was the best nard of all. Dalechamps and Hardouin, however, ridicule this explanation of the term. 
next highest esteem next to this; then the Gallic ${ }^{84}$ and in the third place, that of Crete, ${ }^{85}$ which by some persons is called "agrion," and by others "phu." This last has exactly the leaf of the olusatrum, ${ }^{86}$ with a stalk a cubit in length, knotted, of a whitish colour, inclining to purple, and a root that runs sideways; it is covered, too, with long hair, and strongly resembles the foot of a bird. Field nard is known by the name of baccar. ${ }^{87}$ We shall have further occasion to mention it when we come to speak of the flowers. All these kinds of nard, however, are to be reckoned as herbs, with the exception of Indian nard. Of these, the Gallic kind is pulled up along with the root, and washed in wine; after which it is dried in the shade, and wrapped up in paper, in small parcels. It is not very different from the Indian nard, but is lighter than that of Syria; the price at which it sells is three denarii per pound. The only way of testing the leaves of all these varieties of nard, is to see that they are not brittle and parched, instead of being dried naturally and gradually. Together with the nard that grows in Gaul, there always ${ }^{88}$ springs up a herb, which is known by the name of hirculus, or the "little goat," on account of its offensive smell, it being very similar to that of the goat. This herb, too, is very much used in the adulteration of nard, though it differs from it in the fact that it has no stem, and its leaves are smaller; the root, too, is not bitter, and is entirely destitute of smell.

CHAP. 27. (13.)-ASARUM, OR FOAL-FOOT.

The herb asarum, ${ }^{89}$ too, has the properties of nard, and, indeed, by some persons is known as wild nard. It has a leaf,

${ }^{84}$ Generally supposed to be the Valeriana Celtica of modern naturalists. See B. xxi. c. 79 .

${ }_{85}$ Probably the Valeriana Italica of modern naturalists.

86 See B. xix. c. 48.

87 Known in this country as fox-glove, our Lady's gloves, sage of Jerusalem, or clown's spikenard. See B. xxi. c. 16 .

88 Not always, but very seldom, Brotier says. Clusius has established, from observation, that this plant is only a variety of the Valeriana Celtica.

89 Fée remarks, that the name "baccara," in Greek, properly belonged to this plant, but that it was transferred by the Romans to the field nard, with which the Asarum had become confounded. It is the same as the Asarum Europæum of modern naturalists ; but it does not, as Pliny asserts, flower twice in the year. 
however, more like that of the ivy, only that it is rounder and softer. The flower is purple, the root very similar to that of the Gallic nard, and the seed is like a grape. It is of a warm and vinous flavour, and blossoms twice a year, growing upon. hill sides that are densely shaded. The best kind is that found in Pontus, and the next best that of Phrygia; that of Illyricum being only of third-rate quality. The root is dug up when it is just beginning to put forth its leaves, and then dried in the sun. It very soon turns mouldy, and loses its properties. There has, also, been lately found a certain herb in some parts of Greece, the leaves of which do not differ in the slightest degree from those of the Indian nard.

\section{CHAP. 28.-AMOMUM.-AMOMIS.}

The clustered amomum ${ }^{90}$ is very extensively used; it grows upon a kind of wild vine that is found in India, though some persons have been of opinion that it is borne by a shrub, resembling the myrtle in appearance, and about the same height as the palm. This plant, also, is plucked along with the root, and is carefully pressed together with the hands; for it very soon becomes brittle. That kind is held in the highest esteem, the leaves of which bear a strong resemblance to those of the pomegranate, being free from wrinkles, and of a red colour. The second quality is that which is of a pallid hue. That which has a green, grassy appearance, is not so good, and the white is the worst of all ; it assumes this appearance when old. The price of clustered amomum is sixty denarii per pound, but in dustit sells at only forty-nine. Amomum is produced, also, in that part of Armenia which is known as Otene; as, also, in Media and Pontus. It is adulterated with the leaves of the pomegranate and a solution of gum, which is employed

90 It is by no means settled among naturalists, what plant the Amomum of the ancients was; indeed, there has been the greatest divergence of opinion. Tragus takes it to be a kind of bindweed : Matthioli, the Piper Asthiopicum of Linnæus: Cordus and Scaliger, the rose of Jericho, the Anastatica hierocuntica of Linnæus. Gesner thinks it to have been the garden pepper, the Solanum bacciferum of Tournefort: Cæsalpinus the cubeb, the Piper cubeba of Linnæus: Plukenet and Sprengel the Cissus vitiginea, while Fée and Paulet look upon it as not improbably identical with the Amomum racemosum of Linnæus. The name is probably derived from the Arabic hahmâma, the Arabians having first introduced it to the notice of the Greeks. 
in order to make the leaves adhere and form clusters, like those of the grape.

There is another substance, also, which is known by the name of amomis; ${ }^{91}$ it is not so full of veins as amomum, harder, and not so odoriferous; from which it would appear, either that it is altogether a different plant, or else that it is amomum gathered in an unripe state.

\section{CHAP. 29.- CARDAMOMUM.}

Similar to these substances, both in name as well as the shrub which produces it, is the cardamomum, ${ }^{92}$ the seeds of which are of an oblong shape. It is gathered in the same manner both in India and Arabia. There are four different kinds of cardamomum. That which is of a very green colour, unctuous, with sharp angles, and very difficult to break, is the most highly esteemed of all. The next best is of a reddish white tint, while that of third-rate quality is shorter and blacker, the worst of all being mottled and friable, and emitting but little smell ; which, in its genuine ${ }^{93}$ state ought to be very similar to costum. Cardamomum grows also in Media. The price of the best is three denarii per pound.

\section{CHAP. 30.-THE COUNTRY OF FRANKINCENSE.}

Next in affinity to cardamomum would have been cinnamomum, ${ }^{94}$ and this we should have now proceeded to speak of, were it not more convenient first to make mention of the treasures of Arabia, and the reasons for which that country has received the names of "Happy" and "Blest." The chief productions of Arabia are frankincense and myrrh, which last it bears in

91 Supposed to have been only the Amomum, in an unripe state, as Pliny himself suggests.

${ }_{92}$ Still known in pharmacy as "cardamum." It is not, however, as Pliny says, found in Arabia, but in India ; from which it probably reached the Greeks and Romans by way of the Red Sea. There are three kinds known in modern commerce, the large, the middle size, and the small. M. Bonastre, "Journal de Pharmacie," May, 1828, is of opinion, that the word cardamomum signifies "amomum in pods," the Egyptian kardh meaning "pod," or "'husk." It is, however, more generally supposed, that the Greek word, capoia, "heart," enters into its composition.

${ }_{93}$ "Verus" seems a preferable reading here to "vero," which has been adopted by Sillig.

${ }_{94}$ See c. 42 of the present Book. 
common with the country of the Troglodytæ. (14.) There is no country in the world that produces frankincense except Arabia, ${ }^{95}$ and, indeed, not the whole of that. Almost in the very centre of that region, are the Atramitæ, ${ }^{96}$ a community of the Sabæi, the capital of whose kingdom is Sabota, a place situate on a lofty mountain. At a distance of eight stations from this is the incense-bearing region, known by the name of Saba. The Greeks say that the word signifies a "secret mystery." This district looks towards the north-east, and is rendered inaccessible by rocks on every side, while it is bounded on the right by the sea, from which it is shut out by cliffs of tremendous height. The soil of this territory is said to be of a milky white, a little inclining to red. The forests extend twenty schœni in length, and half that distance in breadth. The length of the schœnus, according to the estimate of Eratosthenes, is forty stadia, or, in other words, five miles; some persons, however, have estimated the schœnus at no more than thirty-two stadia. In this district some lofty hills take their rise, and the trees, which spring up spontaneously, run downwards along the declivities to the plains. It is generally agreed that the soil is argillaceous, and that the springs which there take their rise are but few in number, and of a nitrous quality. Adjoining are the Minæi, the people of another community, through whose country is the sole transit for the frankincense, along a single narrow road. The

95 Virgil, Georg. B. ii, 1. 139, mentions Panchaia, in Arabia, as being more especially the country of frankincense. That region corresponds with the modern Yemen. It is, however, a well-ascertained fact, that it grows in India as well, and it is supposed that the greater part of it used by the ancients was in reality imported from that country. The Indian incense is the prodact of a tree belonging to the terebinth class, named by Roxburgh, who first discovered it, Boswellia thurifera. It is more especially found in the mountainous parts of India. On the other hand, it has been asserted that the Arabian incense was the product of a coniferous tree, either the Juniperus Lycia, the Juniperus Phœnicea, or the Juniperus thurifera of Linnæus. But, as Fée justly remarks, it would appear more reasonable to look among the terebinths of Arabia for the incerse tree, if one of that class produces it in India, and more especially because the coniferous trees produce only resins, while the terebinths produce gum resins, to which class of vegetable products frankincense evidently belonged. In commerce, the gum resin, Olibanum, the produce of the Boswellia serrata, and imported from the Levant, bears the name of frankincense.

96 See B. vi. c. 32. Their name is still preserved in the modern Hadraniaut, to the east of Aden. 


\section{5}

Chap. 31.] THE TREES THAT BEAR FRANKINCENSE.

Minæi were the first people who carried on any traffic in frankincense, which they still do to a greater extent than any other persons, and hence it is that it has received the appellation of "Minæan." It is the Sabæi alone, and no other people among the Arabians, that behold the incense-tree ; and, indeed, not all of them, for it is said that there are not more than three thousand families which have a right to claim that privilege, by virtue of hereditary succession; and that for this reason those persons are called sacred, and are not allowed, while pruning the trees or gathering the harvest, to receive any pollution, either by intercourse with women, or coming in contact with the dead; by these religious observances it is that the price of the commodity is so considerably enhanced. Some persons, however, say, that the right of gathering incense in the forests belongs to all these people in common, while others again state, that they take their turns year by year.

\section{CHAP. 31.-THE TREES THAT BEAR FRANKINCENSE.}

Nor is it by any means agreed what is the appearance of the incense-tree. We have sent several expeditions against Arabia, and the Roman arms have penetrated into the greater part of that country ; indeed, Caius Cæsar. ${ }^{97}$ the son of Augustus, even earned considerable renown there; and yet this tree has been described by no Latin writer, at least that I know of. The descriptions given of it by the Greek writers vary very considerably: some of them say that it has exactly the leaf of the pear-tree, only somewhat smaller, and of a grassgreen colour. Others, again, say, that it has a rather reddish leaf, like that of the mastich, and others, that it is a kind of terebinth, ${ }^{98}$ and that King Antigonus, to whom a branch of it was brought, was of that opinion. King Juba, in the work which he wrote and dedicated to Caius Cæsar, the son of Augustus, who was inflamed by the wide-spread renown of Arabia, states, that the tree has a spiral stem, and that the branches bear a considerable resemblance to those of the Pontic maple, while it secretes a sort of juice very similar to that of

${ }^{97}$ See B. vi. cc. 31 and 32. He was the son cf Agrippa and Julia, the danghter of Augustus, by whom he was adopted.

98 This seems the most probable among these various surmises and conjectures. 
the almond-tree. Such, he says, is the appearance of the tree as seen in Carmania and Egypt, where it was introduced and planted under the auspices of the Ptolemies when reigning there. It is well known that it has a bark not unlike that of the laurel, and, indeed, some persons have asserted that their leaves are similar. At all events, such was the case with the tree as it grew at Sardes: for the kings of Asia also took considerable care to have it planted there. The ambassadors who in my time have come to Rome from Arabia, have made all these matters more uncertain, even, than they were before; a thing at which we may justily be surprised, seeing that some sprigs even of the incense-tree have been brought among us, from which we have some reason to conclude that the parent tree is round and tapering, and that it puts forth its shoots from a trunk that is entirely free from knots.

\section{CHAP. 32.-VARIOUS KINDS OF FRANKINCENSE.}

In former times, when they had fewer opportunities of selling it, they used to gather the frankincense only once a year; but at the present day, as there is a much greater demand for it, there is a second crop as well. The first, and what we may call the natural, vintage, takes place about the rising of the Dog-star, a period when the heat is most intense ; on which occasion they cut the tree where the bark appears to be the fullest of juice, and extremely thin, from being distended to the greatest extent. The incision thus made is gradually extended, but nothing is removed; the consequence of which is, that an unctuous foam oozes forth, which gradually coagulates and thickens. When the nature of the locality requires it, this juice is received upon mats of palm-leaves, though in some places the space around the tree is made hard by being well rammed down for the purpose. The frankincense that is gathered after the former method, is in the purest state, though that which falls on the ground is the heariest in weight: that which adheres to the tree is pared off with an iron instrument, which accounts for its being found mingled with pieces of bark.

The forest is allotted in certain portions, and such is the mutual probity of the owners, that it is quite safe from all depredation; indeed, there is no one left to watch the trees after the incisions are made, and yet no one is ever known to 
these by the name of stagonia ${ }^{2}$ and atomus, ${ }^{3}$ while the smaller pieces are called orobia. ${ }^{4}$ The fragments which are broken off by shaking the tree are known to us as manna. ${ }^{5}$ Even at the present day, however, there are drops found which weigh onethird of a mina, or, in other words, twenty-eight denarii. Alexander the Great, when a boy, was on one occasion loading the altars with frankincense with the greatest prodigality, upon which his tutor Leonides ${ }^{6}$ remarked to him that it would be time to worship the gods in such a lavish manner as that, when he had conquered the countries that produced the frankincense. After Alexandria had conquered Arabia; he despatchẻd to Leonides a ship freighted with frankincense, and sent him word, requesting that he would now worship the gods without stint or limit.

The incense, after being collected, is carried on camels' backs to Sabota, ${ }^{7}$ at which place a single gate is left open for its admission. To deviate from the high road while conveying it, the laws have made a capital offence. At this place the priests take by measure, and not by weight, a tenth part in honour of their god, whom they call Sabis ; indeed, it is not allowable to dispose of it before this has been done: out of this tenth the public expenses are defrayed, for the divinity. generously entertains all those strangers who have made a certain number of days' journey in coming thither. The incense can only be exported through the country of the Gebanitæ, and for this reason it is that a certain tax is paid to their king as well. Thomna, ${ }^{9}$ which is their capital, is distant from Gaza, a city of Judæa, on the shores of our sea, $4436^{10}$

2 Meaning "drop" incense.

3 "Undivided" incense.

4 From their being the size of an ő $\rho$ oßos, or " chick-pea."

5 There is some doubt as to the correctness of this reading. The "manna" here mentioned is quite a different substance to the manna of modern commerce, obtained from the Fraxinus ornus of naturalists.

6 He was a kinsman of Olympias, the mother of Alexander, and a man of very austere habits. Plutarch says, that on this occasion Alexander sent to Leonidas 600 talents' weight of incense and myrrh.

7 See B. vi. c. 32 .

8 Probably the same as the deity, Assabinus, mentioned by Pliny in c. 42 of the present Book. Theophrastus mentions him as identical with the sun, others, again, with Jupiter. Theophrastus says that the god received not a tenth part, but a third.

9 As to this place and the Gehanitæ, see B. vi. c. 32.

10 There must surely be some mistake in these numbers. 
miles, the distance being divided into sixty-five days' journey by camel. There are certain portions also of the frankincense which are given to the priests and the king's secretaries: and in addition to these, the keepers of it, as well as the soldiers who guard it, the gate-keepers, and various other employes, have their share as well. And then besides, all along the route, there is at one place water to pay for, at another fodder, lodging at the stations, and various taxes and imposts besides; the consequence of which is, that the expense for each camel before it arrives at the shores of our ${ }^{11}$ sea is six hundred and eighty-eight denarii ; after all this, too, there are certain payments still to be made to the farmers of the revenue of our empire. Hence it is that a pound of the best frankincense sells at six denarii, the second quality five, and the third three. Among us, it is adulterated with drops of white resin, a substance which bears a strong resemblance to it: but the fraud may be easily detected by the methods which have been already mentioned. ${ }^{12}$ It is tested by the following qualities; its whiteness, size, brittleness, and the readiness with which it takes fire when placed on heated coals; in addition to which, it should not give to the pressure of the teeth, but from its natural brittleness crumble all to pieces.

$$
\text { CHAP. 33. (15.)-MYRRH. }
$$

According to some authors, myrrh ${ }^{13}$ is the produce of a tree that grows in the same forests as the incense-tree, though most say that they grow in different places : but the fact is that myrrh grows in many parts of Arabia, as will be seen when we come to speak of the several varieties of it. A sort that is highly esteemed is brought from the islands ${ }^{14}$ also, and the Sabæi even cross the sea to procure it in the country of the Troglodytæ. It is grown also by being transplanted, and when thus cultivated is greatly preferred to that which is grown in the forests. The plant is greatly improved by raking

11 The Mediterranean.

12 In c. 19 of the present Book.

13 It is supposed to be the product of an amyris, but is not now esteemed as a perfume; but is used in medicine as a tonic. Forskhal has attributed to the Amyris kataf, or kafal, the production of myrrh. According to Ehrenberg, a very similar tree, though constituting a different species, the Balsamodendrum myrrha, also produces this substance. Ft is imported into Europe from both Abyssinia and Arabia. It was much used by the incients, to flavour their wines.

14 See B. vi. c. 32.

VOL. III. 
and baring the roots; indeed, the cooler the roots are kept, the better it is.

\section{CHAP. 34.-THE TREES WHICH PRODUCE MYYRR.}

The tree grows to the height of five cubits, and has thorns upon it: the trunk is hard and spiral, and thicker than that of the incense-tree, and much more so at the root than at the upper part of the tree. Some authors have said that the bark is smooth like that of the arbute, others, that it is rough and covered with thorns : it has the leaf of the olive, but more wavy, with sharp points at the edges: Juba says, however, that it resembles the leaf of the olusatrum. Some again say that it resembles the juniper, ${ }^{15}$ only that it is rougher and bristling with thorns, and that the leaves are of a rounder shape, though they have exactly the taste of the juniper. There have been some writers who have incorrectly asserted that both myrrh and frankincense are the product of the same tree.

\section{CHAP. 35.-THE NATURE AND VARIOUS KINDS OF MYRRH.}

Incisions are made in the myrrh-tree also twice a year, and at the same season as in the incense-tree; but in the case of the myrrh-tree they are all made the way up from the root as far as the branches which are able to bear it. The tree spontaneously exudes, before the incision is made, a liquid which bears the name of stacte, ${ }^{16}$ and to which there is no myrrh that is superior. Second only in quality to this is the cultivated myrrh: of the wild or forest kind, the best is that which is gathered in summer. They give no tithes of myrrh to the god, because it is the produce of other countries as well ; but the growers pay the fourth part of it to the king of the Gebanita. Myrrh is bought up indiscriminately by the common people, and then packed into bags; but our perfumers separate it without any difficulty, the principal tests of its goodness being its unctuousness and its aromatic smell. (16.) There are several ${ }^{17}$ kinds

15 Theophrastus says the terebinth.

16 From the Greek $\sigma \tau a \dot{\zeta} \zeta \omega$, " to drop." Fée observes, that the moderns know nothing positive as to the mode of extracting myrrh from the tree. See the account given by Ovid, Met. B. x. 1 . 500 et seq. of the transformation of Myrrha into this tree,- "The warm drops fall from the tree. The tears, even, have their own honour; and the myrrh that distils from the bark bears the name of its mistress, and in no age will remain unknown."

${ }_{17}$ Fée remarks, that at the present day we are acquainted only with one kind of myrrh; the fragments which bear an impression like those of nails 
of myrrh; the first among the wild myrrhs is the Troglodytic; and the next are the Minæan, which includes the Atramitic, and that of Ausaritis, in the kingdom of the Gebanitæ. A third kind is the Dianitic, ${ }^{18}$ and a fourth is the mixed myrrh, or "all-sorts ;" ${ }^{19}$ a fifth, again, is the Sambracenian, which is brought from a city in the kingdom of the Sabæi, near the sea; and a sixth is known by the name of Dusaritic. There is a white myrrh also, which is produced in only one spot, and is carried for sale to the city of Messalum. The Troglodytic myrrh is tested by its unctuousness, and its peculiarly dry appearance: it has also a dirty, rough look with it, but is more acrid than the other kinds. The Sambracenian myrrh has none of these faults, and is more sightly in appearance than any of them, though it is far from being so powerful. In general, however, the proof of its goodness consists in its being separated in little pieces of uneven shape, formed by the concretion of a whitish juice, which dries up little by little. When broken it ought to exhibit white marks like the finger-nails, and to be slightly bitter to the taste. That of second quality is of a mottled appearance within; while of worse quality is that which is of a black colour within; the very worst of all is that which is black on the outside as well.

The price of myrrh varies according to the number of purchasers. Stacte is sold at prices which vary from three denarii to forty per pound, while the very highest price of the cultivated myrrh is eleven denarii. Erythræan myrrh, the same, it is pretended, as Arabian myrrh, is sixteen denarii per pound, Troglodytic also, is sixteen denarii ; and that known as odoraria, or odoriferous myrrh, sells at fourteen. Myrrh is adulterated with pieces of mastich, and other gums; it is also drugged with the juice of wild cucumber, in order to produce a certain bitterness, and with litharge for the purpose of increasing its weight. Other sophistications may be discovered on tasting it, and the gum will adhere to the teeth. But the being not a distinct kind, but a simple variety in appearance only. He thinks, also, that Pliny may very possibly be describing several distinct resinous products, under the one name of myrrh. An account of these rarious districts will be found in B. vi. c. 32 .

18 Hardouin suggests that it may be so called from the island of Dia, mentioned by Strabo, B. xvi.

19 "Collatitia." The reading, however, is very doubtful. 
cleverest mode of adulterating it is with Indian myrrh, ${ }^{20}$ a substance which is gathered from a certain prickly shrub which grows there. This is the only thing that India produces of worse quality than the corresponding produce of other countries: they may, however, be very easily distinguished, that of India being so very much inferior.

\section{CHAP. 36. (17.) 一 MASTICH.}

The transition, therefore, ${ }^{21}$ is very easy to mastich, which grows upon another prickly shrub of India and Arabia, known by the name of laina. Of mastich as well there are two different kinds ; for in Asia and Greece there is also found a herb which puts forth leaves from the root, and bears a thistly head, resembling an apple, and full of seeds. Upon an incision being made in the upper part of this plant drops distil from it, which can hardly be distinguished from the genuine mastich. There is, again, a third sort, ${ }^{22}$ found in Pontus, but more like bitumen than anything else. The most esteemed, however, of all these, is the white mastich of Chios, the price of which is twenty denarii per pound, while the black mastich sells at twelve. It is said that the mastich of Chios exudes from the lentisk in the form of a sort of gum : like frankincense, it is adulterated with resin.

\section{CHAP. 37. - LADANUM AND STOBOLON.}

Arabia, too, still boasts of her ladanum. ${ }^{23}$ Many writers

20 What this was is now unknown. Fée suggests that it may have been bdellium, which is found in considerable quantities in the myrrh that is imported at the present day.

21 This is most probably the meaning of Pliny's expression-"Ergo transit in mastichen "" though Hardouin reads it as meaning that myrrh sometimes degenerates to mastich : and Fée, understanding the passage in the same sense, remarks that the statement is purely fabulous. Mastich, he says, is the produce of the Pistacia lentiscus of Linnæus, which abounds in Greece and the other parts of southern Europe. The greater part of the mastich of commerce comes from the island of Chio. It is impossible to conjecture to what plant Pliny here alludes, with the head of a thistle.

22 This kind, Fée says, is quite unknown to the moderns.

23 This substance is still gathered from the Cistus creticus of Linnæus, which is supposed to be the same as the plant leda, mentioned by Pliny. It is also most probably the same as the Cisthon, mentioned by Pliny in B. xxiv. c. 48 . It is very commonly found in Spain. The substance is gathered from off the leaves, not by the aid of goats, but with whips furnished with several thongs, with which the shrubs are beaten. There are two sorts of ladanum known in commerce; the one friable, and mixed with earthy substances, and known as "ladanum in tortis ;" the other black, and 
have stated that this substance is the fortuitous result of an accidental injury inflicted upon a certain odoriferous plant, under the following circumstances: the goat, they say, which is in general an animal that is extremely mischievous to foliage, is particularly fond of the shrubs that are odoriferous, as if, indeed, it were really sensible of the value that is set upon them. Hence it is that as the animal crops the sprouting shoots of the branches which are swollen with a liquid juice of remarkable sweetness, these juices drop and become mingled together, and are then wiped up by the shaggy hairs of its unlucky beard. Being there mingled with the dust, these juices form knots and tufts, and are then dried by the sun; and hence the circumstance is accounted for that in the ladanum which is imported by us we find goats' hairs. This, however, we are told, occurs nowhere but among the Nabatæi, ${ }^{24}$ a people of Arabia, who border upon Syria. The more recent writers call this substance by the name of stobolon, and state that in the forests of Arabia the trees are broken by the goats while browzing, and that the juices in consequence adhere to their shaggy hair; but the genuine ladanum, they assure us, comes from the island of Cyprus. I make mention of this in order that every kind of odoriferous plant may be taken some notice of, even though incidentally and not in the order of their respetive localities. They say also that this Cyprian ladanum is collected in the same manner as the other, and that it forms a kind of greasy substance or œsypum, ${ }^{25}$ which adheres to the beards and shaggy legs of the goats; but that it is produced from the flowers of the ground-ivy, which they have nibbled when in quest of their morning food, a time at which the whole island is covered with dew. After this, they say, when the fogs are dispersed by the sun, the dust adheres to their wet coats, and the ladanum is formed, which is afterwards taken off of them with a comb.

There are some authors who give to the plant of Cyprus, from which it is made, the name of leda; and hence it is that soft to the fingers, the only adventitious substances in which are a little sand and a few hairs.

24 See B. vi. c. 32.

25 For some further account of this substance, see B. xxix. c. 10. Filthy as it was, the cesypum, or sweat and grease of sheep, was used by the Roman ladies as one of their most choice cosmetics. Ovid, in his "Art of Love," more than once inveighs against the use of it. 
we find it also called ledanum. They say, also, that a viscous substance settles upon this plant, and, that, by the aid of strings wound around it, its leaves are rolled into balls, from which a kind of cake is made. Hence it is, that in Cyprus, as well as in Arabia, there are two kinds of ladanum; the one natural, and mingled with earth, and the other artificial: the former is friable, while the latter is of a viscous nature.

It is stated, also, that this substance is the produce of a shrub originally found in Carmania, and propagated by plants, by order of the Ptolemies, in the parts beyond Egypt; while other authorities are found, which say that it grows on the incense tree, and is gathered like gum, from incisions made in the bark, after which it is collected in bags of goat-skin. That of the most approved quality, sells at the rate of forty asses per pound. Ladanum is adulterated with myrtle berries, and filth taken from the fleeces of other animals besides the goat. If genuine, it ought to have a wild and acrid smell, in some measure redolent of the desert places where it is produced : it is dry and parched in appearance, but becomes soft the moment it is touched. When ignited, it gives a brilliant flame, and emits a powerful but pleasant odour; if mixed with myrtle berries, its spurious quality is immediately discovered by their crackling in the fire. In addition to this, the genuine ladanum has more grits, or stony particles, adhering to it, than dust.

\section{CHAP. 38. - ENH XMMON.}

In Arabia, too, the olive-tree distils a sort of tear, with which the Indians make a medicament, known by the Greeks as enhæmon; ${ }^{26}$ it is said to be of wonderful efficacy in contracting and healing wounds and sores. These trees, ${ }^{27}$ situate on the coasts there, are covered by the sea at high water, without the berries suffering the slightest injury, although it is a well-known fact, that the salt collects upon the leaves.

${ }^{26}$ From the Greek है $\nu a \mu$ ov, "styptic," or "blood-stopping." It is at the present day called gum "de lecce" in Italy. Fée says that it is not often procured from the olive-trees of France, though it is found very commonly on those of Naples and Calabria. It has no active powers, he says, as a medicine.

${ }_{27}$ Hardouin suggests that they may be the pelagiæ, mentioned again in B. xiii. c. 51 . 
All these trees are peculiar to Arabia, but it has some few besides, in common with other countries, of which we shall make mention elsewhere, the kinds growing in Arabia being of inferior quality. The people of that country have a wonderful regard for the perfumes of foreign parts, and import them from places at a considerable distance; so soon are men sated with what they have of their own, and so covetous are they of what belongs to others.

\section{CHAP. 39.-THE TREE CALLED BRATUS.}

Hence it is, that they import from the country of the Elymæi ${ }^{28}$ the wood of a tree called bratus, ${ }^{29}$ which is similar in appearance to a spreading cypress. Its branches are of a whitish colour, and the wood, while burning, emits a pleasant odour; it is highly spoken of by Claudius Cæsar, in his History ${ }^{30}$ for its marvellous properties. He states that the Parthians sprinkle the leaves of it in their drink, that its smell closely resembles that of the cedar, and that the smoke of it is efficacious in counteracting the effects of smoke emitted by other wood. This tree grows in the countries that lie beyond the Pasitigris, ${ }^{31}$ in the territory of the city of Sittaca, upon Mount Zagrus.

\section{CHAP. 40.-THE TREE CALLED STOBRUM.}

The Arabians import from Carmania also the wood of a tree called stobrum, ${ }^{32}$ which they employ in fumigations, by steeping it in palm wine, and then setting fire to it. The odour first ascends to the ceiling, and then descends in volumes

${ }^{2 s}$ See B. vi. c. 31.

29 Although the savin shrub, the Juniperus Sabina of Linnæus, bears this name in Greek, it is evident, as Fée says, that Pliny does not allude to it, but to a coniferous tree, as it is that family which produces a resinous wood with a balsamic odour when ignited. Bauhin and others would make the tree meant to be the Thuya occidentalis of Linnæus; but, as Fée observes, that tree is in reality a native originally of Canada, while the Thuya orientalis is a native of Japan. He suggests, however, that the Thuya articulata of Mount Atlas may have possibly been the citrus of Pliny.

30 See end of B. v.

31 All these are mentioned in B. vi. c. 31 .

32 It is not known what wood is meant under this name. Aloe, and some other woods, when ignited are slightly narcotic. 
to the floor; it is very agreeable, but is apt to cause an oppression of the head, though unattended with pain; it is used for promoting sleep in persons when ill. For these branches of commerce, they have opened the city of Carræ ${ }^{33}$ which serves as an entrepot, and from which place they were formerly in the habit of proceeding to Gabba, at a distance of twenty days' journey, and theice to Palæstina, in Syria. But at a later period, as Juba informs us, they began to take the road, for the purposes of this traffic, to Charax ${ }^{34}$ and the kingdom of the Parthians. For my own part, it would appear to me that they were in the habit of importing these commodities among the Persians, even before they began to convey them to Syria or Egypt; at least Herodotus bears testimony to that effect, when he states that the Arabians paid a yearly tribute of one thousand talents, in frankincense, to the kings of Persia.

From Syria they bring back storax, ${ }^{35}$ which, burnt upon the hearth, by its powerful smell dispels that loathing of their own perfumes with which these people are affected. For in general there are no kinds of wood in use among them, except those which are odoriferous; indeed, the Sabæi are in the habit of cooking their food with incense wood, while others, again, employ that of the myrrh tree; and hence, the smoke and smells that pervade their cities and villages are no other than the very same which, with us, proceed from the altars. For the purpose of qualifying this powerful smell, they burn storax in goat-skins, and so fumigate their dwellings. So true it is, that there is no pleasure to be found, but what the continual enjoyment of it begets loathing. They also burn this substance to drive away the serpents, which are extremely numerous in the forests which bear the odoriferous trees.

\section{CHAP. 41. (18.)-Why aRABIA WAS CaLLED " Happy."}

Arabia produces neither cinnamon nor cassia; and this is the country styled "Happy" Arabia! False and ungrateful does she prove herself in the adoption of this surname, which she would imply to have been received from the gods above; whereas, in reality, she is indebted for it far more to the gods

33 See B. v. c. 21.

34 See B. vi. c. 30 .

35 See c. 55 of the present Book. 
below. ${ }^{36}$ It is the luxury which is displayed by man, even in the paraphernalia of death, that has rendered Arabia thus "happy;" and which prompts him to burn with the dead what was originally understood to have been produced for the service of the gods. Those who are likely to be the best acquainted with the matter, assert that this country does not produce, in a whole year, so large a quantity of perfumes as was burnt by the Emperor Nero at the funeral obsequies of his wife Poppæa. And then let us only take into account the vast number of funerals that are celebrated throughout the whole world each year, and the heaps of odours that are piled up in honour of the bodies of the dead; the vast quantities, too, that are offered to the gods in single grains; and yet, when men were in the habit of offering up to them the salted cake, they did not show themselves any the less propitious; nay, rather, as the facts themselves prove, they were even more favourable to us than they are now. But it is the sea of Arabia that has even a still greater right to be called " happy," for it is this that furnishes us with pearls. At the very lowest computation, India, the Seres, and the Arabian Peninsula, withdraw from our empire one hundred millions of sesterces every year-so dearly do we pay for our luxury and our women. How large a portion, too, I should like to know, of all these perfumes, really comes to the gods of heaven, and the deities of the shades below?

\section{CHAP. 42. (19.)-CINNAMOMUM. ${ }^{37}$ XYLOCINNAMUM.}

Fabulous antiquity, and Herodotus ${ }^{38}$ more particularly, have related that cinnamomum and cassia are found in the nests of certain birds, and principally that of the phœnix, in the districts where Father Liber was brought up; and that these substances either fall from the inaccessible rocks and trees in which the nests are built, in consequence of the weight of the pieces of flesh which the birds carry up, or else are brought down by the aid of arrows loaded with lead. It is said, also,

${ }^{36}$ Because its perfumes were held in such high esteem, for burning on the piles of the dead. This, of course, was done primarily to avoid the offensive smell.

37 The bark of the Cinnamomum Zeylanicum of the modern naturalists, the cinnamon-tree of Ceylon.

$38 \mathrm{~B}$. iii. 
that cassia grows around certain marshes, but is protected by a frightful kind of bat armed with claws, and by winged serpents as well. All these tales, however, have been evidently invented for the purpose of enhancing the prices of these commodities. Another story, too, bears them company, to the effect that under the rays of the noon-day sun, the entire peninsula exhales a certain indescribable perfume composed of its numerous odours; that the breezes, as they blow from it, are impregnated with these odours, and, indeed, were the first to announce the vicinity of Arabia to the fleets of Alexander the Great, while still far out at sea. All this, however, is false ; for cinnamomum, or cinnamum, which is the same thing, grows in the country of the Ethiopians, ${ }^{39}$ who are united by intermarriages with the Troglodytæ. These last, after buying it of their neighbours, carry it over vast tracts of sea, upon rafts, which are neither steered by rudder, nor drawn or impelled by oars or sails. Nor yet are they aided by any of the resources of art, man alone, and his daring boldness, standing in place of all these; in addition to which, they choose the winter season, about the time of the equinox, for their voyage, for then a south easterly wind is blowing; these winds guide them in a straight course from gulf to gulf, and after they have doubled the promonotory of Arabia, the north east wind carries them to a port of the Gebanitæ, known by the name of Ocilia ${ }^{40}$ Hence it is that they steer for this port in preference; and they say that it is almost five years before the merchants are able to effect their return, while many perish on the voyage. In return for their wares, they bring back articles of glass and copper, cloths, buckles, bracelets, and necklaces; hence it is that this traffic depends more particularly upon the capricious tastes and inclinations of the female sex.

The cinnamon shrub ${ }^{41}$ is only two cubits in height, at the most, the lowest being no more than a palm in height. It is about four fingers in breadth, and hardly has it risen six fingers from the ground, before it begins to put forth shoots and

39 See B. vi. c. 34.

40 See B. vi. c. 26.

41 As Fée observes, this description does not at all resemble that of the cinnamon-tree of Ceylon, as known to us. M. Bonastre is of opinion that the nutmeg-tree was known to the ancients under this name; but, as Fée observes, the nutmeg could never have been taken for a bark, and cinnamon is described as such in the ancient writers. He inclines to think that their cinnamon was really the bark of a species of amyris. 
suckers. It has then all the appearance of being dry and withered, and while it is green it has no odour at all. The leaf is like that of wild marjoram, and it thrives best in dry localities, being not so prolific in rainy weather; it requires, also, to be kept constantly clipped. Though it grows on level ground, it thrives best among tangled brakes and brambles, and hence it is extremely difficult to be gathered. It is never gathered unless with the permission of the god, by whom some suppose Jupiter to be meant; the Ethiopians, however, call him Assabinus. ${ }^{42}$ They offer the entrails of forty-four oxen, goats, and rams, when they implore his permission to do so, but after all, they are not allowed to work at it before sunrise or after sunset. A priest divides the branches with a spear, and sets aside one portion of them for the god; after which, the dealer stores away the rest in lumps. There is another account given, which states that a division is made between the gatherers and the sun, and that it is divided into three portions, after which lots are twice drawn, and the share which falls to the sun is left there, and forthwith ignites spontaneously.

The thinnest parts in the sticks, for about a palm in length, are looked upon as producing the finest cinnamon; the part that comes next, though not quite so long, is the next best, and so on downwards. The worst of all is that which is nearest the roots, from the circumstance that in that part there is the least bark, the portion that is the most esteerned: hence it is that the upper part of the tree is preferred, there being the greatest proportion of bark there. As for the wood, it is held in no esteem at all, on account of the acrid taste which it has, like that of wild marjoram; it is known as xylocinnamum. ${ }^{43}$ The price of cinnamomum is ten denarii per pound. Some writers make mention of two kinds of cinnamon, the white and the black : the white was the one that was formerly preferred, but now, on the contrary, the black is held in the highest estimation, and the mottled, even, is preferred to the white. The most certain test, however, of the goodness of cinnamon is its not being rough, and the fact that the pieces when rubbed together do not readily crumble to powder. That which is soft is more particularly rejected, which is the case, also, when the outer bark too readily falls off.

42 See c. 33 of the present Book, and the Note.

${ }^{43}$ Or "wood of cinnamon." 
The right of regulating the sale of the cinnamon belongs solely to the king of the Gebanitx, who opens the market for it by public proclamation. The price of it was formerly as much as a thousand denarii per pound; which was afterwardsincreased to half as much again, in consequence, it is said, of the forests having been set on fire by the barbarians, from motives of resentment; whether this took place through any injustice exercised by those in power, or only by accident, has not been hitherto exactly ascertained. Indeed, we find it stated by some authors, that the south winds that prevail in these parts are sometimes so hot as to set the forests on fire. The Emperor Vespasianus Augustus was the first to dedicate in the temples of the Capitol and the goddess Peace chaplets of cinnamon inserted in embossed ${ }^{44}$ gold. I, myself, once saw in the temple of the Palatium, which his wife Augusta ${ }^{45}$ dedicated to her husband the late emperor Augustus, a root of cinnamon of great weight, placed in a patera of gold : from it drops used to distil every year, which congealed in hard grains. It remained there until the temple was accidentally destroyed by fire.

CHAP. 43.-CASSIA.

Cassia $^{46}$ is a shrub also, which grows not far from the plains where cinnamon is produced, but in the mountainous localities; the branches of it are, however, considerably thicker than those of cinnamon. It is covered with a thin skin rather than a bark, and, contrary to what is the case with cinnamon, it is looked upon as the most valuable when the bark falls off and crumbles into small pieces. The shrub is three cubits in height, and the colours which it assumes are threefold: when it first shoots from the ground, for the length of a foot, it is white; after it has attained that height, it is red for half a foot, and beyond that it is black. This last is the part that is held in the highest esteem, and next to it the portion that comes next, the white part being the least valued of all. They cut the ends of the branches to the length of two fingers, and

44 "Interrasili." Gold partly embossed, and partly left plain, was thus called.

45 The Empress Livia.

46 There has been considerable doubt what plant it was that produced the cassia of the ancients. Fée, after diligently enquiring into the subject, inclines to think that it was the Laurus cassia of Linnæus, the same tree that produces the cassia of the present day. 
then sew them in the fresh skins of cattle that have been killed expressly for the purpose; the object being that the skins may putrefy, and the maggots generated thereby may eat away the woody parts, and so excavate ${ }^{47}$ the bark; which is so intensely bitter, that it is quite safe from their attacks. That which is the freshest is the most highly esteemed; it has a very delicate smell, and is so extremely hot to the taste, that it may be said to burn the tongue, rather than gradually warm the mouth. It is of a purple colour, and though of considerable volume, weighs but very little in comparison; the outer coat forms into short tubes which are by no means easily broken : this choice kind of cassia, the barbarians call by the name of lada. There is another sort, again, which is called balsamodes, ${ }^{48}$ because it has a smell like that of balsam, but it is bitter; for which reason it is more employed for medicinal purposes, just as the black cassia is used for unguents. There is no substance known that is subject to greater variations in price : the best qualities sell at fifty denarii per pound, others, again, at five.

(20.) To these varieties the dealers have added another, which they call daphnoides, ${ }^{49}$ and give it the surname of isocinnamon $;^{50}$ the price at which it sells is three hundred denarii per pound. It is adulterated with storax, and, in consequence of the resemblance of the bark, with very small sprigs of laurel. Cassia is also planted in our ${ }^{51}$ part of the world, and, indeed, at the extreme verge of the Empire, on the banks of the river Rhenus, where it flourishes when planted in the vicinity of hives of bees. It has not, however, that scorched colour which is produced by the excessive heat of the sun; nor has it, for the same reason, a similar smell to that which comes from the south.

\section{CHAP. 44.-CANCAMUM AND TARUM.}

From the confines of the country which produces cinnamon

47 There is little doubt that all this is fabulous.

48 Or, "smelling like balsam."

49 "Looking like laurel."

50 "Equal to cinnamon." Fée thinks that it is a variety of the Laurus cassia.

${ }^{51} \mathrm{He}$ probably alludes to the Daphne Cnidium of Linnæus, which, as Fée remarks, is altogether different from the Laurus cassia, or genuine cassia. 
and cassia, cancamum ${ }^{52}$ and tarum ${ }^{53}$ are imported; but these substances are brought by way of the Nabatæan Troglodytæ, a colony of the Nabatæi.

\section{CHAP. 45. (21.) - SERICHATUM AND GABALTUM.}

Thither, too, are carried serichatum ${ }^{54}$ and gabalium, aromatics which the Arabians rear for their own consumption, and which are only known by name in our part of the world, though they grow in the same country as cinnamon and cassia. Still, however, serichatum does reach us occasionally, and is employed by some persons in the manufacture of unguents. It is purchased at the rate of six denarii per pound.

\section{CHAP. 46. -MYROBALANUM.}

In the country of the Troglodytæ, the Thebais, and the parts of Arabia which separate Judæa from Egypt, myrobalanum ${ }^{55}$ is commonly found; it is provided by Nature for unguents, as from its very name would appear. From its name, also, it is evident that it is the nut of a tree, with a leaf similar to that of the heliotropium, which we shall have to mention when speaking of the herbs. The fruit of this tree is about the size of a filbert. The kind that grows in Arabia is known as Syriaca, and is white, while, on the other hand, that which grows in the Thebais is black: the former is preferred for the quality of the oil extracted from it, though that which is pro-

52 A gum resin of some unknown species, but not improbably, Fée thinks, the produce of some of the Amyrides. Sprengel thinks that it was produced from the Gardenia gummifera.

53 Aloe-wood.

54 According to Poinsinet, these Arabic words derive their origin from the Slavonic ; the first signifying a "cordial drug," or "alexipharmic," and the other a drug "which divides itself into tablets." It is impossible to divine what drugs are meant by these names.

55 Signifying the "unguent acorn," or "nut." There is little doubt that the behen or ben nut of the Arabians is meant, of which there are several sorts. It is used by the Hindoos for calico printing and pharmacy, and was formerly employed in Europe in the arts, and for medical purposes. It is no longer used as a perfume. The "oil of ben " used in commerce is extracted from the fruit of the Moringa oleifera of naturalists. It is inodorous ; for which reason, Fée is of opinion that the name signifies "the oily nut," and quotes Dioscorides, who says, B. iv., that an oil is extracted from this balanus, which is used as an ingredient in unguents, in place of other oils. F'é also says that at the present day it is used by perfumers, to fix or arrest the evanescent odours of such flowers as the jasmine and the lily. 
duced in the Thebais yields it in larger quantities. Among these various kinds, that which is sent from the country of the Troglodytæ is the worst of all. There are some persons who prefer that of Ethiopia ${ }^{56}$ to all of these, the nut of which is black, and not oleaginous ; it has only a very small kernel, but the liquid which is extracted from it is more odoriferous than that of the other kinds; it grows, too, in a champaign, open country. It is said that the Egyptian nut is even more oleaginous, being of a reddish colouf with a thicker shell, and that the plant, although it grows in wet, marshy spots, is shorter and drier than the other kinds. The Arabian nut, again, is said to be of a green colour and of smaller size, but harder and more compact, from the circumstance that it grows in mountainous districts. The best of all, however, is that of Petra, which comes from a city mentioned ${ }^{56^{*}}$ on a previous occasion; it has a black shell, but the kernel is white. The perfumers, however, only extract the juices from the shells ; but medical men pound the kernels, pouring warm water on them, little by little, as they do it.

\section{CHAP. 47. (22.)-PHCENICOBALANUS.}

The fruit of the palm in Egypt, which is known by the name of adipsos, ${ }^{57}$ is put to a similar use in unguents, and is held next in esteem after the myrobalanum. It is of a green colour, has exactly the smell of a quince, and has no stone or nut within. It is gathered a little before it begins to ripen. That which is left ungathered is known as phœnicobalanus ; ${ }^{58}$ it turns black, and has a tendency to inebriate the person who eats of it. The price of myrobalanum is two denarii per pound. The shop-keepers give this name also to the dregs of the unguent that is made with it.

${ }^{56}$ This Ethiopian variety is quite unknown, and is, as Fée remarks, most probably of a different species from the genuine myrobalanus.

56* See B. vi. c. 32 .

57 "Curing thirst." Dioscorides, B. i. c. 148, says that it was so called from being full of juice, which quenched thirst like water.

${ }_{58}$ "Palm-nut." Fée thinks it not improbable that one of the datepalms is meant, if we may judge from the name. He suggests that possibly the Elais or avoira of Guinea, the Elais Guineensis, which is found as far as Upper Egypt, and which produces a fine oil known as palm-oil, is meant, or possibly the Douma Thebaica, a palm-tree frequently met with in Egypt. On fermentation, a vinous drink is extracted from the last, which is capable of producing intoxication. 
CHAP. 48.-THE SWEET-SCENTED CALAMUS; ${ }^{69}$ THE SWEET-SCENTED RUSH.

Scented calamus also, which grows in Arabia, is common to both India and Syria, that which grows in the last country being superior to all the rest. At a distance of one hundred and fifty stadia from the Mediterranean, between Mount Libanus and another mountain of no note (and not, as some have supposed, Antilibanus), there is a valley of moderate size, situate in the vicinity of a lake, the marshy swamps of which are dried up every summer. At a distance of thirty stadia from this lake grow the sweet-scented calamus and rush. We shall here make some further mention of this rush as well, although we have set apart another Book for plants of that description, seeing that it is our object here to describe all the different materials used for unguents. These plants differ in appearance in no respect from others of their kind; but the calamus, which has the more agreeable smell of the two, attracts by its odour at a considerable distance, and is softer to the touch than the other. The best is the kind which is not so brittle, but breaks into long flakes, and not short, like a radish. In the hollow stalk there is a substance like a cobweb, which is generally known by the name of the "flower:" those plants which contain the most of it are esteemed the best. The other tests of its goodness are its being of a black colour-those which are white not being esteemed; besides which, to be of the very best quality it should be short, thick, and pliant when broken. The price of the scented calamus is eleven, and of the rush fifteen denarii per pound. It is said that the sweet-scented rush is to be met with also in Campania.

\section{CHAP. 49.- - HAMMONIACUM.}

We have now departed from the lands which look towards

59 Fée remarks, that this must not be confounded with the Calamus aromaticus of the moderns, of which Pliny speaks in B. xxv. c. 100, with sufficient accuracy to enable us to identify it with the Acorus calamus of Linnæus. It is not ascertained by naturalists what plant is meant by Pliny in the present instance, though Fée is of opinion that a gramineous plant of the genus Andropogon is meant. M. Guibourt has suggested that the Indian Gentiana chirayta is the plant. From what Pliny says in B. xiii. c. 21 , it appears that this calamus grew in Syria, which is also the native country of the Andropogon schcenanthus. 
the ocean to enter upon those which have an aspect towards our seas. (23.) Africa, which lies below Athiopia, distils a tear-like gum in its sands, called hammoniacum, ${ }^{60}$ the name of which has passed to the oracle of Hammon, situate near the tree which produces it. This substance, which is also called metopion, ${ }^{61}$ bears a strong resemblance to a resin or a gum. There are two kinds of ammoniacum; that to which the name is given of thrauston, and which bears a resemblance to male frankincense, being the kind that is the most esteemed, and that which is known as phyrama, being of an unctuous and resinous nature. This substance is adulterated by means of sand, which has all the appearance of having adhered to it during its growth: hence it is greatly preferred when the pieces are extremely small, and in the purest state possible. The price of hammoniacum of the best quality is forty asses per pound.

\section{CHAP. 50.- SPHAGNOS.}

Below these countries, and in the province of Cyrenaica, the perfume called sphagnos ${ }^{62}$ is found in the highest state of perfection: there are some who call it by the name of bryon. The sphagnos of Cyprus holds the second rank, and that of Phœnicia the third. It is said that this plant is produced in Egypt also, and in Gaul as well, and I see no reason to doubt that such is the fact, for this name is given to certain white

${ }^{60}$ See B. xxiv. c. 14. The gum resin ammoniacum is still imported into Europe from Africa and the East, in the form of drops or cakes. It is a mildly stimulating expectorant, and is said to be the produce of the Dorema ammoniacum. There are still two sorts in commerce: the first in large masses of a yellow, dirty colour, mingled with heterogeneous substances, and of a plastic consistency. This is the phyrama of Pliny, or mixed ammoniac. The other is in tears, of irregular form and a whitish colour, brittle and vitreous when broken. This is the thrauston, or "friable" ammoniac of Pliny. Jackson says, that the plant which produces it is common in Morocco, and is called feskouk, resembling a large stalk of fennel. The ammoniac of Morocco is not, however, imported into this country, being too much impregnated with sand, in consequence of not being gathered till it falls to the ground.

${ }^{61}$ Solinus tells us, that the tree itself is called Metops.

62 It is clear that, under this name, certain lichens of a hairy or filamentary nature are meant. They adhere, Dioscorides tells us, to the cedar, the white poplar, and the oak. The white ones belong, probably, to the Usnea florida of Linnæus, the red ones to the Usnea barbata, and the black ones to the Alectoria jubata, an almost inodorous lichen.

TOL. III. 
shaggy tufts upon trees, such as we often see upon the quercus: those, however, of which we are speaking, emit a most ex. quisite odour. The most esteemed of all are the whitest, and those situate at the greatest height upon the tree. Those of second quality are red, while those which are black are not of the slightest value. The sphagnos, too, that is produced on islands and among rocks, ${ }^{63}$ is held in no esteem, as well as all those varieties which have the odour of the palm-tree, and not that which is so peculiarly their own.

\section{CHAP. 51.-CYPROS.}

The cyprus ${ }^{6+}$ is a tree of Egypt, with the leaves of the ziziphus, ${ }^{65}$ and seeds like coriander, ${ }^{66}$ white and odoriferous. These seeds are boiled in olive oil, and then subjected to pressure; the product is known to us as cypros. The price of it is five denarii per pound. The best is that produced on the banks of the Nile, near Canopus, that of second quality coming from Ascalon in Judæa, and the third in estimation for the sweetness of its odour, from the island of Cyprus. Some people will have it that this is the same as the tree which in Italy we call ligustrum. ${ }^{67}$

\section{CHAP. 52.-ASPALATHOS, OR ERYSISCEPTRUM.}

In the same country, ${ }^{68}$ too, grows aspalathos, ${ }^{69}$ a white, thorny shrub, the size of a moderate tree, and with flowers like the rose, the root of which is in great request for unguents. It is said that every shrub over which the rainbow is extended is possessed of the sweet odour that belongs to the aspalathos, but that if the aspalathos is one of them, its

63 Probably the Roccella tinctoria of Linnæus, a lichen most commonly fonnd upon rocks.

61 'The henné, the Lawsonia inermis of the modern naturalists, a shrub found in Egypt, Syria, and Barbary. From this tree the henna is made with which the women of the East stain the skin of their hands and feet.

65 The jujube-tree. See B. xv. c. 14 .

66 See B. xx. c. 82.

67 Or privet.

68 But in B. xxiv. c. 68 , he says that this plant grows in the island of Rhodes.

69 According to Fée, this is the same as the Lignum Rhodianum, or wood of Rhodes, of commerce, sometimes also called, but incorrectly, wood of roses. It is, probably, the same as the Convolvulus scoparius of Linnæus. 
scent is something quite indescribable. Some persons call this plant erysisceptrum, ${ }^{70}$ and others, again, sceptrum. The proof of its genuineness is its red or fiery colour; it is also compact to the touch, and has the, smell of castoreum : ${ }^{71}$ it is sold at the rate of five denarii per pound.

\section{CHAP. 53.- MARON.}

In Egypt, too, grows marum, ${ }^{72}$ though of inferior quality to that of Lydia, which last has larger leaves, covered with spots. Those of the other are shorter and smaller, and give out a powerful scent.

\section{CHAP. 54. (25.) - BALSAMUM ; OPOBALSAMUM ; AND XYLOBAL- SAMUM.}

But to all other odours that of balsamum ${ }^{73}$ is considered preferable, a plant that has been only bestowed by Nature upon the land of Judæa. In former times it was cultivated in two gardens only, both of which belonged to the kings of that country: one of them was no more than twenty jugera in extent, and the other somewhat smaller. The emperors Vespasianus and Titus had this shrub exhibited at Rome; indeed, it is worthy of signal remark, that since the time of Pompeius Magnus, we have been in the habit of carrying trees even in our triumphal processions. At the present day this tree pays us homage and tribute along with its native land, but it has been found to be of altogiether a different nature to that which

70 Or "red sceptre," probably so called from the flowers clustering along" the whole length of the branches.

${ }^{71}$ A liquid matter extracted from the beaver.

72 Generally regarded as identical with the Teucrium Marum of Linnæus, a sweet-smelling shrub found in the south of Europe and the East, by us commonly known as "herb mastich," somewhat similar to marjoram. Fée says that the marum of Egypt is a kind of sage, the Salvia Althiopis of Linnæus.

${ }_{73}$ Balsam (or baim of Mecca, as it is sometimes called) is the produce of two trees, probably varieties of one another, of the terebinth family, belonging to the genus Amyris. So far from being a native solely of Judæa, Bruce assures us that its original country was that which produces myrrh, in the vicinity of Babelmandel, and that the inhabitants use the wood solely for fuel. In Judæa it appears to have been cultivated solely in gardens; and it was this tree which produced the famous balm of Gileail of Scripture. The balsam trees known to us do not at all correspond with Pliny's description, as they do not resemble either the vine or myrtle, nor are their leaves at all like those of rue. 
our own as well as foreign writers had attributed to it: for, in fact, it bears a much stronger resemblance to the vine than to the myrtle. This recent acquisition by conquest has learned, like the vine, to be reproduced by mallet ${ }^{i 4}$-shoots, and it covers declivities just like the vine, which supports its own weight without the aid of stays. When it puts forth branches it is pruned in a similar manner, and it thrives by being well raked at the roots, growing with remarkable rapidity, and bearing fruit at the end of three years. The leaf bears a very considerable resemblance to that of rue, and it is an evergreen. The Jews vented their rage upon this shrub just as they were in the habit of doing against their own lives and persons, while, on the other hand, the Romans protected it ; indeed, combats have taken place before now in defence of a shrub. At the present day the reproduction of it has become a duty of the fiscal authorities, and the plants were never known to be more numerous or of larger growth; they never exceed the height, however, of a couple of cubits.

There are three different kinds of balsamum. The first has a thin and hair-like foliage, and is known by the name of eutheriston. $^{75}$ The second is of a rugged appearance, bending downwards, full of branches, and more odoriferous than the first; the name of this is trachy. The third kind is the eumeces, so called, because it is taller than the others; it has a smooth, even, bark. It is the second in quality, the eutheriston being inferior to the trachy. The seed of this plant has a flavour strongly resembling that of wine; it is of a reddish colour, and not without a certain amount of unctuousness; the grains of inferior quality are lighter in weight and of a greener hue: the branches of the shrub are thicker than those of the myrtle. Incisions are made in it either with glass, or else a sharp stone, or knives made of bone : it being highly injurious to touch the vital parts with iron, for in such case it will immediately wither away and die. On the other hand, it will allow of all the superfluous branches being pruned away with an instrument of iron even. The hand of the

74 "Malleolis:" So called when the new shoot of the tree springing from a branch of the former year, is cut off for the sake of planting, with a bit of the old wood on each side of it, in the form of a mallet.

75 "Easily cut." 'This and the other kinds, the names of which mean "rough barked," and "good length," are probably only varieties of the same tree, in different states. 
person who makes the incision is generally balanced by an artificial guide, in order that he may not accidentally inflict a wound in the wood beyond the bark.

A juice distils from the wound, which is known to us as opobalsamum; it is of extraordinary sweetness, ${ }^{76}$ but only exudes in tiny drops, which are then collected in wool, and deposited in small horns. When taken from out of these, the substance is placed in new earthen vessels; it bears a strong resemblance to a thick oil, and is of a white colour when fresh. It soon, however, turns red, and as it hardens loses its transparency. When Alexander the Great waged war in those parts, it was looked upon as a fair summer day's work to fill a single concha ${ }^{77}$ with this liquid; the entire produce of the larger garden being six congii, and of the smaller one a single congius; the price, too, at which it was sold was double its weight in silver. At the present day the produce of a single tree, even, is larger; the incisions are made three times evers summer, after which the tree is pruned.

The cuttings, too, form an article of merchandize: the fifth year after the conquest of Judæa, these cuttings, with the suckers, were sold for the price of eight hundred thousand sesterces. These cuttings are called xylobalsarnum, ${ }^{78}$ and are boiled down for mixing with unguents, and in the manufactories have been substituted for the juices of the shrub. The bark is also in great request for medicinal purposes, but it is the tears that are so particularly valuable; the seed holding

76 This is said, probably, in allusion to the smell, and not the taste. Fée remarks, that Pliny speaks with a considerable degree of exaggeration, as its odour is very inferior to that of several balsams which contain benzoic acid. The balsam obtained by incision, as mentioned by Pliny, is not brought to Europe, but only that obtained by the process of decontion; which is known as "balm of Mecca," or of Judæa. It is difficult to believe, according to Fée, that it was adulterated with the substances here mentioned by. Pliny; oil of roses having been always a very precious commodity, wax being likely to change its nature entirely, and gums not being of a nature to combine with it. Its asserted effects upon milk he states to be entirely fabulous; the statement is derived from Dioscorides.

77 The concha, or "shell," was a Greek and Roman liquid measure, of which there were two sizes. The smaller was half a cyathus, .0412 of an English pint; the larger was about three times the size of the former; and was known also as the oxybaphum.

i8 0r "wood of balsam." It is still known in European commerce by its ancient name. The fruit is called Carpobalsamum. 
the second rank in estimation, the bark the third, and the wood being the least esteemed of all. Of the wood, that kind which resembles boxwood is considered the best: it has also the strongest smell. The best seed is that which is the largest in size and the heaviest in weight; it has a biting or rather burning taste in the mouth. Balsamum is adulterated with hypericon ${ }^{78^{*}}$ from Petra, but the fraud is easily detected, from the fact that the grains of the latter are larger, comparatively empty, and longer than those of balsamum; they are destitute also of any pungency of smell, and have a flavour like that of pepper.

As to the tears of balsamum, the test of their goodness is their being unctuous to the touch, small, of a somewhat reddish colour, and odoriferous when subjected to friction. That of second-rate quality is white; the green and coarse is inferior, and the black is the worst of all; for, like olive-oil, it is apt to turn rancid when old. Of all the incisions, the produce is considered the best of those from which the liquid has flowed before the formation of the seed. In addition to what has been already stated, it is often adulterated with the juice of the seed, and it is with considerable difficulty that the fraud is detected by a slight bitterness in the taste, which ought to be delicate and without the slightest mixture of acidity, the only pungency being that of the smell. It is adulterated also with oil of roses, of cyprus, of mastich, of balanus, of turpentine, and of myrtle, as also with resin, galbanum, and Cyprian wax, just as occasion may serve. But the very worst adulteration of all, is that which is effected with gum, a substance which is dry when emptied into the hand, and falls to the bottom when placed in water; both of which are characteristics of the genuine commodity. Balsamum, in a genuine state, should be quite hard, but when it is mixed with gum a brittle pellicle forms upon it. The fraud can also be detected by the taste, and when placed upon hot coals it may easily be seen if there has been any adulteration with wax and resin; the flame too, in this case, burns with a blacker smoke than when the balsamum is pure. When mixed with honey its qualities are immediately changed, for it will attract flies even in the hand. In addition to these various tests, a drop of pure balsamum, if placed in luke-warm water will settle to the bottom of the

$76^{*}$ See B. xxvi. cc. 53, 54. 
vessel, whereas, if it is adulterated, it will float upon the surface like oil, and if it has been drugged with metopion or hammoniacum, a white circle will form around it. But the best test of all is, that it will cause milk to curdle, and leave no stain upon cloth. In no commodity are there practised more palpable frauds than in this, for a sextarius of balsamum which is sold by the fiscal authorities at three hundred denarii, is sold again for a thousand, so vast is the profit to be derived from increasing this liquid by sophistication. The price of xylobalsamum is six denarii per pound.

\section{CHAP. 55.- STORAX.}

That part of Syria joining up to Judæa, and lying above Phœnicia, produces storax, which is found in the vicinity of Gabala and Marathus, ${ }^{79}$ as also of Casius, a mountain of Seleucia. The tree ${ }^{80}$ bears the same name, and has a strong resemblance to, the quince. The tear has a harsh taste, with a pleasant smell; in the interior it has all the appearance of a reed, and is filled with a liquid juice. About the rising of the Dogstar, certain small winged worms hover about this substance and eat it away, for which reason it is often found in a rotten state, with worm-holes full of dust. The storax next in esti. mation after that already mentioned, comes from Pisidia, Sidon, Cyprus, and Cilicia; that of Crete being considered the very worst of all. That which comes from Mount Amanus, in Syria, is highly esteemed for medicinal purposes, and even more so by the perfumers. From whatever country it comes, that which is of a red colour is preferred, and it should be both unctuous as well as viscous to the touch; the worst kind is that which crumbles like bran, and is covered all over with a whitish mould. This substance is adulterated with the resin of cedar or with gum, and sometimes with honey or bitter al-

79 These localities are mentioned in B. v.

80 The Storax officinalis of Linnæus, a tree found in the south of Furope and the Levant. The variety found in France, and known as the Aliboufier, produces no storax, or at least a very small proportion. The storax of commerce appears in three states-grain storax, with which Pliny does not appear to have been acquainted; amygdalite, which is perhaps the sort which he speaks of as adulterated with bitter almonds; and lump storax, of reddish brown colour, which is frequently mixed with wood dust, or worm dust, as mentioned by Pliny, and is but little esteemed. The tree is also called Liquidambar styraciflua. 
monds; all which sophistications may, however, be detected by the taste. The price of storax of the best quality is seventeen denarii per pound. It comes also from Pamphylia, but this last is more arid, and not so fall of juice.

\section{CHAP. 56. - GALBANUM.}

Syria produces galbanum too, which grows upon the same mountain of Amanus : it exudes from a kind of giant-fennel ${ }^{81}$ of the same name as the resin, though sometimes it is known as stagonitis. The kind that is the most esteemed is cartilaginous, clear like hammoniacum, and free from all ligneous substances. Still, however, it is sometimes adulterated with beans, or with sacopenium. ${ }^{82}$ If ignited in a pure state, it has the property of driving away serpents ${ }^{83}$ by its smoke. It is sold at five denarii per pound, and is only employed for medicinal purposes.

\section{CHAP. 57. (26.)-PANAX.}

Syria, too, furnishes panax ${ }^{84}$ an ingredient used in unguents. This plant grows also at Psophis in Arcadia, about the sources of the Erymanthus, in Africa also, and in Macedonia. This is a peculiar kind of giant-fennel, which stands five cubits in height : it first throws out four leaves, and then six, which lie close to the ground, round, and of very considerable size; those, however, which grow towards the top resemble the leaves of the olive. It bears its seed in certain tufts, which hang down, just as in the fennel. The juice is obtained by incisions

81 A shrub of the family of Ombelliferæ, belonging to the genus bubon. It is a native of Asia Minor and Syria.

82 See B. xix. c. 52 , and B. xx. c. 75.

83 This was a common notion with the Romans. Virgil, Georg. B. iii. 1. 415 , says :-

"Galbaneoque agitare graves nidore chelydros."

Though considered to produce a pleasant perfume by the ancients, it is no longer held in estimation for that quality, and is only employed in some slight degree for medical purposes.

84 The produce of the Pastinaca opopanax of Linnæus, or the Panax Copticum of Bauhin, an umbelliferous plant which abounds in the East, and is not uncommon in the south of France. The gum called Opopanax was formerly used, and its supposed virtues are indicated by its name. which signifies " the juice which is the universal remedy." 
made in the stalk at harvest-time, and in the root in autumn. When in a coagulated state, it is esteemed according to its whiteness. The next in value is that of a pallid colour, while the black is held in no esteem. The price of that of the best quality is two denarii per pound.

CHAF. 58.-SPONDYLIUM.

The difference between this kind of giant-fennel and that known as spondylium, ${ }^{85}$ consists only in the leaf, which is smaller, and divided like that of the plane-tree. It grows in shady places only. The seed bears the same name as the plant, and has a strong resemblance to that of hart-wort: it is only employed in medicine.

CHAP. 59.- MALOBATHRUM.

Syria produces the malobathrum ${ }^{86}$ also, a tree which bears a folded leaf, with just the colour of a leaf when dried. From this plant an oil is extracted for unguents. Egypt produces it in still greater abundance; but that which is the most esteemed of all comes from India, where it is said to grow in the marshes like the lentil. It has a more powerful odour than saffron, and has a black, rough appearance, with a sort of brackish taste. The white is the least approved of all, and it very soon turns musty when old. In taste it ought to be similar to nard, when placed under the tongue. When made luke-warm in wine, the odour which it emits is superior to any other. The prices at which this drug ranges are something quite marrellous, being from one denarius to four hundred per pound; as for the leaf, it generally sells at sixty denarii per pound.

CHAP. 60. (27.)-OMPHACIUM.

Omphacium ${ }^{87}$ is also a kind of oil, which is obtained from 85 The umbelliferous plant known as the Heracleum spondylium of Linnæus. It is commonly found in France, where it is called Berce-brancursine. It received its name from the resemblance of its smell to that of the sphondyle, a fetid kind of wood-beetle.

${ }^{86}$ Some suppose this tree to be the Laurus cassia of Linnæus, or wild cinnamon; others take it for the betel, the Piper betel of Linnæus. Clusius thinks that the name is derived from the Indian Tamalpatra, the name given from time immemorial to the leaf of a tree known by the Arabs as the Cadegi-indi, possibly the same as the Katou-carua of the Malabars.

${ }^{87}$ From the Greek $\dot{\delta} \mu \phi a ́ k \iota \nu \nu$, being made of unripe grapes. As Fée 
two trees, the olive and the vine, by two different methods. It is produced from the former by pressing the olive while it is still in the white state. That is of an inferior quality which is made from the druppa-such being the name that is given to the olive before it is ripe and fit for food, but already beginning to change its colour. The difference between them is, that the latter kind is green, the former white. The omphacium that is made from the vine is extracted from either the psythian $^{88}$ or the Aminean grape, when the grapes are about the size of a chick-pea, just before the rising of the Dogstar. The grape is gathered when the first bloom is appearing upon it, and the verjuice is extracted, after which the residue ${ }^{9}$ is left to dry in the sun, due precautions being taken against the dews of the night. The verjuice, after being collected, is put into earthen vessels, and then, after that, stored in jars of Cyprian copper. ${ }^{90}$ The best kind is that which is of a reddish colour, acrid, and dry to the taste. The price at which it sells is six denarii per pound. Omphacium is also made another way - the unripe grape is pounded in a mortar, after which it is dried in the sun, and then divided into lozenges.

\section{CHAP. 61. (28.) -BRYON, cENANTHE, AND MaSSARIS.}

Bryon ${ }^{91}$ also bears an affinity to these substances, being the clusters of berries produced by the white poplar. The best kinds grow in the vicinity of Cnidos, or in Caria, in spots that are destitute of water, or else in dry and rugged localities. A

remarks, that made from the olive is correctly described as a kind of oil, but that made from the grape must have been a rob, or pure verjuice. These two liquids must have had totally different qualities, and resembled each other in nothing but the name. 'That extracted from the olive is mentioned again in B. xxiii. c. 4, in reference to its medicinal properties.

88 These grapes are described in B. xiv. c. 4 and c. 11.

89 "Reliquum corpus." It is not clear what is the meaning of this. The passage is either in a corrupt state, or defective.

90 A singular metal, one would think, for keeping verjuice in.

${ }^{91}$ From the Greek $\beta$ ov́ov, "moss." He speaks again of these grapes of the white poplar in B. xxiv. c. 34 ; also in c. 51 of the present Book. Hardouin thinks that he is speaking of moss. Fée is of opinion, that the blossoms or buds of the tree are meant, which have a fragrant smell. This is the more probable, as we find Pliny here speaking of the œnanthe, or vineflower, by which Fée supposes that he means the blossom of the Vitis vinifera of Linnæus, which exhales a delightful periune. 
bryon of second-rate quality is produced from the cedar of Lycia. ${ }^{92}$ Enanthe, too, bears an affinity to these substances, being the clusters of the wild vine: it is gathered when it is in flower, or, in other words, when it has the finest smell: after which it is dried in the shade upon a linen sheet spread. beneath it, and then stored away in casks. The best sort is that which comes from Parapotamia $;{ }^{93}$ the next best kinds are those made at Antiochia and Laodicea in Syria; and that of third-rate quality, comes from the mountainous parts of Media ; this last, however, is preferable for medicinal purposes. Some persons give the preference over all to that grown in the island of Cyprus. As to that which comes from Africa, it is solely used for medicinal purposes, being known by the name of massaris. ${ }^{94}$ Whatever country it may happen to be, the white wild vine produces an œnanthe of superior quality to the black.

\section{CHAP. 62.- ELATE OR SPATHE.}

There is another tree ${ }^{95}$ also, that contributes to the manufacture of unguents, by some persons known under the name of elate, but which we call abies; others again call it a palm, and others give it the name of spathe. That of Hammonium. is the most esteemed, and that of Egypt next, after which comes the Syrian tree. It is only odoriferous, however, in places that are destitute of water. The tears of it are of an unctuous nature, and are employed as an ingredient in unguents, to modify the harshness of the oil.

\section{CHaP. 63. - CINNAMON OR COMaCUM.}

In Syria, too, is produced that kind of cinnamon which is also known as comacum. ${ }^{96}$ This is a juice which is extracted from

${ }^{92}$ The bud, probably, of the Juniperus Lycia.

${ }_{93}$ See B. vi. c. 31 . chus.

${ }^{94}$ Said to have been a surname given by some nations to the god Bac-

${ }^{95}$ It is generally supposed by the commentators, that Pliny makes a mistake here, and that the elate or spathe was not a tree, but the envelope or capsule, containing the flowers and fruit of a tree, which is supposed by some to have been really the Phœnix dactylifera, or date-paln. There ean be little doubt that he is mistaken in his mention of the abies or firtree here. See B. xxiii. c. 53 .

${ }^{96}$ Bauhin thinks that this juice or oil was extracted from the nutmeg, 
a nut, and very different from the extract of the real cinnamomum, though it somewhat resembles it in its agreeable smell. The price at which it sells is forty asses per pound.

Somma,Ry.-Remarkable facts, narratives, and observations, nine hundred and seventy-four.

Roman aUthors QUOTED.-M. Varro, ${ }^{1}$. Mucianus, ${ }^{2}$ Virgil, ${ }^{3}$ Fabianus, ${ }^{4}$ Sebosus, ${ }^{5}$ Pomponius Mela, ${ }^{6}$ Flavius, ${ }^{7}$ Procilius, ${ }^{8}$ Hyginus, ${ }^{9}$ Trogus, ${ }^{10}$ Claudius Cæsar, ${ }^{11}$ Cornelius Nepos, ${ }^{12}$ Sextus Niger $^{13}$ who wrote a Greek treatise on Medicine, Cassius Hemina, ${ }^{14}$ L. Piso, ${ }^{15}$ Tuditanus, ${ }^{16}$ Antias. ${ }^{17}$

\section{Foretgn authors Quoted.-Theophrastus, ${ }^{18}$ Herodotus, ${ }^{19}$ Cal-}

the Myristica moschata of Thunberg, and Bonastre is of the same opinion. But, as Fée observes, the nutmeg is a native of India, and Pliny speaks of the Comacum as coming from Syria. Some authors, he adds, who are of this opinion, think also that the other cinnamomum mentioned by Pliny was no other than the nutmeg, which they take to be the same as the chrysobalanos, or "golden nut," of Galen.

${ }_{1}$ See end of B. ii. 2 See end of B. ii.

3 See end of B. vii.

4 Fabianus Papirius : see end of B. ii.

5 See end of B. ii.

6 See end of B. iii.

7 The son of a freedman; some further particulars are given of him by Pliny in B. xxxiii. c. 1. By his talents and eloquence, he attained considerable distinction at Rome. He was made a senator by Appius Claudius, and was curule ædile B.c. 303 . He published a collection of legal rules, cntitled the "Jus Flavianum."

8 See end of $B$. viii.

10 See end of B. vii.

12 See end of B. ii.

9 See end of B. iii.

11 See end of B. v.

13 Probably the same as the Niger mentioned by Dioscorides as a writer on Materia Medica. He is also mentioned by Epiphanius and Galen; but Dioscorides charges him with numerous blunders in his accounts of vegetable productions.

14 A compiler of Roman history, who wrote at the beginning of the second century before Christ. He wrote Annals of Rome from the earliest to his own times: only a few fragments of his work have survived.

15 See end of B. ii.

16 C. Sempronius Tuditanus, consul of Rome, B.c 129. He wrote a book of historical Commentaries. He was maternal grandfather of the orator Hortensius.

17 See end of B. ii.

19 See end of B. ii.

18 See end of B. iii. 
listhenes, ${ }^{20}$ Isigonus, ${ }^{21}$ Clitarchus, ${ }^{22}$ Anaximenes, ${ }^{23}$ Duris, ${ }^{24}$ Nearchus, ${ }^{25}$ Onesicritus, ${ }^{26}$ Polycritus, ${ }^{27}$ Olympiodorus, ${ }^{28}$ Diognetus, ${ }^{29}$ Nicobulus, ${ }^{30}$ Anticlides, ${ }^{31}$ Chare ${ }^{32}$ of Mitylene, Menæchmus, ${ }^{33}$ Dorotheus ${ }^{34}$ of Athens, Lycus ${ }^{35}$ Antæus ${ }^{36}$ Ephippus, ${ }^{37}$ Dion, ${ }^{38}$ Demodes, ${ }^{39}$ Ptolemy Lagus, ${ }^{40}$ Marsyas ${ }^{41}$ of Macedon,

20 A native of Olynthus. His mother, Hero, was a cousin of the philosopher Aristotle, under whose tutelage he was educated. It is generally supposed that he was put to death by order of Alexander the Great, but in what manner is a matter of uncertainty. He wrote a History of Greece, and numerous other learned works. Some MSS. are still extant, professing to be his writings; but they are generally looked upon as spurious.

21 See end of B. vii. $\quad{ }_{22}$ See end of B. vii.

${ }^{23}$ A native of Lampsacus, and disciple of Diogenes the Cynic. He accompanied Alexander the Great in his Asiatic expedition. He wrote a history of the reigns of Philip and Alexander, and a history of Greece, in twelve books. Only a few fragments of his works are left.

24 See end of B. vii. 25 See end of B. vi.

26 See end of B. ii.

- 'There was a native of Mendæ, in Sicily, of this name, who wrote a history of Dionysius, the tyrant of Syracuse. It was, probably, a different person of this name who wrote a work on the East; if such is the case, Pliny most probably quotes from the work of the latter.

${ }_{28}$ Nothing seems to be known of this writer; but it is suggested that he may have accompanied Nearchus and Onesicritus in the East.

29 See end of $\mathrm{B}$. vi.

30 Nothing is known of him; but Hardouin suggests that he may have accompanied Alexander the Great in his Eastern expedition.

31 See end of B. iv.

32 An officer at the court of Alexander the Great, who wrote a collection of anecdotes respecting the private life and reign of that emperor, some fragments of which are preserved by Athenæus.

${ }^{33}$ See end of B. iv.

${ }^{34} \mathrm{He}$ is supposed to have been the same with the person of that name who wrote a history of Alexander the Great; but nothing further is known of him.

${ }_{35}$ A physician of Neapolis, who is supposed to have lived in the early part of the first century after Christ.

${ }^{36}$ A writer on medicine, of whom all further particulars have perished.

${ }^{37}$ Possibly Ephippus of Olynthus, a Greek historian of the reign of Alexander the Great.

${ }^{38}$ See end of B. viii.

39 An ancient Greek historian, mentioned also by Strabo ; but no further particulars are known of him.

${ }^{40}$ The founder of the dynasty of the Egyptian Ptolemies, which ended in Cleopatra, B.c. 38 : he wrote a narrative of the wars of Alexander, which is frequently quoted by the later writers, and served as the groundwork for Arrian's history.

41 A native of Pella, who wrote a history of Macedonia down to the 
Zoilus $^{42}$ of Macedon, Democritus, ${ }^{43}$ Amphilochus, ${ }^{44}$ Aristomachus, ${ }^{45}$ Alexander Polyhistor, ${ }^{46}$ Juba, ${ }^{47}$ Apollodorus ${ }^{48}$ who wrote on Perfumes, Heraclides ${ }^{49}$ the physician, Archidemus ${ }^{50}$ the physician, Dionysius ${ }^{51}$ the physician, Democlides ${ }^{52}$ the physician, Euphron ${ }^{53}$ the physician, Mnesides ${ }^{51}$ the physician, Diagoras $^{55}$ the physician, Iollas ${ }^{56}$ the physician, Heraclides ${ }^{37}$ of Tarentum, Xenocrates ${ }^{58}$ of Ephesus, Eratosthenes. ${ }^{59}$

wars of Alexander the Great. There was another writer of the same name, a native of Philippi, who also wrote a treatise, either geographical or historical, relative to Macedonia.

42 A native of Amphipolis, though some make him to have been an Ephesian. The age in which he lived is not exactly known. He attacked the writings of Homer with such uncalled-for asperity, that his name has been proverbial for a snarling, captious critic. He is said to have met with a violent death. His literary productions were numerous, but none of them have come down to us.
43 See end of B. ii.
45 See end of B. xi.
47 See end of B. $\mathrm{v}$.
44 See end of B. viii.
46 See end of B. iii.
48 See end of B. xi.

49 A physician of Heraclea, near Ephesus. He wrote commentaries on the works of Hippocrates.

50 Nothing is known of him; but it has been suggested that he may have been the author of a few fragments on veterinary surgery which still exist.

51 There were many physicians and surgeons of this name, but probably Dionysius of Samos is meant, or else Sallustius Dionysius, quoted by Pliny, B. xxxii. c. 26.

${ }_{52}$ Also called Democedes, a physician of Crotona, who practised at AEgina. He was afterwards physician to Polycrates, the tyrant of Samos, and King Darius, whose foot he cured. His work on medicine has perished.

53 Nothing whatever is known of this writer.

${ }^{54}$ Nothing is known relative to this writer.

55 Nothing is known of him.

56 Or Iölaus, a native of Bithynia, who wrote a work on Materia Medica. He was probably a contemporary of Heraclides of Tarentum, in the third century B.c.

${ }_{57}$ A plysician of Tarentum, who belonged to the Empiric sect. $\mathrm{He}$ wrote several medical works, and is highly commended by Galen. Only a few fragments of his writings remain.

is An historical and geographical writer, frequently quoted by Pliny. From the mention made of him in B. xxxvii. c. 2, it would appear that be flourished during the time of Pliny, or very shortly before.

59 See end of $\mathrm{B}$. ii. 


\section{BOOK XIII.}

\section{THE NATURAL HISTORY OF EXOTIC TREES, AND AN ACCOUNT OF UNGUENTS.}

ChaP. 1. (1.) - UNGUENTS-AT WHAT PERIOD THEY WERE FIRST INTRODUCED.

Thus far we have been speaking of the trees which are valuable for the odours they produce, and each of which is a subject for our wonder in itself. Luxury, however, has thought fit to mingle all of these, and to make a single odour of the whole; hence it is that unguents have been invented. ${ }^{1}$ Who was the first to make unguents is a fact not recorded. In the times of the Trojan war they did not exist, nor did they use incense when sacrificing to the gods; indeed, people knew of no other smell, or rather stench, ${ }^{3}$ I may say, than that of the cedar and the citrus, ${ }^{4}$ shrubs of their own growth, as it arose in volumes of smoke from the sacrifices; still, however, even then, the extract of roses was known, for we find it mentioned as conferring additional value on olive-oil.

We ought, by good rights, to ascribe the first use of unguents to the Persians, for they quite soak themselves in it, and so, by an adventitious recommendation, counteract the bad odours which are produced by dirt. The first instance of the use of unguents that I have been able to meet with is that of the chest ${ }^{5}$ of perfumes which fell into the hands of Alexander, with the rest of the property of King Darius, at the taking of his

1 Fée remarks, that most of the unguents and perfumes of which Pliny here speaks would find but little favour at the present day.

2 This does not appear to be exactly the case, for in the twenty-third Book of the Iliad, l. 1.86, we find "rose-scented" oil mentioned, indeed, Pliny himself alludes to it a little further on.

3 "Nidorem." This term was used in reference to the smell of burnt or roasted animal substances. It is not improbable that he alludes to the stench arising from the burnt sacrifices.

4 The "Thuya articulata." See c. 29 of the present Book.

5 "Scrinium." See B. vii. c. 30 . 
camp. ${ }^{6}$ Since those times this luxury has been adopted by our own countrymen as well, among the most prized and, indeed, the most elegant of all the enjoyments of life, and has begun even to be admitted in the list of honours paid to the dead; for which reason we shall have to enlarge further on that subject. Those perfumes which are not the produce of shrubs ${ }^{7}$ will only be mentioned for the present by name: the nature of them will, however, be stated in their appropriate places.

\section{CHAP. 2.-THE VARIOUS KINDS OF UNGUENTS-TWELVE PRIN-} CIPAL COMPOSITIONS.

The names of unguents are due, some of them, to the original place of their composition, others, again, to the extracts which form their bases, others to the trees from which they are derived, and others to the peculiar circumstance under which they were first made : and it is as well, first of all, to know that in this respect the fashion has often changed, and that the high repute of peculiar kinds has been but transitory. In ancient times, the perfumes the most esteemed of all were those of the island of Delos, ${ }^{8}$ and at a later period those of Mendes. ${ }^{9}$ This degree of esteem is founded, not only on the mode of mixing them and the relative proportions, but according to the degree of favour or disfavour in which the various places which produce the ingredients are held, and the comparative excellence or degeneracy of the ingredients themselves. The perfume of iris, ${ }^{10}$ from Corinth, was long held in the highest esteem, till that of Cyzicus came into fashion. It was the same, too, with the perfume of roses, ${ }^{11}$ from Phaselis, ${ }^{12}$ the

6 The use of perfumes more probably originated in India, than among the Persians.

7 But of seeds or plants

8 The perfumes of Delos themselves had nothing in particular to recommend them; but as it was the centre of the worship of Apollo, it is not improbable that exquisite perfumes formed a large proportion of the offerings brought thither from all parts of the world.

9 In Egypt. See B. v. c. 11. The unguents of Mendes are again mentioned in the present Chapter.

10 Or flower-de-luce. This perfume was called Irinum. The Iris Florentina of the botanists, Fée says, has the smell of the violet. For the composition of this perfune, see Dioscorides, B. i. c. 67 .

1 Rhodinum. 12 See B. v. c. 26. 
repute of which was afterwards eclipsed by those of Neapolis, Capua, and Præneste. Oil of saffron, ${ }^{13}$ from Soli in Cilicia, was for a long time held in repute beyond any other, and then that from Rhodes ; after which perfume of œnanthe, ${ }^{14}$ from $\mathrm{Cy}$ prus, came into fashion, and then that of Egypt was preferred. At a later period that of Adramytteum came into vogue, and then was supplanted by unguent of marjoram, ${ }^{15}$ from $\mathrm{Cos}$, which in its turn was superseded by quince blossom ${ }^{16}$ unguent from the same place. As to perfume of cyprus, ${ }^{17}$ that from the island of Cyprus was at first preferred, and then that of Egypt; when all on a sudden the unguents of Mendes and metopium ${ }^{18}$ rose into esteem. In later times Phœnicia eclipsed Egypt in the manufacture of these last two, but left to that country the repute of producing the best unguent of cyprus.

Athens has perseveringly maintained the repute of her panathenaicon. ${ }^{19}$ There was formerly a famous unguent, known as "pardalium," ${ }^{20}$ and made at Tarsus; at the present day its very composition and the mode of mixing it are quite unknown there: they have left off, too, making unguent of narcissus ${ }^{21}$ from the flowers of that plant.

There are two elements which enter into the composition of unguents, the juices and the solid parts. The former generally consist of various kinds of oils, the latter of odoriferous substances. These last are known as hedysmata, while the oils are called stymmata. ${ }^{22}$ There is a third element, which occu-

13 Crocinum; made from the Crocus sativus of naturalists.

14 See B. xii. c. 62 . It was made from the flowers of the vine, mixed with omphacium.

is Amaracinum. The amaracus is supposed to have been the Origanum majoranoides of the moderns. Dioscorides, B. i. c. 59, says that the best was made at Cyzicus.

16 Melinum. See B. xxiii. c. 54.

17 Cyprinum. See B. xii. c. 51. The cyprus was the modern Lawsonia inermis.

18 Made from the oil of bitter almonds. See B. xv. c. 7.

19 Or "all Athenian." Wo find in Athenæus, B. xv. c. 15, the composition of this unguent.

${ }^{20}$ From what is said by Apollonius in the passage of Athenæus last quoted, it has been thought that this was the same as the unguent called nardinum. It is very doubtful, however.

${ }^{21}$ Narcissinum. See B. xxi. c. 75. Dioscorides gives the composition of this unguent, B. i. c. 54 .

22 Among the stymmata, Dioscorides ranges the sweet-rush, the sweetvoL. III. 
pies a place between the two, but has been much neglected, the colouring matter, namely. To produce a colour, however, cinnabar $^{23}$ and alkanet ${ }^{24}$ are often emploved. If salt ${ }^{25}$ is sprinkled in the oil, it will aid it in retaining its properties; but if alkanet has been employed, salt is never used. Resin and gum are added to fix the odour in the solid perfumes; indeed it is apt to die away and disappear with the greatest rapidity if these substances are not employed.

The unguent which is the most readily prepared of all, and indeed, in all probability, the very first that was ever made, is that composed of bryon ${ }^{26}$ and oil of balanus ${ }^{27}$ substances of which we have made mention already. In later times the Mendesian unguent was invented, a more complicated mixture, as resin and myrrh were added to oil of balanus, and at the present day they even add metopion ${ }^{28}$ as well, an Egyptian oil extracted from bitter almonds; to which have been added omphacium, ${ }^{29}$ cardamum, ${ }^{30}$ sweet rush, ${ }^{31}$ honey, ${ }^{32}$ wine, myrrh, seed of balsamum, ${ }^{33}$ galbanum, ${ }^{34}$ and resin of terebinth,,$^{35}$ as so many ingredients. Among the most common unguents at the present day, and for that reason supposed to be the most ancient, is that composed of oil of myrtle, ${ }^{36}$ calamus, cypress ${ }^{37}$ cyprus, mastich ${ }^{38}$ and pomegranate-rind. ${ }^{39}$ I am scented calamus and xylo-balsamum; and among the hedysmata amomum, nurd̄, myrrh, balsam, costus, and marjoram. 'The latter constituted the base of unguents, the former were only added occasionally.

${ }^{23}$ Cinnabar is never used to colour cosmetics at the present day, from its tendency to excoriate the skin. See B. xxiii. c. 39 .

${ }^{24}$ This is still used for colouring cosmetics at the present day. See B. xxii. c. 23.

${ }^{25}$ Fée remarks, that salt can be of no use ; but by falling to the bottom without dissolving, would rather tend to spoil the unguent.

26 See B. xii. c. 60. The name "bryon" seems also to have been extended to the buds of various trees of the Conifera class and of the white poplar. It is probably to the buds of the last tree that Pliny here alludes. $\quad 27$ Oil of ben. See B. xii. c. 48 .

zs Or metopium. See Note 18 above.

29 Made from olives. See B. xii. c. 60 .

30 See B. xii. c. 29.

31 The modern Andropogon schœnanthus. See B. xii. c. 48 .

32 See B. xii. c. $48 . \quad{ }^{33}$ Carpobalsamum. See. B. xii, c. 54.

${ }^{34}$ See B. xii. c. 56 .

35 Fluid resin of coniferous trees of Europe.

:6 6 See B. xv. c. 35.

${ }^{37}$ Cupressus semper-virens. He does not say what part of the tree was employed.

${ }^{38}$ See B. xii. c. 36 .

${ }^{39}$ See c. 34 of the present Book. 
of opinion, however, that the unguents which have been the most universally adopted, are those which are compounded of the rose, a flower that grows everywhere; and hence for a long time the composition of oil of roses was of the most simple nature, though more recently there have been added omphacium, rose blossoms, cinnabar, calamus, honey, sweetrush, flour of salt or else alkanet, ${ }^{40}$ and wine. The same is the case, too, with oil of saffron, to which have been lately added cinnabar, alkanet, and wine; and with oil of sampsuchum, ${ }^{41}$ with which omphacium and calamus have been compounded. The best comes from Cyprus and Mitylene, where sampsuchum abounds in large quantities.

The commoner kinds of oil, too, are mixed with those of myrrh and laurel, to which are added sampsuchum, lilies, fenugreek, myrrh, cassia, ${ }^{42}$ nard, ${ }^{43}$ sweet-rush, and cinnamon. ${ }^{44}$ There is an oil, too, made of the common quince and the sparrow quince, called melinum, as we shall have occasion to mention hereafter $;^{45}$ it is used as an ingredient in unguents, mixed with omphacium, oil of cyprus, oil of sesamum ${ }^{46}$ balsamum, ${ }^{47}$ sweet-rush, cassia, and abrotonum. ${ }^{48}$ Susinum ${ }^{49}$ is the most fluid of them all : it is made of lilies, oil. of balanus, calamus, honey, cinnamon, saffron, ${ }^{50}$ and myrrh; while the unguent of cyprus ${ }^{51}$ is compounded of cyprus, omphacium

40 The alkanet and cinnabar were only used for colouring.

41 "Sampsuchinum." It is generally supposed that the sampsuchum, and the amaracus were the same, the sweet marjoram, or Origanum marjorana of Linnæus. Fée, however, is of a contrary opinion, See B. xxi. c. 35 . In Dioscorides, B. i. c. 59, there is a difference made between sampsuchinum and amaracinum, though but a very slight one.

${ }_{42}$ The bark of the Cassia lignea of the pharmacopœa, the Laurus cassia of botany. See B. xii. c. 43 .

${ }_{43}$ See B. xii. c. 26 . The Andropogon nardus of Linnæus.

44 See B. xii. c. 41 .

45 See B. xxiii. c. 54 , also B. xv. c. 10 . The Malum struthium, or "sparrow quince," was an oblong variety of the fruit. c. 54 .

${ }_{46}$ Sesamum orientale of Linnæus. See B. xviii. c. 22, and B. xxii.

${ }^{47}$ Balm of Gilead. See B. xii. c. 54 .

48 Southernwood. The Artemisia abrotonum of Linnæus.

49 Or lily unguent, made of the lily of Susa, which had probably a more powerful smell than that of Europe. Dioscorides gives its composition, B. i. c. 63.

${ }^{50}$ The Crocus sativus of Linnæus.

${ }^{51}$ Cyprinim. It has been previously mentioned in this Chapter. 
and cardamum, calamus, aspalathus, ${ }^{52}$ and abrotonum. There are some persons who, when making unguent of cyprus, employ myrrh also, and panax: $:^{53}$ the best is that made at Sidon, and the next best that of Egypt: care must be taken not to add oil of sesamum : it will keep as long as four years, and its odour is strergthened by the addition of cinnamon. Telinum ${ }^{5 *}$ is made of fresh olive-oil, cypirus, ${ }^{55}$ calamus, melilote, ${ }^{56}$ fenugreek, honey, marum, ${ }^{57}$ and sweet marjoram. This last was the perfume most in vogue in the time of the Comic poet Nenander: a considerable time after that known as "megalium" took its place, being so called as holding the very highest rank; $;^{58}$ it was composed of oil of balanus, balsamum, calamus, sweet-rush, xylobalsamum, ${ }^{59}$ cassia, and resin. One peculiar property of this unguent is, that it requires to be constantly stirred while boiling, until it has lost all smell: when it becomes cold, it recovers its odour. ${ }^{60}$

There are some single essences also which, individually, afford unguents of very high character: the first rank is due to malobathrum, ${ }^{61}$ and the next to the iris of Illyricum and the sweet marjoram of Cyzicus, both of them herbs. There are perfumers who sometimes add some few other ingredients to these: those who use the most, employ for the purpose honey, flour of salt, omphacium, leaves of agnus, ${ }^{62}$ and panax, all of them foreign ingredients..$^{63}$ The price of unguent ${ }^{64}$ of

52 See B. xii. c. 52.

${ }_{53}$ The gum resin of the Pastinaca opopanax of Linnæus. See B. xii. c. 57 .

${ }^{54} \mathrm{Or}$ unguent of fenugreek, from the Greek $\tau \tilde{\eta} \lambda \iota_{c}$, meaning that plant, the Trigonella fœnum Græcum of Iinnæus. See B. xxiv. c. 120.

55 See B. ii. c. 26 , and B. xxi. c. $68-70$.

56 The Trifolium melilotus of Linnæus. See B. xxi. c. 30 .

57 See B. xii. c. 53.

$58 \mathrm{He}$ would imply that it was so called from the Greek $\mu \varepsilon \gamma \dot{\mathrm{r}} \mathrm{s}$, " great;" but it was more generally said that it received its name from its inventor, Megalus.

59 See B. xii. c. 5 .

60 Fée does not appear to credit this statement. By the use of the word "ventiletur," "fanned" may be possibly implied.

61 See B. xii. c. 59.

62 The Agnus castus of Linnæus. See B. xxiv. c. 38 . The leaves are quite inodorous, though the fruit of this plant is slightly aromatic.

${ }^{63}$ "Externa." The reading is doubtful, and it is difficuit to say what is the exact meaning of the word.

;4 Cinnamomino. 
cinnamon is quite enormous; to cinnamon there is added oii of balanus, xylobalsamum, calamus, sweet-rusb, seeds of balsamum, myrrh, and perfumed honey: it is the thickest in consistency of all the unguents; the price at which it sells ranges from thirty-five to three hundred denarii per pound. Unguent of nard, ${ }^{66}$ or foliatum, is composed of omphacium or else oil of balanus, sweet-rush, costus, ${ }^{67}$ nard, amomum, ${ }^{68}$ myrrh, and balsamum.

While speaking on this subject, it will be as well to bear in mind that there are nine different kinds of plants of a similar kind, of which we have already made mention ${ }^{69}$ as being employed for the purpose of imitating Indian nard; so abundant are the materials that are afforded for adulteration. All these perfumes are rendered still more pungent by the addition of costus and amomum, which have a particularly powerful effect on the olfactory organs; while myrrh gives them greater consistency and additional sweetness, and saffron makes them better adapted for medicinal purposes. They are most pungent, however, when mixed with amomum alone, which will often produce head-ache even. There are some persons who content themselves with sprinkling the more precious ingredients upon the others after boiling them down, for the purpose of economy; but the strength of the unguent is not so great as when the ingredients have been boiled together. Myrrh used by itself, and without the mixture of oil, forms an unguent, but it is stacte ${ }^{70}$ only that must be used, for otherwise it will be productive of too great bitterness. Unguent of cyprus turns other unguents green, while lily unguent ${ }^{71}$ makes them more unctuous: the unguent of Mendes turns them black, rose unguent makes them white, and that of myrrh of a pallid hue.

Such are the particulars of the ancient inventions, and the various falsifications of the shops in later times; we will now pass on to make mention of what is the very height of refinement in these articles of luxury, indeed, I may say, the beau ideal ${ }^{72}$ of them all.

65 Nardinum.

66 Or leaf unguent, so called from being made of leaves of nard. See B. xii. c. 27 .

67 See B, xii. c. 25.

68 See B. xii. c. 28.

69 See B. xii. c. 26,27 , where the list is given.

70 See B. xii. c. 35 .

72 Summa auctoritas rei.

${ }^{71}$ Susinum. See p. 163. 
(2.) This is what is called the "regal" unguent, from the fact that it is composed in these proportions for the kings of the Parthians. It consists of myrobalanus, ${ }^{73}$ costus, amomum, cinnamon, comacum, ${ }^{74}$ cardamum, spikenard, marum, myrrh, cassia, storax ${ }^{75}$ ladanum, ${ }^{76}$ opobalsamum, Syrian calamus ${ }^{77}$ and Syrian sweet-rush, ${ }^{7 \varnothing}$ œnanthe, malobathrum, serichatum, ${ }^{79}$ cyprus, aspralathus, panax, saffron, cypirus, sweet marjoram, lotus, ${ }^{80}$ honey, and wine. Not one of the ingredients in this compound is produced either in Italy, that conqueror of the world, or, indeed, in all Europe, with the exception of the iris, which grows in Illyricum, and the nard, which is to be found in Gaul: as to the wine, the rose, the leaves of myrtle, and the olive-oil, they are possessed by pretty nearly all countries in common.

CHAP. 3.-DIAPASMA, MAGMA; THE MODE OF TESTING UNGUENTS.

Those unguents which are known by the name of "diapasma," 81 are composed of dried perfumes. The lees ${ }^{82}$ of unguents are known by the name of "magma. ${ }^{83}$ " In all these preparations the most powerful perfume is the one that is added the last of all. Unguents keep best in boxes of alabaster, ${ }^{84}$ and perfumes ${ }^{85}$ when mixed with oil, which conduces all the more to their durability the thicker it is, such as the oil of almonds, for instance. Unguents, too, improve with age; but the sun is apt to spoil them, for which reason they are usualiy stowed away in a shady place in vessels of lead. When their goodness is being tested, they are placed on the back of the hand, lest the heat of the palm, which is more fleshy, should have a bad effect upon them.

73 See B. xii. c. 46.

75 See B. xii. c. 55 .

77 See B. xii. c. 48 .

79 See B. xii. c. 45 .

80 Fée suggests that this may be the Nymphæa cœrulea of Savigny, a plant that is common in the Nile, and the flowers of which exhale a sweet odour.

81 The diapasmata were dry, odoriferous powders, similar to those used at the present day in sachets and scent-bags.

82 "Fæcem unguenti."

83 This word is still used in pharmacy to denote the husks or residuary matter left after the extraction of the juice.

st See B. xxxvi. c. 12. See also Mark xiv. 7, and John xii. 3. Leaden boxes were also used for a similar purpose.

85 Odores. 
CHAP. 4. (3.) -THE EXCESSES TO WHICH LUXURY HAS RUN IN UNGUENTS.

These perfumes form the objects of a luxury which may be looked upon as being the most superfluous of any, for pearis and jewels, after all, do pass to a man's representative, ${ }^{86}$ and garments have some durability; but unguents lose their odour in an instant, and die away the very hour they are used. The very highest recommendation of them is, that when a female passes by, the odour which proceeds from her may possibly attract the attention of those even who till then are intent upon something else. In price they exceed so large a sum even as four hundred denarii per pound: so vast is the amount that is paid for a luxury made not for our own enjoy: ment, but for that of others; for the person who carries the perfume about him is not the one, after all, that smells it.

And yet, even here, there are some points of difference that deserve to be remarked. We read in the works of Cicero, ${ }^{87}$ that those unguents which smell of the earth are preferable to. those which smell of saffron; being a proof, that even in a matter which most strikingly bespeaks our state of extreme corruptness, it is thought as well to temper the vice by a little show of austerity. ${ }^{88}$ There are some persons too who look more particularly for consistency ${ }^{89}$ in their unguents, to which they accordingly give the name of "spissum $; ;^{89 *}$ thus showing that they love not only to be sprinkled, but even to be plastered over, with unguents. We have known the very soles ${ }^{90}$ even of the feet to be sprinkled with perfumes; a refinement which was taught, it is said, by M. Otho ${ }^{91}$ to the Emperor Nero. How,

86 "Heres." The person was so called who succeeded to the property; whether real or personal, of an intestate.

${ }_{87}$ See B. xvii. c. 3, where he quotes this passage from Cicero at length. It appears to be from De Orat. B. iii. c. 69. Both Cicero and Pliny profess to find a smell that arises from the earth itself, through the agency of the sun. But, as Fée remarks, pure earth is perfectly inodorous. He suggests, however, that this odour attributed by the ancients to the earth, may in reality have proceeded from the fibrous roots of thyme and other plants. If such is not the real solution, it seems impossible to suggest any other.

88 By giving preference to the more simple odours.

89 "Crassitudo."

sg* Or "thick" unguent.

90 We learn from Athenæus, and a passage in the Aulularia of Plautus, that this was done long before Nero's time, among the Greeks.

${ }_{91}$ Who succeeded Galba. He was one of Nero's favourite companions in his debaucheries. 
I should like to know, could a perfume be at all perceptible, or, indeed, productive of any kind of pleasure, when placed on that part of the body? We have heard also of a private person giving orders for the walls of the bath-room to be sprinkled with unguents, while the Emperor Caius ${ }^{92}$ had the same thing done to his sitting-bath : ${ }^{93}$ that this, too, might not be looked upon as the peculiar privilege of a prince, it was afterwards done by one of the slaves that belonged to Nero.

But the most wonderful thing of all is, that this kind of luxurious gratification should have made its way into the camp even : at all events, the eagles and the standards, dusty as they are, and bristling with their sharpened points, are anointed on festive ${ }^{91}$ days. I only wish it could, by any possibility, be stated who it was that first taught us this practice. It was, no doubt, under the corrupting influence of such temptations as these, that our eagles achieved the conquest ${ }^{95}$ of the world : thus do we seek to obtain their patronage and sanction for our vices, and make them our precedent for using unguents even beneath the casque. ${ }^{96}$

\section{CHAP. 5.-WHEN UNGUENTS WERE FIRST USED BY THE ROMANS.}

I cannot exactly say at what period the use of unguents first found its way to Rome. It is a well-known fact, that when King Antiochus and Asia ${ }^{97}$ were subdued, an edict was published in the year of the City 565, in the censorship of P. Licinius Crassus and L. Julius Cæsar, forbidding any one to sell exotics $;{ }^{98}$ for by that name unguents were then called. But, in the name of Hercules! at the present day, there are some persons who even go so far as to put them in their drink, and the bitterness produced thereby is prized to a high degree, in order that by their lavishness on these odours they may thus gratify the senses of two parts ${ }^{99}$ of the body at the same moment. ${ }^{1}$ It is a well-known historical fact, that L. Plotius, ${ }^{2}$

92 Caligula. ${ }^{93}$ Solium.

94 After victories, for instance, or when marching orders were given.

95 This is said in bitter irony.

97 Asia Minor more particularly. 96 Sub casside.

99 The organs of taste and of smell.

1 We have this fact alluded to in the works of Plautus, Juvenal, Martial, and A2lian. The Greeks were particularly fond of mixing myrrh with their wine. Nard wine is also mentioned by Plautus. Miles Gl. iii. 2, 11. 2 Or Lucius Plautius Plancus. $\mathrm{He}$ was proscribed by the triumvirs, 
the brother of L. Plancus, who was twice consul and censor, after being proscribed by the Triumvirs, was betrayed in his place of concealment at Salernum by the smell of his unguents, a disgrace which more than outweighed all the guilt ${ }^{3}$ attending his proscription. For who is there that can be of opinion that such men as this do not richly deserve to come to a violent end?

\section{CHAP. 6. -THE PALM-TREE.}

In other respects, Egypt is the country that is the best suited of all for the production of unguents; and next to it, Campania, ${ }^{4}$ from its abundance of roses.

(4.) Judæa, too, is greatly renowned for its perfumes, and even still more so for its palm-trees, ${ }^{5}$ the nature of which I shall take this opportunity of enlarging upon. There are some found in Europe also. 'They are not uncommon in Italy, but are quite barren there. ${ }^{6}$ The palms on the coast of Spain bear fruit, but it is sour. ${ }^{7}$ The fruit of those of Africa is sweet, but quickly becomes vapid and loses its flavour; which, however is not the case with the fruit of those that grow in the East. ${ }^{8}$ From these trees a wine is made, and bread by some nations, ${ }^{9}$ and they afford an aliment for numerous quadrupeds. It will be with very fair reason then, that we shall confine our description to the palm-tree of foreign countries. There are

with the sanction of his brother. In consequence of his use of perfumes, the place of his concealment "got wind ;" and in order to save his slaves, who were being tortured to death because they would not betray him, he voluntarily surrendered himself.

3 Attaching to the triumvirate.

4 Capua, its capital, was the great seat of the unguent and perfume manufacture in Italy.

5 The Phœnix dactylifera of Linnæus. See also B. xii. c. 62, where he seems also to allude to this tree.

${ }^{6}$ At the present day this is not the fact. The village of La Bordighiera, situate on an eminence of the Apennines, grows great quantities of dates, of good quality. At Hieres, Nice, San Remo, and Genoa, they are also grown.

7 This, too, is not the fact. The dates of Valencia, Seville, and other provinces of Spain, are sweet, and of excellent quality.

${ }_{8}$ Pliny is wrong again in this statement. The date of Barbary, Tunis, Algiers, and Bildulgerid, the "land of dates," is superior in every respect to that of the East.

9 The Asthiopians, as we learn from Theophrastus, B. ii. c. 8. 
none in Italy that grow spontaneously, ${ }^{10}$ nor, in fact, in any other part of the world, with the exception of the warm countries : indeed, it is only in the very hottest climates that this tree will bear fruit.

\section{CHAP. 7.-THE NATURE OF THE PALM-TREE.}

The palm-tree grows in a light and sandy soil, and for the most part of a nitrous quality. It loves the vicinity of flowing water; and as it is its nature to imbibe the whole of the year, there are some who are of opinion that in a year of drought it will receive injury from being manured even, if the manure is not first mixed with running water : this, at least, is the idea entertained by some of the Assyrians.

The varieties of the palm are numerous. First of all, there are those which do not exceed the size of a shrub; they are mostly barren, though sometimes they are known to produce fruit; the branches are short, and the tree is well covered with leaves all round. In many places this tree is used as a kind of rough-cast, ${ }^{11}$ as it were, to protect the walls of houses against damp. The palms of greater height form whole forests, the trunk of the tree being protected all round by pointed leaves, which are arranged in the form of a comb; these, it must be understood, are wild palms, though sometimes, by some wayward fancy or other, they are known to make their appearance among the cultivated varieties. The other kinds are tall, round, and tapering; and being furnished with dense and projecting knobs or circles in the bark, arranged in regular gradation, they are found easy of ascent by the people in the East; in order to do which, the climber fastens a loop of osier round his body and the trunk, and by this contrivance ascends the tree with astonishing ${ }^{12}$ rapidity. All the foliage is at the summit, and the fruit as well; this last being situate, not among the leaves, as is the case with other trees, but hanging in clusters from shoots of its own among the branches, and partaking of the nature both of the grape and the apple. The leaves ferminate in a sharp edge, like that of a knife, while the sides are deeply indented-a peculiarity.

10 Or in a wild state.

11 "Tectorii vicem." They were probably planted in rows, close to the wall.

12 This mode of ascending the date-palm is still practised in the East. 
which first gave the idea of a troop of soldiers presenting face on two sides at once; at the present day they are split asunder ${ }^{13}$ to form ropes and wythes for fastening, as well as light umbrellas ${ }^{14}$ for covering the head.

The more diligent ${ }^{15}$ enquirers into the operations of Nature state that all trees, or rather all plants, and other productions of the earth, belong to either one sex or the other; a fact which it may be sufficient to notice on the present occasion, and one which manifests itself in no tree more than in the palm. The male tree blossoms at the shoots; the female buds without blossoming, the bud being very similar to an ear of corn. In both trees the flesh of the fruit shows first, and after that the woody part inside of it, or, in other words, the seed : and that this is really the case, is proved by the fact, that we often find small fruit on the same shoot without any seed in it at all. This seed is of an oblong shape, and not rounded like the olive-stone. It is also divided down the back by a deep indentation, and in most specimens of this fruit there is exactly in the middle a sort of navel, as it were, from which the root of the tree first takes its growth. ${ }^{16}$ In planting this seed it is laid on its anterior surface, two being placed side by side, while as many more are placed above; for when planted singly, the tree that springs up is but weak and sickly, whereas the four seeds all unite and form one strong tree. The seed is divided from the flesh of the fruit by several eoats of a whitish colour, some of which are attached to the body of it; it lies but loosely in the inside of the fruit, adhering only to the summit by a single thread. ${ }^{17}$

The flesh of this fruit takes a year to ripen, though in some places, Cyprus ${ }^{18}$ for instance, even if it should not reach maturity, it is very agreeable, for the sweetness of its flavour: the leaf of the tree too, in that island, is broader than else. where, and the fruit rounder than usual: the body of the fruit

13 See B. xvi. c. 37.

14 "Umbracula." The fibres of the leaves were probably platted or woven, and the "umbracula" made in much the same manner as the straw and fibre hats of the present day.

15 Most of this is borrowed from Theophrastus, Hist. Plant. ii. 9.

16 Fée remarks, that this account is quite erroneous.

17 This he copies also from Theophrastus, B. ii. c. 8.

18 Theophrastus, B. ii. c. 8 , mentions this as a kind of date peculiar to Cyprus. 
however, is never eaten, but is always spit ${ }^{19}$ out again, after the juice has been extracted. In Arabia, the palm fruit is said to have a sickly sweet taste, although Juba says that he prefers the date found among the Arabian Scenitæ, ${ }^{20}$ and to which they give the name of "dablan," before those of any other country for flavour. In addition to the above particulars, it is asserted that in a forest of natural growth the female $^{21}$ trees will become barren if they are deprived of the males, and that many female trees may be seen surrounding a single male with downcast heads and a foliage that seems to be bowing caressingly towards it; while the male tree, on the other hand, with leaves all bristling and ereet, by its exhalations, and even the very sight of it and the dust ${ }^{22}$ from off it, fecundates the others: if the male tree, too, should happen to be cut down, the female trees, thus reduced to a state of widowhood, will at once. become barren and unproductive. So well, indeed, is this sexual union between them understood, that it has been imagined even that fecundation may be ensured through the agency of man, by means of the blossoms and the down ${ }^{23}$ gathered from off the male trees, and, indeed, sometimes by only sprinkling the dust from off them on the female trees.

\section{CHAP. 8.- HOW THE PALM-TREE IS PLANTED.}

Palm-trees are also propagated by planting $;^{24}$ the trunk is first divided with certain fissures two cubits in length which communicate with the pith of the tree, and is then buried in the earth. A slip also torn away from the root will produce a sucker with vitality, and the same may be obtained from the more tender among the branches. In Assyria, the tree itself

19 This is said solely in relation to the date of Cyprus.

20 Or "dwellers in tents ;" similar to the modern Bedouins.

21 Fée remarks, that in these words we find the first germs of the sexual system that has been established by the modern botanists. He thinks that it is clearly shown by this account, that Pliny was acquainted with the fecundation of plants by the agency of the pollen.

22 In allusion to the pollen, possibly. See the last Note.

23 "Lanugine." It is possible that in the use of this word, also, he may allude to the pollen. Under the term "pulvis," "dust," he probably alludes in exaggerated terms to the same theory.

24 The same methods of propagating the palm are still followed in the East, and in the countries near the tropics. 
is sometimes laid level, and then covered over in a moist soil; upon which it will throw out roots all over, but it will grow only to be a number of shrubs, and never a tree: hence it is that they plant nurseries, and transplant the young trees when a year old, and again when two years old, as they thrive all the better for being transplanted; this is done in the spring season in other countries, but in Assyria about the rising of the Dog-star. In those parts they do not touch the young trees with the knife, but merely tie up the foliage that they may shoot upwards, and so attain considerable height. When they are strong they prune them, in order to increase their thickness, but in so doing leave the branches for about half a foot; indeed, if they were cut off at any other place, the operation would kill the parent tree. We have already ${ }^{25}$ mentioned that they thrive particularly well in a saltish soil; hence, when the soil is not of that nature, it is the custom to scatter salt, not exactly about the roots, but at a little distance off. There are palm-trees in Syria and in Egypt which divide into two trunks, and some in Crete into three and as many as five even. ${ }^{26}$ Some of these trees bear immediately at the end of three years, and in Cyprus, Syria, and Egypt, when they are four years old; others again at the end of five years : at which period the tree is about the height of a man. So long as the tree is quite young the fruit has no seed within, from which circumstance it has received the nickname of the " eunuch."

CHAP. 9.-THE DIFFERENT VARIETIES OF PALM-TREES, AND THEIR CHARACTERISTICS.

There are numerous varieties of the palm-tree. In Assyria, and throughout the whole of Persis, the barren kinds are made use of for carpenters' work, and the various appliances of luxury. There are whole forests also of palm-trees adapted for cutting, ${ }^{28}$ and which, after they are cut, shoot again from

25 In c. 7 of the present Book. See also B. xvii. c. 3.

${ }^{26}$ Fée mentions one near Elvas in Spain, which shot up into seven distinct trees, as it were, from a single trunk. The Douma Thebaica, he says, of Syria and Egypt, a peculiar kind of palm, is also bifurcated. The fruit of it, he thinks, are very probably the Phænico-balanus of B. xii. c. 47.

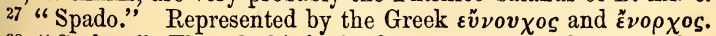

28 "Cæduæ." Though this is the fact as to some palm-trees, the greater part perish after being cut; the vital bud occupying the summit, and the trunk not being susceptible of any increase. 
the root; the pith of them towards the top, which is usually called the brain $^{29}$ of the tree, is sweet to the taste, and the tree will live even after it has been extracted, which is the case with no other kind. The name of this tree is "chamæreps;" it has a broader and softer leaf than the others, which is extremely useful for various kinds of wickerwork $;^{31}$ these trees are very numerous in Crete, and even more so in Sicily. The wood of the palm-tree, when ignited, burns both brightly and slowly. ${ }^{32}$ In some of those that bear fruit, ${ }^{33}$ the seed of the fruit is shorter than in others, while in some, again, it is longer; in some it is softer than in others, and in some harder; in some it is osseous and crescent-shaped; polished with a tooth, superstition employs the stone as an antidote against charms and fascination. This stone is enclosed in several coats, more or less in number; sometimes they are of a thick texture, and sometimes very thin.

Hence it is that we find nine and forty different kinds of palm-trees, if any one will be at the trouble of enumerating all their various barbarous names, and the different wines that are extracted from them. The most famous of all, are those which, for the sake of distinction, have received the name of "royal" palms, because they were preserved solely by the kings of Persia; these used to grow nowhere but at Babylon, and there only in the garden of Bagöus, ${ }^{34}$ that being the Persian for an eunuch, several of whom have even reigned over that country! This garden was always carefully retained within ${ }^{35}$ the precincts of the royal court.

In the southern parts of the world, the dates known as

29 Cerebrum.

30 The Chamæreps humilis of the modern botanists. It is found, among other countries, in Spain, Morocco, and Arabia.

31 Vitilia.

32 "Vivaces." Perhaps it may mean that the wood retains the fire for a long time, when it burns.

${ }^{3}$ Fée suggests that Pliny may possibly have confounded the fruit of other palms with the date.

34 This seems to have been a general name, as Pliny says, meaning an eunuch; but it is evident that it was also used as a proper name, as in the case of the eunuch who slew Artaxerxes, Ochus, B.c. 338, by poison, and of another eunuch who belonged to Darius, but afterwards fell into the hands of Alexander, of whom he became an especial favourite. The name is sometimes written "Bagoüs," and sometimes " Bagoas."

35 Dominantis in aula. 
"syagri, ${ }^{36}$ hold the highest rank, and next after them those that are called "margarides." These last are short, white, and round, and bear a stronger resemblance to grapes than to dates; for which reason it is that they have received their name, in consequence of their close resemblance to "margaritæ," or pearls. It is said that there is only one tree that bears them, and that in the locality known as Chora. ${ }^{37}$ The same is the case also with the tree that bears the syagri. We have heard a wonderful story too, relative to this last tree, to the effect that it dies and comes to life again in a similar manner to the phœnix, which, it is generally thought, has borrowed its name from the palm-tree, in consequence of this peculiarity; at the moment that I am writing this, that tree is still bearing fruit. As for the fruit itself, it is large, hard, and of a rough appearance, and differing in taste from all other kinds, having a sort of wild flavour peculiar to itself, and not unlike that of the flesh of the wild boar; it is evidently this circumstance from which it has derived its name of "syagrus."

In the fourth rank are the dates called "sandalides," from their resemblance to a sandal in shape. It is stated, that on the confines of Ethiopia there are but five of these trees at the most, no less remarkable for the singular lusciousness of their fruit, than for their extreme rarity. Next to these, the dates known as "caryotæ " 38 are the most esteemed, affording not only plenty of nutriment, but a great abundance of juice; it is from these that the principal wines ${ }^{39}$ are made in the East; these wines are apt to affect the head, a circumstance from which the fruit derives its name. But if these trees are remarkable for their abundance and fruitfulness, it is in Judæa that they enjoy the greatest repute; not, indeed, throughout the whole of that territory, but more particularly at Hiericus, ${ }^{40}$ although those that grow at Archelais, Phaselis, and Livias, vallies in the same territory, are highly esteemed. The more

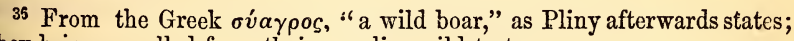
they being so called from their peculiar wild taste.

37 See B. vi. c. 39 .

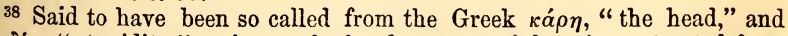
iwoia, "stupidity," owing to the heady nature of the wine extracted from the fruit.

${ }^{39}$ See B. vi. c. 32 , and B. xiv. c. 19.

40 The Jericho of Scripture. 
remarkable quality of these is a rich, unctuous juice; they are of a milky consistency, and have a sort of vinous flavour, with a remarkable sweetness, like that of honey. The Nicolaän ${ }^{41}$ dates are of a similar kind, but somewhat drier; they are of remarkable size, so much so, indeed, that four of them, placed end to end, will make a cubit in length. A less fine lind, but of sister quality to the caryotæ for flavour, are the "adelphides," 42 hence so called; these come next to them in sweetness, but still are by no means their equals. A third kind, again, are the patetæ, which abound in juice to excess, so much so, indeed, that the fruit bursts, in its excess of liquor, even upon the parent tree, and presents all the appearance of having been trodden ${ }^{43}$ under foot.

There are numerous kinds of dates also, of a drier nature, which are long and slender, and sometimes of a curved shape. Those of this sort which we consecrate to the worship of the gods are called "chydæi" 44 by the Jews, a nation remarkable for the contempt which they manifest of the divinities. Those found all over Thebais and Arabia are dry and small, with a shrivelled body: being parched up and scorched by the constant heat, they are covered with what more nearly resembles a shell ${ }^{45}$ than a skin. In Athiopia the date is quite brittle even, so great is the driness of the climate; hence the people are able to knead it into a kind of bread, just like so much

41 Athenæus, B. xiv. c. 22, tells us that these dates were thus called from Nicolaus of Damascus, a Peripatetic philosopher, who, when visiting Rome with Herod the Great, made Augustus a present of the finest fruit of the palm-tree that could be procured. This fruit retained its name of "Nicolaän," down to the middle ages.

42 Pliny would imply that they are so called from the Greek $\alpha \dot{\varepsilon} \varepsilon \lambda \phi \iota a$, "a sister," as being of sister quality to the caryotæ; but it is much more probable, as Fée remarks, that they got this name from being attached in pairs to the same pedicie or stalk.

45 Pliny certainly seems to imply that they are so called from the Greek $\pi a \tau \dot{\varepsilon} \omega$, "to tread under foot," and Hardouin is of that opinion. Fée, however, thinks the name is from the Hebrew or Syriac "patach," "to expand," or "open," or else from the Hebrew "pathah," the name of the first vowel, from some fancied resemblance in the form.

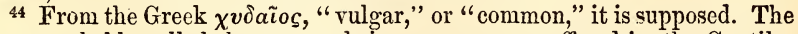
Jews probably called them so, as being common, or offered by the Gentiles to their idols and divinities. Pliny evidently considers that in the name given to them no compliment was intended to the deities of the heathen mythology.

${ }_{45}$ From its extreme driness, and its shrivelled appearance. 
flour. ${ }^{46}$ It grows upon a shrub, with branches a cubit in length : it has a broad leaf, and the fruit is round, and larger than an apple. The name of this date is "coïx." 47 It comes to maturity in three years, and there is always fruit to bo found upon the shrub, in various stages of maturity. The date of Thebais is at once packed in casks, with all its natural heat and freshness ; for without this precaution, it quickly becomes vapid; it is of a poor, sickly taste, too, if it is not exposed, before it is eaten, to the heat of an oven.

The other kinds of dates appear to be of an ordinary nature, and are generally known as "tragemata ;" ${ }_{48}$ but in some parts of Phœnicia and Cilicia, they are commonly called "balani," a name which has been also borrowed by us. There are numerous kinds of them, which differ from one another in being round or oblong; as also in colour, for some of them are black, and others red-indeed it is said that they present no fewer varieties of colour than the fig: the white ones, however, are the most esteemed. They differ also in size, according to the number which it requires to make a cubit in length; some, indeed, are no larger than a bean. Those are the best adapted for keeping which are produced in salt and sandy soils, Judæa, and Cyrenaïca in Africa, for instance : those, however, of Egypt, Cyprus, Syria, and Seleucia in Assyria, will not keep : hence it is that they are much used for fattening swine and other animals. It is a sign that the fruit is either spoilt or old, when the white protuberance disappears, by which it has adhered to the cluster. Some of the soldiers of Alexander's army were choked by eating green dates $;^{49}$ and $\cdot$ a similar effect is produced in the country of the Gedrosi, by the natural quality of the fruit; while in other places, again, the same results arise from eating them to excess. Indeed, when in a fresh state, they are so remarkably luscious, that there would be no end to

46 From Theophrastus, B. i. c. 16.

${ }^{47} \mathbf{K} \boldsymbol{v} \kappa \omega \mathrm{s}$ in the Greek. It is supposed by Sprengel to be the same as the Cycas circinnalis of Linnæus ; but, as Fée remarks, that is only found in India.

${ }_{48}$ From the Greek, meaning "sweetmeats," or " dessert fruit :" he probably means that in Syria and some parts of Phœnicia they were thus called.

${ }_{49}$ This story, which is borrowed from Theophrastus, B. iv. c. 5 , is doubted by Fée, who says that in the green state they are so hard and nauseous, that it is next to impossible to eat sufficient to be materially incommoded by them. 
eating them, were it not for fear of the dangerous consequences that would be sure to ensue.

CHAP. 10. (5.) - THE TREES OF SYRIA: THE PISTACIA, THE COTTANA, THE DAMASCENA, AND THE MYXA.

In addition to the palm, Syria has several trees that are peculiar to itself. Among the nut-trees there is the pistacia, ${ }^{50}$ well known among us. It is said that, taken either in food or drink, the kernel of this nut is a specific against the bite of serpents. Among figs, too, there are those known as "caricæ," ${ }^{51}$ together with some smaller ones of a similar kind, the name of which is " cottana." There is a plum, too, which grows upon Mount Damascus, ${ }^{52}$ as also that known as the "myxa;" ${ }^{33}$ these last two are, however, now naturalized in Italy. In Egypt, too, they make a kind of wine from the myxa.

CHAP. 11. - THE CEDAR. TREES WHICH HAVE ON THEM THE FRUIT OF THREE YEARS AT ONCE.

Phœnicia, too, produces a small cedar, which bears a strong resemblance to the juniper. ${ }^{54}$ of this tree there are two varieties; the one found in Lycia, the other in Phœnicia..$^{\circ}$ The difference is in the leaf: the one in which it is hard, sharp, and prickly, being known as the oxycedros, ${ }^{56}$ a branchy tree and rugged with knots. The other kind is more esteemed for its powerful odour. The small cedar produces a fruit the size of a grain of myrrh, and of a sweetish taste. There are two kinds of the larger cedar ${ }^{57}$ also; the one that blossoms bears

50 The Pistacia vera of Linnæus. It was introduced into Rome in the reign of Tiberius. The kernel is of no use whatever in a medical point of view, and what Pliny says about its curing the bite of serpents is perfectly fabulous.

"S1 See B. xv. c. 19. The "carica" was properly the "Carian" fig. "Ficus carica" is, however, the name given to the common fig by the modern botanists.

52 The parent of our Damascenes, or damsons. See B. xv. c. 13.

53 Supposed to be the Corda myxa of Linnæus. See B. xv. c. 15.

54 The Juniperus communis of Linnæus.

55 The Juniperus Lycia, and the Juniperus Phœnicia, probably, of Linnæus. It has been supposed by some, that it is these trees that produce the frankincense of Africa; but, as Fée observes, the subject is enveloped in considerable obscurity.

56 The "sharp-leaved" cedar. The Juniperus oxycedrus of Linnæus.

57 The "Pinus cedrus" of Linnæus. The name "cedrus" was given by the ancients not only to the cedar of Lebanon, but to many others of the Coniferæa as well, and more particularly to several varieties of the juniper, 
no fruit, while, on the other hand, the one that bears fruit has no blossom, and the fruit, as it falls, is being continually replaced by fresh. The seed of this tree is similar to that of the cypress. Some persons give this tree the name of " cedrelates." The resin produced from it is very highly praised, and the wood of it lasts for ever, for which reason it is that they have long been in the habit of using it for making the statues of the gods. In a temple at Rome there is a statue of Apollo Sosianus $^{58}$ in cedar, originally brought from Seleucia. There is a tree similar to the cedar, found also in Arcadia ; and there is a shrub that grows in Phrygia, known as the "cedrus."

\section{CHAP. 12. (6.) 一 THE TEREBINTH. ${ }^{59}$}

Syria, too, produces the terebinth, the male tree of which bears no fruit, and the female consists of two different varieties $;^{60}$ one of these bears a red fruit, the size of a lentil, while the other is pale, and ripens at the same period as the grape. This fruit is not larger than a bean, is of a very agreeable smell, and sticky and resinous to the touch. About Ida in Troas, and in Macedonia, this tree is short and shrubby, but at Damascus, in Syria, it is found of very considerable size. Its wood is remarkably flexible, and continues sound to a very advanced age: it is black and shining. The blossoms appear in clusters, like those of the olive-tree, but are of a red colour ; the leaves are dense, and closely packed. It produces follicules, too, from which issue certain insects like gnats, as also a kind of resinous liquid ${ }^{61}$ which oozes from the bark.

\section{CHAP. 13. -THE SUMACH-TREE.}

The male sumach-tree ${ }^{62}$ of Syria is productive, but the female is barren. The leaf resembles that of the elm, though it is a little longer, and has a downy surface. The footstalks of the leaves lie always alternately in opposite directions, and

${ }^{5 s}$ See B. xxxvi. c. 4.

${ }^{59}$ Pistacia terebinthus of Linnæus.

${ }^{60}$ These varieties, Fée says, are not observed by modern naturalists.

${ }^{61}$ Garidel has remarked, that the trunk of this tree produces coriaceous vesicles, filled with a clear and odoriferous terebinthine, in which pucerons, or aphides, are to be seen floating.

62 "Rhus." The Rhus coriaria of Linnæus. Pliny is wrong in distinguishing this tree into sexes, as all the flowers are hermaphroditical, and therefore fruitful. 
the branches are short and slender. This tree is used in the preparation of white skins. ${ }^{63}$ The seed, which strongly resembles a lentil in appearance, turns red with the grape; it is known by the name of "ros," and forms a necessary ingredient in various medicaments. ${ }^{64}$

\section{CHAP. 14. (7.) -THE TREES OF EGYPT. THE FIG-TREE OF ALEXANDHIA.}

Egypt, too, has many trees which are not to be found elsewhere, and the kind of fig more particularly, which for this reason has been called the Egyptian fig. ${ }^{65}$ In leaf this tree resembles the mulberry-tree, as also in size and general appearance. It bears fruit, not upon branches, but upon the trunk itself : the fig is remarkable for its extreme sweetness, and has no seeds ${ }^{66}$.in it. This tree is also remarkable for its fruitfulness, which, however, can only be ensured by making incisions $^{67}$ in the fruit with hooks of iron, for otherwise it will not come to maturity. But when this has been done, it may be gathered within four days, immediately upon which another shoots up in its place. Hence it is that in the year it produces seven abundant crops, and throughout all the summer there is an abundance of milky juice in the fruit. Even if the incisions are not made, the fruit will shoot afresh four times during the summer, the new fruit supplanting the old, and forcing it off before it has ripened. The wood, which is of a very peculiar nature, is reckoned among the most useful known. When cut down it is immediately plunged into standing water, such being the means employed for drying ${ }^{68}$ it. At first it sinks to the bottom, after which it begins to float, and in a certain length of time the additional moisture sucks it dry, which has the effect of penetrating and soaking all ${ }^{69}$

${ }_{6}^{6.3}$ It is still used by curriers in preparing leather.

6t See B. xxiv. c. 79. The fruit, which has a pleasant acidity, was used for culinary purposes by the ancients, as it is by the Turks at the present day.

${ }_{65}$ The Ficus sycamorus of Linnæus. It receives its name from being a fig-tree that bears a considerable resemblance to the "morus," or mulberry-tree.

66 This is not the case.

${ }_{67}$ This appears to be doubtful, although, as Fée says, the fruit ripens but very slowly.

68 This, Fée says, is a fallacy

69 "Aliam omnem." This reading seems to be very doubtful, 
other kinds of wood. It is a sign that it is fit for use ${ }^{70}$ when it begins to float.

\section{CHAP. 15. -THE FIG-TREE OF CYPRUS.}

The fig-tree that grows in Crete, and is known there as the Cyprian fig, ${ }^{71}$ bears some resemblance to the preceding one; for it bears fruit upon the trunk of the tree, and upon the branches as well, when they have attained a certain degree of thickness. This tree, however, sends forth buds without any leaves ${ }^{72}$ but similar in appearance to a root. The trunk of the tree is similar to that of the poplar, and the leaves to those of the elm. It produces four crops in the year, and germinates the same number of times, but its green ${ }^{73}$ fruit will not ripen unless an incision is made in it to let out the milky juice. The sweetness of the fruit and the appearance of the inside are in all respects similar to those of the fig, and in size it is about as large as a sorb-apple.

\section{CHAP. 16. (8.) 一THE CAROB-TREF.}

Similar to this is the carob-tree, by the Ionians known as the "ceraunia," "74 which in a similar manner bears fruit from the trunk, this fruit being known by the name of "siliqua," or "pod.". For this reason, committing a manifest error, some persons ${ }^{75}$ have called it the Egyptian fig; it being the fact that this tree does not grow in Egypt, but in Syria and Ionia, in the vicinity, too, of Cnidos, and in the island of Rhodes. It is always covered with leaves, and bears a white flower with a very powerful odour. It sends forth shoots at

70 This wood was very extensirely used in Egypt for making the outer cases, or coffins, in which the mummies were enclosed.

71 This account is borrowed almost entirely from Theophrastus, Hist. Plant. B. iv. c. 2. A variety of the sycamore is probably meant. It is still found in the Isle of Crete.

${ }_{72} \mathrm{He}$ seems to mean that the buds do not shoot forth into leaves; the reading, however, varies in the editions, and is extremely doubtful.

73 Grossus.

74 The Ceratonia siliqua of Linnæus. It is of the same size as the sycamore, but resembles it in no other respect. It is still common in the localities mentioned by Pliny, and in the south of Spain.

i5 Theophrastus in the number, Hist. Plant. i. 23, and iv. 2. It bears no resemblance to the fig-tree, and the fruit is totally different from the fig. Pliny, too, is wrang in saying that it does not grow in Egypt; the fact being that it is found there in great abundance. 
the lower part, and is consequently quite yellow on the surface, as the young suckers deprive the trunk of the requisite moisture. When the fruit of the preceding year is gathered, about the rising of the Dog-star, fresh fruit immediately makes its appearance; after which the tree blossoms while the constellation of Arcturus ${ }^{76}$ is above the horizon, and the winter imparts nourishment to the fruit.

CHAP. 17. (9.) - THE PERSIAN TREE. IN WHAT TREES THE FRUITS GERMINATE THE ONE BELOW THE OTHER.

Egypt, too, produces another tree of a peculiar description, the Persian ${ }^{77}$ tree, similar in appearance to the pear-tree, but retaining its leaves during the winter. This tree produces without intermission, for if the fruit is pulled to-day, fresh fruit will make its appearance to-morrow : the time for ripening is while the Etesian ${ }^{78}$ winds prevail. The fruit of this tree is more oblong than a pear, but is enclosed in a shell and a rind of a grassy colour, like the almond; but what is found within, instead of being a nut as in the almond, is a plum, differing from the almond ${ }^{79}$ in being shorter and quite soft. This fruit, although particularly inviting for its luscious sweetness, is productive of no injurious effects. The wood, for its goodness, solidity, and blackness, is in no respect inferior to that of the lotus: people have been in the habit of making statues of it. The wood of the tree which we have mentioned as the "balanus," 80 although very durable, is not so highly esteemed as this, as it is knotted and twisted in the greatcr part: hence it is only employed for the purposes of shipbuilding.

76 See B. xviii. c. 74.

77 Fée identifies it with the Egyptian almond, mentioned by Pliny in B. xv. c. 28; the Myrobalanus chebulus of Wesling, the Balanites \#gyptiaca of Delille, and the Xymenia \#gyptiaca of Linnæus. Schreber and Sprengel take it to be the Cordia Sebestana of Linnæus; but that is a tree peculiar to the Antilles. The fruit is in shape like a date, enclosing a large stone with five sides, and covered with a little viscous flesh, of somewhat bitter, though not disagreeable flavour. It is found in the vicinity of Sennaar, and near the Red Sea. The Arabs call it the "date of the Desert."

78 See B. xviii. c. 68.

80 Or ben. See B. xii。 cc. 46,47 .

79 See B. xv. C. 34. 
CHAP. 18. -THE CUCUS.

On the other hand, the wood of the cucus ${ }^{81}$ is held in very high esteem. It is similar in nature to the palm, as its leaves are similarly used for the purposes of texture: it differs from it, however, in spreading out its arms in large branches. The fruit, which is of a size large enough to fill the hand, is of a tawny colour, and recommends itself by its juice, which is a mixture of sweet and rough. The seed in the inside is large and of remarkable hardness, and turners use it for making curtain rings. ${ }^{82}$ The kernel is sweet, while fresh; but when dried it becomes hard to a most remarkable degree, so much so, that it can only be eaten after being soaked in water for several days. The wood is beautifully mottled with circling veins, ${ }^{83}$ for which reason it is particularly esteemed among the Persians.

\section{CHAP. 19.-THE EGYPTIAN THORN.}

No less esteemed, too, in the same country, is a certain kind of thorn, ${ }^{84}$ though only the black variety, its wood being imperishable, in water even, a quality which renders it particularly valuable for making the sides of ships: on the other hand, the white kinds will rot very rapidly. It has sharp, prickly thorns on the leaves even, and bears its seeds in pods; they are employed for the same purposes as galls in the preparation of leather. The flower, too, has a pretty effect when made into garlands, and is extremely useful in medicinal preparations. A gum, also, distils from this tree; but the principal merit that it possesses is, that when it is cut down, it will grow again within three years. It grows in the vicinity of Thebes, where we also find the quercus, the Persian tree, and the olive: the spot that produces it is a piece of woodland, distant three

${ }^{81}$ Many have taken this to be the cocoa-nut tree; but, as. Fée remarks, that is a tree of India, and this of Egypt. There is little doubt that it is the doum of the Arabs, the Cucifera Thebaica of Delille. The timber of the trunk is much used in Egypt, and of the leaves carpets, bags, and panniers are made. In fact, the description of it and its fruit is almost identical with that here given by Pliny.

82 The seed or stone of the doum is still used in Egypt for making the beads of chaplets : it admits of a very high polish.

${ }^{83}$ Materies crispioris elegantix.

${ }^{84}$ See B. xxiv. c. 67. This is, no doubt, the Acacia Nilotica of Linnæus, which produces the gum Arabic of modern commerce. 
hundred stadia from the Nile, and watered by springs of its own.

(10.) Here we find, too, the Egyptian ${ }^{85}$ plum-tree, not much unlike the thorn last mentioned, with a fruit similar to the medlar, and which ripens in the winter. This tree never loses its leaves. The seed in the fruit is of considerable size, but the flesh of it, by reason of its quality, and the great abundance in which it grows, affords quite a harvest to the inhabitants of those parts; after cleaning it, they subject it to pressure, and then make it up into cakes for keeping. There was formerly ${ }^{86}$ a woodland district in the vicinity of Memphis, with trees of such enormous size, that three men could not span one with their arms : one of these trees is remarkable, not for its fruit, or any particular use that it is, but for the singular phænomenon that it presents. In appearance it strongly resembles a thorn, ${ }^{87}$ and it has leaves which have all the appearance of wings, and which fall immediately the branch is touched by any one, and then immediately shoot again.

\section{CHAP. 20. (11.) - NINE KINDS OF GUM. THE SARCOCOLLA.}

It is universally agreed, that the best gum is that produced from the Egyptian thorn; ${ }^{88}$ it is of variegated appearance, of azure colour, clean, free from all admixture of bark, and adheres to the teeth; the price at which it sells is three denarii per pound. That produced from the bitter almond-

${ }^{85}$ This is from Theophrastus, Hist. Plant. B. iv. c. 3. Fée suggests that it may have been a kind of myrobalanus. Sprengel identifies it with the Cordia sebestana of the botanists.

86 "Fuit." From the use of this word he seems uncertain as to its existence in his time; the account is copied from Theophrastus, Hist. Plant. B. iv. c. 3. Fée suggests that he may here allude to the Baobab, the Adansonia digitata, which grows in Senegal and Sennaar to an enormous size. Prosper Alpinus speaks of it as existing in Egypt. The Arabs call it El-omarah, and the fruit El-kongles.

${ }^{87}$ The Mimosa polyacanthe, probably. Fée says that the mimosæ, respectively known as casta, pudibunda, viva, and sensitiva, with many of the inga, and other leguminous trees, are irritable in the highest degree. The tree here spoken of he considers to be one of the acacias. The passage in Theophrastus speaks of the leaf as shrinking, and not falling, and then as simply reviving.

${ }_{88}$ The Acacia Nilotica of Linnæus, from which we derive the gum Arabic of commerce; and of which a considerable portion is still derived from Egypt. 
tree and the cherry ${ }^{89}$ is of an inferior kind, and that which is gathered from the plum-tree is the worst of all. The vine, too, produces a gum, ${ }^{50}$ which is of the greatest utility in healing the sores of children; while that which is sometimes found on the olive-tree ${ }^{91}$ is used for the tooth-ache. Gum is also found on the elm ${ }^{92}$ upon Mount Corycus in Cilicia, and upon the juniper, ${ }^{93}$ but it is good for nothing ; indeed, the gum of the elm found there is apt to breed gnats. From the sarcocollat ${ }^{94}$ also-such is the name of a certain tree-a gum exudes that is remarkably useful to painters ${ }^{95}$ and medical men; it is similar to incense dust in appearance, and for those purposes the white kind is preferable to the red. The price of it is the same as that mentioned above. ${ }^{96}$

\section{CHAP. 21. -THE PAPYRUS: THE USE OF PAPER; WHEN IT WAS FIRST INVENTED.}

We have not as yet taken any notice of the marsh plants, nor yet of the shrubs that grow upon the banks of rivers: before quitting Egypt, however, we must make some mention of the nature of the papyrus, seeing that all the usages of civilized life depend in such a remarkable degree upon the employment of paper-at all events, the remembrance of past events. M. Varro informs us that paper owes its discovery to

89 These gums are chemically different from gum Arabic, and they are used for different purposes in the arts.

90 The vine does not produce a gum; but when the sap ascends, a juice is secreted, which sometimes becomes solid on the evaporation of the aqueous particles. This substance contains acetate of potassa, which, by the decomposition of that salt, becomes a carbonate of the same base.

91 This is not a gum, but a resinous product of a peculiar nature. It is known to the moderns by the name of "olivine."

${ }_{92}$ The sap of the eim leaves a saline deposit on the hark, principally formed of carbonate of potassa. Fée is at a loss to know whether Pliny here alludes to this or to the manna which is incidentally formed by certain insects on some trees and reeds. But, as he justly says, would Pliny say of the latter that it is "ad nihil utile" - "good for nothing"?

93 A resinous product, no doubt. The frankincense of Africa has been attributed by some to the Juniperus Lycia and Phœnicia.

${ }^{94}$ The Penæa Sarcocolla of Linnæus. The gum resin of this tree is still brought from Abyssinia, but it is not used in medicine. This account is from Dioscorides, B. iii. c. 99. The name is from the Greek $\sigma \dot{\alpha} \rho \xi$, "flesh," and $\kappa o ́ \lambda \lambda \alpha$, "glue."

${ }^{95}$ See B. xxiv. e. 78.

96 Three denarii per pound. 
the victorious ${ }^{97}$ career of Alexander the Great, at the time when Alexandria in Egypt was founded by him; before which period paper had not been used, the leaves of the palm having been employed for writing at an early period, and after that the bark of certain trees. In succeeding ages, public documents were inscribed on sheets of lead, while private memoranda were impressed upon linen cloths, or else engraved on tablets of wax; indeed, we find it stated in Homer, ${ }^{98}$ that tablets were employed for this purpose even before the time of the Trojan war. It is generally supposed, too, that the country which that poet speaks of as Egypt, was not the same that is at present understood by that name, for the Sebennytic and the Saitic ${ }^{99}$ Nomes, in which all the papyrus is produced, have been added since his time by the alluvion of the Nile; indeed, he himself has stated ${ }^{1}$ that the main-land was a day and a night's sail from the island of Pharos ${ }^{2}$, which island at the present day is united by a bridge to the city of Alexandria. In later times, a rivalry having sprung up between King Ptolemy and King Eumenes, ${ }^{3}$ in reference to their respective libraries, Ptolemy prohibited the export of papyrus; upon which, as Varro relates, parchment was invented for a similar purpose at Pergamus. After this, the use of that commodity, by which immortality is ensured to man, became universally known.

\section{CHAP. 22.-THE MODE OF MAKING PAPER.}

Papyrus grows either in the marshes of Egypt, or in the sluggish waters of the river Nile, when they have overflowed and are lying stagnant, in pools that do not exceed a couple of cubits in depth. The root lies obliquely, ${ }^{4}$ and is about the

${ }^{97}$ It is hardly necessary to state that this is not the fact. This plant is the Cyperus papyrus of Linnæus, the "berd" of the modern Egyptians.

98 Il. B. vi. 1. 168. See B. xxxiii. c. 4, where the tablets which are here called "pugillares," are styled "codicilli" by Pliny.

99 His argument is, that paper made from the papyrus could not be known in the time of Homer, as that plant only grew in certain districts which had been rescued from the sea since the time of the poet.
1 Od. B. iv. 1. 355 .
2 See B. ii. c. 87 .

3 There is little doubt that parchment was really known many years before the time of Eumenes II., king of Pontus. It is most probable that this king introduced extensive improvements in the manufacture of parchment, for Herodotus mentions writing on skins as common in his time; and in B. v. c. 58 , he states that the Ionians had been accustomed to give the name of skins, $\delta \iota \phi \theta^{\prime}$ e $\rho \iota$, to books.

4 Brachiali radicis obliquæ crassitudine. 
thickness of one's arm; the section of the stalk is triangular, and it tapers gracefully upwards towards the extremity, being not more than ten cubits at most in height. Very much like a thyrsus ${ }^{5}$ in shape, it has a head on the top, which has no see $d^{j *}$ in it, and, indeed, is of no use whatever, except as a flower employed to crown the statues of the gods. The natives use the roots by way of wood, not only for firing, but for various other domestic purposes as well. From the papyrus itself they construct boats ${ }^{6}$ also, and of the outer coat they make sails and mats, as well as cloths, besides coverlets and ropes; they chew it also, both raw and boiled, though they swallow the juice only.

The papyrus grows in Syria also, on the borders of the same lake around which grows the sweet-scented calamus ${ }^{7}$ and King Antiochus used to employ the productions of that country solely as cordage for naval purposes; for the use of spartum ${ }^{8}$ had not then become commonly known. More recently it has been understood that a papyrus grows in the river Euphrates, in the vicinity of Babylon, from which a similar kind of paper may easily be produced : still, however, up to the present time the Parthians have preferred to impress ${ }^{9}$ their characters upon cloths

CHAP. 23. (12)—TIIE NINE DIFFERENT KINDS OF PAPER.

Paper is made from the papyrus, by splitting it with a

${ }^{5}$ This was a pole represented as being carried by Bacchus and his Bacchanalian train. It was mostly terminated by the fir cone, that tree being dedicated to Bacchus, in consequence of the use of its cones and turpentine in making wine. Sometimes it is surmounted by vine or fig leaves, with grapes or berries arranged in form of a cone.

${ }^{5 *}$ This is not the fact: it has seed in it, though not very easily perceptible. The description here given is otherwise very correct.

${ }^{6}$ Among the ancients the term papyrus was used as a general appellation for all the different plants of the genus Cyperus, which was used for making mats, boats, baskets, and numerous other articles: but one species only was employed for making paper, the Cyperus papyrus, or Byblos. Fée states that the papyrus is no longer to be found in the Delta, where it formerly abounded.

7 See B. xii. c. 48.

8 Sometimes translated hemp. A description will be given of it in B. xix. c. 7 .

9 "Intexere." This would almost appear to mean that they embroidered or interwove the characters. The Persians still write on a stuff made of white silk, gummed and duly prepared for the purpose. 
needle into very thin leaves, due care beins taken that they should be as broad as possible. That of the first quality is taken from the centre of the plant, and so in regular succession, according to the order of division. "Hieratica" 10 was the name that was anciently given to it, from the circumstance that it was entirely reserved for the religious books. In later times, through a spirit of adulation, it received the name of " $\mathrm{Au}$ gusta," just as that of second quality was called "Liviana," from his wife, Livia ; the consequence of which was, that the name "hieratica" came to designate that of only third-rate quality. The paper of the next quality was called "amphitheatrica," from the locality ${ }^{11}$ of its manufacture. The skilful manufactory that was established by Fannius ${ }^{12}$ at Rome, was in the habit of receiving this last kind, and there, by a very careful process of insertion, it was rendered much finer; so much so, that from being a common sort, he made it a paper of first-rate quality, and gave his $0 \mathrm{wn}^{13}$ name to it: while that which was not subjected to this additional process retained its original name of "amphitheatrica." Next to this is the Saitic paper, so called from the city of that name, ${ }^{14}$ where it is manufactured in very large quantities, though of cuttings of inferior ${ }^{15}$ quality. The Tæniotic paper, so called from a place in the vicinity, ${ }^{16}$ is manufactured from the materials that lie nearer to the outside skin; it is sold, not according to its quality, but by weight only. As to the paper that is known

10 Or " holy" paper. The priests would not allow it to be sold, lest it might be used for profane writing; but after it was once written upon, it was easily procurable. The Romans were in the habit of purchasing it largely in the latter state, and then washing off the writing, and using it as paper of the finest quality. Hence it received the name of "Augustus," as representing in Latin its Greek name " hieraticus," or "sacred." In length of time it became the common impression, as here mentioned, that this name was given to it in honour of Augustus Cæsar.

11 Near the amphitheatre, probably, of Alexandria.

$12 \mathrm{He}$ alludes to Q. Remmius Fannius Palæmon, a famous grammarian of Rome, though originally a slave. Being manumitted, he opened a school at Rome, which was resorted to by great numbers of pupils, notwithstanding his notoriously bad character. He appears to have established, also, a manufactory for paper at Rome. Suetonius, in his treatise on Illustrious Grammarians, gives a long account of him. He is supposed to have been the preceptor of Quintilian.

13 Fanniana.

15 Ex vilioribus ramentis.

14 In Lower Egypt.

16 Of Alexandria, probably. 
as "emporetica,"17 it is quite useless for writing upon, and is only employed for wrapping up other paper, and as a covering for various articles of merchandize, whence its name, as being: used by dealers. After this comes the bark of the papyrus, the outer skin of which bears a strong resemblance to the bulrush, and is solely used for making ropes, and then only for those which have to go into the water. ${ }^{18}$

All these various kinds of paper are made upon a table, moistened with Nile water; a liquid which, when in a muddy state, has the peculiar qualities of glue. ${ }^{19}$ This table being first inclined, ${ }^{20}$ the leaves of papyrus are laid upon it lengthwise, as long, indeed, as the papyrus will admit of, the jagged edges being cut off at either end; after which a cross layer is placed over it, the same way, in fact, that hurdles are made. When this is done, the leaves are pressed close together, and then dried in the sun; after which they are united to one another, the best sheets being always taken first, and the inferior ones added afterwards. There are never more than twenty of these sheets to a roll. ${ }^{21}$

\section{CHAP. 24. -THE MODE OF TESTING THE GOODNESS OF PAPER.}

There is a great difference in the breadth of the various kinds of paper. That of best quality ${ }^{22}$ is thirteen fingers wide, while the hieratica is two fingers less. The Fanniana is ten fingers wide, and that known as "amphitheatrica," one less. The Saitic is of still smaller breadth, indeed it is not so wide as the mallet with which the paper is beaten; and the emporetica is particularly narrow, being not more than six fingers in breadth.

In addition to the above particulars, paper is esteemed according to its fineness, its stoutness, its whiteness, and its smoothness. Claudius Cæsar effected a change in that which

17 "Shop-paper," or " paper of commerce."

is Otherwise, probably, the rope would not long hold together.

19 Fée remarks, that this is by no means the fact. With M. Poiret, he questions the accuracy of Pliny's account of preparing the papyrus, and is of opinion that it refers more probably to the treatment of some other vegetable substance from which paper was made.

20 Primo supinâ tabulæ schedâ. rolled.

21 "Scapus." This was, properly, the cylinder on which the paper was

22 Augustan. 
till then had been looked upon as being of the first quality : for the Augustan paper had been found to be so remarkably fine, as to offer no resistance to the pressure of the pen; in addition to which, as it allowed the writing upon it to run through, it was continually causing apprehensions of its being blotted and blurred by the writing on the other side; the remarkable transparency, too, of the paper was very unsightly to the eye. To obviate these inconveniences, a groundwork of paper was made with leaves of the second quality, over which was laid a woof, as it were, formed of leaves of the first. He increased the width also of paper; the width [of the common sort] being made a foot, and that of the size known as "macrocollum," ${ }^{23}$ a cubit; though one inconvenience was soon detected in it, for, upon a single leaf $\mathrm{f}^{24}$ being torn in the press, more pages were apt to be spoilt than before..$^{25}$ In consequence of the advantages above-mentioned, the Claudian has come to be preferred to all other kinds of paper, though the Augustan is still used for the purposes of epistolary correspondence. The Livian, which had nothing in common with that of first quality, but was entirely of a secondary rank, still hoids its former place.

\section{CHAP. 25.-THE PECULIAR DEFECTS IN PAPER.}

The roughness and inequalities in paper are smoothed down with a tooth ${ }^{26}$ or shell; but the writing in such places is very apt to fade. When it is thus polished the paper does not take the ink so readily, but is of a more lustrous and shining surface. The water of the Nile that has been originally employed in its manufacture, being sometimes used without due precaution, will unfit the paper for taking writing: this fault, however, may be detected by a blow with the mallet, or even by the smell, ${ }^{27}$ when the carelessness has been extreme. These

${ }^{23}$ Or "long glued" paper : the breadth probably consisted of" that of two or more sheets glued or pasted at the edges, the seam running down the roll.

${ }^{24}$ Scheda. One of the leaves of the papyrus, of which the roll of twenty, joined side by side, was formed.

25 This passage is difficult to be understood, and various attempts have been made to explain it. It is not unlikely that his meaning is that the breadth being doubled, the tcaring of one leaf or half breadth entailed of necessity the spoiling of another, making the corresponding half breadth.

${ }_{26}$ He perhaps means a portion of an elephant's tusk.

27 Meaning a damp, musty smell. 
spots, too, may be detected by the eye; but the streaks that run down the middle of the leaves where they have been pasted together, though they render the paper spongy and of a soaking nature, can hardly ever be detected before the ink runs, while the pen is forming the letters; so many are the openings for fraud to be put in practice. The consequence is, that another labour has been added to the due preparation of paper.

CHAP. 26. -THE PASTE USED IN THE PREPaRATION OF PAPER.

The common paper paste is made of the finest flour of wheat mixed with boiling water, and some small drops of vinegar sprinkled in it: for the ordinary workman's paste, or gum, if employed for this purpose, will render the paper brittle. Those, however, who take the greatest pains, boil the crumb of leavened bread, and then strain off the water: by the adoption of this method the paper has the fewest seams caused by the paste that lies between, and is softer than the nap of linen even. All kinds of paste that are used for this purpose, ought not to be older or newer than one day. The paper is then thinned out with a mallet, after which a new layer of paste is placed upon it; then the creases which have formed are again pressed out, and it then undergoes the same process with the mallet as before. It is thus that we have memorials preserved in the ancient handwriting of Tiberius and Caius Gracchus, which I have seen in the possession of Pomponius Secundus, ${ }^{28}$ the poet, a very illustrious citizen, almost two hundred years since those characters were penned. As for the handwriting of Cicero, Augustus, and Virgil, we frequently see them at the present day.

\section{CHAP. 27. (13.)-THE BOOKS OF NUMA.}

There are some facts of considerable importance which make against the opinion expressed by M. Varro, relative to the invention of paper. Cassius Hemina, a writer of very great antiquity, has stated in the Fourth Book of his Annals, that Cneius Terentius, the scribe, while engaged in digging on his

${ }^{28}$ See B. vii. c. 18 , and B. xiv. c. 6 . Also the Life of .Pliny, in the Introduction to Vol. i. p. vii. 
land in the Janiculum, came to a coffer, in which Numa had been buried, the former king of Rome, and that in this coffer were also found some books ${ }^{29}$ of his. This took place in the consulship of Publius Cornelius Cethegus, the son of Lucius, and of M. Brebius 'Tamphilus, the son of Quintus, the interval between whose consulship and the reign of Numa was five hundred and thirty-five years. These books were made of paper, and, a thing that is more remarkable still, is the fact that they lasted so many years buried in the ground. In order, therefore, to establish a fact of such singular importance, I shall here quote the words of Hemina himself-" Some persons expressed wonder how these books could have possibly lasted so long a time-this was the explanation that Terentius gave: "In nearly the middle of the coffer there lay a square stone, bound on every side with cords enveloped in wax; ${ }^{30}$ upon this stone the books had been placed, and it was through this precaution, he thought, that they had not rotted. The books, too, were carefully covered with citrus leaves, ${ }^{31}$ and it was through this, in his belief, that they had been protected from the attacks of worms.' In these books were written certain doctrines relative to the Pythagorean philosophy; they were burnt by Q. Petilius, the prætor, because they treated of philosophical subjects." 32

Piso, who had formerly been censor, relates the same facts in the First Book of his Commentaries, but he states in addition, that there were seven books on Pontifical Rights, and seven on the Pythagorean philosophy. ${ }^{33}$ Tuditanus, in his Fourteenth Book, says that they contained the decrees of Numa: Varro, in the Seventh Book of his "Antiquities of Mankind," " states that they were twelve in number; and Antias, in his Second Book, says that there were twelve written in Latin, on pontifical

29 This story, no dorbt, deserves to be rejected as totally fabulous, even though we have Hemina's word for it.

30 See B. xvi. c. 70.

31 B. xii. c. 7 , and B. xiii. c. 31 . It was thought that the leaves and juices of the cedar and the citrus preserved books and linen from the attacks of noxious insects.

32 And because, as Livy says, their doctrines were inimical to the then existing religion.

33 Val. Maximus says that there were some books written in Latin, on the pontifical rights, and others in Greek on philosophical subjects.

${ }^{34}$ Humanæ Antiquitates. 
matters, and as many in Greek, containing philosophical precepts. The same author states also in his Third Book why it was thought proper to burn them.

It is a fact acknowledged by all writers, that the Siby ${ }^{35}$. brought three books to Tarquinius Superbus, of which two were burnt by herself, while the third perished by fire with the Capitol ${ }^{36}$ in the days of Sylla. In addition to these facts, Mucianus, who was three times consul, has stated that he had recently read, while governor of Lycia, a letter written upon paper, and preserved in a certain temple there, which had been written from Troy, by Sarpedon; a thing that surprises me the more, if it really was the fact that even in the time of Homer the country that we call Egypt was not in existence. ${ }^{37}$ And why too, if paper was then in use, was it the custom, as it is very well known it was, to write upon leaden tablets and linen cloths? Why, too, has Homer ${ }^{38}$ stated that in Lycia tablets ${ }^{39}$ were given to Bellerophon to carry, and not a paper letter?

Papyrus, for making paper, is apt to fail occasionally; such a thing happened in the time of the Emperor Tiberius, when there was so great a scarcity ${ }^{40}$ of paper that members of the senate were appointed to regulate the distribution of it: had not this been done, all the ordinary relations of life would have been completely disarranged.

CHAP. 28. (14.)-THE TREES OF XTHIOPIA.

Ethiopia, which borders upon Egypt, has in general no remarkable trees, with the exception of the wool-bearing ${ }^{41}$ ones, of which we have had occasion to speak $^{42}$ in our description of the trees of India and Arabia. However, the produce

${ }^{35}$ See B. xxxiv. c. 11. 36 See B. xxxiii. c. 5 .

$37 \mathrm{He}$ implies that it could not have been written upon paper, as the papyrus and the districts which produced it were not in existence in the time of Homer. No doubt this so-called letter, if shown at all, was a forgery, a "pia fraus." See c. 21 of the present Book.

38 Il. B. vi. 1. 168.

39 "Codicillos," as meaning characters written on a surface of wood. $\pi i \nu a \xi$, as Homer calls it.

40 It was probably then that the supply of it first began to fail ; in the sixth century it was still used, but by the twelfth it had wholly fallen into disuse.

41 The cotton-tree, Gossypium arboreum of Linnæus.

42 See B. xii. c. $21,22$.

VOL. III. 
of the tree of Athiopia bears a much stronger resemblance to wool, and the follicule is much larger, being very similar in appearance to a pomegranate ; as for the trees, they are otherwise similar in every respect. Besides this tree, there are some palms, of which we have spoken already. ${ }^{43}$ In describing the islands along the coast of Athiopia, we have already made mention ${ }^{44}$ of their trees and their odoriferous forests.

CHAP. 29. (15.) - THE TREes OF MOUNT ATLAS. THE CITRUS, AND THE TABLES MADE OF THE WOOD THEREOF.

Mount Atlas is said to possess a forest of trees of a peculiar character, ${ }^{45}$ of which we have already spoken..$^{46}$ In the vicinity of this mountain is Mauretania, a country which abounds in the citrus, ${ }^{47}$ a tree which gave rise to the mania ${ }^{48}$ for fine tables, an extravagance with which the women reproach the men, when they complain of their vast outlay upon pearls. There is preserved to the present day a table which belonged to M. Cicero, ${ }^{49}$ and for which, notwithstanding his. comparatively moderate means, and what is even more surprising still, at that day too, he gave no less than one ${ }^{50}$ million sesterces: we find mention made also of one belonging to Gallus Asinius, which cost one million one hundred thousand sesterces. Two tables were also sold by auction which had belonged to King Juba; the price fetched by one was one million two hundred thousand sesterces, and that of the other something less. There has been lately destroyed by fire, a table which came down from the family of the Cethegi, and which had been sold for the sum of one million four hundred thousand sesterces, the price of a considerable domain, if any one, indeed, could be found who would give so large a sum for an estate.

43 In c. 9 of the present Book.

44 See B. vi. c. $36,37$.

45 Desfontaines observed in the vicinity of Atlas, several trees peculiar to that district. Among others of this nature, he names the Pistacia Atlantica, and the Thuya articulata.

46 See B. v. c. 1.

47 Generally supposed to be the Thuya articulata of Desfontaines, the Cedrus Atlantica of other botanists.

48 This rage for fine tables made of the citrus is alluded to, among others, by Martial and Petronius Arbiter. See also Lucan, A. ix. B. 426, et. seq.

49 It is a rather curious fact that it is in Cicero's works that we find the earliest mention made of citrus tables, 2nd Oration ag. Verres, s. $4:-$ "You deprived Q. Lutatius Diodorus of Lilybæum of a citrus table of remarkable age and beauty."

50 Somewhere about $£ 9000$. 
The largest table that has ever yet been known was one that belonged to Ptolemæus, king of Mauretania; it was made of two semicircumferences joined together down the middle, being four feet and a half in diameter, and a quarter of a foot in thickness: the most wonderful fact, however, connected with it, was the surprising skill with which the joining had been concealed, ${ }^{51}$ and which rendered it more valuable than if it had been by nature a single piece of wood. The largest table that is made of a single piece of wood, is the one that takes its name ${ }^{52}$ from Nomius, a freedman of Tiberius Cæsar. The diameter of it is four feet, short by three quarters of an inch, and it is half a foot in thickness, less the same fraction. While speaking upon this subject, I ought not to omit to mention that the Emperor Tiberius had a table that exceeded four feet in diameter by two inches and a quarter, and was an inch and a half in thickness : this, however, was only covered with a veneer of citrus-wood, while that which belonged to his freedman Nomius was so costly, the whole material of which it was composed being knotted ${ }^{53}$ wood.

These knots are properly a disease or excrescence of the root, and those used for this purpose are more particularly esteemed which have lain entirely concealed under ground; they are much more rare than those that grow above ground, and that are to be found on the branches also. Thus, to speak correctly, that which we buy at so vast a price is in reality a defect in the tree: of the size and root of it a notion may be easily formed from the circular sections of its trunk. The tree resembles the wild female cypress ${ }^{54}$ in its foliage, smell, and the appearance of the trunk. A spot called Mount Ancorarius, in Nearer Mauretania, used formerly to furnish the most esteemed citrus-wood, but at the present day the supply is quite exhausted.

ChaP. 30.-THE POINTS THAT ARE DESIRABLE OR OTHERWISE IN THESE TABLES.

The principal merit of these tables is to have veins ${ }^{55}$ arranged

51 This is considered nothing remarkable at the present day, such is the skill displayed by our cabinet-makers.

52 Called "Nomiana."

53 Tuber.

54 The European cyprus, the Cupressus sempervirens of Linn:eus.

55 These veins were nothing in reality but the lines of the layers or 
in waving lines, or else forming spirals like so many little whirlpools. In the former arrangement the lines run in an oblong direction, for which reason these are called " tiger" 56 tables; while in the latter the marks are circling and spiral, and hence they are styled "panther" ${ }^{57}$ tables. There are some tables also with wavy, undulating marks, and which are more particularly esteemed if these resemble the eyes on a peacock's tail. Next in esteem to these last, as well as those previously mentioned, is the veined wood, ${ }^{56}$ covered, as it were, with dense masses of grain, for which reason these tables have received the name of "apiatæ." ${ }_{59}$ But the colour of the wood is the quality that is held in the highest esteem of all : that of wine mixed with honey ${ }^{60}$ being the most prized, the veinsbeing peculiarly refulgent. Next to the colour, it is the size that is prized ; at the present day whole trunks are greatly admired, and sometimes several are united in a single table.

The peculiar defects in these kinds of tables are woodiness, ${ }^{61}$ such being the name given to the table when the wood is dull, common-looking, indistinct, or else has mere simple marks upon it, resembling the leaves of the plane-tree; also, when it resembles the veins of the holm-oak or the colour of that tree; and, a fault to which it is peculiarly liable from the effect of heat or wind, when it has flaws in it or hair-like lines resembling flaws; when it has a black mark, too, running through it resembling a murena in appearance, various streaks that look like crow scratches, or knots like poppy heads, with a colour all over nearly approaching to black, or blotches of a sickly hue. The barbarous tribes bury this wood in the ground while green, first giving it a coating of wax. When it comes into the workmen's hands, they put it for seven days beneath a heap of corn, and then take it out for as many strata lignea, running perpendicularly in the trunk, and the number of which denotes the age of the tree.

56 "Tigrinæ."

57 "Pantherinæ." The former tables were probably made of small pieces from the trunk, the latter from the sections of the tubers or knots.

58 "Crispis."

59 Or "parsley-seed" tables. It has also been suggested that the word comes from "apis," a bee; the wood presenting the appearance of being covered with swarms of bees.

60 "Mulsum." This mixture will be found frequently mentioned in the next Book.

61 Lignum. 
more : it is quite surprising how greatly it loses in weight by this process. Shipwrecks have recently taught us also that this wood is dried by the action of sea-water, and that it thereby acquires a hardness ${ }^{62}$ and a degree of density which render it proof against corruption: no other method is equally sure to produce these results. These tables are kept best, and shine with the greatest lustre, when rubbed with the dry hand, more particularly just after bathing. As if this wood had been created for the behoof of wine, it receives no injury from it.

(16.) As this tree is one among the elements of more civilized life, I think that it is as well on the present occasion to dwell a little further upon it. It was known to Homer even, and in the Greek it is known by the name of "thyon," 63 or sometimes "thya." He says that the wood of this tree was among the unguents that were burnt for their pleasant odour by Circe, ${ }^{61}$ whom he would represent as being a goddess; a circumstance which shows the great mistake committed by those who suppose that perfumes are meant under that name, ${ }^{6 *}$ seeing that in the very same line he says that cedar and larch were burnt along with this wood, a thing that clearly proves that it is only of different trees that he is speaking. Theophrastus, an author who wrote in the age succeeding that of Alexander the Great, and about the jear of the City of Rome 440, has awarded a very high rank to this tree, stating that it is related that the raftering of the ancient temples used to be made of this wood, and that the timber, when employed in roofs, will last for ever, so to say, being proof against all decay,-quite incorruptible, in fact. He also says that there is nothing more full of wavy veins ${ }^{65}$ than the root of this tree, and that there is no workmanship in existence more precious than that made of this material. The finest kind of citrus grows, he says, in the vicinity of the Temple of Jupiter Hammon; he states also that it is produced in the lower part of Cyrenaica. He has made no mention, however, of the tables that are made of it; indeed, we have no more ancient accounts of

${ }^{62}$ Fée remarks that this is incorrect, and that this statement betrays an entire ignorance of the vegetable physiology.

63 Oviov, "wood of sacrifice."

${ }^{64}$ Od. B. v. 1. 60. Pliny makes a mistake in saying "Circe;" it should be "Calypso.

64* Oivov.

${ }^{65}$ Crispius. 
them than those of the time of Cicero, from which it would appear that they are a comparatively recent invention.

\section{CHAP. 31.-THE CITRON-TREE.}

There is another tree also which has the same name of "citrus," ${ }^{66}$ and bears a fruit that is held by some persons in particular dislike for its smell and remarkable bitterness; while, on the other hand, there are some who esteem it very highly. This tree is used as an ornament to houses; it requires, however, no further description.

\section{CHAP. 32. (17.)-THE LOTUS.}

Africa, too, at least that part of it which looks towards our shores, produces a remarkable tree, the lotus, ${ }^{67}$ by some known as the "celtis," which has also been naturalized in Italy, ${ }^{68}$. though it has been somewhat modified by the change of soil. The finest quality of lotus is that found in the vicinity of the Syrtes and among the Nasamones. It is the same size as the pear-tree, although Cornelius Nepos states to the effect that it is but short. The leaves have numerous incisions, just as with those of the holm-oak. There are many varieties of the lotus, which are characterized more particularly by the difference in their respective fruits. The fruit is of about the size of $a^{*}$ bean, and its colour is that of saffron, though before it is ripe it is continually changing its tints, like the grape. It has branches thickly set with leaves, like the myrtle, and not, as with us in Italy, like the cherry. In the country to which this tree is indigenous, the fruit of it is so remarkably sweet and luscious, that it has even given its name to a whole territory, and to a nation ${ }^{69}$ who, by their singular hospitality, have even seduced strangers who have come among them, to lose all remembrance of their native country. It is said also, that those who eat this fruit are subject to no maladies of the stomach. The fruit which has no stone in the inside is the best: this stone in the other kind seems to be of an osseous nature. A wine is also extracted from this fruit very similar

66 He alludes to the citron, the Citrus Medica of Linnæus. See B. xii. c.7.

${ }^{67}$ The Rhamnus lotus of Linnæus; the Zizyphus lotus of Desfontaines.

68 The Celtis australis of Linnæus. Fée remarks that Pliny is in error in giving the name of Celtis to the lotus of Africa.

69 The Lotophagi. See B. v. c. 7. 
to honied wine; according to Nepos, however, it will not last above ten days; he states also that the berries are chopped up with alica, ${ }^{70}$ and then put away in casks for the table. Indeed, we read that armies have been fed upon this food when marching to and fro through the territory of Africa. The wood is of a black colour, and is held in high esteem for making flutes; from the root also they manufacture handles for knives, and various other small articles.

Such is the nature of the tree that is so called in Africa; the same name being also given to a certain ${ }^{71}$ herb, and to a stalk ${ }^{72}$ that grows in Egypt belonging to the marsh plants. This last plant springs up when the waters of the Nile have retired after its overflow: its stalk is similar to that of the bean, and its leaves are numerous and grow in thick clusters, but are shorter and more slender than those of the bean. The fruit grows on the head of the plant, and is similar in appearance to a poppy in its indentations ${ }^{73}$ and all its other characteristics; within there are small grains, similar to those of millet. ${ }^{74}$ The inhabitants lay these heads in large heaps, and there let them rot, after which they separate the grain from the residue by washing, and then dry it; when this is done they pound it, and then use it as flour for making a kind of bread. What is stated in addition to these particulars, is a very singular ${ }^{75}$ fact ; it is said that when the sun sets, these poppy-heads shut and cover themselves in the leaves, and at sun-rise they open again; an alternation which continues until the fruit is perfectly ripe, and the flower, which is white, falls off.

(18.) Even more than this, of the lotus of the Euphrates, ${ }^{76}$ it is said that the head and flower of the plant, at nightfall, sink into the water, and there remain till midnight, so deep in the water, that on thrusting in one's arm, the head cannot be reached : after midnight it commences to return upwards, and gradually becomes more and more erect till sunrise, when it

${ }^{70}$ A kind of grain diet. See B. xviii. c. 29 , and B. xxii. c. 61 .

71 The Melilotus officinalis of Linnæus.

${ }_{72}$ The Nymphæa Nelumbo of Linnæus, or Egyptian bean.

${ }^{73} \mathrm{He}$ speaks of the indentations on the surface of the poppy-head.

74 See B. xxii. c. 28.

${ }^{75}$ Fée remarks that there is nothing singular about it, the sun more or less exercising a similar influence on all plants.

76 The same as the Nymphæa Nelumbo of the Nile, according to Fée. 
emerges entirely from the water and opens its flower; after which it still continues to rise, until at last it is to be seen raised quite aloft, high above the level of the water. This lotus has a root about the size of a quince, enveloped in a black skin, similar to that with which the chesnut is covered. The substance that lies within this skin is white, and forms very pleasant food, but is better cooked, either in water or upon hot ashes, then in a raw state. Swine fatten upon nothing better than the peelings of this root.

CHAP. 33. (19.) - THE tREes OF CYRENATCA. THE PALIURUS.

The region of Cyrenaica places before the lotus its paliurus, ${ }^{77}$ which is more like a shrub in character, and bears a fruit of a redder colour. This fruit contains a nut, the kernel of which is eaten by itself, and is of a very agreeable flavour. The taste of it is improved by wine, and, in fact, the juices are thought to be an improvement to wine. The interior of Africa, as far as the Garamantes and the deserts, is covered with palms, remarkable for their extraordinary size and the lusciousness of their fruit. The most celebrated are those in the vicinity of the Temple of Jupiter Hammon.

CHAP. 34. - NINE VARIETIES OF THE PUNIC APFLE. BaLAUSTIUM.

But the vicinity of Carthage is claimed more particularly as its own by the fruit the name of which is the "Punic apple;"; though by some it is called "granatum."79 This fruit has been distinguished into a variety of kinds; the name of "apyrenum" ${ }^{80}$ being given to the one which has ${ }^{81}$ woody seeds inside, but is naturally whiter than the others, the pips being of a more agreeable flavour, and the membranes by which they are separated not so bitter. Their conformation in

77 Probably the Rhamnus paliurus of Linnæus; the Spina Christi of other botanists.

78 The pomegranate, the Punica granatum of botanists.

79 Or "grained apple."

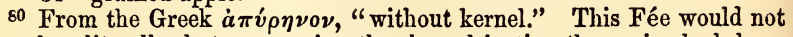
translate literally, but as meaning that by cultivation the grains had been reduced to a very diminutive size. See B. xxiii. c. 57 .

${ }_{81}$ This variety appears to be extinct. Fée doubts if it ever existed.

82 See B. xxiii. c. 57 
other respects, which is very similar to the partitions of the cells in the honeycomb, is much the same in all. Of those that have a kernel there are five kinds, the sweet, the acrid, the mixed, the acid, and the vinous: those of Samos and Egypt are distinguished into those with red, and those with white foliage. ${ }^{22}$ The skin, while the fruit is yet sour, is held in high esteem for tanning leather. The flower of this tree is known by the name of "balaustium," and is very useful for medicinal purposes ${ }^{83}$ also for dyeing cloths a colour which from it has derived its name. ${ }^{85}$

CHAP. 35. (20.) -THE TREeS OF ASIA AND GREECE; THE EPIPACTIS, THE ERICA, THE CNIDIAN GRAIN OR THYMELAA, PYROSACHNE, CNESTRON, OR CNEORON.

In Asia and Greece are produced the following shrubs, the epipactis, ${ }^{86}$ by some known as "elleborine," the leaves of which are of small size, and when taken in drink, are an antidote against poison; just in the same way that those of the erica ${ }^{87}$ are a specific against the sting of the serpent.

(21.) Here is also found another shrub, upon which grows the grain of Cnidos, ${ }^{88}$ by some known as "linum;" the name of the shrub itself being thymelæa, ${ }^{89}$ while others, again, call it "chamelæa, ${ }^{90}$ others pyrosachne, others cnestron, and others cneorum; it bears a strong resemblance to the wild olive, but has a narrow leaf, which has a gummy taste in the mouth. The shrub is of about the size of the myrtle; its seed is of the same colour and appearance, but is solely used for medicinal purposes.

CHAP. 36.-THE TRAGION: TRAGACANTHE.

The island of Crete is the only place that produces the 82 See B. xxiii. c. 57.

83 See B. xxiii. c. 60.

85 "Puniceus," namely, a kind of purple.

S6 See B. xxvii. c. 52. Sprengel thinks that this is the Neottia spiralis of Schwartz; but Fée is of opinion that it has not hitherto been identified. ${ }_{87}$ Probably the Erica arborea of Linnæus, or "heath" in its several varieties.

${ }^{88}$ Granum Cnidium. The shrub is the Daphne Cnidium of Linnæus.

89 The "thyme-olive."

90 The "ground olive," or "small olive." Dioscorides makes a distinction between these two last; and Sprengel has followed it, naming the ?.'st Daphne Cnidium, and the first Daphne Cneorum. 
shrub called " tragion." 91 It is similar in appearance to the terebinth; ${ }^{92}$ a similarity which extends to the seed even, said to be remarkably efficacious for healing wounds made by arrows. The same island produces tragacanthe ${ }^{93}$ also, with a root which resembles that of the white thorn; it is very much preferred $^{9 t}$ to that which is grown in Media or in Achaia; the price at which it sells is three denarii per pound.

CHAP. 37.-THE TRAGOS OR SCORPIO; THE MYRICA OR BRYA; THE OSTRYS.

Asia, too, produces the tragos ${ }^{95}$ or scorpio, a thorny shrub, destitute of leaves, with red clusters upon it that are employed in medicine. Italy produces the myrica, which some persons call the "tamarix;" ${ }^{96}$ and Achaia, the wild brya, ${ }^{97}$ remarkable for the circumstance that it is only the cultivated kind that bears a fruit, not unlike the gall-nut. In Syria and Egypt this plant is very abundant. It is to the trees of this last country that we give the name of " unhappy;" " but yet those of Greece are more unhappy still, for that country produces the tree known as " ostrys," or, as it is sometimes called, "ostrya," 99 a solitary tree that grows about rocks washed by the water, and very similar in the bark and branches to the ash. It re-

91 See B. xxvii. c. 115.

${ }^{92}$ He says elsewhere that it is like the juniper, which, however, is not. the case. Guettard thinks that the tragion is the Androsæmon fetidum, the Hyperium hircinum of the modern botanists. Sprengel also adopts the same opinion. Fée is inclined to think that it was a variety of the Pistacia lentiscus.

${ }^{93}$ Goat's thorn. The Astragalus Creticus of Linnæus.

$94 \mathrm{He}$ speaks of gum tragacanth.

95 See B. xxvii. c. 116. Sprengel identifies it with the Salsola tragus of Linnæus.

${ }_{96}$ Probably the Tamarix Gallica of Linnæus. Fée says, in relation to the myrica, that it would seem that the ancients united in one collective name, several plants which resembled each other, not in their botanical characteristics, but in outward appearance. To this, he says, is owing the fact that Dioscorides calls the myrica a tree, Favorinus a herb; Dioscorides says that it is fruitful, Nicander and Pliny call it barren; Virgil calls it small, and Theophrastus says that it is large.

${ }_{97}$ Fée thinks that it is the Tamarix orientalis of Delille.

98 "Infelix," meaning "sterile." He seems to say this more particularly in reference to the brya, which Egypt produces. As to this use of the word "infelix," see B. xvi. c. 46.

${ }^{99}$ Sprengel and Fée identify this with the Ostrya vulgaris of Willdenow, the Carpinus ostrya of Linnæus. 
sembles the pear-tree in its leaves, which, however, are a little longer and thicker, with wrinkled indentations running down the whole length of the leaf. The seed of this tree resembles barley in form and colour. The wood is hard and solid; it is said, that if it is introduced into a house, it is productive of painful deliveries and of shocking deaths.

\section{CHAP. 38. (22.) -THE EUONYMOS.}

There is no tree productive of a more auspicious presage than one which grows in the Isle of Lesbos, and is known by the name of euonymos. ${ }^{1}$ It bears some resemblance to the pomegranate tree, the leaf being in size between the leaf of that and the leaf of the laurel, while in shape and softness it resembles that of the pomegranate tree: it has a white blossom, ${ }^{2}$ by which it immediately gives us notice of its dangerous properties. $^{3}$ It bears a pod ${ }^{4}$ very similar to that of sesame, within which there is a grain of quadrangular shape, of coarse make and poisonous to animals. The leaf, too, has the same noxious effects; sometimes, however, a speedy alvine discharge is found to give relief on such occasions.

\section{CHAP. 39.-THE TREE CALLED EON.}

Alexander Cornelius has called a tree by the name of "eon," 5 with the wood of which, he says, the ship Argo was built. This tree has on it a mistletoe similar to that of the oak, which is proof against all injury from either fire or water,

1 Or the "luckily named." It grew on Mount Ordymnus in Lesbos. See Theophrastus, B. ii. c. 31 .

2 The Evonymus Europæus, or else the Evonymus latifolius of botanists, is probably intended to be indicated; but it is a mistake to say that it is poisonous to animals. On the contrary, Fee says that sheep will fatten on its leaves very speedily.

3 "Statim pestem denuntians." Pliny appears to be in error here. In copying from Theophrastus, he seems to have found the word фóvos used, really in reference to a blood-red juice which distils from the plant; but as the same word also means slaughter, or death, he seems to have thought that it really bears reference to the noxious qualities of the plant.

4 Fée censures the use of the word "siliqua," as inappropriate, although the seed does resemble that of sesamum, the Sesamum orientale of Linnæus.

5 Or eonis. Fée suggests that in this story, which probably belongs to the region of Fable, some kind of oak may possibly be alluded to. 
in the same manner, in fact, as that of no other tree known. This tree, however, appears to have been known to no other author, that I am aware of.

\section{CHAP. 40.-THE ANDRACHLE. ${ }^{6}$}

Nearly all the Greek writers interpret the name of the tree called "andrachle," as meaning the same as "purslain:" 7 whereas purslain is, in reality, a herb, and, with the difference of a single letter, is called "andrachne." The andrachle is a wild tree, which never grows in the plain country, and is similar to the arbute tree in appearance, only that its leaves are smaller, and never fall off. The bark, too, is not rough, but might be taken to be frozen all over, so truly wretched is its appearance.

\section{CHAP. 41.-THE COCCYGIA ; THE APHARCE.}

Similar, too, in leaf to the preceding tree, is the coccygia, ${ }^{8}$ though not so large; it has this peculiarity, that it loses its fruit while still in the downy ${ }^{9}$ state-they then call it "pappus"-a thing that happens to no other tree. The apharce ${ }^{10}$ is another tree that is similar to the andrachle, and like it, bears twice in the year : just as the grape is beginning to flower the first fruit is ripening, while the second fruit ripens at the commencement of winter; of what nature this fruit is we do not find stated.

\section{CHAP. 42.-THE FERULA.}

We ought to place the ferula ${ }^{11}$ also in the number of the exotics, and as making one of the trees. For, in fact, we distinguish the trees into several different kinds : it is the nature of some to have wood entirely in place of bark, or, in other

"In the former editions, "adrachne"-the Arbutus integrifolia, Fée says, and not the Arbutus andrachne of Linnæus, as Sprengel thinks.

" "Porcillaca." The Portulaca oleracea of Linnæus.

8 The Rhus cotinus of Linnæus, a sort of sumach.

9 This is not the fact; the seeds when ripe are merely lost to view in the large tufts of down which grow on the stems.

10 Generally supposed to be the same as the alaternus, mentioned in B. xvi. c. 45. Some writers identify it with the Phyllirea angustifolia of Linnæus.

11 Probably the Ferula communis of Linnæus, the herb or shrub known as "fennel giant." 
words, on the outside; while, in the interior, in place of wood, there is a fungous kind of pith, like that of the elder; others, again, are hollow within, like the reed. The ferula grows in hot countries and in places beyond sea, the stalk being divided into knotted joints. There are two kinds of it; that which grows upwards to a great height the Greeks call by the name of " narthex," 12 while the other, which never rises far from the ground, is known as the "narthecya." 13 From the joints very large leaves shoot forth, the largest lying nearest to the ground: in other respects it has the same nature as the anise, which it resembles also in its fruit. The wood of no shrub is lighter than this; hence it is very easily carried, and the stalks of it make good walking-sticks ${ }^{14}$ for the aged.

\section{CHAP. 43. - THE THAPSIA.}

The seed of the ferula has been by some persons called " thapsia;" ${ }^{15}$ deceived, no doubt, by what is really the fact, that the thapsia is a ferula, but of a peculiar kind, with leaves like those of fennel, and a hollow stalk not exceeding a walking-stick in length; the seed is like that of the ferula, and the root of the plant is white. When an incision is made in the thapsia, a milky juice oozes from it, and, when pounded, it produces a kind of juice; the bark even is never thrown ${ }^{16}$ away. All these parts of the shrub are poisonous, and, indeed, it is productive of injurious effects to those engaged in digging it up; for if the slightest wind should happen to be blowing towards them from the shrub, the body begins to swell, and erysipelas attacks the face $:$ it is for this reason that, before beginning work, they anoint the face all over with a solution of wax. Still, however, the medical men say that, mixed with other ingredients, it is of considerable use in the

12 The Ferula glauca of Linnæus.

13 The Ferula nodiflora of Linnæus.

14 It is still used for that purpose in the south of Europe. The Roman schoolmasters, as we learn from Juvenal, Martial, and others, employed it for the chastisement of their scholars. Pliny is in error in reckoning it among the trees, it really having no pretensions to be considered such. It is said to have received its name from "ferio," to "beat."

15 Sprengel thinks that this is the Thapsia asclepium of the moderns; but Fée takes it to be the Thapsia villosa of Linnæus.

${ }_{16}$ It was valued, Dioscorides says, for its cathartic properties. 
- treatment of some diseases. It is employed also for the cure of scald-head, and for the removal of black and blue spots upon the skin, as if, indeed, we were really at a loss for remedies in such cases, without having recourse to things of so deadly a nature. These plants, however, act their part in serving as a pretext for the introduction of noxious agents; and so great is the effrontery now displayed, that people would absolutely persuade one that poisons are a requisite adjunct to the practice of the medical art.

The thapsia of Africa $^{17}$ is the most powerful of all. Some persons make an incision in the stalk at harvest-time, and bore holes in the root, too, to let the juice flow; after it has become quite dry, they take it away. Others, again, pound the leaves, stalk, and root in a mortar, and after drying the juice in the sun, divide it into lozenges. ${ }^{18}$ Nero Cæsar, at the beginning of his reign, conferred considerable celebrity on this plant. In his nocturnal skirmishes ${ }^{19}$ it so happened that he received several contusions on the face, upon which he anointed it with a mixture composed of thapsia, frankincense, and wax, and so contrived the next day effectually to give the lie to all rumours, by appearing with a whole skin. ${ }^{20}$ It is a well-known fact, that fire ${ }^{21}$ is kept alight remarkably well in the hollow stalk of the ferula, and that for this purpose those of Egypt are the best.

CHAP. 44. (23.)-THE CAPPARIS OR CYNOSBATON, OTHERWISE OPHIOSTAPHYLE.

In Egypt, too, the capparis ${ }^{22}$ is found, a shrub with a wood

17 Either the Thapsia garganica of Willdenow, or the Thapsia villosa, found in Africa and the south of Europe, though, as Pliny says, the thapsia of Europe is mild in its effects compared with that of Africa. It is common on the coast of Barbary.

18 Pastillos.

19 Nocturnis grassationibus.

20 It is still used in Barbary for the cure of tetter and ringworm.

21 The story was, that Prometheus, when he stole the heavenly fire from Jupiter, concealed it in a stalk of narthex.

${ }_{22}$ The "caper-tree," the Capparis spinosa of Linnæus. Fée suggests that Pliny may possibly allude, in some of the features which he describes, to kinds less known ; such, for instance, as the Capparis inermis of Forskhal, found in Arabia ; the Capparis ovata of Desfontaines, found in Barbary; the Capparis Sinaica, found on Mount Sinai, and remarkable frr the size of its fruit; and the Capparis Eggyptiaca of Lamarck, commonly found in Egypt. 
of much greater solidity. The seed of it is a well-known article of food, ${ }^{23}$ and is mostly gathered together with the stalk. It is as well, however, to be on our guard against the foreign kinds $;^{24}$ for that of Arabia has certain deleterious properties, that from Africa is injurious to the gums, and that from Marmarica is prejudicial to the womb and causes flatulence in all the organs. That of Apulia, too, is productive of vomiting, and causes derangement in the stomach and intestines. Some persons call this shrub "cynosbaton," 25 others, again, "ophiostaphyle."

\section{CHAP. 45.-THE SARIPHA.}

The saripha, ${ }^{27}$ too, that grows on the banks of the Nile, is one of the shrub genus. It is generally about two cubits in height, and of the thickness of one's thumb: it has the foliage of the papyrus, and is eaten in a similar manner. The root, in consequence of its extreme hardness, is used as a substitute for charcoal in forging iron.

\section{CHAP. 46. (24.)-THE ROYAL THORN.}

We must take care, also, not to omit a peculiar shrub that is planted at Babylon, and only upon a thorny plant there, as it will not live anywhere else, just in the same manner as the mistletoe will.live nowhere but upon trees. This shrub, however, will only grow upon a kind of thorn, which is known as the royal thorn. ${ }^{28}$ It is a wonderful fact, but it germinates the very same day that it has been planted. This is done

${ }_{23}$ The stalk and seed were salted or pickled. The buds or unexpanded flowers of this shrub are admired as a pickle or sauce of delicate flavour.

${ }^{24}$ Fée remarks that this is not the truth, all the kinds possessing the same qualities. There may, however, have been some difference in the mode of salting or pickling them, and possibly productive of noxious effects.

${ }_{25}$ Probably from its thorns, that being the name of the sweet-briar, or dog-rose. 26 " Serpent grapes."

${ }_{27}$ Sprengel and Fée take this to be the Cyperus fastigiatus of Linnæus, which Forskhal found in the river Nile.

${ }^{28}$ Spina regia. Some writers have considered this to be the same with the Centaurea solstitialis of Linnæus. Sprengel takes it to be the Cassyta filiformis of Linnæus, a parasitical plant of India. We must conclude, however, with Fée, that both the thorn and the parasite have not hitherto been identified. 
at the rising of the Dog-star, after which it speedily takes possession of the whole tree. They use it in the preparation of wine, and it is for this purpose that it is planted. This thorn grows at Athens also, upon the Long Walls there. ${ }^{29}$

\section{CHAP. 47.-THE CYTISUS.}

The cytisus ${ }^{30}$ is also a shrub, which, as a food for sheep, has been extolled with wonderful encomiums by Aristomachus the Athenian, and, in a dry state, for swine as well: the same author, too, pledges his word that a jugerum of very middling land, planted with the cytisus, will produce an income of two thousand sesterces per annum. It is quite as useful as the ervum, ${ }^{31}$ but is apt to satiate more speedily : very little of it is necessary to fatten cattle; to such a degree, indeed, that beasts of burden, when fed upon it, will very soon take a dislike to barley. There is no fodder known, in fact, that is productive of a greater abundance of milk, and of better quality; in the medical treatment of cattle in particular, this shrub is found a most excellent specific for every kind of malady. Even more than this, the same author recommends it, when first dried and then boiled in water, to be given to nursing women, mixed with wine, in cases where the milk has failed them: and he says that, if this is done, the infant will be all the stronger and taller for it. In a green state, or, if dried, steeped in water, he recommends it for fowls. Both Democritus and Aristomachus promise us also that bees will never fail us so long as they can obtain the cytisus for food. There is no crop that we know of, of a similar nature, that costs a smaller price. It is sown at the same time as barley, or, at all events, in the spring, in seed like the leek, or else planted in the autumn, and before the winter solstice, in the stalk. When sown in grain, it ought to be steeped in water, and if

29 The Makron Teichos. See B. iv. c. 11.

30 From the various statements of ancient authors, Fée has come to the conclusion that this name was given to two totally different productions. The cytisus which the poets speak of as grateful to bees and goats, and sheep, he-takes to be the Medicago arborea of Linnæus, known to us as Medic trefoil, or lucerne; while the other, a tree with a black wood, he considers identical with the Cytisus laburnum of Linnæus, the laburnum, or false ebony tree.

31 A kind of vetch or tare. See B. xviii. 
there should happen to be no rain, it ought to be watered when sown: when the plants are about a cubit in height, they are replanted in trenches a foot in depth. It is transplanted at the equinoxes, while the shrub is yet tender, and in three years it will arrive at maturity. It is cut at the vernal equinox, when the flower is just going off; a child or an old woman is able to do this, and their labour may be had at a trifling rate. It is of a white appearance, and if one would wish to express briefly what it looks like, it is a trifoliated shrub, ${ }^{32}$ with small, narrow leaves. It is always given to animals at intervals of a couple of days, and in winter, when it is dry, before being given to them, it is first moistened with water. Ten pounds of cytisus will suffice for a horse, and for smaller animals in proportion : if I may here mention it by the way, it is found very profitable to sow garlic and onions between the rows of cytisus.

This shrub has been found in the Isle of Cythnus, from whence it has been transplanted to all the Cyclades, and more recently to the cities of Greece, a fact which has greatly increased the supply of cheese: considering which, I am much surprised that it is so rarely used in Italy. This shrub is proof, too, against all injuries from heat, from cold, from hail, and from snow : and, as Hyginus adds, against the depredations of the enemy even, the wood ${ }^{33}$ produced being of no value whatever.

CHAP. 48. (25.)—THE TREES AND SHRUBS OF THE MEDITERRANEAN. THE PHYCOS, PRASON, OR ZOSTER.

Shrubs and trees grow in the sea $a^{34}$ as well; those of our sea $^{35}$ are of inferior size, while, on the other hand, the Red Sea and all the Eastern Ocean are filled with dense forests. No other language has any name for the shrub which is known to the Greeks as the "phycos," 36 since by the word "alga"

32 "Frutex." When speaking of it as a shrub, he seems to be confounding the tree with the plant.

33 Evidently in allusion to the tree.

34 He alludes to various kinds of fucus or sea-weed, which grows to a much larger size in the Eastern seas.

35 The Mediterranean.

36 Whence the word "fucus" of the naturalists.

37 Fée suggests that this may be the Laminaria saccharina of Linnæus, being one of the "ulvæ" often thrown up on the coasts of Europe.

roL. III. 
mere herb is generally understood, while the "phycos" is a complete shrub. This plant has a broad leaf of a green colour, which is by some called "prason," 38 and by others is known as "zoster." 39 Another kind," again, has a hairy sort of leaf, very similar to fennel, and grows upon rocks, while that previously mentioned grows in shoaly spots, not far from the shore. Both kinds shoot in the spring, and die in autumn..$^{41}$ The phycos ${ }^{42}$ which grows on the rocks in the neighbourhood of Crete, is used also for dyeing purple; the best kind being that produced on the north side of the island, which is the case also with sponges of the very best quality. A third kind, 43 again, is similar in appearance to grass; the root of it is knotted, and so is the stalk, which resembles that of a reed.

\section{CHAP. 49.-THE SEA BRYON.}

There is another kind of marine shrub, known by the name of "bryon ;" 44 it has the leaf of the lettuce, only that it is of a more wrinkled appearance; it grows nearer land, too, than the last. Far out at sea we find a fir-tree ${ }^{45}$ and an oak, ${ }^{46}$ each a cubit in height; shells are found adhering to their branches. It is said that this sea-oak is used for dyeing wool, and that some of them even bear acorns ${ }^{47}$ in the sea, a fact which has been ascertained by shipwrecked persons and divers. There are other marine trees also of remarkable size, found in the vicinity of Sicyon; the sea-vine, ${ }^{48}$ indeed, grows everywhere. The sea-fig ${ }^{49}$ is destitute of leaves, and the bark is red. There

38 The "green" plant.

39 The " girdle" plant.

40 The Fucus barbatus, probably, of Linnæus, or else the Fucus eroïdes.

41 They are in reality more long-lived than this.

42 Fée suggests that it is the Roccella tinctoria of Linnæus.

43 'The Zostera marina' of Linnæus, according to Fée.

44 The Ulva lactuca of the moderns, a very common sea-weed.

45 The Fucus ericoïdes, Fée suggests, not unlike a fir in appearance.

46 Quereus. According to Gmellin, this is the Fucus vesiculosus of Linnæus. Its leaves are indented, somewhat similarly to those of the oak.

${ }^{17}$ Polybius, as quoted by Athenæus, says that in the Lusitanian Sea there are oaks that bear acorns, on which the thunnies feed and grow fat.

$48 \mathrm{On}$ the contrary, Theophrastus says, B. iv. c. 7 , that the sea-vine grows near the sea, from which Fée is disposed to consider it a phanerogamous plant. If, on the other hand, it is really a fucus, he thinks that the Fucus uvarius may be meant, the vesicles of which resemble a grape in shape.

${ }_{43}$ He speaks of a madrepore, Fée thinks, the identity of which it is 
is a palm-tree ${ }^{50}$ also in the number of the sea-shrubs. Beyond the columns of Hercules there is a sea-shrub that grows with the leaf of the leek, and others with those of the carrot, ${ }^{51}$ and of thyme. Both of these last, when thrown up by the tide, are transformed ${ }^{52}$ into pumice.

\section{CHAP. 50.-PLANTS OF THE RED SEA.}

In the East, it is a very remarkable thing, that immediately after leaving Coptos, as we pass through the deserts, we find nothing whatever growing, with the exception of the thorn that is known as the "thirsty" 53 thorn; and this but very rarely. In the Red Sea, however, there are whole forests found growing, among which more particularly there are plants that bear the laurel-berry and the olive $;^{54}$ when it rains also certain fungi make their appearance, which, as soon as they are touched by the rays of the sun, are turned into pumice. ${ }^{55}$ The size of the shrubs is three cubits in height; and they are all filled with sea-dogs, ${ }^{56}$ to such a degree, that it is hardly safe to look at them from the ship, for they will frequently seize hold of the very oars.

\section{CHAP. 51.-PLANTS OE THE INDIAN SEA.}

The officers ${ }^{57}$ of Alexander, who navigated the Indian seas, have left an account of a marine tree, the foliage of which is green while in the water; but the moment it is taken out, it

difficult to determine. Professor Pallas speaks of an Alcyonidium ficus, which lives in the Mediterranean and in the ocean, and which resembles a fig, and has no leaves, but its exterior is not red.

${ }_{50}$ Fée queries whether this may not be the Gorgonia palma of Linnæus, which has received its name from its resemblance to a small palm-tree.

51 These three, Fée thinks, are madrepores or zoophytes, which it would be vain to attempt to identify.

${ }_{52}$ That is, they dry up to the consistency of pumice.

53 "Sitiens." Delille considers this as identical with his Acacia seyal, a thorny tree, often to be seen in the deserts of Africa.

${ }^{54}$ Probably zoophytes now unknown.

${ }_{55}$ Fée suggests that he may allude to the Madrepora fungites of Linnæus, the Fungus lapideus of Bauhin. These are found in the Red Sea and the Indian Ocean ; but, of course, the story of their appearance during rain is fabulous.

${ }^{56}$ Sharks; see B. ix. c. 70.

57 The companions of Onesicritus and Nearchus. 
dries and turns to salt. They have spoken also of bulrushes ${ }^{58}$ of stone bearing a strong resemblance to real ones, which grew along the sea-shore, as also certain shrubs ${ }^{59}$ in the main sea, the colour of an ox's horn, branching out in various directions, and red at the tips. These, they say, were brittle, and broke like glass when touched, while, on the other hand, in the fire they would become red-hot like iron, and when cool resume their original colour.

In the same part of the earth also, the tide covers the forests that grow on the islands, although the trees there are more lofty ${ }^{60}$ than the very tallest of our planes and poplars! 'The leaves of these trees resemble that of the laurel, while the blossom is similar to the violet, both in smell and colour: the berries resemble those of the olive, and they, too, have an agreeable smell: they appear in the autumn, and the leaves of the trees never fall off. The smaller ones are entirely covered by the waves, while the summits of those of larger size protrude from the water, and ships are made fast to them; when the tide falls the ressels are similarly moored to the roots. We find the same persons making mention of certain other trees which they saw out at sea, which always retained their leaves, and bore a fruit very similar to the lupine.

CHAP. 52.-THE PLANTS OF THE TROGLODYTIC SEA; THE HAIR OF ISIS : THE CHARITO-BLEPHARON.

Juba relates, that about the islands of the Troglodytx there is a certain shrub found out at sea, which is known as the " hair of Isis :" 61 he says that it bears a strong resemblance to coral, is destitute of leaves, and if cut will change its colour, becoming quite black and hard, and so brittle as to break if it falls. He speaks also of another marine plant, to which he gives the name of "Charito-blepharon," 62 and which,

58 Fée hazards a conjecture that this may be the Gorgonia scirpea of Pallas, found in the Indian Seas.

${ }_{59}$ One of the Gorgoniæ, Fée thinks ; but its characteristics are not sufficiently stated to enable us to identify it.

60 A fable worthy of Sinbad the Sailor!

61 "Isidis crinem." Fée says that this is evidently black coral, the Gorgonia antipathes of Linnæus.

62 "The eyelid of the Graces." Fée is almost tempted to think that he means red coral. 
he says, is particularly efficacious in love-charms. ${ }^{60}$ Bracelets ${ }^{64}$ and necklaces are made of it. He says also that it is sensible ${ }^{65}$ when it is about to be taken, and that it turns as hard as horn, so hard, indeed, as to blunt the edge of iron. If, on the other hand, it is cut before it is sensible of the danger, it is immediately transformed to stone.

SUmmary.-Remarkable facts, narratives, and observations, four hundred and sixty-eight.

Roman authors QUoted.-M. Varro, ${ }^{66}$ Mucianus, ${ }^{67}$ Virgil, ${ }^{66}$ Fabianus, ${ }^{69}$ Sebosus, ${ }^{70}$ Pomponius Mela, ${ }^{71}$ Fabius $^{72}$ Procilius, ${ }^{73}$ Hyginus, ${ }^{74}$ Trogus, ${ }^{75}$ Claudius Cæsar, ${ }^{76}$ Cornelius Nepos, ${ }^{77}$ Sextius Niger ${ }^{78}$ who wrote in Greek on Medicine, Cassius Hemina, ${ }^{79}$ L. Piso, ${ }^{80}$ Tuditanus, ${ }^{81}$ Antias ${ }^{82}$

Foneign aUthors QUoted. - Theophrastus, ${ }^{83}$ Herodotus, ${ }^{84}$ Callisthenes, ${ }^{85}$ Isigonus, ${ }^{86}$ Clitarchus, ${ }^{87}$ Anaximenes, ${ }^{88}$ Duris, ${ }^{89}$ Nearchus, ${ }^{90}$ Onesicritus,${ }^{91}$ Polycritus, ${ }^{92}$ Olympiodorus, ${ }^{93}$ Diognetus, ${ }^{94}$ Cleobulus, ${ }^{95}$ Anticlides, ${ }^{96}$ Chares ${ }^{97}$ of Mitylene, Menæchmus, ${ }^{98}$ Dorotheus ${ }^{99}$ of Athens, Lycus, ${ }^{1}$ Antæus, ${ }^{2}$ Ephip-

63 Amatoriis.

64 Spatalia. Armlets or bracelets.

c5 By this apparently fabulous story, one would be almost inclined to think that he is speaking of a zoophyte.

66 See end of B. ii. 67 See end of B. ii.

68 See end of $B$ vii.

69 Papirius Fabianus. See end of B. ii.

$7 \mathrm{C}$ See end of B. ii. $\quad 71$ See end of B. iii.

72 Fabius Pictor. See end of B. $\mathbf{x}$.

73 See end of B. viii. $\quad 74$ Sce end of B. iii.

75 Trogus Pompeius. See end of B. vii.

76 See end of B. $\nabla$. 77 See end of B. ii.

78 See end of B. xii. $\quad 79$ See end of B. xii.

on See end of B. ii. $\quad 81$ See end of B. xii.

82 See end of B. ii. $\quad 63$ See end of B. iii.

84 See end of B. ii. $\quad 85$ See end of B. xii.

86 See end of B. vii. $\quad 87$ See end of B. vi.

88 See end of B. xii. $\quad 89$ See end of B. vii.

90 See end of B. vi. $\quad 91$ See end of B. ii.

92 See end of B. xii. $\quad 93$ See end of B. xii.

ot See end of B. vi. $\quad 95$ See end of B. iv.

96 See end of B. iv. $\quad 97$ See end of B. xii.

98 See end of B. iv. $\quad 99$ See end of B. viii.

1 See end of B. xii. 2 See end of B. xii. 
pus, $^{3}$ Dion, ${ }^{4}$ Adimantus, ${ }^{5}$ Ptolemy Lagus, ${ }^{6}$ Marsyas ${ }^{7}$ of Macedon, Zoilus ${ }^{8}$ of Macedon, Democritus, ${ }^{9}$ Amphilochus, ${ }^{10}$ Alexander Polyhistor, ${ }^{12}$ Aristomachus, ${ }^{12}$ King Juba, ${ }^{13}$ Apollodorus ${ }^{14}$ who wrote on Perfumes, Heraclides ${ }^{15}$ the physician, Botrys ${ }^{16}$ the physician, Archidemus ${ }^{17}$ the physician, Dionysius $^{18}$ the physician, Democlides ${ }^{19}$ the physician, Euphron ${ }^{80}$ the physician, Mnesides ${ }^{21}$ the physician, Diagoras ${ }^{22}$ the physician, Iollas ${ }^{23}$ the physician, Heraciides ${ }^{24}$ of Tarentum, Xenocrates $^{25}$ of Ephesus.

3 See end of B. xii.

4 See end of B. viii.

5 Nothing certain is known of him ; but he appears to be the geographer, a native of Lampsacus, mentioned by Strabo in B. xiii.

${ }^{6}$ See end of $\mathrm{B}$. xii.

$\&$ See end of B. xii.

7 See end of B. xii.

9 See end of B. ii.

10 See end of B. viii.

11 See end of B. iii.

12 A writer on Agriculture, or domestic economy; but nothing further is known of him.

13 See end of B. $v$.

14 Perhaps the same writer that is mentioned at the end of $\mathrm{B}$. xi.

15 For two physicians of this name, see end of $B$. xii.

16 One of his prescriptions is preserved in the works of Galen. Nothing else is known of him.

18 See end of $B$. xii.

20 See end of B. xii.

22 See end of B. xii.

24 See end of B. xii.

${ }_{17}$ See end of B. xii.

19 See end of B. xii.

21 See end of $B$. xii.

${ }^{23}$ See end of B. xii.

25 See end of B. xii. 


\section{BOOK XIV.}

TIIE NATURAL HISTORY OF THE FRUIT TREES.

CHAPS. $1 \& 2$. (1.)-THE NATURE OF THE VINE. ITS MODE OF FRUCTIFICATION.

Those which have been hitherto mentioned, are, nearly all of them, exotic trees, which it is impossible to rear in any other than their native soil, and which are not to be naturalized in strange countries. ${ }^{1}$ It is now for us to speak of the more ordinary kinds, of all of which Italy may be looked upon as more particularly the parent. ${ }^{2}$ Those who are well acquainted with the subject, must only bear in mind that for the present we content ourselves with merely stating the different varieties of these trees, and not the mode of sultivating them, although there is no doubt that the characteristics of a tree depend very considcrably upon its cultivation. At this fact' I cannot sufficiently express my astonishment, that of some trees all memory has utterly perished, and that the very names of some, of which we find various authors making mention, have wholly disappeared. ${ }^{3}$ And yet who does not readily admit that now, when intercommunications have been opened between all parts of the world, thanks to the majestic sway of the Roman empire, civilization and the arts of life have made a rapid progress, owing to the interchange of commodities and the common enjoyment by all of the blessings of peace, while at the same time a multitude of objects which

1 This must be understood with considerable modification-many - of the tropical trees and plants have been naturalized, and those of America more particularly, in Europe.

${ }^{2} \mathrm{He}$ is probably wrong in looking upon the vine as indigenous to Italy. It was known in very early times in Egypt and Greece, and it is now generally considered that it is indigenous throughout the tract that stretches to the south, from the the mountains of Mazandiran on the Caspian to the shores of the Persian Gulf and the Indian Sea, and eastward through Khorassan and Cabul to the base of the Himalayas.

3 The art of printing, Fée remarks, utterly precludes the recurrence of such a fact as this. 
formerly lay concealed, are now revealed for our indiscriminate use?

Still, by Hercules! at the present day there are none to be found who have any acquaintance with much that has been handed down to us by the ancient writers; so much more comprehensive was the diligent research of our forefathers, or else so much more happily employed was their industry. It is a thousand years ago since Hesiod, ${ }^{4}$ at the very dawn, so to say, of literature, first gave precepts for the guidance of the agriculturist, an example which has since been followed by no small number of writers. Hence have originated considerable labours for ourselves, seeing that we have not only to enquire into the discoveries of modern times, but to ascertain as well what was known to the ancients, and this, too, in the very midst of that oblivion which the heedlessness of the present day has so greatly tended to generate." What causes then are we to assign for this lethargy, other than those feelings which we find actuating the public in general throughout all the world? New manners and usages, no doubt, have now come into vogue, and the minds of men are occupied with subjects of a totally different nature; the arts of avarice, in fact, are the only ones that are now cultivated.

In days gone by, the sway and the destinies of states were bounded by their own narrow limits, and consequently the genius of the people was similarly circumscribed as well, through a sort of niggardliness that was thus displayed by Fortune: hence it became with them a matter of absolute necessity to employ the advantages of the understanding: kings innumerable received the homage of the arts, and in making a display of the extent of their resources, gare the highest rank to those arts, entertaining the opinion that it was through them that they should ensure immortality. Hence it was that due rewards, and the various works of civilization, were displayed in such vast abundance in those times. For these later ages, the enlarged boundaries of the habitable world, and the vast extent of our empire, have been a positive injury. Since the Censor has been chosen for the extent of his property, since the judge has been selected according to the magnitude of his fortune, since it has become the fashion to consider that

4 In allusion to his poem, the "Works and Days," the prototype of Virgil's Georgics. 
nothing reflects a higher merit upon the magistrate and the general than a large estate, since the being destitute of heirs ${ }^{5}$ has begun to confer upon persons the very highest power and influence, since legacy-hunting ${ }^{6}$ has become the most lucrative of all professions, and since it has been considered that the only real pleasures are those of possessing, all the true enjoyments of life have been utterly lost sight of, and all those arts which have derived the name of liberal, from liberty, ${ }^{7}$ that greatest blessing of life, have come to deserve the contrary appellation, servility alone being the passport to profit.

This servility each one has his own peculiar way of making most agreeable, and of putting in practice in reference to others, the motives and the hopes of all tending to the one great object, the acquisition of wealth : indeed, we may everywhere behold men even of naturally excellent qualities preferring to foster the vicious inclinations of others rather than cultivate their own talents. We may therefore conclude, by Hercules! that pleasure has now begun to live, and that life, truly so called, has ceased to be. ${ }^{8}$ As to ourselves, however, we shall continue our researches into matters now lost in oblivion, nor shall we be deterred from pursuing our task by the trivial nature ${ }^{9}$ of some of our details, a consideration which has in no way influenced us in our description of the animal world. And yet we find that Virgil, that most admirable poet, has allowed this to influence him, in his omission to enlarge upon the beauties of the garden; for, happy and graceful poet as he is, he has only culled what we may call the flower of his subject: indeed, we find that he has only named ${ }^{10}$ in all some fifteen varieties of the grape, three of the olive, the same number of the pear, and the citron of Assyria, and has passed over the rest in silence altogether.

(2). With what then ought we to begin in preference to the vine, the superiority in which has been so peculiarly con-

5 He alludes to the legacy-hunters with which Rome abounded in his time. They are spoken of by Seneca, Tacitus, and Juvenal, in terms of severe reprobation.

6 This seems to be the meaning of "captatio ;" much like what we call " toadying," or " toad-eating."

7 The "liberales artes," were those, the pursuit of which was not considered derogatory to the dignity of a free man.

8 Vita ipsa desiit.

9 Humilitas.

10 In the Georgies. 
ceded to Italy, that in this one blessing we may pronounce her to have surpassed those of all other nations of the earth, with the sole exception of those that bear the various perfumes? and even there, when the vine is in flower, there is not a perfume known which in exquisite sweetness can surpass it. The vine has been justly reckoned ${ }^{11}$ by the ancients among the trees, on account of its remarkable size. In the city of Populonium, we see $a$ statue of Jupiter formed of the trunk of a single vine, which has for ages remained proof against all decay; and at Massilia, there is a patera made of the same wood. At Metapontum, the temple of Juno has long stood supported by pillars formed of the like material; and even at the present day we ascend to the roof of the temple of Diana at Ephesus, by stairs constructed, it is said, of the trunk of a single vine, that was brought from Cyprus; the vines of that island often attaining a most remarkable size. There is not a wood in existence of a more lasting nature than this; I am strongly inclined, however, to be of opinion that the material of which these various articles were constructed was the wild vine.

\section{CHAP. 3.-THE NATURE OF THE GRAPE, AND THE CULTIVATION OF THE VINE.}

The cultivated vine is kept down by pruning every year; and all the strength of the tree is drawn as much as possible into the shoots, or else thrown downwards to the sets $; ;^{12}$ indeed, it is only allowed to expand with the view of ensuring an abundant supply of juice, a result which is obtained in various modes according to the peculiarities of the climate and the nature of the soil. In Campania they attach ${ }^{13}$ the vine to the poplar : embracing the tree to which it is thus wedded, the vine grasps the branches with its amorous arms, and as it climbs, holds on with its knotted trunk, till it has reached the very summit; the height being sometimes so stupendous that the vintager when hired is wont to stipulate for his funeral pile and a grave at the owner's expense. The vine keeps

11 Theophrastus reckons it among the trees; Columella, B. ii., considers it to occupy a middle position between a tree and a shrub. Horace, B. i. Ode 18, calls it a tree, " arbor.'

12 Or "layers," "propagines."

13 Nubunt, properly " marry." This is still done in Naples, and other parts of Italy. The use of vine stays there are unknown. 
continually on the increase, and it is quite impossible to separate the two, or rather, I may say, to tear them asunder. Valerianus Cornelius has regarded it as one of the most remarkable facts that could be transmitted to posterity, that single vines have been known to surround villas and countryhouses with their shoots and creeping tendrils ever on the stretch. At Rome, in the porticoes of Livia, a single vine, with its leaf-clad trellises, protects with its shade the walks in the open air; the fruit of it yields twelve amphoræ of must. 14

Everywhere we find the vine overtopping the elm even, and we read that Cineas, ${ }^{14^{*}}$ the ambassador of King Pyrrhus, when admiring the great height of the vines at Aricia, wittily making allusion to the peculiar rough taste of wine, remarked that it was with very good reason that they had hung the parent of it on so lofty a gibbet. There is a tree in that part of Italy which lies beyond the Padus, ${ }^{15}$ known as the "rumpotinus," 15* or sometimes by the name of "opulus," the broad circular ${ }^{16}$ storeys of which are covered with vines, whose branches wind upwards in a serpentine form to the part where the boughs finally divide ${ }^{17}$ and then, throwing out their tendrils, disperse them in every direction among the straight and finger-like twigs which project from the branches. There are vines also, about as tall as a man of moderate height, which are supported by props, and, as they throw out their bristling tendrils, form whole vineyards : while others, again, in their inordinate love for climbing, combined with skill on the part of the proprietor, will cover even the very centre ${ }^{18}$ of the court-yard with their shoots and foliage.

14 "Mustum." Pure, unfermented juice of the grape.

14* See B. vii. c. $24 . \quad 15$ Italia Transpadana.

15* See B. xxiv. c. 112. The Bauhins are of opinion that this is the Acer opulus of Willdenow, common in Italy, and very branchy.

16 "Tabulata in orbem patula." He probably alludes to the branches extending horizontally from the trunk.

17 "In palmam ejus."

18 There is no doubt that the whole of this passage is in a most corrupt state, and we can only guess at its meaning. Sillig suggests a new reading, which, unsupported as it is by any of the MSS., can only be regarded as fanciful, and perhaps as a very slight improvement on the attempts to obtain a solution of the difficulty. Pliny's main object seems to be to contrast the vines that entwine round poles and rise perpendicularly with those that creep horizontally. 
So numerous are the varieties of the vine which even Italy alone presents.

In some of the provinces the vine is able to stand of itself without anything to support it, drawing in its bending branches, and making up in its thickness for its stunted size. In other places, again, the winds will not allow of this mode of culture, as in Africa, for instance, and various parts of the province of Gallia Narbonensis. These vines, being prevented from growing beyond the first branches, and hence always retaining a resemblance to those plants which stand in need of the hoe, trail along the ground just like them, and every here and there suck ${ }^{19}$ up the juices from the earth to fill their grapes : it is in consequence of this, that in the interior of Africa the clusters ${ }^{20}$ are known to exceed the body of an infant in size. The wine of no country is more acid than those of Africa, but there is nowhere to be found a grape that is more agreeable for its firmness, a circumstance which may very probably have given rise to its name of the "hard grape." varieties of the grape, although they are rendered innumerable by the size, the colour, and the flavour of the berry, they are multiplied even still more by the wines that they produce. In one part they are lustrous with a rich purple colour, while in another, again, they glow with a rosy tint, or else are glossy with their verdant hue. The grapes that are merely white or black are the common sorts. The bumastus ${ }^{22}$ swells out in form like a breast, while that known as the "dactylus," 23 has a berry of remarkable length. Nature, too, displays such varieties in these productions of hers, that small grapes are often to be found adhering to the largest vines, but of surpassing sweetness; they are known by the name of "leptorragæ.", Some, again, will keep throughout the winter, if care is taken to hang them to the ceiling ${ }^{25}$ with a string;

19 By throwing out fresh shoots every here and there. Fée, however, seems to think that he means that the grapes themselves, as they trail along the ground, suck up the juices with their pores. These are known in France as "running vines," and are found in Berry and Anjou.

${ }_{20}$ He must evidently be speaking of the size of the bunches. See the account of the grapes of Canaan, in Numbers xiii. 24.

21 "Durus acinus," or, according to some readings, "duracinus."

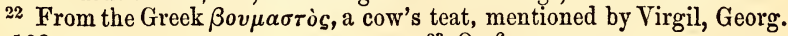
ii. 102.

2* From the Greek $\lambda \varepsilon \pi \tau \nu \rho \tilde{\alpha} \gamma \varepsilon c$, " small-berried."

23 Or finger-grape.

25 Pensili concamaratæ nodo. 
while others, again, will keep by virtue of their own natural freshness and vigour, if put into earthen jars, which are then enclosed in dolia, ${ }^{26}$ and covered up with the fermenting husks of grapes. Some grapes receive from the smoke of the blacksmith's forge that remarkable flavour which it is also known to impart to wines: it was the high name of the Emperor Tiberius that brought into such great repute the grapes that had been smoked in the smithies of Africa. Before his time the highest rank at table was assigned to the grapes of Rhætia, ${ }^{27}$ and to those growing in the territory of Verona.

Raisins of the sun have the name of "passi," from having been submitted ${ }^{28}$ to the influence of the sun. It is not un. common to preserve grapes in must, and so make them drunk with their own juices; while there are some that are all the sweeter for being placed in must after it has been boiled; others, again, are left to hang on the parent tree till a new crop has made its appearance, by which time they have become as clear and as transparent ${ }^{29}$ as glass. Astringent pitch, if poured upon the footstalk of the grape, will impart to it all that body and that firmness which, when placed in dolia or amphoræ, it gives to wine. More recently, too, there has been discovered a vine which produces a fruit that imparts to its wine a strong flavour of pitch: it is the famous grape that confers such celebrity on the territory of Vienne, ${ }^{30}$ and of which several varieties have recently enriched the territories of the Arverni, the Sequani, and the Helvii : ${ }^{31}$ it was unknown in the time of the poet Virgil, who has now been dead these ninety years. ${ }^{32}$

In addition to these particulars, need I make mention of the fact that the vine ${ }^{33}$ has been introduced into the camp and

26 We have no corresponding word for the Latin "dolium." It was an oblong earthen vessel, used for much the same purpose as our vats; new wine was generally placed in it. In times later than that of Pliny the dolia were made of wood.

${ }^{27}$ Hardouin speaks of these grapes as still growing in his time in the Valtelline, and remarkable for their excellence. heat.

28 "A patientia." Because they have suffered from the action of the

29 From the thinness of the skin.

30 See c. 24 , also B. xxiii. c. 24 . 31 See B.iii. c. 5, and B. xxxiii. c. 24.

32 He died in the year B.c. 19.

${ }^{33}$ A vine sapling was the chief mark of the centurion's authority. 
placed in the centurion's hand for the preservation of the supreme authority and command? that this is the high reward which summons the lagging ranks to the eagles raised aloft, ${ }^{34}$ and that even in chastisement for faults it tends to reflect honour upon the punishment? ${ }^{35}$ It was the vineyard, too, that first afforded a notion, ${ }^{36}$ the practical utility of which has been experienced in many a siege. Among the medicinal preparations, too, the vine holds so high a place, that its very wines taken by themselves are efficacious as remedies for disease. $^{37}$

\section{CHAP. 4. (2.) - NINETY-ONE VARIETIES OF THE VINE.}

Democritus, who has declared that he was acquainted with every variety of the grape known in Greece, is the only person who has been of opinion that every kind could be enumerated; but, on the other hand, the rest of the authors have stated that they are quite innumerable ${ }^{38}$ and of infinite extent, an assertion the truth of which will be more evident, if we only consider the vast number of wines. I shall not attempt, then, to speak of every kind of vine, but only of those that are the most remarkable, seeing that the varieties are very nearly as numberless as the districts in which they grow. It will suffice, then, to point out those which are the most remarkable among the vines, or else are peculiar for some wonderful property.

The very highest rank is giren to the Aminean ${ }^{39}$ grape, on

34 The reading " elatas," has been ndopted. If "lentas" is retained, it may mean, " promotion, slow though it be," for the word "aquila" was often used to denote the rank of the "primipilus," who had the charge of the eagle of the legion.

35 Because it was the privilege solely of those soldiers who were Roman citizens to be beaten with the vine sapling.

36 He alludes to the "vinea" used in besieging towns; the first notion of which was derived from the leafy roof afforded by the vines when creeping on the trellis over-head. It was a moveable machine, affording a roof under which the besiegers protected themselves against darts, stones, fire, and other missiles. Raw hides or wet cloths constituted the uppermost layer.

37 See B. xxiii. c. 19.

38 Many years ago, there were in the gardens of the Luxembourg one thousand four hundred varieties of the French grape, and even then there were many not to be found there; while, at the same time, it was considered that the French kinds did not form more than one-twentieth part of the species known in Europe.

39 This vine was said to be of Grecian origin, and to have been con- 
account of the body and durability of its wine, which improves with old age. There are five varieties of the Aminean grape; of these, the smaller germana, or " sister" grape, has a smaller berry than the rest, and flowers more strongly, being able to bear up against rain and tempestuous weather; a thing that is not the case with the larger germana, though it is less exposed to danger when attached to a tree than when supported only by a trellis. Another kind, again, has obtained the name of the "gemella," or "twin" grape, because the clusters always grow ${ }^{40}$ in couples: the flavour of the wine is extremely rough, but it is remarkable for its strength. Of these several varieties the smaller one suffers from the south wind, but receives nutriment from all the others, upon Mount Vesuvius, for instance, and the hills of Surrentum : in the other parts of Italy it is never grown except attached to trees. The fifth kind is that known as the lanata, or "woolly" grape; so that we need not be surprised at the wool-bearing trees ${ }^{41}$ of the Seres or the Indians, for this grape is covered with a woolly down of remarkable thickness. It is the first of the Aminean vines that ripens, but the grape decays with remarkable rapidity.

The second rank belongs to the vines of Nomentum, ${ }^{12}$ the wood of which is red, from which circumstance the vines have received from some the name of "rubellæ." The grapes of this vine produce less wine than usual, in consequence of the extraordinary quantity of husk and lees they throw off: but the vine is remarkably strong, is well able to stand the frost, and is apt to receive more detriment from drought than from rain, from heat than from cold; hence it is that those are looked upon as the best that are grown in cold and moist localities. That variety which has the smallest grape is con-

veyed by a Thessalian tribe to Italy, where it was grown at Aminea, a village in the Falernian district of Campania. It is supposed to have been the same as the gros plant of the French. The varieties mentioned by Pliny seem not to have been recognized by the moderns.

40 Fée does not give credit to this statement.

41 In allusion to the cotton-tree, or else the mulberry leaves covered with the cocoons of the silkworm. See B. vi. c. 20, and B. xii. c. 21 . Virgil, in the Georgics, has the well-known line:

"Velleraque ut foliis depectant tenuia Seres."

42 See B. iii. c. 9. There are many vines, the wood of which is red, but this species has not been identificd. 
sidered the most fruitful : the one which has a jagged leaf is less productive.

The vine known as the "apiana," ${ }_{43}$ has received that name from the bee, an insect which is remarkably fond of it : there are two varieties of this vine. This grape, too, is covered in its young state with a kind of down; the main difference between the two varieties is, that the one ripens more rapidly than the other, though this last ripens with considerable quickness. A cold locality is not at all hurtful to them, although there is no grape that ripens sooner : these grapes, however, very soon rot in the rain. The wines produced by this grape are sweet at first, but contract a rough flavour in the course of years. This vine is cultivated more than any other in Etruria. Thus far we have made mention of the more celebrated vines among those which are peculiar and indigenous to Italy; the rest have been introduced from Chios or 'Thasos.

The small Greek ${ }^{44}$ grape is not inferior to the Aminean for the excellence of its quality: the berry is remarkably thinskinned, and the cluster so extremely small, ${ }^{45}$ that it is not worth while cultivating it, except on a soil of remarkable richness. The eugenia, ${ }^{46}$ so called from its high qualities, has been introduced into the Alban territory from the hills of Tauromenium : ${ }^{47}$ it is found, however, to thrive only there, for if transplanted elsewhere it degenerates immediately : in fact, there is in some vines so strong an attachment to their native soil, that they leave behind them all their high repute, and are never transplanted in their full entirety. This is the case, too, with the Rhætian and the Allobrogian grapes, of which we have made mention above as the pitch-flavoured ${ }^{\$ 8}$ grape; these are justly deemed excellent in their own coun-

43 From "apis," a "bee." He alludes, it is thought, to the muscatel grape, said to have had its name from "musca," a "fly ;" an insect which is greatly attracted by its sweetness.

41 Græcula.

45 Fée is inclined to think that he alludes to the vine of Corinth, the dried fruit of which are the currants of commerce.

46 From the Greek ívyévica.

47 Now Taormina, in Sicily, where, Fée says, it is still to be found. The grapes are red, similar to those of Mascoli near Etna, and much esteemed.

48 Picata. See p. 221. 
try, while elsewhere they are held in no esteem at all. Still, however, in consequence of their remarkable fertility, they make up for quality by abundance: the eugenia thrives in spots which are scorching hot, the Rhætian vine in places of a more moderate temperature, and the Allobrogian in cold, exposed situations, the fruit being of a black colour, and ripened by the agency of frost.

The wines produced from the vines of which we have hitherto made mention, even though the grapes are black, become, all of them, when old, of a white ${ }^{49}$ complexion. The other vines are of no note in particular, though sometimes, thanks to some peculiarity either in the climate or the soil, the wines produced from them attain a mature old age; such, for instance, as the Fecenian ${ }^{50}$ vine, and the Biturigian, ${ }^{51}$ which blossoms at the same time with it, but has not so many grapes. The blossoms of these last-mentioned vines are not liable to receive injury, both because they are naturally but transitory, and have the power of resisting the action of both wind and storm; still, however, those that grow in cold spots are considered superior to those produced in a warm site, and those found in moist places superior to those grown in dry, thirsty localities.

The vine known as the "visula" s2 *, * * * more than abundance of fruit, being unable to endure the extreme variations of the atmosphere, though it is very well able to stand a continuation of either cold or heat. Of this last kind the smaller one is the best, but difficult to please in its choice; in a rich earth it is apt to rot, while in a thin soil it will come to nothing at all: in its fastidiousness it requires a soil of middling quality, and hence it is that it is so commonly found on the hills of the Sabine territory. Its grape is unsightly in appearance, but has a very pleasant flavour: if it is not gathered at the very moment that it is ripe, it will fall, even before it decays. The extreme size of the leaves, and its natural hardi-

49 I. e., pale straw colour.

50 It has been supposed that this vine received its name from "fæx ;" the wine depositing an unusually large quantity of lees.

${ }^{51}$ It is doubtful whether this vine had its name from being grown in the district now called Bourges, or that of Bourdeaux. Dalechamps identifies it with the plant d'Orleans.

${ }_{52}$ The origin of its name is unknown. The text is evidently defective. VOL. III. 
ness, are its great protection against the disastrous effects of hail.

The grapes known as "helvolæ" ${ }^{53}$ are remarkable for the peculiarity of their colour, which is a sort of midway between purple and black, but varies so frequently that it has made some persons give them the name of "varianæ." Of the two sorts of helvolæ, the black is the one generally preferred: they both of them produce every other year, but the wine is best when the vintage has been less abundant.

The vine that is known as the "precia" ${ }_{54}$ is also divided into two varieties, distinguished by the size of the grape. These vines produce a vast quantity of wood, and the grape is very good for preserving in jars ${ }^{, 55}$ the leares are similar in appearance to that of parsley. ${ }^{56}$ The people of Dyrrhachium hold in high esteem the vine known as the "basilica," the same which in Spain is called the "cocolobis." 57 The grapes of this vine grow in thin clusters, and it can stand great heat, and the south winds. The wine produced from it is apt to fly to the head:58 the produce of the vine is very large. The people in Spain distinguish two kinds of this vine, the one with the oblong, the other with the round grape; they gather this fruit the very last of all. The sweeter the cocolobis is, the more it is valued; but even if it has a rough taste, the wine will become sweet by keeping, while, on the other hand, that which was sweet at first, will acquire a certain roughness; it is in this last state that the wine is thought to rival that of Alba. ${ }^{59}$ It is said that the juice of this grape is remarkably efficacious when drunk as a specific for diseases of the bladder.

53 By this name it would be understood that they were of an intermediate colour between rose and white, a not uncommon colour in the grape. Pliny, however, says otherwise, and he is supported by Columella.

$54 \mathrm{C}$. Bauhin took this to mean one of the garden currant trees, the Ribes uva crispa of Linnæus, called by Bauhin Grossularia simplici acinc, or else Spinosa agrestis. But, as Fée observes, the ancients were not so ignorant as to confound a vine with a currant-bush.

55 Like the Portuguese grapes of the present day.

56 Crisped and indented.

57 This variety, according to Christian de la Vega, was cultivated abundantly in Grenada. The word cocolab, according to some, meant cock's comb. It is mentioned as a Spanish word by Columella.

58 Dalechamps says, that a similar wine was made at Montpellier, and that it was called "piquardant."

59 See B. xxiii. cc. $20,21$. 
The " albuelis" 60 produces most of its fruit at the top of the tree, the visula at the bottom; hence, when planted around the same tree, in consequence of these peculiarities in their nature, they bear between them a two-fold crop. One of the black grape vines has been called the "inerticula," ${ }^{61}$ though it might with more propriety have been styled the " sobria;", 62 the wine from it is remarkably good, and more particularly when old; but though strong, it is productive of no ill effects, and, indeed, is the only wine that will not cause intoxication.

The abundance of their produce again recommends other vines to us, and, in the first place, that known as the "helvennaca." ${ }^{63}$ Of this vine there are two kinds; the larger, which is by some called the "long" helvennaca, and the smaller kind, which is known as the "emarcum," "6t not so prolific as the first, but producing a wine of more agreeable flavour; it is distinguished by its rounded leaf, but they are both of them of slender make. It is requisite to place forks beneath these vines for the support of their branches, as otherwise it would be quite impossible for them to support the weight of their produce : they receive nutriment from the breezes that blow from the sea, and foggy weather is injurious to them. There is not one among the vines that manifests a greater aversion to Italy, for there it becomes comparatively leafless and stunted, and soon decays, while the wine which it produces there will not keep beyond the summer: no vine, however, thrives better in a poor soil. Græcinus, who has copied from the works of Cornelius Celsus, gives it as his opinion that it is not that the nature of this vine is repugnant to the climate of Italy, but that it is the mode of cultivating it that is

${ }^{60}$ Probably from "albus," "white." Poinsinet thinks that it may have been so called from the Celtic word $a l b$, or $a l p$, a mountain, and that it grew on elevated spots. This, however, is probably fanciful. qualities.

${ }_{62}$ Or "sober" vine.

${ }^{63}$ Hardouin says that in his time it was still cultivated about Macerata, in the Roman States. Fée thinks that it may be one of the climbing vines, supported by forks, cultivated in the central provinces of France. See also B. xxiii. c. 19, as to the effects produced by its wine.

${ }_{64}$ Poinsinet gives a Celto-Scythian origin to this word, and says that it means "injured by fogs." This appears to be supported in some measure by what is stated below. 
wrong, and the anxiety to force it to put forth its shoots; a mode of treatment, he thinks, which absorbs all its fertility, unless the soil in which it is planted happens to be remarkably rich, and by its support prevents it from being exhausted. It is said that this vine is never carbuncled, ${ }^{65}$ a remarkable quality, if, indeed, it really is the fact that there is any vine in existence that is exempt from the natural influences of the climate.

The spionia, by some called the "spinea,"6r is able to bear heat very well, and thrives in the autumn and rainy weather: indeed, it is the only one among all the "vines that does well amid fogs, for which reason it is peculiar to the territory of Ravenna. ${ }^{67}$ The venicula ${ }^{68}$ is one of those that blossom the strongest, and its grapes are particularly well adapted for preserving in jars. The Campanians, however, prefer to give it the name of " scircula," while others, again, call it " stacula." Tarracina has a vine known as the "numisiana;" it has no qualities of its own, but has characteristics just according to the nature of the soil in which it is planted: the wine, however, if kept in the earthen casks ${ }^{69}$ of Surrentum, is remarkable for its goodness, that is to say, as far south as Vesuvius. On arriving in that district, we find the Murgentina, ${ }^{70}$ the very best among all those that come from Sicily. Some, indeed, call the vine " Pompeiana," "71 and it is more particularly fruitful when grown in Latium, just as the "horconia" 72 is productive nowhere but in Campania. Of a contrary nature is the vine known as the " argeica," and by Virgil called "argitis :"78 it makes the ground all the more ${ }^{74}$ productive, and is remark-

65 See B. xvii. c. 37.

66 Or " thorny" vine. Fée queries why it should be thus called.

67 This humid, marshy locality was noted for the badness of its grapes, and consequently of its wine.

68 Hardouin thinks that this is the "Marze mina" of the Venetians: whence, perhaps, its ancient name.

69 "Testis." See B. xxxv. c. 46.

${ }^{70}$ From Murgentum, in Sicily. See B. iii. c. 14.

71 From Pompeii, afterwards destroyed. See B. iii c. 9.

72 Hardouin, as Fée thinks, without good reason, identifies this with the "Arelaca" of Columella.

73 Georgics, ii. 99.

74 This seems to be the meaning of "ultro solum lætius facit." These two lines have been introduced by Sillig, from one of the MSS., for the first time. 
ably stout in its resistance to rain and the effects of old age, though it will hardly produce wine every year ; it is remarkable for the abundant crops which it bears, though the grapes are held but in small esteem for eating. The vine known as the "metica" lasts well for years, and offers a successful resistance to all changes of weather; the grape is black, and the wine assumes a tawny hue when old.

(3.) The varieties that have been mentioned thus far are those that are generally known; the others belong to peculiar countries or individual localities, or else are of a mixed nature, the produce of grafting. Thus the vine known as the "Tudernis,"75 is peculiar to the districts of Etruria, and so too is the vine that bears the name of "Florentia." At Arretium the talpona, the etesiaca, and the consemina, are particularly excellent. ${ }^{76}$ The talpona, ${ }^{77}$ which is a black grape, produces a pale, straw-coloured ${ }^{78}$ must : the etesiaca ${ }^{79}$ is apt to deceive; the more the wine it produces the better the quality, but it is a remarkable fact, that just as it has reached that point its fecundity ceases altogether. The consemina ${ }^{80}$ bears a black grape, but its wine will not keep, though the grape itself is a most excellent keeper ; it is gathered fifteen days later than any other kind of grape: this vine is very fruitful, but its grape is only good for eating. The leaves of this tree, like those of the wild vine, turn the colour of blood just before the fall : the same is the case also with some ${ }^{81}$ other varieties, but it is a proof that they are of very inferior quality.

The irtiola ${ }^{\mathrm{s}}$ is a vine peculiar to Umbria and the terri-

75 Hardouin thinks that it is so called from Tuder, a town of Etruria. See B. iii. c. 19.

${ }^{76}$ Sillig suggests that the reading here is corrupt, and that Pliny means to say that the vine called Florentia is particularly excellent, and merely to state that the talpona, \&c., are peculiar to Arretium: for, as he says, speaking directly afterwards in disparagement of them, it is not likely he would pronounce them "opima," of "first-rate quality."

77 From "talpa," a "mole," in consequence of its black colour.

78 "Album."

79 Probably so called from the Etesian winds, which improved its growth.

${ }^{80}$ Perhaps meaning "double-seeded." We may here remark, that the wines of Tuscany, though held in little esteem in ancient times, are highly esteemed at the present day.

81 The leaves of most varieties turn red just before the fall.

82 And Baccius thinks that this is the kind from which the raisins of the 
tories of Mevania and Picenum, while the pumula ${ }^{83}$ belongs to Amiternum. In the same districts we find the vine called bannanica, ${ }^{84}$ which is very deceptive, though the people are remarkably fond of its fruit. The municipal town of Pompeii has given its name to the Pompeia, ${ }^{85}$ although it is to be found in greater abundance in the territory of Clusium. The Tiburina, also, is so called from the municipal town of Tibûr, although it is in this district that they have lately discovered the grape known as the "oleaginea," from its strong resemblance to an olive : this being the very last kind of grape that has been introduced. The Sabines and the Laurentes are the only people acquainted with the vinaciola. ${ }^{87} \mathrm{As}$ to the vines of Mount Gaurus, ${ }^{88}$ I am aware that, as they have been transplanted from the Falernian territory, they bear the name of "Falernian :" but it is a fact that the Falernian vine, when transplanted, rapidly degenerates. Some persons, too, have made out a Tarentine variety, with a grape of remarkable sweetness : the grapes of the "capnios," 89 the "bucconiatis," 90 and the "tarrupia," grow on the hills of Thurii, and are never gathered till after the frost commences. Pisæ enjoys the Parian vine, and Mutina the prusinian, ${ }^{91}$ with a black grape, the wine of which turns pale within four years. It is a very remarkable thing, but there is a grape here that turns round with the sun, in its diurnal motion, a circumstance from which it has received the name of "streptos." 92 In Italy, the sun, common in Italy, and more particularly in the Valley of Bevagna, the Mevania of Pliny, are made.

83 Perhaps from "pumilio," a dwarf.

84 The "royal" vine, according to Poinsinet, who would derive it from the Sclavonic "ban."

${ }_{85}$ Previously mentioned, p. 228.

86 The residence of Horace, now Tivoli.

87 Baccius says that the wine of this grape was thin like water, and that the vine was trained on lofty trees, a mode of cultivation still followed in the vicinity of Rome. Laurentum was situate within a short distance of it, near Ostia.

s8 See B. iii. c. 9.

89 So called from the smoky or intermediate colour of its grapes. Fée suggests that this may be the slow-ripening grape of France, called the "verjus," or "rognon de coq."

90 Possibly meaning the "mouthful."

91 Perhaps so called from Prusa in Bithynia, a district which bore excellent grapes.

92 Or the "turning" grape. A fabulous story no doubt, originating in 
Gallic vine is a great favourite, while beyond the Alps that of Picenum ${ }^{93}$ is preferred. Virgil has made mention ${ }^{94}$ of the Thasian vine, the Mareotis, the lagea, and several other foreign varieties, which are not to be found in Italy.

There are some vines, again, that are remarkable, not for their wine, but for their grapes, such, for instance, as the ambrosia, ${ }^{95}$ one of the "duracinus" "96 kind, a grape which requires no potting, but will keep perfectly well if left on the vine, so remarkable is the strength with which it is endowed for withstanding the effects of cold, heat, and stormy weather. The "orthampelos," ${ }^{97}$ too, is a vine that requires neither tree nor stay, as it is well able to sustain its own weight. This, however, is not the case with the "dactylis," ${ }_{98}$ the stem of which is no thicker than the finger. The "columbina" ${ }^{99}$ is one of those with the finest clusters, and still more so is the purple " bimammia ;" -it does not bear in clusters, ${ }^{1}$ but only secondary bunches. There is the tripedanea, ${ }^{2}$ too, a name which it owes to the length of its clusters, and the scirpula, ${ }^{3}$ with its shrivelled berry; the Rhætica, ${ }^{4}$ too, so called in the Maritime Alps, though very different from the grape of that name which is so highly esteemed, and of which we hare previously spoken; for in this variety the clusters are small, the grapes lie closely packed,

the name, probably. Fée suggests that it may have originated in the not uncommon practice of letting the bunches hang after they were ripe, and then twisting them, which was thought to increase the juice.

${ }_{93}$ In the modern Marches of Ancona.

94 Georgics, ii. 91, et seq.

Sunt Thasiæ vites, sunt et Mareotides albæ :

Et passo Psithia utilior, tenuisque Lageos,

Tentatura pedes olim, vincturaque linguam,

Purpureæ, Preciæque-

95 A muscatel, Fée thinks.

s6 Or "hard-berried." Fée thinks that the maroquin, or Morocco grape, called the "pied de poule" (or fowl's foot), at Montpellier, may be the duracinus.

97 Or "upright vine." In Anjou and Herault the vines are of similar character.

98 The "finger-like" vine.

99 The "pigeon" vine.

1 Though very fruitful, it does not bear in large clusters (racemi), but only in small bunches (uvæ).

2 The "three-foot" vine.

3 Perhaps meaning the "rush" grape, from its shrivelled appearance.

4 See c. 3 of this Book. 
and it produces but a poor wine. It has, however, the thinnest skin of all the grapes, and a single stone, ${ }^{5}$ of very diminutive size, which is known as the "Chian ;" the grapes on the cluster are remarkably large. There is also the black Aminean, to which the name of Syriaca is given : the Spanish vine, too, the very best of all those of inferior quality.

The grapes that are known as escariæ, ${ }^{7}$ are grown on trellises. Of the duracinus ${ }^{8}$ kind, there are those known as the white and the black varieties; the bumastus, too, is similarly distinguished in colour. Among the vines too, that have not as yet been mentioned, there are the Figian and the Rhodian ${ }^{9}$ kinds, as also the uncialis, so called, it would seem, from its grape being an ounce in weight. There is the picina ${ }^{10}$ too, the blackest ${ }^{11}$ grape known, and the stephanitis, ${ }^{12}$ the clusters of which Nature, in a sportive mood, has arranged in the form of a garland, the leaves being interspersed ${ }^{13}$ among the grapes; there are the grapes, too, known as the "forenses,"14 and which quickly come to maturity, recommend themselves to the buyer by their good looks, and are easily carried from place to place.

On the other hand, those known as the "cinerea" ${ }^{15}$ are condemned by their very looks, and so are the rabuscula ${ }^{16}$ and the asinusca $;{ }^{17}$ the produce of the alopecis,${ }^{18}$ which resembles in colour a fox's tail, is held in less disesteem. The Alexandrina ${ }^{19}$ is the name of a vine that grows in the vicinity of Pha-

5 The ordinary number of pips or stones is five. It is seldom that we find but one. Virgil mentions this grape, Georg. ii. 95.

6 "Chium." This reading is doubtful. Fée says that between Narni and Terni, eight leagues from Spoleto, a small grape is found, without stones. It is called "uva passa," or "passerina." So, too, the Sultana raisin of commerce.

7 "Grown for the table." 8 Or "hard-berry."

9 Mentioned by Virgil, Georg. ii. $101 . \quad 10 \mathrm{Or}$ pitch-grape.

11 Perhaps the "noirant," or "teinturier" of the French.

12 Or "garland-clustered" vine.

13 Fée says that this is sometimes accidentally the case, but is not the characteristic of any variety now known.

14 Or " market-grapes."

15 The "ash-coloured."

16 The "russet-coloured."

17 Probably so called from its grey colour, like that of the ass.

18 Or "fox" vine. This variety is unknown.

13 So called from Alexandria, in 'Troas, not in Egypt. Phalacra was in the vicinity of Mount Ida. 
lacra: it is of stunted growth, and has branches a cubit in length; the grape is black, about the size of a bean, with a berry that is soft, and remarkably small : the clusters hang in a slanting direction, and are remarkably sweet; the leaves are small and round, without any division. ${ }^{20}$ Within the last seven years there has been introduced at Alba Helvia, ${ }^{21}$ in the province of Gallia Narbonensis, a vine which blossoms but a single day, and is consequently proof against all accidents: the name given to it is "Narbonica," and it is now planted throughout the whole of that province.

\section{Chap. 5. (4.)-ReMarkable FaCtS CONNECTEd With the CULTURE OF THE VINE.}

The elder Cato, who was rendered more particularly illustrious by his triumph ${ }^{22}$ and the censorship, and even more so by his literary fame, and the precepts which he has given to the Roman people upon every subject of utility, and the proper methods of cultivation in particular; a man who, by the universal confession, was the first husbandman of his age and without a rival-has mentioned a few varieties only of the vine, the very names of some of which are by this utterly forgotten. ${ }^{23}$ His statement on this subject deserves our separate consideration, and requires to be quoted at length, in order that we may make ourselves acquainted with the different varieties of this tree that were held in the highest esteem in the year of the City of Rome 600, about the time of the capture of Carthage and Corinth, the period of his death : it will show too, what great advances civilization has made in the last two hundred and thirty years. The following are the remarks which he has made on the subject of the vine and the grape.

20 As the leaves of the vine are universally divided, it has been considered by many of the commentators that this is not in reality a vine, but the Arbutus uva ursi of Linnæus. The fruit, however, of that ericaceous plant is remarkably acrid, and not sweet, as Pliny states. Fée rejects this solution.

${ }^{21}$ Aubenas, in the Vivarais, according to Hardouin; Alps, according to Brotier. We must reject this assertion as fabulous.

22 In B.c. 194, for his successes in Spain.

${ }^{23}$ Mode of culture, locality, climate, and other extraneous circumstances, work, no doubt, an entire change in the nature of the vine. 
"Where the site is considered to be most favourable to the growth of the vine, and exposed to the warmth of the sun, you will do well to plant the small ${ }^{24}$ Aminean, as well as the two eugenia, ${ }^{25}$ and the smaller helvia. ${ }^{26}$ On the other hand, where the soil is of a denser nature or more exposed to fogs, the greater Aminean should be planted, or else the Murgentine, ${ }^{27}$ or the Apician of Lucania. The other varieties of the grape are, for the most part, adapted to any kind of soil ; they are best preserved in a lora. ${ }^{28}$ The best for keeping by hanging, are the duracinus kind, the greater Aminean, and the Scantian ${ }^{29}$ these, too, will make excellent raisins for keeping if dried at the blacksmith's forge." There are no precepts in the Latin language on this subject more ancient than these, so near are we to the very commencement of all our practical knowledge! The Aminean grape, of which mention has been made above, is by Varro called the "Scantian."

In our own times we have but few instances of any consummate skill that has been manifested in reference to this subject: the less excuse then should we have for omitting any particular which may tend to throw a light upon the profits that may be derived from the cuiture of the vine, a point which on all occasions is regarded as one of primary importance. Acilius Sthenelus, a man of plebeian rank, and the son of a freedman, acquired very considerable repute from the cultivation of a vineyard in the territory of Nomentum, not more than sixty jugera in extent, and which he finally sold for four hundred thousand sesterces. Vetulenus Agialus too, a freedman as well, acquired very considerable note in the district of Liternum, ${ }^{30}$ in Campania, and, indeed, received a more extensive share of the public favour, from the fact that he cultivated the spot

24 Probably the first of the five that he has mentioned in c. 4.

25 He has only mentioned one sort in c. 4 .

26 See c. 4.

27 See c. 4.

28 We have no corresponding word for this beverage in the English language-a thin, poor liquor, made by pouring water on the husks and stalks after being fully pressed, allowing them to soak, pressing them again, and then fermenting the liquor. It was also called "vinum operarium," or "labourer's wine." As stated in the present instance, grapes were sometimes stored in it for keeping.

${ }^{23}$ A variety of the Aminean, as stated below.

30 See B. iii. c. 9. 
which had been the place of exile of Scipio Africanus. ${ }^{31}$ The greatest celebrity of all, however, was that which, by the agency of the same Sthenelus, was accorded to Rhemmius Palæmon, who was also equally famous as a learned grammarian. This person bought, some twenty years ago, an estate at the price of six hundred thousand sesterces in the same district of Nomentum, about ten miles distant from the City of Rome. The low price of property ${ }^{32}$ in the suburbs, on every side of the City, is well known; but in that quarter in particular, it had declined to a most remarkable extent; for the estate which he purchased had become deteriorated by longcontinued neglect, in addition to which it was situate in the very worst part of a by no means favourite locality. ${ }^{33}$ Such was the nature of the property of which he thus undertook the cultivation, not, indeed, with any commendable views or intentions at first, but merely in that spirit of vanity for which he was notorious in so remarkable a degree. The vineyards were all duly dressed afresh, and hoed, under the superintendence of Sthenelus; the result of which was that Palæmon, while thus playing the husbandman, brought this estate to such an almost incredible pitch of perfection, that at the end of eight years the vintage, as it hung on the trees, was knocked down to a purchaser for the sum of four hundred thousand sesterces; while all the world was running to behold the heaps upon heaps of grapes to be seen in these vineyards. The neighbours, by way of finding some excuse for their own indolence, gave all the credit of this remarkable success to Palæmon's profound erudition; and at last Annæus Seneca, ${ }^{34}$ who both held the highest rank in the learned world, and an amount of power and influence which at last proved too much for him-this same Seneca, who was far from being an admirer of frivolity, was seized with such vast admiration of this estate, as not to feel ashamed at conceding this victory to a man who was otherwise the object of his hatred, and who would be sure to make the very most of it, by giving him four times the original cost

31 The elder Africanus. He retired in voluntary exile to his countryseat at Liternum, where he died.

32 Mercis.

${ }^{33}$ The suggestion of Sillig has been adopted, for the ordinary reading is evidently corrupt, and absurd as well-" not in the very worst part of a favourite locality"-just the converse of the whole tenor of the story.

34 The philosopher, and tutor of Nero. 
for those very vineyards, and that within ten years from the time that he had taken them under his management. This was an example of good husbandry worthy to be put in practice upon the lands of Cæcuba and of Setia; for since then these same lands have many a time produced as much as seven culei to the jugerum, or in other words, one hundred and forty amphoræ of must. That no one, however, may entertain the belief that ancient times were surpassed on this occasion, I would remark that the same Cato has stated in his writings, that the proper return was seven culei to the jugerum: all of them so many instances only tending most convincingly to prove that the sea, which in our rashness we trespass upon, does not make a more bounteous return to the merchant, no, not even the merchandize that we seek on the shores of the Red and the Indian Seas, than does a well-tilled homestead to the agriculturist.

\section{CHAP. 6. -THE MOST ANCIENT WINES.}

The wine of Maronea, ${ }^{35}$ on the coast of Thrace, appears to have been the most celebrated in ancient times, as we learn from the writings of Homer. I dismiss, however, all the fabulous stories and various traditions which we find relative to its origin, except, indeed, the one which states that Aristæus, ${ }^{36}$ a native of the same country, was the first person that mixed honey ${ }^{37}$ with wine, natural productions, both of them, of the highest degree of excellence. Homer ${ }^{38}$ has stated that the Maronean wine was mixed with water in the proportion of twenty measures of water to one of wine. The wine that is still produced in the same district retains all its former strength, and a degree of vigour that is quite insuperable. ${ }^{39}$ Mucianus, who thrice held the consulship, and one of our most recent authors, when in that part of the world was witness himself to the fact, that with one sextarius of this wine it was the custom to mix no less than eighty sextarii of

35 Said to have been so called from Maron, a king of Thrace, who dwelt in the vicinity of the Thracian Ismarus. See B. iv. c. 18. Homer mentions this wine in the Odyssey, B. ix. c. 197, et seq. It was red, honeysweet, fragrant. The place is still called Marogna, in Roumelia, a country the wines of which are still much esteemed.

${ }^{36}$ See B. vii. c. 57 .

3s B. ix. c. 208.
37 Thus making "mulsum."

39 Indomitus. 
water: he states, also, that this wine is black, ${ }^{40}$ has a strong: bouquet, and is all the richer for being old.

The Pramnian wine, too, which Homer ${ }^{41}$ has also similarly eulogized, still retains its ancient fame: it is grown in the territory of Smyrna, in the vicinity of the shrine of the Mother ${ }^{42}$ of the Gods.

Among the other wines now known, we do not find any that enjoyed a high reputation in ancient times. In the year of the consulship of L. Opimius, when C. Gracchus, ${ }^{43}$ the tribune of the people, engaging in sedition, was slain, the growth of every wine was of the very highest quality. In that year, the weather was remarkable for its sereneness, and the ripening of the grape, the "coctura," was fully effected by the heat of the sun. This was in the year of the City 633. There are wines still preserved of this year's growth, nearly two hundred years ago; they have assumed the consistency of honey, with a rough taste; for such, in fact, is the nature of wines, that, when extremely old, it is impossible to drink them in a pure state; and they require to be mixed with water, as long keeping renders them intolerably bitter. ${ }^{45} \mathrm{~A}$ very small quantity of the Opimian wine, mixed with them, will suffice for the seasoning of other wines. Let us suppose, according to the estimated value of these wines in those days, that the original price of them was one hundred sesterces per amphora : if we add to this six per cent. per annum, a legal and moderate interest, we shall then be able to ascertain what was the exact price of the twelfth part of an amphora at the beginning of the reign of Caius Cæsar, the son of Germanicus, one hundred and sixty years after that consulship. In relation to this fact, we have a remarkable instance, ${ }^{46}$ when we call to mind the life of Pom-

${ }^{10} \mathrm{By}$ " black" wines he means those that had the same colour as our port.

41 Il. xi. 638 . Od. x. 234.

${ }^{42}$ Cybele. A wine called "Pramnian" was also grown in the island of Icaria, in Lesbos, and in the territory of Ephesus. The scholiast on Nicander says that the grape of the psythia was used in making it. Dioscorides says that it was a "protropum," first-class wine, made of the juice that voluntarily flowed from the grapes, in consequence of their own pressure.

44 "Cooking," literally, or "boiling." 43 B.c. 121. old.

45 The wines of Burgundy, in particular, become bitter when extremely 46 - See B. vii. c. 18. 
ponius Secundus, the poet, and the banquet which he gave to that prince ${ }^{47}$ - so enormous is the capital that lies buried in our cellars of wine! Indeed, there is no one thing, the value of which more sensibly increases up to the twentieth year, or which decreases with greater rapidity after that period, supposing that the value of it is not by that time greatly enhanced. ${ }^{48}$ Very rarely, indeed, up to the present day, has it been known for a single ${ }^{49}$ piece of wine to cost a thousand sesterces, except, indeed, when such a sum may have been paid in a fit of extravagance and debauchery. The people of Vienne, it is said, are the only ones who have set a higher price than this upon their "picata," wines, the various kinds of which we have already mentioned $;^{50}$ and this, it is thought, they only do, vying with each other, and influenced by a sort of national self-esteem. This wine, drunk in a cool state, is generally thought to be of a colder ${ }^{51}$ temperature than any other.

\section{CHAP. 7. (5.) 一THE NATURE OF WINES.}

It is the property of wine, when drunk, to cause a feeling of warmth in the interior of the viscera, and, when poured upon the exterior of the body, to be cool and refreshing. It will not be foreign to my purpose on the present occasion to state the advice which Androcydes, a man famous for his wisdom, wrote to Alexander the Great, with the view of putting a check on his intemperance: "When you are about to drink wine, 0 king!" said he, "remember that you are about to drink the blood of the earth: hemlock is a poison to man, wine a poison ${ }^{52}$ to hemlock." And if Alexander had only followed this advice, he certainly would not have had to answer

47 Caligula. wine.

$48 \mathrm{By}$ some remarkable and peculiar quality, such as in the Opimian

50 See c. 3 of the present Book, where these "picata," or "pitchedwines," have been further described.

51 On the contrary, Fée says, the coldest wines are those that contain the least alcohol, whereas those of Vienne (in modern Dauphiné) contain more than the majority of wines.

$52 \mathrm{He}$ implies that wine is an antidote to the poisonous effects of hemlock. This is not the case, but it is said by some that vinegar is. It is the plant hemlock (cicuta) that is meant, and not the fatal draught that was drunk by Socrates and Philopœmen. See further in B. xxiii. c. 23, and B. xxv. c. 95 . 
for slaying his friends ${ }^{63}$ in his drunken fits. In fact, we may feel ourselves quite justified in saying that there is nothing more useful than wine for strengthening the body, while, at the same time, there is nothing more pernicious as a luxury, if we are not on our guard against excess.

\section{CHAP. 8. (6.) - FIFTY KINDS OF GENEROUS WINES.}

Who can entertain a doubt that some kinds of wine are more agreeable to the palate than others, or that even out of the very same vat ${ }^{5 t}$ there are occasionally produced wines that are by no means of equal goodness, the one being much superior to the other, whether it is that it is owing to the cask ${ }^{55}$ or to some other fortuitous circumstance? Let each person, therefore, constitute himself his own judge as to which kind it is that occupies the pre-eminence. Livia ${ }^{56}$ Augusta, who lived to her eighty-second year, ${ }^{57}$ attributed her longevity to the wine of Pucinum, ${ }^{58}$ as she never drank any other. This wine is grown near a bay of the Adriatic, not far from Mount Timavus, upon a piece of elevated rocky ground, where the sea-breeze ripens a few grapes, the produce of which supplies a few amphoræ: there is not a wine that is deemed superior to this for medicinal purposes. I am strongly of opinion that this is the same wine, the produce of the Adriatic Gulf, upon which the Greeks have bestowed such wonderful encomiums, under the name of Prætetianum.

The late Emperor Augustus preferred the Setinum to all others, and nearly all the emperors that have succeeded him have followed his example, having learnt from actual experience that there is no danger of indigestion and flatulence resulting from the use of this liquor: this wine is grown in the country ${ }^{59}$ that lies just above Forum Appii. ${ }^{60}$ In former times the Cæcubum enjoyed the reputation of being the most

${ }_{53}$ Clitus and Callisthenes.

55 The testa or amphora, made of earth.

${ }^{51}$ Lacus.

" 56 As the wife of Augustus is meant, this reading appears preferable to "Julia."

s7 Dion Cassius says " eighty-sixth."

5s See B. iii. c. 22 , and B. xvii. c. 3. Pucinum was in Istria, and the district is said still to produce good wine; according to Dalechamps, the place is called Pizzino d'Istria.

59 The hills of Setia, looking down on the Pomptine Marshes: now Sezza, the wine of which is of no repute.

60 See B. iii. c. 9 . 
generous of all the wines; it was grown in some marshy swamps, planted with poplars, in the vicinity ${ }^{61}$ of the Gulf of Amyclæ. This vineyard has, however, now disappeared, the result of the carelessness of the cultivator, combined with its own limited extent, and the works on the canal which Nero commenced, in order to provide a navigation from Lake Avernus to Ostia.

The second rank belonged to the wine of the Falernian territory, of which the Faustianum was the most choice variety; the result of the care and skill employed upon its cultivation. This, however, has also degenerated very considerably, in consequence of the growers being more solicitous about quantity ${ }^{63}$ than quality. The Falernian ${ }^{63}$ vineyards begin at the bridge of Campania, on the left-hand as you journey towards the Urbana Colonia of Sylla, which was lately a township of the city of Capua. As to the Faustian vineyards, they extend about four miles from a village near Cædiciæ, ${ }^{64}$ the same village being six miles from Sinuessa. There is now no wine known that ranks higher than the Falernian; it is the only one, too, among all the wines that takes fire on the application of flame. ${ }^{65}$ There are three varieties of it-the rough, the sweet, and the thin. Same persons make the following distinctions: the Caucinum, they say, grows on the summit of this range of hills, the Faustianum on the middle slopes, and the Falernum at the foot: the fact, too, should not be omitted, that none of the grapes that produce these more famous wines have by any means an agreeable flavour.

To the third ${ }^{66}$ rank belonged the various wines of Alba, in the vicinity of the City, remarkable for their sweetness, and some-

61. See B. iii. c. 9. Between Fundi and Setia; a locality now of no repute for its wines. In B. xxiii. c. 19, Pliny says, that the Cæcuban vine was extinct : but in B. xvii. c. 3, he says that in the Pomptine Marshes it was to be found.

${ }_{62}$ This was the case, it has been remarked, with Madeira some years ago.

${ }^{63}$ This is the most celebrated of all the ancient wines, as being more especially the theme of the poets.

64 See B. xi. c. 97. The wines of the Falernian district are no longer held in any esteem; indeed, all the Campanian wines are sour, and of a disagreeable flavour.

${ }_{65}$ It appears to have been exceedingly rich in alcohol.

${ }^{66}$ But in B. xxiii. c. 20, he assigns the first rank to the Albanum ; possibly, however, as a medicinal wine. The wines of Latium are no longer held in esteem. 
times, though rarely, rough ${ }^{67}$ as well: the Surrentine $e^{68}$ wines, also, the growth of only stayed vines, which are especially recommended to invalids for their thinness and their wholesomeness. Tiberius Cæsar used to say that the physicians had conspired thus to dignify the Surrentinum, which was, in fact, only another name for generous vinegar; while Caius Cæsar, who succeeded him, gave it the name of "noble vappa." 69 Vying in reputation with these are the Massic wines, from the spots which look from Mount Gaurus towards Puteoli and Bair. ${ }^{70}$ As to the wines of Stata, in the vicinity of Falernum, there is no doubt that they formerly held the very highest rank, a fact which proves very clearly that every district has its own peculiar epochs, just as all other things have their rise and their decadence. The Calenian ${ }^{71}$ wines, too, from the same neighbourhood, used to be preferred to those last mentioned, as also the Fundanian, ${ }^{72}$ the produce of vines grown on stays, or else attached to shrubs. The wines, too, of Veliternum ${ }^{33}$ and Priverna, ${ }^{74}$ which were grown in the vicinity of the City, used to be highly esteemed. As to that produced at Signia, ${ }^{75}$ it is by far too rough to be used as a wine, but is very useful as an astringent, and is consequently reckoned among the medicines for that purpose.

The fourth rank, at the public banquets, was given by the late Emperor Julius-he was the first, in fact, that brought

67 See B. xxiii. c. 21.

68 From Surrentum, the promontory forming the southern horn of the Bay of Naples. Ovid and Martial speak in praise of these wines; they were destitute of richness and very dry, in consequence of which they required twenty-five years to ripen.

${ }^{69}$ Or " dead vinegar." "Vappa" was vinegar exposed to the air, and so destitute of its properties, and quite insipid.

${ }_{70}$ Excellent wines are still produced in the vicinity of this place. Massicum was one of the perfumed wines. Gaurus itself produced the "Gauranum," in small quantity, but of high quality, full-bodied and thick.

${ }_{71}$ For the Calenian Hills, see B. iii. c. 9 ; see also B. xxiii. c. 12, for some further account of the wines of Stata. The wines of that district are now held in no esteem.

${ }^{72}$ From Fundi. See B. iii. c. 9.

73 Now Castel del Volturno : although covered with vineyards, its wines are of no account. This wine always tasted as if mixed with some foreign substance.

${ }_{74}$ Now Piperno. It was a thin and pleasant wine.

75 Now Segni, in the States of the Church.

TOL. III. 
them into favour, as we find stated in his Letters ${ }^{76}$ - to the Mamertine wines, the produce of the country in the vicinity of Messana, ${ }^{77}$ in Sicily. The finest of these was the Potulanum, ${ }^{78}$ so called from its original cultivator, and grown on the spots that lie nearest to the mainland of Italy. The Tauromenitanum also, a wine of Sicily, enjoys a high repute, and flaggons ${ }^{79}$ of it are occasionally passed off for Mamertinum.

Among the other wines, we find mentioned upon the Upper Sea those of Prætutia and Ancona, as also those known as the "Palmensia," not improbably because the cluster springs from a single shoot. ${ }^{81}$ In the interior we find the wines of Cæsena $^{82}$ and that known as the Mæcenatian, ${ }^{83}$ while in the territory of Verona there are the Rhætian wines, only inferior, in the estimation of Virgil, to the Falernian. ${ }^{84}$ Then, too, at the bottom of the Gulf ${ }^{53}$ we find the wines of Adria. ${ }^{86}$ On the shores of the Lower Sea there are the Latiniensian ${ }^{87}$ wines, the Graviscan, ${ }^{88}$ and the Statonian $:^{89}$ in Etruria, the wines of Luna bear away the palm, and those of Genua ${ }^{90}$ in Liguria. Massilia, which lies between the Pyrenees and the Alps, produces two varieties of wine, one of which is richer and thicker than the other, and is used for seasoning other wines, being generally known as "succosum." 91 The repu-

76 Written to the Senate, also to Cicero. We learn from Suetonius that they were partly written in cipher.

${ }_{77}$ Messina, at the present day, exports wines of very good quality, and which attain a great age.

${ }_{78}$ It was sound, light, and not without body.

79 "Lagenæ." The same spot, now Taormina in Sicily, between Catania and Messina, still produces excellent wines.

${ }^{80}$ See P. iii. c. 18. Fée says that this is thought to have been the wine of Syrol, of last century, grown near Ancona.

\$1 "Palma." Notwithstanding this suggestion, it is more generally supposed that they had their name from the place called Palma, near Marano, on the Adriatic. Its wines are still considered of agreeable flavour.

82 The wines of modern Cezena enjoy no repute, owing, probably, to the mode of making them.

83 Probably so called because it was brought into fashion by Mreenas.

${ }^{84}$ See Georg. ii. 95. The wines of the 'Iyrol, the ancient Rhietia, are still considered as of excellent quality.

85 Of Adria, or the Adriatic Sea.

so See B. iii. c. 20 . These wines are of little repute.

87 In Latium. See B. iii. c. 9.

88 From Graviscæ. See B. iii. c. 8.

89 See B. ii. c. 96 , B. iii. ๔. 9 , and B. xxxvi. c. 49.

so The wines of Genoa are of middling quality only, and but little known.

${ }^{21}$ Or "juicy" wine. 
tation of the wine of Beterræ $\Re^{92}$ does not extend beyond the Gallic territories $;^{93}$ and as for the others that are produced in Gallia Narbonensis, nothing can be positively stated, for the growers of that country have absolutely established manufactories for the purposes of adulteration, where they give a dark hue to their wines by the agency of smoke; I only wish I could say, too, that they do not employ various herbs and noxious drugs for the same purpose $;^{94}$ indeed, these dealers are even known to use aloes for the purpose of heightening the flavour and improving the colour of their wines.

The regions of Italy that are at a greater distance from the Ausonian Sea, are not without their wines of note, such as those of Tarentum, ${ }^{95}$ Servitia, ${ }^{96}$ and Consentia, ${ }^{97}$ and those, again, of Tempsa, Babia, and Lucania, among which the wines of Thurii hold the pre-eminence. But the most celebrated of all of them, owing to the fact that Messala ${ }^{98}$ used to drink it, and was indebted to it for his excellent health, was the wine of Lagara, ${ }^{99}$ which was grown not far from Grumentum. ${ }^{1}$ In Campania, more recently, new growths under new names have gained considerable credit, either owing to careful cultivation, or else to some other fortuitous circumstances: thus, for instance, we find four miles from Neapolis the Trebellian, ${ }^{2}$ near

92 Now Reziers, in the south of France. The wines of this part are considered excellent at the present day. That of Frontignan grows in its vicinity. Fée is inclined to think, from Pliny's remarks here, that the ancients and the moderns differed entirely in their notions as to what constitutes good or bad wine.

${ }_{93} \mathrm{He}$ means, beyond modern Provence, and Languedoc: districts famous for their excellent wines, more particularly the latter.

${ }_{91}$ Fée deems all this quite incredible. Our English experience, however, tells us that it is by no means so; much of the wine that is drunk in this country is indebted for flavour as well as colour to anything but the grape.

${ }_{95}$ 'The wines of modern Otranto are ordinarily of good quality.

96 Baccius reads "Seberiniana," büt is probably wrong. If he is not, it might allude to the place now known as San Severino, and which produces excellent wine. Fée thinks that these wines were grown in the territory of Salerno, which still enjoys celebrity for its muscatel wines.

${ }_{97}$ See B. iii. e. 10 . The wines of modern Cosenza still enjoy a high reputation.

${ }_{93}$ M. Valerius Messala Corvinus, the writer and partisan of Augustus. See end of B. ix.

${ }_{99}$ A place supposed to have been situated near Thurii.

1 See B. iii. c. 15.

2 Said by Galen to be very wholesome, as well as pleasant. The wines of the vicinity of Naples are still held in high esteem. 
Capua the Cauline, ${ }^{3}$ wine, and the wine of Trebula ${ }^{4}$ grown in the territory so called, though but of a common sort : Campania boasts of all these, as well as of her Trifoline ${ }^{5}$ wines. As to the wines of Pompeii, ${ }^{6}$ they have arrived at their full perfection in ten years, after which they gain nothing by age : they are found also to be productive of headache, which often lasts so long as the sixth hour ${ }^{7}$ of the next day.

These illustrations, if I am not greatly mistaken, will go far to prove that it is the land and the soil that is of primary importance, and not the grape, and that it is quite superfluous to attempt to enumerate all the varieties of every kind, seeing that the same vine, transplanted to several places, is productive of features and characteristics of quite opposite natures. The vineyards of Laletanum ${ }^{8}$ in Spain ${ }^{9}$ are remarkable for the abundance of wine they produce, while those of Tarraco $0^{10}$ and of Lauron ${ }^{11}$ are esteemed for the choice qualities of their wines: those, too, of the Balearic Isles ${ }^{12}$ are often put in comparison with the very choicest growths of Italy.

I am by no means unaware that most of my readers will be of opinion that I have omitted a vast number of wines, seeing that every one has his own peculiar choice; so much so, that wherever we go, we hear the same story told, to the effect that one of the freedmen of the late Emperor Augustus, who - was remarkable for his judgment and his refined taste in wines, while employed in tasting for his master's table, made this observation to the master of the house where the emperor was staying, in reference to some wine the growth of that particular country: "The taste of this wine," said he, "is

3 Galen says that it was very similar to the Falernian.

4 See B. iii. c. 9.

5 The Trifoline territory was in the vicinity of Cumæ. It is possible that the wine may have had its name from taking three years to come to maturity; or possibly it was owing to some peculiarity in the vine.

6 They have been already mentioned in c. 4 . See B. iii. c. 9.

7 Twelve o'clock in the day.

8 See B. iii. c. 4 .

9 In Catalonia, which still produces abundance of wine, but in general of inferior repute.

10 The wines of Tarragona are still considered good.

11. A place in the province of Hispania Tarraconensis, destroyed by Sertorius.

12 They still enjoy a high repute. The fame of their Malvoisie has extended all over the world. 
new to me, and it is by no means of first-rate quality; the emperor, however, you will see, will drink of no other." 13 Indeed I have no wish to deny that there may be other wines deserving of a very high reputation, but those which I have already enumerated are the varieties upon the excellence of which the world is at present agreed.

\section{CHAP. 9. (7.)-THIRTY-EIGHT VARIETIES OF FOREIGN WINES.}

We will now, in a similar manner, give a description of the varieties found in the parts beyond sea. After the wines mentioned by Homer, and of which we have already spoken, ${ }^{14}$ those held in the highest esteem were the wines of Thasos and Chios, ${ }^{15}$ and of the latter more particularly the sort known as "Arvisium." By the side of these has been placed the wine of Lesbos, ${ }^{17}$ upon the authority of Erasistratus, a famous physician, who flourished about the year of the City of Rome 450. At the present day, the most esteemed of all is the wine of Clazomenæ, ${ }^{18}$ since they have learned to season it more sparingly with sea-water. The wine of Lesbos has naturally a taste of sea-water. That from Mount Tmolus ${ }^{19}$ is not so much esteemed by itself ${ }^{20}$ for its qualities as a wine, as for its peculiar sweetness. It is on account of this that it is mixed with other wines, for the purpose of modifying their harsh flavour, by imparting to them a portion of its own sweetness; while at the same time it gives them age, for immediately after the mixture they appear to be much older than they really are. Next in esteem after these are the wines of

13 He means to illustrate the capricious tastes that existed as to the merits of wines.

14 In c. 6 of this Book.

${ }_{15}$ The Chian held the first rank, the Thasian the second.

16 From Arvisium, or Ariusium, a hilly district in the centre of the island. The wine of Chios still retains its ancient celebrity.

17 It was remarkable for its sweetness, and aromatics were sometimes mixed with it. Homer calls it harmless. Lesbos still produces choice wines.

18 Near Smyrna. I'robably similar to the Pramnian wine, mentioned in c. 6 .

19 See B. v. c. 30. This wine is mentioned again in the next page; it is generally thought, that he is wrong in making the Tmolites and the Mesogites distinct wines, for they are supposed to have been identical.

${ }^{20}$ If drunk by itself, and not as a flavouring for other wines. 
Sicyon, ${ }^{21}$ Cyprus, ${ }^{22}$ Telmessus, ${ }^{23}$ Tripolis, ${ }^{24}$ Berytus, ${ }^{25}$ Tyre, ${ }^{26}$ and Sebennys; this last is grown in Egypt, being the produce of three varieties of grape of the very highest quality, known as the Thasian, ${ }^{27}$ the $x^{2}$ thalus, ${ }^{28}$ and the peuce. ${ }^{29}$ Next in rank are the hippodamantian ${ }^{30}$ wine, the Mystic, ${ }^{31}$ the cantharite, ${ }^{32}$ the protropum ${ }^{33}$ of Cnidos, the wine of the catacecaumene, ${ }^{34}$ the Petritan, ${ }^{35}$ and the Myconian $;^{36}$ as to the Mesogitic, ${ }^{37}$ it has been found to give head-ache, while that of Ephesus is far from wholesome, being seasoned with sea-water and defrutum. ${ }^{38}$ It is said that the wine of Apamea ${ }^{39}$ is remarkably well adapted for making mulsum, ${ }^{40}$ like that of Prætutia in Italy : for this is a quality peculiar to only certain kinds of wine, the mixture of two sweet liquids being in

21 Bacchus had a temple there:

22 The wines of Cyprus are the most choice of all the Grecian wines at the present day.

${ }_{23}$ In Lycia.

${ }_{21}$ In Syria. Wine is no longer made there, but the grapes are excellent, and are dried for raisins.

${ }_{25}$ Now Beyrout. It does not seem that wine is made there now. The Mahometan religion may have tended to the extinction of many of these wines.

26 At the village of Sour, on the site of ancient Tyre, the grape is only cultivated for raisins.

2i See also c. 22 : probably introduced from Thasos.

2) The "smoky" grape. 29 The "pitchy" grape.

so A strong wine, Hardouin thinks, from whence its name-"strong enough to subdue a horse."

31 From the small island of Mystus, near Cephallenia.

32 So called from the vine the name of which was "canthareus."

33 Made, as already stated, from the juice that flowed spontaneously from the grapes. See also p. 250 .

34 Or the "burnt up" country, a volcanic district of Mysia, which still retains its ancient fame for its wine. Virgil alludes to this wine in Georg. iv. l. 380 :-

-Cape Mæonii carchesia Bacchi.

${ }^{35}$ Perhaps from Petra in Arabia: though Fée suggests Petra in the Balearic Islands.

${ }_{36}$ See B. iv. c. 22. In the island of Myconos in the Archipelago an excellent wine is still grown.

37 From Mount Mesogis, which divides the tributaries of the Caysster from those of the Meander. It is generally considered the same as the Tmolites.

${ }_{38}$ Must or grape-juice boiled down to one half.

39 See B. v. c. 29.

10 "Mulsum," or honied wine, was of two kinds; honey mixed with wine, and honey mixed with must or grape-juice. 
general not attended with good results. The protagion ${ }^{41}$ is quite gone out of date, a wine which the school of Asclepiades has reckoned as next in merit to those of Italy. The physician Apollodorus, in the work which he wrote recommending King Ptolemy what wines in particular to drink-for in his time the wines of Italy were not generally known-has spoken in high terms of that of Naspercene in Pontus, next to which he places the Oretic, ${ }^{42}$ and then the CEneatian, ${ }^{43}$ the Leucadian, ${ }^{44}$ the Ambraciotic, ${ }^{45}$ and the Peparethian, ${ }^{46}$ to which last he gives the preference over all the rest, though he states that it enjoyed an inferior reputation, from the fact of its not being considered fit for drinking until it had been kept six years.

\section{CHAP. 10. (8.) - SEVEN KINDS OF SALTED WiNes.}

Thus far we have treated of wines, the goodness of which is due to the country of their growth. In Greece the wine that is known by the name of "bion," and which is administered for its curative qualities in several maladies (as we shall have occasion to remark when we come to speak on the subject of Medicine ${ }^{47}$ ), has been justly held in the very highest esteem. This wine is made in the following manner: the grapes are plucked before they are quite ripe, and then dried in a hot sun: for three days they are turned three times a day, and on the fourth day they are pressed, after which the juice is put in casks, ${ }^{48}$ and left to acquire age in the heat of the sun. ${ }^{49}$

The people of Cos mix sea-water in large quantities with their wines, an invention which they first learned from a slave, who adopted this method of supplying the deficiency that had been caused by his thievish propensities. When this is mixed with white must, the mixture receives the name of "leu-

${ }^{41}$ From its Greek name, it would seem to mean "of first quality."

42 So called from a place in Eubœa, the modern Negropont. See. B. iv. c. 20. Negropont produces good wines at the present day.

43. The locality is unknown.

${ }^{44}$ From Leucadia, or Leucate; see B. iv. c. 2 ; the vine was very abundant there.

45 From Ambracia. See B. iv. c 2.

${ }^{46}$ From the island of Peparethus. See. B. iv. c. 23, where he says that from its abundance of vines it was called ह่voıvòs, or "Evenus."

47 B. xxiii. c. 1, and c. $26 . \quad 48$ "Cadis."

49 Fée remarks that this method is still adopted in making several of the liqueurs. 
cocoum." 50 In other countries again, they follow a similar plan in making a wine called "tethalassomenon." ${ }^{11}$ They make a wine also known as "thalassites," ${ }^{52}$ by placing vessels full of must in the sea, a method which quickly imparts to the wine all the qualities of old age. ${ }^{53}$ In our own country too, Cato has shown the method of making Italian wine into Coan: in addition to the modes of preparation above stated, he tells us that it must be left exposed four years to the heat of the sun, in order to bring it to maturity. 'The Rhodian ${ }^{54}$ wine is similar to that of Cos, and the Phorinean is of a still salter flavour. It is generally thought that all the wines from beyond sea arrive at their middle state of maturity in the course of $\operatorname{six}^{55}$ or seven years.

\section{CHAP. 11. (9.) - EIGHTEEN VARTETEIS OF STEEET WINE. RAISIN-WINE AND HEPSEMA.}

All the luscious wines have but little ${ }^{56}$ aroma : the thinner the wine the more aroma it has. The colours of wines are four, white, ${ }^{57}$ brown, ${ }^{58}$ blood-coloured, ${ }^{59}$ and black. ${ }^{60}$ Psythium ${ }^{61}$ and melampsythium ${ }^{62}$ are varieties of raisin-wine which have the peculiar flavour of the grape, and not that of wine. Scybelites $^{63}$ is a wine grown in Galatia, and Aluntium ${ }^{64}$ is a wine of Sicily, both of which have the flavour of mulsum. ${ }^{65}$

to White wine of Cos. Fée thinks that Pliny means to say that the sea water turns the must of a white or pale straw colour, and is of opinion that he has been wrongly informed.
51 "Sea-water" wine.
52 "Sea-seasoned" wine.

${ }^{53}$ Fée says, that if the vessels were closed hermetically this would have little or no appreciable effect; if not, it would tend to spoil the wine.

${ }_{51}$ Athenæus says that the Rhodian wine will not mix so well with seawater as the Coan. Fée remarks that if Cato's plan were followed, the wine would become vinegar long before the end of the four years.

${ }_{55}$ Sillig thinks that the proper reading is "in six" only.

56 The sweet wines, in modern times, have the most bouquet or aroma.

57 "Albus," pale straw-colour. 58 " Fulvus," amber-colour.

59 Bright and glowing, like Tent and Burgundy.

60 "Niger," the colour of our port.

61 Supposed to be a species of Pramnian wine, mentioned in c. 6. This was used, as also the Aminean, for making omphacium, as mentioned in B. xii. c. 60 . See also c. 18 of this Book.

62 "Black psythian."

${ }_{63}$ Mentioned by Galen among the sweet wines.

64 See B. iii. c. 14 . Now Solana in Sicily, which produces excellent wine. 65 Honied wine. 
As to siræum, by some known as "hepsema," and which in our language is called "sapa," 66 it is a product of art and not of Nature, being prepared from must boiled down to one-third : when must is boiled down to one-half only, we give it the name of " defrutum." All these mixtures have been devised for the adulteration of honey. ${ }^{67} \mathrm{As}$ to those varieties which we have previously mentioned, their merits depend upon the grape, and the soil in which it is grown. Next after the raisin-wine of Crete, ${ }^{68}$ those of Cilicia and Africa are held in the highest esteem, both in Italy as well as the adjoining provinces. It is well known that it is made of a grape to which the Greeks have given the name of " stica," and which by us is called "apiana :" 69 it is also made of the scirpula. The grapes are left on the vine to dry in the sun, or else are boiled in the dolium. ${ }^{71}$ Some persons make this wine of the sweet and early white ${ }^{72}$ grape: they leave the grapes to dry in the sun, until they have lost pretty nearly half their weight, after which they crush them and subject them to a gentle pressure. They then draw off the juice, and add to the pulp that is left an equal quantity of well-water, the product of which is raisin-wine of second quality. ${ }^{73}$ The more careful makers not only do this, but take care also after drying the grapes to remove the stalks, and then steep the raisins in wine of good quality until they swell, after which they press them. This kind of raisin-wine is preferred to all others: with the addition of water, they follow the same plan in making the wine of second quality.

The liquor to which the Greeks give the name of " aigleucos,"74 is of middle quality, between the sirops and what is properly called wine; with us it is called " semper mustum."75 It is only made by using great precaution, and taking care that the must does not ferment $;^{76}$ such being the state of the ${ }^{66}$ This was evidently a kind of grape sirop, or grape jelly. "Rob" is perhaps, as Hardouin suggests, a not inappropriate name for it.

${ }^{67}$ When cold, they would have nearly the same consistency.

68 The raisin wine of Crete was the most prized of all as a class.

${ }^{69}$ Mentioned in c. 4. Probably a muscatel grape.

70 See c. 4 of this Book.

71 Or " vat." The common reading was "oleo," which would imply that they were plunged into boiling oil. Columella favours the latter reading, B. xii. c. 16.

${ }_{73}$ Passum secundarium.

75 "Always must." 72 The reading is probably defective here. 74 Or "always sweet." ${ }^{76}$ Fervere, "boil," or "effervesce." 
must in its transformation into wine. To attain this object, the must is taken from the vat and put into casks, which are immediately plunged into water, and there left to remain until the winter solstice is past, and frosty weather has made its appearance. There is another kind, again, of natural aigleucos, which is known in the province of Narbonensis by the name of "dulce,"77 and more particularly in the district of the Vocontii. In order to make it, they keep the grape hanging on the tree for a considerable time, taking care to twist the stalk. Some, again, make an incision in the bearing shoot, as deep as the pith, while others leave the grapes to dry on tiles. The only grape, however, that is used in these various processes is that of the vine known as the "helvennaca."78

Some persons add to the list of these sweet wines that known as " diachyton." "79 It is made by drying grapes in the sun, and then placing them for seren days in a closed place upon hurdles, some seven feet from the ground, care being taken to protect them at night from the dews: on the eighth day they are trodden out: this method, it is said, produces a liquor of exquisite bouquet and flavour. The liquor known as melitites $^{80}$ is also one of the sweet wines : it differs from mulsum, in being made of must; to five congii of rough-flavoured must they put one congius of honey, and one cyathus of salt, and they are then brought to a gentle boil: this mixture is of a rough flavour. Among these varieties, I ought to place what is known as " protropum ;"s1 such being the name given by some to the must that runs spontaneously from the grapes before they are trodden out. Directly it flows it is put into flaggons, and allowed to ferment; after which it is left to ripen for forty days in a summer sun, about the rising of the Dog-star.

77 "Sweet" drink. Fée seems to think that this sweet wine must have been something similar to champagne. Hardouin says that it corresponds to the vin doux de Limoux, or blanquette de Limoux, and the vin Muscat d'Azile.

78 See c. 3 of this Book.

79 "Poured," or "strained through."

so "Honey wine." A disagreeable medicament, Fée thinks, rather than a wine.

81 Somewhat similar to the vin de premiere goutte of the French. It would seem to have been more of a liqueur than a wine. Tokay is made in a scmewhat similar manner. 
CHAP. 12. (10.) - THREe VARIETIES OF SECOND-RATE WINE.

Those cannot properly be termed wines, which by the Greeks are known under the name of "deuteria," 82 and to which, in common with Cato, we in Italy give the name of "lora," 83 being made from the husks of grapes steeped in water. Still, however, this beverage is reckoned as making one of the "labourers" " 84 wines. There are three varieties of" it: the first ${ }^{85}$ is made in the following manner :-After the must is drawn off, one-tenth of its amount in water is added to the husks, which are then left to soak a day and a night, and then are again subjected to pressure. A second kind, that which the Greeks are in the habit of making, is prepared by adding one-third in water of the quantity of must that has been drawn off, and after submitting the pulp to pressure, the result is reduced by boiling to one-third of its original quantity. A third kind, again, is pressed out from the wine-lees; Cato gives it the name of "fæcatum." 86 None of these beverages, however, will keep for more than a single year.

\section{CHAP. 13. (11.) - AT WHAT PERIOD GENEROUS WINES WERE FIRST COMMONLY MADE IN ITALY.}

While treating of these various details, it occurs to me to mention that of the eighty different kinds throughout the whole earth, which may with propriety be reckoned in the class of generous ${ }^{87}$ wines, fully two-thirds ${ }^{88}$ are the produce of Italy, which consequently in this respect far surpasses any other country: and on tracing this subject somewhat higher up, the fact suggests itself, that the wines of Italy have not been in any great favour from an early period, their high

82 Or "second" press wines.

84 Vinum operarium.

83 De Re Rust. c. 153.

${ }^{85}$ This method is still adopted, Fée says, in making "piquette," or "small wine," throughout most of the countries of Europe.

$860 \mathrm{Or}$ "wine-lee drink." It would make an acid beverage, of disagreeable taste.

87 "Nobilia." In c. 29 he speaks of 195 kinds, and, reckoning all the varieties, double that number.

${ }_{88}$ Fée observes that the varieties of the modern wines are quite innumerable. He remarks also that Pliny does not speak of the Asiatic wines mentioned by Athenæus, which were kept in large bottles, hung in the chimney corner; where the liquid, by evaporation, acquired the consistency of salt. 'The wines of other countries evidently were little known to Pliny. 
repute having only been acquired since the six hundredth year of the City.

CHAP. 14. (12.)-THE INSPECTION OF WINE ORDERED BY KING ROMULUS.

Romulus made libations, not with wine but with milk; a fact which is fully established by the religious rites which owe their foundation to him, and are observed even to the present day. The Posthumian Law, promulgated by King Numa, has an injunction to the following effect:- "Sprinkle not the funeral pyre with wine ;" a law to which he gave his sanction, no doubt, in consequence of the remarkable scarcity of that commodity in those days. By the same law, he also pronounced it illegal to make a libation to the gods of wine that was the produce of an unpruned vine, his object being to compel the husbandmen to prune their vines; a duty which they showed themselves reluctant to perform, in consequence of the danger which attended climbing the trees. ${ }^{89} \mathbf{M}$. Varro informs us, that Mezentius, the king of Etruria, succoured the Rutuli against the Latini, upon condition that he should receive all the wine that was then in the territory of Latium.

(13.) At Rome it was not lawful for women to drink wine. Among the various anecdotes connected with this subject, we find that the wife of Egnatius Mecenius ${ }^{90}$ was slain by her husband with astick, because she had drunk some wine from the vat, and that he was absolved from the murder by Romulus. Fabius Pictor, in his Book of Annals, has stated that a certain lady, for having opened a purse in which the keys of the wine-cellar were kept, was starved to death by her family: and Cato tells us, that it was the usage for the male relatives to give the females a kiss, in order to ascertain whether they smelt of " temetum;" for it was by that name that wine was then known, whence our word "temulentia," signifying drunkenness. Cn. Domitius, the judge, once gave it as his opinion, that a certain woman appeared to him to have drunk more wine than was requisite for her health, and without the knowledge of her husband, for which reason he condemned her to lose her dower. For a very long time there was the greatest

89 "Circa pericula arbusti." This is probably the meaning of this very elliptical passage. See p. 218 .

${ }_{90}$ Called Metellus, by Valerius Maximus, B. vi. c. 3. 
economy manifested at Rome in the use of this article. L. Papirius, ${ }^{91}$ the general, who, on one occasion, commanded against the Samnites, when about to engage, vowed an offering to Jupiter of a small cupfull of wine, if he should gain the victory. In fact, among the gifts presented to the gods, we find mention made of offerings of sextarii of milk, but never of wine.

The same Cato, while on his voyage to Spain, from which he afterwards returned triumphant, ${ }^{92}$ would drink of no other wine but that which was served out to the rowers-very different, indeed, to the conduct of those who are in the habit of giving to their guests even inferior wine ${ }^{93}$ to that which they drink themselves, or else contrive to substitute inferior in the course of the repast. ${ }^{94}$

\section{CHAP. 15.-WINES DRUNK BY THE ANCIENT ROMANS.}

The wines that were the most esteemed among the ancient Romans were those perfumed with myrrh, ${ }^{95}$ as mentioned in the play of Plautus, entitled the "Persian," ${ }^{96}$ though we find it there stated that calamus ${ }^{97}$ ought to be added to it. Hence it is, that some persons are of opinion that they were particularly fond of aromatites: ${ }^{98}$ but Fabius Dossennus quite decides the question, in the following line :- "I sent them good wine, myrrh-wine ;"99 and in his play called "Acharistio," we find these words-" Bread and pearled barley, myrrh-wine too." I find, too, that Scævola and I. Flius, and Ateius Capito, were of the same opinion; and then we read in the play known as the "Pseudolus :" - "But if it is requisite for him to draw forth what is sweet from the place, has he aught of that?" to which Charinus makes answer, "Do you ask

${ }^{91}$ See B. xvii. c. 11.

92 Over the Celtiberi.

93 The younger Pliny, B. ii. Ep. 2, censures this stingy practice. See also Martial, B. iii. Epig. 60.

94 That this, however, was not uncommonly done, we may judge from the remark made by the governor of the feast, John ii. 10, to the bridegroom.

${ }_{95}$ Called " myrrhina." Fée remarks that the flavour of myrrh is acrid and bitter, its odour strong and disagreeable, and says that it is difficult to conceive how the ancients could drink wine with this substance in solution.

96 As the "Persa" has come down to us, we find no mention of myrrh in the passage alluded to.

${ }_{97}$ See B. xii. c. 49 . This is mentioned in the Persa, A. i. sc. 3, I. 7.

98 Aromatic or perfumed wines.

99 Murrhinam.

1 The C'heat or Impostor: a play of Plautus. See A. ii. sc. 4, l. 51, et seq. 
the question? He has myrrh wire, raisin wine, defrutum, ${ }^{2}$ and honey;" from which it would appear that myrrh wine was not only reckoned among the wines, but among the sweet wines too.

\section{CHAP. 16. (14.)-SOME REMARKABLE FACTS CONNECTED WITH} WINE-LOFTS. THE OPIMIAN WINE.

The fact of the existence of the Opimian wine gives undoubted proof that there were wine-lofts, ${ }^{3}$ and that wine was racked off in the year of Rome 633, Italy being already alive to the blessings she enjoyed. Still, however, the several varieties that are now so celebrated were not so in those days; and hence it is that all the wines that were grown at that period have only the one general name of "Opimian" wines, from the then consul Opimius. So, too, for a long time afterwards, and, indeed, so late as the times of our grandfathers, the wines from beyond sea were held in the highest esteem, even though Falernian was already known, a fact which we learn from the line of the Comic writer, "I shall draw five cups of Thasian and two of Falernian."

P. Licinius Crassus, and L. Julius Cæsar, who were Censors in the year from the Building of the City 665, issued an edict forbidding the sale of either Greek or Aminean wine at a higher price than eight asses the quadrantal ${ }^{5}$ - for such, in fact, are the exact words of the edict. Indeed, the Greek wines were so highly valued, that not more than a single cup was served to a guest during the repast.

CHAP. 17. - AT WHAT PERIOD FOUR KINDS OF WINB WERE FIRST SERVED AT TABLE.

M. Varro gives us the following statement as to the wines that were held in the highest esteem at table in his day: "L. Lucullus, when a boy, never saw an entertainment at his father's house, however sumptuous it might be, at which Greek

2 Must boiled down to half its original quantity.

3 Apothecas. The "apothecr" were rooms at the top of the house, in which the wines were placed for the purpose of seasoning. Sometimes a current of smoke was directed through them. They were quite distinct from the "cella vinaria," or "wine-cellar." The Opimian wine is mentioned in c. 4 .

${ }_{4}^{4}$ This writer is unknowb.

5 Or amphora. 
wine was handed round more than once during the repast: whereas he himself, when he returned from Asia, distributed as a largess among the people more than a hundred thousand congiaria ${ }^{6}$ of the same wine. C. Sentius, whom we have seen Prætor, used to say that Chian wine never entered his house until his physician prescribed it to him for the cardiac ${ }^{7}$ disease. On the other hand, Hortensius left ten thousand casks of it to his heir." Such is the statement made by Varro.

(15.) And besides, is it not a well-known fact that Cæsar, when Dictator, at the banquet given on the occasion of his triumph, allotted to each table an amphora of Falernian and a cadus of Chian? On the occasion, too, of his triumph for his victories in Spain, he put before the guests both Chian as well as Falernian; and again, at the banquet given on his third consulship, ${ }^{8}$ he gave Falernian, Chian, Lesbian, and Mamertine; indeed, it is generally agreed that this was the first occasion on which four different kinds of wine were served at table. It was after this, then, that all the other sorts came into such very high repute, somewhere about the year of the City 700.

CHAP. 18. (16.) 一 THF USES OF THE WILD VINE. WHAT JUICES ARE NATURALLY THE COIDEST OF ALL.

I am not surprised, then, that for these many ages there have been invented almost innumerable varieties of artificial wines, of which I shall now make some mention; they are all of them employed for medicinal purposes. We have already stated in a former Book how omphacium, ${ }^{9}$ which is used for unguents, is made. The liquor known as "œnanthinum" is made from the wild vine, ${ }^{10}$ two pounds of the flowers of which are steeped in a cadus of must, and are then changed at the end of thirty days. In addition to this, the root and the

${ }^{6}$ Vessels containing a congius, or the eighth of an amphora, nearly six pints English.

7 As to this malady, see B. xi. c. 71.

8 B.c. 46.

9 B. xii. c. 61.

10 Or "labrusca." "Enanthinum " means "made of vine flowers." The wild vine is not a distinct species from the cuitivated vine: it is only a variety of it, known in botany as the Vitis silvestris labrusca of Tournefort. Fée thinks that as the must could only be used in autumn, when the wild sine was not flowering, the flowers of it must bave been dried. 
husks of the grapes are employed in dressing leather. The grapes, too, a little after the blossom has gone off, are singularly efficacious as a specific for cooling the feverish heat of the body in certain maladies, being, it is said, of a nature remarkable for extreme coldness. A portion of these grapes wither away, in consequence of the heat, before the rest, which are thence called solstitial ${ }^{13}$ grapes; indeed, the whole of them never attain maturity; if one of these grapes, in an unripe state, is given to a barn-door fowl to eat, it is productive of a dislike to grapes for the future. ${ }^{14}$

\section{CHAP. 19. - SIXTY-SIX VARIETIES OF ARTIFICIAL WINE.}

The first of the artificial wines has wine for its basis; it is called "adynamon,"15 and is made in the following manner. Twenty sextarii of white must are boiled down with half that quantity of water, until the amount of the water is lost by evaporation. Some persons mix with the must ten sextarii of sea-water and an equal quantity of rain-water, and leave the whole to evaporate in the sun for forty days. This beverage is given to invalids to whom it is apprehended that wine may prove injurious.

The next kind of artificial wine is that made of the ripe grain of millet $;{ }^{16}$ a pound and a quarter of it with the straw is steeped in two congii of must, and the mixture is poured off at the end of six months. We have already stated ${ }^{17}$ how various kinds of wine are made from the tree, the shrub, and the herb, respectively known as the lotus.

From fruit, too, the following wines are made, to the list of which we shall only add some necessary explanations :-First of all, we find the fruit of the palm ${ }^{18}$ employed for this pur-

13 "Solstitiales." Becanse they withstand the heat of the solstice. Marcellus Empiricus calls them "caniculati," because they bear the heat of the Dog-star.

14 Fée remarks that this assertion is quite erroneous.

15 From the Greek, meaning "without strength." The mixture, Fée remarks, would appear to be neither potable nor wholesome.

${ }^{16}$ See B. xviii. c. 24. A kind of beer might be made with it, Fée says; but this mixture must have been very unpalatable.

17 See B. xiii. c. 32 .

18 A vinous drink may be made in the manner here stated ; but the palmwine of the peoples of Asia and Africa is only made of the fermented sap of the tree. See B. xiii. c. 9 . 
pose by the Parthians as well as the Indians, and, indeed. throughout all the countries of the East. A modius of the kind of ripe date called "chydææ" 19 is added to three congii of water, and after being steeped for some time, they are subjected to pressure. Sycites ${ }^{20}$ is a preparation similarly made from figs : some persons call it " palmiprimum," ${ }^{21}$ others, again, "catorchites:" if sweetness is not the maker's object, instead of water there is added the same quantity of husk juice ${ }^{22}$ of grapes. Of the Cyprian fig ${ }^{23}$ a very excellent vinegar, too, is made, and of that of Alexandria ${ }^{24}$ a still superior.

A wine is made, too, of the pods of the Syrian carob, ${ }^{25}$ of pears, and of all kinds of apples. That known as "rhoites" is made from pomegranates, and other varieties are prepared from cornels, medlars, sorb apples, dried mulberries, and pinenuts $;^{27}$ these last are left to steep in must, and are then pressed; the others produce a sweet liquor of themselves. We shall have occasion before long to show how Cato ${ }^{28}$ has pointed out the method of making myrtites : ${ }^{29}$ the Greeks, howerer, adopt a different method in making it. They first boil tender sprigs of myrtle with the leaves on in white must, and after pounding them, boil down one pound of the mixture in three congii of must, until it is reduced to a couple of congii. The beverage that is prepared in this manner with the berries of wild myrtle is known as "myrtidanum;" 30 it will stain the hands.

Among the garden plants we find wines made of the following kinds: the radish, asparagus, cunila, origanum, parsley-

19 He says "caryotæ," and not chydæx, in B. xiii. c. 4. The modius was something more than our peck.

${ }^{20}$ From the Greek $\sigma \dot{v} \kappa \eta$, a "fig." This wine was made, Fée thinks, from the produce of some variety of the sycamore. See B. xiii. c. 14 .

21 "Prime palm" apparently.

22 Tortivum, probably : the second squeezing.

${ }^{23}$ See B. xiii. c. 15 .

21 See B. xiii. c. 14.

25 See B. xiii. c. 16.

26 From jóa, a "pomegranate."

${ }^{27}$ Dioscorides calls it "strobilites." Fée says that they could be of no service in producing a vinous drink.

${ }^{28}$ See B. xv. c. 37.

${ }^{29}$ Or " myrtle wine."

${ }^{30}$ Myrtle will not make a wine, but simply a medicament, in which wine is the menstruum.

vOL. III. 
seed, abrotonum, ${ }^{31}$ wild mint, rue, ${ }^{32}$ catmint, ${ }^{33}$ wild thyme, ${ }^{31}$ and horehound. ${ }^{35}$ A couple of handfuls of these ingredients are put into a cadus of must, as also one sextarius of sapa, ${ }^{36}$ and half a sextarius of sea-water. A wine is made of the naphew ${ }^{37}$ turnip by adding two drachms of naphew to two sextarii of must. A wine is made also from the roots of squills. ${ }^{\text {is }}$ Among the flowers, that of the rose furnishes a wine: the leaves are put in a linen cloth and then pounded, after which they are thrown into must with a small weight attached to make them sink to the bottom, the proportion being forty drachms of leaves to twenty sextarii of must; the vessel in which it is kept must not be opened before the end of three months. A wine, too, is made of Gallic nard, ${ }^{39}$ and another kind of the wild ${ }^{40}$ variety of that plant.

I find, also, that various kinds of aromatites ${ }^{41}$ are prepared, differing but very little in their mode of composition from that of the unguents, being made in the first instance, as I have already stated, ${ }^{42}$ of myrrh, and then at a later period of Celtic nard, ${ }^{43}$ calamus, and aspalathus, ${ }^{44}$ of which cakes are made, and are then thrown into either must or sweet wine. Others, again, make these wines of calamus, scented rush, ${ }^{45}$ costus, ${ }^{46}$. Syrian nard, ${ }^{47}$ amomum, ${ }^{48}$ cassia, ${ }^{49}$ cinnamon, saffron, ${ }^{50}$ palm-dates, and foal-foot, ${ }^{51}$ all of which are made up into cakes in a similar manner. Other persons, again, put half a pound of nard and malobathrum ${ }^{52}$ to two congii of must; and it is in this manner that at the present day, with the addition of

31 Artemisia abrotonum of Linnæus.

${ }^{33}$ Nepeta cataria of Linnæus.

32 Ruta graveolens of Linnæus.

35 Marrubium vulgare of Linnæus.

${ }^{36}$ Grape-juice boiled down to one-third.

37 Brassica napus of Linnæus.

38 Scilla marina of Linnæus.

${ }^{39}$ Nardus Gallicus, or Valeriana Celtica of Linnæus. See B. xii. c. 26.

40 Nardus silvestris or baccaris.

42 In c. 15 of this Book.

41 Aromatic wines.

${ }^{44}$ Convolvulus scoparius of Linnæus.

45 Andropogon schœnanthus of Linnæus.

46 Costus Indicus of Linnæus.

47 Andropogon nardus of Linnæus.

48 See B. xiii. c. 2.

50 Crocus sativus of Linnæus.

43 Valeriana Celtica.

51 Asarum Europæum of Linnæus.

52 See B. xii. c. 59. 
pepper and honey, the wines are made by some known as confection wines ${ }^{53}$ and by others as peppered ${ }^{54}$ wines. We find mention made of nectarites also, a beverage extracted from a herb known to some as "helenion," 55 to others as "Medica," ${ }^{56}$ and to others, again, as symphyton, ${ }^{57}$ Idæa, Orestion, or nectaria, the root of which is added in the proportion of forty drachms to six sextarii of mnst, being first similarly placed in a linen cloth.

As to other kinds of herbs, we find wormwood wine, ${ }^{58}$ made of Pontic wormwood in the proportion of one pound to forty sextarii of must, which is then boiled down until it is reduced to one third, or else of slips of wormwood put in wine. In a similar manner, hyssop wine ${ }^{59}$ is made of Cilician hyssop, ${ }^{60}$ by adding three ounces of it to two congii of must, or else by pounding three ounces of hyssop, and adding them to one congius of must. Both of these wines may be made also in another method, by sowing these plants around the roots of vines. It is in this manner, too, that Cato tells us how to make hellebore ${ }^{61}$ wine from black hellebore; and a similar method is used for making scammony ${ }^{62}$ wine. The vine has a remarkable propensity ${ }^{63}$ of contracting the flavour of any plant that may happen to be growing near it; and hence it is that in the marshy lands of Patavium, the grape has the peculiar flavour of the willow. So, in like manner, we find at Thasos hellebore planted among the vines, or else wild cucumber, or scammony; the wine that is produced from these vines is known by the name of "phthorium," it being productive of abortion.

53 Condita.

54 Piperata.

55 Inula helenium of Linnæus. See B. xxi. c. 91 .

56 Medicago sativa of Linnæus.

57 Symphytum officinale of Linnæus, being all different varieties.

58 "Absinthites;" made of the Artemisia Pontica of Linnæus. A medicinal wine is still prepared with wormwood; and "apsinthe," a liqueur much esteemed in France, is made from it.

¿9 Hyssopites.

60 Hyssopites officinalis of Linnæus.

61 Helleborites.

62 Scammonites.

63 Fée says that this is not the fact; and queries whether the vulgar notion still entertained on this subject, may not be traced up to our author. It is a not uncommon belief that roses smell all the sweeter if onions are planted near them. 
Wines are made, too, of other herbs, the nature of which will be mentioned in their respective places, the stæchas $^{6 t}$ for instance, the root of gentian ${ }^{65}$ tragoriganum, ${ }^{66}$ dittany, ${ }^{67}$ foalfoot, ${ }^{68}$ daucus, ${ }^{69}$ elelisphacus, ${ }^{70}$ panax, ${ }^{71}$ acorus, ${ }^{72}$ conyza, ${ }^{73}$ thyme,$^{74}$ mandragore, ${ }^{75}$ and sweet rush..$^{76}$ We find the names mentioned, also, of scyzinum, ${ }^{77}$ itæomelis, and lectisphagites, compounds of which the receipt is now lost.

The wines that are made from the shrubs are mostly extracted from the two kinds of cedar, ${ }^{78}$ the cypress, ${ }^{79}$ the laurel, ${ }^{80}$ the juniper, ${ }^{81}$ the terebinth, ${ }^{82}$ and in Gaul the lentisk. ${ }^{83}$ To make these wines, they boil either the berries or the new wood of the shrub in must. They employ, also, the wood of the dwarf olive, ${ }^{84}$ the ground-pine, ${ }^{85}$ and the germander ${ }^{86}$ for a similar purpose, adding at the same time ten drachms of the flower to a congius of must.

${ }^{61}$ Lavendula stœchas of Linnæus. See B. xxvii. c. 107.

65 Gentiana lutea of Linnæus. See B. xxv. c. 34 . Gentian wine is still made.

66 Thymus tragoriganum of Linnæus. See B. xx. c. 68 .

67 Origanum dictannus of Linnæus. See B. xxv. c. 63.

65 Asarum Europæum of Linnæus. See B. xii. c. 27.

${ }^{69}$ Query, if not carrot? See B. xxv. c. 64 .

70 A variety of salvia or sage: it will be mentioned again, further on.

71 Laserpitium hirsutum of Linnæus. See B. xxv. cc. 11, 12, and 13.

72 Acorus calamus of Linræus. See B. xxv. c. 100.

${ }_{73}$ See B. xxi. c. $32 . \quad{ }^{74}$ See B. xxi. c. 31.

75 Atrapora mandragora of Linnæus. This wine would act as a narcotic poison; it would appear.

${ }_{76}$ Andropogon schœnanthus of Linnæus. See B. xxi. c. 72.

${ }^{77}$ The origin and meaning of these names are unknown.

78 See B. xii. c. 11. Juniperus Lycia, and Juniperus Phœnicea of Linnæus.

79 Cupressus sempervirens of Linnæus.

80 Laurus nobilis of Linnæus. See B. xv. c. 39.

s1 Juniperus communis of Linnæus.

S2 See B. xiii. c. 12. The Pistacia terebinthus of Linnæus.

83 See B. xii. c. 36 . The Pistacia lentiscus of Linnæus.

81 " Chamelæa." The Granium Cnidium, Daphne Cnidium, and Daphne cneorum of Linnæus. See B. xiii. c. 35 . Venomous plants, which, taken internally, would be productive of dangerous results.

${ }_{85}$ Chamæpitrys. The Teucrium chamæpitrys of Linnæus. See B. xxv. c. 20 .

${ }^{86}$ Chamædrys. The Teucrium chamædrys of Linnæus. See B. xxiv. c. 80. Dioscorides mentions most of these so-called wines. 
CHAP. 20. (17.) - HYDROMELI, OR MELICRATON.

There is a wine also made solely of honey and water. ${ }^{87}$ For this purpose it is recommended that rain-water ${ }^{88}$ should be kept for a period of five years. Those who shew greater skill, content themselves with taking the water just after it has fallen, and boiling it down to one third, to which they then add one third in quantity of old honey, and keep the mixture exposed to the rays of a hot sun ${ }^{89}$ for forty days after the rising of the Dog-star ; others, however, rack it off in the course of ten days, and tightly cork the vessels in which it is kept. This beverage is known as "hydromeli," and with age acquires the flavour of wine. It is nowhere more highly esteemed than in Phrygia. ${ }^{90}$

\section{CHAP. 21.-OXYMELI.}

Vinegar ${ }^{91}$ even has been mixed with honey; nothing, in fact, has been left untried by man. To this mixture the name of oxymeli has been given; it is compounded of ten pounds of honey, five semi-sextarii of old vinegar, one pound of sea-salt, and five sextarii of rain-water. This is boiled gently till the mixture has bubbled in the pot some ten times, ${ }^{92}$ after which it is drawn off, and kept till it is old $;^{93}$ all these wines, however, are condemned ${ }^{94}$ by Themison, an author of high autho. rity. And really, by Hercules! the use of them does appear to be somewhat forced, ${ }^{95}$ unless, indeed, we are ready to maintain that these aromatic wines are so many compounds taught us by Nature, as well as those that are manufactured of perfumes, or that shrubs and plants have been generated only for the purpose of being swallowed in drink. However, all these particulars, when known, are curious and interesting, and show how successfully the human intellect has pried into every secret.

87 Mead, or metheglin. See B. xxii. c. 51 .

${ }_{88}$ There is no ground, Fée says, for this recommendation.

${ }^{89}$ Stoves are now used for this purpose.

90 "Hydromelum," on the other hand, made of water and apples, was the same as our modern cider. ${ }_{91}$ See B. xxiii. c. 9.

92 "Subfervefactis." "Just come on the boil."

93 The oxymel of modern times contains no salt, and is only used as a medicament.

${ }^{94}$ As drinks, no doubt; and with good reason, as to most of them.

95 Coactus. 
None of these wines, however, will keep beyond a year, ${ }^{96}$ with the sole exception of those which we have spoken of as requiring age ; many of these, indeed, there can be no doubt, do not improve after being kept so little as thirty days.

\section{CHAP. 22. (18.)-TWELVE KINDS OF WINE WITH MIRACULOUS PROPERTIES.}

There are some miraculous properties, too, in certain wines. It is said that in Arcadia there is a wine grown which is productive of fruitfulness ${ }^{97}$ in women, and of madness in men ; while in Achaia, and more especially in the vicinity of Carynia, there is a wine which causes abortion; an effect which is equally produced if a woman in a state of pregnancy happens only to eat a grape of the vine from which it is grown, although in taste it is in no way different from ordinary grapes : again, it is confidently asserted that those who drink the wine of Trœzen never bear children. Thasos, it is said, produces two varieties of wine with quite opposite properties. By one kind sleep is produced, ${ }^{98}$ by the other it is prevented. There is also in the same island a vine known as the "theriaca," wine and grapes of which are a cure for the bites of serpents. The libanian vine ${ }^{1}$ also produces a wine with the smell of frankincense, with which they make libations to the gods, while, on the other hand, the produce of that known as " aspendios,", is banished from all the altars: it is said, too, that this last vine is never touched by any bird.

The Egyptians call by the name of "Thasian," 3 a certain grape of that country, remarkable for its sweetness and its

96 Our medicinal wines will mostly keep longer than this, owing probably to the difference in the mode of making the real wines that form their basis.

${ }_{97}$ There is little doubt that this is fabulous : wine taken in excess, we know, is productive of loss of the senses, frenzy in the shape of delirium tremens.

${ }_{98}$ This is not unlikely; for, as Fée remarks, the red wines, containing a large proportion of alcohol, act upon the brain and promote sleep, while the white wines, charged with carbonic gas, are productive of wakefulness.

${ }^{99}$ Or healing vine. See B. xxiii. c. 11.

1 "Libanios." Probably incense was put in this wine, to produce the flavour.

2 From $\dot{\alpha}$, "not," and $\sigma \pi \dot{\varepsilon} \nu \delta \varepsilon \iota \nu$, " to make libation."

3 See c. 9 of this Book. It was introduced, probably, from Thasos. 
laxative qualities. On the other hand, there is in Lycia a certain grape which proves astringent to the stomach when relaxed. Egypt has a wine, too, known as "ecbolas," " which is productive of abortion. There are some wines, which at the rising of the Dog-star change their nature in the winelofts ${ }^{5}$ where they are kept, and afterwards recover ${ }^{6}$ their original quality. The same is the case, too, with wines when carried across the seas: those that are able to withstand the motion of the waves, appear afterwards to be twice as old ${ }^{7}$ as they really are.

CHAP. 23. (19.) - WHAT WINES IT IS NOT LAWFUL TO USE IN THE SACRED RITES.

As religion is the great basis of the ordinary usages of life, I shall here remark that it is considered improper to offer libations to the gods with any wines which are the produce of an unpruned vine, or of one that has been struck by lightning, or near to which a dead man has been hung, or of grapes that have been trodden out by sore feet, or made of must from husks that have been cut, ${ }^{8}$ or from grapes that have been polluted by the fall of any unclean thing upon them. The Greek wines are excluded also from the sacred ministrations, because they contain a portion of water.

The vine itself is sometimes eaten; the tops of the shoots ${ }^{9}$ are taken off and boiled, and are then pickled in vinegar ${ }^{10}$ and brine.

\section{CHAP. 24.-HOW MUST IS USUALLY PREPARED.}

It will be as well now to make some mention of the methods

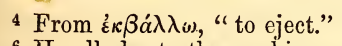

5 Apothecis.

$6 \mathrm{He}$ alludes to the working of wines in periods of extreme heat; also in the spring.

7 Of our modern wines, Madeira and Bourdeaux improve by being carried across sea. Burgundy, if any thing, deteriorates, by the diminution of its bouquet.

8 After the grapes had been trodden and pressed, the husks were taken out and their edges cut, and then again subjected to pressure : the result was known as "tortivum," or "circumcisivum," a wine of very inferior quality.

9 He alludes to the young shoots, which have an agreeable acidity, $o$ wing to acetic and tartaric acids.

10 Acetic acid; the result, no doubt, of the faulty mode of manufacture universally prevalent; their wines contained evidently but little alcohol. 
used in preparing wines; indeed, several of the Greeks have written separate treatises on this subject, and have made a complete art of it, such, for instance, as Euphronius, Aristomachus, Commiades, and Hicesius. The people of Africa are in the habit of neutralizing such acidity ${ }^{11}$ as may be found with gypsum, and in some parts with lime. The people of Greece, on the other hand, impart briskness to their wines when too flat, with potters' earth, pounded marble, salt, or sea-water; while in Italy, again, brown pitch is used for that purpose in some parts, and it is the universal practice both there as well as in the adjoining provinces to season their new wines with resin: sometimes, too, they season them with old wine-lees or vinegar. ${ }^{12}$ They make various medicaments, also, for this purpose with the must itsolf. They boil it down till it becomes quite sweet, and has lost a considerable portion of its strength; though thus prepared, they say it will never last beyond a single year. In some places they boil down the must till it becomes sapa ${ }^{13}$ and then mix it with their wines for the purpose of modifying their harshness. Both for these kinds of wines, as, indeed, all others, they always employ vessels which have themselves received an inner coat of pitch; the method of preparing them will be set forth in a succeeding Book. ${ }^{14}$

\section{CHAP. 25. (20.) -PITCH AND RESIN.}

Of the trees from which pitch and resin distil, there are some which grow in the East, and others in Europe: the province of Asia, ${ }^{15}$ which lies between the two, has also some of both kinds. In the East, the very best commodity of this lsind, and of the finest quality, is that produced by the terebinth, ${ }^{16}$ and, next to it, that from the lentisk, ${ }^{17}$ which is also known as the mastich. The next in quality to these is the juice of the cypress, ${ }^{18}$ being of a more acrid flavour than any other.

11 See B. xxiii. c. 24 , and B. xxxvi. c. 48 .

12 A process very likely, as Fée remarks, to turn the wines speedily to vinegar.

${ }^{13}$ Down to one-third. This practice of using boiled grape-juice as a seasoning, is still followed in Spain in making some of the liqueurs; but it is not generally recommended.

14 B. xvi. c. 21.

16 B. xiii. c. 12 .

15 Asia Minor, namely.

18 It produces but a very minute quantity of resin, which is no longeran article of commerce. 
All the above juices are liquid and of a resinous nature only, but that of the cedar ${ }^{19}$ is comparatively thick, and of a proper consistency for making pitch. The Arabian resin ${ }^{20}$ is of a pale colour, has an acrid smell, and its fumes are stifling to those employed in boiling it. That of Judæa is of a harder nature, and has a stronger smell than that from the terebinth ${ }^{21}$ even. The Syrian ${ }^{22}$ resin has all the appearance of Attic honey, but that of Cyprus is superior to any other; it is the colour of honey, and is of a soft, fleshy nature. The resin of Colophon $^{23}$ is yellower than the other varieties, but when pounded it turns white; it has a stifling smell, for which reason the perfumers do not employ it. That prepared in Asia from the produce of the pitch-tree is very white, and is known by the name of " spagas."

All the resins are soluble in oil $;^{25}$ some persons are of opinion also that potters' chalk may be so dissolved : ${ }^{26}$ I feel ashamed ${ }^{27}$ to avow that the principal esteem in which the resins are held among us is as depilatories for taking the hair off men's bodies.

The method used for seasoning wines is to sprinkle pitch in the must during the first fermentation, which never lasts beyond nine days at the most, so that a bouquet is imparted to the wine, ${ }^{28}$ with, in some degree, its own peculiar piquancy of flavour. It is generally considered, that this is done most effectually by the use of raw flower ${ }^{29}$ of resin, which imparts a considerable degree of briskness to wine: while, on the other hand, it is thought that crapula ${ }^{30}$ itself, if mixed, tends

19 See B. xiii. c. 11, and B. xvi. c. 21 . Not the cedar of Lebanon, probably, which only gives a very small quantity of resin, but one of the junipers. binth.

${ }^{20}$ Fée suggests that this may have been the resin of the Arabian tere-

${ }^{21}$ See B. xxiv. e. 22.

${ }_{22}$ Perhaps from the Pistacia terebinthus of Linnæus.

${ }_{23}$ This was made from the terebinth : but the modern resin of Colophon is extracted from varieties of the coniferæ.

25 See B. xxiv. c. 22.

${ }^{26}$ Earths are not soluble in oils.

27 As being a mark of extreme effeminacy.

23 The greater the quantity of alcohol, the more resin the wine would be able to hold in solution.

:9 See B. xvi. c. 22.

30 "Crapula" properly means head-ache, and what is not uncommonly known as "seedness." Resined wine was thought to be productive of 
to mitigate the harshness of the wine and subdue its asperity, and when the wine is thin and flat, to give it additional strength and body. It is in Liguria more particularly, and the districts in the vicinity of the Padus, that the utility is recognized of mixing crapula with the must, in doing which the following rule is adopted: with wines of a strong and generous nature they mix a larger quantity, while with those that are poor and thin they use it more sparingly. There are some who would have the wine seasoned with both crapula and flower of resin at the same time. ${ }^{31}$ Pitch too, when used for this purpose, has much the same properties as must when so employed.

In some places, the must is subject to a spontaneous fermentation a second time: when this unfortunately happens it loses all its flavour, and then receives the name of " vappa,"32 a word which is applied as an opprobrious appellation even to worthless men of degenerate spirit: in vinegar, on the other hand, notwithstanding its tart and acrid taste, there are very considerable virtues, and without it we should miss many of the comforts ${ }^{33}$ of civilized life.

In addition to what we have already stated, the treatment and preparation of wines are the object of such remarkable attention, that we find some persons employing ashes, and others gypsum and other substances of which we have already ${ }^{34}$ spoken, for the purpose of improving its condition: the ashes, ${ }^{35}$ however, of the shoots of vines or of the wood of the quercus, are in general preferred for this purpose. It is recommended also,

these effects, and hence obtained the name. This kind of wine was used itself, as we see above, in seasoning the other kinds. Fée remarks, that in reality resins have no such effect as imparting body to weak wines.

31 The whole of this passage is hopelessly corrupt, and we can only guess at the meaning.

${ }_{32}$ We have already stated that "vappa" is properly vinegar, which has been exposed to the air and has lost its flavour. In this fresh chemical change, which he calls a second fermentation, the wine becomes vinegar; and probably in the cases he mentions, for some peculiar reason, its speedy transition to "vappa" could not be arrested.

${ }_{33}$ Mixed with water, it was the "posca," or common drink of the Roman soldiers; and it was used extensively both by Greeks and Romans in their cooking, and at meals.

34 In c. 24.

35 By the mixture of ashes, Fée says, the wines would lose their colour, and have a detestable alkaline flavour. 
to take sea-water far out at sea, and to keep it in reserve, ${ }^{36}$ to be employed for this purpose : at all events, it ought to be taken up in the night and during the summer solstice, while the north-east wind is blowing; but if taken at the time of the vintage, it should be boiled before being used.

The pitch most highly esteemed in Italy for preparing vessels for storing wine, is that which comes from Bruttium. It is made from the resin that distils from the pitch-tree; that which is used in Spain is held in but little esteem, being the produce of the wild pine ; it is bitter, dry, and of a disagreeable smell. While speaking of the wild trees in a succeeding Book, ${ }^{37}$ we shall make mention of the different varieties of pitch, and the methods used in preparing it. The defects in resin, besides those which ${ }^{38}$ we have already mentioned, are a certain degree of acridity, or a peculiar smoky flavour, while the great fault in pitch is the being over-burnt. The ordinary test of its goodness is a certain luminous appearance when broken to pieces; it ought to stick, too, to the teeth, with a pleasant, turt flavour.

In Asia, the pitch which is most esteemed is that of Mount Ida, in Greece of Pieria; but Virgil ${ }^{39}$ gives the preference to the Narycian ${ }^{40}$ pitch. The more careful makers mix with the wine black mastich, which comes from Pontus, ${ }^{41}$ and resembles bitumen in appearance, as also iris ${ }^{42}$-root and oil. As to coating the ressels with wax, it has been found that the wine is apt to turn acid : ${ }^{43}$ it is a better plan to put wine in vessels that have held vinegar, than in those which have previously contained sweet wine or mulsum. Cato ${ }^{44}$ recommends that wines should be got up-concinnari is his word-by putting of lie-ashes boiled down with defrutum, one-fortieth part to the culeus, or else a pound and a half of salt, with pounded marble as well: he makes mention of sulphur also, but only gives the very last place to resin. When the fermentation of the wine is coming to an end, he recommends the addition of the must

36 A perfect absurdity, Fée remarks.

37 B. xvi. cc. $16-23$.

38 Bitterness, driness, and a disagreeable smell.

39 Georg. ii. 498.

40 See B. iv. c. 12.

41 See B. xii. c. 36.

42 See B. xxi. c. 19.

43 Bees' wax, Fée remarks, would not have this effect, but vinegar vessels would.

${ }^{44}$ De Re Rust. c. 23. 
to which he gives the name of "tortivum," ${ }^{45}$ meaning that which is pressed out the very last of all. For the purpose of colouring wine we also add certain substances as a sort of pigment, and these have a tendency to give it a body as well. By such poisonous sophistications is this beverage compelled to suit our tastes, and then we are surprised that it is injurious in its effects!

It is a proof that wine is beginning to turn bad, if a plate of lead, on being put in it, changes its colour. ${ }^{46}$

\section{CHAP. 26.-VINEGAR-LEES OF WINE.}

It is a peculiarity of wine, among the liquids, to become mouldy, or else to turn to vinegar. There are whole volumes which treat of the various methods of preventing this.

The lees of wine when dried will take fire and burn without the addition of fuel: the ashes so produced have very much the nature of nitre, ${ }^{47}$ and similar virtues; the more so, indeed, the more unctuous they are to the touch.

\section{CHAP. 27. (21.) -WINE-VESSELS-WINE-CELLARS.}

The various methods of keeping and storing wines in the cellar are very different. In the vicinity of the Alps, they put their wines in wooden vessels hooped around $;{ }^{48}$ during their cold winters, they even keep lighted fires, to protect the wines from the effects of the cold. It is a singular thing to mention, but still it has been occasionally seen, that these vessels have burst asunder, and there has stood the wine in frozen masses ; a miracle almost, as it is not ordinarily the nature of wine to freeze, cold having only the effect of benumbing it. In more temperate climates, they place their wines in dolia, ${ }^{49}$ which they bury in the earth, either covering them entirely or in part, according to the temperature. Sometimes, again, they expose their wines in the open air, while at others they are placed beneath sheds for protection from the atmosphere.

45 The second "squeezings."

46 If the wine is turning to vinegar, subacetate of lead will be formed.

47 They are tartrates, and have no affinity at all with nitre.

${ }^{48}$ Casks, in fact, similar to those used in France at the present day. In Spain they use earthen jars and the skins of animals.

49 Oblong earthen vessels, used as vats. 
The following are among the rules given for the proper management of wines:-One side of the wine-cellar, or, at all events, the windows, ought to face the north-east, or at least due east. All dunghills and roots of trees, and everything of a repulsive smell, ought to be kept at as great a distance as possible, wine being very apt to contract an odour. Fig-trees too, either wild or cultivated, ought not to be planted in the vicinity. Intervals should also be left between the vessels, in order to prevent infection, in case of any of them turning bad, wine being remarkably apt to become tainted. The shape, too, of the vessels is of considerable importance: those that are broad and bellying ${ }^{51}$ are not so good..$^{52}$ We find it recommended too, to pitch them immediately after the rising of the Dog-star, and then to wash them either with sea or salt water, after which they should be sprinkled with the ashes of tree-shoots or else with potters' earth ; they ought then to be cleaned out, and perfumed with myrrh, a thing which ought to be frequently done to the wine-cellars as well. Weak, thin wines should be kept ${ }^{53}$ in dolia sunk in the ground, while those in which the stronger ones are kept should be more exposed to the air. The vessels ought on no account to be entirely filled, room being left for seasoning, by mixing either raisin wine or else defrutum flavoured with saffron; old pitch and sapa are sometimes used for the same purpose. The lids, too, of the dolia ought to be seasoned in a similar manner, with the addition of mastich and Bruttian pitch.

It is strongly recommended never to open the vessels, except in fine weather; nor yet while a south wind is blowing, or at a full moon.

The flower ${ }^{54}$ of wine when white is looked upon as a good sign; but when it is red, it is bad, unless that should happen to be the colour of the wine. The vessels, too, should not be hot to the touch, nor should the covers throw out a sort of sweat. When wine very soon flowers on the surface and emits an odour, it is a sign that it will not keep.

As to defrutum and sapa, it is recommended to commence boiling them when there is no moon to be seen, or, in other

51 "Ventruosa." He means "round." ${ }^{52}$ As oblong ones, probably.

53 While fermenting, and before racking off.

54 Flos vini, the Mycoderma vini of Desmazieres, a mould or pellicule which forms on the surface, and afterwards falls and is held in suspension. 
words, at the conjunction of that planet, and at no other time. Leaden ${ }^{55}$ ressels should be used for this purpose, and not copper ${ }^{56}$ ones, and walnuts are generally thrown into them, from a notion that they absorb ${ }^{57}$ the smoke. In Campania they expose the very finest wines in casks in the open air, it being the opinion that it tends to improve the wine if it is exposed to the action of the sun and moon, the rain and the winds.

\section{CHAP. 28. (22.)-DRUNKENNESS.}

If any one will take the trouble duly to consider the matter, he will find that upon no one subject is the industry of man kept more constantly on the alert than upon the making of wine; as if Nature had not given us water as a beverage, the one, in fact, of which all other animals make use. We, on the other hand, even go so far as to make our very beasts of burden drink $^{58}$ wine : so vast are our efforts, so vast our labours, and so boundless the cost which we thus lavish upon a liquid which deprives man of his reason and drives him to frenzy and to the commission of a thousand crimes! So great, however, are its attractions, that a great part of mankind are of opinion that there is nothing else in life worth living for. Nay; what is even more than this, that we may be enabled to swallow all the more, we have adopted the plan of diminishing its strength by pressing it through ${ }^{59}$ filters of cloth, and have devised numerous inventions whereby to create an artificial thirst. To promote drinking, we find that even poisonous mixtures have been invented, and some men are known to take a dose of hemlock before they begin to drink, that they may have the fear of death before them to make them take their wine: ${ }^{60}$ others, again, take powdered pumice ${ }^{61}$ for the

55 Vessels of lead are never used for this purpose at the present day; as that metal would oxidize too rapidly, and liquids would have great difficulty in coming to a boil. A slow fire must have been used by the ancients.

${ }_{56}$ They were thought to give a bad flavour to the sapa or defrutum.

57 A mere puerility, as Fée remarks.

58 He does not state the reason, nor does it appear to be known. At the present day warmed wine is sometimes given to a jaded horse, to put him on his legs again.

59 Though practised by those who wished to drink largely, this was considered to diminish the flavour of delicate wines.

60 See B. xxii. c. 23 , and B. xxv. c. 95 ; also c. 7 of the present Book. Wine is no longer considered an antidote to cicuta or lemlock.

61 Sce B. xxxvi. c. 42. 
same purpose, and various other mixtures, which I shculd feel quite ashamed any further to enlarge upon.

We see the more prudent among those who are given to this habit have themselves parboiled in hot-baths, from whence they are carried away half dead. Others there are, again, who cannot wait till they have got to the banqueting couch, ${ }^{62}$ no, not so much as till they have got their shirt on, ${ }^{63}$ but all naked and panting as they are, the instant they leave the bath they seize hold of large vessels filled with wine, to show off, as it were, their mighty powers, and so gulp down the whole of the contents only to vomit them up again the very next moment. This they will repeat, too, a second and even a third time, just as though they had only been begotten for the purpose of wasting wine, and as if that liquor could not be thrown away without having first passed through the human body. It is to encourage habits such as these that we have introduced the athletic exercises ${ }^{64}$ of other countries, such as rolling in the mud, for instance, and throwing the arms back to show off a brawny neck and chest. Of all these exercises, thirst, it is said, is the chief and primary object.

And then, too, what vessels are employed for holding wine ! carved all over with the representations of adulterous intrigues, as if, in fact, drunkenness itself was not sufficiently capable of teaching us lessons of lustfulness. Thus we see wines quaffed out of impurities, and inebriety invited even by the hope of a reward,-invited, did I say?-may the gods forgive me for saying so, purchased outright. We find one person induced to drink upon the condition that he shall have as much to eat as he has previously drunk, while another has to quaff as many cups as he has thrown points on the dice. Then it is that the roving, insatiate eyes are setting a price upon the matron's chastity; and yet, heavy as they are with wine, they do not fail to betray their designs to her husband. Then it is that all the secrets of the mind are revealed; one man is heard to disclose the provisions of his will, another lets fall some expression of fatal import, and so fails to keep to himself words which will be sure to come home to him with a cut

62 This seems to be the meaning of "lectum;" but the passage is ob-
scure.

61 He satirizes, probably, some kind of gymnastic exercises that had been introduced to promote the speedy passage of the wine through the body. 
throat. And how many a man has met his death in this fashion! Indeed, it has become quite a common proverb, that " in wine ${ }^{65}$ there is truth."

Should he, however, fortunately escape all these dangers, the drunkard never beholds the rising sun, by which his life of drinking is made all the shorter. From wine, too, comes that pallid hue, ${ }^{66}$ those drooping eyelids, those sore eyes, those tremulous hands, unable to hold with steadiness the overflowing vessel, condign punishment in the shape of sleep agitated by Furies during the restless night, and, the supreme reward of inebriety, those dreams of monstrous lustfulness and of forbidden delights. Then on the next day there is the breath reeking of the wine-cask, and a nearly total obliviousness of everything, from the annihilation of the powers of the memory. And this, too, is what they call " seizing the moments of life!":67 whereas, in reality, while other men lose the day that has gone before, the drinker has already lost the one that is to come.

They first began, in the reign of Tiberius Claudius, some forty years ago, to drink fasting, and to take whets of wine before meals; an outlandish ${ }^{68}$ fashion, however, and only patronized by physicians who wished to recommend themselves by the introduction of some novelty or other.

It is in the exercise of their drinking powers that the Parthians look for their share of fame, and it was in this that Alcibiades among the Greeks earned his great repute. Among ourselves, too, Novellius Torquatus of Mediolanum, a man who held all the honours of the state from the prefecture to the pro-consulate, could drink off three congii ${ }^{69}$ at a single draught, a feat from which he obtained the surname of "Tricongius :" this he did before the eyes of the Emperor Tiberius, and to his extreme surprise and astonishment, a man who in his old age was very morose, ${ }^{70}$ and indeed very cruel in general; though in his younger days he himself had been too much addicted to wine. Indeed it was owing to that recommendation that it was generally thought that L. Piso was

65 " In vino veritas."

${ }^{65}$ Fée remarks that this is one proof that the wine of the ancients was essentially different in its nature from ours. In our day wine gives anything but a "pallid" hue.
6i "Rapere vitam."
68 See B. xxiii. c. 23.

69 Three gallons and three pints!! There must have been some jugglery in this performance.

70 Probably towards those guilty of excesses in wine. 
selected by him to have the charge and custody ${ }^{71}$ of the City of Rome; he having kept up a drinking-bout at the residence of Tiberius, just after he had become emperor, two days and two nights without intermission. In no point, too, was it generally said that Drusus Cæsar took after his father Tiberius more than this. ${ }^{72}$ Torquatus had the rather uncommon gloryfor this science, too, is regulated by peculiar laws of its ownof never being known to stammer in his speech, or to relieve the stomach by vomiting or urine, while engaged in drinking. He was always on duty at the morning guard, was able to empty the largest vessel at a single draught, and yet to take more ordinary cups in addition than any one else; he was always to be implicitly depended upon, too, for being able to drink without taking breath and without ever spitting, or so much as leaving enough at the bottom of the cup to make a plash upon the pavement $;^{73}$ thus showing himself an exact observer of the regulations which have been made to prevent all shirking on the part of drinkers.

Tergilla reproaches Cicero, the son of Marcus Cicero, with being in the habit of taking off a couple of congii at a single draught, and with having thrown a cup, when in a state of drunkenness, at M. Agrippa ${ }^{74}$ such, in fact, being the ordinary results of intoxication. But it is not to be wondered at that Cicero was desirous in this respect to eclipse the fame of M. Antonius, the murderer of his father; a man who had, before the time of the younger Cicero, shown himself so extremely anxious to maintain the superiority in this kind of qualification, that he had even gone so far as to publish a book upon the subject of his own drunkenness. ${ }^{75}$ Daring in this work to speak in his own defence, he has proved very satisfactorily, to my thinking, how many were the evils he had inflicted upon the world through this same vice of drunkenness. It was but a. short time before the battle of Actium that he vomited forth

71 As Præfectus Urbis.

72 Love of drinking.

${ }_{73}$ The mode of testing whether any "heeltaps" were left or not. It was this custom, probably, that gave rise to the favourite game of the cottabus.

${ }^{74} \mathrm{Dr}$. Middleton, in his Life of Cicero, in his unlimited partiality for the family, quotes this as an instance of courage and high spirit.

75 According to Paterculus, he was fond of driving about in a chariot, crowned with ivy, a golden goblet in his hand, and dressed like Bacchus, by which title he ordered himself to be addressed.

vol. III. 
this book of his, from which we have no great difficulty in coming to the conclusion, that drunk as he already was with the blood of his fellow-citizens, the only result was that he thirsted for it all the more. For, in fact, such is the infallible characteristic of drunkenness, the more a person is in the habit of drinking, the more eager he is for drink; and the remark of the Scythian ambassador is as true as it is well known-the more the Parthians drank, the thirstier they were for it.

CHAP. 29.-LIQUORS With THE STRENGTH OF WINE MADE FROM WATER AND CORN.

The people of the Western world have also their intoxicating drinks, made from corn steeped in water. ${ }^{76}$ These beverages are prepared in different ways throughout Gaul and the provinces of Spain; under different names, too, though in their results they are the same. The Spanish provinces have even taught us the fact that these liquors are capable of being kept till they have attained a considerable age. Egypt, ${ }^{77}$ too, has invented for its use a very similar beverage made from corn; indeed, in no part of the world is drunkenness ever at a loss. And then, besides, they take these drinks unmixed, and do not dilute them with water, the way that wine is modified; and yet, by Hercules! one really might have supposed that there the earth produced nothing but corn for the people's use. Alas! what wondrous skill, and yet how misplaced! means have absolutely been discovered for getting drunk upon water even.

There are two liquids that are peculiarly grateful to the human body, wine within and oil without; both of them the produce of trees, and most excellent in their respective kinds. Oil, indeed, we may pronounce an absolute necessary, nor has mankind been slow to employ all the arts of invention in the manufacture of it. How much more ingenious, however, man has shown himself in devising various kinds of drink will be evident from the fact, that there are no less

76 He alludes to beer, or rather sweet wort, for hops were not used till the latter part, probably, of the middle ages. Lupines were sometimes used for flavouring beer.

77 Diodorus Siculus says that the Egyptian beer was nearly equal to wine in strength and flavour. 
than one hundred and ninety-five different kinds of it; indeed, if all the varieties are reckoned, they will amount to nearly double that number. The various kinds of oil are much less numerous-we shall proceed to give an account of them in the following Book.

Sommary.-Remarkable facts, narratives, and observations, five hundred and ten.

Roman adthoks QUOTED.-Cornelius Valerianus, ${ }^{78}$ Virgil, ${ }^{79}$ Celsus, ${ }^{80}$ Cato the Censor, ${ }^{81}$ Saserna, ${ }^{82}$ father and son, Scrofa, ${ }^{83}$ M. Varro, ${ }^{84}$ D. Silanus, ${ }^{85}$ Fabius Pictor, ${ }^{86}$ Trogus, ${ }^{87}$ Hyginus, ${ }^{88}$ Flaccus Verrius, ${ }^{89}$ Græcinus, ${ }^{90}$ Julius Atticus, ${ }^{91}$ Columella, ${ }^{92}$ Massurius Sabinus, ${ }^{93}$ Fenestella ${ }^{94}$ Tergilla, ${ }^{95}$ Maccius Plautus, ${ }^{96}$ Flavius, ${ }^{97}$ Dossennus, ${ }^{98}$ Scævola, ${ }^{99}$ Elius, ${ }^{1}$ Ateius Capito, ${ }^{2}$

78 See end of B. iii.

80 See end of B. vii.

82 See end of B. $\mathbf{x}$.

84 See end of B. ii.

85 Decimus Junius Silanus. He was commissioned by the senate, about B.c. 146, to translate into Latin the twenty-eight books of Mago, the Carthaginian, on Agriculture. See B. xviii. c. 5 .
86 See end of $B$. $x$.
88 See end of B. iii.
87 See end of B. vii.
89 See end of B. iii.

79 See end of B. vii.

81 See end of B. iii.

83 See end of B. xi.

90. Julius Græcinus. He was one of the most distinguished orators of his time. Having refused to accuse M. Julius Silanus, he was put to death A.D. 39. He wrote a work, in two books, on the culture of the vine.

$91 \mathrm{He}$ was a contemporary of Celsus and Columella, the latter of whom states that he wrote a work on a peculiar method of cultivating the vine. See also B. xvii. c. 18.

93 See end of $\mathrm{B}$. vii.

92 See end of $\mathrm{B}$. viii,

94 See end of $B$. viii.

95 Nothing is known of him. He may possibly have written on Husbandry, and seems to have spoken in dispraise of the son of Cicero. See c. 28 of the present Book.

96. The famous Roman Comic poet, born B.c. 184. Twenty of his comedies are still in existence.

97 For Alfius Flavius, see end of B. ix. ; for Cneius Flavius, see end of B. xii.

98 Or Dorsenus Fabius, an ancient Comic dramatist, censured by Horace for the buffoonery of his characters, and the carelessness of his productions. In the 15th Chapter of this Book, Pliny quotes a line from his Acharistio.

99 Q. Mutius Scævola, consul B.c. 95, and assassinated by C. Flavius Fimbria, having been proscribed by the Marian faction. He wrote several works on the Roman law, and Cicero was in the number of his disciples.

1 Sextus Elius Pætus Catus, a celebrated jurisconsult, and consul B.c. 198. He wrote a work on the Twelve Tables.

2 See end of B. iii. 
Cotta Messalinus, L. Piso, ${ }^{4}$ Pompeius Lenæus, ${ }^{5}$ Fabianus, ${ }^{6}$ Sextius Niger, ${ }^{7}$ Vibius Rufus. ${ }^{8}$

Foreign adthors Qdoted.-Hesiod, ${ }^{9}$ Theophrastus, ${ }^{10}$ Aristotle, ${ }^{11}$ Democritus, ${ }^{12}$ King Hiero, ${ }^{13}$ King Attalus Philometor, ${ }^{14}$ Archytas, ${ }^{15}$ Xenophon, ${ }^{16}$ Amphilochus ${ }^{17}$ of Athens, Anaxipolis ${ }^{18}$ of Thasos, Apollodorus ${ }^{19}$ of Lemnos, Aristophanes ${ }^{20}$ of Miletus, Antigonus $^{21}$ of Cymæ, Agathocles ${ }^{22}$ of Chios, Apollonius ${ }^{23}$ of Pergamus, Aristander ${ }^{24}$ of Athens, Botrys ${ }^{25}$ of Athens, Bacchius ${ }^{26}$ of Miletus, Bion ${ }^{27}$ of Soli, Chærea ${ }^{28}$ of Athens, Chæristus ${ }^{29}$ of Athens, Diodorus ${ }^{30}$ of Priene, Dion ${ }^{31}$ of Colophon, Epigenes ${ }^{32}$ of Rhodes, Euagon ${ }^{33}$ of Thasos, Euphronius ${ }^{34}$ of Athens, Androtion $^{35}$ who wrote on agriculture, Aschrion ${ }^{36}$ who wrote on agriculture, Lysimachus ${ }^{37}$ who wrote on agriculture, Dionysius $^{38}$ who translated Mago, Diophanes ${ }^{39}$ who made an Epitome of the work of Dionysius, Asclepiades ${ }^{40}$ the Physician, Onesicritus, ${ }^{41}$ King Juba. ${ }^{42}$

${ }^{3}$ Son of Corvinus Messala. He appears to have been a man of bad repute: of his writings nothing seems to be known.

5 See end of $B$. ii.

4 A freedman of Pompey, by whose command he translated into Latin the work of Mithridates on Poisons. After Pompey's death, he maintained himself by keeping a school at Rome.

${ }^{6}$ For Fabianus Papirius, see end of B. ii. Fabianus Sabinus is supposed to have been the same person.

7 See end of B. xii.

$8 \mathrm{He}$ is mentioned by the elder Seneca, but nothing whatever is known of him.
9 See end of B. vii.
11 See end of B. ii.
13 See end of B. viii.
15 See end of $B$. viii.
17 See end of $B$. viii.
19 See end of $B$. viii.
21 See end of $B$. viii.
23 See end of B. viii.
25 See end of B. xiii.
27 See end of $B$. vi.
10 See end of B. iii.
12 See end of $B$. ii.
14 See end of B. viii.
16 See end of B. iv.
18 See end of $B$. viii.
20 See end of B. viii.
22 See end of $B$. viii.
24 See end of $B$. viii.
26 See end of $B$. viii.
28 See end of $B$. viii.

29 Supposed to have been a writer on Agriculture, but nothing further is known of him.

31 See end of B. viii.

33 See end of B. $x$.

35 See end of $\mathbf{B}$. viii.

37 See end of B. viii.

39 See end of B. viii.

-n See end of B. ii.

30 See end of $B$. viii.

32 See end of B. ii.

34 See end of B. viii.

36 See end of B. viii.

${ }^{39}$ See end of B. xii.

$4^{4}$ See end of $B$. vii.

${ }^{42}$ See end of B. v. 


\section{BOOK XV.}

THE NATURAL HISTORY OF THE FRUIT-TREES.

CHAF. 1. (1.) -THE OLIVE. - HOW LONG IT EXISTED ONLY IN GREECE. A'T WHAT PERIOD IT WAS FIRST INTRODUCED INTO ITALY, SPAIN, AND AFRICA.

Theophrastus, ${ }^{1}$ one of the most famous among the Greek writers, who flourished about the year 440 of the City of Rome, has asserted that the olive $\mathrm{e}^{\mathrm{l}^{*}}$ does not grow at a distunce of more than forty ${ }^{2}$ miles from the sea. Fenestella tells us that in the year of Rome 173, being the reign of Tarquinius Priscus, it did not exist in Italy, Spain, or Africa; ${ }^{3}$ whereas at the present day it has crossed the Alps even, and has been introduced into the two provinces of Gaul and the middle of Spain. In the year of Rome 505, Appius Claudius, grandson of Appius Claudius Cæcus, and L. Junius being consuls, twelve pounds of oil sold for an as ; and at a later period, in the year 680, M. Seius, son of Lucius, the curule ædile, regulated the price of olive oil at Rome, at the rate of ten pounds for the as, for the whole year. A person will be the less surprised at this, when he learns that twenty-two years after, in the third consulship of $\mathrm{Cn}$. Pompeius, Italy was able to export olive oil to the provinces.

Hesiod, ${ }^{4}$ who looked upon an acquaintance with agriculture

1 Hist. Plant. iv. c.

1* The Olea Europæa of Linnæus. See B.xxi. c. 31.

2 This has not been observed to be the fact. It has been known to grow in ancient Mesopotamia, more than one hundred leagues from the sea.

3 It is supposed that it is indigenous to Asia, whence it was introduced into Africa and the South of Eirrope. There is little doubt that long before the period mentioned by Pliny, it was grown in Africa by the Carthaginians, ard in the South of Gaul, at the colony of Massilia.

4 This work of Hesiod is no longer in existence; but the assertion is exaggerated, even if he alludes to the growth of the tree from seed. Fée remarks that a man who has sown the olive at twenty, may gather excellent fruit before he arrives at old age. It is more generally propagated by slips or sets. If the trunk is destroyed by accident, the roots will throw out fresh suckers. 
as conducive in the very highest degree to the comforts of life, has declared that there was no one who had ever gathered fruit from the olive-tree that had been sown by his own hands, so slow was it in reaching maturity in those times; whereas, now at the present day, it is sown in nurseries even, and if transplanted will bear fruit the following year.

\section{CHAP. 2. - THE NATURE OF THE OLIVE, AND OF NEW OLIVE OIL.}

Fabianus inaintains that the olive will grow ${ }^{5}$ neither in very cold climates, nor yet in very hot ones. Virgil ${ }^{6}$ has mentioned three varieties of the olive, the orchites, ${ }^{7}$ the radius, ${ }^{8}$ and the posia; ${ }^{9}$ and says that they require no raking or pruning, nor, in fact, any attention whatever. There is no doubt that in the case of these plants, soil and climate are the things of primary importance; but still, it is usual to prune them at the same time as the vine, and they are improved by lopping between them every here and there. The gathering of the olive follows that of the grape, and there is even a greater degree of skill required in preparing ${ }^{10}$ oil than in making wine; for the very same olives will frequently give quite different results. The first oil of all, produced from the raw ${ }^{11}$ olive before it has begun to ripen, is considered preferable to all the others in flavour; in this kind, too, the first ${ }^{12}$ droppings of the press are the most esteemed, diminishing gradually in goodness and value; and this, whether the wicker-work ${ }^{13}$ basket is used in making it, or whether, following the more

5 This is the case. We may remark that the tree will grow in this country, but the fruit never comes to maturity.

6 Georg. ii. 85, also ii. 420 .

7 Probably the Olea maximo fructu of Tournefort. It has its name from the Greek ő $\rho \iota \varsigma$, the "testis," a name by which it is still known in some parts of Provence.

8 Or "shuttle" olive. Probably the modern pickoline, or long olive.

9 Probably the Olea media rotunda præcox of Tournefort. It is slightly bitter.

10 This is so much the case, that though the olives of Spain and Portngal are among the finest, their oils are of the very worst quality.

11 It does not appear that the method of preparing oil by the use of boiling water was known to the ancients. Unripe olives produce an excellent oil, but in very small quantities. "Hence they are rarely used for the purpose.

${ }_{12}$ Called "virgin," or " native" oil in France, and very highly esteemed.

13 Sporta. 
recent plan, the pulp is put in a stick strainer, with narrow spikes and interstices. ${ }^{14}$ The riper the berry, the more unctuous the juice, and the less agreeable the taste. ${ }^{15}$ To obtain a result both abundant and of excellent flavour, the best time to gather it is when the berry is just on the point of turning black. In this state it is called "druppa" by us, by the Greeks, "drypetis."

In addition to these distinctions, it is of importance to observe whether the berry ripens in the press or while on the branch; whether the tree has been watered, or whether the fruit has been nurtured soiely by its own juices, and has imbibed nothing else but the dews of heaven.

CHAP. 3. (2.) - OLIVE OIL : THE COUNTRIES IN WHICH IT IS PKODUCED, AND ITS VARIOUS QUALITIES.

It is not with olive oil as it is with wine, for by age it acquires a bad flavour, ${ }^{16}$ and at the end of a year it is already old. This, if rightly understood, is a wise provision on the part of Nature: wine, which is only produced for the drunkard, she has seen no necessity for us to use when new; indeed, by the fine flavour which it acquires with age, she rather invites us to keep it; but, on the other hand, she has not willed that we should be thus sparing of oil, and so has rendered its use common and universal by the very necessity there is of using it while fresh.

In the production of this blessing as well, ${ }^{17}$ Italy holds the highest rank among all countries, ${ }^{18}$ and more particularly the territory of Venafrum, ${ }^{19}$ that part of it in especial which produces the Licinian oil ; the qualities of which have conferred upon the Licinian olive the very highest renown. It is our

14 "Exilibus regulis." A kind of wooden strainer, apparently invented to supersede the wicker, or basket strainer.

15 It is more insipid the riper the fruit, and the less odorous.

16 By absorbing the oxygen of the air. It may be preserved two or three years even, in vessels hermetically closed. The oil of France kecps better than any other.

17 As well as the grape.

18 In consequence of the faulty mode of manufacture, the oil of Italy is now inferior to that of France. The oil of Aix is particularly esteemed.

19 In Campania. See B. xvii. c. 3. Horace and Martial speak in praise of the Venafran olive. Hardouin suggests that Licinius Crassus may have introduced the Licinian olive. 
unguents which have brought this oil into suoh great esteem, the peculiar odour of it adapting itself so well to the full developement of their qualities; at the same time its delicate flavour equally enlists the palate in its behalf. In addition to this, birds will never touch the berry of the Licinian olive.

Next to Italy, the contest is maintained, and on very equal terms, between the territories of Istria and of Bætica. The next rank for excellence is claimed by the other provinces of our Empire, with the exception of Africa, ${ }^{20}$ the soil of which is better adapted for grain. That country Nature has given exclusively to the cereals; of oil and wine she has all but deprived it, securing it a sufficient share of renown by its abundant harvests. As to the remaining particulars connected with the olive, they are replete with erroneous notions, and I shall have occasion to show that there is no part of our agricultural economy upon which people have been more generally mistaken.

(3.) The olive is composed of a stone, oil, flesh, and amurca $:^{21}$ the last being a bitter liquid, principally composed of water; hence it is that in seasons of drought it is less plentiful, and more abundant when rains ${ }^{22}$ have prevailed. The oil is a juice peculiar to the olive, a fact more particularly stated in reference to its unripe state, as we have already mentioned when speaking of omphacium. ${ }^{23}$ This oil continues on the increase up to the rising of Arcturus, ${ }^{24}$ or in other words, the sixteenth day before the calends of October; ${ }^{25}$ after which the increase is in the stone and the flesh. When drought has been followed by abundant rains, the oil is spoilt, and turns to amurca. It is the colour of this amurca that makes the olive turn black; hence, when the berry is just beginning to turn that colour, there is but little amurca in it, and before that period none at all. It is an error then, on the part of persons, to suppose that that is the commencement of maturity,

20 The heat of Africa is unfarourable to the olive.

${ }^{21}$ The fæces, marc, or lees. This is a crude juice contained in the cellular tissue of the fruit, known as viridine or chlorophylle.

${ }_{22}$ This is owing, Fée says, to a sort of fermentation, which alters the tissue of the cells containing the oil, displaces the constituent elements, and forms others, such as mucus, sugar, acetic acid, ammoniac, \&c. When ripe, the olive contains four oils; that of the skin, the flesh, the stone, and the kernel.

: In B. xii. c. 60.

${ }^{24}$ See B. xviii. c. 74.

2b 16 th of September. 
which is in reality only the near approach of corruption. A second error, too, is the supposition that the oil increases proportionably to the flesh of the berry, it being the fact that the oil is all the time undergoing a change into flesh, and the stone is growing larger and larger within. It is for this reason more particularly, that care is taken to water the tree at this period; the real result of all this care and attention, as well as of the fall of copious rains, being, that the oil in reality is absorbed as the berry increases in size, unless fine dry weather should happen to set in, which naturally tends to contract the volume of the fruit. According to Theophrastus, ${ }^{26}$ heat is the sole primary cause of the oleaginous principle; for which reason it is, that in the presses, ${ }^{27}$ and in the cellars even, great fires are lighted to improve the quality of the oil.

A third error arises from misplaced economy: to spare the expense of gathering, people are in the habit of waiting till the berry falls from the tree. Others, again, who wish to follow a middle course in this respect, beat the fruit off with poles, and so inflict injury on the tree and ensure loss in the succeeding year; indeed, there was a very ancient regulation in existence relative to the gathering of the olive- "Neither pull nor beat the olive-tree. ${ }^{28}$ " Those who would observe a still greater degree of precaution, strike the branches lightly with a reed on one side of them; but even then the tree is reduced to bearing fruit but once in two years, ${ }^{29}$ in consequence of the injury done to the buds. Not less injurious, however, are the results of waiting till the berries fall from the tree; for, by remaining on it beyond the proper time, they deprive the crop that is coming on of its due share of nutriment, by occupying its place: a clear proof of which is, that if they are not gathered before the west winds prevail, they are found to have acquired renewed strength, and are all the later before they fall.

\section{CHAP. 4.-FIFTEEN VARIETIES OF OLIVES.}

The first olive that is gathered after the autumn is that

26 De Causis, B. i. c. 23.

27 This cannot possibly increase the oil, but it would render it more fluid, and thereby facilitate its escape from the cells of the berry.

${ }_{28}$ But Cato, Re Rust. c. 144, adds the very significant words, "injussu domini aut eustodis." "Without the leave of the owner or the keeper."

${ }_{29}$ It is found that the olive, after an abundant season, will not bear in the following year; probably the result of exhaustion. 
known as the "posia," 30 the berry of which, owing to a vicious method of cultivation, and not any fault on the part of $\mathrm{Na}$ ture, has the most flesh upon it. Next to this is the orchites, which contains the greatest quantity of oil, and then, after that, the radius. As these are of a peculiarly delicate nature, the heat very rapidly takes effect upon them, and the amurca they contain causes them to fall. On the other hand, the gathering of the tough, hard-skinned olive is put off so late as the month of March, it being well able to resist the effects of moisture, and, consequently, very small. Those varieties known as the Licinian, the Cominian, the Contian, and the Sergian, by the Sabines called the "royal" ${ }^{11}$ olive, do not turn black before the west winds prevail, or, in other words, before the sixth day before $e^{32}$ the ides of February. At this period it is generally thought that they begin to ripen, and as a most excellent oil is extracted from them, experience would seem to give its support to a theory which, in reality, is altogether wrong. The growers say that in the same degree that cold diminishes the oil, the ripeness of the berry augments it; whereas, in reality, the goodness of the oil is owing, not to the period at which the olives are gathered, but to the natural properties of this peculiarvariety, in which the oil is remarkably slow in turning to amurca.

A similar error, too, is committed by those who keep the olives, when gathered, upon a layer of boards, and do not press the fruit till it has thrown out a sweat; it being the fact that every hour lost tends to diminish the oil and increase the amurca: the consequence is, that, according to the ordinary computation, a modius of olives yields no more than six pounds of oil. No one, however, ever takes account of the quantity of amurca to ascertain, in reference to the same lind of berry, to what extent it increases daily in amount. Then, again, it is a very general error ${ }^{33}$ among practical persons to suppose that the oil increases proportionably to the increased size of the berry; and more particularly so when it is so clearly proved that such is not the case, with reference to

30 More commonly spelt "pausia."

31 "Regia." It is impossible to identify these varieties.

328 th of February.

33 This assertion of Pliny is not generally true. The large olives of Spain yield oil very plentifully. 
the variety known as the royal olive, by some called majorina, and by others phaulia $;^{34}$ this berry being of the very largest size, and yet yielding a minimum of juice. In Egypt, ${ }^{35}$ too, the berries, which are remarkably meaty, are found to produce but very little oil; while those of Decapolis, in Syria, are so extremely small, that they are no bigger than a caper; and yet they are highly esteemed for their flesh. ${ }^{36}$ It is for this reason that the olives from the parts beyond sea are preferred for table to those of Italy, though, at the same time, they are very inferior to them for making oil.

In Italy, those of Picenum and of Sidicina ${ }^{37}$ are considered the best for table. These are kept apart from the others and steeped in salt, after which, like other olives, they are put in amurca, or else boiled wine; indeed, some of them are left to float solely in their own oil, ${ }^{38}$ without any adventitious mode of preparation, and are then known as colymbades : sometimes the berry is crushed, and then seasoned with green herbs to flavour it. Even in an unripe state the olive is rendered fit for eating by being sprinkled with boiling water; it is quits surprising, too, how readily it will imbibe sweet juices, and retain an adventitious flavour from foreign substances. With this fruit, as with the grape, there are purple ${ }^{39}$ varieties, and the posia is of a complexion approaching to black. Besides those already mentioned, there are the superba ${ }^{40}$ and a remarkably luscious kind, which dries of itself, and is even sweeter than the raisin: this last variety is extremely rare, and is to

34 Probably a member of the variety known to naturalists as the Olea fructu majori, carne crassâ, of Tournefort, the royal olive or " triparde " of the French. The name is thought to be from the Greek $\phi \tilde{a} v \lambda$ os, the fruit being considered valueless from its paucity of oil.

${ }_{35}$ 'There are but few olive-trees in either Egypt or Decapolis at the present day, and no attempts are made to extract oil from them.

36 "Carnis." He gives this name to the solid part, or pericarp.

37 See B. iii. c. 9.

38 These methods are not now adopted for preserving the olive. The fruit are first washed in an alkaline solution, and then placed in salt and

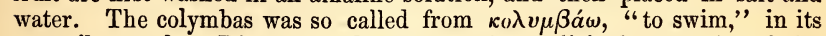
own oil, namely. Dioscorides descants on the medicinal properties of the colymbades. B. i. c. 140 .

${ }_{30}$ There are several varieties known of this colour, and more particularly the fruit of the Olea atro-rubens of Gouan.

40 'The Spanish olive, Hardouin says. Fée thinks that the name "superba," "haughty," is given figuratively, as meaning rough and austere. 
be found in Africa and in the vicinity of Emerita ${ }^{41}$ in Lusitania.

The oil of the olive is prevented from getting ${ }^{42}$ thick and rancid by the admixture of salt. By making an incision in the bark of the tree, an aromatic odour may be imparted ${ }^{43}$ to the oil. Any other mode of seasoning, such, for instance, as those used with reference to wine, is not at all gratifying to the palate; nor do we find so many varieties in oil as there are in the produce of the grape, there being, in general, but three different degrees of goodness. In fine oil the odour is more penetrating, but even in the very best it is but shortlived.

\section{UHAP. 5. (4.) - THE NATURE OF OLIVE OIL.}

It is one of the properties of oil to impart warmth to the body, and to protect it against the action of cold; while at the same time it promotes coolness in the head when heated. The Greeks, those parents of all vices, have abused it by making it minister to luxury, and employing it commonly in the gymnasium : indeed, it is a well-known fact that the governors of those establishments have sold the scrapings $\mathrm{s}^{44}$ of the oil used there for a sum of eighty thousand sesterces. The majesty of the Roman sway has conferred high honour upon the olive : crowned with it, the troops of the Equestrian order are wont to defile upon the ides of July $;^{45}$ it is used, too, by the victor in the minor triumphs of the ovation. ${ }^{46}$ At Athens,

${ }^{41}$ The olives of the present Merida, in Spain, are of a rough, disagreeable flavour.

${ }^{42}$ This seems to be the meaning of "pinguis ;" but, as Fée observes, salt would have no such effect as here stated, but would impart a disagree-able flavour to the oil.

${ }^{43}$ Fée regards this assertion as quite fabulous.

44 It will be stated in B. xxviii. c. 13 , to what purposes this abominable collection of filth was applied.

45 15th of July. He alludes to the inspection of the Equites, which originally belonged to the Censors, but afterwards to the Emperors. On this occasion there was "recognitio," or "review," and then a "transvectio," or "procession" of the horsemen.

46 The ovation was a lesser triumph, at which the general entered the city not in a chariot, but on foot. In later times, however, the victor entered on horseback : and a wreath of myrtle, sometimes laurel, was worn by bim. For further particulars as to the ovation, see c. 38 of the present Book. 
also, they are in the habit of crowning the conqueror with olive; and at Olympia, the Greeks employ the wild olive ${ }^{47}$ for a similar purpose.

\section{Chap. 6. (5.)-THE CULTURE OF THE OLIVE: ITS MODE OF PRE- SERVATION. THE METHOD OF MAKING OLIVE OIL.}

We will now proceed to mention the precepts given by Cato ${ }^{48}$ in relation to this subject. Upon a warm, rich ${ }^{49}$ soil, he recommends us to sow the greater radius, the Salentina, the orchites, the posia, the Sergian, the Cominian, and the albicera ${ }^{50}$ but with a remarkable degree of prudence he adds, that those varieties ought to be planted in preference which are considered to thrive best in the neighbouring localities. In a cold ${ }^{51}$ and meagre soil he says that the Licinian olive should be planted; and he informs us that a rich or hot soil has the effect, in this last variety, of spoiling the oil, while the tree becomes exhausted by its own fertility, and is liable to be attacked by a sort of red moss. ${ }^{52} \mathrm{He}$ states it as his opinion that the olive grounds ought to have a western aspect, and, indeed, he approves of no other.

(6.) According to him, the best method of preserving olives is to put the orchites and the posia, while green, in a strong brine, or else to bruise them first, and preserve them in mastich oil.53 The more bitter the olive, he says, the better the oil; but they should be gathered from the ground the very moment they fall, and washed if they are dirty. $\mathrm{He}$ says that three days will be quite sufficient for drying them, and that if it is frosty weather, they should be pressed on the fourth, care being taken to sprinkle them with salt. Olives, he informs us, ${ }^{5 t}$ lose oil by being kept in a boarded store-room, and deteriorate in quality ; the same being the case, too, if the oil is

47 Or "oleaster."

48 De Re Rust. c. 6.

49 A middling or even poor soil is chosen for the olive at the present day.

59 Apparently meaning the "white wax" olive. .

${ }^{31}$ In warm countries, a site exposed to the north is chosen: in colder ones, a site which faces the south.

${ }^{52}$ See B. xvii. c. 37 . This moss has not been identified with precision; but the leaf of the olive is often attacked by an erysiphus, known to naturalists as the Alphitomorpha communis ; but it is white, not of a red colour.

53 Fée queries how any one could possibly eat olives that had been steeped in a solution of mastich. They must have been nauseous in the extreme. 54 De Re Rust. c. 64. 
left with the amurca and the pulp,,$^{55}$ or, in other words, the Hesh of the olive that forms the residue and becomes the dregs. For this reason, he recommends that the oil should be poured off several times in the day, and then put into vessels or cauldrons ${ }^{56}$ of lead, for copper vessels will spoil it, he says. All these operations, however, should be carried on with presses heated and tightly closed, ${ }^{57}$ and exposed to the air as little as possible-for which reason he recommends that wood should never be cut there, the most convenient fuel for the fires being the stones of the berries. From the cauldron the oil should be poured into vats, ${ }^{58}$ in order that the pulp and the amurca may be disengaged in a solidified form : to effect which object the ressels should be changed as often as convenient, while at the same time the osier baskets should be carefully cleaned with a sponge, that the oil may run out in as clean and pure a state as possible.

In later times, the plan has been adopted of invariably crushing the olives in boiling water, and at once putting them whole in the press-a method of effectually extracting the amurca-and then, after crushing them in the oil-press, subjecting them to pressure once more. It is recommended, that not more than one hundred modii should be pressed at one time: the name given to this quantity is " factus," 59 while the oil that flows out at the first pressure is called the "flos." 60 Four men, working at two presses day and night, ought to be able to press out three factuses of olives.

CHAP. 7. (7.)-FORTY -EIGHT VARIETIES OF ARTIFICIAL OILS. THE CICUS-TREE OR CROTON, OK SILI, OK SESAMUM.

In those tithes artificial oils had not been introduced, and

55 "Fracibus." The opinion of Pliny, that olives deteriorate by being left in the store-room, is considered to be well founded; the olives being apt to ferment, to the deterioration of the oil : at the same time, he is wrong in supposing that the amount of oil diminishes by keeping the berries.

56 "Cortinas." If we may judge from the name, these vessels were threefooted, like a tripod.

57 There are no good grounds for this recommendation, which is based on the erroneous supposition that heat increases the oil in the berry. The free circulation of the air also ought not to be restricted, as nothing is gained by it. In general, the method of extracting the oil is the same with the moderns as with the ancients, though these last did not employ the aid of boiling water.

59 A " making," or "batch." $5 s$ Labra.

60 Or "flower." 
hence it is, I suppose, that we find no mention made of them by Cato; at the present day the varieties are very numerous. We will first speak of those ${ }^{61}$ which are produced from trees, and among them more particularly the wild olive. ${ }^{62}$ This olive is small, and much more bitter than the cultivated one, and hence its oil is only used in medicinal preparations: the oil that bears the closest resemblance to it is that extracted from the chamelæa, ${ }^{63}$ a shrub which grows among the rocks, and not more than a palm in height; the leaves and berries being similar to those of the wild olive. A third oil is that made of the fruit of the cicus, ${ }^{64}$ a tree which grows in Egypt in great abundance; by some it is known as croton, by others as sili, and by others, again, as wild sesamum : it is not so very long since this tree was first introduced here. In Spain, too, it shoots up with great rapidity to the size of the olive-tree, having a stem like that of the ferula, the leaf of the vine, and a seed that bears a resemblance to a small pale grape. Our people are in the habit of calling it " ricinus," 65 from the resemblance of the seed to that insect. It is boiled in water, ${ }^{66}$ and the oil that swims on the surface is then skimmed off: but in Egypt, where it grows in a greater abundance, the oil is extracted without employing either fire or water for the purpose, the seed being first sprinkled with salt, and then subjected to pressure : eaten with food this oil is repulsive, but it is very useful for burning in lamps.

Amygdalinum, by some persons known as "metopium," 67

61 It may be remarked, that in this Chapter Pliny totally confounds fixed oils, volatile oils, and medicinal oils. Those in the list which he here gives. and which are not otherwise noticed in the Notes, may be considered to belong to this last class.

${ }_{62}$ The oleaster furnishes but little oil, and it is seldom extracted. The oil is thinner than ordinary olive oil, and has a stronger odour.

63 The Daphne Cneorum and Daphne Cnidium of botanists. See B. xiii. c. 35 , also B. xxiv. c. 82 . Fée doubts if an oil was ever made from the chamelæa.

64 See B. xxiii. c. 41: the Ricinus communis of Linnæus, which abounds in Egypt at the present day. Though it appears to have been formerly sometimes used for the table, at the present day the oil is only known as "castor" oil, a strong purgative. It is one of the fixed oils. The Jews and Abyssinian Christians say that it was under this tree that Jonah sat. 65 A " tick."

56 This method, Fée says, is still pursued in America.

67 See B. xiii. c. 2 . One of the fixed oils. 
is made of bitter almonds dried and beaten into a cake, after which they are steeped in water, and then beaten again. An oil is extracted from the laurel also, with the aid of olive oil. Some persons use the berries only for this purpose, while others, again, employ the. leaves ${ }^{68}$ and the outer skin of the berries: some add storax also, and other odoriferous substances. The best kind for this purpose is the broad-leaved or wild laurel, ${ }^{69}$ with a black berry. The oil, too, of the black myrtle is of a similar nature; that with the broad leaf ${ }^{70}$ is reckoned also the best. The berries are first sprinkled with warm water, and then beaten, after which they are boiled: some persons take the more tender leaves, and boil them in olive oil, and then subject them to pressure, while others, again, steep them in oil, and leave the mixture to ripen in the sun. The same method is also adopted with the cultivated myrtle, but the wild variety with small berries is generally preferred; by some it is known as the oxymyrsine, by others as the chamæmyrsine, and by others, again, as the acoron, ${ }^{71}$ from its strong resemblance to that plant, it being short and branching.

An oil is made, too, from the citrus, ${ }^{72}$ and from the cypress; also, from the walnut, ${ }^{73}$ and known by the name of " caryinon," "74 and from the fruit of the cedar, being generally known as " pisselæon." Oil is extracted from the grain of Cnidos, ${ }^{76}$ the seed being first thoroughly cleaned, and then

68 An essential oil may be extracted from either; it is of acrid taste, green, and aromatic; but does not seem to have been known to the ancients. The berries give by decoction a fixed oil, of green colour, sweet, and odoriferous. The oils in general here spoken of by Pliny as extracted from the laurel, are medicinal oils.

69 The Laurus latifolia of Bauhin.

70 The Myrtus latifolia Romana of Bauhin. It yields an essential oil, and by its decoction might give a fixed oil, in small quantity, but very oduriferous. As boiled with olive oil, he treats it as a volatile oil.

71 See B. xxv. c. 100. This myrtle is the Ruscus aculeatus of Linnæus.

72 See B. xiii. c. 29 , and B. xxiii. c. 45 . A volatile oil might be extracted from the citrus, if one of the thuyæ, as also from the cypress.

${ }_{73}$ See B. xxiii. c. 45 . It is a fixed oil, still considerably used in some parts of Europe.

${ }^{74}$ From the Greek $\kappa a \rho v i a$, a "walnut."

75 "Pitch oil." See B. xxiv. c. 11. This would be a volatile oil.

${ }^{76}$ See B. xxiii. c. 45 , also B, xiii. c. 35 . Fée is of opinion, that as no fixed oil can be extracted from the Daphne Cnidium or Daphne Cneorum, Pliny must allude to a medicinal composition, like the oil of wild myrtle, previously mentioned. 
pounded; and from mastich ${ }^{77}$ also. As to the oil called "cyprinum," "78 and that extracted from the Egyptian ${ }^{79}$ berry, we have already mentioned the mode in which they are prepared as perfumes. The Indians, too, are said to extract oils from the chesnut, ${ }^{80}$ sesamum, and rice, ${ }^{81}$ and the Ichthyophagi ${ }^{82}$ from fish. Scarcity of oil for the supply of lamps sometimes compels us to make it from the berries ${ }^{83}$ of the planetree, which are first steeped in salt and water.

Enanthinum, ${ }^{84}$ again, is made from the œnanthe, as we have already stated when speaking of perfumes. In making gleucinum, ${ }^{85}$ must is boiled with olive-oil at a slow heat; some persons, however, do not employ fire in making it, but leave a vessel, filled with oil and must, surrounded with grape husks, for two and twenty days, taking care to stir it twice a day: by the end of that period the whole of the must is imbibed by the oil. Some persons mix with this not only sampsuchum, but perfumes of still greater price: that, too, which is used in the gymnasia is scented with perfumes as well, but those of the very lowest quality. Oils are made, too, from aspalathus, ${ }^{86}$ from calamus,${ }^{87}$ balsamum, ${ }^{88}$ cardamum, ${ }^{89}$ melilot, Gallic nard, panax, ${ }^{90}$ sampsuchum, ${ }^{91}$ helenium, and root of cinnamomum, ${ }^{92}$ the plants being first left to steep in oil, and then pressed. In a similar manner, too, rhodinum ${ }^{93}$ is made from roses, and juncinum from the sweet rush, bearing a remarkable ${ }^{94}$ resemblance to rose-oil : other oils, again, are extracted

77 A fixed oil. See B. xii. c. 36 . The seeds were used for making it. See B. xxiii. c. 45.

${ }_{78}$ See B. xii. c. 51, and B. xxiii. c. 45 . The leaves of the Lawsonia are very odoriferous.

79 The myrobalanus, or ben. See B. xii. c. 46 , and B. xxiii. c. 46.

80 Neither the chesnut nor rice produce any kind of fixed oil.

81 See B. xvii. c. 13.

82 Or Fish-eaters. See B. xxxii. c. 38 . This is one of the fixed oils.

${ }_{83}$ In reality, no fixed oil can be obtained from them.

$84 \mathrm{Or}$ wild vine. See B. xii. c. 61 , and B. xiii. c. 2.

85 Not an oil, so much as a medicinal preparation. Dioscorides mentions as component parts of it, omphacium, sweet rush, Celtic nard, aspalathus, costus, and must. It received its name from $\gamma \lambda \varepsilon \varepsilon \tilde{v} \kappa o s$, " must."

${ }^{86}$ The Convolvulus scoparius of Linnæus. See B. xii. c. 52, and B. xiii. c. 2.

${ }^{88}$ See B. xii. c. 54 , and B. xiii. c. 2.

90 See B. xii. c. 57 .

${ }_{92}$ See B. xii. c. 41 .

94 Fée doubts the possibility of such a resemblance.

${ }^{87}$ See B. xii. c. 95.

89 See B. xii. c. 29.

${ }^{91}$ See B. xiii. e. 2, p. 163.

93 See B. xiii. c. 2.

voL. III. 
from henbane, ${ }^{95}$ lupines, ${ }^{96}$ and narcissus. Great quantities of oil are made in Egypt, too, of radish ${ }^{97}$ seed, or else of a common grass known there as chortinon. ${ }^{98}$ Sesamum ${ }^{99}$ also yields an oil, and so does the nettle, ${ }^{1}$ its oil being known as " cnidinum." In other countries, too, an oil is extracted from lilies ${ }^{3}$ left to steep in the open air, and subjected to the influence of the sun, moon, and frosts. On the borders of Cappadocia and Galatia, they make an oil from the herbs of the country, known as "Selgicum," remarkably useful for strengthening the tendons, similar, in fact, to that of Iguvium ${ }^{5}$ in Italy. From pitch an oil ${ }^{6}$ is extracted, that is known as " pissinum;" it is made by boiling the pitch, and spreading fleeces over the vessels to catch the steam, and then wringing them out: the most approved kind is that which comes from Bruttium, the pitch of that country being remarkably rich and resinous: the colour of this oil is yellow.

There is an oil that grows spontaneously in the maritime parts of Syria, known to us as "elæomeli ;" it is an unctuous substance which distils from certain trees, of a thicker consistency than honey, but somewhat thinner than resin; it has a sweet flavour, and is employed for medicinal purposes. Old olive oil ${ }^{8}$ is of use for some kinds of maladies; it is thought to

${ }_{95}$ Hyoscyamus. A medicinal oil is still extracted from it. See B. xxiii. c. 49 .

96 This medicinal oil is no longer used. The Lupinus albus was formerly held in greater esteem than it is now.

97 The Raphanus sativus of Linnæus. See B. xix. c. 26. This is one of the fixed oils; varieties of it are rape oil, and colza oil, now so extensively used.

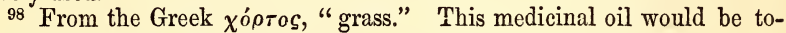
tally without power or effect.

99 A fixed oil is still extracted in Egypt from the grain known as sesamum.

1 See B. xxii. c. 15 .

2 From $\kappa \nu i \delta \eta$, a "nettle." The nettle, or Urtica urens of Linnæus, has no oleaginous principles in its seed.

3 Lily oil is still used as a medicinal composition : it is made from the petals of the white lily, Lilium candidum of Linnæus.

4 From Selga, a town of Pisidia. See B. xxiii. c. 4.9 .

5 See B. iii. c. 9, and B. xxiii. c. 49 .

6 A volatile oil, mixed with a small proportion of empyreumatic oil and carbon.

7 "Oil-honey." Probably a terebinthine, or oleo-resin. See B. xxiii. c. 50 .

8 When rancid and oxygenized by age, it has an irritating quality, and may be found useful for herpetic diseases. 
be particularly useful, too, in the preservation of ivory from decay : ${ }^{9}$ at all events, the statue of Saturn, at Rome, is filled with oil in the interior.

\section{CHAP. 8. (8.)-AMURCA.}

But it is upon the praises of amurca ${ }^{10}$ more particularly, that Cato ${ }^{11}$ has enlarged. He recommends that vats and casks ${ }^{12}$ for keeping oil should be first seasoned with it, to prevent them from soaking up the oil ; and he tells us that threshingfloors should be well rubbed with it, to keep away ants, and to prevent any chinks or crannies from being left. The mortar, too, of walls, he says, ought to be seasoned with it, as well as the roofs and floors of granaries ; and he recommends that wardrobes should be sprinkled with amurca as a preservative against wood-worms and other noxious insects. He says, too, that all grain of the cereals should be steeped in it, and speaks of it as efficacious for the cure of maladies in cattle as well as trees, and as useful even for ulcerations in the inside and upon the face of man. We learn from him, also, that thongs, all articles made of leather, sandals, and axletrees used to be anointed with boiled amurca; which was employed also to preserve copper vessels against verdigrease, ${ }^{14}$ and to give them a better colour; as also for the seasoning of all utensils made of wood, as well as the earthen jars in which dried figs were kept, or of sprigs of myrtle with the leaves and berries on, or any other articles of a similar nature: in addition to which, he asserts that wood which has been steeped in amurca will burn without producing a stifling smoke. ${ }^{15}$

According to M. Varro, ${ }^{16}$ an olive-tree which has been licked by the tongue of the she-goat, or upon which she has

${ }^{3}$ It very probably will have this effect; but at the expense of the colour of the ivory, which very soon will turn yellow.

10. It has quite lost its ancient repute : the only use it is now put to is the manufacture of an inferior soap. See B. xxiii. c. 37 .

11 De Re Rust. ec. 130, 169.

12 Dolia and cadi. Fée observes, that this, if done with the modern vessels, would have a tendency to make the oil turn rancid.

13 On the contrary, Fée is inclined to think it would attract them, from its mucilaginous properties.

14 Olive oil, however, has a tendency to generate verdigrease in copper ressels.

15 This, as Fée remarks, is probably so absurd as not to be worth discussing. ${ }_{16}$ Re Rust. B. i. c. 2. 
browsed when it was first budding, ${ }^{17}$ is sure to be barren. Thus much in reference to the olive and the oils.

\section{CHAP. 9. (9.) -THE VARIOUS KINDS OF FRUIT-TREES AND THEIR NATURES. FOUR VARIETIES OF PINE-NUTS.}

The other fruits found on trees can hardly be enumerated, from their diversity in shape and figure, without reference to their different flavours and juices, which have again been modified by repeated combinations and graftings.

(10.) The largest fruit, and, indeed, the one that hangs at the greatest height, is the pine-nut. It contains within a number of small kernels, enclosed in arched beds, and covered with a coat of their own of rusty iron-colour ; Nature thus manifesting a marvellous degree of care in providing its seeds with a soft receptacle. Another variety of this nut is the terentina ${ }^{18}$ the shell of which may be broken with the fingers; and hence it becomes a prey to the birds while still on the tree. A third, again, is known as the "sappinia, ${ }^{19}$ " being the produce of the cultivated pitch-tree: the kernels are enclosed in a skin more than a shell, which is so remarkably soft that it is eaten together with the fruit. A fourth variety is that known as the "pityis ;" it is the produce of the pinaster, ${ }^{20}$ and is remarkable as a good specific for coughs. The kernels are sometimes boiled in honey ${ }^{21}$ among the Taurini, who then call them "aquiceli." The conquerors at the Isthmian games are crowned with a wreath of pine-leaves.

CHAP. 10. (11.) -THE QUINCE. FOUR KINDS OF CYDONIA, AND
FOUR VARIETIES OF THE STRUTHEA.

Next in size after these are the fruit called by us "cotonea," ${ }^{22}$ by the Greeks "Cydonia," ${ }^{23}$ and first introduced

17 If she happens to have destroyed the buds, but not otherwise.

18 The Pinus cembro, probably, of Linnæus.

19 See B. xvi. c. 23 . 'The nuts of the pine are sweet, and have an agreeable flavour.

${ }_{20}$ Probably the wild pine, the Pinus silvestris of the moderns. The nuts are slightly resinous.

21 Neither the people of Turin nor of any other place are known at the present day to make this preparation.

22 The quince, the Pirus Cydonia of Linnæus.

${ }^{23}$ From Cydonia, a city of Crete. "The Latin name is only a corruption of the Greek one: in England they were formerly called "melicotones." 
from the island of Crete. These fruit bend the branches with their weight, and so tend to impede the growth of the parent tree. The varieties are numerous. The chrysomelum ${ }^{24}$ is marked with indentations down it, and has a colour inclining to gold ; the one that is known as the "Italian" quince, is of a paler complexion, and has a most exquisite smell : the quinces of Neapolis, too, are held in high esteem. The smaller varieties of the quince which are known as the "struthea," 25 have a more pungent smell, but ripen later than the others; that called the "musteum," ${ }^{26}$ ripens the soonest of all. The cotoneum engrafted ${ }^{27}$ on the strutheum, has produced a peculiar variety, known as the "Mulvianum," the only one of them all that is eaten raw. ${ }^{28}$ At the present day all these varieties are kept shut up in the antechambers of great men, ${ }^{29}$ where they receive the visits of their courtiers; they are hung, too, upon the statues ${ }^{30}$ that pass the night with us in our chambers.

There is a small wild ${ }^{31}$ quince also, the smell of which, next to that of the strutheum, is the most powerful; it grows in the hedges.

\section{CHAP. 11. - SIX VARIETIES OF THE PEACH.}

Under the head of apples, ${ }^{32}$ we include a variety of fruits, although of an entirely different nature, such as the Persian ${ }^{33}$ apple, for instance, and the pomegranate, of which, when speaking of the tree, we have already enumerated ${ }^{34}$ nine varieties. The pomegranate has a seed within, enclosed in a

${ }^{24}$ Or "golden appie." The quince was sacred to Venus, and was an emblem of love.

${ }^{25}$ Apparently meaning the "sparrow quince." Dioscorides, Galen, and Athenæus, however, say that it was a large variety. Qy. if in such case, it might not mean the ostrich quince?

26 " Early ripener."

${ }^{27}$ Quinces are not grafted on quinces at the present day, but the pear is.

${ }^{28}$ Fée suggests that this is a kind of pear.

29 Probably on account of the fragrance of their secnt.

30 We learn from other sources that the bed-chambers were frequently ornamented with statues of the divinities.

31 The Mala cotonea silvestris of Bauhin; the Cydonia vulgaris of modern botanists,

32 "Mala." The term "malum," somewhat similar to "pome" with us, was applied to a number of different fruits : the orange, the citron, the pomegranate, the apricot, and others.

${ }_{33}$ Or peach.

${ }^{34}$ See B. xiii. c. 34. 
skin; the peach has a stone inside. Some among the pears, also, known as "libralia," 35 show, by their name, what a remarkable weight they attain.

(12.) Among the peaches the palm must be awarded to the duracinus : ${ }^{36}$ the Gallic and the Asiatic peach are distinguished respectively by the names of the countries of their origin. They ripen at the end of autumn, though some of the early ${ }^{37}$ kinds are ripe in the summer. It is only within the last thirty years that these last have been introduced; originally they were sold at the price of a denarius a piece. Those known as the "supernatia" 38 come from the country of the Sabines, but the "popularia" grow everywhere. This is a very harmless fruit, and a particular favourite with invalids : some, in fact, have sold before this as high as thirty sesterces apiece, a price that has never been exceeded by any other fruit. This, too, is the more to be wondered at, as there is none that is a worse keeper : for, when it is once plucked, the longest time that it will keep is a couple of days; and so sold it must be, fetch what it may.

\section{CHAP. 12. (13). - TWELVE KINDS OF PLUMS.}

Next comes a vast number of varieties of the plum, the parti-coloured, the black, ${ }^{39}$ the white, ${ }^{40}$ the barley ${ }^{41}$ plumso called, because it is ripe at barley-harvest-and another of the same colour as the last, but which ripens later, and is of a larger size, generally known as the "asinina," 42 from the little esteem in which it is held. There are the onychina, too, the

35 Or "pound-weight" pears : the Pirus volema of Linnæus.

36 Or "hard-berry"-probably in reference to the firmness of the flesh. It is generally thought to be the nectarine.

37 "Præcocia." It is generally thought that in this name originates the word "apricot," the Prunus Armeniaca of Linnæus. There is, however, an early peach that ripens by the middle of July, though it is very doubtful if it was known to Pliny.

38 "From above."

39 Perhaps the Prunus ungarica of naturalists, the black damask plum; or else the Prunus perdrigona, the perdrigon.

40 Probably the Prunus galatensis of naturalists.

4i "Hordearia :" the Prunus præcox of naturalists ; probably our harvest plum.

42 Or "ass"-plum. The Prunus acinaria of naturalists : the cherry plum of the French. 
cerina ${ }^{43}$ - more esteemed, and the purple ${ }^{44}$ plum : the Armenian, ${ }^{4 \overline{5}}$ also an exotic from foreign parts, the only one among the plums that recommends itself by its smell. The plum-tree grafted on the nut exhibits what we may call a piece of impudence quite its own, for it produces a fruit that has all the appearance of the parent stock, together with the juice of the adopted fruit: in consequence of its being thus compounded of both, it is known by the name of "nuci-pruna." 46 Nut-prunes, as well as the peach, the wild plum, ${ }^{47}$ and the cerina, are often put in casks, and so kept till the crop comes of the following year. All the other varieties ripen with the greatest rapidity, and pass off just as quickly. More recently, in Bætica, they have begun to introduce what they call "malina," or the fruit of the plum engrafted on the apple-tree, ${ }^{48}$ and " amygdalina," the fruit of the plum engrafted on the almond-tree, ${ }^{49}$ the kernel found in the stone of these last being that of the almond $;^{50}$ indeed, there is no specimen in which two fruits have been more ingeniously combined in one.

Among the foreign trees we have already spoken ${ }^{51}$ of the Damascene $^{52}$ plum, so called from Damascus, in Syria, but introduced long since into Italy ; though the stone of this plum is larger than usual, and the flesh smaller in quantity. This plum will never dry so far as to wrinkle; to effect that, it needs the sun of its own native country. The myxa, ${ }^{53}$ too,

${ }^{43}$ Or "wax plum." The Prunus cereola of naturalists : the mirabelle of the French.

44 Possibly the Prunus enucleata of Lamarck: the myrobalan of the French. Many varieties, however, are purple.

45 There are two opinions on this: that it is the Prunus Claudiana of Lamarck, the "Reine Claude" of the French ; or else that it is identical with the apricot already mentioned, remarkable for the sweetness of its smell.

47 The Prunus insititia of Linnæus.

48 The result of this would only be a plum like that of the tree from which the graft was cut.

49 The same as with reference to the graft on the apple.

50 This is probably quite fabulous. ${ }^{51}$ B. xiii. c. 10.

52 The Prunus Damascena of the naturalists ; our common damson, with its numerous varieties.

${ }_{53}$ Probably the Cordia myxa of Linnæus; the Sebestier of the French. It has a viscous pulp, and is much used as a pectoral. It grows only in Syria and Egypt; and hence Fée is inclined to reject what Pliny says as to its naturalization at Rome, and the account he gives as to its being engrafted on the sorb. 
may be mentioned, as being the fellow-countryman of the Damascene: it has of late been introduced into Rome, and has been grown engrafted upon the sorb.

\section{CHAP. 13.-THE PEACH.}

The name of "Persica," or "Persian apple," given to this fruit, fully proves that it is an exotic in both Greece as well as Asia, ${ }^{54}$ and that it was first introduced from Persis. As to the wild plum, it is a well-known fact that it will grow anywhere; and I am, therefore, the more surprised that no mention has been made of it by Cato, more particularly as he has pointed out the method of preserving several of the wild fruits as well. As to the peach-tree, it has been only introduced of late years, and with considerable difficulty; so much so, that it is perfectly barren in the Isle of Rhodes, the first resting-place ${ }^{55}$ that it found after leaving Egypt.

It is quite untrue that the peach which grows in Persia is poisonous, and produces dreadful tortures, or that the kings of that country, from motives of revenge, had it transplanted in Egypt, where, through the nature of the soil, it lost all its evil properties-for we find that it is of the "persea" 56 that the more careful writers have stated all this, ${ }^{57}$ a totally different tree, the fruit of which resembles the red myxa, and, indeed, cannot be successfully cultivated anywhere but in the East. The learned have also maintained that it was not introduced from Persis into Egypt with the view of inflicting punishment, but say that it was planted at Memphis by Perseus; for which reason it was that Alexander gave orders that the victors should be crowned with it in the games which he instituted there in honour of his $^{38}$ ancestor: indeed, this tree has always leaves and fruit upon it, growing immediately upon the others. It must be quite evident to every one that all our plums have been introduced since the time of Cato. ${ }^{59}$

54 I. e. Asia Minor.

55 Hospitium.

56 See B. xiii. c. 17. The Balanites Egyptiaca of Delille.

57 It was this probably, and not the peach-tree, that would not bear fruit in the isle of Rhodes.

58 Perseus.

59 Fée remarks that the wild plum, the Prunus silvestris or insititia of Linnæus, was to be found in Italy before the days of Cato. 
CHAP. 14. (14.) 一THIRTY DIFFERENT KINDS OF POMES. AT WHAT PERIOD FOREIGN FRUITS WERE FIRST INTRODUCED INTO ITALY, AND WHENCE.

There are numerous varieties of pomes. Of the citron ${ }^{60}$ we have already made mention when describing its tree; the Greeks gave it the name of "Medica," 61 from its native country. The jujube ${ }^{62}$-tree and the tuber ${ }^{63}$ are equally exotics; indeed, they have, both of them, been introduced only of late years into Italy; the latter from Africa, the former from Syria. Sextus Papinius, whom we have seen consul, ${ }^{64}$ introdúced them both in the latter years of the reign of Augustus, produced from slips which he had grown within his camp. The fruit of the jujube more nearly resembles a berry than an apple: the tree sets off a terrace ${ }^{65}$ remarkably well, and it is not uncommon to see whole woods of it climbing up to the very roofs of the houses.

Of the tuber there are two varieties; the white, and the one called "syricum," 66 from its colour. Those fruits, too, may be almost pronounced exotic which grow nowhere in Italy but in the territory of Verona, and are known as the wool-fruit. ${ }^{67}$ They are covered with a woolly down; this is found, it is true, to a very considerable extent, on both the strutheum variety of quince and the peach, but still it has given its name to this particular fruit, which is recommended to us by no other remarkable quality.

CHAP. 15. -THE FRUITS THAT HAVE BEEN MOST RECENTIYY INTRODUCED.

Why should I hesitate to make some mention, too, of other

60 See B. xii. c. 7.

61 Of Media.

62 Its fruit will ripen in France, as far north as Tours. It is the Zizyphus vulgaris of Lamarck. It resembles a small plum, and is sometimes used as a sweetmeat. The confection sold as jujube paste is not the dried jelly of this fruit, but merely gum arabic and sugar, coloured.

${ }_{63}$ A variety of the jujube, Fée is inclined to think. A nut-peach has also been suggested.

${ }^{64}$ A.U.c. 779.

65 Or perhaps embankment : "agger."

66 A reddish colour. For the composition of this colour, see B. Exxv. c. 24.

67 "Lanata ;" perhaps rather the "downy" fruit; a variety of quince, Fée thinks. Pliny probably had never seen this fruit, in his opinion, and only speaks after Virgil, Ecl. ii. 1. 51. "Ipse ego cana legam tenera lanugine mala." 
varieties by name, seeing that they have conferred everlasting remembrance on those who were the first to introduce them, as having rendered some service to their fellow-men? Unless I am very much mistaken, an enumeration of them will tend to throw some light upon the ingenuity that is displayed in the art of grafting, and it will be the more easily understood that there is nothing so trifling in itself from which a certain amount of celebrity cannot be ensured. Hence it is that we have fruits which derive their names from Matius, ${ }^{68}$ Cestius, Mallius, and Scandius. ${ }^{69}$ Appius, too, a member of the Claudian family, grafted the quince on the Scandian fruit, in consequence of which the produce is known as the Appian. This fruit has the smell of the quince, and is of the same size as the Scandian apple, and of a ruddy colour. Let no one, however, imagine that this name was merely given in a spirit of flattery to an illustrious family, for there is an apple known as the Sceptian, ${ }^{70}$ which owes its name to the son of a freedman, who was the first to introduce it: it is remarkable for the roundness of its shape. To those already mentioned, Cato $^{71}$ adds the Quirinian and the Scantian varieties, which last, he says, keep remarkably well in large vessels. ${ }^{72}$ The latest kind of all, however, that has been introduced is the small apple known as the Petisian, ${ }^{73}$ remarkable for its delightful flavour : the Amerinian ${ }^{74}$ apple, too, and the little Greek ${ }^{75}$ have conferred renown on their respective countries.

The remaining varieties have received their name from various circumstances - the apples known as the "gemella" i6 are always found hanging in pairs upon one stalk, like twins,

68 See B. xii. c. 6 . The Matian and the Cestian apple are thought by Dalechamps to have been the French " court-pendu," or " short stalk."

69 The Scandian is thought to have been a winter pear.

70 Adrian Junius takes this to be the "kers-appel " of the Flemish.

71 De Re Rust. cc. 7 and 143.

73 Hardouin says that this is the "Pomme d'api" of the French; it is the "Court-pendu" with Adrian Junius.

74 The "Pomme de Saint Thomas," according to Adrian Junius: Dalechamps identifies it with the pomme de Granoi. See B.iii. c. 19, and cc. 17 and 18 of the present Book.

75 "Græcula." So called, perhaps, from Tarentum, situated in Magna Græcia.

${ }_{76}$ Twins. This variety is unknown. 
and never growing singly. That known as the "syricum" "7 is so called from its colour, while the "melapium" 78 has its name from its strong resemblance to the pear. The "musteum" "79 was so called from the rapidity with which it ripens; it is the melimelum of the present day, which derives its appellation from its flavour, being like that of honey. The "orbiculatum," 80 again, is so called from its shape, which is exactly spherical-the circumstance of the Greeks having called it the "epiroticum" proves that it came originally from Epirus. The orthomastium ${ }^{81}$ has that peculiar appellation from its resemblance to a teat; and the "spadonium" 82 of the Belgæ is so nicknamed from the total absence of pips. The melofolium ${ }^{83}$ has one leaf, and occasionally two, shooting from the middle of the fruit. That known as the "pannuceum" 84 shrivels with the greatest rapidity; while the "pulmoneum" 85 has a lumpish, swollen appearance.

Some apples are just the colour of blood, owing to an original graft of the mulberry; but they are all of them red on the side which is turned towards the sun. There are some small wild ${ }^{86}$ apples also, remarkable for their fine flavour and the peculiar pungency of their smell. Some, again, are so remarkably ${ }^{87}$ sour, that they are held in disesteem ; indeed their acidity is so extreme, that it will even take the edge from off a knife. The worst apples of all are those which from their mealiness have received the name of "farinacea; ${ }^{88 "}$ they are

77 Or " red" apple. The red calville of the French, according to Hardouin ; the Pomme suzine, according to Dalechamps.

78 The Girandotte of the French ; the appel-heeren of the Dutch.

79 The "early ripener." Dalechamps identifies it with the pomme Saint Jean, the apple of St. John.

80 The Pomme rose, or rose apple, according to Dalechamps.

81 Or "erect teat." The Pomme taponne of the French, according to Dalechamps.

82 Or eunuch. The Passe pomme, or Pomme grillotte of the French.

83 Or "leaf apple." Fée remarks that this occasionally happens, but the apple does not form a distinct variety.

84 The Pomme pannete, according to Dalechamps: the Pomme gelee of Provence.

85 Or "lung" apple. The Pomme folane, according to Dalechamps.

86 The Pirus malus of Linnæus, the wild apple, or estranguillon of the French.

s7 It is doubtful whether he does not allude here to a peculiar variety.

88 Or "mealy" apples. 
the first, however, to ripen, and ought to be gathered as soon as possible.

\section{CHAP. 16. (15.) - FORTY-ONE VARIETIES OF THE PEAR.}

A similar degree of precocity has caused the appellation of "superbum" 89 to be given to one species of tho pear: it is a small fruit, but ripens with remarkable rapidity. All the world are extremely partial to the Crustumian ${ }^{90}$ pear ; and next to it comes the Falernian, ${ }^{91}$ so called from the drink ${ }^{92}$ which it affords, so abundant is its juice. This juice is known by the name of "mill" in the variety which, of a black colour, is by some called the pear of Syria. ${ }^{93}$ The denominations given to the others vary according to the respective localities of their growth. Among the pears, the names of which have been adopted in our city, the Decimian pear, and the PseudoDecimian-an offshoot from it-have conferred considerable renown upon the name of those who introduced them. The same is the case, too, with the variety known as the "Dolabellian," ponian, ${ }^{95}$ surnamed the mammosum, ${ }^{96}$ the Licerian, the Sevian, the Turranian, a variety of the Serian, but distinguished from it by the greater length of the stalk, the Favonian ${ }^{97}$ a red pear, rather larger than the superbum, together with the Laterian ${ }^{98}$ and the Anician, which come at the end of autumn, and are pleasant for the acidity of their flavour.

s9 Or "proud" pear. The Petite muscadelle, according to Dalechamps. Adrian Junius says that it is the water-peere of the Dutch.

90 From Crustumium in Italy ; the Poire perle, or pearl pear, according to Dalechamps : the Jacob's peere of the Flemish.

91 The Poire sucrée, or "sugar-pear," according to Hardouin ; the Bergamotte, according to Dalechamps.

92 "Potu." He would appear to allude to the manufacture of perry.

93 The Syrian pear is commended by Martial; it has not been identified, however.

${ }_{94}$ The Poire musot, according to Dalechamps. Adrian Junius says that it is the Engelsche braet-peere of the Flemish.

${ }_{95}$ The Pirus Pompeiana of Linnæus. Dalechamps identifies it with the Bon chretien, and Adrian Junius with the Taffel-peere of the Flemish. 96 The "breast-formed."

97 The Pirus Favonia of Linnæus : the Grosse poire muscadelle of the French,

98 'The Poire prevost, according to Dalechamps. 
One variety is known as the "Tiberian," from its having been a particular favourite with the Enperor Tiberius; it is more coloured by the sun, and grows to a larger size, otherwise it would be identical with the Licerian variety.

The following kinds receive their respective names from their native countries: the Amerinian, ${ }^{1}$ the latest pear of all, the Picentine, the Numantine, the Alexandrian, the Numidian, the Greek, a variety of which is the Tarentine, and the Signine, ${ }^{2}$ by some called "testaceum," from its colour, like earthenware; a reason which has also given their respective names to the "onychine" 3 and the "purple" kinds. Then, again, we have the "myrapium," the "laureum," and the "nardinum,"5 so called from the odour they emit; the "hordearium," from the season at which it comes ${ }^{7}$ in; and the " ampullaceum," ${ }^{8}$ so called from its long narrow neck. Those, again, that are known as the "Coriolanian" 9 and the "Bruttian," owe their names to the places of their origin; added to which we have the cucurbitinum, ${ }^{10}$ and the "acidulum," so named from the acidity of its juice. It is quite uncertain for what reason their respective names were given to the varieties known as the "barbaricum" and the "Venerium," "which last is known also as the "coloratum;" 12 the royal pear ${ }^{13}$ too, which

99 The Poire foré, according to Dalechamps.

1 The Saint Thomas's pear of the Flemish.

2 The Poire chat of the French, according to Dalechamps; the Riet-peere of the Flemish.

3 "Like onyx." The Cuisse-madame, according to Dalechamps.

4 The Calveau rosat, according to Dalechamps. Perhaps the Poire d'ambre, or amber pear, of the French.

5 The Poire d'argent, or silver pear, according to Dalechamps.

6 Or "barley pear." The Poire de Saint Jean, according to Dalechamps; the musquette or muscadella, according to Adrian Junius.

7 Barley-harvest.

8 So called from its resemblance to the "ampulla," a big-bellied vessel with a small neck, identified with the Poire d'angoisse by Dalechamps.

9 The Poire de jalousie, according to Dalechamps.

10 Or gourd pear. This is the "isbout" according to Adrian Junius, the Poire courge of Dalechamps, and the Poire de sarteau, or de campane of others.

11 The Poire de Venus, according to Adrian Junius; the Poire acciole, according to Dalechamps.

12 Coloured pear.

13 "Regium." The Poire carmagnole, according to Dalechamps; the Mispeel-peere of the Flemish, according to Adrian Junius. 
has a remarkably short stalk, and will stand on its end, as also the patrieium, and the voconium, ${ }^{14}$ a green oblong kind. In addition to these, Virgil ${ }^{15}$ has made mention of a pear called the "volema," 16 a name which he has borrowed from Cato, ${ }^{17}$ who makes mention also of kinds known as the "sementivum" 18 and the "musteum." 19

CHAP. 17.-VARIOUS METHODS OF GRAFTING TREES.

EXPIATIONS FOR LIGHTNING.

This branch of civilized life has long since been brought to the very highest pitch of perfection, for man has left nothing untried here. Hence it is that we find Virgil ${ }^{20}$ speaking of grafting the nut-tree on the arbutus, the apple on the plane, and the cherry on the elm. Indeed, there is nothing further in this department that can possibly be devised, and it is a long time since any new variety of fruit has been discovered. Religious scruples, too, will not allow of indiscriminate grafting; thus, for instance, it is not permitted to graft upon the thorn, for it is not easy, by any mode of expiation, to avoid the disastrous effects of lightning; and we are told ${ }^{21}$ that as many as are the kinds of trees that have been engrafted on the thorn, so many are the thunderbolts that will be hurled against that spot in a single flash.

The form of the pear is turbinated; the later kinds remain on the parent tree till winter, when they ripen with the frost; such, for instance, as the Greek variety, the ampullaceum, and the laureum; the same, too, with apples of the Amerinian and the Scandian kinds. Apples and pears are prepared for

14 The Poire sarteau, according to Dalechamps.

15 Georgics, ii. 87.

16 "A handful" - probably the pound or pounder pear : the Bergamotte, according to Hardouin; the Bon chreticn of summer, according to Adrian Junius.

17 De Re Rust. c. 7.

18 Or "Seedling."

19 The "early ripener." Fée suggests that this may be a variety of the Bon chretien.

20 Georgics, ii. 69. This statement of Virgil must be regarded as fabulous; grafting being impracticable with trees not of the same family, and not always successful even then.

21 This was probably some superstition taught by the augurs for the purpose of euveloping their profession in additional nystery and awe. 
keeping just like grapes, and in as many different ways; but, with the exception of plums, they are the only fruit that are stored in casks. ${ }^{22}$ Apples and pears have certain vinous ${ }^{23}$ properties, and like wine these drinks are forbidden to invalids by the physicians. These fruits are sometimes boiled up with wine and water, and so make a preserve ${ }^{24}$ that is eaten with bread; a preparation which is never made of any other fruit, with the exception of the quinces, known as the "cotoneum" and the "strutheum."

\section{CHAP. 18. (16.) - THE MODE OF KEEPING VARIOUS FRUITS AND GRAPES.}

For the better preserving of fruits it is universally recommended that the storeroom should be situate in a cool, dry spot, with a well-boarded floor, and windows looking towards the north; which in fine weather ought to be kept open. Care should also be taken to keep out the south wind by window panes, ${ }^{25}$ while at the same time it should be borne in mind that a north-east wind will shrivel fruit and make it unsightly. Apples are gathered after the autumnal equinox; but the gathering should never begin before the sixteenth day of the moon, or before the first hour of the day. Windfalls should always be kept separate, and there ought to be a layer of straw, or else mats or chaff, placed beneath. They should, also, be placed apart from each other, in rows, so that the air may circulate freely between them, and they may equally gain the benefit of it. The Amerinian apple is the best keeper, the melimelum the very worst of all.

(17.) Quinces ought to be stored in a place kept perfectly closed, so as to exclude all draughts; or else they should be boiled in honey ${ }^{26}$ or soaked in it. Pomegranates are made 22 Cadis.

${ }^{23}$ He probably alludes here to cider and perry. See p. 300, and B. xxiii. c. 62 .

24 "Pulmentarii vicem;" properly "a substitute for pulmentarium," which was anything eaten with bread, such as meat, vegetables, \&c. He alludes to marmalade. The French raisine is a somewhat similar preparation from pears and quinces boiled in new wine.

25 "Specularibus." He alludes to windows of transparent stone, lapis specularis, or mica; windows of glass being probably unknown in his time. 'The ordinary windows were merely openings closed with shutters. See B. xxxvi. c. 45 .

${ }^{26}$ He must allude to a kind of quince marmalade. 
hard and firm by being first put in boiling ${ }^{27}$ sea-water, and then left to dry for three days in the sun, care being taken that the dews of the night do not touch them; after which they are hung up, and when wanted for use, washed with fresh water. M. Varro ${ }^{28}$ recommends that they should be kept in large vessels filled with sand: if they are not ripe, he says that they should be put in pots with the bottom broken out, and then buried ${ }^{29}$ in the earth, all access to the air being carefully shut, and care being first taken to cover the stalk with pitch. By this mode of treatment, he assures us, they will attain a larger size than they would if left to ripen on the tree. As for the other kinds of pomes, he says that they should be wrapped up separately in fig-leaves, the windfalls being carefully excluded, and then stored in baskets of osier, or else covered over with potters' earth.

Pears are kept in earthen vessels pitched inside; when filled, the vessels are reversed and then buried in pits. The Tarentine pear, Varro says, is gathered very late, while the Anician keeps very well in raisin wine. Sorb apples, too, are similarly kept in holes in the ground, the vessel being turned upside down, and a layer of plaster placed on the lid: it should be buried two feet deep, in a sunny spot; sorbs ${ }^{30}$ are also hung, like grapes, in the inside of large vessels, together with the branches.

Some of the more recent authors are found to pay a more scrupulous degree of attention to these various particulars, and recommend that the gathering of grapes or pomes, which are intended for keeping, should take place while the moon is on the wane, ${ }^{31}$ after the third hour of the day, and while the weather is clear, or dry winds prevail. In a similar manner, the selection, they say, ought to be made from a dry spot, and the fruit should be plucked before it is fully ripe, a moment being chosen while the moon is below the horizon. Grapes, they say, should be selected that have a strong, hard malletstalk, and after the decayed berries have been carefully removed with a pair of scissors, they should be hung up inside of

27 As Fée remarks, the fruit, if treated thus, would soon lose all the properties for which it is valued.

${ }_{28}$ De Re Rust. B. i. c. 59.

29 A faulty proceeding, however dry it may be.

30 This fruit, Fée remarks, keeps but indifferently, and soon becomes soft, vinous, and acid.

${ }^{31}$ An absurd superstition. 
a large vessel which has just been pitched, care being taken to close all access to the south wind, by covering the lid with a coat of plaster. The same method, they say, should be adopted for keeping sorb apples and pears, the stalks being carefully covered with pitch; care should be taken, too, that the ressels are kept at a distance from water.

There are some persons who adopt the following method for preserving grapes. They take them off together with the branch, and place them, while still upon it, in a layer of plaster, ${ }^{32}$ taking care to fasten either end of the branch in a bulb of squill. ${ }^{33}$ Others, again, go so far as to place them within vessels containing wine, taking care, however, that the grapes, as they hang, do not touch it. Some persons put apples in plates of earth, and then leave them to float in wine, a method by which it is thought that a vinous flavour is imparted to them : while some think it a better plan to preserve all these kinds of fruit in millet. Most people, however, content themselves with first digging a hole in the ground, a couple of feet in depth; a layer of sand is then placed at the bottom, and the fruit is arranged upon it, and covered with an earthen lid, over which the earth is thrown. Some persons again even go so far as to give their grapes a coating of potters' chalk, and then hang them up when dried in the sun; when required for use, the chalk is removed with water ${ }^{34}$ Apples are also preserved in a similar manner; but with them wine is employed for getting off the chalk. Indeed, we find a very similar plan pursued with apples of the finest quality; they have a coating laid upon them of either plaster or wax; but they are apt, if not quite ripe when this was done, by the increase in their size to break their casing. ${ }^{54^{*}}$ When apples are thus prepared, they are always laid with the stalk downwards. ${ }^{35}$ Some persons pluck the apple together with the branch, the ends of which they thrust into the pith of elder, ${ }^{35^{*}}$ and then bury it in

32 A method not unlikely to spoil the grape, from the difficulty of removing the coat thus given to it.

${ }^{33}$ A very absurd notion, as Fée observes. To keep fruit in millet is also condemned.

34 Which, of course, must deteriorate the flavour of the grape.

$3^{\circ}$ It is doubtful if they will increase in size, when once plucked.

35 The modern authorities recommend the precisely opposite plan.

35* As absurd as the use of the bulb of squill.

TOL. III. 
the way already pointed out. ${ }^{36}$ There are some who assign to each apple or pear its separate vessel of clay, and after carefully pitching the cover, enclose it again in a larger vessel : occasionally, too, the fruit is placed on a layer of flocks of wool, or else in baskets, ${ }^{37}$ with a lining of chaff and clay. Other persons follow a similar plan, but use earthen plates for the purpose; while others, again, employ the same method, but dig a hole in the earth, and after placing a layer of sand, lay the fruit on top of it, and then cover the whole with dry earth. Persons, too, are sometimes known to give quinces a coating of Pontic ${ }^{38}$ wax, and then plunge them in honey.

Columella ${ }^{39}$ informs us, that fruit is kept by being carefully put in earthen vessels, which then receive a coating of pitch, and are placed in wells or cisterns to sink to the bottom. The people of maritime Liguria, in the vicinity of the Alps, first dry their grapes in the sun, ${ }^{40}$ and wrap them up in bundles of rushes, which are then covered with plaster. The Greeks follow a similar plan, but substitute for rushes the leaves of the planetree, or of the vine itself, or else of the fig, which they dry for a single day in the shade, and then place in a cask in alternate layers with husks ${ }^{41}$ of grapes. It is by this method that they preserve the grapes of Cos and Berytus, which are inferior to none in sweetness. Some persons, when thus preparing them, plunge the grapes into lie-ashes the moment they take them from the vine, and then dry them in the sun; they then steep them in warm water, after which they put them to dry again in the sun: and last of all, as already mentioned, wrap them up in bundles formed of layers of leaves and grape husks. There are some who prefer keeping their grapes in sawdust, ${ }^{42}$ or else in shavings of the fir-tree, poplar, and ash: while others think it the best plan to hang them up in the granary, at a careful distance from the apples, directly after the gathering, being under the impression that the very best corering for them as they hang is the dust ${ }^{43}$ that naturally arises

36 In a pit two feet deep, \&c. See above.

37 Capsæ.

38 See B. xxi. c. 49.

40 These must make raisins of the sun.

41 These must have been perfectly dry, or else they would tend to rot the grapes or raisins.

${ }_{42}$ Columella, for instance, B. xii. c. 43.

13 The dust is in reality very liable to spoil the fruit, from the tenacity 
from the floor. Grapes are effectually protected against the attacks of wasps by being sprinkled with oil ${ }^{43^{*}}$ spirted from the mouth. Of palm-dates we have already spoken. ${ }^{44}$

CHAP. 19. (18.) 一 TWENTY-NINE VARIETIES OF THE FIG.

Of all the remaining fruits that are included under the name of "pomes," the fig ${ }^{45}$ is the largest : some, indeed, equal the pear, even, in size. We have already mentioned, while treating of the exotic fruits, the miraculous productions of Egypt and Cyprus ${ }^{46}$ in the way of figs. The fig of Mount $\mathrm{Ida}^{47}$ is red, and the size of an olive, rounder however, and like a medlar in flavour; they give it the name of Alexandrian in those parts. The stem is a cubit in thickness; it is branchy, has a tough, pliant wood, is entirely destitute of all milky juice, ${ }^{48}$ and has a green bark, and leaves like those of the linden tree, but soft to the touch. Onesicritus states that in Hyrcania the figs are much sweeter than with us, and that the trees are more prolific, seeing that a single tree will bear as much as two hundred and seventy modiii ${ }^{49}$ of fruit. The fig has been introduced into Italy from other countries, Chalcis and Chios, for instance, the varieties being very numerous: there are those from Lydia also, which are of a purple colour, and the kind known as the "mamillana," 50 which is very similar to the Lydian. The callistruthiæ are very little superior to the last in flavour; they are the coldest by nature of all the figs. As to the African fig, by many people preferred to any other, it has been made the subject of very considerable discussion, as it is a kind that has been introduced very recently into Africa, though it bears the name of that country.

with which it adheres. In all these methods, little attention would seem to be paid to the retention of the flavour of the fruits.

${ }^{43^{\circ}}$ A detestable practice, Fée says, as the oil makes an indelible mark on the grape, and gives it an abominable flavour. It is the best method to put the fruit in bags of paper or hair.

${ }_{44}$ See B. xiii. c. 19.

45 There are about forty varieties now known.

46 B. xiii. c. 14, 15 . These are the Ficus sycomorus of Linnæus.

${ }^{47}$ In Troas; called the Aiexandrian fig, from the city of Alexandria there. Fée doubts if this was really a fig, and suggests that it might be the fruit of a variety of Diospyros.

48 No fig-tree now known is destitute of this.

49 Fée treats this as an exaggeration.

${ }^{50}$ From "mamilla," a teat. 
As to the fig of Alexandria, ${ }^{51}$ it is a black variety, with the cleft inclining to white; it has had the name given to it of the "delicate" 52 fig: the Rhodian fig, too, and the Tiburtine, ${ }^{53}$ one of the early kinds, are black. Some of them, again, bear the name of the persons who were the first to introduce them, such, for instance, as the Livian ${ }^{54}$ and the Pompeian ${ }^{55}$ figs : this last variety is the best for drying in the sun and keeping for use, from year to year; the same is the case, too, with the marisca, ${ }^{50}$ and the kind which has a leaf spotted all over like the reed..$^{57}$ There is also the Herculanean fig, the albicerata, ${ }^{58}$ and the white aratia, a very large variety, with an extremely diminutive stalk.

The earliest of them all is the porphyritis, ${ }^{59}$ which has a stalk of remarkable length : it is closely followed by the popularis, ${ }^{60}$ one of the very smallest of the figs, and so called from the low esteem in which it is held: on the other hand, the chelidonia $^{61}$ is a kind that ripens the last of all, and towards the beginning of winter. In addition to these, there are figs that are at the same time both late and early, as they bear two crops in the year, one white and the other black, ${ }^{62}$ ripening at harvest-time and vintage respectively. There is another late fig also, that has received its name from the singular hardness of its skin ; one of the Chalcidian varieties bears as many as three times in the year. It is at Tarentum only that the remarkably sweet fig is grown which is known by the name of " ona."

Speaking of figs, Cato has the following remarks: "Plant the fig called the 'marisca' on a chalky or open site, but for the African variety, the Herculanean, the Saguntine, ${ }^{63}$ the

57 In Egypt. The Figue servantine, or cordeliere.

52 "Delicata." The "bon-bouche."

${ }^{53}$ Fée suggests that this may have been the small early fig.

${ }^{54}$ From Livia, the wife of Augustus.

${ }_{55}^{55}$ From Pompeius Magnus. ${ }^{56}$ Apparently meaning the "marsh" fig.

${ }^{57}$ The Laconian reed, Theophrastus says, B. iv. c. 12.

58 The "white-wax" fig.

59 Fée queries whether it may not be the Grosse bourjasotte.

60 Or "people's" fig. The small early white fig.

61 Or "swallow"-fig.

62 Or it may mean "white and black," that being the colour of the fig. Such a variety is still known.

${ }_{63}$ A Spanish variety; those of the south of Spain are very highly estemed. 
winter fig and the black Telanian ${ }^{64}$ with a long stalk, you must select a richer soil, or else a ground well manured." Since his day there have so many names and kinds come up, that even on taking this subject into consideration, it must be apparent to every one how great are the changes which have taken place in civilized life.

There are winter figs, too, in some of the provinces, the Mœsian, for instance ; but they are made so by artificial means, such not being in reality their nature. Being a small variety of the fig-tree, they cover it up with manure at the end of autumn, by which means the fruit on it is overtaken by winter while still in a green state: then when the weather becomes milder the fruit is uncovered along with the tree, and so restored to light. Just as though it had come into birth afresh, the fruit imbibes the heat of the new sun with the greatest avidity - a different sun, in fact, to that ${ }^{65}$ which originally gave it life-and so ripens along with the blossom of the coming crop; thus attaining maturity in a year not its own, and this in a country, ${ }^{66}$ too, where the greatest cold prevails.

CHAP. 20.-HISTORICAL ANECDOTES CONNECTED WITH THE FIG.

${ }^{67}$ The mention by Cato of the variety which bears the name of the African fig, strongly recalls to my mind a remarkable fact connected with it and the country from which it takes its name.

Burning with a mortal hatred to Carthage, anxious, too, for the safety of his posterity, and exclaiming at every sitting of the senate that Carthage must be destroyed, Cato one day brought with him into the Senate-house a ripe fig, the produce of that country. Exhibiting it to the assembled senators, "I ask you," said he, "when, do you suppose, this fruit was plucked from the tree ?"' All being of opinion that it had been but lately gathered, - "Know then," was his reply, " that this fig was plucked at Carthage but the day before yesterday ${ }^{68}$ - so near is the enemy

51 The modern "black" tig.

65 The sun of the former year.

66 In Mœsia-the present Servia and Bulgaria.

67 Another war is said to have originated in this fruit. Xerxes was tempted by the fine figs of Athens to undertake the invasion of Greece.

os "Tertium ante diem." In dating from an event, the Romans in- 
to our walls." It was immediately after this occurrence that the third Punic war commenced, in which Carthage was destroyed, though Cato had breathed his last, the year after this event. In this trait which are we the most to admire? was it ingenuity ${ }^{69}$ and foresight on his part, or was it an accident that was thus aptly turned to advantage? which, too, is the most surprising, the extraordinary quickness of the passage which must have been made, or the bold daring of the man? The thing, however, that is the most astonishing of all-indeed, I can conceive nothing more truly marvellous-is the fact that a city thus mighty, the rival of Rome for the sovereignty of the world during a period of one hundred and twenty years, owed its fall at last to an illustration drawn from a single fig!

Ihus did this fig effect that which neither Trebia nor Thrasimenus, not Cannæ itself, graced with the entombment of the Roman renown, not the Punic camp entrenched within three miles of the city, not even the disgrace of seeing Hannibal riding up to the Colline Gate, could suggest the means of accomplishing. It was left for a fig, in the hand of Cato, to show how near was Carthage to the gates of Rome!

In the Forum even, and in the very midst of the Comitium ${ }^{70}$ of Rome, a fig-tree is carefully cultivated, in memory of the consecration which took place on the occasion of a thunderbolt ${ }^{71}$ which once fell on that spot; and still more, as a memorial of the fig-tree which in former days overshadowed Romulus and Remus, the founders of our empire, in the Lupercal Cave. This tree received the name of "ruminalis," from the circumstance that under it the wolf was found giving the breast-rumis it was called in those days-to the two infants. A group in bronze was afterwards erected to consecrate the remembrance of this miraculous event, as, through the agency of Attus Navius the augur, the tree itself had. cluded both days in the computation; the one they dated from, and the day of, the event.

69 In sending for the fig, and thinking of this method of speaking to the feelings of his fellow-countrymen.

${ }^{70}$ A place in the Forum, where public meetings were held, and certain offences tried.

71 He alludes to the Puteal, or enclosed space in the Forum, consecrated by Scribonius Libo, in consequence of the spot having been struck by lightning. 
passed spontaneously from its original locality ${ }^{72}$ to the Comitium in the Forum. And not without some direful presage is it that that tree has withered away, though, thanks to the care of the priesthood, it has been since replaced. ${ }^{73}$

There was another fig-tree also, before the temple of Saturn,${ }^{74}$ which was removed on the occasion of a sacrifice made by the Vestal Virgins, it being found that its roots were gradually undermining the statue of the god Silvanus. Another one, accidentally planted there, flourished in the middle of the Forum, ${ }^{75}$ upon the very spot, too, in which, when from a direful presage it had been foreboded that the growing empire was about to sink to its rery foundations, Curtius, at the price of an inestimable treasure-in other words, by the sacrifice of such unbounded virtue and piety-redeemed his country by a glorious death. By a like accident, too, a vine and an olivetree have sprung up in the same spot, ${ }^{76}$ which have ever since been carefully tended by the populace for the agreeable shade which they afford. The altar that once stood there was afterwards removed by order of the deified Julius Cæsar, upon the occasion of the last spectacle of gladiatorial combats ${ }^{77}$ which he gave in the Forum.

\section{CHAP. 21.-CAPRIFICATION.}

The fig, the only one among all the pomes, hastens to maturity by the aid of a remarkable provision of Nature. (19.) The wild-fig, ${ }^{78}$ known by the name of " caprificus," never ripens itself, though it is able to impart to the others the principle of which it is thus destitute; for we occasionally find Nature making a transfer of what are primary causes, and being generated from decay. To effect this purpose the wild fig-tree

${ }^{72}$ On the banks of the Tiber, below the Palatine Mount. The whole of this passage is in a most corrupt siate, and it is difficult to extract a meaning from it.

${ }^{73}$ By slips from the old tree, as Tacitus seems to say- "in novos foetus revivisceret."

${ }^{74}$ At the foot of the Capitoline Hill.

75 Probably near where the Curtius Lacus had stood in the early days of Rome. The story of Metius Curtius, who leaped into the yawning gulph in the Forum, in order to save his country, is known to every classical reader.

76 The Forum.

77 See B. xix. c. 6.

is The Ficus Carica of Linnæus. It does bear fruit, though small, and disagreeable to the taste. 
produces a kind of gnat. ${ }^{99}$ These insects, deprived of all sustenance from their parent tree, at the moment that it is hastening to rottenness and decay, wing their flight to others of kindred though cultivated kind. 'There feeding with avidity upon the fig, they penetrate it in numerous places, and by thus making their way to the inside, open the pores of the fruit. ${ }^{80}$ The moment they effect their entrance, the heat of the sun finds admission too, and through the inlets thus made the fecundating air is introduced. These insects speedily consume the milky juice that constitutes the chief support of the fruit in its infant ${ }^{81}$ state, a result which would otherwise be spontaneously effected by absorption : and hence it is that in the plantations of figs a wild fig is usually allowed to grow, being placed to the windward of the other trees in order that the breezes may bear from it upon them. Improving upon this discovery, branches of the wild fig are sometimes brought from a distance, and bundles tied together are placed upon the cultivated tree. This method, however, is not necessary when the trees are growing on a thin soil, or on a site exposed to the north-east wind; for in these cases the figs will dry spontaneously, and the clefts which are made in the fruit effect the same ripening process which in other instances is brought about by the agency of these insects. Nor is it requisite to adopt this plan on spots which are liable to dust, such, for instance, as is generally the case with fig-trees planted by the side of much-frequented roads: the dust having the property of drying up ${ }^{82}$. the juices of the fig, and so absorbing the milky humours. There is this superiority, however, in an advantageous site over the methods of ripening by the agency of dust or by caprification, that the fruit is not so apt to fall; for the secretion of the juices being thus prevented, the fig is not so heavy as it would otherwise be, and the branches are less brittle.

All figs are soft to the touch, and when ripe contain grains ${ }^{83}$

79 This insect is one of the Hymenoptera; the Cynips Psenes of Linnæus and Fabricius. There is another insect of the same genus, but not so well known.

80 Fee observes that the caprification accelerates the ripeness of the fruit, but at the expense of the flavour. For the same purpose the upper part of the fig is often pricked with a pointed quill.

81 "Infantiam pomi "-literally, "the infancy of the fruit."

82 Fée denies the truth of this assertion.

83 Frumenta. 
in the interior. The juice, when the fruit is ripening, has the taste of milk, and when dead ripe, that of honey. If left on the tree they will grow old; and when in that state, they distil a liquid that flows in tears ${ }^{81}$ like gum. Those that are more highly esteemed are kept for drying, and the most approved kinds are put away for keeping in baskets. ${ }^{85}$ The figs of the island of Ebusus ${ }^{86}$ are the best as well as the largest, and next to them are those of Marrucinum. ${ }^{87}$ Where figs are in great abundance, as in Asia, for instance, huge jars ${ }^{83}$ are filled with them, and at Ruspina, a city of Africa, we find casks ${ }^{89}$ used for a similar purpose: here, in a dry state, they are extensively used instead of bread, ${ }^{90}$ and indeed as a general article of provision. ${ }^{91}$ Cato, ${ }^{92}$ when laying down certain definite negulations for the support of labourers employed in agriculture, recommends that their supply of food should be lessened just at the time ${ }^{93}$ when the fig is ripening: it has been a plan adopted in more recent times, to find a substitute for salt with cheese, by eating fresh figs. To this class of fruit belong, as we have already mentioned, ${ }^{91}$ the cottana and the carica, together with the cavnea, ${ }^{95}$ which was productive of so bad an omen to M. Crassus at the moment when he was embarking ${ }^{96}$ for his expedition against the Parthians, a dealer happening to be crying them just at that very moment. L. Vitellius, who was more recently appointed to the censorship, ${ }^{97}$ introduced all these varieties from Syria at his. countryseat at $\mathrm{Alba},{ }^{98}$ having acted as legatus in that province in the latter years of the reign of Tiberius Cæsar.

84 A mixture of the sugar of the fruit with the milky juice of the tree, which is a species of caoutchouc.

85 Capsis.

${ }_{8 \dot{\circ}}$ See B. iii. c. 11. The Balearic Isles still produce great quantities of excellent dried figs.

88 Orcæ.

87 See B. iii. c. 17. 89 Cadi.

90 Ground, perhaps, into a kind of flour.

91 Opsonii vicem. "Opsonium" was anything eaten with bread, such as vegetables, meat, and fish, for instance.

${ }_{92}$ De Re Rust. c. 56.

${ }_{93}$ Because they would be sure, under any circumstances, to eat plenty of them. 94 See B. xiii. c. 10.

${ }_{95}$ These were so called from Caunus, a city of Caria, famous for its dried figs. Pronounced "Cavneas," it would sound to the superstitious, "Cave ne eas," "Take care that you go not."

96 At Brundisium.

98 Alba Longa. See B. iii. c. ᄋ.

97 A.U.C. 801. 
CHAP. 22. (20.) - THREE VARIETIES OF THE MEDLAR.

The medlar and the sorb ${ }^{99}$ ought in propriety to be ranked under the head of the apple and the pear. Of the medlar ${ }^{1}$ there are three varieties, the anthedon, ${ }^{2}$ the setania, ${ }^{3}$ and a third of inferior quality, which bears a stronger resemblance to the anthedon, and is known as the Gallici kind. The setania is the largest fruit, and the palest in colour; the woody seed in the inside of it is softer, too, than in the others, which are of smaller size than the setania, but superior to it in the fragrance of their smell, and in being better keepers. The tree itself is one of very ample ${ }^{5}$ dimensions : the leaves turn red before they fall: the roots are numerous, and penetrate remarkably deep, which renders it almost impossible to grub it up. This tree ${ }^{6}$ did not exist in Italy in Cato's time.

CHAP. 23. (21). - FOUR VARIETIES OF THE SORB.

There are four varieties of the sorb: there being some that have all the roundness ${ }^{7}$ of the apple, while others are conical like the pear, ${ }^{8}$ and a third sort are of an oval ${ }^{9}$ shape, like some of the apples: these last, however, are apt to be remarkably acid. The round kind is the best for fragrance and sweetness, the others having a vinous flavour; the finest, however, are those which have the stalk surrounded with tender leaves. A fourth kind is known by the name of "torminalis :"10 it is only employed, however, for remedial pur-

99 The sorb belongs to the genus pirus of the naturalists.

1 The Mespilus germanica of the botanists.

2 The azarolier, a tree of the south of Europe, the Mespilus apii folio laciniato of $\mathrm{C}$. Bauhin.

3 The Mespilus Italica folio laurino serrato of C. Bauhin, the Mespilus cotoneaster of J. Bauhin.

4 Its identity is rnatter of uncertainty; but it has been thought to be the Cratægus oxyacantha of modern botanists.

5 By "amplissimus," he must mean that it spreads out very much in proportion to its height, as it is merely a shrub.

${ }^{6}$ Fée thinks it a tree indigenous to the north.

7 The ordinary sorb-apple of horticulturists.

8 The sorb-pear.

9 Varying but little, probably, from the common sorb, the Sorbus domestica of Jinnæus.

${ }_{10}$ Fée is inclined to think that it is the Sorbus terminalis of Lamarck. Anguillara thinks that it is the Cratægus of 'Theophrastus, considered by 
poses. The tree is a good bearer, but does not resemble the other kinds, the leaf being nearly that of the plane-tree; the fruit, too, is particularly small. Cato ${ }^{11}$ speaks of sorbs being preserved in boiled wine.

\section{CHAP. 24. (22.) -NINE VARIETIES OF THE NUT.}

The walnut, ${ }^{12}$ which would almost claim precedence of the sorb in size, yields the palm to it in reference to the esteem ${ }^{13}$ in which they are respectively held; and this, although it is so favourite an accompaniment of the Fescennine ${ }^{14}$ songs at nuptials. This nut, taken as a whole, is very considerably smaller than the pine nut, but the kernel is larger in proportion. Nature, too, has conferred upon it a peculiar honour, in protecting it with a two-fold covering, the first of which forms a hollowed cushion for it to rest upon, and the second is a woody shell. It is for this reason that this fruit has been looked upon as a symbol consecrated to marriage, ${ }^{15}$ its offspring being thus protected in such manifold ways: an explanation which bears a much greater air of probability than that which would derive it from the rattling which it makes when it bounds from the floor. ${ }^{16}$ The Greek names that have been given to this fruit fully prove that it, like many others, has been originally introduced from Persis; the best kinds being known in that language by the names of "Persicum,"17 and "basilicon;"18 these, in fact, being the names by which they

Sprengel to be identical with the Cratægus azarolus of Linnæus. In ripening, the fruit of the sorb undergoes a sort of vinous fermentation : hence a kind of cider made of it.

11 De Re Rust. cc. 7 and 145.12 The Juglans regia of Linnæus.

13 Tastes have probably altered since this was written.

14 These were rude and sometimes obscene songs sung at festivals, and more particularly marriages. While these songs were being sung at the ajoor of the nuptial chamber, it was the custom for the husband to scramble walnuts among the young people assembled there. The walnut is the nut mentioned in Solomon's Song, vi. 11.

${ }_{15} \mathrm{Or}$, more probably, from the union of the two portions of the inner shell.

16 "Tripudium sonivium:" implying that it was considered sacred to marriage, from the use made of it by the friends of the bridegroom when thrown violently against the nuptial chamber, with the view of drowning the cries of the bride. A very absurd notion, to all appearance.

17 The "Persian" nut.

18 The "king's" nut. The walnut-tree still abounds in Persia, and is found wild on the slopes of the Himalaya. 
were first known to us. It is generally agreed, too, that one peculiar variety has derived its name of " caryon," 19 from the headache which it is apt to produce by the pungency ${ }^{20}$ of its smell.

The green shell of the walnut is used for dyeing ${ }^{21}$ wool, and the nuts, while still small and just developing themselves, are employed for giving a red hue to the hair $:^{22}$ a discovery owing to the stains which they leave upon the hands. When old, the nut becomes more oleaginous. The only difference in the several varieties consists in the relative hardness or brittleness of the shell, it being thin or thick, full of compartments or smooth and uniform. This is the only fruit that Nature has enclosed in a covering formed of pieces soldered together; the shell, in fact, forming a couple of boats, while the kernel is divided into four separate compartments ${ }^{23}$ by the intervention of a ligneous membrane.

In all the other kinds, the fruit and the shell respectively are of one solid piece, as we find the case with the hazel-nut, ${ }^{24}$ and another variety of the nut formerly known as "Abellina," ${ }^{25}$ from the name ${ }^{26}$ of the district in which it was first produced : it was first introduced into Asia and Greece from Pontus, whence the name that is sometimes given to it-the "Pontic nut." This nut, too, is protected by a soft beard, ${ }^{27}$ but both the shell and the kernel are round, and formed of a single piece: these nuts are sometimes roasted. ${ }^{28}$ In the middle of the kernel we find a germen or navel.

A third class of nuts is the almond, ${ }^{29}$ which has an outer

19 Implying that it comes from the Greek $\kappa \dot{\alpha} \rho \eta$, " the head." Some etymologists think that it is from the Celto-Scythian carw, a boat; such being the shape of the two parts of the inner shell.

20 It is still a common notion, Fée says, that it is highly injurious to sleep beneath a walnut-tree.

21 It is still used for this purpose.

22 Red hair was admired by the Romans. The Roman females used this juice also for dyeing their hair when grey.

23 They are not entirely separate.

24 The Corylus avellana maxima of Willdenow.

25 The filbert, the Corylus tubulosa of Willdenow.

26 Abellinum, in Campania. See B. iii. c. 9.

27 The down on the nut is more apparent when it is young; but it is easily rubbed off. The outer coat is probably meant.

${ }_{28}$ Hazel nuts are sometimes roasted in some parts of Europe; but not with us.

29 The Amygdalus communis of Linnæus. 
covering, similar to that of the walnut, but thinner, with a second coat in the shape of a shell. The kernel, however, is unlike that of the walnut, in respect of its broad, flat shape, its firmness, and the superior tastiness of its flavour. It is a matter of doubt whether this tree was in existence in Italy in the time of Cato; we find him speaking of Greek nuts, ${ }^{30}$ but there are some persons who think that these belong to the walnut class. He makes mention, also, of the hazel-nut, the calva, ${ }^{31}$ and the Prænestine ${ }^{32}$ nut, which last he praises beyond all others, and says $\mathrm{s}^{33}$ that, put in pots, they may be kept fresh and green by burying them in the earth.

At the present day, the almonds of Thasos and those of Alba are held in the highest esteem, as also two kinds that are grown at Tarentum, one with a thin, ${ }^{34}$ brittle shell, and the other with a harder ${ }^{35}$ one: these last are remarkably large, and of an oblong shape. There is the almond known as the "mollusca," ${ }^{36}$ also, which breaks the shell of itself. There are some who would concede a highly honourable interpretation to the name given to the walnut, and say that "juglans" means the "glans," or "acorn of Jove." It is only very lately that I heard a man of consular rank declare, that he then had in his possession walnut-trees that bore two $0^{37}$ crops in the year.

Of the pistachio, which belongs also to the nut class, we have already spoken ${ }^{38}$ in its appropriate place : Vitellius introduced this tree into Italy at the same time as the others that

30 De Re Rust. c. 8 . Some think that this was the bitter almond ; and the word "acriore," uised by Pliny, would almost seem to imply that such is the case.

31 Apparently the "smooth" or "bald" nut. May not a variety something like the hickory nut of America be meant?

${ }^{32}$ Festus says that a kind of nut was so called, because the Prænestines, when besieged by Hannibal at Casilinum, subsisted upon them. See Livy, B. xxiii. Fée considers it only another name for the common hazel nut. 33 De Re Rust, c. 145.

${ }^{34}$ The soft-shelled almond, or princess almond of the French: the Amygdalus communis fragilis of naturalists.

35 This last variety does not seem to have been identified: the hardshell almonds do not appear to be larger than the others.

${ }^{36}$ Or "soft" almond, a variety only of the Amygdalus fragilis.

37 There is little doubt that Fée is right in his assertion, that this great personage imposed on our author; as no trees of this family are known to bear two crops.

38 B. xiii. c. 10 . 
we mentioned ${ }^{39}$ and Flaccus Pompeius, a Roman of Equestrian rank, who served with him, introduced it at the same period into Spain.

\section{CHAP. 25. (23.)-EIGHTEFN VARIETIES OF THE CHESNUT.}

We give the name of nut, too, to the chesnut, ${ }^{40}$ although it would seem more properly to belong to the acorn tribe. The chesnut has its armour of defence in a shell bristling with prickles like the hedge-hog, an envelope which in the acorn is only partially developed. It is really surprising, however, that Nature should have taken such pains thus to conceal an object of so little value. We sometimes find as many as three nuts beneath a single outer shell. The skin ${ }^{41}$ of the nut is limp and flexible: there is a membrane, too, which lies next to the body of the fruit, and which, both in this and in the walnut, spoils the flavour if not taken off. Chesnuts are the most pleasant eating when roasted $:^{42}$ they are sometimes ground also, and are eaten by women when fasting for religious scruples, ${ }^{43}$ as bearing some resemblance to bread. It is from Sardes ${ }^{41}$ that the chesnut was first introduced, and hence it is that the Greeks have given it the name of the "Sardian acorn ;" for the name "Dios balanon" ${ }^{45}$ was given at a later period, after it had been considerably improved by cultivation.

At the present day there are numerous varieties of the chesnut. Those of Tarentum are a light food, and by no means difficult of digestion; they are of a flat shape. There is a rounder variety, known as the "balanitis ;" 46 it is very easily peeled, and springs clean out of the shell, so to say, of

${ }^{39}$ In c. xxi. of this Book.

${ }^{40}$ The tree is the Fagus castanea of Linnæus.

41 Cortex.

12 The common mode of eating it at the present day. The Italians also take off the skin and dry the nut; thus keeping it from year to year. When required for eating, it is softened by the steam of boiling water.

43 Not improbably said in allusion to the fasts introduced by the Jews, who had become very numerous in Rome.

41 It was said to have come from Castana; a city of Pontus, whence its name "Castanea." It is probably indigenous to Europe.

45 The Greek for "Jove's acorn."

${ }^{46}$ Or "acorn chesnut." The same variety, Fée says, that is found in the vicinity of Perigueux, small, nearly round, and without any particulır flavour. 
its own accord. The Salarian ${ }^{47}$ chesnut has a smooth outer shell, while that of Tarentum is not so easily handled. ${ }^{48}$ The Corellian is more highly esteemed, as is the Etereian, which is an offshoot from it produced by a method upon which we shall have to enlarge when we come to speak of grafting. ${ }^{49}$ This last has a red skin, ${ }^{50}$ which causes it to be preferred to the three-cornered chesnut and our black common sorts, which are known as "coctivæ." "51 Tarentum and Neapolis in Campania are the most esteemed localities for the chesnut: other kinds, again, are grown to feed pigs upon, ${ }^{52}$ the skin of which is rough and folded inwards, so as to penetrate to the heart of the kernel.

CHAP. 26. (24.)—THE CAROB.

The carob, ${ }^{53}$ a fruit of remarkable sweetness, does not ap. pear to be so very dissimilar to the chesnut, except that the skin $^{5 t}$ is eaten as well as the inside. It is just the length of a finger, and about the thickness of the thumb, being sometimes of a curved shape, like a sickle. The acorn cannot be reckoned in the number of the fruits; we shall, therefore, speak of it along with the trees of that class..$^{55}$

\section{CHAP. 27.-THE FLESHY FRUITS. THE MULBERRY.}

The other fruits belong to the fleshy kind, and differ both in the shape and the flesh. The flesh of the various berries, ${ }^{56}$ of the mulberry, and of the arbute, are quite different from one another-and then what a difference, too, between the grape, which is only skin and juice, ${ }^{57}$ the myxa plum, and the flesh of some berries, ${ }^{58}$ such as the olive, for

${ }^{47}$ The Ganebelone chesnut of Perigueux, Fée says, answers to this description.

${ }_{48}$ On account of the prickles on the outer shell. ${ }_{49}$ B. xvii. c. 26.

50 Fée says that the royal white chesnut of the vicinity of Perigueux answers to this.

51 "Boiling" chesnuts.

${ }_{52} \mathrm{He}$ alludes to wild or horse chesnuts, probably.

${ }^{53}$ See B. xiii. c. 16.

54 This skin is not eatable. It is fibrous and astringent.

55 In B. xvi. c. 6.

56 "Acinis." The grape, ivy-berry, elder-berry, and others.

57 "Inter cutem succumque."

58 Baccis. Some confusion is created by the non-existence of English 
instance! In the flesh of the mulberry there is a juice of a vinous flavour, and the fruit assumes three different colours, being at first white, then red, and ripe when black. The mulberry blossoms one of the very last, ${ }^{59}$ and yet is among the first to ripen : the juice of the fruit, when ripe, will stain the hands, but that of the unripe fruit will remove the marks. It is in this tree that human ingenuity has effected the least improvement $t^{60}$ of all; there are no varieties here, no modifications effected by grafting, nor, in fact, any other improvement except that the size of the fruit, by careful management, has been increased. At Rome, there is a distinction made between the mulberries of Ostia and those of Tusculum. A variety grows also on brambles, but the flesh of the fruit is of a very different nature. ${ }^{61}$

\section{CHAP. 28.-THE FRUTT OF THE ARBUTUS.}

The flesh of the ground-strawberry ${ }^{62}$ is very different to that of the arbute-tree, ${ }^{63}$ which is of a kindred kind : indeed, this is the only instance in which we find a similar fruit growing upon a tree and on the ground. The tree is tufted and bushy; the fruit takes a year to ripen, the blossoms of the young fruit flowering while that of the preceding year is arriving at maturity. Whether it is the male tree or the female that is unproductive, authors are not generally agreed.

This is a fruit held in no esteem, in proof of which it has

words to denote the difference between "acinus" and "bacca." The latter is properly the "berry ;" the grape being the type of the "acinus."

59 See B. xvi. c. 41 . The mulberry is the Morus nigra of modern naturalists. It is generally thought that this was the only variety known to the ancients; but Fée queries, from the story of Pyramus and Thisbe, which represents the mulberry as changing from white to blood colour, that the white mulberry was not unknown to them; but through some cause, now unknown, was gradually lost sight of.

60 This is still the case with the mulberry.

${ }^{61}$ See B. xvi. c. 71, and B. xxiv. c. 73. He alludes to the blackberry.

62 The common strawberry, the Fragaria vesca of Linnæus. See B. xxi. c. 50. A native of the Alps and the forests of Gaul, it was unknown to the Greeks.

63 The Arbutus unedo of Linnæus. It is one of the ericaceous trees, and its fruit bears a considerable resemblance to the strawberry-otherwise there is not the slightest affinity between them. The taste of the arbute is poor indeed, compared to that of the strawberry. 
gained its name of " unedo," ${ }^{44}$ people being generally content with eating but one. The Greeks, however, have found for it two names-" comaron" and "memecylon," from which it would appear ${ }^{65}$ that there are two varieties. It has also with us another name besides that of " unedo," being known also as the "arbutus." Juba states that in Arabia this tree attains the height of fifty cubits.

\section{CHAP. 29.-THE RELATIVE NATURES OF BERRY FRUITS.}

There is a great difference also among the various acinus fruits. First of all, among the grapes, we find considerable difference in respect to their firmness, the thinness or thickness of the skin, and the stone inside the fruit, which in some varieties is remarkably small, and in others even double in number : these last producing but very little juice. Very different, again, are the berries of the ${ }^{1} \mathrm{jy}^{67}$ and the elder $;^{68}$ as also those in the pomegranate, ${ }^{69}$ these being the only ones that are of an angular shape. These last, also, have not a membrane for each individual grain, but one to cover them all in common, and of a pale colour. All these fruits consist, too, of juice and flesh, and those more particularly which have but small seeds inside.

There are great varieties, too, among the berry ${ }^{70}$ fruits; the berry of the olive being quite different from that of the laurel, the berry of the lotus ${ }^{71}$ from that of the cornel, and that of the myrtle from the berry of the lentisk. The berry, however, of the aquifolium ${ }^{72}$ and the thorn ${ }^{73}$ is quite destitute of juice.

The cherry ${ }^{74}$ occupies a middle place between the berry and the acinus fruit: it is white at first, which is the case also

64 He suggests that it is so called from " unum edo," "I eat but one;" a rather fanciful etymology, it would seem.

65 This supposition is not warranted, from merely the fact of there being two names.

${ }^{68}$ See B. xxiv. c. 35 .

70 "Baccis." Berries, properly so called.

67 See B. xvi. c. 52.

69 See B. xiii. c. 34 .

71 The Celtis Australis of Linnæus.

72 Supposed by some to be the holly. See B. xxv. c. 72.

73 He alludes to a variety of the cratægus.

74 The Cerasus vulgaris of modern botanists. It is said to have obtained its name from Cerasus, in Asia Minor, where Lucullus found it.

VOL. III. 
with nearly all the berries. From white, some of the berries pass, to green, the olive and the laurel, for instance; while in the mulberry, the cherry, and the cornel, the change is to red; and then in some to black, as with the mulberry, the cherry, and the olive, for instance.

CHAP. 30. (25.) - NINE VARIETIES OF THE CHERRY.

The cherry did not exist in Italy before the period of the victory gained over Mithridates by L. Lucullus, in the year of the City 680 . He was the first to introduce this tree from Pontus, and now, in the course of one hundred and twenty years, it has travelled beyond the Ocean, and arrived in Britannia even. The cherry, as we have already stated, ${ }^{75}$ in spite of every care, it has been found impossible to rear in Egypt. Of this fruit, that known as the "Apronian" 76 is the reddest variety, the Lutatian ${ }^{77}$ being the blackest, and the Cæcilian ${ }^{78}$ perfectly round. The Junian ${ }^{79}$ cherry has an agreeable flavour, but only, so to say, when eaten beneath the tree, as they are so remarkably delicate that they will not bear carrying. The highest rank, however, has been awarded to the duracinus ${ }^{80}$ variety, known in Campania as the "Plinian" 81 cherry, and in Belgica to the Lusitanian ${ }^{82}$ cherry, as also to one that grows on the banks of the Rhenus. This last kind has a third colour, being a mixture ${ }^{83}$ of black, red, and green, and has always the appearance of being just on the turn to ripening. It is less than five years since the kind known as the "laurelcherry" was introduced, of a bitter but not unpleasant flavour,

$75 \mathrm{He}$ must allude to what he has stated in B. xii. c. 3, for he has nowhere said that the cherry will not grow in Egypt. It is said that the cherry is not to be found in Egypt at the present day.

${ }_{76}$ The gnotte cherry of the French, the mazzard of the English.

77 A variety of the mazzard, Fée thinks.

78 Some take this for the Cerasus Juliana, the guignier of the French, our white heart; others, again, for the merisier, our morello

79 It is most generally thought that this is the Cerasus avium of botanists, our morello, which is a very tender cherry.

${ }^{80}$ Or " hard berry," the Prunus bigarella of Linnæus, the red bigaroon.

81 Fée queries whether it may not have received its name of "Pliniana" in compliment to our author, or one of his family.

82 Hardouin thinks that this Portuguese cherry is the griotte, or mazzard.

${ }_{83}$ No such cherry is known at the present day. 
the produce of a graft $^{84}$ upon the laurel. The Macedonian cherry grows on a tree that is very small, ${ }^{85}$ and rarely exceeds three cubits in height; while the chamæcerasus ${ }^{86}$ is still smaller, being but a mere shrub. The cherry is one of the first trees to recompense the cultivator with its yearly growth ; it loves cold localities and a site exposed to the north. ${ }^{87}$ The fruit are sometimes dried in the sun, and preserved, like olives, in casks.

CHAP. 31. (26.) 一THE CORNEL. THE LENTISK.

The same degree of care is expended also on the cultivation of the cornel ${ }^{88}$ and the lentisk ; ${ }^{89}$ that it may not be thought, forsooth, that there is anything that was not made for the craving appetite of man! Various flavours are blended together, and one is compelled to please our palates by the aid of another-hence it is that the produce of different lands and various climates are so often mingled with one another. For one kind of food it is India that we summon to our aid, and then for another we lay Egypt under contribution, or else Crete, or Cyrene, every country, in fact : no, nor does man stick at poisons ${ }^{90}$ even, if he can only gratify his longing to devour everything: a thing that will be still more evident when we come to treat of the nature of herbs.

CHAP. 32. (27.) - THIRTEEN DIFFERENT FLAVOURS OF JUICES.

While upon this subject, it may be as well to state that there are no less than thirteen different flavours ${ }^{91}$ belonging

84 Such a graft is impossible; the laurel-cherry must have had some other origin.

${ }^{85}$ Fée suggests that this may be the early dwarf cherry.

36 Or "ground-cherry;" a dwarf variety, if, indeed, it was a eherry-tree at all, of which Fée expresses some doubt.

${ }^{87}$ This explains, Fée says, why it will not grow in Egypt.

88 The Cornus mas of Linnæus. The fruit of the cornel has a tart flavour, but is not eaten in modern Europe, except by school-boys.

89 That produces mastich. See B. xii. c. 36 .

$90 \mathrm{He}$ alludes more especially, perhaps, to the use of cicuta or hemlock by drunkards, who looked upon it as an antidote to the effects of wine. See B. xiv. c. 7.

91 Fée remarks, that in this enumeration there is no method. Linnæus enumerates eleven principal flavours in the vegetable kingdom-dry or insipid, aqueous, viscous, salt, acrid, styptic, sweet, fat, bitter, acid, and nauseous ; these terms, howrever seem, some of them, to be very indefinite. 
in common to the fruits and the various juices: the sweet, the luscious, the unctuous, the bitter, the rough, the acrid,,$^{92}$ the pungent, the sharp, the sour, and the salt; in addition to which, there are three other kinds of flavours of a nature that is truly singular. The first of these last kinds is that flavour in which several other flavours are united, as in wine, for in. stance; for in it we are sensible of the rough, the pungent, , $^{93}$ and the luscious, all at the same moment, and all of them flavours that belong to other substances. The second of these flavours is that in which we are sensible at the same instant of a flavour that belongs to another substance, and yet of one that is peculiar to the individual object of which we are tasting, such as that of milk, for instance: indeed, in milk we cannot correctly say that there is any pronounced flavour that is either sweet, or unctuous, or luscious, a sort of smooth taste ${ }^{94}$ in the mouth being predominant, which holds the place of a more decided flavour. The third instance is that of water, which has no flavour whatever, nor, indeed, any flavouring principle $;^{95}$ but still, this very absence of flavour is considered as constituting one of them, and forming a peculiar class ${ }^{96}$ of itseif ; so much so, indeed, that if in water any taste or flavouring principle is detected, it is looked upon as impure.

In the perception of all these various flavours the smell plays a very considerable ${ }^{97}$ part, there being a very great affinity between them. Water, however, is properly quite inodorous : and if the least smell is to be perceived, it is not pure water. It is a singular thing that three of the principal elements ${ }^{98}$ of Nature-water, air, and fire-should have neither taste nor smell, nor, indeed, any flavouring principle whatever.

92 It requires considerable discernment to appropriate nicely its English synonym to these four varieties of tastes, "acer, acutus, acerbus, and acidus," more especially when we find that the "bitter" and the "rough" are occupied already by the "amarus" and the "austerus."

${ }^{93}$ In allusion, probably, to the pungency of the aroma or bouquet.

94 Lenitate.

${ }_{95}$ This seems to be the meaning of "succus."

96 The "insipid."

97 This is so much the case, that the most nauseous medicine may be taken almost with impunity - so far as taste is concerned-by tightly pressing the nostrils while taking it.

98 Fée remarks that this is true of fire, and of distilled or perfectly pure water; but that physiologists are universally agreed that the air has its own peculiar smell. 
CHAP. 33. (28.) - THE COLOUR AND SMELL OF JUICES.

Among the juices, those of a vinous ${ }^{99}$ flarour belong to the pear, the mulberry, and the myrtle, and not to the grape, a very singular fact. An unctuous taste is detected in the olive, ${ }^{1}$ the laurel, the walnut, and the almond; sweetness exists in the grape, the fig, and the date; while in the plum class we find a watery ${ }^{2}$ juice. There is a considerable difference, too, in the colours assumed by the various juices. That of the mulberry, the cherry, the cornel, and the black grape resembles the colour of blood, while in the white grape the juice is white. The humour found in the summit of the $\mathrm{fig}^{3}$ is of a milky nature, but not so with the juice found in the body of the fruit. In the apple it is the colour of foam, ${ }^{4}$ while in the peach it is perfectly colourless, and this is the case, too, with the duracinus, ${ }^{5}$ which abounds in juice; for who can say that he has ever detected any colour in it?

Smell, too, presents its own peculiar marvels; in the apple it is pungent, ${ }^{6}$ and it is weak in the peach, while in the sweet 7 fruits we perceive none at all: so, too, the sweet wines are inodorous, while the thinner ones have more aroma, and are much sooner fit for use than those of a thicker nature. ${ }^{8}$ The odoriferous fruits are not pleasing to the palate in the same degree, seeing that the flavour ${ }^{9}$ of them does not come up to their smell: hence it is that in the citron we find the smell

99 All fruits that are rich in sugar and amidine, Fée says, either have; or acquire in time, a vinous flavour, by the development of a certain quantity of alcohol.

1 In the fruit with a fixed oil, this principle succeeds, when they are ripe, to the mucilaginous.

${ }_{2}^{2}$ He must mean a thinner juice, though still sweet.

3 About the peduncle or stalk of the fig. The juice here, Fée says, is a real sugar, of the same nature as that which circulates throughout the whole fruit: the juice in the interior of which is produced by another order of vessels.

4 The juice is only foamy when the vinous fermentation is established. It has that appearance, however, when the fruit is bitten with the teeth.

5 The "hard-berry," or nectarine.

6. In the sense of aromatic, or penetrating.

7 He probably means those of a luscious or sirupy nature, without any acidity whatever.

$8 \mathrm{He}$ seems to mean that the thick, luscious wines require longer keeping, before they will gain any aroma at all. This would be done, probably, at the expense of their sweetness.

9 Or he may mean, that a fine flavour and a fine smell cannot co-exist. 
so extremely penetrating, ${ }^{10}$ and the taste sour in the highest degree. Sometimes the smell is of a more delicate ${ }^{11}$ nature, as in the quince, for instance; while the fig has no odour whatever.

\section{CHAP. 34.-THE VARIOUS NATURES OF FRUIT.}

Thus much, then, for the various classes and kinds of fruit: it will be as well now to classify their various natures within a more limited scope. Some fruits grow in a pod which is sweet itself, and contains a bitter seed: whereas in most kinds of fruit the seed is agreeable to the palate, those which grow in a pod are condemned. Other fruits are berries, with the stone within and the flesh without, as in the olive and the cherry: others, again, have the berry within and the stone without, the case, as we have already stated, with the berries that grow in Egypt. ${ }^{22}$

Those fruits, known as "pomes," have the same characteristics as the berry fruits; in some of them we find the body of the fruit within and the shell without, as in the nut, for example; others, again, have the meat of the fruit without and the shell within, the peach and the plum, for instance: the refuse part being thus surrounded with the flesh, while in other fruits the flesh is surrounded by the refuse part. ${ }^{13}$

nuts are enclosed in a shell, chesnuts in a skin; in chesnuts the skin is taken off, but in medlars it is eaten with the rest. Acorns are covered with a crust, grapes with a husk, and pomegranates with a skin and an inner membrane. The mulberry is composed of flesh and juice, while the cherry consists of juice and skin. In some fruits the flesh separates easily from the woody part, the walnut and the date, for instance; in others it adheres, as in the case of the olive and the laurel berry: some kinds, again, partake of both natures, the peach, for example; for in the duracinus ${ }^{14}$ kind the flesh adheres to the stone, and cannot be torn away from it, while in the other

10 The reading here should be "acutissimus," probably, instead of "acerrimus." The odour exists in the rind of the citron and in the outer coat of the quince; if these are removed, the fruit becomes inodorous.

11 "Tenuis." He may possibly mean "faint."

12 The fruit of the ben, or myrobalanus, the Balanites Esgyptiaca. See B. xiii. cc, 17 and 19 .

13 Vitium.

14 IIard-berry or nectarine. See c. 11. 
sorts they are easily separated. In some fruits there is no stone or shell ${ }^{15}$ either within or without, one variety of the date, ${ }^{16}$ for instance. In some kinds, again, the shell is eaten, just the same as the fruit; this we have already mentioned as being the case with a variety of the almond found in Egypt. ${ }^{17}$ Some fruits have on the outside a twofold refuse covering, the chesnut, the almond, and the walnut, for example. Some, again, are composed of three separate parts-the body of the fruit, then a woody shell, and inside of that a kernel, as in the peach.

Some fruits grow closely packed together, such as grapes and sorbs: these last, just like so many grapes in a cluster, cling round the branch and bend it downwards with their weight. On the other hand, some fruits grow separately, at a distance from one another; this is the case with the peach. Some fruits are enclosed in a sort of matrix, as with the grains of the pomegranate: some hang down from a stalk, such as the pear, for instance: others hang in clusters, grapes and dates, for example. Others, again, grow upon stalks and bunches united: this we find the case with the berries of the ivy and the elder. Some adhere close to the branches, like the laurel berry, while other varieties lie close to the branch or hang from it, as the case may be: thus we find in the olive some fruit with short stalks, and others with long. Some fruits grow with a little calyx at the top, the pomegranate, for example, the medlar, and the lotus ${ }^{18}$ of Egypt and the Euphrates.

Then, too, as to the various parts of fruit, they are held in different degrees of esteem according to their respective recommendations. In the date it is the flesh that is usually liked, in those of Thebais it is the crust $;^{19}$ the grape and the caryota date are esteemed for their juice, the pear and the apple for their firmness, the melimelum ${ }^{20}$ for its soft meat,

15 Lignum : literally, "wood." "There is no wood, either within or without." He has one universal name for what we call shell, seed, stones, pips, grains, \&c.

16 "The "spado," or " eunuch" date. See B. xiii. c. 8.

17 See B. xiii. c. 17. The fruit of the ben is alluded to, but, as Fée observes, Pliny is wrong in calling it an almond, as it is a pulpy fruit.

18 The Nymphæa nelumbo of Linnæus.

19 Or shell, which, as Fée remarks, participates but very little in the properties of the flesh.

${ }_{20}$ Or "honey" apple; see c. 15 of this Book. 
the mulberry for its cartilaginous consistency, and nuts for their kcrnels. Some fruits in Egypt are esteemed for their skin; the carica ${ }^{21}$ for instance. This skin, which in the green fig is thrown away as so much refuse peeling, when the fig is dried is very highly esteemed. In the papyrus, ${ }^{22}$ the ferula ${ }^{23}$ and the white thorn ${ }^{24}$ the stalk itself constitutes the fruit, and the shoots of the fig-tree ${ }^{25}$ are similarly employed.

Among the shrubs, the fruit of the caper ${ }^{26}$ is eaten along with the stalk; and in the carob, ${ }^{27}$ what is the part that is eaten but so much wood? Nor ought we to omit one peculiarity that exists in the seed of this fruit-it can be called neither flesh, wood, nor cartilage, and yet no other name has been found for it.

CHAP. 35. (29).-THE MYYRTLE.

The nature of the juices that are found in the myrtle are particularly remarkable, for it is the only on $\mathrm{e}^{28}$ of all the trees, the berries of which produce two kinds of oil ${ }^{29}$ as well as of wine, besides myrtidanum, ${ }^{30}$ of which we have already spoken. The berry of this was also put to another use in ancient times, for before pepper ${ }^{31}$ was known it was employed in place of it as a seasoning; so much so, indeed, that a name has been derived from it for the highly-seasoned dish which to this day is known by the name of " myrtatum." 32 It is by the aid of these berries, too, that the flavour of the flesh of the wild boar is improved, and they generally form one of the ingredients in the flavouring of our sauces.

CHAP. 36.-HISTORICAL ANECDOTES RELATIVE TO THE MYRTLE.

This tree was seen for the first time in the regions of ${ }^{21}$ Or "Carian" fig. See c. 19 of this Book.

22 See B. xiii. c. 11 .

${ }^{23}$ See B. xiii. c. 42 , and B. xx. cc. 9 and 23.

${ }^{24}$ See B. xiii. c. 26 , and B. xxiv. c. 66 .

${ }^{25}$ See B. xiii. c. 22. Fée remarks that it is singular how the ancients could eat the branches of the fig-tree, the juice being actually a poison.

26 See B. xiii. c. $44 . \quad 27$ See c. 26 of this Book.

${ }^{28} \mathrm{He}$ is wrong : the same is the case with the berries of the laurel, and, indeed, many other kinds of berries.

29 See c. 7 of this Book.

31 See B. xii. c. 14.

30 See B. xiv. c. 9.

32 A kind of sausage, seasoned with myrtle. See also B. xxvii c. 49. 
Europe, which commence on this side of the Ceraunian mountains ${ }^{33}$ growing at Circeii ${ }^{34}$ near the tomb of Elpenor there : ${ }^{35}$ it still retains its Greek ${ }^{36}$ name, which clearly proves it to be an exotic. There were myrtles growing on the site now occupied by Rome, at the time of its foundation; for a tradition exists to the effect that the Romans and the Sabines, after they had intended fighting, on account of the virgins who had been ravished by the former, purified themselves, first laying down their arms, with sprigs of myrtle, on the very same spot which is now occupied by the statues of Venus Cluacina; for in the ancient language " cluere" means to purify.

This tree is employed, too, for a species of fumigation $;^{37}$ being selected for that purpose, because Venus, who presides over all unions, is the tutelary divinity of the tree. ${ }^{38} \mathrm{I}$ am not quite sure, too, whether this tree was not the very first that was planted in the public places of Rome, the result of some ominous presage by the augurs of wondrous import. For at the Temple of Quirinus, or, in other words, of Romulus himself, one of the most ancient in Rome, there were formerly two myrtle-trees, which grew for a long period just in front of the temple; one of these was called the Patrician tree, the other the Plebeian. The Patrician myrtle was for many years the superior tree, full of sap and vigour; indeed, so long as the Senate maintained its superiority, so did the tree, being of large growth, while the Plebeian tree presented a meagre, shrivelled appearance. In later times, however, the latter tree gained the superiority, and the Patrician myrtle began to fail just at the period of the ${ }^{39}$ Marsic War, ${ }^{40}$ when the power of the Senate was so greatly weakened: and little by little did this once majestic tree sink into a state of utter exhaustion and sterility. There was an ancient altar ${ }^{41}$ also, consecrated

${ }^{33} \mathrm{He}$ means the Acroceraunian chain in Epirus, mentioned in B. iii.

${ }^{34}$ See B. iii. c. 9.

${ }^{35}$ He was one of the companions of Ulysses, fabled by Homer and Ovid to have been transformed by Circe into a swine.

${ }^{36}$ Mupoiz $\eta$ was its Greek name. ${ }^{37}$ See B. xxv. c. 59.

${ }_{38}$ See B. xii. c. 2. Ovid, Fasti, B. iv.1. 15, et seq., says that Venus concealed herself from the gaze of the Satyrs behind this tree.

${ }^{39}$ Either this story is untrue, or we have a right to suspect that some underhand agency was employed for the purpose of imposing on the superstitious credulity of the Roman people.

${ }_{40}$ Or Social War. See B. ii. c. 85 .

${ }^{41}$ Near the altar of Consus, close to the meta of the Circus. 
to Venus Myrtea, known at the present day by the name of Murcia.

\section{CHAP. 37.- ELEVEN VARIETIES OF THE MYRTLE.}

Cato ${ }^{42}$ makes mention of three varieties of the myrtle, the black, white, and the conjugula, perhaps so called from its reference to conjugal unions, and belonging to the same species as that which grew where Cluacina's statues now stand : at the present day the varieties are differently distinguished into the cultivated and the wild ${ }^{43}$ myrtle, each of which includes a kind with a large leaf. The kind known as "oxymyrsine," gardeners classify several varieties of the cultivated kind; the "Tarentine," ${ }^{45}$ they speak of as a myrtle with a small leaf, the myrtle of this country ${ }^{46}$ as having a broad leaf, and the hexasticha ${ }^{47}$ as being very thickly covered with leaves, growing in rows of six : it is not, however, made any use of. There are two other kinds, that are branchy and well covered. In my opinion, the conjugula is the same that is now called the Roman myrtle. It is in Egypt that the myrtle is most odoriferous.

Cato $^{48}$ has taught us how to make a wine from the black myrtle, by drying it thoroughly in the shade, and then putting it in must: he says, also, that if the berries are not quite dry, it will produce an oil. Since his time a method has been discovered of making a pale wine from the white variety; two sextarii of pounded myrtle are steeped in three semi-sextarii of wine, and the mixture is then subjected to pressure.

The leaves ${ }^{49}$ also are dried by themselves till they are capable of being reduced to a powder, which is used for the treatment of sores on the human body: this powder is of a slightly corrosive nature, and is employed also for the purpose of checking the perspiration. A thing that is still more re-

${ }_{42}$ De Re Rust. c. 8 ,

${ }^{43}$ The so-called wild myrtle does not in reality belong to the genus Myrtus.

${ }_{44}$ See B.xxiii. c. 83; the Ruscus aculeatus of the family of the Asparagea.

45 The common myrtle, Myrtus communis of the naturalists.

46 Or Roman myrtle, a variety of the Myrtus communis.

${ }_{47}$ The "six row" myrtle. Fée thinks that it belongs to the Myrtus angustifolia Botica of Bauhin.

is De Re Rust. 125.

49 See B. xxili. c. 81. 
markable, this oil is possessed of a certain vinous flavour, being, at the same time, of an unctuous nature, and remarkably efficacious for improving ${ }^{50}$ wines. When this is done, the wine strainer ${ }^{51}$ is dipped in the oil before it is used, the result of which is that it retains the lees of the wine, and allows nothing but the pure liquor to escape, while at the same time it accompanies the wine and causes a marked improvement in its flavour.

Sprigs of myrtle, if carried by a person when travelling on foot, are found to be very refreshing ${ }^{52}$ on a long journey. Rings, too, made of myrtle which has never been touched by iron, are an excellent specific for swellings in the groin. ${ }^{53}$

\section{CHAP. 38.-THE MYRTLE USED AT ROME IN OVATIONS.}

The myrtle has played ${ }^{54}$ its part, also, in the successes of war. Posthumius Tubertus, who gained a victory over the Sabines in his consulship, ${ }^{55}$ was the first person who entered the City enjoying the honour of an ovation, ${ }^{56}$ for having achieved this success with ease and without bloodshed: upon which occasion he made his entry crowned with the myrtle of Venus Victrix, and thereby rendered her tree an object of regard $^{57}$ to our enemies even. Ever since this occasion, the wreath of those who have enjoyed an ovation has been made of myrtle, with the exception of M. Crassus, ${ }^{58}$ who, on his victory over the fugitive slaves and Spartacus, made his entry crowned with laurels. Massurius informs us, also, that some generals, on the occasion of a triumph even, have worn a wreath of myrtle in the triumphal car. L. Piso states that

${ }^{50}$ A new proof, as Fée remarks, that the ancients had peculiar notions of their own, as to the flavour of wine; myrtle berries, he says, would impart to wine a detestable aromatic flavour.

51 "Saccis :" the strainer being made of cloth. See B. xiv. e. 28.

${ }^{52}$ They would be of no assistance whatever, and this statement is entirely fictitious.

${ }_{53}$ He may possibly mean hernia.

54 In addition to all those particulars, he might have stated that the Lares, or household gods, were crowned with myrtle, and that it was not allowed to enter the Temple of Bona Dea.

${ }_{55}$ A.U.c. 251.

56 See the Notes to c. 35 of this Book.

57 Because the enemy would be less likely to envy us a bloodless triumph.

$58 \mathrm{He}$ disdained the more humble myrtle crown, and intrigued successfully with the Senate to allow him to wear a wreath of laurel. 
Papirius Maso, who was the first to enjoy a triumph for a victory over the Marsi-it was on the Alban Mount ${ }^{59}$-was in the habit of attending at the games of the Circus, wearing a wreath of myrtle: he was the maternal grandfather of the second Scipio Africanus. Marcus Valerius ${ }^{60}$ wore two wreaths, one of laurel, the other of myrtle; it was in consequence of a vow which he had made to that effect.

\section{CHAP. 39. (30.) -THE LAUREL; THIRTEEN VARIETIES OF IT.}

The laurel is especially consecrated to triumphs, is remarkably ornamental to houses, and guards the portals of our emperors ${ }^{61}$ and our pontiffs: there suspended alone, it graces the palace, and is ever on guard before the threshold. Cato ${ }^{62}$ speaks of two varieties of this tree, the Delphic ${ }^{63}$ and the Cyprian. Pompeius Lenæus has added another, to which he has given the name of " mustax," from the circumstance of its being used for putting under the cake known by the name of "mustaceum. ${ }^{6 *}$ " He says that this variety has a very large leaf, flaccid, and of a whitish hue; that the Delphic laurel is of one uniform colour, greener than the other, with berries of rery large size, and of a red tint approaching to green. He says, too, that it is with this laurel that the victors at Delphi ${ }^{65}$ are crowned, and warriors who enjoy the honours of a triumph at Rome. The Cyprian laurel, he says, has a short leaf, is of a blackish colour, with an imbricated ${ }^{66}$ edge, and crisped.

59 The Senate refused him a triumph; and he accordingly celebrated one on the Alban Mount, B.c. 231. Paulus Diaconus says that his reason for wearing a myrtle crown was his victory over the Corsicans on the Myrtle Plains, though where they were, or what victory is alluded to, is not known.

60 The brother of Valerius Publicola.

61 We learn from two passages in Ovid that the laurel was suspended over the gates of the emperors. This, as Fée remarks, was done for two reasons : because it was looked upon as a protection against lightning, and because it was considered an emblem of immortality.

62 De Re Rust. 133.

63 Or "laurel of Apollo :" it was into this tree that Daphne was fabled to have been changed. See Ovid's Met. B. i. 1. 557, et seq.

61 Cato, De Re Rust.c. 121, tells us that this cake was made of fine wheat, must, anise, cummin, suet, cheese, and scraped laurel sprigs. Laurel leaves were placed under it when baked. This mixture was considered a light food, good for the stomach !

${ }_{65}$ At the Pythian Games celebrated there.

66 Meaning that it curves at the edge, something like a pent-house. 
Since his time, however, the varieties have considerably augmented. There is the tinus ${ }^{67}$ for instance, by some considered as a species of wild laurel, while others, again, regard it as a tree of a separate class; indeed, it does differ from the laurel as to the colour, the berry being of an azure blue. The royal ${ }^{68}$ laurel, too, has since been added, which has of late begun to be known as the "Augustan:" both the tree, as well as the leaf, are of remarkable size, and the berries have not the usual rough taste. Some say, however, that the royal laurel and the Augustan are not the same tree, and make out the former to be a peculiar kind, with a leaf both longer and broader than that of the Augustan. The same authors, also, make a peculiar species of the bacalia the commonest laurel of all, and the one that bears the greatest number of berries. With them, too, the barren laurel ${ }^{69}$ is the laurel of the triumphs, and they say that this is the one that is used by warriors when enjoying a triumph $-\mathrm{a}$ thing that surprises me very much; unless, indeed, the use of it was first introduced by the late Emperor Augustus, and it is to be considered as the progeny of that laurel, which, as we shall just now have occasion to mention, was sent to him from heaven; it being the smallest of them all, with a crisped ${ }^{70}$ short leaf, and very rarely to be met with.

In ornamental gardening we also find the taxa ${ }^{71}$ employed, with a small leaf sprouting from the middle of the leaf, and forming a fringe, as it were, hanging from it; the spadonia, ${ }^{72}$ too, without this fringe, a tree that thrives remarkably well in the shade: indeed, however dense the shade may be, it will soon cover the spot with its shoots. There is the chamædaphne, ${ }^{73}$ also, a shrub that grows wild; the Alexandrian ${ }^{74}$

67 Or tine tree, the Viburnum tinus of Linnæus, one of the caprifolia. It is not reckoned as one of the laurels, though it has many of the same characteristics. 68 Regia.

69 The barren laurel of the triumphs was the Laurus nobilis of Linnæus, which has only male flowers.

${ }^{70}$ The Laurus vulgaris folio undulato of the Parisian Hortus, Fée says.

71 Not a laurel, nor yet a dicotyledon, Fée says, but one of the Asparagea, probably the Ruscus hypoglossum of Linnæus, sometimes known, however, as the Alexandrian laurel.

${ }^{72}$ Or "eunuch" laurel; a variety, probably, of the Laurus nobilis.

73 The "ground laurel :" according to Sprengel, this is the Ruscus racemosus of Linnæus. See B. xxiv. c. 81 .

${ }^{74}$ From Alexandria in Troas : the Ruscus hypophyllum of Linnæus, it is supposed. 
laurel, by some known as the Idean, by others as the " hypoglottion,", 75 by others as the "carpophyllon," 76 and by others, again, as the "hypelates."' "Fr From the root it throws out branches three quarters of a foot in length; it is much used in ornamental gardening, and for making wreaths, and it has a more pointed leaf than that of the myrtle, and superior to it in softness, whiteness, and size : the seed, which lies between the leaves, is red. This last kind grows in great abundance on Mount Ida and in the vicinity of Heraclea in Pontus: it is only found, however, in mountainous districts.

The laurel, too, known as the daphnoides, ${ }^{78}$ is a variety that has received many different names: by some it is called the Pelasgian laurel, by others the euthalon, and by others the stephanon Alexandri. ${ }^{79}$ This is also a branchy shrub, with a thicker and softer leaf than that of the ordinary laurel: if tasted, it leavies a burning sensation in the mouth and throat: the berries are red, inclining to black. The ancient writers have remarked, that in their time there was no species of laurel in the island of Corsica. Since then, however, it has been planted there, and has thrived well.

CHAP. 40. - HISTORICAL ANECDOTES CONNECTED WITH THE LAUREL.

This tree is emblematical of peace $:^{80}$ when a branch of it is extended, it is to denote a truce between enemies in arms. For the Romans more particularly it is the messenger of joyful tidings, and of victory: it accompanies the despatches ${ }^{81}$ of the general, and it decorates the lances and javelins of the soldiers and the fasces which precede their chief. It is of this tree that branches are deposited on the lap of Jupiter All-good and All-great, ${ }^{82}$ so often as some new victory has imparted uni-

75 "The tongue below." This, Fee justly says, would appear to be a morc appropriate name for the taxa, mentioned above.

${ }^{76}$ From the berry being attached to the leaf.

77 "The thrower out from below," perhaps.

78 Sprengel thinks that it is the Clematis vitalba of Linnæus. Fuchsius identifies it with the Daphne laureola of Linnæus ; and Fée thinks it may be either that or the Daphne mezereum of Linnæus.

79 "Crown of Alexander."

80 Curiously enough, it is generally considered now more suggestive of war than of peace.

81 The despatches were wrapped in laurel leaves.

82 Optimus Maximus. 
versal gladness. This is done, not because it is always green, nor yet because it is an emblem of peace-for in both of those respects the olive would take the precedence of it-but because it is the most beauteous tree on Mount Parnassus, and was pleasing for its gracefulness to Apollo even; a deity to whom the kings of Rome sent offerings at an early period, as we learn from the case of L. Brutus. ${ }^{83}$ Perhaps, too, honour is more particularly paid to this tree because it was there that Brutus $^{84}$ earned the glory of asserting his country's liberties, when, by the direction of the oracle, he kissed that laurelbearing soil. Another reason, too, may be the fact, that of all the shrubs that are planted and received in our houses, this is the only one that is never struck by lightning. ${ }^{85}$ It is for these reasons, in my opinion, that the post of honour has been awarded to the laurel more particularly in triumphs, and not, as Massurius says, because it was used for the purposes of fumigation and purification from the blood of the enemy.

In addition to the above particulars, it is not permitted to defile the laurel and the olive by applying them to profane uses; so much so, indeed, that, not even for the propitiation of the divinities, should a fire be lighted with them at either altar or shrine. ${ }^{86}$ Indeed, it is very evident that the laurel protests against such usage by crackling ${ }^{87}$ as it does in the fire, thus, in a manner, giving expresssion to its abhorrénce of such treatment. The wood of this tree when eaten is good as a specific for internal maladies and affections of the sinews. ${ }^{98}$

It is said that when it thundered, the-Emperor Tiberius was

${ }^{83} \mathrm{~L}$. Junius Brutus, the nephew of Tarquin. Pliny alludes to the message sent to Delphi, for the purpose of consulting the oracle on a serpent being seen in the royal palace.

84 He alludes to the circumstance of the priestess being asked who should reign at Rome after Tarquin; upon which she answered, "He who first kisses his mother ;" on which Brutus, the supposed idiot, stumbled to the ground, and kissed the earth, the mother of all.

${ }^{85}$ A mere absurdity; the same has been said of the beech, and with equal veracity.

86 He makes a distinction between "altar" and "ara" here. The former was the altar of the superior Divinities, the latter of the superior and inferior as well.

87 The crackling of the laurel is caused by efforts of the essential oil to escape from the parenchyma or cellular tissue of the leaf, which it breaks with considerable violence when burning.

ss Nervorum. See B. xxiii. c. 80. 
in the habit of putting on a wreath of laurel to allay his apprehensions of disastrous effects from the lightning. ${ }^{89}$ There are also some remarkable facts connected with the laurel in the history of the late Emperor Augustus: once while Livia Drusilla, who afterwards on her marriage with the Emperor assumed the name of Augusta, at the time that she was affianced to him, was seated, there fell into her lap a hen of remarkable whiteness, which an eagle let fall from aloft without its receiving the slightest injury: on Livia viewing it without any symptoms of alarm, it was discovered that miracle was added to miracle, and that it held in its beak a branch of laurel covered with berries. The aruspices gave orders that the hen and her progeny should be carefully preserved, and the branch planted and tended with religious care. This was accordingly done at the country-house belonging to the Cæsars, on the Flaminian Way, near the banks of the Tiber, eight miles from the City; from which circumstance that road has since received the title "Ad gallinas." 90 From the branch there has now arisen, wondrous to relate, quite a grove: and Augustus Cæsar afterwards, when celebrating a triumph, held a branch of it in his hand and wore a wreath of this laurel on his head; since which time all the succeeding emperors have followed his example. Hence, too, has originated the custom of planting the branches which they have held on these occasions, and we thus see groves of laurel still existing which owe their respective names to this circumstance. It was on the above occasion, too, that not improbably a change was effected in the usual laurel of the triumph. ${ }^{91}$ The laurel is the only one among the trees that in the Latin language has given an appellation to a man, ${ }^{92}$ and it is the only one the leaf of which has a distinct name of its own,-it being known by the name of "laurea." The name of this tree is still retained by one place in the city of Rome, for we find a spot on the Aventine

89 Suetonius, c. 66, confirms this. Fée says that the same superstition, still exists in some parts of France. See B. ii. c. 56.

so "The Poultry."

${ }_{91}$ See c. 39 of this Book.

92 See B. xxxi. c. 3. As Poinsinet remarks, this is not strictly true; the name "Vinucius" most probably came from "vinea," a vineyard. Numerous names were derived also from seeds and vegetables; Piso, Cicero, and Lactuca, for instance, among a host of others. "Scipio," too, means a "walking-stick." 
Mount still known by the name of "Loretum," ${ }_{93}$ where formerly a laurel-grove existed. The laurel is employed in purifications, and we may here mention, incidentally, that it will grow from slips ${ }^{94}$-though Democritus and Theophrastus have expressed their doubts as to that fact.

We shall now proceed to speak of the forest trees.

Stmmary.-Remarkable facts, narratives, and observations, one hundred and twenty.

Roman adThors QUoted. - Fenestella ${ }^{95}$ Fabianus, ${ }^{96}$ Virgil, ${ }^{97}$ Corn. Valerianus, ${ }^{98}$ Celsus, ${ }^{99}$ Cato the Censor, ${ }^{1}$ Saserna ${ }^{2}$ father and son, Scrofa, ${ }^{3}$ M. Varro, ${ }^{4}$ D. Silanus, ${ }^{5}$ Fabius Pictor, ${ }^{6}$ Trogus, ${ }^{7}$ Hyginus,${ }^{8}$ Flaccus Verrius, ${ }^{9}$ Græcinus, ${ }^{10}$ Atticus Julius, ${ }^{11}$ Columella ${ }^{12}$ Massurius Sabinus, ${ }^{13}$ Tergilla, ${ }^{14}$ Cotta Messalinus, ${ }^{15}$ L. Piso, ${ }^{16}$ Pompeius Lenæus, ${ }^{17}$ Maccius Plautus, ${ }^{18}$ Flavius, ${ }^{19}$ Dossenus, ${ }^{20}$ Scævola, ${ }^{21}$ AElius, ${ }^{22}$ Ateius Capito, ${ }^{23}$ Sextius Niger, ${ }^{24}$ Vibius Rufus. ${ }^{25}$

Foreign aUTHORS QUOTED.-Aristotle, ${ }^{26}$ Democritus, ${ }^{27}$ King Hiero, ${ }^{28}$ King Attalus Philometor, ${ }^{29}$ Archytas, ${ }^{30}$ Xenophon, ${ }^{31}$ Amphilochus ${ }^{32}$ of Athens, Anaxipolis ${ }^{33}$ of Thasos, Apollodorus ${ }^{34}$ of Lemnos, Aristophanes ${ }^{35}$ of Miletus, Antigonus ${ }^{36}$ of Cymæ,

93 The "laurel-grove."

95 See end of B. viii.

97 See end of B. vii.

99 See end of B. vii.

2 See end of B. $x$.

4 See end of B. ii.

6 See end of B. $x$.

8 See end of B. iii.

10 See end of B. xiv.

12 See end of $B$. viii.

14 See end of B. xiv.

16 See end of B. ii.

18 See end of B. xiv.

20 See end of B. xiv.

22 See end of B. xiv.

24 See end of B. xii.

26 See end of B. ii.

28 See end of B. viii.

30 See end of $\mathrm{B}$. viii.

32 See end of $B$. viii.

${ }^{34}$ See end of $B$. viii.

36 See end of $B$. viii.

VOL. III.
94 See B. xvii. c. 11.

95 See end of $\mathrm{B}$. ii.

98 See end of B. iii.

1 See end of B. iii.

3 See end of B. xi.

5 See end of B. xiv.

7 See end of B. vii.

9 See end of B. iii.

11 See end of B. xiv.

13 See end of B. vii.

15 See end of B. xiv.

17 See end of B. xiv.

19 See end of B. xii.

21 See end of B. xiv.

23 See end of B. iii.

25 See end of B. xiv.

27 See end of B. ii.

29 See end of B. viii.

31 See end of B. iv.

33 See end of B. viii.

35 See end of B. viii. 
Agathocles $^{37}$ of Chios, Apollonius ${ }^{38}$ of Pergamus, Aristander ${ }^{39}$ of Athens, Bacchius ${ }^{40}$ of Miletus, Bion ${ }^{41}$ of Soli, Chæreas ${ }^{42}$ of Athens, Chæristus ${ }^{43}$ of Athens, Diodorus ${ }^{44}$ of Priene, Dion ${ }^{45}$ of Colophon, Epigenes ${ }^{46}$ of Rhodes, Euagon ${ }^{47}$ of Thasos, Euphronius $^{48}$ of Athens, Androtion ${ }^{49}$ who wrote on Agriculture, Eschrion ${ }^{50}$ who wrote on Agriculture, Lysimachus ${ }^{51}$ who wrote on Agriculture, Dionysius ${ }^{52}$ who translated Mago, ${ }^{53}$ Diophanes $^{54}$ who made an Epitome of the work of Dionysius, Asclepiades ${ }^{55}$ the Physician, Erasistratu ${ }^{56}$ the Physician, Commiades ${ }^{57}$ who wrote on the preparation of Wines, Aristomachus ${ }^{58}$ who wrote on the same subject, Hicesius ${ }^{59}$ who wrote on the same subject, Themis $^{60}$ the Physician, Onesicritus, ${ }^{61}$ King Juba ${ }^{62}$
37 See end of B. viii.
38 See end of $B$. viii.
40 See end of $B$. viii.
42 See end of $B$. viii.
39 See end of B. viii.
41 See end of B. vi.
43 See end of B. xiv.

$44 \mathrm{He}$ is mentioned also by Varro and Columella, as a writer upon agriculture; but all further particulars of him are unknown.

45 See end of $B$. viii.

47 See end of B. $x$.

49 See end of $B$. viii.

51 See end of B. viii.

53 See end of B. viii.

55 See end of B. vii.

46 See end of B. ii.

48 See end of B. viii.

50 See end of $B$. viii.

52 See end of B. xii.

54 See end of B. viii.

56 See end of B. xi.

57 Beyond what Pliny here says, nothing is known of him.

58 See end of B. xi.

59 A physician who lived probably at the end of the first century B.c. He was a disciple of Erasistratus, and founded a medical school at Smyrna. He is quoted by Athenæus, and in B. xxvii. c. 14, Pliny calls him "a physician of no small authority." He seems to have been a voluminous writer; but none of his works have survived.

60 See end of B. xi.

62 See end of B. v.

61 See end of B. ii. 


\section{BOOK XVI.}

\section{THE NATURAL HISTORY OF THE FOREST TREES.}

\section{ChaP. 1. COUNTRIES that HAVE NO TREES.}

We have given the precedence in this account to the fruittrees and others which, by their delicious juices, first taught man to give a relish to his food and the various aliments requisite for his sustenance, whether it is that they spontaneously produce these delightful flavours, or whether we have imparted them by the methods of adoption and intermarriage, ${ }^{1}$ thus bestowing a favour, as it were, upon the very beasts and birds. The next thing, then, would be to speak of the glandiferous trees, the trees which proffered the earliest nutriment to the appetite of man, and proved themselves his fostermothers in his forlorn and savage state-did I not feel myself constrained on this occasion to make some mention of the surprise which I have felt on finding by actual experience what is the life of mortals when they inhabit a country that is without either tree or shrub.

(1.) I have already stated ${ }^{2}$ that in the East many nations that dwell on the shores of the ocean are placed in this necessitous state; and I myself have personally witnessed the condition of the Chauci, ${ }^{3}$ both the Greater and the Lesser, situate in the regions of the far North. In those climates a vast tract of land, invaded twice each day and night by the overflowing waves of the ocean, opens a question that is eternally proposed to us by Nature, whether these regions are to be looked upon as belonging to the land, or whether as forming a portion of the sea?

Here a wretched race is found, inhabiting either the more elevated spots of land, or else eminences artificially constructed, and of a height to which they know by experience that the highest tides will never reach. Here they pitch their cabins ;

1 The methods of grafting and inoculation.

2 B. xiii. c. 50 . 'They dwelt between the Ems and the Elbe.

3 See B. iv. c. 29. 
and when the waves cover the surrounding country far and wide, like so many mariners on board ship are they: when, again, the tide recedes, their condition is that of so many shipwrecked men, and around their cottages they pursue the fishes as they make their escape with the receding tide. It is not their lot, like the adjoining nations, to keep any flocks for sustenance by their milk, nor even to maintain a warfare with wild beasts, every shrub, even, being banished afar. With the sedge $^{4}$ and the rushes of the marsh they make cords, and with these they weave the nets employed in the capture of the fish ; they fashion the mud, ${ }^{5}$ too, with their hands, and drying it by the help of the winds more than of the sun, cook their food by its aid, and so warm their entrails, frozen as they are by the northern blasts; their only ${ }^{6}$ drink, too, is rainwater, which they collect in holes dug at the entrance of their abodes : and yet these nations, if this very day they were vanquished by the Roman people, would exclaim against being reduced to slavery! Be it so, then-Fortune is most kind to many, just when she means to punish them. ${ }^{8}$

CHAP. 2.-WONDERS CONNECTED WITH TREES IN THE NORTHERN REGIONS.

Another marvel, too, connected with the forests! They cover all the rest of Germany, and by their shade augment the cold. But the highest of them all are those not far distant from the Chauci already mentioned, and more particularly in the vicinity of the two lakes ${ }^{9}$ there. The very shores are lined with oaks, ${ }^{10}$ which manifest an extraordinary eagerness to

4 "Ulvâ." This appears to be a general name for all kinds of aquatic fresh-water plants; as "alga" is that of the various sea-weeds.

${ }_{5}^{5}$ He alludes to turf for firing; the Humus turfa of the naturalists.

${ }^{6}$ Of course this applies only to those who dwelt near the sea-shore, and not those more inland.

7 Guichardin remarks, that Pliny does not here bear in mind the sweets of liberty.

\& So Laberius says, "Fortuna multis parcere in pœnam solet;" "Fortune is the saving of many, when she means to punish them."

${ }_{9} \mathrm{He}$ alludes to the vicinity of the Zuyder Zee. See B. iv. c. 29. The spots where these forests once stood are now cultivated plains, covered with villages and other works of the industry of man.

10 "Quercus." We shall see, in the course of this Book, that its identity has not been satisfactorily established. 
attain their growth : undermined by the waves or uprooted by the blasts, with their entwining roots they carry vast forests along with them, and, thus balanced, stand upright as they float along, while they spread afar their huge branches like the rigging of so many ships. Many is the time that these trees have struck our fleets with alarm, when the waves have driven them, almost purposely it would seem, against their prows as they stood at anchor in the night; and the men, destitute of all remedy and resource, have had to engage in a naval combat with a forest of trees!

(2.) In the same northern regions, too, is the Hercynian ${ }^{11}$ Forest, whose gigantic oaks, ${ }^{12}$ uninjured by the lapse of ages, and contemporary with the creation of the world, by their near approach to immortality surpass all other marvels known. Not to speak of other matters that would surpass all belief, it is a well-known fact that their roots, ${ }^{13}$ as they meet together, upheave vast hills; or, if the earth happens not to accumulate with them, rise aloft to the very branches even, and, as they contend for the mastery, form arcades, like so many portals thrown open, and large enough to admit of the passage of a squadron of horse.

(3.) All these trees, in general, belong to the glandiferous class, ${ }^{14}$ and have ever been held in the highest honour by the Roman people.

\section{CHAP. 3. (4.)-THE ACORN DAK. THE CIVIC CROWN.}

It is with the leaves of this class of trees that our civic crown is made, the most glorious reward that can be bestowed on military valour, and, for this long time past, the emblem of the imperia $1^{15}$ clemency; since the time, in fact, when, after

11 See B. iv. c. 28, and the Note, Vol. i. p. 348. The village of Hercingen, near Waldsee, is supposed to retain the ancient name.

12 "Robora." It will be seen in this Book that the robur has not been identified, any more than the quercus.

13 Fée treats this story as utterly fabulous. The branches of the Ficus Indica grow downwards, and so form arcades certainly; but such is not the case with any European tree.

${ }_{14}$ Not only oaks, but a variety of other trees, were included under this name by the ancients; the "glans" embracing not only the acorn, but the mast of the beech, and the hard fruits of other trees.

${ }_{15} \mathrm{He}$ alludes to the crown of oak-leaves, which was suspended on the gates before the palace of the emperors. A civic crown had been roted by the senate to Julius Cæsar, on the ground of having saved his country. 
the impiety of civil war, it was first deemed a meritorious action not to shed the blood of a fellow-citizen. Far inferior to this in rank are the mural ${ }^{16}$ crown, the vallar, ${ }^{17}$ and the golden ${ }^{18}$ one, superior though they may be in the value of the material : inferior, too, in merit, is the rostrate ${ }^{19}$ crown, though ennobled, in recent times more particularly, by two great names, those of M. Varro, ${ }^{20}$ who was presented with it by Pompeius Magnus, for his great achievements in the Piratic War, and of M. Agrippa, on whom it was bestowed by Cæsar, at the end of the Sicilian War, which was also a war against pirates.

In former days the beaks ${ }^{21}$ of vessels, fastened in front of the tribunal, graced the Forum, and seemed, as it were, a crown placed upon the head of the Roman people itself. In later times, however, they began to be polluted and trodden under foot amid the seditious movements of the tribunes, the public interest was sacrificed to private advantage, each citizen sought solely his own advancement, and everything looked upon as holy was abandoned to profanation-still, from amid all this, the Rostra ${ }^{22}$ emerged once again, and passed from beneath the feet of the citizens to their heads. Augustus presented to Agrippa the rostrate crown, while he himself received the civic crown ${ }^{23}$ at the hands of all mankind.

\section{CHAP. 4. - THE ORIGIN OF THE PRESENTATION OF CROWNS.}

\section{In ancient times crowns ${ }^{25}$ were presented to none but a}

16 Given to the first man who scaled the wall of a besieged place. It was made of gold, and decorated with turrets.

${ }_{17}$ Given to the first soldier who surmounted the vallum or entrenchments. It was made of gold, and ornamented with "valli," or palisades.

18 One of the varieties of the triumphal crown was the "corona aurea," or " golden crown."

19 Made of gold, and decorated with the "rostra," or "beaks" of ships.

20 See B. vii. c. 31 .

21 The orator's stage in the Forum was decorated with the "rostra," or "beaks" of the ships of the Antiates; hence it received the name of "Rostrum." The locality of the Rostra was changed by Julius Cæsar.

${ }^{22}$ Alluding to the prostitution of the Rostra by the tribunes and others for the purposes of sedition, and the presentation by Augustus of the rostrate crown to Agrippa.

${ }_{23}$ Which was suspended, as already mentioned, at the gate of his palace.

25 Athenæus and Fabius Pictor say that Janus was the first wearer of a erown: Pherecydes says it was Saturn, Diodorus Siculus Jupiter, and Leo Egyptiacus Isis, who wore one of wheat. 
divinity, hence it is that Homer ${ }^{26}$ awards them only to the gods of heaven and to the entire army ; but never to an individual, however great his achievements in battle may have been. It is said, too, that Father Liber was the first of all who placed a crown on his head, and that it was made of ivy. ${ }^{27}$ In succeeding times, those engaged in sacrifices in honour of the gods began to wear them, the victims being decked with wreaths as well. More recently, again, they were employed in the sacred games $;^{28}$ and at the present day they are bestowed on such occasions, not upon the victor, indeed, but upon his country, which receives, it is proclaimed, this crown at his hands. ${ }^{29}$ Hence arose the usage of conferring wreaths upon warriors when about to enjoy a triumph, for them to consecrate in the temples: after which it became the custom to present them at our games. It would be a lengthy matter, and, indeed, foreign to the purpose of this work, to enter upon a discussion who was the first Roman that received each kind of crown; in fact, they were acquainted with none but such as were given as the reward of military prowess. It is a wellknown fact, however, that this people has more varieties of crowns than those of all other nations put together.

\section{CHAP. 5.-PERSONS PRESENTED WITH A CROWN OF LEAVES.}

Romulus presented Hostus Hostilius ${ }^{30}$ with a crown of leaves, for being the first to enter Fidenæ. This Hostus was the grandfather of King Tullus Hostilius. P. Decius the elder, the military tribune, was presented with a crown of leaves by the army which had been saved by his valour, under the com. mand of Cornelius Cossus, ${ }^{31}$ the consul, in the war with the Samnites. This crown was made at first of the leaves of the holm oak, but afterwards those of the æsculus ${ }^{32}$ were preferred, as being a tree sacred to Jupiter: this, however, was soon employed indifferently with the quercus, according as

26 Il. xiii, 736.

27 See cc. 34 and 35 of the present Book.

28 The Olympian, Pythian, Isthmian, and Nemæan games.

29 See B. vii. c. 27.

${ }^{30} \mathrm{He}$ is called Tullus Hostilius by Dionysius of Halicarnassus, the same as his grandson.

31 A.U.c. 411. The leaves of the holm-oak were employed by Romulus on the occasion above-mentioned.

${ }_{32}$ These varieties of the oak will be considered in the next chapter. 
each might happen to present itself, the honourable distinction given to the acorn being the only thing observed. Rigorous laws were, however, enacted, to maintain the lofty glories of this wreath, by which it was placed upon an equality even with the supreme honours of the wreath that is given by Greece in presence of Jove ${ }^{33}$ himself, and to receive which the exulting city of the victor is wont to break ${ }^{34}$ a passage through its very walls. These laws are to the effect that the life of a fellow-citizen must be preserved, and an enemy slain; that the spot where this takes place must have been held by the enemy that same day; that the person saved shall admit the fact, other witnesses being of no use at all; and that the person saved shall have been a Roman citizen.

To preserve an ally merely, even though it should be the life of a king that is so saved, confers no right to this high reward, nor is the honour at all increased, even if it is the Roman general that has been thus preserved, it being the intention of the framers of the law that it should be the status of the citizen that is everything. When a man has received this wreath, it is his privilege to wear it for the rest of his life. When he makes his appearance at the celebration of the games, ${ }^{35}$ it is customary for the Senate even to rise from their seats, and he has the right of taking his seat next to the senators. Exemption, too, from all civic duties is conferred upon him as well as his father and his father's father. Siccius Dentatus, as we have already mentioned ${ }^{36}$ on an appropriate occasion, received. fourteen civic crowns, and Manlius Capitolinus ${ }^{37}$ six $^{38}$ one, among the rest, for having saved the life of his general, Servilius. Scipio Africanus declined to accept the civic crown for having saved the life of his father at the battle of Trebia. Times these, right worthy of our everlasting admiration, which accorded honour alone as the reward of exploits so mighty, and which, while other crowns were recommended by being made of gold, disdained to set a price upon the safety of a citizeu, and loudly proclaimed thereby that it is unrighteous to save the life of a man for motives of lucre.

33 At the Olympic games celebrated in honour of Jupiter. At Olympia there was a statue of that god, one of the master-pieces of Phidias.

${ }_{34}$ Implying thereby, that the city that could produce a man who could so distinguish himself, stood in no need of walls.

35 In the Circus.

36 In B. vii. c. 29.

37 B. vii. c. 29.

${ }^{38}$ Livy says eight. He saved the life of Servilius, the Master of the Horse. 
CHAP. 6. (5.)-THIRTEEN VARIETIES OF THE ACORN.

It is a well-known fact that acorns ${ }^{39}$ at this very day constitute the wealth of many nations, and that, too, even amid these times of peace. Sometimes, also, when there is a scarcity of corn they are dried and ground, the meal being employed for making a kind of bread. Even to this very day, in the provinces of Spain, ${ }^{40}$ we find the acorn introduced at table in the second course: it is thought to be sweeter when roasted in the ashes. By the law of the Twelve Tables, there is a provision made that it shall be lawful for a man to gather his acorns when they have fallen upon the land of another.

The varieties of the glandiferous trees are numerous, and they are found to difter in fruit, locality, sex, and taste; the acorn of the beech having one shape, that of the quercus another, and that, again, of the holm-oak another. The various species also, among themselves, offer a considerable number of varieties. In addition to this, some of these trees are of a wild nature, while the fruits of others are of a less acrid flavour, owing to a more careful cultivation. Then, too, there is a difference between the varieties which grow on the mountains and those of the plains; the males differ from the females, and there are considerable modifications in the flavour of their fruit. That of the beech ${ }^{41}$ is the sweetest of all ; so much so, that, according to Cornelius Alexander, the people of the city of Chios, when besieged, supported themselves wholly on mast. The different varieties cannot possibly be distinguished by their respective names, which vary according to

39 "Glandes." Under this name, for which we do not appear to have any English equivalent, were included, as already mentioned, not only the acorn of the oak, but the nut or mast of the beech, and probably most of the hard or kernel fruits. In the present instance Pliny probably alludes only to the fruit of the oak and the beech. Acorns are but little used as an article of food in these days. Roasted, they have been proposed as a substitute for coffee.

40 The acorn of the Quercus ballota of Linnæus is probably meant, which is still much used in the province of Salamanca, and forms an agreeable article of food. This acorn, Fée says, contains a considerable proportion of saccharine matter, and is better roasted in the ashes than boiled in water. It is not, however, used as a dessert, as in the time of the Romans. These acorns are sold at market in Andalusia in the month of October.

41 So far as it goes, the kernel of the mast or beech-nut is not unpalatable; but in the English beech it is very diminutive. 
their several localities. The quercus ${ }^{42}$ and the robur ${ }^{43}$ we see growing everywhere, but not so with the æesculus ; ; $^{44}$ while a fourth kind, known as the cerrus ${ }^{45}$ is not so much as known throughout the greater part of Italy. We shall distinguish them, therefore, by their characteristic features, and when circumstances render it necessary, shall give their Greek names as well.

\section{CHAP. 7. (6.)-THE BEECH.}

The acorn of the beech ${ }^{46}$ is similar in appearance to a kernel, enclosed in a shell of triangular shape. The leaf is thin and one of the very lightest, is similar in appearance to that of the poplar, and turns yellow with remarkable rapidity. From the middle of the leaf, and upon the upper side of it, there mostly shoots a little green berry, with a pointed top. ${ }^{47}$ The beech is particularly agreeable to rats and mice; and hence it is, that where this tree abounds, those creatures are sure to be plentiful also. The leaves are also very fattening for dormice, and good for thrushes too. Almost all trees bear an average crop but once in two years; this is the case with the beech more particularly.

\section{CHAP. 8. -THE OTHER ACORNS-WOOD FOR FUEL.}

The other trees that bear acorns, properly so called, are the

${ }^{12}$ The word "quercus" is frequently used as a general name for the oak; but throughout the present Book it is most employed as meaning a distinct variety of the oak, one of the larger kinds, F'é says, and answering to the Quercus racemosa of Lamarck, the Quercus robur of Linnæus, and the Rouvre of the French.

${ }_{43}$ This also has been much employed as a general name for the oak; but here, and in other parts of this Book, it is applied to one variety. Fée thinks that it answers to the Quercus sessiliflora of Smith, sometimes also called "rourre" by the French.

${ }^{44}$ The Quercus æseulus of Linnæus. It is not improbable that this oak is a different tree from the "Æisculus" of Horace and Virgil, which was perhaps either a walnut, or a variety of the beech.

${ }_{45}$ It has been suggested that this is the same with the Quercus cerrus of Linnæus, and the Quercus crinita of Lamarck, the gland of which is placed in a prickly cupule. It is rarely found in France, but is often to be met with in Piedmont and the Apennines.

${ }_{46}$ The Fagus silvatica of Lamarck. Its Latin name, "fagus," is supposed to have been derived from the Greek $\phi \dot{a} \gamma \omega$, "to eat." An oil is extracted from the acorns or nuts, that is much used in some parts of France.

${ }_{47}$ He speaks probably of one of the galls which are found attached to the leaves of the forest trees. 
robur, the æsculus, the cerrus, the holm-oak, ${ }^{48}$ and the corktree $:^{49}$ it is contained in a rivelled calyx, which embraces more or less of it, according to the several varieties. The leaves of these trees, those of the holm-oak excepted, are weighty, pulpy, long, and jagged at the edges, and they do not turn yellow before they fall, as with the beech : they are also longer or shorter, as the case may be.

There are two kinds ${ }^{50}$ of holm-oak : one of them, which belongs to Italy, has a leaf not very unlike that of the olive; some of the Greeks give it the name of " milax," ${ }^{51}$ and in our provinces it is known as the aquifolia. The acorn of these two kinds is shorter and more slender than in the others: Homer ${ }^{52}$ calls it " acylos," and by that name distinguishes it from the ordinary acorn: it is generally said that the male tree of the holm-oak bears no fruit.

The best acorn, and the very largest, is that which grows upon the quercus, and the next to it is the fruit of the rsculus : that of the robur, again, is diminutive, and the fruit of the cerrus has a meagre, wretched look, being enclosed in a calyx covered with prickles, like the outer coat of the chesnut. With reference to the acorn of the quercus, that which grows upon the female tree ${ }^{53}$ is sweeter and more tender, while that of the male is more solid and compact. The acorn, however, of the latifolia ${ }^{54}$ is the most esteemed, an oak so

48 "Mex." Fée thinks that the varieties known as the Prinos and the Ballota were often confounded by the ancients with the "ilex" or "holmoak." This tree, he says, bears no resemblance to the ordinary oak, except in the blossoms and the fruit. It is the Ilex of Linnæus, the "yeuse," or "green oak," of the French.

19 The Quercus suber of Linnæus; it is found more particularly in the department of the Landes in France.

${ }_{50}$ As Fée remarks, Pliny is clearly in error here; one kind being the veritable ilex or holm oak, the other, the aquifolium or holly, quite a different tree.

51 The smilax or milax wasa real holm oak, but the aquifolia was the holly.

${ }^{52} \mathrm{Od}$. xi. 242. Fée remarks that the berry of the holly has no resem-. blance to the acorn whatever, and he says that this statement of Pliny almost leads him to think that the second variety here mentioned by him was not in reality the holly' but a variety of the quercus.

53 Fée observes that, properly speaking, there is no sex in the oak, the individuals being neither male nor female. The Flora Danica however, as he observes, gives the name of "Quercus fœmina" to the Quercus racemosa of Lamarck.

54 Or "broad-leaved" oak; one of the varieties of the Quercus sessiliflora of Smith-Flor. Brit. 
called from the remarkable broadness of its leaves. The acorns differ also among themselves in size, and the comparative fineness of the outer shell; as also in the circumstance that some have beneath the shell a rough coat of a rusty colour, while in others a white flesh immediately presents itself. Those, too, are more particularly esteemed, the two extremities of the nut of which, taken lengthwise, are as hard as a stone: and it is considered preferable that this peculiarity should present itself rather in the shell than in the flesh : in either case, however, it only exists in the fruit of the male tree. In some kinds, again, the acorn is oval, in others round; while in others it is of a more pointed form. The colour, too, varies considerably, according as it is blacker or whiter; this last being held in the highest esteem. The extremities of the acorn are bitter, but the flesh in the middle of it is sweet; ${ }^{55}$ another difference, too, consists in the comparative length or shortness of the stalk.

As for the trees themselves, the one that bears the acorn of largest size is known as the "hemeris;" ${ }^{66}$ a small tree with a thick bushy foliage all around it, and often hollowed at the place where the branch is joined to the trunk. The quercus has a stronger wood, and less susceptible of decay: this also is a very branchy tree, but is much taller than the last, while the trunk is considerably thicker. The ægilops, ${ }^{57}$ however, is the highest of them all, and is much attached to wild, uncultivated spots. Next to this in height is the latifolia, but its wood is far from being so useful either for building purposes or for charcoal. When rough-hewn it is very apt to spoil, hence it is that it is generally used in an unhewn state. As charcoal, it is considered only economical in smelting copper ; for the moment the workman ceases to blow, the fire dies out, and hence it requires to be repeatedly rekindled; while at the same time it gives out great quantities of sparks. The best

55 This statement is contrary to general experience in modern times, the flavour of the acorn being uniformly acrid and bitter throughout. It is not impossible, however, that the flavour may have been more palatable in ancient times.

56 A variety of the common oak, the Quercus racemosa of Lamarck; Sprengel takes it to be the Quercus ballota of Desfontaines.

57 The Quercus ægilops of Linnæus. It is a native of Piedmont, some parts of Italy, and the island of Crete. 
charcoal is that obtained from the wood of young trees. ${ }^{58}$ Square billets of wood, newly cut, are piled compactly together with clay, and built up in the form of a chimney; the pile is then set fire to, and incisions are made in the coat of clay as it gradually hardens, by the aid of long poles, for the purpose of letting the moisture of the wood evaporate.

The worst kind of all, however, both for timber and for making charcoal, is the oak known as the "haliphlœos," 59 the bark of which is remarkably thick, and the trunk of considerable size, but mostly hollow and spongy : it is the only one of this species that rots while the tree is still alive. In addition to this, it is very frequently struck by lightning, although it is not so remarkably lofty in height: for this reason it is not considered lawful to employ its wood for the purposes of sacrifice. It is but rarely that it bears any acorns, and when it does they are bitter: no animal will touch them, with the sole exception of swine, and not even they, if they can get any other food. An additional reason also for its exclusion from all religious ceremonials, is the circumstance that the fire is very apt to go out in the middle of the sacrifice when the wood of it is used for fuel.

The acorn of the beech, when given to swine, ${ }^{60}$ makes them brisk and lively, and renders the flesh tender for cooking, and light and easy of digestion; while, on the other hand, that of the holm oak has the effect of making them thin, pallid, meagre, and lumpish. The acorn of the quercus is of a broad shape, and is the heaviest as well as the sweetest of them all. According to Nigidius, the acorn of the cerrus occupies the next rank to this, and, indeed, there is no acorn that renders the flesh of swine more firm, though at the same time it is apt to impart a certain degree of hardness. The same author assures us also, that the acorn of the holm oak is a trying diet for swine, unless it is given in very small quan-

58 Pliny's account of making charcoal is derived from Theophrastus, B. iii. c. 10. Fée remarks that it differs little from the method adopted in France at the present day.

59 The Quercus Hispanica, probably, of Lamarek, of which Fée thinks the Quercus pseudo-suber of Desfontaines is a variety; it is found in Greece and on the shores of the Mediterranean, near Gibraltar. The Greek name signifies the "sea cork-tree."

69 The statement here given as to the effect of beech-mast on swine, is destitute, Fée remarks, of all foundation. If fed upon it, their flesh will naturally be of a soft, spongy nature. 
tities at a time. He says, too, that this acorn is the last to fall, and that the flesh of swine, if fed upon the acorns of the æsculus, the robur, or the cork-tree, will be of a spongy nature.

\section{CHAP. 9.-THE GALL-NUT.}

All ${ }^{61}$ the glandiferous trees produce the gall-nut as well: they only bear acorns, however, in alternate years. The gallnut of the hemeris ${ }^{62}$ is considered the choicest of all, and the best adapted for the preparation of leather: that of the latifolia closely resembles it, but is somewhat lighter, and not by any means so highly approved. This last tree produces the black gall-nut also-for there are two varieties of it-this last being deemed preferable for dyeing wool.

(7.) The gall-nut begins to grow just as the sun is leaving the sign of Gemini, ${ }^{63}$ and always bursts forth in its entirety in a single night. ${ }^{6 \pm}$ The white variety grows, too, in a single day, but if the heat happens to overtake it, it shrinks immediately, and never arrives at its proper size, which is about that of a bean. The black gall-nut will remain green for a longer period, and sometimes attains the size of an apple $e^{65}$ even. The best kind is that which comes from Commagene, ${ }^{66}$ and the most inferior are those produced by the robur: it may easily be tested by means of certain holes in it which admit of the passage of the light. ${ }^{67}$

CHAP. 10.-OTHER PRODUCTIONS ON THESE TREES BESIDES THE ACORN.

The robur, in addition to its fruit, has a great number of other productions : it bears ${ }^{68}$ the two varieties of the gall-nut, ${ }^{61}$ This assertion is perhaps too general; gall-nuts are produced in very small quantities by the holm-oak.

62 A variety of the Quercus racemosa, which produces the green gallnut of Aleppo, considered in modern, as in ancient, times the choicest in quality.

63 Theophrastus says the end of June.

64 Its growth, in reality, is not so rapid as this.

65 Such a thing is never seen at the present day.

66 In Syria. We have mentioned the galls of Aleppo in Note 62.

67 This is the case when the inside has been eaten away by the insect that breeds there ; of course, in such case it is hollow, light, and worthless.

6॰ The ancients were not aware that the gall was produced from the eggs 
and a production which closely resembles the mulberry, ${ }^{69} \mathrm{ex}-$ cept that it differs from it in being dry and hard: for the most part it bears a resemblance to a bull's head, and in the inside there is a fruit very similar to the stone of the olive. Little balls ${ }^{70}$ also are found growing on the robur, not unlike nuts in appearance, and containing within them a kind of soft wool, which is used for burning in lamps ; for it will keep burning without oil, which is the case also with the black gall-nut. It bears another kind, too, of little ball, covered with hair, ${ }^{71}$ but used for no purpose: in spring, however, this contains a juice like honey. In the hollows formed by the union of the trunk and branches of this tree there are found also small round balls, ${ }^{72}$ which adhere bodily to the bark, and not by means of a stalk: at the point of junction they are white, but the rest of the body is spotted all over with black : inside they are of a scarlet colour, but on opening them they are found to be empty, and are of a bitter taste.

Sometimes, too, the robur bears a kind of pumice, ${ }^{73}$ as well as little balls, which are formed of the leaves rolled up; upon the veins of the leaves, too, there are watery pustules, of a whitish hue, and transparent while they are soft; in these a kind of gnat ${ }^{74}$ is produced, and they come to maturity just in the same way that the ordinary gall-nut does.

\section{CHAP. 11. (8.)-CACHRYS.}

The robur bears cachrys, ${ }^{75}$ too ; such being the name given of the cynips, deposited upon the leaf or bark of the tree. Tan and gallic acid are its principal component parts.

${ }^{69}$ A substance quite unknown now ; but it is very doubtful if Pliny is rightly informed here.

${ }_{70} \mathrm{~A}$ fungous gall, produced by the Cynips fungosa. It is not used for any domestic purpose at the present day.

71 This kind of gall is now unknown. Fée questions the assertion about its juice.

72 The Cynips quercus baccarum of Linnæus, one of the common galls.

73 The root cynips, the Cynips radicum of Fourcroi, produces these galls, which lie near the root, and have the appearance of ligneous nodosities. It is harder than wood, and contains cells, in which the larva of the insect lies coiled up.

${ }^{74}$ This is a proof, as Fée remarks, that the ancients had observed the existence of the cynips; though, at the same time, it is equally evident that they did not know the important part it acts in the formation of the gall.

${ }^{75}$ This word, as employed by Theophrastus, means a catkin, the Julus , 
to a small round ball that is employed in medicine for its caustic properties. It grows on the fir likewise, the larch, the pitch-tree, the linden, the nut-tree, and the plane, and remains on the tree throughout the winter, after the leaves have fallen. It contains a kernel very similar to that of the pinenut, and increases in size during the winter. In spring the ball opens throughout, and it finally drops when the leaves are beginning to grow.

Such is the multiplicity of the products borne by the robur in addition to its acorns; and not only these, but mushrooms ${ }^{76}$ as well, of better or worse quality, the most recent stimulants that have been discovered for the appetite; these last are found growing about its roots. Those of the quercus are the most highly esteemed, while those of the robur, the cypress, and the pine are injurious. ${ }^{77}$ The robur produces mistletoe ${ }^{78}$ also, and, if we may believe Hesiod, ${ }^{79}$ honey as well : indeed, it is a well-known fact, that a hone ${ }^{80}$-like dew falling from heaven, as we have already mentioned, ${ }^{81}$ deposits itself upon the leaves of this tree in preference to those of any other. It is also well known that the wood of this tree, when burnt, produces a nitrous ${ }^{82}$ ash.

amentum of the botanists ; but it is doubtful if Pliny attaches this meaning to the word, as the lime or linden-tree has no catkin, but an inflorescence of a different character. It is not improbable that, under this name, he alludes to some excrescence.

76 These were the "boletus" and the "suillus;" the last of which seem only to have been recently introduced at table in the time of Pliny. See B. xxii. c. 47 .

${ }_{77} \mathrm{He}$ alludes clearly to fungi of radically different qualities, as the nature of the trees beneath which they grow cannot possibly influence them, any further than by the various proportions of shade they afford. The soil, however, exercises great influence on the quality of the fungus; growing upon a hill, it may be innoxious, while in a wet soil it may be productive of death.

79 Works and Days, 1. 230.

80 Pliny seems to have here taken in a literal sense, what has been said figuratively by Virgil, Ecl. iv. 1. 26 :

"Et duræ quercus sudabunt roscida mella ;" and by Ovid, in relation to the Golden Age, Met. i. 113 :

"Flavaque de viridi stillabant ilice mella."

Fée remarks, that we find on the leaf of the lime-tree a thin, sugary deposit, left by insects, and that a species of manna exudes from the Coniferæ, as also the bark of the beech. 'This, however, is never the case with the oak.

81 B. xi. c. 12.

${ }_{82}$ By this word, Fée observes, we must not understand the word "nitre," 
CHAP. 12.-THE KERMES BERKY.

The holm oak, however, by its scarlet berry ${ }^{83}$ alone challenges competition with all these manifold productions. This grain appears at first sight to be a roughness on the surface of the tree, as it were, a small kind of the aquifolia ${ }^{84}$ variety of holm oak, known as the cusculium. ${ }^{85}$ To the poor in Spain it furnishes ${ }^{86}$ the means of paying one half of their tribute. We have already, when speaking 87 of the purple of the murex, mentioned the best methods adopted for using it. It is produced also in Galatia, Africa, Pisidia, and Cilicia: the most inferior kind is that of Sardinia.

\section{CHAP. 13.-AGARIC.}

It is in the Gallic provinces more particularly that the glandiferous trees produce agaric ${ }^{88}$ such being the name given to a white fungus which has a strong odour, and is very useful as an antidote. It grows upon the top of the tree, and gives out a brilliant light ${ }^{99}$ at night: this, indeed, is the sign by which its presence is known, and by the aid of this light it may be gathered during the night. The ægilops is the only one among the glandiferous trees that bears a kind of dry cloth, ${ }^{90}$ covered with a white mossy shag, and this, not only attached to the bark, but hanging down from the branches as well, a cubit even in length : this substance has a strong

in the modern sense, but the sub-carbonate of potash; while the ashes of trees growing on the shores of the sea produce a sub-carbonate of soda.

83 "Coccus." This is not a gall, but the distended body of an insect, the kermes, which grows on a peculiar oak, the "Quercus coccifera," found in the south of Europe.

${ }_{84}$ We have previously mentioned, that he seems to have confounded the holly with the holm oak.

${ }^{85}$ Poinsinet, rather absurdly, as it would appear, finds in this word the origin of our word "cochineal.",

${ }_{86}$ The kermes berry is but little used in Spain, or, indeed, anywhere else, since the discovery of the cochineal of America.

87 B. ix. c. 65 .

88 Not the white agaric, Fée says, of modern pharmacy ; but, as no kind of agaric is found in the oak, it does not seem possible to identify it. See B. $\mathrm{xxv}$. c. 57 .

s9 It is evident that no fungus would give out phosphoric light; but it may have resulted from old wood in a state of decomposition.

9D It is pretty clear that one of the lichens of the genus, usnea is here referred to. Amadue, or German tinder, seems somewhat similar.

VOL. III. 
odour, as we have already ${ }^{91}$ stated, when speaking of the perfumes.

The cork is but a very small tree, and its acorn is of the very worst $^{92}$ quality, and rarely to be found as well: the bark $^{93}$ is its only useful product, being remarkably thick, and if removed it will grow again. When straitened out, it has been known to form planks as much as ten feet square. This substance is employed more particularly attached as a buoy to the ropes ${ }^{94}$ of ships' anchors and the drag-nets of fishermen. It is employed also for the bungs of casks and as a material for the winter shoes ${ }^{95}$ of females; for which reason the Greeks not inappropriately call them ${ }^{96}$ " the bark of a tree."

There are some writers who speak of it as the female of the holm oak; and in the countries where the holm does not grow, they substitute for it the wood of the cork-tree, more particularly in cartwrights' work, in the vicinity of Elis and Lacedæmon for instance. The cork-tree does not grow throughout the whole of Italy, and in $n 0^{97}$ part whatever of Gaul.

\section{CHAP. 14. (9.)-TREES OF WHICH THE BARK IS USED.}

The bark also of the beech, the lime, the fir, and the pitchtree is extensively used by the peasantry. Panniers and baskets are made of it, as also the large flat hampers which are employed for the carriage of corn and grapes: roofs of

91 B. xii. c. 50.

92 On the contrary, Fée says, the acorn of the Quercus suber is of a sweet and agreeable flavour, and is much sought as a food for pigs. The hams of Bayonne are said to owe their high reputation to the acorns of the corktree.

93 The word "cork" is clearly derived from the Latin " cortex,". "bark." See Beckmann's History of Inventions, V. i. p. 320, et seq., Bohn's Edition, for a very interesting account of this tree.

94 This passage, the meaning of which is so obvious, is discussed at some length by Beckmann, Vol. i. pp. 321, 322 .

95 It is still employed for making soles which are impervious to the wet.

96 It is doubtful whether this name was given to the shoes, or the females who wore them, and we have therefore preserved the doubt, in the ambiguous "them." Beckmann also discusses this passage, p. 321. He informs us, p. 322 , that the Roman ladies who wished to appear taller than they really were, were in the habit of putting plenty of cork under their soles.

${ }^{97}$ At the present day, it grows in the greatest abundance in France, the Landes more particularly. 
cottages, ${ }^{98}$ too, are made of this material. When a spy has been sent out he often leaves information for his general, written upon fresh bark, by cutting letters in the parts of it that are the most juicy. The bark of the beech is also employed for religious purposes in certain sacred rites. ${ }^{99}$ This tree, however, when deprived of its bark, will not survive.

\section{CHAP. 15. (10.) - SHINGLES.}

The best shingles are those made of the wood of the robur; the next best being those furnished by the other glandiferous trees and the beech. Those most easily made are cut from the wood of the resinous trees, but they do not last, ${ }^{1}$ with the exception of those made of pine. Cornelius Nepos informs us, that Rome was roofed solely with shingles down to the time of the war with Pyrrhus, a period of four hundred and seventy years. It is well known that it was remarkable for the fine forests in its vicinity. Even at the present day, the name of Jupiter Fagutalus points out in what locality there stood a grove of beeches; ${ }^{2}$ the Querquetulan Gate shows where the quercus once stood, and the Viminal Hill is the spot where the "vimen" 3 was sought in ancient times. In many other parts, too, there were groves to be found, and sometimes as many as two. Q. Hortensius, the Dictator, on the secession of the plebeians to the Janiculum, passed a law in the Asculetum, ${ }^{4}$ that what the plebeians had enacted should be binding upon every Roman citizen. $^{5}$

\section{CHAP. 16.-THE PINE.}

In those days they regarded as exotics, because they did not exist in the vicinity ${ }^{6}$ of the City, the pine and the fir, as well as all the other varieties that produce pitch ; of which we shall now proceed to speak, in order that the method of seasoning

98 This is still the case in some of the poorer provinces of Spain.

99 As Fée remarks, Mars is no longer the Divinity in honour of whom: characters are traced on the bark of trees.

${ }^{1}$ On the contrary, Fée says, the resinous woods are the most proof of all against the action of the air.

2 Festus says that the Fagutal, a shrine of Jupiter, was so called from a beech tree (fagus) that stood there, and was sacred to that god.

3 Or osier.

4 Or "plantation of the æsculus."

6 Fée regards this as an extremely doubtful assertion.

$$
5 \text { A.U.c. } 367 .
$$


wine, from the very first, may be fully known. Whereas there are several among the trees already mentioned in Asia or the East, that produce pitch, in Europe there are but six varieties of kindred trees that supply it. In this number there are the pine $^{7}$ and the pinaster, ${ }^{8}$ which have long thin leaves like hair, and pointed at the end. The pine yields the least resin of them all : in the pine nut, indeed, of which we have previously spoken, ${ }^{9}$ it is sometimes to be found, but hardly in sufficient quantities to warrant us in reckoning the pine among the resinous trees.

\section{CHAP. 17. -THE PINASTER.}

The pinaster is nothing else but a wild pine $:$ it rises to a surprising height, and throws out branches from the middle, just as the pine does from the top. This tree yields a more copious supply of resin than the pine: the mode in which this is done we shall set forth ${ }^{10}$ on a future occasion. It grows also in flat countries. Many people think that this is the same tree that grows along the shores of Italy, and is known as the "tibulus ;" "11 but this last is slender, and more compact than the pine; it is likewise free from knots, and hence is used in the construction of light gallies ${ }^{12}$ they are both almost entirely destitute of resin.

CHAP. 18.-THE PITCH-TREE: THE FIR.

The pitch-tree ${ }^{13}$ loves the mountain heights and cold localities. This is a funereal tree, and, as an emblem of death, is placed before the door of the deceased, and is left to grow in the ricinity of the funeral pile. Still, however, it is now some time since it was admitted into our gardens, in consequence of the facility with which it is clipped into various shapes. It gives out considerable quantities of resin, ${ }^{14}$ which

7 The Pinus pinea of Linnæus, the cultivated pine.

8 The Pinus silvestris of Linnæus, the wild pine; the Pinus maritima of Lamarck is a variety of it.
${ }^{9}$ B. xv. c. 9.
10 In c. 23 of this Book.

11 A variety of the Pinus silvestris of Linnæus.

12 "Liburnicæ." See B. ix. cc. 5 and 48.

13 The Abies excelsa of Decandolle-the Pesse or Faux sapin (false fir) of the French. This tree, however, has not the pectinated, or comb-like leaf, mentioned by Pliny in c. 38.

11 It is still known in commerce as "false incense;" and is often sold 
is intermingled with white granulations like pearls, and so similar in appearance to frankincense, that when mixed, it is impossible to distinguish them; hence the adulterations we find practised in the Seplasia. ${ }^{15}$ All this class of trees have a short bristly leaf, thick and hard, like that of the cypress. The branches of the pitch-tree are of moderate size, and extend from almost the very root of the tree, adhering to the sides like so many arms : the same is the case with the fir, ${ }^{16}$ the wood of which is held in great esteem for ship-building.

This tree grows upon the summits of lofty mountains, as though, in fact, it had an antipathy to the sea, and it does not at all differ from the pitch-tree in appearance: the wood is also very highly esteemed for the construction of rafters, and many other appliances of life. A flow of resin, which in the pitch-tree constitutes its great merit, is looked upon as a defect in the fir, ${ }^{17}$ though it will generally exude in some small quantity on exposure of the wood, to the action of the sun. On the other hand, the wood which in the fir-tree is remarkably fine, in the pitch-tree is only used for making shingles, vats, and a few other articles of joiners' work.

\section{CHAP. 19. -THE LARCH : THE TORCH-TREE.}

The fifth kind of resinous tree has the same localities, and is very similar in appearance; it is known as the larch. ${ }^{13}$ The wood of this tree is far more valuable, being unimpaired by time, and proof against all decay; it is of a reddish colour, and of an acrid smell. Resin ${ }^{19}$ flows from this wood in still greater quantities; it is of the colour of honey, more viscous than the other varieties, and never turns hard.

as incense for the rites of the Roman church : while sometimes it is purposely employed, as being cheaper.

${ }^{15}$ A great street in Capua, which consisted entirely of the shops of sellers of unguents and perfumes.

16 It has the same pyramidal form as the pitch-tree. It is still much used in ship-building, both for its resinous and durable qualities and the lightness of the wood.

${ }_{17}$ The presence of resin is not looked upon as any defect in the fir at the present day. It produces what is known in commerce as "Strasbourg turpentine."

18 The Abies larix of Linnæus, and the Larix Europæa, it is thought, of Decandolles.

19 It is the Venice turpentine of commerce. Each tree will furnish seven or eight pounds each year for half a century. 
A sixth variety is the torch-tree, ${ }^{20}$ properly so called, which gives out more resin than any of the others, with the exception of the pitch-tree; but its resin is more liquid than that of this last. The wood, too, of this tree is more particularly employed for kindling fires and giving torch-light in religious ceremonials. Of this tree it is the male only that bears what is known to the Greeks by the name of "syce," remarkable for its extremely powerful odour. When the larch $^{22}$ is changed into the torch-tree, it is a proof that it is in a diseased state.

The wood of all these trees, when set fire to, gives out immoderate volumes of sooty smoke, ${ }^{23}$ and sputters every now and then with a sudden crackling noise, while it sends out redhot charcoal to a considerable distance-with the sole exception of that of the larch, which will neither burn ${ }^{24}$ nor char, nor, in fact, suffer any more from the action of fire than a stone. All these trees are evergreens, and are not easily ${ }^{25}$ distinguished by the foliage, even by those who are best acquainted with them, so nearly related are they to one another. The pitchtree, however, is not so high as the larch; which, again, is stouter, and has a smoother back, with a more velvety leaf, more unctuous to the touch, thicker, and more soft and flexible. $^{26}$ The pitch-tree, again, has a leaf more sparsely scattered and drier ; it is thinner also, and of a colder nature, rougher all over in appearance, and covered with a resinous deposit: the wood of this tree is most like that of the fir. The larch, when

$20 \mathrm{It}$ is doubtful if the treda, or torch-tree, has been identified. Some take it to be the Pinus mugho of Miller, the torch-pine of the French; others, again, suggest that it is the same as the Pinus cembro of the botanists.

${ }^{21}$ So called from its resemblance to a fig. Fée says that there is little doubt that this pretended fruit was merely a resinous secretion, which hardens and assumes the form of a fig.

${ }^{22}$ He somewhat mistranslates a passage of Theophrastus here, who, without transforming the larch into another tree, says that it is a sign of disease in the larch, when its secretions are augmented to such a degree that it seems to turn itself into resin.

23 The lamp-black of commerce is made from the soot of the pine.

24 This statement, though supported by that of Vitruvius, B. ii. c. 9, is quite erroneous. The wood of the larch gives out more heat than that of the fir, and produces more live coal in proportion.

25 This, Fée remarks, is the fact.

${ }_{26}$ This description is inexact, and we should have some difficulty in recognizing here the larch as known to us. 
the roots are once burnt, will not throw out fresh shoots, which the pitch-tree will do, as was found to be the case in the island of Lesbos, after the Pyrrhæan grove had been burnt there.

In the same species too, the variety of $\operatorname{sex}^{27}$ is found to constitute a considerable difference: the male is the shorter tree, and has a harder wood; while the female is taller, and bears a leaf more unctuous to the feel, smooth and free from all rigidity. The wood of the male tree is hard and awry, and consequently not so well suited for carpenters' work; while that of the female is softer, as may be very easily perceived on the application of the axe, a test, in fact, which, in every variety, immediately shows us which trees are males; the axe in such case meeting with a greater resistance, falling with a louder noise, and being withdrawn from the wood with considerably greater difficulty : the wood of the male tree is more parched too, and the root is of a blacker hue. In the vicinity of Mount Ida, in Troas, the circumstance whether the tree grows in the mountain districts or on the sea-shore, makes another considerable difference. In Macedonia and Arcadia, and in the neighbourhood of Elis, the names of the several varieties have been totally altered, and it has not been agreed by authors which name ought to be given to each : we have, therefore, contented ourselves with employing the Roman denominations solely.

The fir is the largest of them all, the female being the taller of the two; the wood, too, is softer and more easily worked. This tree is of a rounder form than the others, and its leaves are closely packed and feathered, so as not to admit of the passage of rain; the appearance, too, of the tree is altogether more cheerful, From the branches of these different varieties, with the sole exception of the larch, ${ }^{28}$ there hang numbers of scaly nuts of compact shape, like so many catkins. The nuts found upon the male fir have a kernel in the fore-part, which is

27 Pliny is in error here, there being no distinction of sex in the coniferous trees. All that he relates relative to the differences between the male and female pine is consequently false. He has, however, in this instance, only perpetuated an erroneous opinion of Theophrastus.

28 This is an erroneous statement. The larch has its cone, as well as the rest. It is possible, however, that its small size may have caused it to be overlooked by Pliny. 
not the case with those on the female tree. In the pitch-tree, again, these kernels, which are very small and black, occupy the whole of the catkin, which is smaller and more slender than in the other varieties; hence it is that the Greeks call this tree by the name of phthirophoron. ${ }^{29}$ In this tree, too; the nuts on the male are more compressed, and less moist with resin.

\section{CHAP. 20.-THE YEW.}

Not to omit any one of them, the yew ${ }^{20}$ is similar to these other trees in general appearance. It is of a colour, however, but slightly approaching to green, and of a slender form; of sombre and ominous aspect, and quite destitute of juice : it is the only one, too, among them all, that bears a berry. In the male tree the fruit is injurious ; indeed, in Spain more particularly, the berries contain a deadly poison. ${ }^{31}$ It is an ascertained fact that travellers' vessels, ${ }^{32}$ made in Gaul of this wood, for the purpose of holding wine, have caused the death of those who used them. Sextius says, that in Greece this tree is known by the name of "smilax," and that in Arcadia it is possessed of so active a poison, that those who sleep beneath it, or even take food ${ }^{33}$ there, are sure to meet their death from it. There are authors, also, who assert that the poisons which we call at the present day "toxica," and in which arrows are dipped, were formerly called taxica, ${ }^{34}$ from this tree. It has been discovered, also, that these poisonous qualities are quite neutralized by driving a copper nail into the wood of the tree.

${ }^{29}$ Or "louse-bearing." As Fee says, it is difficult to see the analogy.

30 The Taxus baccata of Linnæus. The account here given is in general very correct.

31 It is supposed that Pliny derives this notion as to the yew berry from Julius Cæsar, who says that "Cativulcus killed himself with the yew, a tree which grows in great abundance in Gaul and Germany." It is, however, now known that the berry is quite innocuous; but the leaves and shoots are destructive of animal life.

32 "Viatoria;" probably not unlike our travelling flasks and pocket-pistols. This statement made by Pliny is not at all improbable.

${ }^{33}$ This statement does not deserve a serious contradiction.

34 It is not improbable, however, that $\tau o \xi_{0} \nu$, an "arrow," is of older date than "taxus," as signifying the name of the yew. 
CHAP. 21. (11.)-METHODS OF MAKING TAR-HOW CEDRIUM IS MADE.

In Europe, tar is extracted from the torch-tree ${ }^{35}$ by the agency of fire; it is employed for coating ships and for many other useful purposes. ${ }^{36}$ The wood of the tree is chopped ${ }^{37}$ into small billets, and then put into a furnace, which is heated by fires lighted on every side. The first steam that exudes flows in the form of water into a reservoir made for its reception: in Syria this substance is known as "cedrium ;" 38 and it possesses such remarkable strength, that in Egypt the bodies of the dead, after being steeped in it, are preserved from all corruption. ${ }^{39}$

\section{CHAP. 22.-METHODS BY WHICH THICK PITCH IS PREPARED.}

The liquid that follows is of a thicker consistency, and constitutes pitch, properly so called. This liquid, thrown again into a brazen cauldron, and mixed with vinegar, becomes still ${ }^{40}$ thicker, and when left to coagulate, receives the name of "Bruttian" 41 pitch. It is used, however, only for pitching the insides of dolia ${ }^{42}$ and other vessels, it differing from the other kinds in being more viscous, of a redder colour, and more unctuous than is usually the case. All these varieties of pitch are prepared from the pitch-tree, by putting red-hot stones, with the resinous wood, in troughs made of strong oak; or if these troughs are not attainable, by piling up billets of the

${ }^{35}$ Numerous varieties of the coniferæ supply us with tar, and Pliny is in error in deriving it solely from the torch-tree, the Pinus mugho of Linnæus:

${ }^{37}$ It is still obtained in a similar way.

${ }^{38}$ Fée remarks, that Pliny is in error here; this red, watery fluid formed in the extraction of tars, being quite a different thing from "cedrium," the alkitran or kitran of the Arabs; which is not improbably made from a cedar, or perhaps the Juniperus Phœnicea, called "Cedrus" by the two Bauhins and Tournefort. He says that it is not likely that the Egyptians would use this red substance for the purpose of preserving the dead, charged as it is with empyreumatic oil, and destitute of all properties peculiar to resins. ${ }^{39}$ See B. xxi. c. 3 , and B. xxiv. c. 23.

40 This is impracticable; neither vinegar, wine, nor water, will mingle with pitch. These resins, however, if stirred up briskly in hot water, become of a paler colour, and acquire an additional suppleness.

${ }_{41}$ Perhaps so called from Calabria, a country where the pine abounded, and part of which was cailed Bruttium.

42 Or wine-vats. 
wood in the method employed for the manufacture of charcoal. ${ }^{43}$ It is this pitch that is used for seasoning wine, being first pounded and reduced to a fine powder: it is of a blacker colour, too, than the other sort. The same resin, if boiled gently with water, and then strained off, becomes viscous, and assumes a red colour; it is then known as "distilled ${ }^{41}$ pitch :" for making this, the refuse portions of the resin and the bark of the tree are generally selected.

Another method is adopted for the manufacture of that used as crapula. ${ }^{45}$ Raw flower of resin is taken, direct from the tree, with a plentiful sprinkling of small, thin chips of the wood. These are then pounded ${ }^{46}$ down and passed through a sieve, after which they are steeped in water, which is heated till it comes to a boil. The unctuous portion that is extracted from this is the best resin : it is but rarely to be met with, and then only in a few places in Italy, in the vicinity of the Alps: it is in considerable request for medicinal purposes. For this, they generally boil a congius of white resin to two congii of rain-water : 47 some persons, however, think it better ${ }^{48}$ to boil it without water for one whole day by a slow fire, taking care to use a vessel of white copper. ${ }^{49}$ Some, again, are in the habit of boiling the resin of the terebinth ${ }^{50}$ in a fiat $p^{51}{ }^{51}$ placed upon hot ashes, and prefer it to any other kind. The resin of the mastich ${ }^{52}$ is held in the next degree of estimation. ${ }^{53}$

${ }^{43}$ See c. 8 of the present Book.

44 Stillaticia.

45 See B. xiv. c. 25.

46 This operation removes from the pitch a great portion of its essential oil, and disengages it of any extraneous bodies that may have been mixed with it.

${ }_{47}$ Fée remarks that there is no necessity for this selection, though no doubt rain-water is superior to spring or cistern water, for some purposes, from its holding no terreous salts in solution.

48 This would colour the resin more strongly, Fée says, and give it a greater degree of friability.

49 See B. xxxiv. c. 20.

50 See B. xiv. c. 25 , and B. xxiv. c. 22.

51 "Sartago." Generally understood to be the same as our frying-pan. F'e remarks that this method would most inevitably cause the mass in fusion to ignite; and should such not be the case, a coloured resin would be the result, coloured with a large quantity of carbon, and destitute of all the essential oil that the resin originally contained.

${ }_{52}$ See B. xiv. c. 20.

${ }^{53}$ The terebinthine of the mastich, Fée says, is an oleo-resin, or in other words, composed of an essential oil and a resin. 
CHAP. 23. (12.)-HOW THE RESIN CALLED ZOPISSA IS PREPARED.

We must not omit, too, that the Greeks call by the name of zopissa ${ }^{54}$ the pitch mixed with wax which has been scraped from off the bottoms of sea-going ships $;^{55}$ for there is nothing, in fact, that has been left untried by mankind. This composition is found much more efficient for all those purposes in which pitch and resin are employed, in consequence of the superior hardness which has been imparted to it by the seasalt.

The pitch-tree is opened ${ }^{56}$ on the side that faces the sun, not by means of an incision, but of a wound made by the removal of the bark: this opening being generally two feet in width and one cubit from the ground, at the very least. The body of the tree, too, is not spared in this instance, as in others, for even the very chips from off it are considered as having their use; those, however, from the lower part of the tree are looked upon as the best, the wood of the higher parts giving the resin a bitter ${ }^{57}$ taste. In a short time all the resinous juices of the entire tree come to a point of confluence in the wound so inflicted: the same process is adopted also with the torch-tree. When the liquid ceases to flow, the tree is opened in a similar manner in some other part, and then, again, elsewhere: after which the whole tree is cut down, and the pith ${ }^{58}$ of it is used for burning. ${ }^{59}$

So, too, in Syria they take the bark from off the terebinth; and, indeed, in those parts they do not spare even the root or branches, although in general the resin obtained from those parts is held in disesteem. In Macedonia they subject the whole of the male larch to the action of fire, but of the female ${ }^{60}$

54 Apparently meaning "boiled pitch."

55 See B. xxiv. c. 26.

${ }_{56}$ This account has been borrowed from Theophrastus, Hist. Plant. B ix. c. ii. The modern method of extracting the resin of the pine is very similar. 57 There is no foundation whatever for this statement.

${ }_{58}$ The pith of the pine cannot be separated from the wood, and, indeed, is not easily distinguished from it. Fée says that in some of these trees masses of resin are found in the cavities which run longitudinally with the fibres, and queries whether this may not be the "marrow" or "pith" of the tree mentioned by Pliny.

${ }_{59}$ As a torch or candle, probably.

60 This division of the larch into sexes, as previously mentioned, is only fanciful, and bas no foundation in fact. The result of this operation, Fée says, would be only a sort of tar. 
only the roots. Theopompus has stated in his writings that in the territory of the Apolloniates there is found a kind of mineral pitch, ${ }^{61}$ not inferior to that of Macedonia. The best pitch ${ }^{62}$ everywhere is that obtained from trees planted on sunny spots with a north-east aspect; while that which is produced from more shaded localities has a disagreeable look and a repulsive odour. Pitch, too, that is produced amid the cold of winter is of inferior quality, being in smaller quantity, too, and comparatively colourless. Some persons are of opinion that in mountainous localities this liquid is produced in the greatest abundance, and that it is of superior colour and of a sweeter taste and has a finer smell so long as it remains in a state of resin; but that when, on the other hand, it is subjected to boiling, it yields a smaller quantity of pitch, because so much of it goes ${ }^{63}$ off in a serous shape. They say that the resinous trees, too, that grow on mountains are thinner than those that are found on plains, but that they are apt, both of them, to be unproductive in clear, dry weather.

Some trees, too, afford a flow of resinous juice the year after the incision is made, some, again, in the second year, and others in the third. The wound so made is filled with resin, but not with bark, or by the cicatrization of the outer coat; for the bark in this tree never unites. Among these varieties some authors have made the sappium ${ }^{64}$ to constitute a peculiar kind, because it is produced from the seed of a kindred variety, as we have already stated when speaking of the nuts ${ }^{65}$ of trees; and they have given the name of tæda ${ }^{66}$ to the lower parts of the tree; although in reality this tree is nothing else but a pitch-tree, which by careful cultivation has lost some small portion of its wild character. The name "sappinus" is also given to the timber of these trees when cut, as we shall have occasion to mention ${ }^{67}$ hereafter.

${ }^{61}$ See B. xxxv. c. 51. He alludes to the bitumen known as asphalt, bitumen of Judæa, mineral pitch, mountain pitch, malthe, pissalphate.

6:2 These particulars, borrowed from Theophrastus, are in general correct.

${ }_{63}$ This is not the fact; the essential oil in which the resin so greatly abounds, becomes volatile with remarkable facility.

${ }_{61}$ Most probably one of the varieties of the pine; but the mode in which Pliny expresses himself renders it impossible to identify it with any precision.

65 B. xv. c. 9.

${ }_{66}$ The name borne also by the torch-tree.

67 See c. 76 of this Book. 
Chap. 24. (13.) - TREes the WOOd OF WHich is Highly VALUEd. FOUR VARIETIES OF THE ASH.

It is for the sake of their timber that Nature has created the other trees, and more particularly the $a s h,{ }^{68}$ whieh yields it in greater abundance. This is a tall, tapering tree, with a feather-like leaf: it has been greatly ennobled by the encomiums of Homer, and the fact that it formed the spear of Achilles : ${ }^{69}$ the wood of it is employed for numerous purposes. The ash which grows upon Mount Ida, in Troas, is so extremely like the cedar, ${ }^{70}$ that, when the bark is removed, it will deceive a purchaser.

The Greeks have distinguished two varieties of this tree, the one long and without knots, the other short, with a harder wood, of a darker colour, and a leaf like that of the laurel. In Macedonia they give the name of "bumelia" $7 \mathrm{i}$ to an ash of remarkably large size, with a wood of extreme flexibility. Some authors have divided this tree into several varieties, according to the localities which it inhabits, and say that the ash of the plains has a spotted wood, while that of the mountain ash is more compact. Some Greek writers have stated that the leaf of the ash is poisonous ${ }^{72}$ to beasts of burden, but harmless to all the animals that ruminate. ${ }^{73}$ The leaves of this tree in Italy, however, are not injurious to beasts of burden even; so far from it, in fact, that nothing has been found to act as so good a specific for the bites of serpents ${ }^{74}$ as to drink the juice extracted from the leaves, and to apply them to the wounds. So great, too, are the virtues of this tree, that no serpent will ever lie in the shadow thrown by it, either in the

$68 \mathrm{He}$ does not speak in this place of the "ornus" or "mountain ash;" nor, as Fée observes, does he mention the use of the bark of the ash as a febrifuge, or of its leaves as a purgative. This ash is the Fraxinus excelsior of Decandolles. 69 Il. xxiv. 277.

70 Pliny makes a mistake here, in copying from Theophrastus, who says that it is the yew that bears so strong a resemblance to the cedar.

71 Or " bull's-ash." This variety does not seem to have been identified.

72 This statement results from his misinterpretation of the language of Theophrastus, who is really speaking of the yew, which Pliny mistakes for the ash.

73 Miller asserts that, if given to cows, this leaf will impart a bad flavour to the milk; a statement which, Fée says, is quite incorrect.

74 A merely fanciful notion, without apparently the slightest foundation: the same, too, may be said of the alleged antipathy of the serpent to the beech-tree, which is neither venomous nor odoriferous. 
morning or the evening, be it ever so long; indeed, they will always keep at the greatest possible distance from it. We state the fact from ocular demonstration, ${ }^{75}$ that if a serpent and a lighted fire are placed within a circle formed of the leaves of the ash, the reptile will rather throw itself into the fire than encounter the leaves of the tree. By a wonderful provision of Nature, the ash has been made to blossom before the serpents leave their holes, and the fall of its leaf does not take place till after they have retired for the winter.

CHAP. 25. (14.) - TWO VARIETIES OF THE IINDEN-TREE.

In the linden-tree the male ${ }^{76}$ and the female are totally different. In the male the wood is hard and knotty, of a redder hue, and with a stronger smell; the bark, too, is thicker, and, when taken off, has no flexibility. The male bears neither seed nor blossom as the female does, the trunk of which is thicker, and the wood white and of excellent quality. It is a singular ${ }^{77}$ thing, but no animal will touch the fruit of this tree, although the juice of the leaves and the bark is sweet. Between the bark and the wood there are a number of thin coats, formed by the union of numerous fine membranes; of these they make those bands ${ }^{78}$ which are known to us as "tiliæ." The finer membranes are called "philyræ," and are rendered famous by the honourable mention that the ancients have made of them as ribbons for wreaths ${ }^{79}$ and garlands. The

75 This story of Pliny has been corroborated by M. de Verone, and as strongly contradicted by Camerarius and Charras : with M. Fée, then, we must leave it to the reader to judge which is the most likely to be speaking the truth. It is not improbable that Pliny may have been imposed upon, as his credulity would not at all times preclude him from being duped.

76 There is no such distinction in the linden or lime, as the flowers are hermaphroditical. They are merely two varieties : the male of Pliny being the Tilia microphylla of Decandolles, and a variety of the Tilia Europæa of Linnæus; and the female being the Tilia platyphyllos, another variety of the Tilia Europæa of Linnæus.

77 Not at all singular, Fée says, the fruit being dry and insipid.

78 In France these cords are still made, and are used for well-ropes, wheat-sheafs, \&c. In the north of France, too, brooms are made of the outer bark, and the same is the case in Westphalia.

79 See B. xxi.c. 4 . Ovid, Fasti, B. v. 1. 337, speaks of the revellers at drunken banquets binding their hair with the philyra. 
wood of this tree is proof against the attacks of worms : ${ }^{80}$ it is of moderate height ${ }^{81}$ only, but of very considerable utility.

\section{CHAP. 26. (15.)-TEN VARIETIES OF THE MAPLE.}

The maple, which is pretty nearly of the same ${ }^{82}$ size as the lime, is inferior to the citrus ${ }^{83}$ only for the beauty of its wood when employed for cabinet work, and the exquisite finish it admits of. There are numerous varieties ${ }^{84}$ of this tree; the light maple, remarkable for the extreme whiteness of its wood, is known as the "Gallic" ${ }^{85}$ maple in Italy beyond the Padus, being a native of the countries beyond the Alps. Another kind is covered with wavy spots running in all directions. In consequence of its superior beauty it has received its name, ${ }^{86}$ from its strong resemblance to the marks which are seen in the tail of the peacock; the finest kinds are those which grow in Istria and Rhætia. An inferior sort of maple is known as "crassivenium." 87

The Greeks distinguish the varieties according to their respective localities. The maple of the plains, ${ }^{58}$ they say, is white, and not wavy ; they give it the name of "glinon." On the other hand, the mountain maple, ${ }^{89}$ they say, is of a more variegated appearance, and harder, the wood of the male tree being more particularly so, and the best adapted for spe-

80 "Teredo." If he means under this name to include the tinea as well, the assertion is far too general, as this wood is caten away by insects, though more slowly than the majority of the non-resinous woods. It is sometimes perforated quite through by the larvæ of the byrrhus, our deathwatch.

81 This is incorrect. It attains a very considerable height, and sometimes an enormous size. The trunk is known to grow to as much as forty or fifty feet in circumference.

82 The maple is much less in size than what the lime or linden really is.

${ }^{83}$ See B. xiii. c. 29.

84 Fée says there are but five varieties of the maple known in France. He doubts whether the common maple, the Acer campestre of Linnæus, was known to the ancients.

85 Fée identifies it with the Acer pseudo-platanus of Linnæus, the Acer montanum candidum of C. Bauhin. This tree is not uncommon in Italy.

86 "Acer pavonaceum :" "peacock maple." He gives a similar account of the spots on the wood of the citrus, B. xiii. c. 19.

${ }^{87}$ Or "thick-veined" maple.

88 Shpposed by Fée to be the Acer Monspessulanus of Linnæus, also the Acer trilobum of Linnæus.

89 A variety of the Acer pseudo-platanus of Linnæus, according to Fée. 
cimens of elegant workmanship. A third kind, again, according to the Greeks, is the zygia, ${ }^{90}$ with a red wood, which is easily split, and a pale, rough bark. Other authors, however, prefer to make of this last a peculiar "species, and give it in Latin the name of "carpinus."

CHAP. 27. (16.)—BRUSCUM : MOLLUSCUM ; THE STAPHYLODENDRON.

But the most beautiful feature of all in the maple is what is known as bruscum, and, even more particularly so, the molluscum. These are both of them tuberosities of this tree, the bruscum presenting veins more violently contorted, while those of the molluscum are disposed in a more simple and uniform manner: indeed, if this last were of sufficiently large size to admit of tables being made of it, there is no doubt that it would be preferred to the wood of the citrus even. At the present day, however, we find it but little used except for the leaves of tablets, or as a veneer for couches. ${ }^{91}$ Tuberosities are also found on the alder, ${ }^{92}$ but as much inferior to those already mentioned, as the alder itself is to the maple. In the maple the male tree ${ }^{93}$ is the first to blossom. The trees that frequent dry spots are preferred to those that grow in watery localities, which is the case also with the ash.

There is found in the countries beyond the Alps a tree, the wood of which is very similar to that of the white maple, and which is known as the staphylodendron. ${ }^{94}$ This tree bears a pod $^{95}$ in which there is found a kernel, which has the flavour of the hazel-nut.

\section{CHAP. 28.-THREE VARIETIES OF THE BOX-TREE.}

One of the most highly esteemed of all the woods is the

90 The Carpinus betulus of Linnæus; the horn-beam or yoke-elm.

91 " Silicios." This word appears to be explained by the accompanying word "laminas ;" but it is very doubtful what is the correct reading.

92 The Alnus glutinosa of Decandolles. In c. 38 , Pliny says, very incorrectly, that the alder has a remarkably thick leaf; and in c. 45 , with equal incorrectness, that it bears neither seed nor fruit.

93 Fée observes, that it is incorrect to say that the male tree blossoms before the female, if such is Pliny's meaning here.

94 From the Greek, meaning "a tree with clusters." It is the Staphylea pinnata of Linnæus, the wild or false pistachio of the French.

95 "Siliqua." This term, Fée says, is very inappropriate to the fruit of this tree, which is contained in a membranous capsule. The kernel is oily, and has the taste of the almond more than the nut. 
box, ${ }^{96}$ but it is seldom veined, and then only the wood of the root. In other respects, it is a wood, so to say, of quiet and unpretending appearance, but highly esteemed for a certain degree of hardness and its pallid hue: the tree, too, is very extensively employed in ornamental gardening. ${ }^{97}$ There are three ${ }^{98}$ varieties of it: the Gallic ${ }^{99}$ box, which is trained to shoot upwards in a pyramidal form, and attains a very considerable height; the oleaster, ${ }^{1}$ which is condemned as being utterly worthless, and emits a disagreeable odour; and a third, known as the "Italian" box, ${ }^{2}$ a wild variety, in my opinion, which has been improved by cultivation. This last spreads more than the others, and forms a thick hedge: it is an evergreen, and is easily clipped.

The box-tree abounds on the Pyrenean ${ }^{3}$ range, the mountains of Cytorus, and the country about Berecynthus. ${ }^{4}$ The trunk grows to the largest size in the island of Corsica, ${ }^{5}$ and its blossom is by no means despicable; it is this that causes the honey there to be bitter. ${ }^{6}$ The seed of the box is held in aversion by all animals. That which grows upon Mount Olympus in Macedonia is not more slender than the other kinds, but the tree is of a more stunted growth. It loves spots exposed to the cold winds and the sun: in fire, too, it manifests all the hardness of iron; it gives out no flame, and is of no use whatever for the manufacture of charcoal. ${ }^{7}$

96 The Buxus sempervirens of Linnæus.

${ }^{97}$ It is still extensively used for a similar purpose.

98 There are only two species now known: that previously mentioned, and the Buxus Balearica of Lamarck. The first is divided into the four varieties, arborescens, angustifolia, suffruticosa, and myrtifolia.

${ }_{99}$ The Buxus sempervirens of Linnæus ; very common in the south of France, and on the banks of the Loire.

I It is doubtful if this is a box at all. The wild olive, mentioned in B. xv. c. 7, has the same name; all the varieties of the box emit a disagreeable smell.

${ }^{2}$ A variety of the Buxus sempervirens, the same as the Buxus suffruticosa of Lamarck.

3 The Pyrenean box is mostly of the arborescent kind.

4 In Phrygia. See B. v. c. 29.

5 The arborescent variety.

6 This is doubted by F'ée, but it is by no means impossible. In Pennsylvania the bees collect a poisonous honey from the Kalmia latifolia.

7 A very good charcoal might be made from it, but the wood is too valuable for such a purpose. It burns with a bright, clear flame, and throws out a considerable heat.

rOL. III. 


\section{CHAP. 29. (17.) - FOUR VARIETIES OF THE ELM.}

Midway between the preceding ones and the fruit-trees stands the elm, partaking of the nature of the former in its wood, and being akin to the latter in the friendship which it manifests for the vine. ${ }^{8}$ The Greeks distinguish two varieties of this tree : the mountain ${ }^{9} \mathrm{elm}$, which is the larger of the two, and that of the plains, which is more shrubby. Italy gives the name of "Atinia" to the more lofty kinds, and gives the preference to those which are of a dry nature and will not grow in damp localities. Another variety is the Gallic elm, ${ }^{11}$ and a third, the Italian, ${ }^{12}$ with leaves lying closer together, and springing in greater numbers from a single stalk. A fourth kind is the wild elm. The Atinia does not produce any samara, ${ }^{13}$ that being the name given to the seed of the elm. All the elms will grow from slips or cuttings, and all of them, with the exception of the Atinia, may be propagated from seed.

Chap. 30. (18.) - The Natures of the varioUs trees aCCORding

TO THEIR LOCALITIES : THE MOUNTAIN TREES, AND THE TREES OF THE PLAIN.

Having now made mention of the more remarkable trees, it remains for me to state some general facts connected with them all. The cedar, the larch, the torch-tree, and the other resinous trees prefer mountainous localities ${ }^{14}$ the same is the case also with the aquifolia, the box, the holm-oak, the juniper, the terebinth, the poplar, the wild mountain-ash, and

8 Although (in common, too, with other trees) it is used as a support for the vine, that does not any the more make it of the same nature as the fruit-trees.

9 The Ulmus effusa of Willdenow; the Ulmus montana of Smith : Flor. Brit.

10 The Ulmus campestris of Linnæus; the Ulmus marita of other betanists,

11 The ordinary elm, Fée thinks.

i2 A variety of the Ulmus campestris, probably.

13 This name is still preserved by botanists. Pliny is incorrect in saying that the large elm produces no seed, the only difference being that the seed is smaller than in the other kinds. Columella, B. v. c. 6 , contradicts the statement here made by Pliny, but says that it appears to be sterile, in comparison with the others.

14 'The Finus maritima of Linnæus, which produces the greater part of the resins used in France, is found, however, in great abundance in the flat country of the Landes. 
the yoke-elm. ${ }^{15}$ On the Apennines there is also found a shrub known as the "cotinus," 16 famous for imparting to cloth a purple colour like that of the murex. The fir, the robur, the chesnut, the lime, the holm-oak, and the cornel will grow equally well on mountain or in valley; while the maple, ${ }^{17}$ the ash, the service, the linden, and the cherry, more particularly prefer a watery spot on the slope of a hilly declivity. It is not often that we see the plum, the pomegranate, the olive, the walnut, the mulberry, or the elder, growing on an elevated site: the cornel, too, the hazel, the quercus, the wild ash, the maple, the ash, the beech, and the yoke-elm, descend to the plains; while the elm, the apple, the pear, the laurel, the myrtle, the blood-red ${ }^{18}$ shrub, the holm-oak, and the brooms ${ }^{19}$ that are employed in dyeing cloths, all of them aspire to a more elevated locality.

The sorb, ${ }^{20}$ and even still more the birch, ${ }^{21}$ are fond of a cold site; this last is a native of Gaul, of singular whiteness and slender shape, and rendered terrible as forming the fasces of the magistracy. From its flexibility it is employed also in making circlets and the ribs of panniers. In Gaul, ${ }^{22}$ too, they extract a bitumen from it by boiling. To a cold site, also, belongs the thorn, which affords the most auspicious torches ${ }^{23}$

${ }_{15}$ On the contrary, the yoke-elm, or horn-beam, grows almost exclusively on the plains; and the same with the cornel and the poplar.

16 The Rhus cotinus of Linnæus, the fustic. See 13. xiii. c. 41. This, however, imparts a yellow colour, while Pliny speaks of a purple. It has been asserted, however, that the roots of it produce a fine red. There is $n o$ tree in Europe that produces a purple for dyeing.

${ }_{17}$ The maple, the ash, and the service-tree, are as often found in the plains as on the hills.

18 See c. 43 , and B. xxiv. c. 43 . The Cornus sanguinea of Linnæus, the blood-red cornel; the branches of which are red in the winter, and the fruit filled with a blood-red juice. This is probably the same shrub as the male cornel, mentioned further on by Pliny.

19 The Genista tinctoria of Linnæus, or "dyers" " broom.

20 Or "service-tree," the Sorbus domestica of Linnæus. It thrives just as well in a warm locality as a cold one.

21 The Betula alba of Linnæus. It was an object of terror not only in the hands of the Roman lictor, but in those of the pedagogue also, and is still to some extent. Hence it was formerly nicknamed "Arbor sapientiæ," the "tree of wisdom."

${ }_{22}$ This is no longer done in France, but it is in Russia, where they extract from it an empyreumatic oil, which is used in preparing Russia leather, and which imparts to it its agreeable smell.

${ }^{23} \mathrm{Bcys}$, both of whose parents were surviving, used to carry before the 
of all for the nuptial ceremony; from the circumstance, as Massurius assures us, that the shepherds, on the occasion of the rape of the Sabine women, made their torches of the wood of this tree: at the present day, however, the woods of the yoke-elm and the hazel are more generally employed for this purpose.

CHAP. 31.-TREES WHICH GROW ON A DRY SOIL : THOSE WHICH

ARE FOUND IN WET LOCALITIES: THOSE WHICH ARE FOUND IN BOTH INDIFEERENTLY.

The cypress, the walnut, the chesnut, and the laburnum, ${ }^{24}$ are averse to water. This last tree is also a native of the Alps, and far from generally known: the wood is hard and white, ${ }^{25}$ and the flowers, which are a cubit ${ }^{26}$ in length, no bee will ever touch. The shrub, too, known as Jupiter's beard, ${ }^{27}$ manifests an equal dislike to water : it is often clipped, and is employed in ornamental gardening, being of a round, bushy form, with a silvery leaf. The willow, the alder, the poplar, ${ }^{28}$ the siler, ${ }^{29}$ and the privet, ${ }^{30}$ so extensively employed for making tallies, ${ }^{31}$ will only grow in damp, watery places; which is the

bride a torch of white thorn. This thorn was, not improbably, the "Cratægus oxyacantha" of Linnæus, which bears a white flower. See B. xxiv. c. 66 .

24 The Cytisus laburnum of Linnæus, also known as "false ebony," still a native of the Alps.

25 But blackish in the centre; whence its name of false ebony.

25 Meaning the clusters of the flowers.

${ }^{27}$ The Anthyllis barba Jovis of modern botanists. The leaves have upon them a silvery down, whence the name "argyrophylla," given to it by Mænch.

28 But in c. 30 , he says that the poplar grows on hilly or mountainons declivities.

${ }^{29}$ This tree has not been satisfactorily identified; but Fée is of opinion that it is probably a variety of the willow, the Salix vitellina of Linnæus. Sprengel thinks that it is the Salix capræa.

30 The Ligustrum vulgare of Linnæus. It has black fruit and a white flower, and is rendered famous by the lines of Virgil-Ecl. ii. 17 :

" $O$ formose puer, nimium ne crede colori;

Alba ligustra cadunt, vaccinia nigra leguntur."

It is evidently this juxtaposition that has prompted Pliny to mention the vaccinium in the succeeding passage. In B. xii. c. 51 , and B. xxiv. c. 45 , Pliny seems inclined to confound this shrub with the Cyprus, the Lawsonia inermis of Linnæus, the Henna of the east, a totally different plant.

31 Wooden tallies used by public officers in keeping theiraccounts. They were employed till the middle ages. 
case also with the vaccinium, ${ }^{32}$ grown in Italy for drugging our slaves, ${ }^{33}$ and in Gaul for the purpose of dyeing the garments of slaves a purple colour. All those trees ${ }^{34}$, which are common to the mountains and the plains, grow to a larger size, and are of more comely appearance when grown on the plains, while those found on the mountains have a betisr wood and more finely veined, with the exception of the apple and the pear.

\section{CHAP. 32. (19.) -DIVISION OF TREES INTO VARIOUS SPECIES.}

In addition to these particulars, some of the trees lose their leaves, while others, again, are evergreens. Before, however, we treat of this distinction, it will be necessary first to touch upon another. There are some trees that are altogether of a wild nature, while there are others, again, that are more civilized, such being the names ${ }^{35}$ by which man has thought fit to distinguish the trees. Indced, these last, which by their fruits or some other beneficial property, or else by the shade which they afford, show themselves the benefactors of man, are not inappropriately called "civilized" 36 trees.

CHAP. 33. (20.) -TREES WHICH DO NOT IOSE THEIR FOLIAGF. THE RHODODENDRON. TREES WHICH DO NOT LOSE THE WHOLF OF THEIR FOLIAGE. PLACES IN WHICH THERE ARE NO TREES.

Belonging to this last class, there are the following trees which do not lose their leaves: the olive, the laurel, the palm, the myrtle, the cypress, the pine, the ivy, the rhododendron, ${ }^{37}$ and, although it may be rather called a herb than a tree, the savin. ${ }^{38}$ The rhododendron, as its name indicates, comes from Greece. By some it is known as the nerium, ${ }^{39}$ and by others as the rhododaphne. It is an evergreen, bear-

32 The Prunus mahaleb, Desfontaines says ; but Fée identifies it with the black heath-berry, or whortle-berry, still called "vaciet" in France. It dues not, however, grow, as Pliny says, in watery places, but in woods and on shrubby hills. ${ }^{33}$ See B. xxi. c. 97.

${ }^{34}$ These observations, Fée says, are borrowed from Theophrastus, Hist. Plant. B. iii. c. 4, and are founded on truth.

35 " Silvestres," and " urbaniores."

36 Urbanæ.

37 The Nerion oleander of Linnæus ; the laurel-rose, or rose of St. An. thony of the French; it has some distant resemblance to the olive-tree, but its leaf is that of the laurel, and its flower very similar to that of the rose.

${ }^{38}$ See B. xxiv. c. 61.

s9 "Nerion" is the Greek name. 
ing a strong resemblance to the rose-tree, and throwing out numerous branches from the stem; to beasts of burden, goats, and sheep it is poisonous, but for man it is an antidote ${ }^{40}$ against the venom of serpents.

(21.) The following among the forest-trees do not lose their leaves: the fir, the larch, the pinaster, the juniper, the cedar, the terebinth, the box, the holm-oak, the aquifolia, the cork, the yew, and the tamarisk. ${ }^{41}$ A middle place between the evergreens and those which are not so, is occupied by the andrachle ${ }^{42}$ in Greece, and by the arbutus ${ }^{43}$ in all parts of the world; as they lose all their leaves with the exception of those on the top of the tree. Among certain of the shrubs, too, the bramble and the calamus, the leaves do not fall. In the territory of Thurii, where Sybaris formerly stood, from the city there was a single oak ${ }^{44}$ to be seen that never lost its leaves, and never used to bud before midsummer: it is a singular thing that this fact, which has been so often alluded to by the Greek writers, should have been passed over in silence by our own. ${ }^{45}$ Indeed, so remarkable are the virtues that we find belonging to some localities, that about Memphis in Egypt, and at Elephantina, in Thebais, the leaves ${ }^{46}$ fall from none of the trees, not the vine even.

CHAF. 34. (22.) - THE NATURE OF THE LEAFES WHICH WITHER AND FALL.

All the trees, with the exception of those already men-

40 It has certain dangerous properties, which cause the herbivorous animals to avoid touching it. It acts strongly on the muscular system, and, as Fée remarks, used as an antidote to the stings of serpents, it is not improbable that its effect would be the worst of the two.

"S See B. xiii. c. 37. The tamarisk of the moderns is not an evergreen, which has caused writers to doubt if it is identical with the tamariscus of the ancients, and to be disposed to look for it among the larger ericæ or heaths. The leaves of the larch fall every year; those of the other evergreens mostly every two or three years.

42 See B. xiii. c. 40.

43 See B. xiii. c. 40 . This assertion of Pliny is erroneous, as these trees are in reality evergreens, though all trees of that class are liable to lose their leaves through certain maladies.

44 "Quercus." The ilex or holm-oak is an evergreen.

45 Pliny is in error here. Varro, De Re Rust. B. i. c. 7, has made mention of this tree.

46 The hot climates possess a greater number of evergreens than the temperate regions, but not of the same species or genus. The vine invariably loses its leaves each year. 
tioned-a list which it would be tedious to enumerate-lose their leaves, and it has been observed that the leaf does not dry up and wither unless it is thin, broad, and soft; while, on the other hand, the leaves that do not fall are those which are fleshy, thick, and narrow. ${ }^{47}$ It is an erroneous theory that the leaf does not fall in those trees the juices of which are more unctuous than the rest; for who could make out that such is the case with the holm-oak, for instance? Timæus, the mathematician, is of opinion that the leaves fall while the sun is passing through the sign of Scorpio, being acted upon by the influences of that luminary, and a certain venom which exists in the atmosphere : but then we have a right to wonder how it is that, the same reasons existing, the same influence is not exercised equally on all.

The leaves of most trees fall in autumn, but in some at a later period, remaining on the tree till the approach of winter, it making no difference whether they have germinated at an earlier period or a later, seeing that some that are the very first to bud are among the last to lose their leaves - the almond, the ash, and the elder, for instance : the mulberry, on the other hand, buds the last of all, and loses its leaves among the very first. The soil, too, exercises a very considerable influence in this respect: the leaves falling sooner where it is dry and thin, and more particularly when the tree is old : indeed, there are many trees that lose them before the fruit is ripe, as in the case of the late fig, for instance, and the winter pear: on the pomegranate, too, the fruit, when ripe, beholds nothing but the trunk of the parent tree. And not even upon those trees which always retain their foliage do the same leaves always remain, for as others shoot up beneath them, the old leaves gradually wither away: this takes place about the solstices more particularly.

CHaP. 35. - TREes Which have Leaves of various colours; TREES WITH LEAVES OF VARIOUS SHAPES. THREE VARIETIES OF THE POPLAR.

The leaves continue the same upon every species of tree,

47 This last assertion, Fée says, is far from true, in relation to the coniferous trees. 
with the exception of the poplar, the ivy, and the croton, which we have already mentioned as being called the "cicus." 48

(23.) There are three kinds of poplar; the white, ${ }^{49}$ the black, ${ }^{50}$ and the one known as the Libyan ${ }^{51}$ poplar, with a very diminutive leaf, and extremely black; much esteemed also for the fungi which grow from it. The white poplar has a particoloured leaf, white on the upper side and green beneath. This poplar, as also the black variety, and the croton, have a rounded leaf when young, as though it had been described with a pair of compasses, but when it becomes older the leaf throws out angular projections. On the other hand, the leaf of the ivy, ${ }^{52}$ which is angular at first, becomes rounder, the older the tree. From the leaves of the poplar there falls a very thick down $;^{53}$ upon the white poplar, which, it is said, has a greater quantity of leaves than the others, this down is quite white, resembling locks of wool. The leaves of the pomegranate and the almond are red.

\section{CHAP. 36.-LEAVES WHICH TURN ROUND EVERY YEAR.}

We find a most remarkable and, indeed, a marvellous peculiarity $^{54}$ existing in the elm, the lime, the olive, the white poplar, and the willow; for immediately after the summer solstice the leaves of these trees turn completely round; indeed, we have no sign which indicates with greater certainty that that period has past.

(24.) These trees also present in their leaves the same difference that is to be observed in those of all the rest: the underside, which looks towards the ground, is of a green,

48 See B. xv. c. 7.

50 The Populus nigra of Linnæus.

49 The Populus alba of Linnæus.

51 The Populus tremula of Linnæus. This statement as to the leaves of the poplar is verified by modern experience.

${ }_{52}$ This does not appear to be exactly correct as to the ivy. The leaves on the young suckers or the old and sterile branches are divided into three or five regular lobes, while those which grow on the branches destined to bear the blossoms are ovals or lanceolated ovals in shape.

53 It is not from the leaves, but from the fruit of the tree that this down falls; the seeds being enveloped with a cottony substance. This passage is hopelessly corrupt.

54 See B. xviii. c. 68 , where he enlarges still further on this asserted peculiarity; he borrows his statement from Theophrastus, Hist. Plant. B. i. c. 16 . 
grassy colour, and has a smooth surface $;^{55}$ while the veins, the callous skin, and the articulations, lie upon the upper face, the veins making incisions in the parts beneath, like those to be seen upon the human hand. The leaf of the olive is whiter above, and not so smooth; the same is the case, too, with that of the ivy. The leaves of all trees $\operatorname{turn}^{56}$ every day towards the sun, the object being that the under side may be warmed by its heat. The upper surface of them all has a down upon it, in however small quantity it may be; in some countries this down is used as a kind of wool. ${ }^{57}$

CHAP. 37. -THE CARE BESTOWED ON THE LEAVES OF THE PALM, AND THE USES TO WHICH THEX ARE APPLIED.

We have already said ${ }^{58}$ that in the East strong ropes are made of the leaves of the palm, and that they are improved by lying in the water. Among ourselves, too, the leaves of the palm are generally plucked immediately after harvest, the best being those that have no divisions in them. These leaves are left to dry under cover for four days, after which they are spread out in the sun, and left out in the open air all night, till they have become quite white and dry: after this they are split before they are put to any use.

\section{CHAP. 38. - REMARKABLE FACTS CONNECTED WITH LEAVES.}

The broadest leaves are those of the fig, the vine, and the plane; while those of the myrtle, the pomegranate, and the olive are narrow. The leaf of the pine and the cedar is fine and resembles hair, while that of the holly and one variety of the holm oak ${ }^{59}$ is prickly-indeed, in the juniper, we find a

55 These statements are quite conformable with the fact.

${ }^{56}$ This statement is quite true, so far as the fact that the leaves have not the same position in the day-time as during the night: the changes of position vary greatly, however, in the different kinds. It is generally thought that an organic irritability is the cause of this phenomenon.

57 This seems to be the meaning of "In aliis gentium lana est." $\mathrm{He}$ alludes, probably, to cotton or silk : see B. vi. c. 20. Thunberg tells us that at Roodesand, near the Cape of Good Hope, there grows so thick a down on the Buplevrum "giganteum of Lamarck, that it is employed to imitate a sort of white velvet, and is used for bonnets, gloves, stockings, \&c.

58 B. xiii. c. 7.

59 "Genere ilicum." It is not improbable that he here refers to the variety 
thorn in place of a leaf. The leaf of the cypress and the tamarisk $^{\mathrm{e} o}$ is fleshy, and that of the alder is remarkable for its thickness. ${ }^{61}$ In the reed, the willow, and the palm, ${ }^{62}$ the leaf is long, and in the latter tree it is double as well : that of the pear is rounded, and it is pointed in the apple. ${ }^{63}$ In the ivy the leaf is angular, and in the plane divided. ${ }^{64}$ In the pitchtree ${ }^{65}$ and the fir the leaf is indented like the teeth of a comb; while in the robur it is sinuous on the whole of the outer margin: in the bramble it has a spiny surface. In some plants the leaf has the property of stinging, the nettle for instance; while in the pine, ${ }^{66}$ the pitch-tree, the fir, the larch, the cedar, and the holly, it is prickly. In the olive and the holm-oak it has a short stalk, in the vine a long one: in the poplar the stalk of the leaf is always quivering, ${ }^{67}$ and the leaves of this tree are the only ones that make a crackling noise ${ }^{68}$ when coming in contact with another.

In one variety of the apple-tree ${ }^{69}$ we find a small leaf protruding from the very middle of the fruit, sometimes, indeed, a couple of them. Then, again, in some trees the leaves are arranged all round the branches, and in others at the extremities of them, while in the robur they are found upon the trunk itself. They are sometimes thick and close, and at others thinly scattered, which is more particularly the case where the leaf is large and broad. In the myrtle ${ }^{i 0}$ they are symmetrically of the holm-oak which he has previously called "aquifolia," apparently confounding it with the holly. See c. 8 of this Book.

60 See B. xiii. c. 37.

${ }_{61}$ This must be understood of the young leaf of the alder, which has a sort of thick gummy varnish on it.

62 B. xiii. c. 7.

${ }_{63}$ B. xv. c. 15. Pliny is not correct here; the leaf of the pear is oval or lanceolated, while that of the apple is oval and somewhat angular, though not exactly "mucronata," or sharply pointed.

${ }^{6+}$ Not exactly "divided," but strongly lobed.

65 If this is the case, the pitch-tree can hardly be identical with the false fir, the Abies excelsa of Decandolles. See c. 18 of this Book, and the Note.

${ }_{66}$ 'This passage would be apt to mislead, did we not know that the leaves of the coniferous trees here mentioned are not prickly, in the same sense as those of the holly, which are armed with very formidable weapons.

${ }_{67}$ More particularly in the Populus tremula, the "quivering" poplar.

68 Crepitantia.

${ }^{69}$ See B. xv. c. 15 . Not a species, but an accidental monstrosity.

70 See B. xv. c. 37 , where he speaks of the Hexastich myrtle. 
arranged, in the box, concave, and, upon the apple, scattered without any order or regularity. In the apple and the pear we find several leaves issuing from the same stalk, and in the elm and the cytisus ${ }^{71}$ they are covered with ramified veins. To the above particulars Cato ${ }^{22}$ adds that the leaves of the poplar and the quercus should not be given to cattle after they have fallen and become withered, and he recommends the leaves of the fig, ${ }^{73}$ the holm-oak, and the ivy for oxen: the leaves, too, of the reed and the laurel are sometimes given them to eat. The leaves of the service-tree fall all at once, but in the others only by degrees. Thus much in reference to the leaves.

CHAP. 39. (25.) -THE NATURAL ORDER OF THE PRODUCTION OF PLANTS.

The following is the order in which the operations of $\mathrm{Na}$ ture take place throughout the year. The first is fecundation, which takes place when the west wind begins to prevail, generally about the sixth day before the ides of February. ${ }^{74} \mathrm{By}$ the agency of this wind all the productions of the earth are impregnated; to such an extent, indeed, that the mares even in Spain are impregnated by it, as we have already stated. ${ }^{75}$ This is the generating principle of the universe, and it receives its name of Favonius, as some think, from our word "fovere," which means "to warm and cherish :" it blows from due west at the opening of the spring. The peasantry call this period of the year the " time of heat," ${ }^{76}$ because Nature is then longing to receive the seeds of her various productions, and is imparting life to everything that is planted. The vegetables conceive ${ }^{77}$ on various days, each according to

71 The leaves of the elm and the tree supposed to be identical with the cytisus of the ancients have no characteristics in common. See B. xiii. c. 47 , and the Notes.

${ }_{72}$ De Re Rust. cc. 5, 30, 45.

${ }^{73}$ Very inappropriate food for cattle, it would appear : the fig leaf being charged with a corrosive milky juice; the leaf of the holm oak, hard and leathery ; and that of the ivy, bitter and nauseous in the highest degree.

${ }^{74}$ Fighth of February.

75 See B. viii. c. 67.

76 Catlitio.

77 He alludes to the period of the rising of the sap; an entirely distinct process from germination. 
its respective nature: some immediately, as with animals, others, again, more slowly, carrying with them for a longer period the produce of their conception, a state which has from that circumstance obtained the name of "germination." When the plant flowers, it may be said to bring forth, and the flower makes its appearance by bursting its little capsule, which has acted to it as an uterus. The period of training and education is the growth of the fruit. This, as well as that of germination, is a laborious process.

\section{CHAP. 40.-TREES WHICH NEVER BLOSSOM. THE JUNIPER.}

The appearance of the blossom bespeaks the arrival of the spring and the birth anew of the year; this blossom is the very pride and delight of the trees. Then it is that they show themselves quite renewed, and altogether different from what they really are; then it is that they quite revel in the contest with each other which shall excel in the various hues and tints which they display. This merit has, however, been denied to many of them; for they do not all blossom, and there are certain sombre trees which do not participate in this joyous season of the year. The holm-oak, the pitch-tree, the larch, and the pine are never bedecked with blossoms, and with them there is no particular forerunner sent forth to announce the yearly birth of their respective fruits. The same is the case, too, with the cultivated and the wild fig, ${ }^{78}$ which immediately present their fruit in place of any blossom. Upon the fig, too, it is remarkable that there are abortive fruit to be seen which never ripen.

The juniper, also, is destitute ${ }^{79}$ of blossom; some writers, however, distinguish two varieties of it, one of which blossoms but bears no fruit, ${ }^{80}$ while the other has no blossom, but presents the berries immediately, which remain on the tree for so long a period as two years: this assertion, however, is

78 This statement, as also that relative to the holm oak, and other trees previously mentioned, is quite incorrect. The blossoms of the fig-tree are very much concealed, however, from view in the involucre of the clinanthium.

79 This is not the fact, though the blossom of the juniper is of humble character, and not easily seen. Theophrastus, B. iii. c. 6, only says that it is a matter of doubt, what Pliny so positively affirms.

so This is the fact; the male tree is sterile, but it fecundates the female. 
utterly fallacious, and all the junipers always present the same sombre appearance. So, too, in life, the fortunes of many men are ever without their time of blossoming.

\section{CHAP. 41.-THE FECUNDATION OF TREES. GERMINATION : THE APPEARANCE OF THE FRUIT.}

All trees germinate, however, ${ }^{81}$ even those which do not blossom. In this respect there is a very considerable difference in relation to the various localities; for in the same species we find that the tree, when planted in a marshy spot, will germinate earlier than elsewhere; next to that, the trees that grow on the plains, and last of all those that are found in the woods: the wild pear, too, is naturally later in budding than the other pears. At the first breath of the west wind ${ }^{82}$ the cornel buds, and close upon it the laurel; then, a little before the equinox, we find the lime and the maple germinating. Among the earlier trees, too, are the poplar, the elm, the willow, the alder, and the nut-trees. The plane buds, too, at an early period.

Others, again, germinate at the beginning of spring, the holly, for instance, the terebinth, the paliurus, ${ }^{82 *}$ the chesnut, and the glandiferous trees. On the other hand, the apple is late in budding, and the cork-tree the very last of all. Some trees germinate twice, whether it is that this arises from some exuberant fertility of the soil, or from the inviting temperature of the atmosphere; this takes place more particularly in the several varieties of the cereals. Excessive germination, however, has a tendency to weaken and exhaust the tree.

Besides the spring budding, some trees have naturally another budding, which depends upon the influence of their own respective constellations, ${ }^{83}$ a theory which we shall find an

${ }^{81}$ These remarks, borrowed from Theophrastus, are generally consistent with our expe:ience.

${ }^{82}$ Fée remarks that Pliny here copies from Theophrastus, a writer of Greece, without making allowance for the difference of localities. Theophrastus, however, gives the laurel an earlier period for budding than Pliny does.

82* The Rhamnus paliurus of Linnæus.

${ }_{83}$ This is entirely fanciful: though it is the case that in some trees, the ligneous ones, namely, there are two germinations in the year, one at the beginning of spring, which acts more particularly on the branches, and the other at the end of summer, which acts more upon the parts nearer the roots. 
opportunity of more conveniently discussing in the next Book but one. ${ }^{81}$ The winter budding takes place at the rising of the Eagle, the summer at that of the Dog-star, and a third budding $^{85}$ again at that of Arcturus. Some persons think that these two buddings are common to all trees, but that they are to be remarked more particularly in the fig, the vine, and the pomegranate; seeing that, when this is the case, the crop of figs, in Thessaly and Macedonia more particularly, is remarkably abundant: but it is in Egypt more especially that illustrations of this vast abundance are to be met with. All the trees in general, when they have once begun to germinate, proceed continuously with it; the robur, however, the fir-tree, and the larch germinate intermittently, ceasing thrice, and as many times ${ }^{86}$ beginning to bud again, and hence it is that they shed the scales of their bark ${ }^{87}$ three several times; a thing that takes place with all trees during the period of germination, the outer coat of the tree bursting while it is budding.

With these last trees the first budding takes place ${ }^{88}$ at the beginning of spring, and lasts about fifteen days ; and they germinate a second time when the sun is passing through the sign of Gemini : hence it is that we see the points of the first buds pushed upwards by those beneath, a joint marking the place where they unite. ${ }^{89}$ The third germination of these trees takes place at the summer solstice, and lasts no more than seven days: at this period we may very distinctly detect the articulations by which the buds are joined to one another as they grow. The vine is the only tree that buds twice; the first time when it first puts forth the grape, and the second time when the grape comes to maturity. In the trees which do not blossom there is only the budding, and then the gradual ripen-

${ }^{81}$ See B. xviii. c. 57.

85 There is no such thing as a third budding.

${ }^{86}$ As already stated, there are never more than two germinations.

87 'This rupture of the epidermis, caused by the formation beneath of new ligneous and conical layers, takes place not solely, as Pliny and Theophrastus state, at the time of germination, but slowly and continuously.

8s On the contrary, they are irregular both in their commencement and their duration.

${ }_{89}$ This is not the case; each bud is independent of the one that has preceded it. A sucker, however, newly developed may give birth to buds not at the extremity, but throughout the whole length of it. 
ing of the fruit. Some trees blossom while they are budding, and pass rapidly through that period; but the fruit is slow in coming to maturity, as in the vine, for instance. Other trees, again, blossom and bud but late, while the fruit comes to maturity with great rapidity, the mulberry, ${ }^{90}$ for example, which is the very last to bud of all the cultivated trees, and then only when the cold weather is gone : for this reason it has been pronounced the wisest among the trees. But in this, the germination, when it has once begun, bursts forth all over the tree at the very same moment; so much so, indeed, that it is accomplished in a single night, and even with a noise that may be audibly heard. ${ }^{91}$

\section{CHAP. 42.- IN WHAT ORDER THE TREES BLOSSOM.}

Of the trees which, as we have already stated, ${ }^{92}$ bud in winter at the rising of the Eagle, the almond blossoms the first of all, in the month of January ${ }^{93}$ namely, while by March the fruit is well developed. Next to it in blossoming is the plum ${ }^{94}$ of Armenia, and then the tuber and the early peach, ${ }^{95}$ the first two being exotics, and the latter forced by the agency of cultivation. Among the forest trees, the first that blossoms in the course of nature is the elder, ${ }^{96}$ which has the most pith of any, and the male cornel, which has none ${ }^{97}$ at all. Among the cultivated trees we next have the apple, and immediately after -so much so, indeed, that it would almost appear that they blossom simultaneously - the pear, the cherry, and the plum. Next to these is the laurel, and then the cypress, and after that the pomegranate and the fig: the vine, too, and the olive are budding when these last trees are in flower, the period of their conception ${ }^{98}$ being the rising of the Vergiliæ, ${ }^{99}$ that being

${ }_{90}$ See B. xviii. c. 67. What Pliny says here is in general true, though its germination does not take place with such rapidity as he states.

${ }_{91}$ A mere fable, of course. $\quad{ }_{92}$ In the last Chapter.

93 In Paris, Fée says, the almond does not blossom till March. If the tree should blossom too soon, it is often at the expense of the fruit.

${ }_{91}$ Probably the apricot. See B. xv. c. 12.

${ }_{95}$ See B. Xv. c. 11.

96 See B. xxiv. c. 8.

97 This, of course, is not the fact. As to the succeeding statements, they are borrowed mostly from Theophrastus, and are in general correct.

98 The rising of the sap.

99 The Pleiades. See B. xviii. cc. 59, 60. 
their constellation. ${ }^{1}$ As for the vine, it blossoms at the summer solstice, and the olive begins to do so a little later. All blossoms remain on the trees seven days, and never fall sooner; some, indeed, fall later, but none remain on more than twice seven days. The blossoms are always off before the eighth day $^{2}$ of the ides of July, the period of the prevalence of the Etesian ${ }^{3}$ winds.

Chap. 43. (26.) - AT what pertod each tree beatis froit. THE CORNEL.

Upon some trees the fruit does not follow immediately upon the fall of the blossom. The cornel ${ }^{4}$ about the summer solstice puts forth a fruit that is white at first, and after that the colour of blood. The female ${ }^{5}$ of this tree, after autumn, bears a sour berry, which no animal will touch; its wood, too, is spongy and quite useless, while, on the other hand, that of the male tree is one of the very strongest and hardest ${ }^{6}$ woods known: so great a difference do we find in trees belonging to the same species. The terebinth, the maple, and the ash produce their seed at harvest-time, while the nut-trees, the apple, and the pear, with the exception of the winter or the more early kinds, bear fruit in autumn. The glandiferous trees bear at a still later period, the setting of the Vergilix, ${ }^{7}$ with the exception of the æsculus, ${ }^{8}$ which bears in the autumn only ; while some kinds of the apple and the pear, and the cork-tree, bear fruit at the beginning of winter.

The fir puts forth blossoms of a saffron colour about the summer solstice, and the seed is ripe just after the setting of the Vergiliæ. The pine and the pitch-tree germinate about fifteen days before the fir, but their seed is not ripe till after the setting of the Vergiliæ.

1 It was supposed in astrology that the stars exercised an effect equally upon animal and vegetable life.

225 th of July.

3 See B. xviii. c. 68.

4 The Cornus mas of botanists; probably the Frutex sanguineus mentioned in c. 30 . See also B. xv. c. 31 .

5 Probahly the Ionicera Alpigena of Linnæus; the fruit of which resembles a cherry, but is of a sour flavour, and produces vomiting.

6 The wood is so durable, that a tree of this kind in the forest of Montmorency is said to be a thousand years old.

7 Sec B. xviii. cc. 59, 60.

8 See c. 6 of this Book. 
CHAP. 44. -TREES WHICH BEAR THE WHOLE YEAR. TREES WHICK HAVE ON THEM THE FRUIT OF THREE YEARS.

The citron-tree, ${ }^{9}$ the juniper, and the holm-oak are looked upon as having fruit on them the whole year through, and upon these trees we see the new fruit hanging along with that of the preceding year. The pine, however, is the most remarkable of them all; for it has upon it at the same moment the fruit that is hastening to maturity, the fruit that is to come to maturity in the ensuing year, and the fruit that is to ripen the next year but one. ${ }^{10}$ Indeed, there is no tree that is more eager to develope its resources; for in the same month in which a nut is plucked from it, another will ripen in the same place; the arrangement being such, that there is no month in which the nuts of this tree are not ripening. Those nuts which split while still upon the tree, are known by the name of azaniæ $;^{11}$ they are productive of injury to the others, if not removed.

CHAP. 45.-TREES WHICH BEAR NO FRUIT: TREES LOOKED UPON AS ILL-OMENED.

The only ones among all the trees that bear nothing whatever, not so much as any seed even, are the tamarisk, ${ }^{12}$ which is used only for making brooms, the poplar, ${ }^{13}$ the alder, the Atinian elm, ${ }^{14}$ and the alaternus, ${ }^{15}$ which has a leaf between that of the holm-oak and the olive. Those trees are regarded as sinister ${ }^{16}$ and are considered inauspicious, which are never propagated from seed, and bear no fruit. Cremutius informs us, that this tree, being the one upon which Phyllis ${ }^{17}$ hanged

9 See B. xii. c. 7.

10 This supposed marvel merely arises from the fact that the fruit has a strong ligneous stalk, which almost precludes the possibility of its dropping off. This is the case, too, not only with the pine, but with numerous other trees as well.

11 "Dried" nuts.

12 See B. xxiv. c. 41.

13 But in B. xxiv. c. 32 , he speaks of the fruit of the black poplar as an antidote for epilepsy. In fact, he is quite in error in denying a seed to any of these trees.

14 See c. 29 of this Book.

15 The Rhamnus alaternus of Linnæus, the Phylica elatior of C. Bauhin. In reality, it bears a small black berry, of purgative qualities.

16 "Infelices," "unhappy" rather.

17 Daughter of Sithon, king of Thrace, who hanged herself on account. of the supposed inconstancy of herlover, Demophöon. See Ovid, Heroid. 2 .

VOL. III

c $\mathbf{C}$ 
herself, is never green. Those trees which produce a gum open of themselves after germination: the gum never thickens until after the fruit has been removed.

\section{CHAP. 46.-TREES WHTCH LOSE THEIR FRUIT OR FLOWERS MOST KEADILY.}

Young trees are unproductive ${ }^{18}$ so long as they are growing. The fruits which fall most readily before they come to maturity are the date, the fig, the almond, the apple, the pear, and the pomegranate, which last tree is also very apt to lose its blossom through excessive dews and hoar frosts. For this reason it is, too, that the growers bend the branches of the pomegranate, lest, from being straight, they may receive and retain the moisture that is so injurious to them. The pear and the almond, ${ }^{19}$ even if it should not rain, but a south wind happen to blow or the weather become cloudy, are apt to lose their blossoms, and their first fruit as well, if, after the blossom has fallen, there is a continuance of such weather. But it is the willow that loses its seed the most speedily of all, long, indeed, before it is ripe ; hence it is that Homer has given it the epithet of "fruitlosing." ${ }_{20}$ Succeeding ages, however, have given to this term an. interpretation conformable to their own wicked practices, it being a well-known fact that the seed of the willow has the effect of producing barrenness in females.

In this respect, however, Nature has employed her usual foresight, bestowing but little care upon the seed of a tree which is produced so easily, and propagated by slips. There is, howerer, it is said, one variety of willow, ${ }^{21}$ the seed of which arrives at maturity: it is found in the Isle of Crete, at the descent from the grotto of Jupiter: the seed is unsightly and ligneous, and in size about as large as a chick-pea.

18 This must not be taken to the letter; indeed, Fée thinks that the proper meaning is :- "Young trees do not produce fruit till they have crrived at a certain state of maturity." Trees mostly continue on the increase till they die.

19 See B. xvii. c. 2. The assertion here made has not been confirmed by experience.

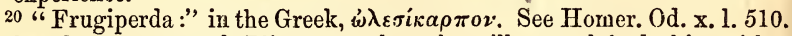
It has been suggested, Pliny says, that the willow seed had this epithet from its effect in causing abortion; but he does not seem to share the opinion.

${ }_{21}$ This cannot be a willow, Fée remarks; indeed, Theoplirastus, B. iii. c. 5 , speaks of a black poplar as growing there. 
CHAP. 47. - TREES WHICH ARE UNPRODUCTIVE IN CERTAIN PLACE.

Certain trees also become unproductive, owing to some fault in the locality, such, for instance, as a coppice-wood in the island of Paros, which produces nothing at all : in the Isle of Rhodes, too, the peach-trees ${ }^{22}$ never do anything more than blossom. This distinction may arise also from the sex; and when such is the case, it is the male ${ }^{23}$ tree that never produces. Some authors, however, making a transposition, assert that it is the male trees only that are prolific. Barrenness may also arise from a tree being too thickly covered with leaves.

CHAP. 48.-THE MODE IN WHICH TREES BEAR.

Some among the fruit-trees ${ }^{24}$ bear on both the sides of the branches and the summit, the pear, for instance, the figtree, and the myrtle. In other respects the trees are pretty nearly of a similar nature to the cereals, for in them we find the ear growing from the summit, while in the leguminous varieties the pod grows from the sides. The palm, as we have already $y^{25}$ stated, is the only one that has fruit hanging down in bunches enclosed in capsules.

\section{CHAP. 49. -TREES IN WHICH THE FRUIT APFEARS BEFORE THE \\ LEA VES.}

The other trees, again, bear their fruit beneath the leaves, for the purpose of protection, with the exception of the fig, the leaf of which is very large, and gives a great abundance of shade; hence it is that we find the fruit placed above it; in addition to which, the leaf makes its appearance after the fruit. There is said to be a remarkable peculiarity connected with one species of fig that is found in Cilicia, Cyprus, and Hellas; the fruit grows beneath the leaves, while at the same time the green abortive fruit, that never reaches maturity, is seen growing on the top of them. There is also a tree that produces an

${ }^{22}$ See $\mathrm{B}$. xv. c 13. It is not impossible that Pliny may have mistaken here the Persea, or Balanites Egyptiaca, for the Persica, or peach. See p. 296.

${ }^{23}$ Fée remarks, that this expression is remarkable as giving a just notion of the relative functions of the male and female in plants. He says that one might almost be tempted to believe that they suspected something of the nature and functions of the pistils and stamens.

24 This statement, which is drawn from Theophrastus, is rather fanciful than rigorously true.

25 B. xiii. c. 7.

c C 2 
early fig, known to the Athenians by the name of "prodromos." ${ }^{26}$ Ir the Laconian varieties of this fruit more particularly, we find trees that bear two crops ${ }^{27}$ in the year.

CHAP. 50. (27.) -TREES THAT BEAR TWO CROPS IN A YEAR. TREES THAT BEAR THREE CROPS.

In the island of Cea there are wild figs that bear three times in one year. By the first crop the one that succeeds is summoned forth, and by that the third. It is by the agency of this last crop that caprification ${ }^{28}$ is performed. In the wild fig, too, the fruit grows on the opposite side of the leaves. There are some pears and apples, too, that bear two crops in the year, while there are some early varieties also. The wild apple bears twice ${ }^{29}$ in the year, its second crop coming on after the rising of Arcturus, ${ }^{30}$ in sunny localities more particularly. There are vines, too, that will even bear three times in the year, a circumstance that has procured for them the name of "frantic" 31 vines. On these we see grapes just ripening, others beginning to swell, and others, again, in blossom, all at the same moment.

M. Varro ${ }^{32}$ informs us, that there was formerly at Smyrna, near ${ }^{33}$ the Temple of the Mother of the Gods, a vine that bore two crops in the year, as also an apple-tree of a similar nature in the territory of Consentia. This, however, is constantly to be witnessed in the territory of Tacapa ${ }^{34}$ in Africa, of which we shall have to speak more fully on another occasion, ${ }^{35}$ so remarkable is the fertility of the soil. The cypress also bears three times in the year, for its berries are gathered in the

${ }^{26}$ Or "forerunner." The Spaniards call a similar fig "brevas," the "ready ripener."

27 See B. xv. c. 19.

28 See B. xv. c. 21.

29 This does not happen in the northern climates; though sometimes it is the case that a fruit-tree blossoms again towards the end of summer, and if the autumn is fine and prolonged, these late fruits will ripen. Such a phenomenon, however, is of very rare occurrence.

30 See B. xviii. c. 74 .

31 "Insanæ." 'There are some varieties of the vine which blossom more than once, and bear green grapes and fully ripe ones at the same moment.

${ }^{32}$ De Re Rust. c. 7 .

3s The suggested reading, "apud matrem magnam," seems preferable to "apud mare," and recelves support from what is said relative to Smyrna in B. xiv. c. 6 .

s5 B. xviii. c. 51.

34 See B. v. c. 3. 
months of January, May, and September, being all three of different size.

There are also certain peculiarities observed in the different modes in which the trees bear their fruit, the arbutus and the quercus being most fruitful in the upper part, the walnut and the marisca ${ }^{36}$ fig in the lower. All trees, the older they grow, the more early they bear, and this more particularly in sunny spots and where the soil is not over-rich. All the forest-trees are slower in bringing their fruit to maturity ; and indeed, in some of them the fruit never becomes fully ripe. ${ }^{37}$ Those trees, too, about the roots of which the earth is ploughed or broken and loosened, bring their fruit to maturity more speedily than those in which this has been neglected; by this process they are also rendered more fruitful.

\section{CHAP. 51.-WHICH TREES BECOME OLD WITH THE GREATEST RAPIDITY, AND WHICH MOST SLOWLY.}

There are great differences also in trees in respect to age. The almond and the pear ${ }^{38}$ are the most fruitful when old, which is the case also with the glandiferous trees and a certain species of fig. Others, again, are most prolific when young, though the fruit is later in coming to maturity, a thing particularly to be observed in the vine; for in those that are old the wine is of better quality, while the produce of the younger trees is given in greater abundance. The apple-tree becomes old very early, and the fruit which it produces when old is of inferior quality, being of smaller size and very liable to be attacked by maggots: indeed, these insects will breed in the tree itself. The fig is the only one of all the fruit-trees that is submitted to any process with the view of expediting the ripening of the fruit, ${ }^{39}$ a marvellous thing, indeed, that a greater value should be set upon produce that comes out of its proper season! All trees which bear their fruit before the proper time become prematurely ${ }^{40}$ old ; indeed, some of them wither

36 B. xv. c. 19.

37 This is not the fact: the fruits of all trees have their proper time for ripening.

${ }^{38} \mathrm{He}$ speaks here in too general terms: the pear, for instance, is not more fruitful when old than when young.

${ }^{39}$ He speaks of the process of caprification. See B. xv, c. 21 .

40 So our proverb, "Soon ripe, soon rotten;" applicable to mankind as well as trees. See B. xxiii. c. 23. 
and die all of a sudden, being utterly exhausted by the too farourable influence of the weather, a thing that happens to the vine more particularly.

(28.) On the other hand, the mulberry becomes aged ${ }^{41}$ but very slowly, and is never exhausted by its crops. Those trees, too, the wood of which is variegated, arrive at old age but slowly,- the palm, the maple, and the poplar, for instance.

(29.) Trees grow old more rapidly when the earth is ploughed and loosened about the ${ }^{42}$ roots ; forest trees at a later: period. Speaking in general terms, we may say that care employed in the culture of trees seems to promote their fertility, while increased fertility accelerates old age. Hence it is that the carefully tended trees are the first to blossom, and the first to bud; in a word, are the most precocious in every respect: but all natural productions which are in any way weakened are more susceptible of atmospheric influences.

\section{CHAP. 52.-TREES WHICH BEAR VARIOUS PRODUCTS. CRAT AGGM.}

Many trees bears more than one production, a fact which we have already mentioned ${ }^{43}$ when speaking of the glandiferous trees. In the number of these there is the laurel, which bears its own peculiar kind of grape, and more particularly the barren laurel, ${ }^{44}$ which bears nothing else; for which reason it is looked upon by some persons as the male tree. The filbert, too, bears catkins, which are hard and compact, but of no use ${ }^{45}$ whatever.

(30.) But it is the box-tree that supplies us with the greatest number of products, not only its seed, but a berry also, known by the name of cratægum ; ${ }^{46}$ while on the north side

${ }^{41}$ See B. xv. c. 27 . The mulberry tree will live for several centuries.

4". 'This stimulates the sap, and adds to its activity: but the tree grows old all the sooner, being the more speedily exhausted.

${ }^{43}$ In cc. $9-14$ of the present Book.

44 This passage is quite unintelligible; and it is with good reason that Fée questions whether Pliny really understood the author that he copied from.

45 Fée remarks, that Pliny does not seem to know that the catkin is an assemblage of flowers, and that without it the tree would be totally barren.

${ }_{46}$ Pliny blunders sadly here, in copying from Theophrastus, B.iii. c. 16. He mixes up a description of the box and the cratægus, or holm-oak, making the latter to be a seed of the former: and he then attributes a mistletoe to the box, which Theophrastus speaks of as growing on the cratægus. 
it produces mistletoe, and on the south hyphear: two products of which I shall shortly have to speak more ${ }^{47}$ at length. Sometimes, indeed, this tree has all four of these products growing upon it at the same moment.

\section{CHAP. 53.-DIFFERENCES IN TREES IN RESPECT OF THE TRUN.KS}

AND BRANCHES.

Some trees are of a simple form, and have but a single trunk rising from the root, together with numerous branches; such as the olive, for instance, the fig, and the vine; others again are of a shrubby nature, such as the paliurus, ${ }^{48}$ the myrtle, and the filbert; which last, indeed, is all the better, and the more abundant its fruit, the more numerous its branches. In some trees, again, there is no trunk at all, as is the case with one species of box ${ }^{49}$ and the lotus ${ }^{50}$ of the parts beyond sea. Some trees are bifurcated, while there are some that branch out into as many as five parts. Others, again, divide in the trunk but have no branches, as in the case of the elder; while others have no division in the trunk but throw out branches, such as the pitch-tree, for instance.

In some trees the branches are symmetrically arranged, the pitch-tree and the fir, for example; while with others they are dispersed without any order or regularity, as in the robur, the apple, and the pear. In the fir the branches are thrown out from the trunk straight upwards, pointing to the sky, and not drooping downwards from the sides of the trunk. It is a singular thing, ${ }^{54}$ but this tree will die if the ends of its branches are cut, though, if taken off altogether, no bad effect is produced. If it is cut, too, below the place where the branches were, the part of the tree which is left will continue to live ; but if, on the other hand, the top only of the tree is removed, the whole of it will die.

47 See c. 93, where he enlarges on the varieties of the mistletoe.

48 See B. xxiv. c. 71.

${ }^{49} \mathrm{He}$ means the garden or border-box, mentioned in c. 28 of this Book.

${ }^{50}$ See B. xiii. c. 17 : the African lotus, probably; the Zizyphus lotus of Desfontaines.

54 This statement is entirely incorrect. If a tree loses tine terminal bud, it will grow no higher, but it will not die if the extremities of the branches are cut. Such, in fact, is much more likely to bappen when they are all cut off, from the extreme loss of juices which must naturally ensue at the several cicatrices united. 
Some trees, again, throw out branches from the roots, the elm for example; while others are branchy at the top, the pine for instance, and the lotus ${ }^{55}$ or Grecian bean, the fruit of which, though wild, resembles the cherry very closely, and is called the lotus at Rome, on account of its sweetness. For sheltering houses these trees are more particularly esteemed, as they throw out their branches to a considerable distance, from a short trunk, thus affording a very extensive shade, and very frequently encroaching upon the neighbouring mansions. There is no tree, however, the shade afforded by which is less long-lived than this, and when it loses its leaves in winter, it affords no shelter from the sun. No tree has a more sightly bark, or one which has greater attractions for the eye; or branches which are longer, stouter, or more numerous; indeed, one might almost look upon them as forming so many trees. The bark ${ }^{56}$ of it is used for dyeing skins, and the root for colouring wool.

The branches of the apple-tree have a peculiar conformation; knots are formed which resemble the muzzles ${ }^{57}$ of wild beasts, several smaller ones being united to a larger.

\section{CHAP. 54.-THE BRANCHES OF TREES.}

Some of the branches are barren, and do not germinate; this takes place either from a natural deficiency of strength, or else some injury received in consequence of having been cut, and the cicatrix impeding the natural functions. The same that the branch is in the trees that spread out, is the eye $\mathrm{e}^{58}$ in the vine, and the joint in the reed. All trees are naturally the thickest in the parts that are nearest the ground. The fir, the larch, the palm, the cypress, and the elm, and, indeed, every tree that has but a single trunk, develope themselves in their remarkable height. Among the branchy trees the cherry is sometimes ${ }^{59}$ found to yield a beam forty cubits in length by two in

${ }_{55}$ The Celtis australis of Linnæus. Pliny is in error in calling this tree the "Grecian bean." In B. xiii. c. 22 , he erroneously calls the African lotus by the name of "celtis," which only belongs to the lotus of Italy; that of Africa being altogether different.

56 The bark, which is astringent, is still used in preparing skins, and a black colouring matter extracted from the root is employed in dyeing wool.

57 Quite an accidental resemblance, if, indeed, it ever existed.

58 "Oculus"-the bud on the trunk.

59 This must be either a mistake or an exaggeration; the cherry never being a very large tree. 
thickness throughout. Some trees divide into branches from the very ground, as in the apple-tree, for example.

\section{. CHAP. 55. (31.)-THE BARK OF TREES.}

In some trees the bark ${ }^{60}$ is thin, as in the laurel and the lime; in others, again, it is thick, as in the robur; in some it is smooth, as in the apple and the fig, while in the robur and the palm it is rough : in all kinds it becomes more wrinkled when the tree is old. In some trees the bark bursts spontaneously, as in the vine for instance, while in others it falls off even, as we see in the apple and the arbutus. In the cork-tree and the poplar, the bark is substantial and fleshy; in the vine and the reed it is membraneous. In the cherry it is similar to the coats of the papyrus, while in the vine, the lime, and the fir, it is composed of numerous layers. In others, again, it is single, the fig and the reed for instance.

\section{CHAP. 56.-THE ROOTS OF TREES.}

There are great differences, too, in the roots of trees. In the fig, the robur, and the plane, they are numerous; in the apple they are short and thin, while in the fir and the larch they are single; and by this single root is the tree supported, although we find some small fibres thrown out from it laterally. They are thick and unequal in the laurel and the olive, in which last they are branchy also; while in the robur they are solid and fleshy. ${ }^{61}$ The robur, too, throws its roots downwards to a very considerable depth. Indeed, if we are to believe Virgil, ${ }^{62}$ the æsculus has a root that descends as deep into the earth as the height to which the trunk ascends in the air. The roots of the olive, the apple, and the cypress, creep almost upon the very surface : in some trees they run straight and horizontally, as in the laurel and the olive; while in others they have a sinuous course-the fig for example. In some trees the roots are bristling with small filaments, as in the fir, and many of the forest trees; the mountaineers cut off

60 It is evident that he is speaking of the epidermis only, and not the cortical layers and the liber.

${ }_{61}$ The roots of trecs being ligneous, "carnosæ," Fée remarks, is an inappropriate term.

6:2 Georg. ii. 291. 
these fine filaments, and weave with them very handsome flasks, ${ }^{63}$ and various other articles.

Some writers say that the roots of trees do not descend below the level to which the sun's heat is able to penetrate; which, of course, depends upon the nature of the soil, whether it happens to be thin or dense. This, however, I look upon ${ }^{64}$ as a mistake: and, in fact, we find it stated by some authors that a fir was transplanted, the roots of which had penetrated eight cubits in depth, and even then the whole of it was not dug up, it being torn asunder. ${ }^{65}$ The citrus has a root that goes the very deepest of all, and is of great extent ; next after it come the plane, the robur, and the various glandiferous trees. In some trees, the laurel for instance, the roots are more tenacious of life the nearer they are to the surface: hence, when the trunk withers, it is cut down, and the tree shoots again with redoubled vigour. Some think that the shorter the roots are, the more rapidly the tree decays; a supposition which is plainly contradicted by the fig, the root of which is among the very largest, while the tree becomes aged at a remarkably early period. I regard also as incorrect what some authors have stated, as to the roots of trees diminishing ${ }^{66}$ when they are old; for I once saw an ancient oak, uprooted by a storm, the roots of which covered a jugerum of ground.

\section{CHAP. 57. -TREeS Which HAVE GROWN SPONTANEOUSLY FROM THE} GROUND.

It is a not uncommon thing for trees when uprooted to receive new strength when replanted, the earth about their roots forming a sort of cicatrix ${ }^{67}$ there. This is particularly the

es "Lagenas." Fée takes this to mean here vessels to hold liquids, and remarks that the workers in wicker cannot attain this degree of perfection at the present day.

${ }_{61}$ Pliny is in error in rejecting this notion.

65 See B. xii. c. 5, and B. xiii. c. 29 . What Pliny states of the fir, or Abies pectinata, Theophrastus relates of the $\pi \varepsilon \dot{v} \kappa \eta$, or Abies excelsa of Decandolles. There is little doubt that in either case the statement is incorrect.

${ }^{66} \mathrm{On}$ the contrary, the roots of trees increase in size till the period of their death.

67 By preventing the action of the air from drying the roots, and so killing the tree. 
case with the plane, which, from the density of its branches, presents a remarkably broad surface to the wind: when this happens, the branches are cut off, and the tree, thus lightened, is replaced in its furrow : this, too, has also been done before now with the walnut, the olive, and many others.

(32.) We have many instances cited also of trees falling to the ground without there being any storm or other perceptible cause, but merely by way of portentous omen, and then rising again of themselves. A prodigy of this nature happened to the citizens of Rome during their wars with the Cimbri : at Nuceria, in the grove consecrated to Juno, an elm inclined to such a degree, even after the top had been cut off, as to overhang the altar there, but it afterwards recovered itself to such an extent as to blossom immediately: it was from that very moment, too, that the majesty of the Roman people began to flourish once again after it had been laid low by disaster and defeat. A similar circumstance is said to have taken place also at Philippi, where a willow, which had fallen down, and the top of which had been taken off, rose again; and at Stagira, in the Museum ${ }^{68}$ there, where the same thing occurred to a white poplar; all which events were looked upon as favourable omens. But what is most wonderful of all, is the fact that a plane, at Antandros, resumed its original position even after its sides had been rough-hewn all round with the adze, ${ }^{69}$ and took root again: it was a tree fifteen cubits long, and four ulnæ in thickness.

CHAP. 58.-HOW TREES GROW SPONTANEOUSLY-DIVERSITIES IN

THEIR NATURE, THE SAME TREES NOT GROWING EVERYWHERE.

The trees which we owe to Nature are produced in three different ways; spontaneously, by seed sown, or by a slip which throws out a root. Art has multiplied the methods of reproduction, as we shall have occasion to state in its own appropriate Book : ${ }^{70}$ at present our sole subject is the operations of Nature, and the manifold and marvellous methods she adopts. The trees, as we have already stated, ${ }^{71}$ do not all of them grow

68 A grove, probably, consecrated to the Muses.

69 These stories must be regarded as either fables or impostures; though it is very possible for a tree to survive after the epidermis has been removed with the adze.

70 See B. xvii. c. 9.

71 In c. 7 of this Book. 
in every locality, nor will they live, many of them, ${ }^{73}$ when transplanted: this happens sometimes through a natural antipathy on the part of the tree, sometimes through an innate stubbornness, but more frequently through the weakness of the variety so transplanted, either the climate being unfavourable, or the soil repulsive to it.

\section{CHAP. 59.-PLANTS THAT WILL NOT GROW IN CERTAIN PLACES.}

Balsamum ${ }^{73}$ will grow nowhere but $\left[\right.$ in $\left.^{74} \mathrm{Judæa}\right]$ : and the eitron of Assyria refuses to bear fruit in any other country. The palm, too, will not grow everywhere, and even if it does grow in some places, it will not bear: sometimes, indeed, it may make a show and promise of bearing, but even then its fruit comes to nothing, it seeming to have borne them thus far in spite of itself. The cinnamon ${ }^{75}$ shrub has not sufficient strength to acclimatize itself in the countries that lie in the vicinity of Syria. Amomum, ${ }^{76}$ too, and nard, ${ }^{77}$ those most delicate of perfumes, will not endure the carriage from India to Arabia, nor yet conveyance by sea; indeed, King Seleucus did make the attempt, but in vain. But what is more particularly wonderful, is the fact that most of the trees by care may be prevailed upon to live when transplanted; for sometimes the soil may be so managed as to nourish the foreigner and give support to the stranger plant; climate, however, can never be changed. The pepper-tree ${ }^{78}$ will live in Italy, and eassia $^{79}$ in the northern climates even, while the incense-tree ${ }^{80}$

72 It is not improbable that he has in view here the passage in Virgil's Georgics, B. ii. l. 109, et seq.

73 Or balm of Gilead. See B. xii. c. 54. Bruce assures us that it is indigenous to Abyssinia ; if so, it has been transplanted in Arabia. It is no more to be found in Judæa.

74 This is inserted, as it is evident that the text without it is imperfect. Fée says that even in Judæa it was transplanted from Arabia.

${ }^{75}$ As to the identification of the cinnamomum of Pliny, see B. xii. cc. 41 and 42 , and the Notes.

${ }^{76}$ As to the question of the identity of the amomum, see B. xii. c. 28.

77 See B. xii. c. 26.

78 This cannot be the ordinary Piper nigrum, or black pepper, which does not deserve the title "arbor." It is, no doubt, the pepper of Italy, which he mentions in B. xii. c. 14 .

79 The Cassia Italica, probably, of B. xii. c. 43. The cassia of the East could not possibly survive in Italy. The fact is, no doubt, that the Romans give the names of cassia, piper, and amomum, to certain indigenous plants, and then persuaded themselves that they had the genuine plants of the East.

so See B. xii. c. 30 . 
has been known to live in Lydia: but how are we to impart to these productions the requisite warmth of the sun, in order to make all the crude juices go off by evaporation, and ripen the resins that distil from them ?

Nearly as great a marvel, too, is the fact that the nature of the tree may be modified by circumstances, and yet the tree itself be none the less vigorous in its growth. Nature originally gave the cedar ${ }^{81}$ to localities of burning heat, and yet we find it growing in the mountains of Lycia and Phrygia. She made the laurel, too, averse to cold, and yet there is no tree that grows in greater abundance on Mount Olympus. At the city of Panticapæum, in the vicinity of the Cimmerian Bosporus, King Mithridates and the inhabitants of the place used every possible endeavour, with a view to certain religious ceremonies, to cultivate the myrtle $e^{82}$ and the laurel : they could not succeed, however, although trees abound there which require a hot climate, such as the pomegranate and the fig, as well as apples and pears of the most approved quality. In the same country, too, the trees that belong to the colder climates, such as the pine, the fir, and the pitch-tree, refuse to grow. But why go search for instances in Pontus? In the vicinity of Rome itself it is only with the greatest difficulty ${ }^{83}$ that the cherry and the chesnut will grow, and the peach-tree, too, at Tusculum : the Greek nut, too, is grown there from grafts only at a cost of considerable labour, while Tarracina abounds with whole woods of it.

\section{CHAP. 60. (33.) 一THE CYPHESS.}

The cypress ${ }^{84}$ is an exotic, and has been reckoned one of the trees that are naturalized with the greatest difficulty; so much so, indeed, that Cato ${ }^{85}$ has expatiated upon it at greater length and more frequently than any of the others. This tree is naturally of a stubborn ${ }^{86}$ disposition, bears a fruit that is utterly

81 Under the name of Cedrus, no doubt, several of the junipers have been included. See B. xiii. c. 11 .

${ }^{82}$ Fée is inclined to doubt this statement. The myrtie has been known to stand the winters of Lower Brittany.

s3 Owing, no doubt, as Fée says, solely to bad methods of cultivation. The same, too, with the grafted peach and the Greek nut or almond.

${ }_{84}$ The Cupressus sempervirens of Linnæus, the Cupressus fastigiata of Decandolle.

85 De Re Rust. ec. $48,151$.

66 "Morosa ;" meaning that it reaches maturity but very slowly. 
useless, a berry that causes a wry $^{87}$ face when tasted, and a leaf that is bitter: it also gives out a disagreeable pungent smell, ${ }^{88}$ and its shade is far from agreeable. The wood that it furnishes is but scanty, so much so indeed, that it may be almost regarded as little more than a shrub. This tree is sacred to Pluto, and hence it is used as a sign of mourning ${ }^{89}$ placed at the entrance of a house : the female ${ }^{90}$ tree is for a long time barren. The pyramidal appearance that it presents has caused it not to be rejected, but for a long time it was only used for marking the intervals between rows of pines: at the present day, however, it is clipped and trained to form hedge-rows, or else is thinned and lengthened out in the various designs ${ }^{91}$ employed in ornamental gardening, and which represent scenes of hunting, fieets, and various other objects: these it covers with a thin small leaf, which is always green.

There are two varieties of the cypress; the one $\mathrm{e}^{92}$ tapering and pyramidal, and which is known as the female; while the male tree ${ }^{93}$ throws its branches straight out from the body, and is often pruned and employed as a rest for the vine. Both the male and the female are permitted to throw out their branches, which are cut and employed for poles and props, being worth, after thirteen years' growth, a denarius a-piece. In respect of income, a plantation of cypress is remarkably profitable, so much so, indeed, that it was a saying in old times that a cypress-wood is a dowry for a daughter ${ }^{94}$ The native country of this tree is the island of Crete, although Cato ${ }^{95}$ calls it Tarentine, Tarentum being the first place, I suppose, in which it was naturalized: in the island of Enaria, ${ }^{96}$ also,

87 Tristis tentantum sensu torquebit amaror.-Virg. Georg. ii. 247.

88 This statement is exaggerated.

89 It is still to be seen very frequently in the cemeteries of Greece and Constantinople.

${ }_{90}$ The cypress is in reality monœcious, the structure of the same plant being both male and female.

${ }_{91}$ This was formerly done with the cypress, in England, to a considerable extent. Such absurdities are now but rare.

${ }_{92}$ The Cupressus fastigiata of Decandolle: and a variety of the Cupressus sempervirens. of Linnæus.

${ }_{93}$ The Cupressus horizontalis of Miller; the variety B of the C. sempervirens of Linnæus.

94 The present name given to this tree in the island of Crete, is the " daughter's dowry."

${ }_{95}$ De Re Rust. c. 151.

96 B. iii. c. 12. 
if the cypress is cut down, it will grow again ${ }^{97}$ from the root. But, in the Isle of Crete, in whatever place the earth is moved, this tree will shoot up ${ }^{98}$ of its own natural vigour, and immediately appear above the soil; indeed, in that island there is no occasion even to solicit the soil, for it grows spontaneously there, on the mountains of Ida more particularly, and those known as the White Mountains. On the very summit of these elevations, from which the snows never depart, we find the cypress growing in great abundance; a thing that is truly marvellous-seeing that, in other countries, it will only grow in warm localities; from which it would appear to have a great dislike to its native climate.

CHAP. 61. -THAT THE EARTH OFTEN BEARS PRODUCTIONS WHICH IT HAS NEVER BORNE BEFORE.

It is not only the quality of the soil and the unchanging influences of the climate that affect the nature of trees, but wet and showery weather also, temporarily at least. Indeed, the torrents very often bring down with them seeds, and sometimes we find those of unknown kinds even floating along. This took place in the territory of Cyrenaica, at the period when laser was first grown there, as we shall have occasion to mention when we speak of the nature of the various herbs. ${ }^{99}$ A forest, too, sprang ${ }^{1}$ up in the vicinity of the city of Cyrene, just after a shower of rain, of a dense, pitchy nature, about the year of the City of Rome 430 .

CHAP. 62. (34.) - THE IVY-TWENTY VARIETIES OF IT.

It is said that the ivy now grows in Asia, ${ }^{2}$ though Theophrastus ${ }^{3}$ has denied that such is the fact, and asserts that it grows nowhere in India, except upon Mount Meros. ${ }^{3 *}$ He says, too, that Harpalus used every possible exertion to naturalize

${ }^{97}$ This, Fée says, is the case with none of the coniferous trees.

${ }^{98}$ Of course this spontaneous creation of the cypress is fabulous; and, indeed, the whole account, which is borrowed from Theophrastus, is greatly exaggerated.

99 B. xix. c. 15. lous.

1 This story, which is borrowed from Theophrastus, is evidently fabu-

3 Hist. Plant. B. iii c. 10.

2 Meaning Asia Minor.

3* See B. vi. c. 23. 
it in Media, but to no purpose ; and that Alexander, in consequence of the rarity of this plant, had himself crowned with it, after the example of Father Liber, when returning victorious with his army from India: and at the present day even, it is used to decorate the thyrsus of that god, and the casques and bucklers employed by the nations of Thrace in their sacred ceremonials. The ivy is injurious ${ }^{5}$ to all trees and plants, and makes its way through tombs and walls; it forms a haunt much frequented by serpents, for its refreshing coolness; so that it is a matter for astonishment that there should have been such remarkable veneration for this plant.

The two principal kinds in the ivy, as in other plants, are the male tree and the female. ${ }^{6}$ The male is said to have a larger trunk than the female, and a leaf that is harder and more unctuous, with a flower nearly approaching to purple: indeed, the flower of both the male and female tree strongly resembles the wild ${ }^{7}$-rose, were it not destitute of smell. Each of these kinds of ivy is divided into three other varieties: the white ${ }^{8}$ ivy, the black, ${ }^{9}$ and a third known as the helix. ${ }^{10}$ These varieties are again subdivided into others, as there is one in which the fruit only is white, and another in which it is only the leaf that is so. In those which have a white fruit, the berry in some cases is closely packed and large, the clusters, which are known as "corymbi," being of a spherical form. So, too, with the selenitium, which has a smaller berry, and fewer clusters; and the same is the case with the black ivy. One kind has a black seed, and another a seed of a saffron ${ }^{11}$ colour-it is this last that poets use for their chaplets, ${ }^{12}$ and the leaves of it are not so black as in the other kinds : by some

4 Bacchus, after the alleged conquest by him of India, was said to have returned crowned with ivy, and seated in a car drawn by tigers.

$5 \mathrm{It}$ is a mistake to suppose that the ivy exhausts the juices of trees. Its tendrils fasten upon the cortical fissures; and, if the tree is but small, its development is apt to be retarded thereby. It is beneficial, rather than destruetive, to walls.

6 This plant is really monœcious or androgynous.

7 The Rosa Eglanteria.

8 The Hedera helix of Linnæus, or, possibly, a variety of it with variegated leaves.

9 The Hedera arborea of C. Bauhin, the common ivy.

10 The Hedera major sterilis of C. Bauhin.

11 The first variety of the common ivy, the Hedera helix of Linnæus.

12 A wreath of ivy was the usual prize in the poetic contests. 
it is known as the ivy of Nysa, by others as that of Bacchus : ${ }^{13}$ it is the one that among the black varieties has the largest clusters of all. Some of the Greek writers even distinguish in this last kind two varieties, according to the colour of the berries, the erythranum ${ }^{14}$ and the chrysocarpus. ${ }^{15}$

It is the helix, however, that has the most peculiarities of all, and in the appearance of the leaf more particularly, which is small, angular, and of a more elegant shape, the leaf in all the other kinds being plain and simple. It differs, too, in the distance between the joints, and in being barren more especially, as it never bears fruit. Some authors, however, think that this difference exists solely in respect of age and not of kind, and are of opinion that what is the helix when young, becomes the ordinary ivy when old. This, howerer, is clearly proved to be an error upon their part, for we find more varieties of the helix than one, and three in particular-that of a grassgreen colour, which is the most abundant of all, the kind with a white leaf, and a third, which is parti-coloured, and known as the Thracian helix. In that of a grass-green colour, the leaves are smaller, more closely packed together, and symmetrically arranged; while in the other kinds the features are altogether different. In the parti-coloured kind, also, one variety has a smaller leaf than usual, similarly arranged, and lying closer together, while in the other none of these features are observed. The leaves, too, are either greater or smaller and differ in the disposition of the spots upon them, and in the white helix some of them are whiter than others: the grassgreen variety, however, is the one that grows to the greatest height.

The white helix is in the habit of killing trees by depriving them of their juices, and increases to such a degree of density as to be quite a tree itself. Its characteristics are, a very large, broad, leaf, and projecting buds, which in all the other kinds are bent inwards; its clusters, too, stand out erect. Although, too, all the ivies have arms that throw out a root, those of this variety are particularly branchy and strong; next to it in strength, are those of the black ivy.

13 See B. v. c. 16, and B. vi. c. 23.

14 The "red berry" and the "golden fruit."

-5 The berries are yellow in the first variety of the common ivy, the Hedera poetica of $\mathrm{C}$. Bauhin.

rOI. III. 
It is a peculiarity of the white ivy to throw out arms from the middle of the leaves, with which it invariably embraces any object that may be on either side of it; this is the case, too, with walls, even though it should not be able to clasp them. If the trunk is cut across in ever so many places, it will still live and thrive, having as many fresh roots as it has arms, by means of which it ensures safety and impunity, while at the same time it sucks and strangles the trees to which it elings. There are great differences also in the fruit of both the white ivy and the black; for in some of them the berry is so bitter that birds will not touch it. There is an ivy also which grows upright, ${ }^{16}$ and stands without any support; being the only one that does so among all the varieties, it has thence obtained the distinctive name of "cissos." The chamæcissos, ${ }^{17}$ on the other hand, is never found except creeping upon the ground.

\section{CHAP. 63. (35.)-THE SMILAX.}

Very similar to the ivy is a plant which first came from Cilicia, but is now more commonly found in Greece, and known by the name of smilax. ${ }^{18}$ It has numerous thick stalks covered with joints, and thorny branches of a shrub-like form : the leaf resembles that of the ivy, but is not angular, while from the foot-stalk it throws out tendrils; the flower is white, and has the smell of the lily. It bears clusters like those of the wild vine and not the ivy, and of a reddish colour. The larger berries contain three stones, the smaller but one only: these berries are black and hard. This plant is looked upon as ill-omened, and is consequently banished from all sacred rites, and is allowed to form no part of chaplets; having received this mournful character from the maiden Smilax, who upon her love being slighted by the youth Crocus, was transformed into this shrub. The common people, being mostly ignorant of this, not unfrequently take it for ivy, and pollute their festivities with its presence; for who, in fact, is unaware

16 This is the case sometimes with the black ivy, the Hedera arborea of C. Bauhin. Only isolated cases, however, are to be met with.

${ }_{17}$ There is an ivy of this kind, the Hedera humi repens of botanists; but most of the commentators are of opirion that it is the ground ivy, the Glechoma hederacea of Linnæus, that is spoken of. Sprengel takes it to be the Anthirrinum Azarina, from which opinion, however, f'ée dissents.

18 The Smilax aspera of Linnæus; the sarsaparilla plant. 
that the ivy is used as a chaplet by poets, as also by Father Liber and Silenus? Tablets are made ${ }^{19}$ of the wood of the smilax, and it is a peculiarity of this wood to give out a slight sound, ${ }^{20}$ if held close to the ear. It is said that ivy is remarkably efficacious for testing wine, and that a vessel made of this wood will let the wine pass through it, while the water will remain behind, if there has been any mixed with it..21

\section{CHAP. 64. (36.)-WATER PLANTS: THE RUSH: TWENTY-EIGH'T VARIETIES OF THE REED.}

Among those plants which thrive best in cold localities, it will be only proper to mention the aquatic shrubs. ${ }^{22}$ In the first rank, we find the reed, equally indispensable for the emergencies of war and peace, and used among the appliances ${ }^{23}$ of luxury even. The northern nations make use of reeds for roofing their houses, and the stout thatch thus formed will last for centuries even; in other countries, too, they make light vaulted ceilings with them. Reeds are employed, too, for writing upon paper, those of Egypt more particularly, which have a close affinity to the papyrus: the most esteemed, however, are the reeds of Cnidos, and those which grow in Asia, on the margin of the Anaitic Lake ${ }^{24}$ there.

The reed of our country is naturally of a more fungous nature, being formed of a spongy cartilage, which is hollow within, and covered by a thin, dry, woody coat without; it easily breaks into splinters, which are remarkably sharp at the edge. In other respects, it is of a thin, graceful shape, articulated with joints, and tapering gradually towards the top, which ends in a thick, hairy tuft. This tuft is not without its uses, as it is employed for filling the beds used in taverns, in place of feathers; or else, when it has assumed a more ligneous consistency, it is pounded, as we see done among the Belgæ, and inserted between the joints of ships, to close the

19 Fée is inclined to question this; but the breadth of the tablets may have been very small in this instance.

20 Of course this is fabulous: though it is not impossible that the writing on the tablets may sometimes have caused "a noise in the world," and that hence the poets may have given rise to this story.

21 Pliny borrows this fabulous story from Cato, De Re Rust. c. 3.

${ }^{22}$ The reeds cannot be appropriately ranked among the shrubs.

${ }^{23}$ For musical purposes, namely.

24 B. v. c. 20. 
seams, a thing that it does most effectually, being more tenacious than glue, and adhering more firmly than pitch.

CHAP. 65.-REEDS USED FOR ARROWS, AND FOR THE PURPOSE OF WRITING.

It is by the aid of the reed ${ }^{25}$ that the nations of the East decide their wars; fixing in it a barbed point, they inflict a wound from which the arrow cannot be withdrawn. By the addition of feathers they accelerate the flight of this instrument of death, and the weapon, if it breaks in the wound, furnishes the combatants with a weapon afresh. With these missiles the warriors darken the very rays of the sun. ${ }^{26}$ It is for this reason more particularly that they desire a clear and serene sky, and hold in abhorrence all windy and rainy weather, which has the effect of compelling them, in spite of themselves, to be at peace with one another.

If a person were carefully to enumerate the peoples of Athiopia, Egypt, Arabia, India, Scythia, Bactria, and Sarmatia, together with all the numerous peoples of the East, and the vast realms of the Parthians, he would find that fully one-half of mankind throughout the whole world live under a dominion imposed by the agency of the arrow. It was their surpassing excellence in this arm that so ennobled the warriors of Crete, though in this respect, as well as in all others, Italy has gained the mastery; there being no reed in existence better adapted for making arrows than that found in the Rhenus, a river of the territory of Bononia : filled with a greater quantity of pith than any of the others, it is light, and easily cleaves the air, while at the same time it has sufficient weight to resist the action of the wind; an advantage that is not possessed in an equal degree by those employed among the Belgæ. These advantages, howerer, are possessed by the most approved kinds that are found in Crete, although those

25 "Calamus." The so-called reed of the East, used for making darts and arrows, does not belong to the genus Arundo, but to those of the Bambos and Nastus.

${ }^{26}$ Few readers of history will fail to recollect the report made to King Ferry V. by Davy Gam, before the battle of Agincourt:- "The enemy are so numerous," said the messenger, "that their arrows will darken the sun." "We must e'en be content to fight in the dark then," was the warrior's reply. 
of India are preferred; in the opinion of some persons, however, these last are of a totally different nature, for by adding a point to them, the natives are able to use them as lances even. Indeed, we find that in India the reed grows to the thickness of a tree, a fact which is proved by the specimens which are everywhere to be seen in our temples. The Indians assure us that in this plant, too, there is the distinction of male and female; the body of the male being more compact, and that of the female of a larger size. In addition to this, if we can credit the fact, a single compartment between the joints is sufficiently large to answer the purposes of a boat. ${ }^{27}$. These reeds are found more particularly on the banks of the river Acesines.

- In every variety of the reed a single root gives birth to numerous stems, and if cut down, they will shoot again with increased fecundity. The root, which is naturally tenacious of life, is also jointed as well as the stem. The reeds of India are the only ones in which the leaves are short; but in all the varieties these leaves take their rise at the joints, and surround the stem with a fine tissue about half way upwards to the next joint, and then leave the stem and droop downwards. The reed, as well as the calamus, although rounded, has two sides, which throw out leaves alternately from above the joints, in such a way that when one springs from the right side, the next issues from the joint above it on the left, and so in turns. Branches, too, shoot occasionally from the stem, being themselvęs reeds of diminutive growth.

CHAP. 66.-FLUTE REEDS: THE REED OF ORCHOMENUS; RETDS USED FOR FOWLING AND FISEING.

The varieties of the reed are numerous. Some are more compact than others, thicker at the joints, and with a shorter interval between them; while others, again, are less compact, with longer intervals between the joints, and not so straight. Another kind of reed is quite hollow; it is known as the "syringia," 28 and is particularly useful for making flutes, having neither pith in it nor any fleshy substance. The reed of Or-

27 See B. vii. c. 2. This is probably an exaggeration. He alludes to the Bambos arundinacea of Lamarck, the Arundo arbor of C. Bauhin.

28 The Arundo donax of Linnæus. 
chomenus has a passage in it open from one end to the other, and is known as the auleticon; ${ }^{29}$ this last is best for making pipes,,$^{30}$ the former ${ }^{31}$ for the syrinx. There is another reed, the wood of which is thicker, and the passage very contracted, being entirely filled with a spongy kind of pith. One kind, again, is shorter, and another longer, the one thinner, the other more thick. That known as the donax, throws out the most shoots, and grows only in watery localities; indeed, this is a point which constitutes a very considerable difierence, those reeds being greatly preferred which grow in a dry soil. The archer's reed forms a peculiar species, as we have already stated $;^{32}$ but that of Crete ${ }^{33}$ has the longest, intervals between the joints, and when subjected to heat is capable of being rendered perfectly pliable ${ }^{34}$ at pleasure. The leaves, too, constitute different varieties, not only by their number, but their colour also. The reed of Laconia is spotted, ${ }^{35}$ and throws out a greater number of shoots at the lower extremities; being very similar in nature, it is thought, to the reeds that we find growing about stagnant waters, and unlike those of the rivers, in being covered with leaves of considerable length; which, climbing upwards, embrace the stem to a considerable distance above the joints. There is also an obliquely-spreading reed, which does not shoot upwards to any height, but spreads out like a shrub, keeping close to the earth; this reed is much sought by animals when young, and is known by some persons as the elegia. ${ }^{36}$ There is in Italy, too, a substance found in the marsh-reeds, called by the name of adarca $:^{37}$ it is only to be found issuing from the cuter skin, below the flossy head of the plant, and is particularly

29 Or the pipe-reed.

${ }^{30}$ The tibia, or pipe, was played lengthwise, like the flageolet or clarionet.

31 A variety of the Arundo donax. The Orchomenian reed is of the same class. The fistula was played sidewars; and seems to have been a name given both to the Syrinx or the Pandæan pipes, and the flute, properly so called.

${ }^{32}$ In the last Chapter. The Arundo donax, probably, so far as European warfare was concerned.

33 A variety of the Arundo donax of Linnæus.

34 This is not the fact.

35 The Arundo versicolor of Miller.

36 Constantinus and Schneider, upon Theophrastus, Hist. Plant. B. iv. c. 11, suspect the correctness of this word.

37 See B. xx. c. 88 , and B. xxxii. c. 52. 
beneficial to the teeth, having, in fact, an equal degree of pungency with mustard.

The terms of admiration in which they are spoken of by the ancients compels me to enter into some more minute details relative to the reed-beds of Lake Orchomenus. Characias ${ }^{38}$ was the name given there to a reed of stout and compact quality, while a thinner one was known as the plotias; this last was to be found growing on the floating islands there, while the former grew upon the banks that were covered by the waters of the lake. A third kind again, which had the name of "auleticon," was the same that is now known as the musical pipe ${ }^{39}$ reed. This reed used to take nine years to grow, as it was for that period that the waters of the lake were continually on the increase; it used to be looked upon as a prodigy of evil omen, if at the end of its rise its waters remained overflowing so long as a couple of years; a thing that was observed at the period of the Athenian disasters at Cheronæa, and on various other occasions. This lake has the name of Lebaida, at the part where the river Cephisus enters it.

When this inundation has lasted so long as a year, the reed is found large enough to be available for the purposes of fowling: at this period it used to be called zeugites. ${ }^{40}$ On the other hand, when the waters subsided at an earlier period, the reeds were known as bombyciæ, ${ }^{41}$ being of a more slender form. In this variety, too, the leaf of the female plant was broader and whiter than that of the others, while that upon which there was little or no down bore the name of the eunuch reed. The stem of this last variety was used for the manufacture of concert ${ }^{42}$ flutes. I must not here pass by in silence the marvellous care which the ancients lavished upon these instruments, a thing which will, in some measure, plead as an apo$\operatorname{logy}$ for the manufacture of them at the present day of silver in preference. The reed used to be cut, as it was then looked upon as being in the best condition, at the rising of Arcturus ; ;3 $^{3}$

38 The Arundo phragmites of Linnæus. The Plotias, no doubt, was only a variety of it.

39 "Arundo tibialis." The story about the time taken by it to grow, and the increase of the waters, is, of course, fabulous.

40 The "yoke reed," or "reed for a double flute."

41 Perhaps so called from the silkiness of its flossy pinicules.

42 This seems to be the meaning of "ad inclusos cantus."

43 B. xviii. c. 74 . 
an usage which prevailed down to the time of Antigenides, the musician, and while flute-playing was of a more simple style. Being thus prepared, the reeds became fit for use in the course of a few years. At that period even the reed required considerable seasoning to render it pliable, and to be instructed, as it were, in the proper modulation of its sounds; the mouthpiece and stops ${ }^{44}$ being naturally contracted, and so producing a music better adapted to the theatrical taste of the day. But in later times, when the music became more varied, and luxury began to exercise its influence upon the musical taste, it became the general usage to cut the reeds before the summer solstice, and to make them fit for use at the end of three months; the stops and mouth-piece being found, when the reeds were cut at that period, to be more open and better adapted for the modifications of sound: it is in this state that the reed is used for similar purposes at the present day. In those times it was a very general persuasion also, that every pipe ought to have the tongue of its own mouth-piece cut from the same reed as itself, and that a section from the part nearest the root was best adapted to form the left-handed flute, ${ }^{45}$ and from the part adjoining the top the right-handed one: those reeds, too, were considered immeasurably superior, which had been washed by the waters of Cephisus itself.

At the present day the sacrificial pipes used by the Tuscans are made of box-wood, while those employed at the games are made of the lotus, ${ }^{46}$ the bones of the ass, or else silver. The fowler's reeds of the best quality are those of Panormus, ${ }^{47}$ and the best reeds for fishing-rods come from Abarita in Africa. ${ }^{48}$

\section{CHAP. 67.-THE VINE-DRESSERS' REED.}

The reed is employed in Italy more particularly, as a sup-

${ }^{44}$ Lingulis.

45 'The words "dextræ" and "sinistræ," denote the treble and the bass flutes; it is thought by some, because the former were held with the right hand, and the latter with the left. Two treble or bass flutes were occasionally played on at the same time.

46 See B. xiii. c. 32 .

47 These were of the variety Zeugites, previously mentioned.

4s Fée suggests, that what he mentions here may not have been a reec at all, but one of the cyperaceous plants, the papyrus, perhaps. 
port for the vine. Cato ${ }^{49}$ recommends that it should be planted in a damp situation, the soil being first turned up with a double mattock, and a distance of three feet left between the young ${ }^{50}$ layers; he says, too, that the wild asparagus ${ }^{51}$ from which the cultivated species is produced, may be planted together with it, as they agree particularly well together.

(37.) He says also that the willow may be planted in its vicinity, than which there is no aquatic plant of more general utility, although the poplar may be preferred for the training of the vine, and the support of the Cæcuban grape; although, too, the alder affords a more efficient protection by the hedges it forms, and, planted in the very water, makes a rampart along the banks in defence of the adjoining country against the violence of the rivers when they overflow; when cut down, too, this last tree is useful for the innumerable suckers which it throws out.

CHAP. 68. -THE WILLOW : IIGHT VARIETIES OF IT.

Of the willow, too, there are several varieties. On ${ }^{52}$ of them throws out its branches to a considerable height; and these, coupled together, serve as perches for the vine, while the bark around the tree itself is used for withes..$^{53}$ Others,,$^{54}$ again, of a more pliable nature, supply a flexible twig, which is used for the purpose of tying; while others throw out osiers of remarkable thinness, adapted by their suppleness and graceful slenderness for the manufacture of wicker-work. ${ }^{55}$ Others, again, of a stouter make, are used for weaving panniers, and many other utensils employed in agriculture; while from a whiter willow the bark is peeled off, and, being remarkably tractable, admits of various utensils being made of it, which require a softer and more pliable material than leather: this last is also found particularly useful in the construction of those articles of luxury, reclining chairs. The willow, when

${ }^{49}$ De Re Rust. c. 6. It was the donax that was thus employed; as it is in France at the present day.

50 Oculis. See B. xvii. c. 33 .

${ }^{51}$ See B. xix. c. 42 .

52 The white willow, Salix Alba of Linnæus.

${ }^{53}$ The Salix vitellina more particularly is used in France for this purpose.

51 The Salix helix of Linnæus.

55 The Salix amygdalina of Linnæus. 
cut, continues to thrive, and, indeed, throws out more thickly from the top, which, when closely clipped, bears a stronger resemblance to a closed fist than the top of a stump. It is a tree, which, in my opinion, deserves to be placed by no means in the lowest rank of trees; for there is none that will yield a more certain profit, which can be cultivated at less expense, or which is less liable to be influenced by changes in the weather.

CHAP. 69. - TREES IN ADDITION TO THE WILLOW, WHICH ARE OF USE IN MAKING WITHES.

Cato ${ }^{56}$ considers the culture of the willow as deserving to hold the third rank in estimation, and he gives it precedence to the cultivation of the olive, tillage for corn, or laying out land for pasture. It is not, however, because the willow is the only tree that produces withes; for they may be procured also from the broom, the poplar, the elm, the blood-red cornel, the birch, and the reed itself when split, or else the leaves of that plant, as we know to be the case in Liguria. The vine, also, will furnish them; the bramble, too, with the thorns removed, as well as the twisted hazel. It is a very singular thing, that a wood after it has been beaten and pounded should be found all the stronger for making withes, but such is a striking peculiarity that exists in the willow. The Greek red $^{57}$ willow is split for this purpose: while the willow ${ }^{58}$ of Ameria is whiter but more brittle, for which reason it is used in an uncut state for tying. In Asia there are three varieties known of the willow; the black ${ }^{59}$ willow, which is best adapted for making withes, the white willow, employed for various agricultural purposes, and a third, which is shorter than the others, and known as the helix. ${ }^{60}$

With us, also, there is the same number of denominations given to as many varieties of the willow; one being known

56 De Re Rust. c. 6. Fée remarks that the notions of modern agriculturists are very different on this point. Baubin.

58 This belongs, probably, to the Salix helix of Linnæus.

59 Fée queries whether this may not be the Salix incana of Schrank and Hoffmann, the bark of which is a brown green.

60 Belonging to the Salix helix of Linnæus. 
as the viminal or purple willow, ${ }^{61}$ another as the nitelina, ${ }^{62}$ from its resemblance to the colour of the nitela, thinner in the trunk than the preceding one, and the third as tre Gallic $^{63}$ kind, being the thinnest of them all.

\section{CHAP. 70.-RUSHES : CANDLE-RUSHES : RUSHES FOR THATCHING.}

The rush, ${ }^{64}$ so frail in form, and growing in marshy spots, cannot be reckoned as belonging to the shrubs, nor yet to the brambles or the stalk plants; nor, indeed, in strict justice, to any of the classes of plants except one that is peculiarly its own. It is extensively used for making thatch and matting, and, with the outer coat taken off, for making candles and funeral torches. In some places, however, the rush is more hard and firm: thus, for instance, it is employed not only by the sailors on the Padus for making the sails of boats, but for the purposes of sea-fishing as well, by the fishermen of Africa, who, in a most preposterous manner, hang the sails made of it behind the masts. ${ }^{6 \overline{5}}$ The people, too, of Mauritania thatch their cottages $^{66}$ with rushes; indeed, if we look somewhat closely into the matter, it will appear that the rush is held in pretty nearly the same degree of estimation there as the papyrus is in the inner regions of the world. ${ }^{67}$

\section{CHAP. 71.-THE ELDER : THE BRAMBLE.}

Of a peculiar nature, too, though to be reckoned among the water ${ }^{68}$-plants, is the bramble, a shrub-like plant, and the elder, which is of a spongy nature, though not resembling giant fennel, from having upon it a greater quantity of wood. It is a belief among the shepherds that if they cut a horn or trumpet from the wood of this tree, it will give all the louder sound if cut in a spot where the shrub has been out of hearing of the crowing of the cock. The bramble bears mulberries, ${ }^{69}$ and

61 Belonging to the Salix purpurea of Linnæus.

62 Field-mouse or squirrel colour. See B. viii. c. 82 . The same, probably, as the Salix vitellina of Linnæus.

${ }^{63}$ A variety, Fée thinks, of the Salix rubens.

64 The Scirpus lacustris of Linnæus.

${ }_{55}$ And not in front of them.

67 Egypt, namely.

68 The bramble is sometimes found on the banks of watery spots and in marshy localities, but more frequently in mountainous and arid spots.

${ }^{39}$ Known to us as blackberries. "This tree is the Rubus fruticosus of 
one variety of it, known as the cynosbatos, ${ }^{70}$ bears a flower similar to the rose. There is a third variety, known to the Greeks as the Idæan ${ }^{71}$ bramble, from the place where it grows : it is slighter than the others, with smaller thorns, and not so hooked. Its flower, mixed with honey, is employed as an ointment for sore eyes and erysipelas: and an infusion of it in water is used for diseases of the stomach. ${ }^{72}$

The elder ${ }^{72^{*}}$ bears a small black berry, which contains a viscous juice, employed more particularly for staining ${ }^{73}$ the hair. The berries, too, are boiled in water and eaten. ${ }^{74}$

\section{CHAP. 72. (38.) -THE JUICES OF TREES.}

There is a juice in the bark of trees, which must be looked upon as their blood, though it is not of a similar nature in all. In the fig it is of a milky consistency, and has the peculiar property of curdling milk, and so forming cheese. ${ }^{75}$ In the cherry-tree this juice is gummy, in the elm clammy, in the apple viscous and fatty, while in the vine and the pear it is watery. The more viscous this humour is, the more longlived the tree. In a word, we find in the bodies of trees-as with all other keings that are animated-skin, blood, flesh, sinews, veins, bones, and marrow; the bark serving them in place of skin. It is a singular fact connected with the mulberry-tree, that when the medical men wish to extract its juice, if the incision is lightly made, by a blow with a stone, and at the second hour of the day in spring, the juice will flow: but if, on the other hand, a wound is inflicted to any depth, it has all the appearance of being dried up.

Immediately beneath the bark in most trees there is a fatty substance, which, from its colour, has obtained the name of alburnum : i6 it is soft, and is the very worst part of the wood,

Linnæus; the same as the Rubus tomentosus, and the Rubus corylifolius of other moderu botanists.

70 The Rosa canina of Linnæus : the dog-rose or Eglantine.

71 The Rubus Idæus of botanists; the ordinary raspberry.

72 See B. xxiv. c. 75. 72* See B. xxiv. c. 35 .

73 They are still used for dyeing, but not for staining the hair.

74 Only as a purgative, probably.

75 Though the acid it contains would curdle milk, still its natural acridity would disqualify it from being used for making cheese.

76 The white sap or inner bark; the aubier of the French. Fée remarks, that its supposed analogy with fat is incorrect. 
and in the robur even will very easily rot, being particularly liable to wood-worm, for which reason it is invariably removed. Beneath this fat lies the flesh ${ }^{77}$ of the tree, and then under that, its bones, or, in other words, the choicest part of the wood. Those trees which have a dry wood, the olive, for instance, bear fruit every other year only: this is more the case with them than with those the wood of which is of a fleshy nature, such as the cherry, for instance. It is not all trees, too, that have this fat and flesh in any abundance, the same as we find to be the case among the more active animals. The box, the cornel, and the olive have none at all, nor yet any marrow, and a very small proportion, too, of blood. In the same way, too, the service-tree has no bones, and the elder no flesh, while both of them have marrow in the greatest abundance. Reeds, too, have hardly any flesh.

\section{CHAP. 73.-THE VEINS AND FIBRES OF TREES.}

In the flesh of some trees we find both fibres ${ }^{78}$ and veins: they are easily distinguished. The veins ${ }^{79}$ are larger, while the fibres are of whiter material, and are to be found in those woods more particularly which are easily split. Hence it is that if the ear is applied to the extremity of a beam of wood, however long, a tap with a graver ${ }^{80}$ even upon the other end may be distinctly heard, the sound penetrating by the passages which run straight through it: by these means it is that we ascertain whether timber runs awry, or is interrupted by knots. The tuberosities which we find on trees resemble the kernels ${ }^{81}$ that are formed in flesh : they contain neither veins nor fibres, but only a kind of tough, solid flesh, rolled up in a sort of ball : it is these tuberosities that are the most esteemed parts ${ }^{82}$ in the citrus and the maple. As to the other kinds of wood

${ }^{77}$. He means the outer ligneous layers of the wood. They differ only in their relative hardness.

73 "Pulpæ." The ligneous fibres which form the tissue of the bark.

79 "Venæ." By this term he probably means the nutritive vessels and the ligneous fibres united. It was anciently the general belief that the fibres acted their part in the nutriment of the tree.

so "Graphium." Properly a stylus or iron pen.

81 "Glandia." This analogy, Fée remarks, does not hold good.

82 See B. xiii. c. 29, and c. 27 of this Book. 
which are employed for making tables, the trees are split into planks lengthwise, and the parts are then selected along which the fibres run, and properly rounded; for the wood would be too brittle to use if it were cut in segments crosswise. ${ }^{83}$ In the beech, the grain of the fibrous part runs crosswise $;^{84}$ hence it is that the ancients held in such high esteem all vessels made with the wood of it. Manius Curius made oath, on one occasion, that he had not touched an article of all the spoil except a single oil cruet $^{85}$ of beech, to use for sacrificing. Wood is always put lengthwise into the water to season, as that part which was nearest the root will sink to a greater ${ }^{86}$ depth than the other. In some wood there is fibre, without veins, and merely consisting of filaments slightly knit together: wood of this nature is remarkably fissile. Other wood, again, is more easily broken across than split, such as the wood of those trees that have no fibre, the olive and the vine, for instance : on the other hand, in the fig-tree, the whole of the body consists of flesh. ${ }^{87}$ The holm-oak, the cornel, the robur, the cytisus, the mulberry, the ebony, the lotus, and the other trees which we have mentioned $^{88}$ as being destitute of marrow, consist entirely of bone. ${ }^{89}$ All these woods are of a blackish colour, with the exception of the cornel, of which glossy yellow hunting-spears are made, marked with incisions for their further embellishment. In the cedar, the juniper, and the larch, the wood is red.

(39.) In Greece the female larch furnishes a wood ${ }^{90}$ which is known as ægis, and is just the colour of honey. This wood has been found to be proof against decay, and forms the pannels used by painters, being never known to gape or split; the portion thus employed is that which lies nearest to the pith. In the fir-tree this part is called "leuson" by the Greeks. In the cedar, too, the hardest part is the wood that lies nearest to the

83 And at an angle with the grain or fibre of the wood.

84 And at right angles. In the Dicotyledons, the disposition of the fibres is longitudinal and transversal.

85 Guttum.

${ }^{86}$ For the simple reason, because the part near the root is of greater diameter.

87 Soft ligneous layers.

88 In c. 72 of this Book.

89 Hard wood-such as we know generally as "heart;" "heart of oak" for instance.

90 Probably that of the ligneous layers nea: the pith or sap. 
sap : after the slimy ${ }^{91}$ pith has been carefully removed, it has a similar degree of hardness to the bones in the bodies of animals. It is said, too, that in Greece the inner part of the elder is remarkably firm: indeed, those whose business it is to make hunting spears, prefer this material to all others, it being a wood composed wholly of skin and bone.

\section{CHAP. 74. - THE FELLING OF TREES.}

The proper time for felling trees that are wanted for barking, the round, tapering trees, for instance, that are employed in temples and for other purposes, is at the period of germination: ${ }^{92}$ for at other times it is quite impossible to detach the bark from the rotten wood that adheres to it, while the wood itself assumes a blackish hue. Squared logs, and wood from which the bark has been lopped, are generally cut in the period that intervenes between the winter solstice and the prevalence of the west winds; or else, if it is necessary to anticipate that period, at the setting of Arcturus and before that of the Iuyre, the very earliest period being the summer solstice : the days of these respective constellations will be mention ed in the appropriate place. ${ }^{93}$

In general it is looked upon as quite sufficient to use all due precaution that a tree is not rough-hewn before it has borne its yearly crop. The robur, if cut in spring, is subject to the attacks of wood-worm, but if cut in winter, willneither rot nor warp: otherwise it is very liable to bend and become awry, as well as to crack; the same is the case, too, with the cork-tree, even if cut down at the proper time. The state of the moon, ${ }^{91}$ too, is of infinite importance, and it is generally recommended that trees should be cut only between the twentieth and the thirtieth days of the month. It is generally agreed, however, by all, that it is the very best time for felling timber, when the moon is in conjunction with the sun, a day which is called by some persons the interlunium, and by others the moon's silence. At all events, it was

91 "Limo:" the alburnum previously mentioned.

92 This practice was formerly forbidden by the forest laws of France.

93 In B. xviii.

94 Pliny borrows this superstition from Theophrastus, Hist. Plant. B. vi. c. 1 . 
under these circumstances that Tiberius Cæsar gave orders for the larches to be cut in Rhætia, that were required for the purpose of rebuilding the bridge of the Naumachia ${ }^{95}$ after it had been destroyed by fire. Some persons say that the moon ought not only to be in conjunction, but below the horizon as well, a thing that can only happen in the night. If the conjunction should chance to fall on the very day of the winter solstice, the timber, they say, that is then felled will be of everlasting duration; the next best being the timber that is cut when the conjunction coincides with the constellations previously mentioned. There are some, too, who add the rising of the Dog-star as a favourable time, and say that it was at this period that the timber was cut which was employed in building the Forum of Augustus.

Wood which is intended for timber ought to be cut neither when ton young nor too old. Some persons, too-and the practice is by no means without its utility - cut round ${ }^{96}$ the tree as far as the pith, and then leave the timber standing, so that all the juices may be enabled to escape. Going back to ancient times, it is a remarkable fact, that in the first Punic War the fleet commanded by Duillius was on the water within sixty days from the time the timber was cut: and, what is still more so, Piso relates that King Hiero had two hundred and twenty ships wholly constructed in forty-five days: in the second Punic War, too, the fleet of Scipio was at sea the fortieth day after the axe had been put to the tree. Such is the energy and dispatch that can be displayed on occasions of emergency.

CHAP. 75. - THE OPINION OF CATO ON THE FELLING OF TIMBER.

Cato, ${ }^{97}$ a man of consummate authority in all practical matters, expresses himself in relation to timber to the following effect:- "For making presses, employ the wood of the sappinus in preference. When you root up the elm, the pine, the nut-

${ }_{95}$ This was the name of mimic sea-fights, exhibited at Rome in the Circus or amphitheatres, or else in lakes dug expressly for the purpose. Hardouin says, there were five Naumachiæ at Rome, in the 14th region of the City.

${ }_{96}$ This practice is no longer followed.

97 De Re Rust. c. 31 ; also cc. 17 and 37. 
tree, or, indeed, any other kind of tree, mind and do so when the moon is on the wane, after midday, and when there is no south wind blowing. The proper time for cutting a tree is when the seed ${ }^{98}$ is ripe, but be careful not to draw it away or plane it while the dew is falling." He then proceeds to say ${ }^{59}$ - "Never touch the timber, except when the moon is on the change, or else at the end of the second quarter: at those periods you may either root up the tree, or fell it as it stands. The next seven days after the full moon are the best of all for grubbing up a tree. Be particularly careful, too, not to roughhew timber, or, indeed, to cut or touch it, unless it is perfectly dry; and by no means while it is covered with frost or dew."

The Emperor Tiberius used also to observe the changes of the moon for cutting his hair. ${ }^{1} \quad M$. Varro ${ }^{2}$ has recommended that the hair should be cut at full moon only, if we would avoid baldness.

\section{CHAP. 76.-THE SIZE OF TREES: THE NATURE OF WOOD : THE SAPPINUS.}

From the larch, and still more the fir, after it has been cut, a liquid ${ }^{3}$ flows for a considerable period: these are the loftiest and straightest of all the trees. The fir is preferred for making the masts and sailyards of ships, on account of its comparative lightness. It is a common feature with these trees, in common with the pine, to have four rows of veins running along the wood, or else two, or sometimes only one. The heart ${ }^{4}$ of these trees is peculiarly well adapted for joiners' work, and the best wood of all is that which has four layers of veins, it being softer than the rest: men of experience in these matters can instantly form a judgment of the quality from the bark. That part in the fir which is nearest to the ground is free from knots: when soaked in river water in the way we have already mentioned, ${ }^{5}$ and then barked, the

98 This practice is observed in modern times.

99 C. 37.

1 Pliny, no doubt, observes an analogy between the hair of the human head, and trees as forming the hair of the earth. The superstition here mentioned, Fee says, was, till very recently, observed in France to a considerable extent.

2 De Re Rust. 1, 37.

3 Terebinthine or turpentine.

* "Ad fabrorum intestina opera medulla sectilis" This passage is probably corrupt. 5 In c. 74.

VOL. III. 
wood of this part is $\mathrm{known}^{6}$ as sappinus; while that of the upper part, which is harder and knotty, goes by the name of "fusterna." In trees, the side which looks towards the northeast is the most robust, and it is universally the case, that those which grow in moist and damp localities are of inferior quality, while in those which grow in warm and sunny spots, the wood is more compact and durable; hence it is, that at Rome the fir is preferred that grows on the shores of the Tyrrhenian Sea to that of the shores of the Adriatic.

There are also considerable differences in the qualities of these trees according to the country of their growth: the most esteemed are those of the Alps and the Apennines; in Gaul, those of $\mathrm{Jura}^{7}$ and Mount Vogesus; those also of Corsica, Bithynia, Pontus, and Macedonia; while the firs of Anea ${ }^{8}$ and Arcadia are of inferior quality. Those, however, of Parnassus and Eubœa are the worst of all, the trees being branchy and knotted, and the wood very apt to rot. As for the cedar, those of Crete, Africa, and Syria are the most esteemed. Wood, if well rubbed with oil of cedar, is proof against wood-worm and decay. The juniper, too, has the same ${ }^{9}$ virtues as the cedar ; in Spain it grows to a very considerable size, in the territory of the Vaccæi ${ }^{10}$ more particularly : the heart of this tree, too, is universally more firm and solid than cedar even. A general fault in all wood is that known as cross-grain, which is formed by contortions of the knots and veins. ${ }^{11}$ In the wood of some trees there are to be found knurs, ${ }^{12}$ like those in marble; these knurs are remarkably hard, and offer a resistance like that of a nail, to the great injury of the saw : in some cases, also, they are formed accidentally, from either a stone, or the branch of another tree lodging there, and being absorbed in the body of the tree.

In the Forum at Megara there long stood a wild olive upon which warriors who had distinguished themselves by their

6 With reference to the fir, namely.

7 B. iii. c. 5 . 8 B. iv. c. 3.

9 An additional proof, perhaps, that the cedar of the ancients is only one of the junipers, and that, as Fée says, they were not acquainted with the real cedar.

10 B. iii. c. 4.

11 "Spiras." It seems to have been the opinion of the ancients that the internal knots of the wood are formed spirally. Such is not the fact, as they consist of independent layers.

12 Centra. 
martial powers had been in the habit of suspending their arms. In the lapse of time the bark of this tree had closed, and quite concealed these arms from view. Upon it, however, depended the fate of the city; for it had been announced by an oracle, that when a tree there should bring forth arms, the fall of the city would be close at hand: and such, in fact, was the result, when the tree was cut down and greaves and helmets were found within the wood. ${ }^{13}$ It is said that stones found under these circumstances have the property of preventing abortion.

(40.) It is generally thought that the largest ${ }^{14}$ tree that has erer been seen, was the one that was exhibited at Rome, by Tiberius Cæsar, as an object of curiosity, upon the bridge of the Naumachia previously mentioned. ${ }^{15}$ It had been brought thither along with other timber, and was preserved till the construction of the amphitheatre of the Emperor Nero: ${ }^{16}$ it was a $\log$ of larch, one hundred and twenty feet long, and of an uniform thickness of a couple of feet. From this fact we can form an estimate of the original height of the tree; indeed, measured from top to bottom it must have been originally of a length that is almost incredible. In our own time, too, in the porticos of the Septa, ${ }^{17}$ there was a log which had been left there by $\mathbf{M}$. Agrippa, as being equally an object of curiosity, having been found too large to be used in the building of the vote office ${ }^{15}$ there : it was twenty feet shorter than the one previously mentioned, and a foot-and-a-half in thickness. There was a fir, too, that was particularly admired, when it formed the mast of the ship, which brought from Egypt, by order of the Emperor Caius, ${ }^{19}$ the obelisk ${ }^{20}$ that was erected in the Vaticanian Circus, with the four blocks of stone intended for its base. It is beyond all doubt that there has been seen nothing on the sea

13 He takes this account from Theophrastus, Hist. Plant. B. v. c. 3.

14 The greatest height, Fee says, of any tree known, is that of the palm, known as ceroxylon; it sometimes attains a height of 250 feet. Adanson speaks of the baobab as being 90 feet in circumference.

${ }_{15}$ In c. 74.

16 See B. xix. c. 6.

17 A spot enclosed in the Campus Martius, for the resort of the people during the Comitia, and when giving their votes.

18 "Diribitorium." This was the place, probably, where the diribitores distributed to the citizens the tabellæ, with which they voted in the Comitia, or else, as Wunder thinks, divided the votes, acting as "tellers," in the modern phrase.

19 Caligula.

20 B. xxxvi. c. 14. 
more wonderful than this ship: one hundred and twenty thousand modii of lentils formed its ballast; and the length of it took up the greater part of the left side of the harbour at Ostia. It was sunk at that spot by order of the Emperor Claudius, three moles, each as high as a tower, being built upon it; they were constructed with cement ${ }^{21}$ which the same vessel had conveyed from Puteoli. It took the arms of four men to span the girth of this tree, and we not unfrequently hear of the price of masts for such purposes, as being eighty thousand sesterces or more: rafts, too, of this wood are sometimes put together, the value of which is forty thousand. In Egypt and Syria, it is said, the kings, for want of fir, used to employ cedar $^{22}$ for building their ships : the largest cedar that we find mentioned is said to have come from Cyprus, where it was cut to form the mast of a galley of eleven tiers of oars that belonged to Demetrius: it was one hundred and thirty feet in length, and took three men to span its girth. The pirates of Germany navigate their seas in vessels formed of a single tree hollowed ${ }^{23}$ out: some of these will hold as many as thirty men.

Of all woods, the most compact, and consequently the heaviest, are the ebony and the box, both of them of a slender make. Neither of these woods will float in water, nor, indeed, will that of the cork tree, if the bark is removed; the same is the case, too, with the wood of the larch. Of the other woods, the driest is that of the tree known at Rome as the lotus, ${ }^{24}$ and next, that of the robur, when the white sap has been removed. The wood of the robur is dark, and that of the cytisus $^{25}$ still more so, approaching, in fact, the nearest of all to the colour of ebony; though there are not wanting writers who assert that the wood of the Syrian terebinth is darker. ${ }^{26}$ An artist of the name of Thericles is highly spoken of for his skill in turning goblets from the wood of the terebinth: and, indeed, that fact is a proof of the goodness of the wood. Terebinth is the only wood that requires to be rubbed with oil, and is im-

21 See B. xxxvi, c. 14. This was a mortar made of volcanic ashes, which hardened under water. It is now known as Pozzuolane.

22 The Pinus cedrus of Linnæus.

${ }^{23}$ The canoes were formed probably of the fir.

24 The Celtis australis of Linnæus.

25 See B. xiii. c. 27.

26 This, Fée says, is not the case, if the Syrian terebinth is the same as the Pistacia terebinthus of Linnæus. 
proved thereby. Its colour is imitated remarkably well with the walnut and the wild pear, which have its peculiar tint imparted to them by being boiled in colouring liquid. The wood of all the trees of which we have here made mention is firm and compact. Next after them comes the cornel, although it can hardly be looked upon as timber, in consequence of its remarkable slimness; the wood of it, in fact, is used for hardly any other purpose than the spokes of wheels, or else for making wedges for splitting wood, and pins or bolts, which have all the hardness of those of iron. Besides these, there are the holm-oak, the wild and the cultivated olive, the chesnut, the yoke-elm, and the poplar. This last is mottled similarly to the maple, and would be used for joiners' work if wood could be good for anything when the branches are so often lopped : that acting upon the tree as a sort of castration, and depriving it of its strength. In addition to these facts, most of these trees, but the robur more particularly, are so extremely hard, that it is quite impossible to bore the wood till it has been soaked in water; and eren then, a nail once driven home cannot be drawn out again. On the other hand, a nail has $n 0^{26}$ hold in cedar. The wood of the lime is the softest of all, and, as it would appear, the hottest by nature; a proof of this, they say, is the fact that it will turn the edge of the adze sooner than any other wood. ${ }^{27}$ In the number, aiso, of the trees that are hot by nature, are the mulberry, the laurel, the ivy, and all those woods from which fire is kindled by attrition.

\section{CHAP. 77. - METHODS OF OBTAINING FIRE FROM WOOD.}

This is a method ${ }^{28}$ which has been employed by the outposts of armies, and by shepherds, on occasions when there has not been a stone at hand to strike fire with. Two pieces of wood are rubbed briskly together, and the friction soon sets them on fire; which is caught on dry and inflammable substances, funguses and leaves being found to ignite the most readily. There is nothing superior to the wood of the ivy for rubbing against,

${ }^{26}$ This is not the case; a nail has a firm hold in all resinous woods.

27 This is evidently a puerile absurdity : but it is borrowed from 'Theophrastus, Hist. Plant. B. v. c. 4.

28 The savages of North America, and, indeed, of all parts of the globe, seem to have been acquainted with this method of kindling fire from the very earliest times. 
or to that of the laurel for rubbing with. A species of wild vine, ${ }^{99}$ too-not the same as the labrusca-which climbs up other trees like the ivy, is highly approved of. The coldest ${ }^{30}$ woods of all are those of the aquatic trees; but they are the most flexible also, and for that reason the best adapted for the construction of bucklers. On an incision being made in them, they will contract immediately, and so close up their wounds, at the same time rendering it more difficult for the iron to penetrate: in the number of these woods are the fig, the willow, the lime, the birch, the elder, and both varieties of the poplar.

The lightest of all these woods, and consequently the most useful, are the fig and the willow. They are all of them employed, however, in the manufacture of baskets and other utensils of wicker-work; while, at the same time, they possess a degree of whiteness and hardness which render them very well adapted for carving. The plane has considerable Hexibility, but it is moist and slimy like the alder. The elm, too, the ash, the mulberry, and the cherry, are flexible, but of a drier nature; the wood, however, is more weighty. The elm is the best of all for retaining its natural toughress, and hence it is more particularly employed for socket beams for hinges, and cases for the pannelling of doors, being proof against warping. It is requisite, however, that the beam to receive the hinge should be inverted when set up, the top of the tree answering to the lower hinge, the root to the upper. The wood of the palm and the cork-tree is soft, while that of the apple and the pear is compact. Such, however, is not the ease with the maple, its wood being brittle, as, in fact, all veined woods are. In every kind of tree, the varieties in the wood are still more augmented by the wild trees and the males. The wood, too, of the barren tree is more solid than that of the fruit-bearing ones, except in those species in which the male trees $^{31}$ bear fruit, the cypress and the cornel, for instance.

CHAP. 78.-TREES WHICH ARE PROOF AGAINST DECAY: TREeS WHICH NEVER SPLIT.

The following trees are proof against decay and the other-

${ }^{29}$ See B. xxiv. c. 49 . The Viticella, belonging to the genus clematis.

30 This unfounded notion is borrowed from Theophrastus, B. v. c. 4.

31 In the modern botanical sense of the word, the male trees do not bear at all. 
wise injurious effects of age-the cypress, the cedar, the ebony, the lotus, the box, the yew, the juniper, and both the wild and cultivated olive. Among the others, the larch, the robur, the cork-tree, the chesnut, and the walnut are also remarkably durable. The cedar, cypress, olive, and box are never known to split or crack spontaneously.

\section{CHAP. 79.-HISTORICAL FACTS CONNECTED WITH THE DURABILITY} OF WOOD.

Of all the woods, the ebony, the cypress, and the cedar are considered to be the most durable, a good proof of which is to be seen in the timber of which the Temple of Diana at Ephesus is built: it being now four hundred years since it was erected, at the joint expense of the whole of Asia ; $;^{32}$ and, what is a wellknown fact, the roof is wholly constructed of planks of cedar. As to the statue of the goddess, there is some doubt of what wood it is made; all the writers say that it is ebony, with the exception of Mucianus, who was three times consul, one of the very latest among the writers that have seen it; he declares that it is made of the wood of the vine, and that it has never been changed all the seven times that the temple has been rebuilt. He says, too, that it was Endæus who made choice of this wood, and even goes so far as to mention the artist's name, a thing that really surprises me very much, seeing that he attributes to it an antiquity that dates before the times of Father Liber, and of Minerva even. He states, also, that, by the aid of numerous apertures, it is soaked with nard, in order that the moist nature of that drug may preserve the wood and keep the seams ${ }^{33}$ close together: I am rather surprised, however, that there should be any seams in the statue, considering the very moderate size it is. He informs us, also, that the doors are made of cypress, and that the wood, which has now lasted very nearly four hundred years, has all the appearance of new. ${ }^{34}$ It is worthy of remark, too, that the wood of these doors, after the pieces had been glued together, was left to season four years before they were put

32 Asia Minor, namely. See B. xxxv. c. 21.

33 The junctures where the pieces of wood are united by glue. This is to be observed very easily in the greater part of the oaken statuary that is so plentiful in the churches of Belgium.

${ }_{34}$ Cypress is perhaps the most lasting of all woods. 
up : cypress was made choice of from the circumstance that it is the only kind of wood that maintains its polish to all future time.

And have we not the statue of Vejovis, ${ }^{35}$ also, made of cypress, still preserved in the Capitol, where it was consecrated in the year of the City 661 ? The Temple of Apollo, too, at Utica, is equally celebrated: there we may see beams of cedar still in existence, and in just the same condition in which they were when erected at the first building of that city, eleven hundred and seventy-eight years ago. At Saguntum, too, in Spain, there is a temple of Diana, which was brought thither by the original founders of the place, from the island of Zacynthus, in the year 200 before the taking of Troy, Bocchus says-It is preserved beneath the town, they say. Hannibal, being induced thereto by feelings of religious veneration, spared this temple, and its beams, made of juniper, are still in existence at this very day. But the most memorable instance of all is that of the temple which was dedicated to the same goddess at Aulis, several ages before the Trojan War : of what wood, however, it was originally built is a fact that has been long lost in oblivion. Speaking in general terms, we may say that those woods are of the greatest durability which are the most odoriferous. ${ }^{36}$

Next to those woods of which we have just spoken, that of the mulberry is held in the highest degree of esteem, and it will even turn black when old. There are some trees, again, that are more durable than others, when employed for certain purposes. The wood of the elm lasts the best in the open air, that of the robur when buried in the ground, and that of the quercus when exposed to the action of water: indeed, the wood of this last, if employed in works above ground, is apt to split and warp. The wood of the larch thrives best in the midst of moisture; the same is the case, too, with that of the black alder. The wood of the robur spoils by exposure to the action of sea-water. The beech and the walnut are far from disapproved of for constructions under water, and, in fact, these are the principal woods, too, that are used for works

35 One of the earliest appellations, probably, of Jupiter among the Romans. See Ovid's Fasti, B. iii. l. 445, et seq.

36 This is correct. 'Their resin defends them from the action of the air, from damp, and the attacks of noxious insects. 
under ground: the same is the case, also, with the juniper; which is equally serviceable when exposed to the atmosphere. 'I'he woods of the beech and the cerrus ${ }^{37}$ very quickly deteriorate, and that of the æsculus will not withstand the action of. water. On the other hand, the alder, when driven into the ground in marshy localities, is of everlasting duration, and able to support the very heaviest weights. The wood of the eherry is strong, while those of the elm and the ash are pliable, though apt to warp: these last will still retain their flexibility, and be less liable to warp, if the wood is left to stand and dry upon the trunk after the pith has been cut around. ${ }^{38}$ It is said that the larch, when used for sea-going ships, is liable to the attacks ${ }^{39}$ of the teredo, as, in fact, all the woods are, with the exception of the wild and cultivated olive. It is a fuct, too, that there are some woods that are more liable to spoil in the sea, and others in the ground.

CHAP. 80. (41.)-VARIETIES OF THE TEREDO.

There are four kinds of insects that attack wood. The teredo has a head remarkably large in proportion to the other part of the body, and gnaws away the wood with its teeth: its attacks, however, are confined solely to the sea, and it is generally thought that this is the only insect that is properly so called. The wood-worm that prevails on the land is known as the "tinea," while those which resemble a gnat in appearance are called "thripes." The fourth kind of wood-worm belongs to the maggot class; some of them being engendered by the corruption of the juices of the wood itself, and others being produced, just as in the trees, by the worm known as the cerastes. ${ }^{40}$ When this worm has eaten away enough of the wood to enable it to turn round, it gives birth to another. The generation of these insects is prevented, however, by the bitterness that exists in some woods, the cypress, and the hardness of others, the box, for instance.

It is said, too, that the fir, if barked about the time of budding, and at the period of the moon already mentioned, ${ }^{41}$ will never spoil in water. The followers of Alexander the Great have left a statement that, at Tylos, an island in the Red Sea,

${ }_{37}$ A variety of the oak. See c. 6 of this Book.

38 As mentioned at the end of c. 74 .

40 See B. xvii. c. 37.

${ }^{39}$ See B. xi. c. 2.

41 In c. 74 . 
there are trees, of which ships are built, the wood of which has been found uninjured at the end of two hundred years, ${ }^{42}$ even if it has been under water all that time. They say, also, that in the same island there is a certain shrub, ${ }^{43}$ about the thickness of a walking-stick only, and spotted like a tiger's skin : it is very heavy, and will break like glass if it happens to fall upon a hard substance.

\section{CHAP. 81. (42.) -THE WOODS USED IN BUILDING.}

We have in Italy some woods that are apt to split of themselves: to prevent this, architects recommend that they should be first seasoned in manure ${ }^{44}$ and then dried, in order to render them proof against the action of the atmosphere. The woods of the fir and larch are well adapted, even when used transversely, for the support of heavy burdens; while the robur and the olive are apt to bend and give way under a weight. The wood of the poplar and the palm are also strong, but this last will bend, though in a manner different from the others; for, while in all other instances the wood bends downwards, in the palm it bends in the contrary direction, ${ }^{45}$ and forms an arch. The woods of the pine and the cypress are proof against decay and all attacks of wood-worm. The walnut is easily warped, but we sometimes see beams even made of it. It gives warning, however, before it breaks, by a loud cracking noise; such was the case at Antandros, at the public baths there-the bathers took the alarm upon hearing the beams crack, and made their escape. The pine, the pitchtree, and the alder are employed for making hollow pipes for the conveyance of water, and when buried in the earth will last for many years. If, however, they are not well covered ever, they will very soon rot; and the resistance they offer to decay will increase in a most surprising degree if the outer surface as well is left in contact with the water.

42 There is nothing very surprising in this, as most woods are preserved better when completely immersed in water, than when exposed to the variations of the atmosphere.

43 He borrows this fable from Theophrastus, B. v. c. 5.

44 This process, Fée says, would be attended with no success.

45 It is not quite clear whether he intends this observation to apply to the poplar and the palm, or to the last only. It is true, however, in neither case, and is contrary, as Fée observes, to all physical laws. 


\section{CHAP. 82.-CARPENTERS' WOODS.}

The wood of the fir is strongest in a vertical ${ }^{46}$ position : it is remarkably well adapted for the pannels of doors, and all kinds of in-door joiners' work, whether in the Grecian, the Campanian, or the Sicilian style. The shavings of this wood when briskly planed, always curl up in circles like the tendrils of the vine. This wood, too, unites particularly well with glue : it is used in this state for making vehicles, and is found to split sooner in the solid parts than in a place where the pieces have been glued together.

\section{CHAP. 83. (43.)-WOODS UNITED WITH GLUE.}

Glue, too, plays one of the principal parts in all veneering and works of marqueterie. For this purpose, the workmen usually employ wood with a threaded rein, to which they give the name of "ferulea," from its resemblance to the grain of the giant fennel, ${ }^{47}$ this part of the wood being preferred from its being dotted and wavy. In every variety there are some woods to be found that will not take the glue, and which refuse to unite either with wood of the same kind or of any other; the wood of the robur for example. Indeed, it is mostly the case that substances will not unite unless they are of a similar nature; a stone, for instance, cannot be made to adhere to wood. The wood of the service-tree, the yoke-elm, the box, and, in a less degree, the lime, have a particular aversion to uniting with the cornel. All the yielding woods which we have already spoken ${ }^{48}$ of as flexible readily adapt themselves to every kind of work ; and in addition to them, the mulberry and the wild fig. Those which are moderately moist are easily sawn and cut, but dry woods are apt to give way beyond the part that is touched by the saw; while, on the other hand, the green woods, with the exception of the robur and the box, offer a more obstinate resistance, filling the intervals between the teeth of the saw with sawdust, and rendering its edge uniform and inert; it is for this reason that the teeth are often made to project right and left in turns,

46 The resistance that woods offer when placed vertically is in the same ratio as that presented by them when employed horizontally. This paragraph is borrowed from Theophrastus, B. iii. c. 4, and B. v. cc. 6, 7, 8.

${ }^{47}$ Ferula. 48 In c. 77. 
a method by which the saw-dust is discharged. The ash is found the most pliable wood of all for working; and, indeed, for making ${ }^{49}$ spears it is better even than the hazel, being lighter than the cornel, and more pliable than the wood of the service-tree. The Gallic variety is so supple, that it is employed in the construction of vehicles even. The elm would rival the trunk of the vine ${ }^{50}$ for some purposes, were it not that its weight is so much against it.

\section{CHAP. 84.-VENEERING.}

The wood, too, of the beech is easily worked, although it is brittle and soft. Cut into thin layers of veneer, it is very flexible, but is only used for the construction of boxes and desks. The wood, too, of the holm-oak is cut into veneers of remarkable thinness, the colour of which is far from unsightly; but it is more particularly where it is exposed to friction that this wood is valued, as being one to be depended upon ; in the axle-trees of wheels, for instance; for which the ash is also employed, on account of its pliancy, the holm-oak for its hardness, and the elm, for the union in it of both those qualities. There are also various workman's tools made of wood, which, though but small, are still remarkably useful; in this respect, it is said that the best materials for making auger handles are the wild olive, the box, the holm-oak, the elm, and the ash. Of the same woods also mallets are made; the larger ones, however, are made of the pine and the holmoak. These woods, too, have a greater degree of strength and hardness if cut in season than when hewn prematurely; indeed, it has been known for hinge-jambs, made of olive, a wood of remarkable hardness, after having remained a considerable time on the spot, to put out buds ${ }^{51}$ like a growing plant. Cato ${ }^{52}$ recommends levers to be made of holly, laurel, or elm; and Hyginus speaks highly of the yoke-elm, the holm-oak, and the cerrus, for the handles of agricultural implements.

The best woods for cutting into layers, and employing as a

49 See c. 24.

50 Fée thinks, from the context, that the meaning is, that the vine was employed in the construction of chariots; it depends entirely on the punctuation adopted.

s1 This could only have happened in the first year that they were so employed. 52 De Re Rust. c. 31 . 
veneer for corering others, are the citrus, the terebinth, the different varieties of the maple, the box, the palm, ${ }^{53}$ the holly, the holm-oak, the root of the elder, and the poplar. The alder furnishes also, as already stated,,$^{54}$ a kind of tuberosity, which is cut into layers like those of the citrus and the maple. In all the other trees the tuberosities are of no value whatever. It is the central part of trees that is most variegated, and the nearer we approach to the root the smaller are the spots and the more wavy. It was in this appearance that originated that requirement of luxury which displays itself in covering one tree with another, and bestowing upon the more common woods a bark of higher price. In order to make a single tree sell many times over, laminæ of veneer have been devised; but that was not thought sufficient-the horns of animals must next be stained of different colours, and their teeth cut into sections, in order to decorate wood with ivory, and, at a later period, to veneer it all over. Then, after all this, man must go and seek his materials in the sea as well! For this purpose he has learned to cut tortoise-shell into sections; and of late, in the reign of Nero, there was a monstrous invention devised of destroying its natural appearance by paint, and making it sell at a still higher price by a successful imitation of wood.

It is in this way that the value of our couches is so greatly enhanced; it is in this way, too, that they bid the rich lustre of the terebinth to be outdone, a mock citrus to be made that shall be more valuable than the real one, and the grain of the maple to be feigned. At one time luxury was not content with wood; at the present day it sets us on buying tortoiseshell in the guise of wood.

CRAP. 85. (44.)-THE AGE OF THEES. A TREe THAT WAS PLANTED BY THE FIRST SCIPIO AFRICANUS. A TREE AT RONE FIVE HUNDRED YEARS OLD.

The life of some trees might really be looked upon as of infinite ${ }^{55}$ duration, if we only think of the dense wilds and

5s It is singular, Fée says, to find the wood of the palm, and that of the poplar, which are destitute of veins, enumerated among those employed for veneering.

54 In c. 27.

${ }^{55}$ According to Adanson, the baobab will live for more than six thousand years. 
inaccessible forests in some parts of the world. In relation, however, to those, the date of which is still within the memory of man, there are some olive-trees still in existence at Liternum, which were planted by the hand of the first Scipio Africanus, as also a myrtle there of extraordinary size ; beneath them there is a grotto, in which, it is said, a dragon keeps watch over that hero's shade. There is a lotus ${ }^{56}$ tree in the open space before the Temple of Lucina at Rome, which was built in the year of the City 379, a year in which the republic had no ${ }^{57}$ magistrates. How much older the tree is than the temple, is a matter of doubt; but that it is older is quite certain, for it was from that same grove that the goddess Lucina ${ }^{58}$ derived her name; the tree in question is now about four hundred and fifty years old. The lotus tree, which is known as the Capillata, is still older than this, though it is uncertain what is its age; it received that name from the circumstance of the Vestal Virgins suspending locks of their hair ${ }^{59}$ from it.

\section{CHAP. 86.-TREES AS OLD AS THE CITY.}

There is another lotus in the Vulcanal, ${ }^{60}$ which Romulus erected with the tenth part of the spoil taken from the enemy: according to Massurius, it is generally considered to be as old as the City. The roots of this tree penetrate as far as the Forum of Cæsar, right across the meeting-places of the municipalities. ${ }^{61}$ There was a cypress of equal age growing with it till towards the latter part of Nero's reign, when it fell to the ground, and no attempts were made to raise it again.

CHAP. 87. - TREES IN THE SUBURBAN DISTRICTS OLDER THAN THE CITY.

Still older than the City is the holm-oak that stands on the Vaticanian Hill: there is an inscription in bronze upon it, written in Etruscan characters, which states that even in those

56 The Celtis australis of Linnæus.

57 In consequence of the disputes between the patricians and plebeians.

58 Thus deriving Lucina from "lucus," a grove.

59 Capillos.

60 An area before the temple of Vulcin.

61 "Stationes municipiorum." A sort of exchange, near the Forum, where the citizens met to discuss the topics of the day. 
days it was an object of religious veneration. The foundation of the town of 'Tibur, too, dates many years before that of the City of Rome: there are three holm-oaks there, said to be more ancient than Tiburnus even, who was the founder of that place; the tradition is that in their vicinity he was inaugurated. Tradition states also that he was a son of Amphiaraüs, who died before 'Thebes, one generation before the period of the Trojan war.

CHAP. 88.-TREES PLANTED BY AGAMEMNON THE FIRST YEAR OF TIIE TROJAN WAR : OTHKR TREES WHICH DATE FROM THE TIME THAT THE PLACE WAS CALLED ILIUM, ANTERIOR TO THE TROJAN WAR.

There are some authors, too, who state that a plane-tree at Delphi was planted by the hand of Agamemnon, as also another at Caphyæ, a sacred grove in Arcadia. At the present day, facing the city of Ilium, and close to the Hellespont, there are trees growing over the tomb $b^{62}$ of Protesilaüs there, which, in all ages since that period, as soon as they have grown of sufficient height to behold Ilium, have withered away, and then begun to flourish again. Near the city, at the tomb of Ilus, there are some oaks ${ }^{63}$ which are said to have been planted there when the place was first known by the name of llium.

CHAP. 89. - TREES PLANTED AT ARGOS BY HERCULES: OTHERS PLANTED BY APOLLO. A TREE MORE ANCIENT THAN A'THENS ITSELF.

At Argos $^{6 t}$ an olive-tree is said to be still in existence, to which Argus fastened Io, after she had been changed into a cow. In the vicinity of Heraclea in Pontus, there are certain altars called after Jupiter surnamed Stratios; two oaks there were planted by Hercules. In the same country, too, is the port of Amycus, ${ }^{65}$ rendered famous by the circumstance that King Bebryx was slain there. Since the day of his death his tomb has been covered by a laurel, which has obtained the name of the "frantic laurel," from the fact that if a portion of it is plucked and taken on board ship, discord and quarrel-

62 See B. iv. c. 18. Of course, this story must be regarded as fabnlous

63 Quercus.

64 These are fables founded upon the known longevity of trees, which, as Fée remarks, Pliny relates with a truly "infantine simplicity."

65 See B. r. c. 43. 
ling are the inevitable result, until it has been thrown overboard. We have already made mention ${ }^{66}$ of Aulocrene, a district through which you pass in going from Apamia into Phrygia: at this place they show a plane upon which Marsyas was hanged, after he had been conquered by Apollo, it having been chosen even in those days for its remarkable height. At Delos, also, there is a palm ${ }^{67}$ to be seen which dates from the birth of that divinity, and at Olympia there is a wild olive, from which Hercules received his first wreath: at the present day it is preserved with the most scrupulous veneration. At Athens, too, the olive produced by Minerva, is said still to exist.

CHAP. 90.-TREES WHICH ARE THE MOST SHORT-LIVED.

On the other hand, the pomegranate, ${ }^{69}$ the fig, and the apple are remarkably short-lived; the precocious trees being still more so than the later ripeners, and those with sweet fruit than those with sour: among the pomegranates, too, that varicty which bears the sweetest fruit lives the shortest time. The same is the case, too, with the vine, ${ }^{69}$ and more particularly the more fruitful varieties. Græcinus informs us that vines have lasted so long as sixty years. It appears, also, that the aquatic trees die the soonest. The laurel, ${ }^{70}$ the apple, and the pomegranate age rapidly, it is true, but then they throw out fresh shoots at the root. The olive must be looked upon, then, as being one of the most long-lived, for it is generally agreed among authors that it will last two hundred years.

\section{ChaP. 91.-TRees that have Been RENdered faMous by REMARKABLE EVENTS.}

In the territory about the suburbs of Tusculum, upon a hill known by the name of Corne, there is a grove which has been consecrated to Diana by the people of Latium from time immemorial ; it is formed of beeches, the foliage of which has all

65 See B. v. c. 29.

67 The palm is by no means a long-lived tree.

68 The pomegranate, on the contrary, has been known to live many centuries.

$69 \mathrm{He}$ has elsewhere said that the vine is extremely long-lived.

70 In the last Chapter he has spoken of a laurel having existed for many centuries. 
the appearance of being trimmed by art. Passienus Crispus, the orator, who in our time was twice consul, and afterwards became still more famous as having Nero for his step-son, on marrying his mother Agrippina, was passionately attached to a fine tree that grew in this grove, and would often kiss and embrace it: not only would he lie down, too, beneath it, but he would also moisten its roots with wine. ${ }^{71}$ In the vicinity of this grove there is a holm-oak, likewise of very considerable celebrity, the trunk of which is no less ${ }^{72}$ than thirty-four feet in circumference; giving birth to ten other trees of remarkable size, it forms of itself a whole forest.

CHAP. 92.-PLANTS THAT HAVE NO PECULIAR SPOT FOR THEIR GROWTH : OTHERS THAT GROW UPON TREES, AND WILL NOT GROW IN THE GROUND. NINE VARIETIES OF THEM: CADYTAS, POLYPODION, PHAULIAS, HIPPOPHASTOṆ.

It is a well-known fact that trees are killed by ivy. ${ }^{73}$ The mistletoe also has a similar influence, although it is generally thought that its injurious effects are not so soon perceptible: and, indeed, this plant, apart from the fruit that it bears, is looked upon as by no means the least remarkable. There are certain vegetable productions which cannot be propagated in the ground, and which grow nowhere but on trees; having no domicile of their own, they live upon others ; such, for instance, is the case with the mistletoe, and a herb that grows in Syria, and is known as the "cadytas." "74 This last entwines around not only trees, but brambles even; in the neighbourhood of Tempe, too, in Thessaly, there is found a plant which is called "polypodion $;{ }^{75}$ the dolichos ${ }^{76}$ is found also, and wild thyme." After the wild olive has been pruned there springs up a plant that is known as "phaulias $;^{78}$ while one that grows upon the

71 To its great detriment, probably.

72 Fée says that no holm-oak is ever known to attain this size.

73 See c. 62.

74 Sprengel says that this is the parasitic plant, which he calls Cassyta filiformis. Fée says that this opinjon, though perhaps not to be absolutely rejected, must be accepted with reserve.

${ }^{75}$ It does not seem to have been identified.

76 See B. xviii. c. 35 .

77 Serpyllum. See B. xx. c. 90.

78 A mistletoe, apparently, growing upon the wild olive. Fée says that no such viscus appears to be known.

VOL. III. 
fuller's thistle is called the "hippophæston;";9 it has a thin, hollow stem, a small leaf, and a white root, the juice of which is considered extremely beneficial as a purgative in epilepsy.

CHAP. 93.-THREE VARIETIES OF MISTLETOE. THE NATURE OF MISTLETOE AND SIMILAR PLANTS.

There are three varieties of the mistletoe. ${ }^{80}$ That which grows upon the fir and the larch has the name of ${ }^{81}$ stelis in Euboa; and there is the hyphear ${ }^{82}$ of Arcadia. It grows also upon the quercus, ${ }^{83}$ the robur, the holm-oak, the wild plum, and the terebinth, but upon no other tree. ${ }^{84}$ It is most plentiful of all upon the quercus, and is then known as "adasphear." In all the trees, with the exception of the holmoak and the quercus, there is a considerable difference in its smell and pungency, and the leaf of one kind has a disagreeable odour; both varieties, however, are sticky and bitter. The hyphear is the best for fattening ${ }^{85}$ cattle with ; it begins, however, by purging off all defects, after which it fattens all such animals as have been able to withstand the purging. It is generally said, however, that those animals which have any radical malady in the intestines cannot withstand its drastic effects. This method of treatment is generally adopted in the summer for a period of forty days.

Besides the above, there is yet another difference ${ }^{86}$ in the mistletoe; that which grows upon the trees which lose their leaves, loses its leaves as well ; while, on the other hand, that which grows upon evergreens always retains its leaves. In whatever way the seed may have been sown, it will never come to anything, unless it has been first swallowed ${ }^{87}$ and

79 See B. xxvii. c. 66. The Calcitrapa stellata of Lamarck. Fée remarks that Pliny has committed a great error, in making it a parasite of the Spina fullonia. Dioscorides only says that the two plants grow in the same spots.

80 The Viscum Europæum of modern naturalists.

s1 The Viscum album of Linnæus; but Sprengel takes it to be the Loranthus Europæus.

8: Fée questions whether this may not be the Loranthus Europæus.

63 The Viscum album of Linnæus; the oak mistletoe or real mistletoe.

84 This is not the fact: it grows upon a vast multitude of other trees.

${ }^{35}$ It is no longer used for this purpose.

86 The mistletoe never in any case loses its leaves, upon whatever tree it may grow.

of 'This is, of course, untrue; but the seeds, after being voided by birds, 
then voided by birds, the wood-pigeon more particularly, and the thrush: such being the nature of the plant, that it will. not come to anything unless the seed is first ripened in the crop of the bird. It never exceeds a single cubit in heignt, and is always green and branchy. The male ${ }^{88}$ plant is fruitful, the female barren; sometimes, indeed, the male even bears no berry.

\section{CHAP. 94.-THE METHOD OF MAKING BIRDLIME.}

Birdlime is made of the berries of the mistletoe, which are gathered at harvest, and while in an unripe state; for if the rainy season comes on, though they increase in size, the viscous juice is apt to lose its virtues. They are then dried, ${ }^{89}$ and when brought to a state of perfect aridity, are first pounded, and then put in water, in which they are left to rot for twelve days; this being, in fact, the only thing that finds improve. ment in decay. After this, they are again beaten in running water with a mallet, and after losing the outer coat there is only the viscous inner pulp remaining. This substance is birdlime; and after it has been thinned by the addition of walnut oil, it is found particularly useful for catching birds, it being quite sufficient if they only touch it with the wings.

CHAP. 95.- - Historical FACTS CONNECTED With the MISTLETOE.

Upon this occasion we must not omit to mention the admiration that is lavished upon this plant by the Gauls. The Druids-for that is the name they give to their magicians ${ }^{90}$ held nothing more sacred than the mistletoe and the tree that bears it, supposing always that tree to be the robur. ${ }^{91}$ Of itself the robur is selected by them to form whole groves, and they perform none of their religious rites without employing branches of it; so much so, that it is very probable that the priests themselves may have received their name

are more likely to adhere to the bark of trees, and so find a nidus for germination.

s8 The exact opposite is the case, the female being the fruitful plant.

89 The method used in Italy for making bird-lime is very similar at the present day. 90 Magos.

91. Decandolle was of opinion, that the mistletoe of the Druids was not a viscum, but the Loranthus Europæus, which is much more commonly found on oaks. 
from the Greek name ${ }^{92}$ for that tree. In fact, it is the notion with them that everything that grows on it has been sent immediately from heaven, and that the mistletoe up.on it is a proof that the tree has been selected by God himself as an object of his especial favour.

The mistletoe, however, is but rarely found upon the robur; and when found, is gathered with rites replete with religious awe. This is done more particularly on the fifth day of the moon, the day which is the beginning of their months and years, as also of their ages, which, with them, are but thirty years. This day they select because the moon, though not yet in the middle of her course, has already considerable power and influence; and they call her by a name which signifies, in their language, the all-healing. ${ }^{93}$ Having made all due preparation for the sacrifice and a banquet beneath the trees, they bring thither two white bulls, the horns of which are bound then for the first time. Clad in a white robe the priest ascends the tree, and cuts the mistletoe with a golden sickle, which is received by others in a white cloak. ${ }^{94}$ They then immolate the victims, offering up their prayers that God will render this gift of his propitious to those to whom he has so granted it. It is the belief with them that the mistletoe, taken in drink, will impart fecundity to all animals that are barren, and that it is an antidote for all poisons. ${ }^{95}$ Such are the religious feelings which we find entertained towards trifling objects among nearly all nations.

Somnary.-Remarkable facts, narratives, and observations, one thousand one hundred and thirty-five.

Rovan aUthors QUoted. - M. Varro, ${ }^{96}$ Fetialis, ${ }^{97}$ Nigidius, ${ }^{98}$ Cornelius Nepos, ${ }^{99}$ Hyginus, $^{1}$ Massurius, ${ }^{2}$ Cato, ${ }^{3}$ Mucianus, ${ }^{4}$

${ }^{92} \Delta \rho \tilde{v} \underline{\underline{c}}$, an "oak." It is much more probable that it was of Celtic ๑rigin.

93 Omnia sanantem.

צᄈ "Sağum." Properly, a " military cloak."

${ }^{95}$ It was, in comparatively recent times, supposed to be efficacious for spilepsy.

${ }^{96}$ See end of B. ii.

${ }_{97}$ Author of a History or Annals of Rome. Nothing further is known of him.

98 See end of B. vi.

1 See end of B. iii.

3 see end of B. iii.

99 See end of B. ii.

2 See end of B. rii.

4 See end of B. ii. 
L. Piso, ${ }^{5}$ Trogus, ${ }^{6}$ Calpurnius Bassus, ${ }^{7}$ Cremutius, ${ }^{8}$ Sextius Niger, ${ }^{9}$ Cornelius Bocchus, ${ }^{10}$ Vitruvius, ${ }^{11}$ Græcinus. ${ }^{12}$

Foreign atthors quoted.-Alexander Polyhistor, ${ }^{13}$ Hesiod, ${ }^{14}$ Theophrastus, ${ }^{15}$ Democritus, ${ }^{16}$ Homer, Timæus ${ }^{17}$ the mathematician.

5 See end of B. ii.

5 See end of B. vii.

7 He is wholly unknown : but is conjectured to have lived in the reign of Caligula or 'Tiberius.

8 See end of B. vii.

9 See end of B. xii.

${ }^{10} \mathrm{He}$ is unknown; but Solinus speaks of him as a valuable writer.

11 M. Vitruvius Pollio, an eminent architect, employed by Augustus. His valuable work on architecture is still extant.

12 See end of B. xiv.

14 See end of B. vii.

${ }_{13}$ See end of B. iii.

16 See end of B. ii.

15 See end of B. iii.

17 See end of B. ii. 


\section{BOOK XVII.}

\section{TIE NATURAL HISTORY OF THE CULTIVATED TREES.}

CHAP. 1. (1.) 一TREES WHICH HAVE BEEN SOLD AT ENORMLUS PHICES.

We have described the trees which grow spontaneously on land and in the sea, ${ }^{1}$ and it now remains for us to speak of those which owe their formation, properly speaking, rather than birth, to art and the inventive genius of man. ${ }^{2}$ Here, however, I cannot but express my surprise, that after the state of penury in which man lived, as already described, ${ }^{3}$ in primitive times, holding the trees of the forest in common with the wild beasts, and disputing with them the possession of the fruits that fell, and with the fowls of the air that of the fruits as they hung on the tree, luxury has now attached to them prices so enormous.

The most famous instance, in my opinion, of this excess, was that displayed by L. Crassus and Cneius Domitius Ahenobarbus. Crassus was one of the most celebrated of the Roman orators ; his house was remarkable for its magnificence, though in some measure surpassed even by that of $Q$. Catulus, ${ }^{4}$ also upon the Palatine Hill ; the same Catulus, who, in conjunction with C. Marius, defeated the Cimbri. But by far the finest house of all that period, it was universally acknowledged, was that of C. Aquilius, a Roman of Equestrian rank, situate upon the Viminal Hill ; a house, indeed, that conferred a greater degree of celebrity upon him than even his acquaintance with the civil law. This, however, did not prevent Crassus being reproached with the magnificence of his. Crassus and Domitius, members, both of them, of the most illus-

1 He alludes to the various shrubs and trees, mentioned as growing in the sea, B. xiii. c. 48 ; but which there is little doubt, in reality belong to the class of fuci.

2 "Fiunt verius quam nascuntur;" a distinction perpetuated in the adage, "Poeta nascitur, non fit."

${ }^{3}$ He probably alludes to his remark in B. xvi. c. 1 .

4 Q. Luctatius Catulus, the colleague of Marius. Being afterwards condemned to die by Marius, he suffocated himself with the fumes of charcoal, 
trious families, after holding the consulship, ${ }^{5}$ were appointed jointly to the censorship, in the year from the building of the City 662, a period of office that was fruitful in strife, the natural result of their dissimilarity of character. On one occasion, Cneius Domitius, naturally a man of hasty temper, and inflamed besides by a hatred that rivalry only tends to stimulate, gravely rebuked Crassus for living, and he a Censor too, in a style of such magnificence, and in a house for which, as he said, he himself would be ready to pay down ten millions of sesterces. Crassus, a man who united to singular presence of mind great readiness of wit, made answer that, deducting six trees only, he would accept the offer; upon which Domitius replied, that upon those terms he would not give so much as a single denarius for the purchase. "Well then, Domitius," was the rejoinder of Crassus, "which of the two is it that sets a bad example, and deserves the reproof of the censorship; I, who live like a plain man in a house that has come to me by inheritance, or you, who estimate six trees at a value of ten millions of sesterces ?" 6 These trees were of the lotus ${ }^{7}$ kind, and by the exuberance of their branches afforded a most delightful shade. Cæcina Largus, one of the grandees of Rome, and the owner of the house, used often to point them out to me in my younger days; and, as I have already made mention ${ }^{8}$ of the remarkable longevity of trees, I would here add, that they were in existence down to the period when the Emperor Nero set fire to the City, one hundred and eighty years after the time of Crassus; being still green and with all the freshness of youth upon them, had not that prince thought fit to hasten the death of the very treess even.

Let no one, however, imagine that the house of Crassus was of no value in other respects, or that, from the rebuke of Domitius, there was nothing about it worthy of remark with the exception of these trees. There were to be seen erected in the atrium four columns of marble from Mount Hymettus, ${ }^{8}$ which in his ædileship he had ordered to be brought over for the decoration of the stage $;^{9}$ and this at a time, too, when no public

5 A.U.c. 659.

6 Valerius Maximus, B.ix. c. 1, relates this story somewhat differently.

7 The Celtis Australis of Linnæus.

8 See B. xxxvi. cc. 3 and 24.

9 When, in his capacity of ædile, he gave theatrical representations for the benefit of the public. 
buildings even as yet possessed any pillars made of that material. Of such recent date is the luxury and opulence which we now enjoy, and so much greater was the value which in those days trees were supposed to confer upon a property! A pretty good proof of which, was the fact that Domitius even, with all his enmity, would not keep to the offer he had made, if the trees were not to be included in the bargain.

The trees have furnished surnames also to the ancients, ${ }^{10}$ such, for instance, as that of Fronditius to the warrior who swam across the Volturnus with a wreath of leaves on his head, and distinguished himself by his famous exploits in the war against Hannibal; and that of Stolo ${ }^{11}$ to the Licimian family, such being the name given by us to the useless suckers that shoot from trees; the best method of clearing away these shoots was discovered by the first Stolo, and hence his name. The ancient laws also took the trees under their protection; and by the Twelve Tables it was enacted, that he who should wrongfully cut down trees belonging to another person, should pay twentyfive asses for each. Is it possible then to imagine that they, who estimated the fruit-trees at so low a rate as this, could ever have supposed that so exorbitant a value would be put upon the lotus as that which I have just mentioned? And no less marvellous, too, are the changes that have taken place in the value of fruit; for at the present day we find the fruit alone of many of the trees in the suburbs valued at no less a sum than two thousand sesterces; the profits derived from a single tree thus being more than those of a whole estate in former times. It was from motives of gain that the grafting of trees and the propagation thereby of a spurious offspring was first devised, so that the growth of the fruits even might be a thing interdicted to the poor. We shall, therefore, now proceed to state in what way it is that such vast revenues are derived from these trees, and with that object shall set forth the true and most approved methods of cultivation; not taking any notice of the more common methods, or those which we find generally adopted, but considering only those points of doubt and uncertainty, in relation to which practical men are most apt to find themselres at a loss : while, at the same time, to

10 As Fée remarks, this usage has been reversed in modern times, and plants often receive their botanical names from men.

11 See B. xviii. c. 4. 
affect any scrupulous exactness in cases where there is no necessity for it, will be no part of our purpose. In the first place, however, we will consider in a general point of view, those influences of soil as well as weather which are exercised upon all the trees in common.

CHAP. 2. (2.) 一THE INFLUENCE OF WEATHER UPON THE TREES: WHAT IS THE PROPER SITUATION FOR THE VINE.

Trees are fond of a site more particularly that faces the north-east $;^{12}$ the breezes rendering their foliage more thick and exuberant, and imparting additional solidity to the wood. This is a point, however, upon which most people are very greatly deceived; thus in vineyards, for instance, the props ought not to be placed in such a position as to shelter the stems from the wind in that quarter, it being only against the northern blasts that this precaution should be taken. Nay, even more than this -if the cold weather only comes on in due season, it contributes very materially to the strengthening of the trees, and promotes the process of germination; while, on the other hand, if at that period the southern ${ }^{13}$ breezes should caress them, they will grow weak and languid, and more particularly so, if the blossom is just coming on. If rainy weather, too, should happen to follow close upon blossoming, the total destruction of the fruit is the necessary result : indeed, if the weather should be only cloudy, or south winds happen to prevail, it is quite sufficient to ensure the loss of the fruit in the almond and the pear. ${ }^{14}$ Rains, if prevalent about the rising of the Vergiliæ, ${ }^{15}$ are most injurious to the vine and the olive, ${ }^{16}$ as it is at that season that germination ${ }^{17}$ is commencing with them; indeed, this is a most

12 Or north north-east, as Fée says. He adds that this aspect in reality is not, favourable to vegetation. Pliny commits the error of copying exactly from Theophrastus, and thereby giving advice to Roman agriculturists, which was properly suited to the climate of Greece only.

${ }_{13}$ This is borrowed from Theophrastus ; but, as Fée remarks, if suitable to the climate of Grcece, it is not so to that of Italy or France, where vegetation is much more promoted by a south wind.

it 'This assertion, Fée says, is erroneous. See B. xvi. c. 46.

15 B. xviii. c. 66 .

16 See c. 30 of this Book. These notions as to critical periods to plants connected with the constellations, Fée says, are now almost dispelled; though they still prevail in France, to some extent.

17 "Coitus." See B. xvi. cc. 39 and 42. 
critical four days for the olive, being the period at which the south wind, as we have already ${ }^{18}$ stated, brings on its dark and lowering clouds. The cereals, too, ripen more unfavourably when south winds prevail, though at the same time it proceeds with greater rapidity. All cold, too, is injurious to vegetation, which comes with the northern winds, or out of the proper season. It is most advantageous to all plants for north-east winds ${ }^{19}$ to prevail throughout the winter.

In this season, too, showers are very necessary; and the reason is self-evident-the trees, being exhausted by the fruit they have borne, and weakened by the loss of their leaves, are, of course, famished and hungry; and it is the showers that constitute their aliment. Experience has led us to believe that there is nothing more detrimental than a warm winter; for it allows the trees, the moment they have parted with their fruits, to conceive again, or, in other words, to germinate, and then exhaust themselves by blossoming afresh. And what is even worse than this, should there be several years of such weather in succession, even the trees themselves will die; for there can be little doubt that the effort must of necessity be injurious, when they put forth their strength, and are at the sarne time deprived of their natural sustenance. The poet ${ }^{20}$ then, who has said that serene winters are to be desired, certainly did not express those wishes in favour of the trees. And no more does rain, if prevalent at the summer-solstice, conduce to the benefit ${ }^{21}$ of the vine: while, at the same time, to say that a dusty winter produces a luxuriant harvest, is certainly the mistake of a too fertile imagination. It is a thing greatly to be wished, too, both in behalf of the trees as well as the cereals, that the snows should lie for a considerable time upon the ground; the reason being that they check the escape of the spirit of the earth by evaporation, and tend to throw it

18 See B. xvi. c. 46.

19 From Theophrastus, De Causis, B. ii. c. 1.

20 He alludes to the words of Virgil, Gecrg. i. 100 :-

"Humida solstitia, atque hiemes orate serenas, Agricolæ; hiberno lætissima pulvere farra."

Fée remarks, that the cultivators of the modern times are more of the opiniori of the poet than the naturalist.

${ }_{21}$ Because rains would cause the young fruit to fall off. $\mathrm{He}$ here attacks the first portion of the precepts of Virgil ; but only, it appears, in reference to the vine 
back again upon the roots of the plants, adding greatly to their strength thereby; and not only this, but they afford a gradual supply of moisture as well, that is both pure and of remarkable lightness, from the fact that snow is only the foam of the waters of heaven. Hence it is that the moisture of snow does not drench and engulph everything all at once, but gradually trickles downwards, in proportion to the thirst of the plant, nurturing it as though from the breast, instead of producing an inundation. The earth, too, ferments under this influence, and becomes filled with her own emanations: not exhausted by the seeds in her bosom, swollen as they are with milk, ${ }^{22}$ she smiles in the warm and balmy hours, when the time comes for opening it. It is in this way, more particularly, that corn fattens apace, except, indeed, in those climates in which the atmosphere is always warm, Egypt for example; for there the continuance of the same temperature and the force of habit are productive of the same effects as the modifications of temperature in other countries.

At the same time it is equally necessary in erery climate that there should be no noxious influence in existence. Thus, for instance, in the greater part of the world, that precocious germination which has been encouraged by the indulgent temperature of the weather, is sure to be nipped by the intense colds that ensue. Hence it is that late winters are so injurious, and such they prove to the trees of the forest even; indeed, these last are more particularly exposed to the ill effects of a late winter, oppressed as they are by the density of their foliage, and human agency being unable to succour them; for it would be quite impossible to cover ${ }^{23}$ the more tender forest trees with wisps of straw. Rains, then, are favourable to vegetation-first of all, during the winter season, and next, just previously to germination; the third period for them being that of the formation of the fruit, though not immediately, and only, in fact, when the produce of the tree shows itself strong and healthy.

22 "Lactescentibus." Fée remarks on the appropriateness of this expression, as the act of germination, he says, in the cereals and all the seeds in which the perisperm is feculent, changes the fecula into an emulsive liquid, in which state the seed may be said, with Pliny, to be "lactescent." trees.

${ }_{23}$ Which appears to have been extensively done with the young garden 
Those trees which are the slowest in bringing their fruits to maturity, and require a more prolonged supply of nutriment, receive benefit also from late rains, such as the vine, the olive, and the pomegranate, for instance. These rains, however, are required at different seasons by the different trees, some of them coming to maturity at one period and some at another; hence it is that we see the very same rain productive of injury to some trees and beneficial to others, even when they are of the very same species, as in the pear for instance : for the winter pear stands in need of rain at one period, and the early pear at another, though at the same time they, all of them, require it in an equal degree. Winter precedes the period of germination, and it is this fact that makes the north-east wind more beneficial than the south, and renders the parts that lie in the interior preferable to those near the coast,- - the former being generally the coldest,-mountainous districts better than level ones, and rain at night better than showers in the day. Vegetation, too, receives a greater degree of benefit from the water when the sun does not immediately soak it up.

Connected, too, with this subject is the question of the best situation for planting vines, and the trees which support them. Virgil ${ }^{24}$ condemns a western aspect, while there are some persons, again, who prefer it to an easterly one: I find, nowever, that most authors approve of the south, though I do not think that any abstract precepts ${ }^{25}$ can be given in relation to the point. The most careful attention on the part of the cultivator ought to be paid to the nature of the soil, the character of the locality, and the respective influences of climate. The method of giving to the vine a southern aspect, as practised in Africa and $* * * *$ is injurious to the tree, as well as unheaithy for the cultivator, from the very circumstance that the country itself lies under a southern meridian: hence it is, that he who selects for his plants there a western or a northerly aspect, will combine on the most advantageous terms the benefits of soil with those of climate. When Virgil condemns a western aspect, there can be no doubt that he includes in his censure a northern aspect as well : and yet, in Cisalpine Italy, where most of the vineyards have an aspect to the north, it has been found by experience that there are none that are more prolific.

24 Georg. ii. 398.

25 Taken altogether, a southern aspect is preferable to all others. 
The winds are also a very important consideration. In the provinces of Gallia Narbonensis, and in Liguria and part of Etruria, it is considered a proof of great want of skill to plant the vine on a site that lies in the teeth of the wind Circius, ${ }^{26}$ while, on the other hand, it is a mark of prudence to catch its breezes in an oblique direction; it is this wind, in fact, that modifies the heat in those countries, though at the same time it is usually so violent, as to sweep away the roofs of the houses.

(3.) There are some persons who employ a method of making the question of weather dependent upon the nature of the soil; thus in the case of a vineyard, for instance, in a dry locality, they give it an eastern or a northern aspect; but where it is planted on a humid site, it is made to face the south. From the varieties of the vine also, they borrow various modifications in reference to site; taking care to plant the early vine in a cold locality, in order that the fruit may ripen before the frosts come on; while such fruit trees and vines as have an antipathy to dews are exposed to the east, that the sun may carry off their humidity at the earliest moment. On the other hand, such as manifest a partiality to dews are planted with a western or eren a northern aspect, to give them an opportunity of enjoying them all the longer. Others, again, borrowing their notions pretty nearly from Nature, have recommended that vines and trees should be planted facing the north-east; indeed Democritus is of opinion, that by so doing the fruit will be all the more odoriferous.

(4.) We have already spoken, in the Second Book, ${ }^{27}$ of the points of the north-east and other winds, and shall have occasion in the succeeding one to make mention of several more of the hearenly phænomena. In the mean time, however, we may observe that it would appear to be a manifest proof of the salubrity of a north-east site, that the leaves are always the first to fall in the trees that have an aspect towards the south. ${ }^{28}$ A similar reason exists, too, in the maritime districts; in certain localities the sea breezes are detrimental, though in most they are nutritious. For some plants, again, it is pleasant to behold the sea at a distance, while at the same time they

26 See B.ii. c. 46 .

27 Cc. 46 and 47.

$28 \mathrm{He}$ seems to lose sight of the fact that they bud before those that look to the north. 
vill gain nothing by approaching closer to its saline exhalations. The same, too, is the influence exercised by rivers and lakes; they will either scorch the vegetation by the fogs they emit, or else modify by their coolness the excess of heat. We have already mentioned ${ }^{29}$ the plants that thrive in the shade, and in the cold even; but in all these matters experience will be found the best of guides.

\section{CHAP. 3.-WHAT SOILS ARE TO BE CONSIDERED THE BEST.}

Next after the influences of the heavens, we have to treat of those of the earth, a task that is in no way more easy than the previous one. It is but rarely that the same soil is found suited to trees as well as corn : indeed, the black ${ }^{30}$ earth which prevails in Campania is not everywhere found suited to the vine, nor yet that which emits light exhalations, or the red ${ }^{31}$ soil that has been so highly praised by many. The cretaceous earth that is found in the territory of Alba Pompeia, and an argillaceous soil, are preferred to all others for the vine, although, too, they are remarkably rich, a quality that is generally looked upon as not suited to that plant. On the other hand, again, the white sand of the district of Ticinum, the black sand of many other places, and the red sand as well, even though mixed with a rich earth, will prove unproductive.

The very signs, also, from which we form our judgment are often very deceptive; a soil that is adorned with tall and graceful trees is not always a favourable one, except, of course, for those trees. What tree, in fact, is there that is taller than the fir? and yet what other plant could possibly exist in the same spot? Nor ought we always to look upon verdant pastures as so many proofs of richness of soil; for what is there that enjoys a greater renown than the pastures of Germany? and yet they consist of nothing but a very thin layer of turf, with sand immediately beneath. Nor yet is the soil which produces herbage ${ }^{32}$ of large growth always to be looked upon as humid; no, by Hercules! no more than a soil is to be looked upon as unctuous and rich, which adheres to the fingers-a

29 B. xvi. ce. 30,31 .

30 A rich black mould, probably.

it A ferruginous argilla.

32 It must of necessity denote a soil rich in humus, though not, of course, adapted for all kinds of cultivation. 
thing that is proved in the case of the argillaceous earths. ${ }^{33}$ The earth when thrown back into the hole from which it has just bcen dug will never ${ }^{34}$ fill it, so that it is quite impossible by that method to form any opinion as to its density or thinness. It is the fact, too, that every ${ }^{35}$ soil, without exception, will cover iron with rust. Nor yet can we determine ${ }^{36}$ the heaviness or lightness of soils in relation to any fixed and ascertained weight: for what are we to understand as the standard weight of earth? A soil, too, that is formed from the alluvion ${ }^{37}$ of rivers is not always to be recommended, for there are some crops that decay all the sooner in a watery soil; indeed, those soils even of this description which are highly esteemed, are never found to be long good for any kind of regetation but the willow.

Among other proofs of the goodness of soil, is the comparative thickness of the stem in corn. In Laborium, a famous champaign country of Campania, the stalk is of such remarkable thickness, that it may be used even to supply the place of wood : ${ }^{38}$ and yet this very soil, from the difficulty that is everywhere experienced in cultivating it, and the labour required in working it, may be almost said to give the husbandman more trouble by its good qualities than it could possibly have done by reason of any defects. The soil, too, that is generally known as charcoal earth, appears susceptible of being improved by being planted with a poor meagre vine: and tufa,"9

${ }^{33} \mathrm{He}$ alludes to the difficulty with which argilla, from its tenacity, is employed in cultivation.

${ }_{3 \pm}$ Columella says the contrary, and so does Virgil, Georg. ii. 226, speaking of this fact as a method of ascertaining the respective qualities of the earth.

${ }^{35}$ Virgil, Georg. ii. 220, says the contrary.

36 In allusion to what Virgil says, Georg. ii. 254 :-

"Quæ gravis est, ipso tacitam se pondere prodit,

Quæque levis ——"

Fée remarks, however, that it is easy enough to analyse the earth, and ascertain the proportions of humus, and of the siliceous, cretaceous, or argillaceous earths; the relative proportions of which render it strong or light, as the case may be.

${ }_{37}$ As Fée says, these earths vary according to the nature of the soils that are brought down by the streams; in general, however, they are extremely prolific.

38 F'e says that Pliny is here guilty of some degree of exaggeration. See B. iii. c. 9, p. 195 of Vol. 1: also B. xviii. c. 29.

39 "Tophus ;" formed of volcanic scoriæ. Fée remarks, that it is some- 
which is naturally rough and friable, we find recommended by some authors. Virgil, ${ }^{40}$ too, does not condemn for the vine a soil which produces fern $:^{41}$ while a salted earth ${ }^{42}$ is thought to be much better entrusted with the growth of vegetation than any other, from the fact of its being comparatively safe from noxious insects breeding there. Declivities, too, are far from unproductive, if a person only knows how to dig them properly; and it is not all ${ }^{43}$ champaign spots that are less accessible to the sun and wind than is necessary for their benefit. We have already ${ }^{44}$ alluded to the fact, that there are certain vines which find nutriment in hoar frosts and fogs.

In every subject there are certain deep and recondite secrets, which it is left to the intelligence of each to penetrate. Do we not, for instance, find it the fact, that soils which have long offered opportunities for a sound judgment being formed on their qualities have become totally altered? In the vicinity of Larissa, in Thessaly, a lake was drained ; ${ }^{45}$ and the consequence was, that the district became much colder, and the olive-trees which had formerly borne fruit now ceased to bear. When a channel was cut for the Hebrus, near the town of Enos, the place was sensible of its nearer approach, in finding its vines frost-bitten, a thing that had never happened before; in the vicinity, too, of Philippi, the country having been drained for cultivation, the nature of the climate became entirely altered. In the territory of Syracuse, a husbandman, who was a stranger to the place, cleared the soil of all the stones, and the consequence was, that he lost his crops from the accumulation of mud; so that at last he was obliged to carry the stones back again. In Syria again, the plough-

what similar in nature to marl, and that though unproductive by itself, it is beneficial when mixed with vegetable earth. Tufa and marl appear to have been often confounded by the ancient writers.

40 Georg. ii. 189.

41 The Pteris aquilina of the modern botanists.

${ }^{42}$ Marine salt, or sub-hydrochlorate of soda, Fée thinks, is here alluded to. It is still used with varied success in some parts of the west of France.

43 Hardouin says, that he here alludes to the proverbial saying among the ancients, "Perflare altissima ventos" - "The winds blow only on the most elevated ground."

${ }^{44}$ In B. xiv. ce. 4 and 12.

45 "Emisso." Fée would appear to think that the lake suddenly made its appearance, after an earthquake, and from the context he would appear to be right. These accounts are all of them borrowed from Theophrastus. 
share which they use is narrow, and the furrows are but very superficial, there being a rock beneath the soil that in summer scorches up the seeds.

Then, too, the effects of excessive cold and heat in various places are similar; thus, for instance, Thrace is fruitful in eorn, by reason of the cold, while Africa and Egypt are so in consequence of the heat that prevails there. At Chalcia, ${ }^{46}$ an island belonging to the Rhodians, there is a certain place which is so remarkably fertile, that after reaping the barley that has been sown at the ordinary time, and gathering it in, they immediately sow a fresh crop, and reap it at the same time as the other corn. A gravelly soil is found best suited for the olive in the district of Venafrum, ${ }^{47}$ while one of extreme richness is required for it in Bætica. The wines of Pucinum ${ }^{48}$ are ripened upon a rock, and the vines of Cæcubum ${ }^{49}$ are moistened by the waters of the Pomptine ${ }^{50}$ marshes; so great are the differences that have been detected by human experience in the various soils. Cæsar Vopiscus, when pleading a cause before the Censors, said that the fields of Rosia ${ }^{51}$ are the very marrow ${ }^{52}$ of Italy, and that a stake, left in the ground there one day, would be found covered by the grass the next: $:^{53}$ the soil, however, is only esteemed there for the purposes of pasturage. Still, however, Nature has willed that we should not remain uninstructed, and has made full admission as to existing defects in soil, even in cases where she has failed to give us equal information as to its good qualities: we shall begin, therefore, by speaking of the defects that are found in various soils.

(5.) If it is the wish of a person to test whether a soil is bitter, or whether it is thin and meagre, the fact may be easily ascertained from the presence of black and undergrown herbs. If, again, the herbage shoots up dry and stunted, it shows that the soil is cold, and if sad and languid, that it is moist and slimy. The eye, too, is able to judge whether it is a red earth or whether it is argillaceous, both of them extremely difficult to work, and apt to load the harrow or ploughshare with
${ }^{46}$ See B. v. c. 36.
48 See B. xiv. c. 8.
50 Tee B. iii. c. 9.

52 Sumen. Properly, "udder." A cow's udder was considered one of the choicest of delicacies by the Romans.

${ }_{53}$ This is, of course, an exaggeration. The stake must have been driven in very deep to disappear so speedily.

VOL. III. 
enormous clods; though at the same time it should be borne in mind that the soil which entails the greatest amount of labour is not always productive of the smallest amount of profit. So, too, on the other hand, the eye can distinguish a soil that is mixed with ashes or with white sand, while earth that is sterile and dense may be easily detected by its peculiar hardness, at even a single stroke of the mattock.

Cato, ${ }^{54}$ briefly and in his peculiar manner, characterizes the defects that exist in the various soils. "Take care," he says, "where the earth is rotten not to shake it either with carts or by driving cattle over it." Now what are we to suppose that this term "rotten" means, as applied to a soil, about which he is so vastly apprehensive as to almost forbid our setting foot upon it? Let us only form a comparison by thinking what it is that constitutes rottenness in wood, and we shall find that the faults which are held by him in such aversion are the being arid, full of holes, rough, white, mouldy, worm. eaten, in fact, just like pumice-stone; and thus has Cato said more in a single word than we could have possibly found means to express in a description, however long. Indeed, if we could find means of expressing the various defects that exist in soils, we should find that there are some of them that are old, not with age (for age cannot ${ }^{55}$ be concerned in relation to the earth), but of their own nature, and are hence unfruitful and powerless for every purpose from the first. The same writer, ${ }^{56}$ too, considers that as the very best of soils, which, situate at the foot of a declivity, runs out into a champaign country, taking a southward direction; such, in fact, being the aspect of the whole of Italy $:^{57}$ he says ${ }^{58}$ also, that the earth generally known as black ${ }^{59}$ earth is of a tender nature, and is consequently the most easily worked and the best for cereals. If we only appreciate with due care the signification of this word "tender,", ${ }_{00}$ we shall find that it expresses its intended meaning remarkably well, and that in this word is comprised every quality that is desirable for the purposes of cultivation.

${ }_{54}$ De Re Rust. 5.

55 This he says in reference to his belief, with Epicurus, in the eternity of matter.

56 De Re Rust. 1.

58 De Re Rust. 151.

57 See B. iii. c. 6 .

59 "Pulla." The "vegetable" earth of modern botanists.

60 "Teneram." 
In a tender soil we shall find fertility combined with moderation, a softness and a pliancy easily adapted to cultivation, and an equal absence of humidity and of dryness. Earth of this nature will shine again after the plough-share has passed through it, just as Homer, ${ }^{61}$ that great fountain-head of all genius, has described it sculptured by the Divinity ${ }^{62}$ upon the arms [of Achilles], adding, too, a thing that is truly marvellous, that it was of a blackish hue, though gold was the material in which it was wrought. This, too, is that kind of earth, which, when newly turned up, attracts the ravenous birds that follow the plough-share, the ravens even going so far as to peck at the heels of the ploughman.

We may in this place appropriately make mention of an opinion that has been pronounced by an Italian writer also with reference to a matter of luxury. Cicero, ${ }^{63}$ that other luminary of literature, has made the following remark: "Those unguents which have a taste of earth ${ }^{61}$ are better," says he, "than those which smack of saffron;" it seeming to him more to the purpose to express himself by the word " taste" 65 than "smell." And such is the fact, no doubt; that soil is the best which has the flavour of a perfume. ${ }^{66}$ If the question should be put to us, what is this odour of the earth that is held in such estimation, our answer is, that it is the same that is often to be recognized at the moment of sunset, without the necessity even of turning up the ground, at the spots where the extremities of the rainbow ${ }^{67}$ have been observed to meet the earth; as also when, after long-continued drought, the rain has soaked the ground. Then it is that the earth exhales this divine odour, that is so peculiarly its own, and to which, imparted to it by the sun, there is no perfume, however sweet, that can possibly be compared. It is this odour that the earth, when turned up, ought to emit, and which, when once found, can never deceive a person; and this will be found the best criterion for judging of the quality of the soil. Such, too, is the odour that is usually perceived

61 Iliad, xviii. 541 and 548.

62 Vulcan.

63 De Oratore, sec. 39.

61 See B. xiii. c. 4.

65 "Sapiunt," rather than "redolent."

${ }^{66}$ This supposed flavour of the earth is, in reality, attributahle to the extraneous vegetable matter which it contains.

67 See B. xii. c. 52, as to this notion. 
on land newly cleared, ${ }^{68}$ when an ancient forest has been just cut down; its excellence is a thing that is universally admitted.

For the culture of the cereals, too, the same land is generally looked upon as the more improved the oftener it has been allowed to rest ${ }^{69}$ from cultivation, a thing that is not the case with vineyards; for which reason all the greater care is required in the selection of their site, if we would not have the opinions of those to appear well founded who entertain the notion that the soil of Italy is already worn out. ${ }^{70}$ In other kinds of soil the work of cultivation depends entirely upon the weather; as, for instance, in those which cannot be ploughed just after rain, because the natural exuberance of the earth renders it viscous and cloggy. On the other hand, in Byzacium, a district of Africa, and a champaign country of such singular fertility as to render grain one hundred and fifty fold, ${ }^{71}$ the soil is such, that in time of drought, not even bulls are able to plough it; while, on another occasion, just after a shower of rain, one poor ass, with an old woman to guide it, is quite sufficient, ${ }^{72}$ as ourselves we have witnessed, to do the ploughing. But as to amending one soil by the agency of another, as some persons recommend, by throwing rich earth over one that is poor and thin, or by laying a soaking light soil over one that is humid and unctuous, it is a labour of perfect madness. ${ }^{73}$ What can a man possibly hope for who cultivates such a soil as this?

CHAF 4. (6.) -THE EIGHT KINDS OF EARTH BOASTED OF BY THE GAULS AND GREEKS.

There is another method, which has been invented both in

${ }_{68}$ The reason being, that in such cases the soil is saturated with thyme, origanum, mint, and other odoriferous herbs.

${ }_{69}$ This opinion is contrary to that expressed by Columella, B. ii. c. 1 ; but the justice of it is universally recognized. Upon this theory, too, is based the modern practice of alternating the crops in successive years, the necessity of providing for heavy rents, not allowing the land to enjoy absolute rest.

70 This has not come to pass even yet, nearly two thousand years since the days of Pliny.

71 See B. v. c. 3, and B. xviii. c. 21.

${ }^{72}$ Fée taxes our author here with exaggeration. For Byzacium, see B. v. c. 3 , and B. xviii. c. 21.

${ }_{73}$ Nevertheless, as Fée remarks, the method is often practised with great success. Pliny is at issue here with Theophrastus, De Causis, B. iii. c. 25 . 
Gaul and Britain, of enriching earth by the agency of itself, being **** and that kind known as marl..$^{74}$ Thissoil is looked upon as containing a greater amount of fecundating principles, and acts as a fat in relation to the earth, just as we find glands existing in the body, which are formed by a condensation of the fatty particles into so many kernels. (7.) This mode of proceeding, too, has not bcen overlooked by the Greeks ; indeed, what subject is there that they have not touched upon? They call by the name of leucargillon ${ }^{75}$ a white argillaceous earth which is used in the territory of Megara, but only where the soil is of a moist, cold nature.

It is only right that I should employ some degree of care and exactness in treating of this marl, which tends so greatly to enrich the soil of the Gallic provinces and the British islands. There were formerly but two varieties known, but more recently, with the progress of agricultural knowledge, several ${ }^{76}$ others have begun to be employed; there being, in fact, the white, the red, the columbine, the argillaceous, the tufaceous, and the sandy marls. It has also one of these two peculiarities, it is either rough or greasy to the touch; the proper mode of testing it being by the hand. Its uses, too, are of a twofold nature-it is employed for the production of the cereals only, or else for the enrichment of pasture land as well. The tufaceous ${ }^{77}$ kind is nutrimental to grain, and so is the white; if found in the vicinity of springs, it is fertile to an immeasurable extent; but if it is rough to the touch, when laid upon the land in too large a quantity, it is apt to burn up the soil. The next kind is the red marl, known as acaunumarga, ${ }^{78}$ consisting of stones mingled with a thin sandy

74 A nattral mixture of argilla and calcareous stones, or subcarbonate of chalk. Fée remarks, that the ancients were not acquainted with the proper method of applying it. Marl only exercises its fertilizing influence after being reduced to dust by the action of the atmosphere, by absorbing the oxygen of the air, and giving to vegetation the carbonic acid that is necessary for their nourishment.

75 "White argilla." This, Fée thinks, is the calcareous marl, three varieties of which are known, the compact, the schistoid, and the friable.

${ }^{76}$ At the present day there are only two varieties of marl recognized, the argillaceous and the calcareous; it is to the latter, Fée thinks, that the varieties here mentioned as anciently recognized, belonged.

77 The Marga terrea of Linnæus. It abounds in various parts of Europe.

78 From the Greek, meaning "not bitter marl." 
earth. These stones are broken upon the land itself, and it is with considerable difficulty during the earlier years that the stalk of the corn is cut, in consequence of the presence of these stones; however, as it is remarkably light, it only costs for carriage one-half of the outlay required in using the other varieties. It is laid but very thinly on the surface, and it is generally thought that it is mixed with salt. Both of these varieties, when once laid on the land, will fertilize it for fifty ${ }^{79}$ years, whether for grain or for hay.

(8.) Of the marls that are found to be of an unctuous nature, the best is the white. There are several varieties of it: the most pungent and biting being the one already mentioned. Another kind is the white chalk that is used for cleaning ${ }^{80}$ silver; it is taken from a considerable depth in the ground, the pits being sunk, in most instances, as much as one hundred feet. These pits are narrow at the mouth, but the shafts enlarge very considerably in the interior, as is the case in mines; it is in Britain more particularly that this chalk is employed. The good effects of it are found to last full eighty years; and there is no instance known of an agriculturist laying it twice on the same land during his life ${ }^{81}$ A third variety of white marl is known as glisomarga $;^{82}$ it consists of fullers' chalk ${ }^{83}$ mixed with an unctuous earth, and is better for promoting the growth of hay than grain; so much so, in fact, that between harvest and the ensuing seed-time there is cut a most abundant crop of grass. While the corn is growing, however, it will allow no other plant to grow there. Its effects will last so long as thirty years; but if laid too thickly on the ground, it is apt to choke up the soil, just as if it had been covered with Signine ${ }^{84}$ cement. The Gauls give to the columbine marl in

79 Marl does not begin to fertilize till several years after it has been laid down; hence, it is generally recommended to marl the land a little at a time, and often. If the ground is fully marled, it requires to be marled afresh in about eight or ten years, and not fifty, as Pliny says.

80 "Argentaria." Used, probably, in the same way as whitening in modern times. See B. xxxv. c. 58 .

81 An exaggeration, no doubt.

82 Probably meaning "smooth marl ;" a variety, Fée thinks, of argillaceous marl, and, perhaps, the potter's argillaceous marl, or potter's argil. He suggests, also that it may have possibly been the Marga fullonum saponacea lamellosa of Valerius; in other words, fullers' earth.

83 Creta fullonia.

${ }^{84}$ See B. $x x x v$. c. 46. 
their language the name of eglecopala $;^{85}$ it is taken up in solid blocks like stone, after which it is so loosened by the action of the sun and frost, as to split into laminæ of extreme thinness; this kind is equally beneficial for grass and grain. The sandy $y^{86}$ marl is employed if there is no other at hand, and on moist slimy soils, even when other kinds can be procured.

The Ubii are the only people that we know of, who, having an extremely fertile soil to cultivate, employ methods of enriching it; wherever the land may happen to be, they dig to a depth of three feet, and, taking up the earth, cover the soil with it in other places a foot in thickness; this method, however, to be beneficial, requires to be renewed at the end of every ten years. The Edui and the Pictones have rendered their lands remarkably fertile by the aid of limestone, which is also found to be particularly beneficial to the olive and the vine. ${ }^{87}$ Every marl, however, requires to be laid on the land immediately after ploughing, in order that the soil may at once imbibe its properties; while at the same time, it requires a little manure as well, as it is apt, at first, to be of too acrid a nature, at least where it is not pasture land that it is laid upon; in addition to which, by its very freshness it may possibly injure the soil, whatever the nature of it may be; so much so, indeed, that the land is never fertile the first year after it has been employed. It is a matter of consideration also for what kind of soil the marl is required; if the soil is moist, a dry marl is best suited for it; and if dry, a rich unctuous marl. If, on the other hand, the land is of a medium quality, chalk or columbine ${ }^{88}$ marl is the best suited for it.

\section{CHAP. 5. (9.) -THE EMPLOYMeNT OF ASHES.}

The agriculturists of the parts of Italy bejond the river

${ }_{85}$ This would rather seem to be a name borrowed from the Greek, $\dot{a} \iota \gamma \lambda \dot{\eta} \varepsilon \iota$, , "shining," and $\pi \varepsilon \lambda \iota \grave{c}$, "white." Notwithstanding the resemblance, however, it is just possible that it may have been derived from the Gallic. Fée queries whether this is the schistoid calcareous marl, or the schistoid argillaceous marl, the laminæ of which divide with great facility, and the varieties of which display many colours.

${ }^{86} \mathrm{~A}$ variety of the terreous marl.

87 It has the effect of augmenting their fruitfulness, and ameliorating the quality of the fruit. Lime is still considered an excellent improver for strong, humid soils.

${ }_{88}$ From this passage, Fée thinks that the Columbine marl must have been of the white, slightly sparkling kind. 
Padus, are such admirers of ashes ${ }^{89}$ for this purpose, that they even prefer it as a manure to the dung of beasts of burden; indeed, they are in the habit of burning dung for this purpose, on account of its superior lightness. They do not, however, use them indiscriminately upon the same soil, nor do they employ ashes for promoting the growth of shrubs, nor, in fact, of some of the cereals, as we shall have occasion ${ }^{90}$ to mention hereafter. There are some persons who are of opinion also that dust ${ }^{91}$ imparts nutriment to grapes, and cover them with it while they are growing, taking care to throw it also upon the roots of the vines and other trees. It is well known that this is done in the province of Gallia Narbonensis, and it is a fact even better ascertained that the grape ripens all the sooner for it; indeed, the dust there contributes more to its ripeness than the heat of the sun.

\section{CHAP. 6.-MANURE.}

There are various kinds of manure, the use of which is of very ancient date. In the times of Homer ${ }^{92}$ even, the aged king is represented as thus enriching the land by the labour of his own hands. Tradition reports that King Augeas was the first in Greece to make use of it, and that Hercules introduced the practice into Italy; which country has, however, immortalized the name of its king, Stercutus, ${ }^{93}$ the son of Faunus, as claiming the honour of this invention. M. Varro ${ }^{94}$ assigns the first rank for excellence to the dung of thrushes kept in ariaries, and lauds it as being not only good for land, but excellent food for oxen and swine as well; indeed, he goes so far as to assert that there is no food that they will grow fat upon more speedily. We really have some reason to augur well of the manners of the present day, if it is true that in the days of our ancestors there were aviaries of such vast extent as to be able to furnish manure for the fields.

89 Though ashes fertilize the ground, more particularly when of an argillaceous nature, they are not so extensively used now as in ancient times. Pliny alludes here more particularly to wood and dunghill ashes.

${ }_{90}$ This, however, he omits to do.

$91 \mathrm{He}$ alludes, probably, to Theophrastus, De Causis, B. iii. c. 22.

92 Odyssey xxiv. 225.

93 From "stercus," "dung." A fabulous perscnage, most probably.

94 De Re Rust. i. 38. 
Columella ${ }^{95}$ gives the second rank to pigeon manure, ${ }^{96}$ and the next to that of the poultry-yard; but he condemns that of the aquatic birds. Some authors, again, are agreed in regarding the residue of the human food ${ }^{97}$ as the very best of all manures; while others would only employ the superfluous portion of our drink, ${ }^{98}$ mixing with it the hair that is to be found in the curriers' workshops. Some, however, are for employing this liquid by itself, though they would mix water with it once more, and in larger quantities even than when originally mixed with the wine at our repasts; there being a double share of noxious qualities to correct, not only those originally belonging to the wine ${ }^{99}$ but those imparted to it by the human body as well. Such are the various methods by which we vie with each other in imparting nutriment to the earth even.

Next to the manures above mentioned, the dung of swine is highly esteemed, Columella being the only writer that condemns it. Some, again, speak highly of the dung of all quadrupeds that have been fed on cytisus, while there are others who prefer that of pigeons. Next to these is the dung of goats, and then of sheep; after which comes that of oxen, and, last of all, of the beasts of burden. Such were the distinctions that were established between the various manures aznong the ancients, such the precepts that they have left us, and these I have here set forth as being not the mere subtle inventions of genius, but because their utility has been proved in the course of a long series of years. In some of the provinces, too, which abound more particularly in cattle, by rea-

${ }_{95}$ De Re Rust. ii. 15.

${ }_{96}$ Mixed with other manures, it is employed at the present day in Normandy.

${ }_{97}$ This manure is still extensively employed in Flanders, Switzerland, and the vicinity of Paris. In the north of England it is mixed with ashes, and laid on the fields. There was an old prejudice, that vegetation grown with it has a fetid odour, but it has for some time been looked upon as exploded.

${ }_{98}$ Or urine. In the vicinity of Paris, a manure is employed ealled urate, of which urine forms the basis.

${ }_{99}$ Fée seems to think that this passage means that the bad smell of urine is imparted to it by the wine that is drunk. It is difficult to say what could have been the noxious qualities imparted by wine to urine as a manure, and Pliny probably would have been somewhat at a loss to explain his meaning. 
son of their prolific soil, we have seen the manure passed through a sieve like so much flour, and perfectly devoid, through lapse of time, ${ }^{1}$ of all bad smell or repulsive look, being changed in its appearance to something rather agreeable than otherwise. In more recent times it has been found that the olive thrives more particularly in soil that has been manured with the ashes ${ }^{2}$ of the lime-kiln. To the ancient rules Varro $^{3}$ has added, that corn land should be manured with horsedung, that being the lightest manure of all, while meadow land, he says, thrives better with a manure of a more heary nature, and supplied by beasts that have been fed upon barley; this last tending more particularly to the better growth of grass. ${ }^{4}$ Some persons, indeed, prefer the dung of the beasts of burden to that of oxen even, the manure of the sheep to that of the goat, and the manure of the ass to all others, the reason being that that animal masticates the most slowly of them all. Experience, however, has pronounced against these dicta of Varro and Columella; but it is universally agreed by all writers that there is nothing more beneficial than to turn ${ }^{5}$ up a crop of lupines, before they have podded, with either the plough or the fork, or else to cut them and bury them in heaps at the roots of trees and vines. It is thought, also, that in places where no cattle are kept, it is advantageous to manure the earth with stubble or even fern. "You can make manure," Cato ${ }^{6}$ says, " of litter, or else of lupines, straw, beanstalks, or the leaves of the holm-oak and quercus. Pull up the wallwort from among the crops of corn, as also the hemlock that grows there, together with the thick grass and sedge that you find growing about the willow-plots; of all this, mixed with rotten leaves, ${ }^{7}$ you may make a litter for sheep and

1 In lapse of time, if exposed to the air, it is reduced to the state of humus or mould.

2 Consisting of lime mixed with vegetable ashes.

3 De Re Rust. i. 38.

4 "Herbas." This would appear to mean grass only here; though Fée seems to think that it means various kinds of herbs.

5 This method is sometimes adopted in England with buckwheat, trefoil, peas, and other leguminous plants; and in the south of France lupines are still extensively used in the same manner, after the usage of the ancient Romans here described. The French also employ, but more rarely, for the same purpose, the large turnip, vetches, peas, trefoil, Windsor beans, sanfoin, lucerne, \&c.; but it is found a very expensive practice,

6 De Re Rust. 37.

7 "Frondam putidam." Fée thinks that this expression is used in 
oxen. If a vine should happen to be but poor and meagre, prune $^{8}$ the shoots of it, and plough them in round about it." The same author says, also, ${ }^{9}$ "When you are going to sow corn in a field, fold your sheep ${ }^{10}$ there first."

\section{CHAP. 7.-CROPS WHICH TEND TO IMPROVE THE LAND: CROPS WHICH EXHAUST IT.}

Cato $^{11}$ says, also, that there are some crops which tend to nourish the earth: thus, for instance, corn land is manured by the lupine, the bean, and the vetch; while, on the other hand, the chick-pea exercises a contrary influence, both because it is pulled up by the roots and is of a salt nature; the same is the case, too, with barley, fenugreek, and fitches, all of which have a tendency to burn up ${ }^{12}$ corn land, as, in fact, do all those plants which are pulled up by the roots. Take care, too, not to plant stone-fruits on corn land. Virgil ${ }^{13}$ is of opinion, also, that corn land is scorched by flax, oats, and poppies.

\section{CHAP. 8. -THE PROPER MODE OF USTNG MANURE.}

It is recommended, ${ }^{14}$ also, that the dung-heap should be kept in the open air, in a spot deep sunk and well adapted to receive the moisture: it should be covered, too, with straw, that it may not dry up with the sun, care being taken to drive a stake of robur into the ground, to prevent serpents from breeding $^{15}$ there. It is of the greatest consequence that the

reference to the "ebulum," dane-wort, wall-wort, or dwarf-elder, previously mentioned.

8 "Concidito." Sillig adopts the reading "comburito," "burn the shoots, and dig in, \&c." But in the original the word is "concidito."

9 De Re Rust. 30.

10 This is still extensively practised in England and France, and other countries. The azote, even, that exhales from the bodies of the animals, is supposed to have a fertilizing influence, to say nothing of the dung, grease of the boày, and urine.

11 De Re Rust. 37.

12 "Exsugunt," "suck up," or "drain," is one reading in Cato; and it is not improbable that it is the correct one.

13 Georg. i. 77,78 :

"Urit enim lini campum seges, urit avenæ, Urunt Lethæo perfusa papavera somno."

14 Fée is of opinion, that, with reference to this branch of agriculture, the ancients displayed more skill and intelligence than the moderns.

15 This absurdity is copied from Varro and Columella. 
manure should be laid upon the land while ${ }^{16}$ the west winds prevail, and during a dry moon. Most persons, however, misunderstand this precept, and think this should be done when the west winds are just beginning to blow, and in the month of February only; it being really the fact that most crops require manuring in other months as well. At whatever period, however, it may be thought proper to manure the land, the greatest care should be taken that the wind is blowing due west at the time, and that the moon is on the wane, and quite dry. Such precautions as these will increase in a most surprising degree the fertilizing effects of manure.

\section{CHAP. 9. (10.) - THE MODES IN WHICH TREES BEAR.}

Having now treated at sufficient length of the requisite conditions of the weather and the soil, we shall proceed to speak of those trees which are the result of the care and inventive skill of man. Indeed, the varieties of them are hardly less numerous than of those which are produced by Nature, ${ }^{17}$ so abundantly have we testified our gratitude in return for her numerous bounties. For these trees, we find, are reared either from seed, or else by transplanting, by layers, by slips torn from the stock, by cuttings, by grafting, or by cutting into the trunk of the tree. But as to the story that the leaves of the palm are planted by the Babylonians, and so give birth ${ }^{18}$ to a tree, I am really surprised that Trogus should have ever believed it. Some of the trees are reproduced by several of the methods above enumerated, others, again, by all of them.

\section{Chap. 10.--PLANTS WHich aRE PROPAGATED BY SEED.}

It is Nature herself that has taught us most of these methods, and more particularly that of sowing seed, as it was very soon evident how the seed on falling to the ground revived

$16 I$. $e$. in the early part of spring. In modern times, the period for manuring varies, according to the usage of different localities, being practised in all the four seasons of the year, according to the crops, weather, and climate.

17 See B. xvi. c. 58 .

18 The palm is grown in Africa from shoots thrown out from the axilla of the leaves; and it is in this circumstance, Fée thinks, that the story told by Trogus must have originated. Some of the ferns throw out adventitious buds from the summit of the leaf, and the orange tree and some others occasionally have them at the base of the leaf. 
again in germination. Indeed, there are some trees that are capable of being propagated in no other way, the chesnut ${ }^{19}$ and the walnut, for instance; with the sole exception, of course, of such as are employed for coppice wood. By this method, too, as well as the others, some trees are propagated, though from a seed of a different nature, such, for instance, as the vine, the apple, and the pear $;^{20}$ the seed being in all these cases in the shape of a pip, and not the fruititself, as in that of the chesnut and the walnut. The medlar, too, can also be propagated by the agency of seed. All trees, however, that are grown by this method are very slow in coming to maturity, ${ }^{21}$ degenerate ${ }^{22}$ very rapidly, and must often be renewed by grafting: indeed, the chesnut even sometimes requires to be grafted.

\section{CHAP. 11.-TREES WHICH NEVER DEGENERATE.}

On the other hand, there are some trees which have the property of never degenerating, in whatever manner they are reproduced, the cypress, palm, and laurel, ${ }^{23}$ for instance : for we find that the laurel is capable of being propagated in several ways. We have already made mention ${ }^{24}$ of the various kinds of laurel; those known as the Augustan, the baccalis, and the tinus $^{25}$ are all reproduced in a similar manner. The berries are gathered in the month of January, after they have been dried by the north-east winds which then prevail ; they are then kept ${ }^{26}$ separate and exposed to the action of the air, being liable to ferment if left in a heap. After this, they are first

19 Virgil says, Georgics ii. 14 :

"Pars autem posito surgunt de semine; ut altæ

Castaneæ, nemorumque Jovi quæ maxime frondet."

20 This method of reproduction is seldom or never employed; plants or cuttings only being used for the purpose.

${ }^{21}$ Besides which, it is doubtful if they will reproduce the variety, the seed of which was originally sown.

${ }_{22}$ In some cases, they are more particularly liable to disease-the apple, for instance.

${ }_{23}$ Because the mode of cultivation adopted has little or no influence upon them. The palm, however, to bear good fruit, requires the careful attention of man. It is not capable of being grafted.

24 In B. xv. c. 39. The laurel may be grown from cuttings or shoots, and from seed.

${ }^{25}$ Known as the Laurus tinus, or $\nabla$ iburnum tinus of Linnæus.

${ }^{26}$ This is not done at the present day, as it is found that the oil which they contain turns rancid, and prevents germination. 
seasoned with smoke, and then steeped in urine, preparatory to sowing. ${ }^{27}$ Some persons put them in baskets of osier, and tread them down with the feet in running water, until the outer skin is removed, as it is found that the moisture ${ }^{28}$ which they contain is detrimental to them, and prevents them from germinating. A trench is then dug, about a palm in depth, and somewhere about twenty of the berries are then put into it, being laid in a heap: this is usually done in the month of March. These kinds of laurel admit of being propagated from layers also ; but the triumphal ${ }^{29}$ laurel can be reproduced from cuttings only.

All the varieties of the myrtle ${ }^{30}$ are produced in Campania from the berry only, but at Rome from layers. Democritus, however, says that the Tarentine myrtle may be re-produced another way. ${ }^{31}$ They take the largest berries and pound them lightly so as not to crush the pips: with the paste that is thus made a rope is covered, and put lengthwise in the ground; the result of which is that a hedge is formed as thick as a wall, with plenty of slips for transplanting. In the same way, too, they plant brambles to make a hedge, by first covering a rope of rushes with a paste made of bramble-berries. In case of necessity, it is possible at the end of three years to transplant the suckers of the laurel and the myrtle that have been thus re-produced.

With reference to the plants that are propagated from seed, Mago treats at considerable length of the nut-trees-he says that the almond ${ }^{32}$ should be sown in a soft argillaceous earth, upon a spot that looks towards the south-that it thrives also in a hard, warm soil, but that in a soil which is either unctuous or moist, it is sure to die, or else to bear no fruit. He recommends also for sowing those more particularly which are of a curved shape like a sickle, and the produce of a young tree,

27 These methods of preparation are no longer employed.

$28^{\prime}$ It is for this reason, as already stated, that they should be sown at once.

${ }^{29}$ See B. xv. c. 39 . He there calls it "sterilis," "barren."

30 See B. xv. c. 37. The myrtle reproduces itself in its native countries with great facility, but in such case the flowers are only single. Where a double flower is required, it is grown from layers.

31 No better, Fée says, than the ordinary method of making a myrtle hedge.

32 The almond requires a dry, light earth, and a southern aspect. 
and he says that they should be steeped for three days in diluted manure, or else the day before they are sown in honey and water. ${ }^{33}$ He says, also, that they should be put in the ground with the point downwards, and the sharp edge towards the north-east; and that they should be sown in threes and placed triangularly, at the distance of a palm from each other, care being taken to water them for ten days, until such time as they have germinated.

Walnuts when sown are placed lengthwise, ${ }^{34}$ lying upon the sides where the shells are joined; and pine nuts are mostly put, in sevens, into perforated pots, or else sown in the same way as the berries are in the laurels which are re-produced by seed. The citron ${ }^{35}$ is propagated from pips as well as layers, and the sorb from seed, by sucker, or by slip : the citron, however, requires a warm site, the sorb a cold and moist one.

\section{CHAP. 12.-PROPAGATION BY SUCKERS.}

Nature, too, ${ }^{36}$ has taught us the art of forming nurseries; when from the roots of many of the trees we see shooting up a dense forest of suckers, an offspring that is destined to be killed by the mother that has borne them. For by the shade of the tree these suckers are indiscriminately stifled, as we often see the case in the laurel, the pomegranate, the plane, the cherry, and the plum. There are some few trees, the elm and the palm for instance, in which the branches spare the suckers; however, they never make their appearance in any of the trees except those in which the roots, from their fondness for the sun and rain, keep close, as they range, to the surface of the ground. It is usual not to place all these suckers at once in the ground upon the spot which they are finally to occupy, but first to entrust them to the nursery, and to allow them to grow in seed-plots, after which they are finally transplanted. This transplanting softens down, in a most remarkable manner, those trees even which grow wild; whether it is that trees, like men, are naturally fond of novelty and

33 These precautions are no longer observed at the present day.

34 'This precaution, too, is no longer observed.

${ }_{35}$ The citron is produced, at the present day, from either the pips, piants, or cuttings.

${ }^{36}$ This passage is borrowed almost verbatim from Virgil, Georgies ii. 50 , et seq. 
change of scene, or that, on leaving the spots of their original growth, or to which they have been transplanted, they lay aside their bad qualities and become tame, iike the wild animals, the moment they are separated from the parent stock.

\section{CHAP. 13.-PROPAGATION BY SLIPS AND CUTTINGS.}

Nature has also discovered another method, which is very similar to the last-for slips torn away from the tree will live. In adopting this plan, care should be taken to pull out the haunch $^{37}$ of the slip where it adheres to the stock, and so remove with it a portion of the fibrous body of the parent tree. It is in this way that the pomegranate, the hazel, the apple, the sorb, the medlar, the ash, the fig, and more particularly the vine, are propagated. The quince, however, if planted in this way will degenerate, ${ }^{38}$ and it has been consequently found a better plan to cut slips and plant them : a method which was at first adopted for making hedges, with the elder, the quince, and the bramble, but came afterwards to be applied to cultivated trees, such as the poplar, the alder, and the willow, which last will grow if even the slip is planted upside down. ${ }^{39}$ In the case of cuttings, they are planted at once in the spot which it is intended they should occupy : but before we pass on to the other methods of propagation, it seems as well to mention the care that should be expended upon making seedplots. ${ }^{40}$

\section{CHAP. 14. - SEED-PLOTS.}

In laying out a seed-plot it is necessary that a soil of the very highest quality should be selected; for it is very often requisite that a nurse should be provided for the young plants, who is more ready to humour them than their parent soil. The ground should therefore be both dry and nutritious, well

37 "Perna." This method of reproduction is still adopted, but it is not to be recommended, as the young tree, before it throws out a root, is liable to be overthrown by high winds. Virgil mentions it, Georg. ii. 23. slow.

${ }_{38}$ Palladius only says that the growth of the quince in such case is very

${ }_{39}$ This experiment has been tried for curiosity's sake, and has succeeded; the roots become dry, lose their fibres, and then develop buds, from which branches issue; while the buds of the summit become changed into rocts. 40 "Seminarii :" "nurseries," as they are more commonly called. 
turned up with the mattock, replete with hospitality to the stranger plants, and as nearly as possible resembling the soil to which it is intended they should be transplanted. But, a thing that is of primary importance, the stones must be carefully gathered from off the ground, and it should be walled in, to ensure its protection from the depredations of poultry; the soil, too, should have as few chinks and crannies as possible, so that the sun may not be enabled to penetrate and burn up the roots. The young trees should be planted at distances ${ }^{41}$ of a foot and a-half, for if they happen to touch one another, in addition to other inconveniences, they are apt to breed worms; for which reason it is that they should be hoed as often as possible, and all weeds pulled up, the young plants themselves being carefully pruned, and so accustomed to the knife.

Cato ${ }^{42}$ recommends, too, that hurdles should be set up upon forks, the height of a man, for the purpose of intercepting the rays of the sun, and that they should be covered with straw to keep off the cold..$^{43}$ He says that it is in this way that the seeds of the apple and the pear are reared, the pine-nut also, and the cypress, ${ }^{44}$ which is propagated from seed as well. In this last, the seed is remarkably ${ }^{45}$ small, so much so, in fact, as to be scarcely perceptible. It is a marvellous fact, and one which ought not to be overlooked, that a tree should be produced from sources so minute, while the grains of wheat and of barley are so very much larger, not to mention the bean. What proportion, too, is there between the apple and the pear tree, and the seeds from which they take their rise? It is from such beginnings, too, as these that springs the timber that is proof against the blows of the hatchet, presses ${ }^{46}$ that weights of enormous size even are unable to bend, masts that support the sails of ships, and battering-rams that are able to

41 The distance, in reality, ought to vary according to the nature and species of the trees, and the height they are to be allowed to attain.

42 De Re Rust. 48.

43 'These precautions are not looked upon as necessary for the indigenous trees at the present day. For the first year, however, Fée says, the hurdles might be found very useful.

${ }_{44}$ As the young cypress is very delicate, in the northern climates, Fée says, this mode of protecting it in the nursery might prove advantageous.

45 There is some exaggeration in this account of the extreme smallness of the seed of the cypress.

46 Wine and oil-presses, for instance.

VOL. III. 
shake even towers and walls! Such is the might, such is the power that is displayed by Nature. But, a marvel that transcends all the rest, is the fact of a vegetable receiving its birth from a tear-like drop, as we shall have occasion to mention ${ }^{4 \tau}$ in the appropriate place.

To resume, however : the tiny balls which contain the seed are collected from the female cypress-for the male, as I have already ${ }^{48}$ stated, is barren. This is done in the months which I have previously ${ }^{49}$ mentioned, and they are then dried in the sun, upon which they soon burst, and the seed drops out, a substance of which the ants are remarkably fond; this fact, too, only serves to enhance the marvel, when we refiect that an insect so minute is able to destroy the first germ of a tree of such gigantic dimensions. The seed is sown in the month of April, the ground being first levelled with rollers, or else by means of rammers $;^{50}$ after which the seed is thickly sown, and earth is spread upon it with a sieve, about a thumb deep. If laid beneath a considerable weight, the seed is unable to spring up, and is consequently thrown back again into the earth; for which reason it is often trodden only into the ground. It is then lightly watered after sunset every three days, that it may gradually imbibe the moisture until such time as it appears above ground. The young trees are transplanted at the end of a year, when about three-quarters of a foot in length, due care being taken to watch for a clear day with no wind, such being the best suited for the process of transplanting. It is a singular thing, but still it is a fact, that if, or the day of transplanting, and only that day, there is the slightest drop of rain or the least breeze stirring, it is attended with danger ${ }^{51}$ to the young trees; while for the future they are quite safe from peril, though at the same time they have a great aversion to all humidity. ${ }^{52}$ The jujube-tree ${ }^{53}$ is

${ }^{47}$ B. xix. c. 48 , and B. xx. c. 11 . As Fée remarks, this is a fabulous assertion, which may still be based upon truth; as in gum-resin, for instance, we find occasionally the seeds of the parent tree accidentally enclosed in the tear-like drops.

48 In B. xvi. c. 47.

49 In c. 11 of this Book.

50 "Volgiolis." This word is found nowhere else, and the reading is doubtful. 51 This is, at least, an exaggeration.

52 See B. xvi. c. 31 ; and c. 60.

${ }^{53}$ It is propagated at the present day both from seed and suckers, but mostly from the latter, as the seed does not germinate for two years. 
propagated from seed sown in the month of April. As to the tuber, ${ }^{54}$ it is the best plan to graft it upon the wild plum, the quince, and the calabrix, ${ }^{55}$ this last being the name that is given to a wild thorn. Every kind of thorn, too, will receive grafts remarkably well from the myxa plum, ${ }^{56}$ as well as from the sorb.

(11.) As to recommending transferring the young plants from the seed-plot to another spot before finally planting them out, I look upon it as advice that would only lead to so much unnecessary trouble, although it is most confidently urged that by this process the leaves are sure to be considerably larger than they otherwise would.

Chap. 15.-The Mode of PRopagating the Elm.

The elm seed is collected about the calends of March, ${ }^{57}$ before the tree is covered with leaves, but is just beginning to have a yellow tint. It is then left to dry two days in the shade, after which it is thickly sown in a broken soil, earth that has been riddled through a fine sieve being thrown upon it, to the same thickness as in the case of the cypress. ${ }^{58}$ If there should happen to be no rain, it is necessary to water the seed. From the nursery the young plants are carried at the end of a year to the elm-plots, where they are planted at intervals of a foot each way. It is better to plant elms in autumn that are to support the vine, as they are destitute ${ }^{59}$ of seed and are only propagated from plants. In the vicinity of the City, the young elms are transplanted into the vineyard at five years old, or, according to the plan adopted by some, when they are twenty feet in height. A furrow is first drawn for

51 See B. xv. c. 14. Probably a variety of the jujube; but if so, it could hardly be grafted on trees of so different a nature as those here mentioned.

${ }^{55}$ This tree has not been identified. Dalechamps thinks that it is a species of gooseberry, probably the same as the Ribes grossularia of Linnwus. It has been also suggested that it may be the Spina cervina of the Italians, the Rhamnus catharticus of Linnæus, the purgative buckthorn.

${ }_{56}$ Fée doubts if the plum can be grafted on the thorn.

57 First of March.

58 The thickness of the thumb. See the last Chapter.

59 He alludes to the Atinian elm, of which he has already said the same in B. xvi. c. 29. 
the purpose, the name given to which is " novenarius," ${ }^{60}$ being three feet in depth, and the same in breadth or even more; into this the young tree is put, and the earth is moulded up around it to the height of three feet every way. These mounds are known by the name of "arula" ${ }^{11}$ in Campania. The intervals are arranged according to the nature of the spot; but where the country is level, it is requisite that the trees should be planted wider apart. Poplars and ashes, too, as they germinate with greater rapidity, ought to be planted out at an earlier period, or, in other words, immediately after the ides of February. ${ }^{62}$ In arranging trees and shrubs for the support of the vine, the form of the quincunx ${ }^{63}$ is the one that is generally adopted, and, indeed, is absolutely necessary : it not only facilitates the action of the wind, but presents also a very pleasing appearance, for whichever way you look at the plantation, the trees will always present themselves in a straight line. The same method is employed in propagating the poplar from seed as the elm, and the mode of transplanting it from the seed-plot is the same as that adopted in transplanting it from the forests.

\section{CHAP. 16. -THE HOLES FOR TRANSPLANTING.}

But it is more particularly necessary in transplanting, that the trees should always be removed to a soil that is similar, or else superior, ${ }^{64}$ to the one in which they grew before. If taken from warm or early ripening localities, they ought not to be removed to cold or backward sites, nor yet, on the other hand, from these last to the former. If the thing can possibly be done, the holes for transplanting should be dug sufficiently long before to admit of their being covered throughout with a thick coat of grass. Mago recommends that they should be dug a whole

${ }^{60}$ From being about nine feet in circumference.

61 A "little altar."

63 I. e. each at an angle with the other, in this form:-

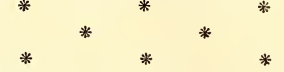

It was probably so called from the circumstanee that each triangle resembles $V$, or five.

${ }_{64}$ This is the reason why a soil of only middling quality is generally selected for nurseries and seed-plots; otherwise it might be difficult to transplant the young trees to an improved soil. 
year beforehand, in order that they may absorb the heat of the sun and the moisture of the showers; or, if circumstances do not admit of this, that fires should be made in the middle of them some two months before transplanting, that being only done just after rain has fallen. He says, too, that in an argillaceous ${ }^{65}$ or a hard soil, the proper measurement is three cubits every way, and on declivitous spots one palm more, care being taken in every case to make the hole like the chimney of a furnace, narrower at the orifice than at the bottom. Where the earth is black, the depth should be two cubits and a palm, and the hole dug in a quadrangular form.

The Greek writers agree in pointing out much the same proportions, and are of opinion that the holes ought not to be more than two feet and a half in depth, or more than two feet wide: at the same time, too, they should never be less than a foot and a half in depth, even though the soil should be wet, and the vicinity of water preclude the possibility of the soil going any deeper. "If the soil is watery," says Cato, ${ }^{66}$ " the hole should be three feet in width at the orifice, and one palm and a foot at the bottom, and the depth four feet. It should be paved, too, with stones, ${ }^{67}$ or, if they are not at hand, with stakes of green willow, or, if these cannot be procured, with a layer of twigs; the depth of the layer so made being a foot and a half."

It appears to me that I ought here to add, after what has been said with reference to the nature of trees, that the holes should be sunk deeper for those which have a tendency to run near the surface of the earth, such as the ash and the olive, for instance. These trees, in fact, and others of a similar nature, should be planted at a depth of four feet, while for the others three feet will be quite sufficient. "Cut down that stump," said Papirius Cursor, the general, ${ }^{68}$ when to the great

${ }^{65}$ The ordinary depth, at the present day, is about two feet; but when in an argillaceous soil, as Pliny says, the hole is made deeper. If the soil is black mould, the hole is not so deep, and of a square form, just as recommended by Pliny.

${ }_{66}$ De Re Rust. 43.

${ }^{67}$ This would be either useless, or positively injurious to the tree.

${ }^{68}$ See B. xiv. c. 14. It seems impossible to say with exactness how this passage came to be inserted in the context; but Sillig is probably right in suspecting that there is a considerable lacuna here. It is not improbable that Pliny may have enlarged upon the depth of the roots of trees, and the method of removing them in ancient times. Such being the case, he might 
terror of the protor of Præneste, he had ordered the lictors to draw ${ }^{69}$ their axes. And, indeed, there is no harm in cutting: away those portions [of the root] which have become exposed. Some persons recommend that a bed should be formed at the bottom, of potsherds or round pebbles, ${ }^{70}$ which both allow the moisture to pass and retain as much as is wanted; while at the same time they are of opinion that flat stones are of no use in such a case, and only prevent the root from penetrating ${ }^{71}$ the earth. To line the bottom with a layer of gravel would be to follow a middle course between the two opinions.

Some persons recommend that a tree should not be transplanted before it is two years old, nor yet after three, while others, again, are of opinion that if it is one year old it is quite sufficient; Cato ${ }^{72}$ thinks that it ought to be more than five fingers in thickness at the time. The same author, too, would not have omitted, if it had been of any importance, to recommend that a mark ${ }^{73}$ should be made on the bark for the purpose of pointing out the southern aspect of the tree; so that, when transplanted, it may occupy exactly the same posi-tion that it has previously done; from an apprehension that the north side of the tree, on finding itself opposite to a southern sun, might split, and the south side be nipped by the north-eastern blasts. Indeed, there are some persons who follow a directly opposite practice even in the vine and the fig; ${ }^{71}$ by placing the north side of the tree, when transplanted, towards the south, and vice versâ; being of opinion that by think it not inappropriate to introduce the story of Papirius, who, when only intending to have a stump cut down that grew in the way, took the opportunity of frightening the prætor of Præneste, by the suddenness of the order to his lictor, and probably the peremptory tone in which it was given. This was all the more serious to the prætor, as Papirius had been rebuking him just before in the severest terms.

69 From the bundle of fasces, or rods

70 This precept is borrowed from Virgil, Georg. ii. 348, et seg.

71 There is little doubt that they took the right view.

72 De Re Rust. 28.

${ }^{73}$ This precaution is omitted by the modern nurserymen, though Fée is inclined to think it might be attended with considerable advantage, as the fibres of the side that has faced the south are not likely to be so firm as ihose of the northern side. This precaution, however, would be of more importance with exotic trees than indigenous ones. It is still practised to some extent with the layers of the vine.

${ }^{74}$ Fée suggests that Pliny may have here misunderstood a passage in Theophrastus, Hist. Plant. ii. 8, with reference to the planting of the fig. 
adopting this plan the foliage becomes all the thicker ${ }^{75}$ and the better able to protect the fruit, which is less liable to fall off in consequence, and that the tree is rendered all the better for climbing. Most people, however, take the greatest care to turn to the south that part of the tree from which the branches have been lopped at the top, little thinking that they expose it thereby to a chance of splitting ${ }^{76}$ from the excessive heat. For my own part, I should prefer that this part of the tree should face that point of the heavens which is occupied by the sun at the fifth $^{77}$ or even the eighth hour of the day. People are also equally unaware that they ought not, through neglect, to let the roots be exposed to the air long enough to get dry; and that the ground should not be worked about the roots of trees while the wind is blowing from the north, or, indeed, from any point of the heavens that lies between north and southeast; or, at all events, that the roots should not be left to lie exposed to these winds; the result of such modes of proceeding being, that the trees die, the grower being all the while in total ignorance of the cause.

$\mathrm{Cato}^{78}$ disapproves, too, of all wind and rain whenever the work of transplanting is going on. Wher this is the case, it will be beneficial to let as much adhere to the roots as possible of the earth in which the tree has grown, and to cover them all round with clods ${ }^{79}$ of earth: it is for this reason that Cato ${ }^{80}$ recommends that the young trees should be conveyed in baskets, a very desirable method, no doubt. The same writer, too, approves of the earth that has been taken from the surface being laid at the bottom of the hole. Some persons say, ${ }^{81}$ that if a layer of stones is placed beneath the root of the pomegranate, the fruit will not split while upon the tree. In transplanting, it

75 There would be no such result, Fée says.

${ }^{7} 6$ This is a useless precaution; but at the same time, Pliny's fears of its consequences are totally misplaced.

77 At 11 A.M., or 2 P.M. ; i.e. between south and south-east, and south and south-west.

78 De Re Rusti. 28.

79 Wet moss, or moist earth, is used for the purpose at the present day.

80 De Re Rust. 28. It is most desirable to transplant trees with a layer of the earth in which they have grown; but if carried out to any extent, it would be an expensive process.

81 "Tradunt." This expression shows that Pliny does not give credit to the statement. Columella and Palladius speak of three stones being laid under the root, evidently as a kind of charm. 
is the best plan to give the roots a bent position, but it is absolutely necessary that the tree should be placed in such a manner as to occupy exactly the centre of the hole. The fig-tree, if the slip when planted is stuck in a squill ${ }^{82}$ - such being the name of a species of bulb-is said to bear with remarkable rapidity, while the fruit is exempt from all attacks of the worm: the same precaution, too, in planting, will preserve the fruit of all other trees in a similar manner. Who is there, too, that can entertain a doubt that the very greatest care ought to be taken of the roots of the fig-tree when trans. planted?-indeed, it ought to bear every mark of being taken, and not torn, from out of the earth. Upon this subject I omit various other practical precepts, such, for instance, as the necessity of moulding up the roots with a rammer, a thing that Cato $^{83}$ looks upon as of primary importance; while, at the same time, he recommends that the wound made in the stock should be first covered with dung, and then bound with a layer of leaves. ${ }^{84}$

\section{CHAP. 17. (12.)-THE INTERVALS TO BE LEFT BETWEEN TREES.}

The present seems to me to be the proper occasion for making some mention of the intervals ${ }^{85}$ that ought to be left between the trees. Some persons have recommended that pomegranates, myrtles, and laurels should be planted closer together than the other trees, leaving, however, a space of nine feet between them. Apple-trees, they say, should be planted a little wider apart, and pear-trees, almonds, and figs even still more so. The best rule, however, is to consult the length of the branches, and the nature of the spot, as well as the shade that is formed by the tree; for it is of great importance to take this last into consideration. The shadow thrown by the large trees even is but of small dimensions, when the branches are disposed around

${ }^{82}$ See B. xix. c. 30 . A somewhat similar practice is also recommended in B. xv. c. 18; but, of course, as Fée remarks, it can lead to no results.

83 De Re Rust. 28.

${ }^{81}$ Fée remarks that this is a useful precaution, more particularly in the case of the coniferous trees, the fig, and others that are rich in juice; but if universally used, would be attended with great expense. The French use for the purpose a mixture of fresh earth and cow-dung, to which they give the name of "onguent Saint-Fiacre." S.ee p. 481.

85 This is from Theophrastus, Hist. Plant. ii. 7. The question, however, depends entirely upon the nature of the tree, the quality of the soil, and various other considerations, as Pliny himself admits. 
the body of the tree in a spherical form, as in the apple and the pear, for instance. In the cherry, on the other hand, and the laurel, the shadow projected is of enormous extent.

\section{CHAP. 18. -THE NATURE OF THE SHADOW THROWN BY TREES.}

The shadows of trees are possessed of certain properties. That of the walnut is baneful ${ }^{86}$ and injurious to man, in whom it is productive of head-ache, and it is equally noxious to everything that grows in its vicinity. The shadow, too, of the pine has the effect of killing ${ }^{87}$ the grass beneath it; but in both of these trees the foliage presents an effectual resistance to the winds, while, at the same time, the vine is destitute of such protection. ${ }^{85}$ The drops of water that fall from the pine, the quercus, and the holm-oak are extremely heary, but from the cypress none fall; the shadow, too, thrown by this last tree is extremely small, its foliage being densely packed. ${ }^{89}$ The shadow of the fig, although widely spread, is but light, for which reason it is allowed to be planted among. vines. The shadow of the elm is refreshing and even nutrimental to whatever it may happen to cover ; though, in the opinion of Atticus, this tree is one of the most injurious of them all; and, indeed, I have no doubt that such may be the case when the branches are allowed to become too long; but at the same time I am of opinion that when they are kept short it can be productive of no possible harm. The plane also gives a very pleasant shade, ${ }^{90}$ though somewhat dense : but in this case we must look more to the luxuriant softness of the grass beneath it than the warmth of the sun; for there is no tree that forms a more verdant couch on which to recline.

The poplar ${ }^{91}$ gives no shade whatever, in consequence of the

86 See B. xv. c. 24. This notion, Fee remarks, still prevails to a very considerable extent.

$87 \mathrm{By}$ depriving it of the light, and the heat of the sun; but, most probably, from no other reason.

88 "Quoniam et protecta vinearum ratione egent." . This passage is probably in a mutilated state.

89 "In se convoluta."

90 The plane was much valued for its shade by convivial parties. Hence we find in Virgil, Georg. iv. 146 - "Atque ministrantem platanum potantibus umbram."

$91 \mathrm{He}$ clearly alludes to the quivering poplar, Populus tremula of Linnæus. 
incessant quivering of its leaves : while that of the alder is very dense, but remarkably nutritive to plants. The vine affords sufficient shade for its wants, the leaf being always in motion, and from its repeated morement tempering the heat of the sun with the shadow that it affords; at the same time too it serres as an effectual protection against heavy rains. In nearly all trees the shade is thin, where the footstalks of the leaves are long.

This branch of knowledge is one by no means to be despised or deserving to be placed in the lowest rank, for in the case of every variety of plant the shade is found to act either as a kind nurse or a harsh step-mother. There is no doubt that the shadow of the walnut, the pine, the pitch-tree, and the fir is poisonous to everything it may chance to light upon.

\section{CHAP. 19.-THE DROPPINGS OF WATER FRON THE LEATES.}

A very few words will suffice for the water that drops from the leaves of trees. In all those which are protected by a foliage so dense that the rain will not pass through, the drops are of a noxious nature. ${ }^{22}$ In our enquiries, therefore, into this subject it will be of the greatest consequence what will be the nature developed by each tree in the soil in which we are intending to plant it. Declivities, taken by themselves, require smaller ${ }^{93}$ intervals between the trees, and in localities that are exposed to the wind it is beneficial to plant them closer together. However, it is the olive that requires the largest intervals to be left, and on this point it is the opinion of Cato, ${ }^{91}$ with reference to Italy, that the very smallest interval ought to be twenty-five feet, and the largest thirty: this, however, varies according to the nature of the site. Tho olive is the largest ${ }^{95}$ of all the trees in Bætica : and in Africa -if, indeed, we may believe the authors who say so-there are many olive-trees that are known by the name of milliariæ, ${ }^{96}$

92 This is quite a fallacy. Even in the much more probable cases of the upas and mangineel, it is not the fact.

93 Theophrastus, De Causis, B. iii. c. 8 , says, that trees that grow on declivities have shorter branches than those of the same kind growing on plains.

94 De Re Rust. c. 16.

${ }_{95}$ This assertion is doubtful; at the present day, in Andalusia, the palm, the poplar, and many other trees are much larger than the olive.

96 "Thousand pounders." This, as Fée remarks, is clearly an exaggeration. 
being so called from the weight of oil that they produce each jear. Hence it is that Mago has prescribed an interval between these trees of no less than seventy-five feet every way, or of forty-five at the very lowest, when the soil happens to be meagre, hard, and exposed to the winds. There is no doubt, however, that Bætica reaps the most prolific harvests from between her olives.

It will be generally agreed that it is a most disgraceful piece of ignorance to lop away the branches more than is absolutely necessary in trees of vigorous growth, and so precipitate old age ; as also, on the other hand, what is generally tantamount to an avowal of unskilfulness on the part of those who have planted them, to have to cut them down altogether. Nothing can reflect greater disgrace upon agriculturists than to have to undo what they have done, and it is therefore much the best to commit an error in leaving a superfluity of room.

CHAP. 20. (13.)--TREFS WHICH GROW BUT SLOWLY : THOSE WHICH GROW WITH RAPIDITY.

Some trees are naturally slow in their growth; and those in particular which grow solely from seed ${ }^{9 i}$ and are long-lived. On the other hand, those that are short-lived grow with great rapidity, such as the fig, pomegranate, plum, apple, pear, myrtle, and willow, for instance; and yet these are the very first to display their productions, for they begin to bear at three years old, and make some show of it even before that period. The pear is the slowest in bearing of all the trees above enumerated. The cypirus, ${ }^{98}$ however, and the shrub known as the pseudo-cypirus ${ }^{99}$ are the earliest in coming to maturity, for they flower almost immediately, and then produce their sced. All trees will come to maturity more rapidly when the suckers are removed, and the nutrimental juices are thrown into the stock only.

\section{CHAP. 21. -TREFS PROPAGATED FROM LATERS.}

Nature; too, has taught us the art of reproduction from lajers. The bramble, by reason of its thinness and the exces-

${ }^{97}$ Virgil, Georg. ii. 57, makes the same remark.

98 This shrub has not been identified.

${ }^{99}$ See B. xii. c. 26. 
sive length to which it grows, bends downwards, and throws the extremities of its branches into the earth; these immediately take root again, and would fill every place far and wide, were it not that the arts of cultivation put a check to it; so much so, indeed, that it would almost appear that men are born for nothing else but to take care of the earth. Hence it is, that a thing that is in itself most noxious and most baneful, has taught us the art of reproduction by layers and quicksets. The ivy, too, has a similar property.

Cato ${ }^{1}$ says, that in addition to the vine, the fig, as well as the olive, the pomegranate, every variety of the apple, the laurel, the plum, the myrtle, the filbert, the nut of Præneste, and the plane, are capable of being propagated by layers.

Layers $^{2}$ are of two kinds; in the one, a branch, while still adhering to the tree, is pressed downwards into a hole that measures four feet every way: at the end of two years it is cut at the part where it curves, and is then transplanted at the expiration of three years more. If it is intended to carry the plant to any distance, it is the best plan to place the layer, directly it is taken up, either in an osier basket or any earthen vessel, for its better security when carried. The other ${ }^{3}$ mode of reproduction by layers is a more costly one, and is effected by summoning forth a root from the trunk of the tree even. For this purpose, earthen vessels or baskets are provided, and are then well packed with earth; through these the extremities of the branches are passed, and by this mode of encouragement a root is obtained growing amid the fruit itself, and at the very summit of the tree; for it is at the summit that this method is generally adopted. In this way has a bold and daring inventiveness produced a new tree aloft and far away from the ground. At the end of two years, in the manner already stated, the layer is cut asunder, and then planted in the ground, basket and all.

The herb savin ${ }^{4}$ is reproduced by layers, as also by slips; it

1 De Re Rust. c. 51.

2 The French call cultivation by layers "marcotte," as applied to trces in general; and "provignage," as applicable to the vine. The two methods described by Pliny are still extensively practised.

3 Taken from Cato, De Re Rust. c. 133.

4 The Juniperus sabina of Linnæus: see B. xxiv. c. 61 . It produces seed, and there is only one variety that is barren; the plant being, in reality, diœceous. 
is said, too, that lees of wine or pounded wall-bricks make it thrive wonderfully well. Rosemary ${ }^{5}$ also is reproduced in a similar manner, as also from cuttings of the branches; neither savin nor rosemary having any seed. The rhododendrum ${ }^{6}$ is propagated by layers and from seed.

\section{CHAP. 22. (14.)-GRAFTING: THE FIRST DISCOVERY OF IT.}

Nature has also taught us the art of grafting by means of seed. We see a seed swallowed whole by a famished bird; when softened by the natural heat of the crop, it is roided, with the fecundating juices of the dung, upon some soft couch formed by a tree; or else, as is often the case, is carried by the winds to some cleft in the bark of a tree. Hence ${ }^{\gamma}$ it is that we see the cherry growing upon the willow, the plane upon the laurel, the laurel upon the cherry, and fruits of various tints and hues all springing from the same tree at once. It is said, too, that the jack-daw, from its concealment of the seeds of plants in holes which serve as its store-houses, gives rise to a similar result.

\section{CHAP. 23.-INOCULATION OR BUDDING.}

In this, too, the art of inoculating ${ }^{8}$ took its rise. By the aid of an instrument similar to a shoe-maker's paring-knife an eye is opened in a tree by paring away the bark, and another bud is then enclosed in it, that has been previously removed with the same instrument from another tree. This was the ancient mode of inoculation with the fig and the apple. That again, described by Virgil, ${ }^{9}$ requires a slight fissure to be made in the knot of a bud which has burst through the bark, and in this is enclosed a bud taken from another tree. Thus far has Nature been our instructor in these matters.

\section{CHAP. 24. -THE VARIOUS KINDS OF GRAFTING.}

A different mode of engrafting, however, has been taught us

5 The rosemary, in reality, is a hermaphroditic plant, and in all cases produces seed.

6 See B. xvi. c. 33 .

7 This, Fée remarks, is in reality no more a case of grafting than the growing of a tree from seed accidentally deposited in the eleft of a rock.

8 Still used for the reproduction of fruit-trees and shrubs in the pleasure garden.

9 Georg. ii. 73 
by chance, another great instructor, and one from whom, perhaps, we have learnt a still greater number of lessons. A careful husbandman, ${ }^{10}$ being desirous, for its better protection, to surround his cottage with a palisade, thrust the stakes into growing ivy, in order to prevent them from rotting. Seized by the tenacious grasp of the still living ivy, the stakes borrowed life from the life of another wood, and it was found that the stock of a tree acted in place of earth.

For this method of grafting the surface is made level with a saw, and the stock carefully smoothed with the pruning-knife. This done, there are two modes of proceeding, the first of which consists in grafting between the bark and the wood. The ancients were fearful at first of cutting into the wood, but afterwards they ventured to pierce it to the very middle, and inserted the graft in the pith, taking care to enclose but one, because the pith, they thought, was unable to receive more. An improved methor has, however, in more recent times, allowed of as many as six grafts being inserted, it being considered desirable by additional numbers to make a provision for the contingency of some of them not surviving. With this view, an incision is carefully made in the middle of the stock, a thin wedge being inserted to preven the sides from closing, until the graft, the end of which is first cut to a point, has been let into the fissure. In doing this many precautions are necessary, and more particularly every care should be taken that the stock is that of a tree suitable for the purpose, and that the graft is taken from one that is proper for grafting. The sap, ${ }^{11}$ too, is variously distributed in the several trees, and does not occupy the same place in all. In the vine and the fig ${ }^{12}$ the middle of the tree is the driest, and it is in the summit that the generative power resides; hence it is, that from the top the grafts are selected. In the olive, again, the sap lies in the

10 This story is borrowed from Theophrastus, De Caus. B. ii. c. 19. Fée remarks, that it is very doubtful if an operation of so coarse a nature could be productive of such results; and he says, that, at all events, the two woods must have been species of the same genus, or else individuals of the same family. The mode of grafting here described is called by agriculturists in foreign countries, "Pliny's graft."

11 These statements as to the locality of the sap are erroneous.

${ }^{12}$ The fig is the only fruit that is not improved by grafting; but then it is not similar to most fruit, being, as Fée says, nothing more than a fleshy floral receptacle. 
middle of the tree, and the grafts are accordingly taken from thence: the upper part being comparatively dry. The graft takes most easily in a tree, the bark of which is of a similar ${ }^{13}$ nature to its own, and which, blossoming at the same time as itself, has an affinity with it in the development of the natural juices. On the other hand, the process of uniting is but slow where the dry is brought in contact with the moist, and the hard bark with the soft.

The other points to be observed are the following: the incision must not be made in a knot, as such an inhospitable rigidity will certainly repel the stranger plant; the incision should be made, too, in the part which is most compact, and it must not be much more than three fingers in length, not in a slanting direction, nor yet such as to pierce the tree from side to side. Virgil $^{14}$ is cf opinion, that the grafts should not be taken from the top, and it is universally agreed that it is best to select them from the shoulders of the tree which look towards the north-east $;^{15}$ from a tree, too, that is a good bearer, and from a young shoot, ${ }^{16}$ unless, indeed, the graft is intended for an old tree, in which case it should be of a more robust growth. In addition to this, the graft ought to be in a state of impregnation, that is to say, swelling ${ }^{17}$ with buds, and giving every promise of bearing the same year; it ought, too, to be two years old, and not thinner than the little finger. The graft is inserted at the smaller end, when it is the object of the grower that it should not grow to any considerable length, but spread out on either side. But it is more particularly necessary that the buds upon the graft should be smooth and regular, and there must be nothing upon it at all scabbed or shrivelled. Success may be fully reckoned on if the pith of the graft is brought in contact with the wood and bark of the stock; that being a much better plan than merely uniting them bark to bark. In pointing the graft,

13 This remark is founded on sound notions of vegetable physiology; but at the same time it is contradictory to what he states in the sequel as to grafting the pear on the plane, the apple on the cornel, \&c.

it Georg. ii. 78 .

15 An unnecessary precaution. It is not the situation of the branches so much as the nature of the soil, traversed by the roots, corresponding to them, that would be likely to have an influence on the graft. There is little doubt that Pliny borrowed the present passage from Columella, De Re Rust. v. 11 ; and De Arbor. 20.

16 This is sound advice.

17 See B. xvi. c. 39,40 , and 41 . 
the pith ought not to be laid bare; still, however, it should be pared with a small knife, so that the point may assume the form of a fine wedge, not more than three fingers in length, a thing that may be very easily effected by first steeping it in water and then scraping it. The graft, however, must not be pointed while the wind is blowing, and care must be taken that the bark is not rubbed off from either graft or stock. The graft must be thrust into the stock up to the point where the bark begins; care, too, must be taken not to wrench off the bark during the process of insertion, nor must it be thrust back so as to form any folds or wrinkles. It is for this reason that a graft should not be used that is too full of sap, no, by Hercules! no more than one that is dry and parched; for by doing so, in the former case, from the excess of moisture, the bark becomes detached, and in the latter, from want of vitality, it yields no secretions, and consequently will not incorporate with the stock.

It is a point most religiously ${ }^{1 s}$ observed, to insert the graft during the moon's increase, and to be careful to push it down with both hands ; indeed, it is really the fact, that in this operation, the two hands, acting at the same moment, are of necessity productive of a more modified and better regulated effort. Grafts that have been inserted with a vigorous effort are later in bearing, but last all the longer; when inserted more tenderly, the contrary is the result. The incision in the stock should not be too open or too large; nor ought it to be too small, for in such case it would either force out the graft or else kill it by compression. But the most necessary precaution of all is to see that the graft is fairly inserted, and that it occupies exactly the middle of the fissure in the stock.

Some ${ }^{19}$ persons are in the habit of making the place for the fissure in the stock with the knife, keeping the edges of the incision together with bands of osier bound tightly round the stock; they then drive in the wedges, the bands keeping the stock from opening too wide. There are some trees

18 In reprehending this absurd notion, Fée bestows a passing censure on the superstitions of this nature, contained in the English Vox Stellarum, one of our almanacks; and in the French "Almanach des Bergers," "Shepherds' Almanack."

19 This is borrowed by Palladius, in the operations of February, tit. 17, and October, tit. 12. 
that are grafted in the seed-plot and then transplanted the very same day. If the stock used for grafting is of very considerable thickness, it is the best plan to insert the graft between the bark and the wood; for which purpose a wedge made of bone is best, for fear lest when the bark is loosened the wood should be bruised. In the cherry, the bark is removed before the incision in the stock is made; this, too, is the only tree that is grafted after the winter solstice. When the bark is removed, this tree presents a sort of downy substance, which, if it happens to adhere to the graft, will very speedily destroy it. When once the graft is safely lodged by the aid of the wedge, it is of advantage to drive it home. It is an excellent plan, too, to graft as near the ground as possible, if the conformation of the trunk and knots will admit of it. The graft should not project firom the stock more than six fingers in length.

Cato ${ }^{20}$ recommends a mixture of argil ${ }^{21}$ or powdered chalk, and cow-dung, to be stirred together till it is of a viscous consistency, and then inserted in the fissure and rubbed all round it. From his writings on the subject it is very evident that at that period it was the practice to engraft only between the wood and the bark, and in no other way; and that the graft was never inserted beyond a couple of fingers in depth..$^{22} \mathrm{He}$ recommends, too, that the pear and the apple should be grafted in spring, as also during fifty days at the time of the surnmer solstice, and during the time of vintage; but that the olive and the fig should be grafted in spring only, in a thirsting, or in other words, a dry moon: he says also, that it should be done in the afternoon, and not while a south wind is blowing. It is a singular thing, that, not content with protecting the graft in the manner already mentioned, and with sheltering it from showers and frosts by means of turis and supple bands of split osiers, he recommends that it should be covered with bugloss ${ }^{23}$ as well-a kind of herb so called-which is to be tied over it and then covered up with straw. At the present day, however, it is thought sufficient to cover the bark with a

20 De Re Rust. 40.

21 This is the onguent Saint-Fiacre of the French, and is still used to protect the graft from all contact with the exterior air.

22 "Altitudinem," as Dalechamps suggests, would appear to be a better reading thun "latitudinem."

23 See B. xxy. c. 40.

roL. III. 
mixture of mud and chaff, allowing the graft to protrude a couple of fingers in length.

Those who wait for spring to carry on these operations, will find themselves pressed for time; for the buds are then just bursting, except, indeed, in the case of the olive, the buds of which are remarkably long in developing themselves, the tree itself having extremely little sap beneath the bark; this, too, is apt, when in too large quantities, to injure the grafts. As to the pomegranate, too, the fig, and the rest of the trees that are of a dry nature, it is far from beneficial to them to put off the process of grafting till a late period. The pear may be grafted even when in blossom, so that with it the operation may be safely delayed to the month of May even. If grafts of fruit trees have to be carried to any distance; it is considered the best plan, with the view of preserving the juices, to insert them in a turnip ; they may also be kept alive by placing them near a stream or a pond, between two hollow tiles covered up at each end with earth. (15.) The grafts of vines, however, are kept in dry holes, in which they are covered over with straw, and then with earth, care being taken to let the tops protrude. ${ }^{24}$

\section{CHAP. 25.-GRAFTING THE VINE.}

$\mathrm{Cato}^{25}$ speaks of three ${ }^{26}$ methods of grafting the vine. The first consists in piercing the stock to the pith, and then inserting the grafts, sharpened at the end, in manner already mentioned, care being taken to bring the pith of the two in contact. The second is adopted in case the two vines are near one another, the sides of them both being cut in a slanting direction where they face each other; after which the pith of the two trees is united by tying them together. In employing the third method, the vine is pierced obliquely to the pith, and grafts are inserted a couple of feet in length; they are then tied down and covered over with prepared earth, care being taken to keep them in an upright position. In our

${ }^{24}$ Borrowed from Columella, B. iv. c. 29. This method is still employed for young plants; in France it is called "salting" the plants.

${ }_{25}$ De Re Rust. 41.

26 The first of these methods is now the only one at all employed with the vine; indeed, it is more generally reproduced by means of layers and suckers. 
time, however, this method has been greatly improved by making use of the Crallic auger, ${ }^{27}$ which pierces the tree without scorching it; it being the fact, that everything that burns the tree weakens its powers. Care, too, is taken to select a graft that is just beginning to germinate, and not to leave more than a couple of the buds protruding from the stock. The vine, too, should be carefully bound with withes of elm, incisions being made in it on either side, in order that the slimy juices may exude through them in preference, which are so particularly injurious to the vine. After this, when the graft has grawn a couple of feet, the withe by which it is fastened should be cut, and the graft left to increase of its own natural vigour.

The proper time ${ }^{28}$ for grafting the vine has been fixed as from the autumnal equinox to the beginning of the budding season. The cultivated plants are generally grafted on the roots of wild ones, where these last are of a drier nature. But if a cultivated tree should be grafted on a wild one, it will very soon degenerate and become wild. ${ }^{29}$ The rest depends entirely on the weather. Dry weather is the best suited for grafting; an excellent remedy for any evil effects that may possibly be caused by the drought, being a few pots of earth placed near the stock and filled with ashes; through which a little water is slowly filtered. Light dews are extremely favourable to grafting by inoculation.

\section{Chap. 26. (16) - GRAFTing BY sCUTCHEONs."}

Grafting by scutcheons would appear to owe its origin to that by inoculation; but it is suited more particularly to a thick bark, such as that of the fig-tree for instanee. For this purpose, all the branches are cut off, in order that they may not divert the sap, after which the smoothest part is sclected

87 It is not accurately known what was the form or particular merit of this auger or wimble.

${ }_{2 y}$ Fée remarks, that the period here named is very indefinite. May and the early part of June are the periods now selected for grafting the vine.

${ }_{29}$ This is borrowed from Varro, De Re Rust. B. i. c. 40. In reality, it makes no difference whether the stock is that of a wild tree or of the cultivated species.

31) "Emplastrum." Properly, the little strip of bark, which is fitted in with the eye, and which is plastered or soldered aown. 
in the stock, and a scutcheon ${ }^{31}$ of the bark removed, due care being taken that the knife does not go below it. A similar piece of bark from another tree, with a protuberant bud upon it, is then inserted in its place, care being taken that the union is so exact that there is no room left for a cicatrix to form, and the juncture so perfect as to leave no access to either damp or air: still, however, it is always the best plan to protect the scutcheon by means of a plaster of clay and a band. Those who favour the modern fashions pretend that this method has been only discovered in recent times; but the fact is, that we find it employed by the ancient Greeks, and described by Cato, ${ }^{32}$ who recommends it for the olive and the fig; and he goes so far as to determine the very dimensions even, in accordance with his usual exactness. The scutcheon, he says, when taken off with the knife should be four ${ }^{33}$ fingers in length, and three in breadth. It is then fitted to the spot which it is to occupy, and anointed with the mixture of his which has been previously described. ${ }^{34}$ This method, too, he recommends for the apple.

Some persons have adopted another plan with the vine, which consists partly of that of grafting by scutcheon, and partly by fissure; they first remove a square piece of bark from the stock, and then insert a slip in the place that is thus laid bare. I once saw at Thuliæ, ${ }^{35}$ near Tibur, a tree that had been grafted ${ }^{36}$ upon all these various ways, and loaded with fruit of every kind. Upon one branch there were nuts to be seen, upon another berries, upon another grapes, upon another pears, upon another figs, and upon others pomegranates, and

31 "Scutula." So called from its resemblance to a "little shield."

32 De Re Rust. 42.

33 Cato says, three and a-half.

34 Chalk and cow-dung. See c. 24 of this Book.

35 Perhaps "Tuliæ;" which would mean, according to Festus, the "cascades" or "waterfalls" of Tibur, now Tivoli.

36 Fée says, that if we take the word "grafted" here in the strictest sense, Pliny must have seen as great a marvel as any of those mentioned in the "Arabian Nights;" in fact, utter impossibilities. He thinks it possible, however, that a kind of mock grafting may have been produced in the case, still employed in some parts of Italy, and known as the "greffe-Diane." A trunk of an orange tree is split, and slips of numerous trees are than passed into it, which in time throw out their foliage and blossoms in various parts of the tree, or at the top; the consequence of which is, that the stock appears to bear several varieties of blossoms at the same noment. It is not improbable that Pliny was thus imposed upon. 
several varieties of the apple; the tree, however, was but very short-lived. But, with all our experiments, we find it quite impossible to rival Nature; for there are some plants that can be reproduced in no other manner than spontaneously, and then only in wild and desert spots. The plane $e^{37}$ is generally considered the best adapted to receive every kind of graft, and next to it the robur; both of them, however, are very apt to spoil the flavour of the fruit. Some trees admit of grafting upon them in any fashion, the fig and the pomegranate for instance; the vine, however, cannot be grafted upon by scutcheon, nor, indeed, any other of the trees which has a bark that is thin, weak, or cracked. So, too, those trees which are dry, or which contain but little moisture, will not admit of grafting by inoculation. This last method is the most prolific of them all, and next to it that by scutcheon, but neither of them can be depended upon, and this last more particularly; for when the adherence of the bark is the only point of union the scutcheon is liable to be immediately displaced by the slightest gust of wind. Grafting by insertion is the most reliable method, and the tree so produced will bear more fruit than one that is merely planted.

(17.) We must not here omit one very singular circumstance. Corellius, a member of the Equestrian order at Rome, and a native of Ateste, grafted a chesnut, in the territory of Neapolis, with a slip taken from the same tree, and from this was produced the chesnut which is so highly esteemed, and from him has derived its name. At a later period again, Etereius, his freedman, grafted the Corellian ${ }^{38}$ chesnut afresh. There is this difference between the two; the Corellian is more prolific, but the Etereian is of superior quality.

CHAP. 27. -PLANTS WHICH GROW FROM A BRANCH.

It is accident that has the credit of devising the other methods of reproduction, and has taught us how to break off a branch of a tree and plant it in the earth, from secing stakes, when driven in the earth, take root, and grow. It is in this way that many of the trees are reproduced, and the fig more particularly; which may be propagated also by all the methods previously stated, with the exception, indeed, of that by cuttings.

37 The plane and the oak are no longer employed for the purpose.

as See B. xv, c. 25. 
The best plan, however, is to take a pretty large branch, and, after sharpening it like a stake, ${ }^{39}$ to drive it to a considerable depth in the earth, taking care to leave only a small portion above ground, and then to cover it over with sand. The pomegranate, too, may be planted in a similar manner, the hole being first widened with a stake; the same, too, with the myrtle. For all trees of this nature a branch is required three feet in length, and not quite the thickness of the arm, care being taken to keep the bark on, and to sharpen the branch to a point at the lower end.

CHAP. 28. -TREES WHICH GROW FROM CUTTINGS; THE MODE OF PLANTING THEM.

The myrtle, too, may be propagated from cuttings, and the mulberry is grown no other way, the religious observances relative to lightning ${ }^{40}$ forbidding it to be grafted on the elm ${ }^{41}$ hence it would appear that the present is a fitting opportunity for speaking of reproduction from cuttings. Care should be taken more particularly to select the slips from fruitful trees, and it should be seen that they are neither bent, scabbed, nor. bifurcated. The cuttings, too, should be thick enough to fill the hand, and not less than a foot in length: the bark, too, should be uninjured, and the end which is cut and lies nearest the root should always be the one inserted in the earth. While the work of germination is going on, the slip should be kept well moulded up, until such time as it has fully taken root.

Chap. 29. (18.)-THE cultivation of the olive.

Cato $^{42}$ has treated so well of the precautions that are necessary in cultivating the olive, that we cannot do better than employ his own words on the subject. "Let the slips of olive," says he, "which you are about to plant in the hole, be three feet long, and be very careful in your treatment of them, so as not to injure the bark when you are smoothing or cutting them. Those that you are going to plant in the nursery, should be a foot in length; and you should plant them the following way: let the spot be turned up with the mattock,

${ }^{39}$ See c. 29 of this Book.

40 See B. xv. c. 17.

41 The mulberry is incapable of being grafted on the elm.

42 De Re Rust. 45. The method of planting here described is still the one most generally approved of for the olive. 
and the soil be well loosened. When you put the cutting in the ground, press it down with the foot only. If there is any difficulty in making it descend, drive it down with a mallet or the handle of the dibble, but be careful not to break the bark in doing so. Take care, too, not to make a hole first with the dibble, for the slip will have the better chance of surviving the other way. When the slip is three years old, due care must be taken to observe the direction in which each side of the bark is situate. If you are planting in holes or furrows, you must put in the cuttings by threes, but be careful to keep them separate. Above ground, however, they should not be more than four fingers distant from one another, and each of them must have a bud or eye above ground. In taking up the olive for transplanting, you must use the greatest caution, and see that there is as much earth left about the roots as possible. When you have covered the roots well up, tread down the earth with the foot, so that nothing may injure the plant."

CHAP. 30.-TRANSPLANTING OPERATIONS AS DISTRIBUTED THROUGHOUT THE VARIOUS SEASONS OF THE YEAR.

If the enquiry is made what is the proper season for planting the olive, my answer will be, "where the soil is dry, at seed-time ; where it is rich, in spring." The following is the advice given by Cato ${ }^{43}$ on the subject: "Begin pruning your olive-yard fifteen days before the vernal equinox; from that period for forty days will be a good time for doing so. In pruning, adopt the following rules: when the ground is extremely productive, remove all the dry branches or such as may have been broken by the wind; where it is not so prolific, you must cut away still more, then tie them well up, and remove all tangled branches, so as to lighten the roots. In auturn clear away the roots of the olive, and then manure them. The man who labours most assiduously and most earnestly will remove the very smallest fibres that are attached to the roots. If, however, he hoes negligently, the roots will soon appear again above ground, and become thicker than ever; the consequence of which will be, that the vigour of the tree will be expended in the roots."

We have already stated, when speaking on the subject of

43 De Re Rust. 44. The rules here given are still very generally observed. 
oil, ${ }^{41}$ what are the different varieties of the olive, in what kind of soil it ought to be planted, and what is the proper aspect for the olive-yard. Mago recommends that the olive should be planted on declivities and in dry spots, in an argillaceous soil, and between autumn and the winter equinox. If, on the other hand, the soil is thick, humid, or somewhat damp even, it ought to be planted between harvest and the winter solstice; advice, however, it should be remembered, applicable to Africa more particularly. At the present day, it is mostly the custom in Italy to plant the olive in spring, but if it is thought desirable to do so in the autumn as well, there are only four days in the forty between the equinox and the setting of the Vergiliæ that are unfavourable for planting it..$^{45}$ It is a practice peculiar to Africa, to engraft the olive on the wild olive only, a tree which is made to be everlasting, as it were ; for when it becomes old the best of the suckers are carefully trained for adoption by grafting, and in this way in another tree it grows young again; an operation which may be repeated continuously as often as needed; so much so, indeed, that the same olive-yard will last for ages. ${ }^{46}$ The wild olive also is propagated both by insertion and inoculation.

It is not advisable to plant the olive in a site where the quercus has been lately rooted up ; for the earth-worms, known as "raucr," which breed in the root of the quercus, are apt to get into that of the olive. It has been found, from practical experience, that it is not advisable to bury the cuttings in the ground nor yet to dry them before they are planted out. Experience has also taught us that it is the best plan to clean an old olive-yard every other year, between the vernal equinox and the rising of the Vergiliæ, and to lay moss about the roots; to dig holes also round the trees every year, just after the summer solstice, two cubits wide by a foot in depth, and to manure them every third year.

Mago, too, recommends that the almond should be planted between the setting of Arcturus ${ }^{47}$ and the winter solstice. All

44 B. xv. c. 6.

45 See c. 2 of this Book, and B. xviii. c. 69.

46 The olive is an extremely long-lived tree; it has been known to live as long as nine or ten centuries. A fragment of the bark, with a little wood attached, if put in the ground, will throw out roots and spring up. Hence it is not to be wondered at, that the ancients looked upon it as immortal.

47 B. xviii. c. 74 . 
the varieties, however; of the pear, he says, should not be planted at the same time, as they do not all blossom together. Those with oblong or round fruit should be planted between the setting of the Vergiliæ and the winter solstice, and the other kinds in the middle of the winter, after the setting of the constellation of the Arrow, ${ }^{48}$ on a site that looks towards the east or north. The laurel should be planted between the setting of the Eagle and that of the Arrow; for we find that the proper time for planting is equally connected with the aspect of the heavenly bodies. For the most part it has been recommended that this should be done in spring and autumn; but there is another appropriate period also, though known to but few, about the rising of the Dog-star, namely ; it is not, however, equally advantageous in all localities. Still, I ought not to omit making mention of it, as I am not setting forth the peculiar advantages of any one country in particular, but am enquiring into the operations of Nature taken as a whole.

In the region of Cyrenaica, the planting is generally done while the Etesian ${ }^{49}$ winds prevail, and the same is the case in Greece, and with the olive more particularly in Laconia. At this period, also, the vine is planted in the island of Cos ; and in the rest of Greece they do not neglect to inoculate and graft, though they do not ${ }^{50}$ plant, their trees just then. The natural qualities, too, of the respective localities, exercise a very considerable influence in this respect; for in Egypt they plant in any month, as also in all other countries where summer rains do not prevail, India and Athiopia, for instance. When trees are not planted in the spring they must be planted in autumn, as a matter of course.

There are three stated periods, then, for germination ${ }^{51}$ spring, the rising of the Dog-star, and that of Arcturus. And, indeed, it is not the animated beings only that are ardent for the propagation of their species, for this desire is manifested in even a greater degree by the earth and all its vegetable productions; to employ this tendency at the proper moment is the most

43 B. xviii. c. 74.

49 B. ii. c. 47 , and B. xviii. c. 68 ,

50 There is a contradiction here; a few lines above, he says that they do plant their trees in Greece at this period. He may possibly mean "sow."

51 See B. xvi. c. 41 . The rules here laid down by Pliny are, as Fée remarks, much too rigorous, and must be modified according to extraneous circumstauces. 
advantageous method of ensuring an abundant increase. These moments, too, are of peculiar importance in relation to the process of grafting, as it is then that the two productions manifest a mutual desire of uniting. Those who prefer the spring for grafting commence operations immediately after the vernal equinox, reckoning on the fact that then the buds are just coming out, a thing that greatly facilitates the union of the barks. On the other hand, those who prefer the autumn graft immediately after the rising of Arcturus, because then the graft at once takes root in some degree, and becomes seasoned for spring, so as not to exhaust its strength all at once in the process of germination. However, there are certain fixed periods of the year, in all cases, for certain trees; thus, the cherry, for instance, and the almond, are either planted or grafted about the winter solstice. For many trees the nature of the locality will be the best guide; thus, where the soil is cold and moist it is best to plant in spring, and where it is dry and hot, in autumn.

Taking Italy in general, the proper periods for these operations may be thus distributed:-T'The mulberry is planted at any time between the ides of February ${ }^{52}$ and the vernal equinox; the pear, in the autumn, but not beyond the fifteenth day before the winter solstice; the summer apples, the quince, the sorb, and the plum, between mid-winter and the ides of February: the Greek carob ${ }^{53}$ and the peach, at any time in autumn before the winter solstice; the various nuts, such as the walnut, pine, filbert, almond, and chesnut, between the calends of March ${ }^{51}$ and the ides of that month ${ }^{55}$ the willow and the broom about the calends of March. The broom is grown from seed, and in a dry soil, the willow from plants, in a damp locality, as already stated on former occasions. ${ }^{56}$

(19.) That I may omit nothing to my knowledge of the facts that I have anywhere been able to ascertain, I shall here add a new method of grafting, which has been discovered by Columella, ${ }^{57}$ as he asserts, by the aid of which trees even of a heterogeneous or dissociable nature may be made to unite;

52 13th of February.

54 1st of March.

56 B. xvi. ce. $30,46,67$, and 78 .

57 De Re Rust. B. v. c. 11. A very absurd and useless method, Fée remarks.
53 B. xv. c 26.

55 15th of March. 
such, for instance, as the fig and the olive. In accordance with this plan, he recommends that a fig-tree should be planted near an olive, at a distance sufficiently near to admit of the fig being touched by a branch of the olive when extended to its full length; as supple and pliant a one as possible being selected for the purpose, and due care being taken all the time to render it seasoned by keeping it constantly on the stretch. After this, when the fig has gained sufficient vigour, a thing that generally happens at the end of three or five years at most, the top of it is cut off, the end of the olive branch being also cut to a point in the manner already stated. ${ }^{58}$ This point is then to be inserted in the trunk of the fig, and made secure with cords, lest, being bent, it should happen to rebound: in this way we find the method of propagating by layers combined with that of grafting. This union between the two parent trees is allowed to continue for three years, and then in the fourth the branch is cut away and left entirely upon the tree that has so adopted it. This method however, is not at present universally known, at all events, so far as $I$ have been able to ascertain.

\section{CHAP. 31.-CLEANING AND BARING THE ROOTS, AND MOULDING} THEM.

In addition to these particulars, the same considerations that $I$ have already ${ }^{59}$ mentioned in reference to warm or cold, moist or dry soils, have also taught us the necessity of trenching around the roots. These trenches, however, in a moist, watery soil, should be neither wide nor deep; while the contrary is the case where the ground is hot and dry; it being the object, in the latter instance, to let them receive and retain as much water as possible. This rule is applicable to the culture of old trees as well; for in very hot places the roots are well moulded in summer, and carefully covered up, to prevent the heat of the sun from parching them. In other places, again, the ground is cleared away from the roots, in order to give free access to the air, while in winter they are carefully moulded to protect them from the frost. The contrary is the case, however, in hot climates, for there they bare the roots in winter

s8 In c. 24 of this Book.

59 All the precepts given in this Chapter have been already given in cc. 3 and 4 of the present Book. 
for the purpose of ensuring a supply of moisture to the parched fibres.

In all places the rule is to make a circular trench three feet in width at the foot of the tree; this, however, it is not possible to do in meadows, where the roots, in their fondness for the sun and showers, range near the surface far and wide. Such, then, are the general observations that we have to make in reference to the planting and grafting of trees that we value for their fruits.

\section{CHAP. 32. (20.) - WILLOW-BEDS.}

It now remains to give an account of those trees which are planted for the sake of others-the vine $e^{60}$ more particularlyand the wood of which is cut from time to time. Holding the very first rank among these we find the willow, a tree that is always planted in a moist soil. 'The hole, however, should be two feet and a half in depth, and the slip a foot and a haif only in length. Willow stakes are also used for the same purpose, and the stouter they are the better: the distance left between these last should be six feet. When they are three years old their growth is checked by cutting them down within a couple of feet from the ground, the object being to make them spread out, so that by the aid of their branches they may be cleared without the necessity of using a ladder; for the willow is the more productive the nearer its branches are to the ground. It is generally recommended to trench round the willow every year, in the month of April. Such is the mode of cultivation employed for the osier willow. ${ }^{61}$

The stake willow ${ }^{62}$ is reproduced both from suckers and cuttings, in a trench of the same dimensions. Stakes may be cut from it at the end of about three years mostly. These stakes are also used to supply the place of the trees as they grow old, being fixed in the ground as layers, and cut away

- from the trunk at the end of a year. A single jugerum of

so The maple, linden, elm, and arundo donax, are still employed, as well as the willow, for this purpose; the latter, however, but very rarely. The account of its cultivation here given is borrowed from Columella, De Re Rust. B. iv. c. 30 .

61 The Salix viminalis of Linnæus, or white osier.

62 The Salix alba of Linnæus. These stakes, or props, are for the support of the vine. 
osier willows will supply osiers ${ }^{63}$ sufficient for twenty-five jugera of vines. It is for a similar purpose that the white poplar ${ }^{64}$ is grown; the trenches being two feet deep and the cutting a foot and a half in length. It is left to dry for a couple of days before it is planted, and a space is left between the plants a foot and a palm in width, after which ihey are covered with earth to the depth of a couple of cubits.

\section{CHAP. 33.-REED-BEDS.}

The reed ${ }^{65}$ requires a soil still moister even than that employed for the willow. It is planted by placing the bulb of the root, that part which some people call the "eye," 66 in a trench three quarters of a foot in depth, at intervals of two feet and a half. A reed-bed will renew itself spontaneously after the old one has been rooted up, a circumstance which it has been found more beneficial to take advantage of than merely to thin them, as was formerly the practice; the roots being in the habit of creeping and becoming interlaced, a thing that ends eventually in the destruction of the bed. The proper time for planting reeds is before the eyes begin to swell, or, in other words, before the calends of March. ${ }^{67}$ The reed continues to increase until the winter solstice, but ceases to do so when it begins to grow hard, a sign that it is fit for cutting. It is generally thought, too, that the reed requires to be trenched round as often as the vine.

The reed also is planted in a horizontal position, ${ }^{68}$ and then covered with earth to a very great depth; by this method as many plants spring up as there are eyes. It is propagated, also, by planting out in trenches a foot in depth, care being taken to cover up two of the eyes, while a third knot is left just on a level with the ground; the head, too, is bent downwards, that it may not become charged with dew. The reed is usually cut when the moon is on the wane. ${ }^{69}$ When required for the vineyard, it is better dried for a year than used in a green state.

${ }_{63}$ For making baskets and bindings.

61 The Populus canescens of Willdenow.

65 The Arundo donax of Linnæus. This account is mostly from Columella, B. iv. c. 32 .

66 B. xvi. c. 67.

67 First of March.

68 This method is condemned by Columella, De Arbor. 29, as the produce is poor, meagre, and weak. It is but little practised at the present day.

63 A mere superstition, of course. 
CHAP. 34. - OTHER PLANTS THAT ARE CUT FGR POLES AND STAKES.

The chesnut is found to produce better stays ${ }^{\text {io }}$ for the vine than any other tree, both from the facility with which they are worked, their extremely lasting qualities, and the circumstance that, when cut, the tree will bud again more speedily than the willow ${ }^{71}$ even. It requires a soil that is light without being gravelly, a moist, sandy one more particularly, or else a charcoal earth, ${ }^{72}$ or a fine tufa ${ }^{73}$ even; while at the same time a northern aspect, however cold and shady, and if upon a declivity even, greatly promotes its growth. It refuses to grow, however, in a gravelly soil, or in red earth, chalk, or, indeed, any kind of fertilizing ground. We have already stated, ${ }^{74}$ that it is reproduced from the nut, but it will only grow from those of the largest size, and then only when they are sown in heaps of five together. The ground above the nuts should be kept broken from the month of Norember to February, as it is at that period that the nuts lose their hold and fall of themselves from the tree, and then take root. There ought to be intervals of a foot in width left between them, ${ }^{75}$ and the hole in which they are planted should be nine inches every way. At the end of two years or more they are transplanted from this seed plot into another, where they are laid out at intervals of a couple of feet.

Layers are also employed for the reproduction of this tree, and there is none to which they are better ${ }^{76}$ adapted: the root of the plant is left exposed, and the layer is placed in the trench at full length, with the summit also protruding from the earth ; the result being, that it shoots from the top as well

70 "Pedamenta," uprights, stays, stakes, or props.

71 This is not the fact, for the chesnut both grows and buds very slowly.

72 A black, hot kind of earth. See c. 3 of this Book.

${ }_{73}$ In reality, the chesnut will not thrive in a tufaceous, or, indeed, in any kind of calcareous, soil.

75 The heaps of five in which they are sown.

76 The chesnut is grown with the greatest difficulty from layers and slips, and never from suckers. Pliny borrows this erroneous assertion from Columella, B. iv. c. 32 . In mentioning the heaps of five nuts, Pliny seems to have had some superstitious observance in view, for Columella only says that they must be sown thickly, to prevent accident. The same is done at the present day, in order to make provision for the depredations of fieldmice, rats, and mice, which are particularly fond of them. 
as the root. When transplanted, however, it is very hard to be reconciled, as it stands in dread of all change. Hence it is, that it is nearly two years before it will begin to shoot upward; from which circumstance it is generally preferred to rear the slips in the nursery from the nut itself, to obtaining them from quicksets. The mode of cultivation does not differ from that employed with the plants already mentioned. ${ }^{77}$ It is trenched around, and carefully loppéd for two successive years; after which it is able to take care of itself, the shade it gives sufficing to stifle all superfluous suckers: before the end of the sixth year it is fit for cutting.

A single jugerum of chesnuts will provide stays for twenty jugera of vineyard, and the branches that are taken from near the roots afford a supply of two-forked uprights ; they will last, too, till after the next cutting of the tree.

The æsculus, ${ }^{78}$ too, is grown in a similar manner, the time for cutting being three years at the latest. Being less difficult, too, to propagate, it may be planted in any kind of earth, the acorn-and it is only with the æesculus that this is donebeing sown in spring, in a hole nine inches in depth, with intervals between the plants of two feet in width. This tree is lightly hoed, four times a year. This kind of stay is the least likely to rot of them all; and the more the tree is cut, the more abundantly it shoots. In addition to the above, they also grow other trees for cutting that we have already mentioned-the ash for instance, the laurel, the peach, the hazel, and the apple; but then they are of slower growth, and the stays made from them, when fixed in the ground, are hardly able to withstand the action of the earth, and much less any moisture. The elder, on the other hand, which affords stakes of the very stoutest quality, is grown from cuttings, like the poplar. As to the cypress, we have already spoken of it at sufficient length. ${ }^{79}$

CHAP. 35. (21.) - THE CULTURE OF THE VINE AND THE VARIOUS SHRUBS WHICH SUPPORT II.

Having now described what we may call the armoury ${ }^{80}$ of

7 The willow and the reed.

78 See B. xvi. cc. 5, 6, and $56 . \quad 79$ In B. xvi. c. 60.

so "Armamentis." More properly, "rigging," or "tackle." He al- 
the vine, it remains for us to treat with a particular degree of care of the nature of the vine itself.

The shoots of the vine, as also of certain other trees, the interior of which is naturally of a spongy quality, have certain knots or joints upon the stem that intercept the pith. The intervals between these joints in the branches are short, and more particularly so towards the extremities. The pith, in itself the vivifying spirit of the tree, is always taking an onward direction, so long as the knot, by being open in the centre, allows it a free passage. If, however, the knot should become solidified and deny it a passage, the pith is then thrown downward upon the knot that lies next below it, and making its escape, issues forth there in the shape of a bud, these buds always making their appearance on each side alternately, as already mentioned in the case of the reed and the giantfennel ${ }^{81}$ in other words, where one bud makes its appearance at the bottom of a knot to the right, the next one takes its place on the left, and so on alternately. In the vine this bud is known as the "gem," 82 as soon as the pith has formed there a small round knob; but before it has done this, the concavity that is left upon the surface is merely called the "eye :" ${ }^{83}$ when situate at the extremity of the shoot, it is known as the "germ." It is in the same way, too, that the stock branches, suckers, grapes, leaves, and tendrils of the vine are developed: and it is a very surprising fact, that all that grows on the right ${ }^{85}$ side of the tree is stronger and stouter than on the left.

Hence it is, that when slips of this tree are planted, it is necessary to cut these knots in the middle, in order to prevent the pith from making its escape. In the same way, too, when planting the fig, suckers are taken, nine inches in length, and after the ground is opened they are planted with the part downwards that grew nearest to the tree, and with a couple of eyes protruding from the earth-in slips of trees, that part is properly called the eye which is to give birth to the future bud. It is for this reason that, in the seed-plots even the lades to the trees from which the uprights or stays for the vine are cut, or which produce osiers for baskets and bindings required in the vintage.

81 See B. xiii. c. 42 , and B. xvi. c. 65 .

82 "Gemma." A name now given by botanists to the buds in general.

8.3 "Oculus." A bud undeveloped is still so called.

8t Germen.

85 This remark is not confirmed by experience. 
slips that are thus planted sometimes bear the same year the fruit that they would have borne if they had remained upon the tree: this takes place when they have been planted in good seasons and are replete with fecundity, for then they bring to maturity the fruits the conception of which was commenced in another spot. Fig-trees that are thus planted may very easily be transplanted in the third year. As some compensation for the rapidity with which this tree becomes ${ }^{86}$ old, it has thus received the privilege of coming to maturity ${ }^{87}$ at a very early period.

The vine throws out a great number of shoots. In the first place, however, none of them are ever used for planting, except those which are useless, and would have been cut away as mere brushwood; while, on the other hand, every part is pruned off that has borne fruit the previous year. In former times, it was the custom to plant the slip with a head at the extremity, consisting of a piece of the hard wood on each side of it, the same, in fact, that is called a mallet shoot ${ }^{88}$ at the present day. In more recent times, however, the practice has been adopted of pulling it off merely with a heel attached to it, as in the fig $;^{89}$ and there is no kind of slip that takes with greater certainty. A third method, again, has been added to the former ones, and a more simple one as well, that of taking the slip without any heel at all. These slips are known by the name of arrow- ${ }^{90}$ shoots, when they are twisted before planting; and the same, when they are neither cut short nor twisted, are called three-budded ${ }^{91}$ slips. The same sucker very often furnishes several slips of this kind. To plant a stock-shoot ${ }^{92}$ of the vine is unproductive, and, indeed, no shoots will bear unless they are taken from a part that has borne fruit already. A slip that has but few knots upon it, is looked upon as likely not to bear; while a great number of buds is considered an indication of fruitfulness. Some persons say that no suckers ought to be planted, but those which have already blossomed. It is far from advantageous ${ }^{93}$ to plant 86 On the contrary, the fig-tree has been known to live to a very great age. s7 See B. xvi. c. 51 .

88 This method of planting the vine is still extensively used; especially the low kinds.

9") Sagittæ.

89 See c. 13 of this Book.

91 Trigemmes.

92 "Pampinarius." This assertion has been found to be erroneous.

93 This practice has been condemned by modern cultivators.

VOL. III.

K K 
arrow-slips, for after being twisted, they are apt to break in transplanting. The slips when planted should be a foot in length, ${ }^{91}$ and not less, and they ought to have five or six knots upon them; with the dimensions above stated, they cannot, however, possibly have less than three buds. It is considered the most advantageous plan to plant them out the same day that they are cut; but if it is found necessary to plant them some time after, they should be kept in the way that we have already mentioned $;^{95}$ particular care being taken not to let them protrude from the earth, lest they should become dried by the action of the sun, or nipped by the wind or frost. When they have been kept too long in a dry place, they must, be put in water for several days, for the purpose of restoring their verdancy and freshness.

The spot selected, whether for nursery or vineyard, ought to be exposed to the sun, and of as great extent as possible; the soil being turned up to a depth of three feet with a twopronged fork. The earth, on being thrown up with the mattock, ${ }^{96}$ swells naturally, ${ }^{97}$ and ridges are formed with it four feet in height, intersected by trenches a couple ${ }^{98}$ of feet in depth. The earth in the trenches is carefully cleansed and raked out, ${ }^{99}$ so that none of it may be left unbroken, care being taken also to keep it exactly level; if the ridges are unequal, it shows that the ground has been badly dug. At the same time the breadth should be measured of each ridge that lies between the trenches. The slips are planted either in holes or else in elongated furrows, and then covered with very fine earth; but where it is a light soil, the grower will lose his pains should he neglect to place a layer of richer mould beneath. Not less than a couple of slips should be planted together, keeping them exactly on a level with the adjoining earth, which should be pressed down and made compact with the dibble. In the seed-plot there should be intervals left between each two settings a foot and a half in breadth and half a foot in length: when thus planted, it is usual, at the end of two years, to cut the mallet-shoots at the knot nearest the ground,

${ }^{94}$ From Columella, B. iii. c. 19.

95 In e. 24 of this Book.

96 "Marra." Probably a mattock, with several prongs.

97 Occupies mare space when thus loosened.

98 As compared with the original level of the ground.

${ }_{99}$ Query, if this is the meaning of "extendi"? 
unless there is some good reason for sparing them. When this is done, they throw out eyes, and with these upon them at the end of three years the quicksets are transplanted.

There is another method, also, of planting ${ }^{1}$ the vine, which a luxurious refinement in these matters has introduced. Four mallet-shoots are tightly fastened together with a cord in the greenest part, and when thus arranged are passed through the shank-bone of an ox or else a tube of baked earth, after which they are planted in the ground, care being taken to leave a couple of buds protruding : in this way they become impregnated with moisture, and, immediately on being cut, throw out fresh wood. The tube is then broken, upon which the root, thus set at liberty, assumes fresh vigour, and the clusters ${ }^{2}$ ultimately bear upon them grapes belonging to the four kinds thus planted together.

In consequence of a more recent discovery, another method has been adopted. A mallet-shoot is split down the middle and the pith extracted, after which the two portions are fastened together, every care being taken not to injure the buds. The mallet-shoot is then planted in a mixture of earth and manure, and when it begins to throw out branches it is cut, the ground being repeatedly dug about it. Columella ${ }^{3}$ assures us that the grapes of this plant will have no stones, but it is a more surprising thing that the slip itself should survive when thus deprived of the pith. ${ }^{4}$ Still, however, I think I ought not to omit the fact that there are some slips that grow without the ordinary articulations of trees upon them; thus, for instance, five or six very small sprigs of box, ${ }^{5}$ if tied together and put in the ground, will take root. It was formerly made a point to take these sprigs from a box-tree that had not been lopped, as it was fancied that in the last case they would not live; experience, however, has since put an end to that notion.

The culture of the vineyard naturally follows the training of the nursery. There are five ${ }^{6}$ different kinds of vine: that

1 This method is no longer used.

2 This, Fée remarks, is not the case : the tree might bear four kinds of grapes, but not four kinds on the same bunch.

${ }_{3}$ De Arbor. c. 9. This is not the fact.

4 He was little aware, Fée says, that all ligneous plants have a radiating pith, distinct from the central one. $\quad 5$ See B. xvi. c. 72.

${ }^{6}$ Oliver de Serres distinguishes only three-the low, middling, and tall vines. 
with the branches running ${ }^{7}$ along the ground, the vine that stands without support, ${ }^{8}$ the vine that is propped and requires no cross-piece, ${ }^{9}$ the vine that is propped and requires a single cross-piece, and the vine that requires a trellis of four compartments. ${ }^{10}$ The mode of cultivation requisite for the propped vine may be understood as equally adapted to the one that stands by itself and requires no support, for this last method is only employed where there is a scarcity of wood for stays. The stay with the single cross-piece in a straight line is known by the name of "canterius." It is the best of all for the wine, for then the tree throws no shadow, and the grape is ripened continuously by the sun, while, at the same time, it derives more advantage from the action of the wind, and disengages the dew with greater facility: the superfluous leaves and shoots, too, are more easily removed, and the breaking up of the earth and other operations about the tree are effected with greater facility. But, above all, by the adoption of this method, the tree sheds its blossoms more beneficially than under any other circumstanees. This cross-piece is generally made of a stake, or a reed, or else of a rope of hair or hemp, as is usually the case in Spain and at Brundisium. When the trellis is employed, wine is produced in greater quantities; this method has its name of " compluviata" from the "compluvium" or square opening in the roofs of our houses; the trellis is divided into four compartments by as many crosspieces. This mode of planting the vine will now be treated of, and it will be found equally applicable to every kind, with the only difference that under this last method the operation is somewhat more complicated.

The vine is planted three different ways; in a soil that has been turned up with the spade-the best of the three; in furrows, which is the next best; and in holes, the least advisable method of all: of the way in which ground is prepared by digging, we have made sufficient mention already. (22.) In preparing the furrows ${ }^{11}$ for the vine it will be quite sufficient

7 See B. xiv. c. 4.

8 See B. xiv. c. 4.

9 "Jugum." The cross-piece running along the top of the stay at, right angles; a rail or trail.

10 "Compluviatæ quadruplici." Four cross-pieces running at right angles to the prop or stay. See B. xvi. c. 68 .

11 When these trenches and furrows are employed by the moderns, they 
if they are a spade in breadth ; but if holes are employed for the purpose, they should be three feet every way. The depth required for every kind of vine is three feet; it should, therefore, be made a point not to transplant any vine that is less than three feet in length, allowing then two buds to be abore the ground. It will be necessary, too, to soften the earth by working little furrows at the bottom of the hole, and mixing it up with manure. Where the ground is declivitous, it is requisite that the hole should be deeper, in addition to which it should be artificially elevated on the edge of the lower side. Holes of this nature, which are made a little longer, to receive two vines, are known as "alvei," or beds. The root of the vine should occupy the middle of the hole, and when firmly fixed in the ground it should incline at the top due east; its first support it ought to receive from a reed.12 The vineyard should be bounded by a decuman ${ }^{13}$ path eighteen feet in width, sufficiently wide, in fact, to allow two carts to pass each other; others, again, should run at right angles to it, ten feet in width, and passing through the middle of each jugerum; or else, if the vineyard is of very considerable extent, cardinal ${ }^{14}$ paths may be formed instead of them, of the same breadth as the decuman path. At the end, too, of every five of the stays a path should be made to run, or, in other words, there should be one continuous cross-piece to every five stays; each space that is thus included from one end to the other forming a bed. ${ }^{15}$

Where the soil is dense and hard it must be turned up only with the spade, and nothing but quicksets should be planted there; but where, on the other hand, it is thin and loose, mallet-shoots even may be set either in hole or furrow. Where the ground is declivitous it is a better plan to draw furrows across than to turn up all the soil with the spade, so that the falling away of the earth may be counteracted by the position of the cross-pieces. ${ }^{16}$ It will be best, too, where the weather

are made to run as much as possible from east to west. Most of the rules bere mentioned by Pliny are still adopted in France.

12 Fée regards this precept as a puerility.

13 See B. xviii. c. 77.

14 See B. xviii. c. 77. Decuman roads or paths ran from east to west; cardinal roads were those at right angles to them.

15 "Pagina." A set, compartment, or bed.

16 "Transtris." "Ridges," would appear to be the proper reading here; 
is wet or the soil naturally dry, to plant the mallet-shoots in autumn, unless, indeed, there is anything in the nature of the locality to counteract it; for while a dry, hot soil makes it necessary to plant in autumn, in a moist, cold one it may be necessary to defer it until the end of spring even. In a parched soil, too, it would be quite in vain to plant quicksets, and it is far from advantageous to set mallet-shoots in a dry ground, except just after a fall of rain. On the other hand, in moist localities, a vine in leaf even may be transplanted and thrive very well, and that, too, even as late as the summer solstice, in Spain, for example. It is of very considerable advantage that there should be no wind stirring on the day of planting, and, though many persons are desirous that there should be a south wind blowing at the time, Cato ${ }^{17}$ is of quite a different way of thinking.

In a soil of medium quality, it is best to leave an interval of five $^{18}$ feet between every two vines; where it is very fertile the distance should be five feet at least, and where it is poor and thin eight at the very most. The Umbri and the Marsi leave intervals between their vines of as much as twenty feet in length, for the purpose of ploughing between them; such a plot of ground as this they call by the name of "porculetum." In a rainy, foggy locality, the plants ought to be set wider apart, but in dry spots nearer to one another. Careful observation has discovered various methods of economizing space; thus, for instance, when a vineyard is planted in shaded ground, a seed-plot is formed there as well; or, in other words, at the same time that the quickset is planted in the place which it is finally to occupy, the mallet-shoot intended for transplanting is set between the vines, as well as between the rows. By adopting this method, each jugerum will produce about sixteen thousand quicksets; and the result is, that two years' fruit is gained thereby, a cutting planted being two years later in bearing than a quickset transplanted. Quicksets, when growing in a vineyard, are cut down at the end of a year, leaving only a single eye above ground;

more especially as it agrees with what has been previously said in this Chapter in reference to declivitous ground.

${ }_{17}$ De Re Rust. 40.

${ }^{18} \mathrm{He}$ differs somewhat in these measurements from Columella, B. iv. c. 11 . 
some manure is then placed upon the spot, and a stay driven in close to the plant. In the same manner it is again cut down at the end ${ }^{19}$ of the second year, and from this it acquires additional strength, and receives nutriment to enable it to endure the onerous task of reproduction. If this is neglected, in its over-haste to bear it will shoot up slim and meagre, like a bulrush, and from not being subjected to such a training, will grow to nothing but wood. In fact, there is no tree that grows with greater eagerness than the vine, and if its strength is not carefully husbanded for the bearing of fruit, it will be sure to grow to nothing but wood.

The best props for supporting the vine are those which we have already mentioned, ${ }^{20}$ or else stays made of the robur and the olive; if these cannot be procured, then props of juniper, cypress, laburnum, or elder, ${ }^{21}$ must be employed. If any other wood is used for the purpose, the stakes should be cut at the end each year: reeds tied together in bundles make excellent cross-rails for the vine, and will last as long as five years. Sometimes the shorter stock-branches of the vines are brought together and tied with vine-cuttings, like so many cords: by this method an arcade is formed, known to us by the name of "funetum."

The vine, by the end of the third year, throws out strong and vigorous stock-branches with the greatest rapidity, and these in due time form the tree; after this, it begins to mount the cross-piece. Some persons are in the habit of "blinding" the vine at this period, by removing the eyes with the end of the pruning-knife turned upwards, their object being to increase the length of the branches-a most injurious practice, however; for it is far better to let the tree become habituated to grow of itself, and to prune away the tendrils every now and then when they have reached the cross-rail, so long as it may be deemed proper to add to its strength. There are some persons who forbid the vine to be touched for a whole year after it has been transplanted, and who say that the pruningknife ought never to be used before it is five years old; and

19 This is condemned by Columella, B. iv. c. 11; but is approved of by Virgil, Cato, and other authors.

20 In c. 34 of this Book.

${ }^{21}$ Stays of elder would be utterly worthless, as they would soon rot, and break directly, upon the least strain. 
then at that period they are for cutting it down so completely as to leave three buds only. Others, again, cut down the vine within a year even after it has been transplanted, but then they take care to let the stem increase every year by three or four joints, bringing it on a level with the cross-piece by the fourth. These two methods, however, both of them, retard the fruit and render the tree stunted and knotty, as we see the case in all dwarf trees. The best plan is to make the parent stem as robust and vigorous as possible, and then the wood will be sure to be strong and hardy. It is far from safe, too, to take slips from a cicatrized stem; such a practice is erroneous, and only the result of ignorance. All cuttings of this nature are sure to be the offspring of acts of violence, and not in reality of the tree itself. The vine, while growing, should be possessed of all its natural strength; and we find that when left entirely to itself, it will throw out wood in every part; for there is no portion of it that Nature does not act upon. When the stem has grown sufficiently strong for the purpose, it should at once be trained to the cross-piece ; if, however, it is but weak, it should be cut down so as to lie below the hospitable shelter of the cross-piece. Indeed, it is the strength of the stem, and not its age, that ought to decide the matter. It is not advisable ${ }^{24}$ to attempt to train a vine before the stem has attained the thickness of the thumb; but in the year after it has reached the frame, one or two stock-branches should be preserved, according to the strength developed by the parent tree. The same, too, must be done the succeeding year, if the weakness of the stem demands it; and in the next, two more should be added. Still, however, there should never be more than four branches allowed to grow; in one word, there must be no indulgence shown, and every exuberance in the tree must in all cases be most carefully repressed; for such is the nature of the vine, that it is more eager to bear than it is to live. It should be remembered, too, that all that is subtracted from the wood is so much added to the fruit. The vine, in fact, would much rather produce shoots and tendrils than fruit, because ${ }^{25}$ its fruit, after all, is but a transitory possession : hence it is that it luxuriates to its own undoing, and instead of really gaining ground, exhausts itself.

24 This applies solely, Fée observes, to the vine trained on the trail or cross-piece.

25 'This certainly appears to be a non sequitur, as applied to the vine. 
The nature, too, of the soil will afford some very useful suggestions. Where it is thin and hungry, even though the vine should display considerable vigour, it should be pruned down below the cross-piece and kept there, so that all the shoots may be put forth below it. The interval, however, between the top of the vine and the cross-piece ought to be but very small; so much so, indeed, as to leave it hopes, as it were, of reaching it, which, however, it must never be suffered to do; for it should never be allowed to recline thereon and spread and run on at its ease. This mode of culture ought, in fact, to be so nicely managed, that the vine should show an inclination rather to grow in body than to run to wood.

The main branch should have two or three buds left below the cross-piece that give promise of bearing wood, and it should be carefully trained along the rail, and drawn close to it in such a manner as to be supported by it, and not merely hang loosely from it. When this is done, it should be tightly fastened also with a binding three buds off, a method which will greatly contribute to check the too abundant growth of the wood, while stouter shoots will be thrown out below the ligature: it is absolutely forbidden, however, to tie the extremity of the main branch. When all this is done, Nature operates in the following way-the parts that are allowed to fall downward, or those which are held fast by the ligature, give out fruit, those at the bend of the branch more particularly. On the other hand, the portion that lies below the ligature throws out wood ; by reason, I suppose, of the interception of the vital spirit and the marrow or pith, previously mentioned : ${ }^{26}$ the wood, too, that is grown under these circumstances will bear fruit in the following year. In this way there are two kinds of stock branches: the first of which, issuing from the solid stock, gives promise of wood only for this year, and is known as the leaf stock-branch $;^{27}$ while that which grows beyond the mark made by the ligature is a fruit stock-branch. ${ }^{28}$ There are other kinds, again, that shoot from the stock-branches when they are a year old, and these are in all cases fruit stock-branches. There is left, also, beneath the cross-piece a shoot that is known as the reserve ${ }^{29}$ shoot, being always a young stock-branch, with not more than three buds upon it. This is intended to give out wood the next year, in

${ }^{26}$ In the present Chapter.

28 Fructuarium.

27 Pampinarium.

${ }^{29}$ Custos. 
case the vine by over-luxuriance should happen to exhaust itself. Close to it there is another bud left, no bigger than a wart; this is known as the "furunculus," 30 and is kept in readiness in case the reserve shoot should fail.

The vine, if enticed to bear fruit before the seventh year from its being planted as a slip, will pine ${ }^{31}$ away, become as slim as a bulrush, and die. It is thought equally undesirable, too, to let an old stock-branch range far and wide, and extend as far as the fourth stay from the stem; to such a branch the name of dragon ${ }^{32}$-branch is given by some, and of juniculus by others; if these are allowed to spread, they will run to wood only, and make male vines, as they are called. When a vine has become quite hard, it is an extremely bad plan to use it, for reproduction by layers. When the vine is five years old the stock-branches are twisted, but each is allowed to throw out some new wood; and so from one to another, care being taken to prune away the old wood. It is always the best plan, however, to leave a reserve shoot; but this should always be very near the main stem of the vine, not at a greater distance, in fact, than that already mentioned. ${ }^{33}$ If, too, the stock branches should throw out too luxuriantly, they must be twisted, the object being that the vine may put forth no more than four secondary branches, or even two only, if it happens to be a single cross-railed vine.

If the vine is to be trained to grow without any stay at all, still it will stand in need, at first, of some support or other, until it has learnt to support itself: in all other respects the mode of proceeding will be the same at first. When pruning, it will be necessary that the thumb-branches ${ }^{34}$ should be arranged in equal numbers on either side, in order that the fruit may not overload one side of the tree; and we may here remark by the way, that the fruit by its weight is apt to bear down the tree and counteract any tendency to increase in height. The vine, unsupported, when more than three feet in height, begins to bend, but the others do not, until they are five feet

30 The pilferer, "or little thief," apparently.

31 This, Fée observes, is not in accordance with the fact.

32 "Draco." Male vines appear to have been a kind that threw out no stock-branches, but ran to wood.

${ }^{33}$ Than three buds, as already mentioned in the present Chapter.

34 "Pollices." Branches, so called from the resemblance, being cut off above the first eye. See Columella, De Re Rust. B. iv. c. 24. 
high at the least; care should be taken, however, never to let them exceed the height of a man of moderate stature. Growers are in the habit of surrounding the vines that creep along the ground with a low fence ${ }^{35}$ for them to lean upon; and round. this fence they dig a trench by way of precaution, for fear lest the branches in their range should meet one another and so come into collision. The greater part of the world, in fact, gather grapes at their vintage, grown in this fashion, and lying upon the ground-at all events, it is so in Africa, Egypt, and Syria; throughout the whole of Asia, too, and in many parts of Europe as well, this method prevails. In such cases the vine ought to be kept down close to the ground, and the root should be nurtured at the same time and in just the same way as in the case of the vine that grows on the cross-piece. Care, too, should be taken to leave only the young thumb-shoots, together with three buds, where it is a prolific soil, two where it is poor and thin: it is better, too, that the shoots should be numerons than individually long. The influences of soil, of which we have made mention already, will make themselves felt all the more powerfully the nearer the grapes grow to the ground.

It is a very advantageous plan to separate $\mathrm{e}^{36}$ the various species of vines and to set them in different compartmentsfor the mixture of different varieties is apt to deteriorate the flavour not only of the must, but the wine even as well. If, again, for some reason or other, the different kinds must be intermingled, it will be requisite to keep all those together which ripen at exactly the same period. The more fertile and the more level the soil, the higher the cross-pieces must be placed. ${ }^{37}$ High cross-pieces, too, are best suited to localities that are subject to heavy dews and fogs, but not to those that are exposed to high winds; on the other hand, where the soil is thin, parched, and arid, or exposed to the wind, the cross-pieces should be set lower. The cross-piece should be fastened to the stay with cords tied as tight as possible, while the bindings used for tying the vine should be thin. As to the various species of vines, and the soils and climates requi-

35 Small forks of hazel are still used for the purpose, in Berri and the Orleanais.

36 This plan is highly recommended by the modern growers.

37 This, as Fée remarks, is based upon sound reason. 
site for the growth of each, we have already treated ${ }^{38}$ of them, when enumerating the several varieties of the vine and the wines which they produce.

With reference to other points connected with the culture of the vine, there are very considerable doubts. Many persons recommend that the vineyard should be turned up with the spade after every dew that falls in the summer. Others, again, forbid this practice when the vine is in bud; for the clothes, they say, of the people coming and going to and fro are apt to catch the buds, and either knock or rub them off; it is for this reason, too, that they are so careful to keep all animals away from the vines, those with long wool in particular, as it is very apt to pull off the buds. Raking, too, they say, is very injurious to the vine while the grape is forming; and it will be quite sufficient, they assure us, if the ground is turned up three times in the year, after the vernal equinox-first, at the rising of the Vergiliæ, ${ }^{39}$ the second at the rising of the Dog-star, and the third time just as the grape is turning black. Some persons make it a rule that an old vineyard shall have one turning up between the time of vintage and the winter solstice, though others, again, are of opinion that it is quite sufficient to bare the roots and manure them. They turn up the ground again after the ides of April, ${ }^{40}$ but before the time for germination, or, in other words, the sixth of the ides of May $;^{41}$ then again before the tree begins to blossom, after it has shed its blossom, and, last of all, when the grape is just on the turn. The most skilful growers say that if the ground is dug up oftener than necessary, the grapes will become so remarkably thin-skinned as to burst. When the ground is turned up, care should be taken to do it before the hot hours of the day; a clayey soil, too, should never be ploughed or dug. The dust that is raised in digging is beneficial ${ }^{42}$ to the vine, it is said, by protecting it from the heat of the sun and the injurious effects of fogs.

The spring clearing ought to be done, it is universally admitted, within ten days after the ides of May, ${ }^{43}$ and before the

38 In B. xiv. cc. 4 and 5 .

40 13th of April.

39 B. xviii. c. 66 .

41 10th of May.

42 A mere puerility - the dust, in fact, being injurious to the grape, by obstructing the natural action of heat and humidity.

43 15th of May. This clearing of the leaves, though still practised, Fée says, is by no means beneficial; the only result is, that the grapes become 
blossoming begins; in addition to which, it should always be done below the cross-piece. As to the second clearing, opinions differ very considerably. Some think it ought to be done when the blossoming is over, others, again, when the grapes are nearly at maturity. This point, however, may be decided by following the advice of Cato on the subject; for we must now pass on to a description of the proper mode of pruning the vine.

Immediately after ${ }^{44}$ the vintage, and while the weather is still warm, the work of pruning ${ }^{45}$ begins ; this, however, ought never to be done, for certain physical reasons, ${ }^{46}$ before the rising of the Eagle, as we shall have occasion to explain in the following Book. Nor should it be done either when the west winds begin to prevail, for even then there is great doubt whether a fault may not be committed by being in too great haste to commence the work. If any return of wintry weather should chance to nip the vines, while still labouring under the wounds recently inflicted on them in pruning, there is little doubt that their buds will become quite benumbed with cold, the wounds will open again, and the eyes, moistened by the juices that distil from the tree, will become frost-bitten by the rigour of the weather. For who is there, ${ }^{46}$ in fact, that does not know that the buds are rendered brittle by frost? All this, however, depends upon accurate calculations in the management of large grounds, and the blame of precipitation cannot with any justice be laid upon Nature. The earlier the vine is pruned, in suitable weather, the greater is the quantity of wood, while the later the pruning, the more abundant is the fruit. Hence it is that it is most advisable to prune the poor meagre vines first, and to defer pruning the more thriving ones to the very last. In pruning, due care should always be taken to cut in a slanting direction, in order $^{47}$ that the rain may run off with all the greater facility. The wounds, too, should look down-

of a higher colour, but in no degree riper than they otherwise would have been.

44 The proper period for pruning varies in reality according to the climate.

45 See B. xviii. c 59 .

46 See Columella, De Re Rust. B. iv. c. 29.

47 'The real reason, as Fée remarks, is the comparative facility of cutting aslant rather than horizontally ; indeed, if the latter were attempted, injury to the wood would be the certain result. 
wards towards the ground, and should be made as lightly as possible, the edge of the knife being well-sharpened for the purpose, so as to make a clean cut each time. Care should be taken, too, to cut always between two buds, and that the eyes are not injured in the operation. It is generally thought that wherever the vine is black, all those parts may be cut off, the healthy parts not being touched; as no useful shoots can be put forth by wood that is bad in itself. If a meagre vine has not good stock-shoots, the best plan is to cut it down to the ground, and then to train new ones. In clearing away the leaves, too, those leaves should not be removed which accompany the clusters, for by so doing the grapes are made to fall off, except where the vine happens to be young. Those leaves are regarded as useless which grow on the sides of the trunk and not from an eye; and so, too, are the bunches which shoot from the hard, strong wood, and are only to be removed by the aid of the knife.

Some persons are of opinion that it is a better plan to fix the stay midway between two vines; and, indeed, by the adoption of this method the roots are cleared with greater facility. It is best, however, where the vine needs but a single crossrail, due care being taken that the rail is a strong one, and the locality not exposed to high winds. In the case of those vines which require trellissed cross-rails, the stay should be placed as near as possible to the burden it has to support; in order, however, that there may be no impediment thrown in the way of clearing the roots, it may be placed at the distance of one cubit from the stock, but not more. It is generally recommended to clear the roots before the pruning ${ }^{48}$ is commenced.

Cato ${ }^{49}$ gives the following general precepts in relation to the culture of the vine:- "Let the vine grow as high as possible, and fasten it firmly, but not too tight. You should treat it in the following manner. Clean the roots of the vine at seedtime, and after pruning it dig about it, and then begin to labour at the ground, by tracing with the plough continuous furrows every way. Plant the young vines in layers as early as possible, and then break up the ground about them. If the

48 The pruning should come first, in every case, Fée says.

49 De Re Rust. c, 33. The advice given by him, though good, is not applieable to all vineyards. 
vine is old, take care and prune it as little as possible. In preference, bend the vine into the ground for layers, if necessary, and cut it at the end of two years. The proper time for cutting the young vine, is when it has gained sufficient strength. If the vineyard is bald of vines, then draw furrows between them, and plant quicksets there: but let no shadow be thrown on the furrows, and take care and dig them often. If the vineyard is old, sow ocinum ${ }^{50}$ there, in case the trees are meagre : but take care and sow there nothing that bears seed. Put manure, chaff, and grape-husks about the roots, or, indeed, anything of a similar nature that will give the tree additional strength. As soon as the vine begins to throw out leaves, set about clearing them. Fasten the young trees in more places than one, so that the stem may not break. As soon as it begins to run along the stay, fasten down the young branches lightly, and extend them, in order that they may gain the right position. When the grape begins to be mottled, then tie down the vine. The first season for grafting the vine is the spring, the other when the grape is in blossom; the last period is the best. If it is your wish to transplant an old vine, you will only be able to do so in case it is no thicker than the arm : first, however, you must prune it, taking care not to have more than two buds upon the stem. Then dig it well up by the roots, being careful to trace them, and using every possible precaution not to injure them. Place it in the hole or furrow exactly in the position in which it has stood before, then cover it with earth, which should be well trodden down. You must then prop it up, fasten it, and turn it in the same direction as before ; after which, dig about it repeatedly." The ocinum that Cato here recommends to be sown in the vineyards, is a fodder known by that name by the ancients; it thrives in the shade remarkably well, and received its name ${ }^{51}$ from the rapidity with which it grows.

(23.) We come now to speak of the method of growing vines upon trees, ${ }^{52}$ a mode that has been condemned ${ }^{53}$ in the strongest terms by the Saserna's, both father and son, and up${ }^{50} \mathrm{~A}$ sort of clover, probably. See B. xviii. c. 42 , and a few lines below.

${ }^{51}$ From the Greek $\dot{\omega} \kappa \varepsilon \dot{\varepsilon} \omega$, "quickly"-Varro says.

52 See c. 15 of this Book.

${ }_{53}$ It is still practised in Dauphine and the department of the Basses Alpes. It is very prevalent, also, in the South of Italy. 
held by Scrofa, these being our most ancient writers on agriculture next to Cato, and men of remarkable skill. Indeed, Scrofa himself will not admit that it is beneficial anywhere except in Italy. The experience of ages, however, has sufficiently proved that the wines of the highest quality are only grown upon vines attached to trees, and that even then the choicest wines are produced by the upper part of the tree, the produce of the lower part being more abundant ; such being the beneficial results of elevating the vine. It is with a view to this that the trees employed for this purpose are selected. In the first rank of all stands the elm, ${ }^{54}$ with the exception of the Atinian variety, which is covered with too many leaves; and next comes the black poplar, which is valued for a similar reason, being not so densely covered with leaves. Most people, too, by no means hold the ash and the fig in disesteem, as also the olive, if it is not overshadowed with branches. We have treated at sufficient length already of the planting and culture of these several trees.

They must not be touched with the knife before the end of three years; and then the branches are preserved, on each side in its turn, the pruning being done in alternate years. In the sixth year the vine is united to the tree. In Italy beyond the Padus, in addition to the trees already mentioned, they plant for their vines the cornel, the opulus, the linden, the maple, the ash, the yoke-elm, and the quercus ; while in Venetia they grow willows for the purpose, on account of the humidity ${ }^{55}$ of the soil. The top of the elm is lopped away, and the branches of the middle are regularly arranged in stages; no tree in general being allowed to exceed twenty feet in height. The stories begin to spread out in the tree at eight feet from the ground, in the hilly districts and upon dry soils, and at twelve in champaign and moist localities. The hands ${ }^{56}$ of the trunk ought to have a southern aspect, and the branches that project from them should be stiff and rigid like so many fingers; at the same time due care should be taken to lop off the thin beardlike twigs, in order to check the growth of all shade. The interval best suited for the trees, if it is the grower's intention to keep the soil turned up with the plough, is forty feet back and front, and twenty at the side; if it is not to be turned

54 All these trees are still employed for the purpose in Italy.

55 B. xvi. c. 68. 
ap, then twenty feet ${ }^{57}$ every way will do. A single tree is often made to support as many as ten vines, and the grower is greatly censured who attaches less than three. It is worse than useless to attach the vine before the tree has gained its full strength, as in such case its rapidity of growth would only tend to kill the tree. It is necessary to plant the vine in a trench three feet in depth, leaving an interval of one foot between it and the tree. In this case there is no necessity for using mallet shoots, or for going to any expense in spading or digging; for this method of training on trees has this advantage in particular, that it is beneficial even to the vine that corn should be sown in the same soil; in addition to which, from its height, it is quite able to protect itself, and does not call for the necessity, as in the case of an ordinary rineyard, of enclosing it with walls and hedges or ditches, made at a considerable expense, to protect it from injury by animals.

In the method of training upon trees, reproduction from quicksets or from layers is the only mode employed of all those that have been previously described; the growing by layers being effected two different ways, as already mentioned. The plan, however, of growing from layers in baskets set upon the stages ${ }^{58}$ of the tree is the most approved one, as it ensures an efficient protection from the ravages of cattle; while, according to another method, a vine or else a stock-branch is bent into the ground near the tree it has previously occupied, or else the nearest one that may be at liberty. It is recommended that all parts of the parent tree that appear above ground should then be scraped, so that it may not throw out wood; while at the same time there are never less than four buds on the part that is put into the ground for the purpose of taking root; there are also two buds left above ground at the head. The vine intended for training on a tree is planted in a furrow four feet long, three broad, and two and a half in depth. At the end of a year the layer is cut to the pith, to enable it to strengthen gradually at the root; after which, the end of the branch is pruned down to. within two buds from the ground. At the end of two years the layer is completely separated from the stock, and buried deeper in the ground, that it may

57 From Columella, B. v. c. 7.

58 This method is no longer employed.

VúL. III. 
not shoot at the place where it has been cut. As to the quicksets, they ought to be removed directly after the vintage.

In more recent times, a plan has been discovered of planting a dragon branch near the tree-that being the name given to an old stock-branch that has become hard and tough in the course of years. For this purpose, it is cut as long as possible, and the bark is taken off from three-fourths of its length, that being the portion which is to be buried in the ground; hence it is, too, that it is called a "barked" 59 plant. It is then laid at full length in the furrow, the remaining part protruding from the ground and reclining against the tree. This method is the most speedy one that can be adopted for growing the vine. If the vine is meagre or the soil impoverished, it is usual to keep it cut down as near to the ground as possible, until such time as the root is strengthened. Care, too, should be taken not to plant it covered with dew ${ }^{60}$ nor yet while the wind is blowing from the north. The vine itself ought to look towards the north-east, but the young stock-shoots should have a southern aspect.

There should not be too great haste ${ }^{61}$ in pruning a young vine, but a beginning should be made by giving the wood and foliage a circular form, care being taken not to prune it until it has become quite strong; it should be remembered, too, that the vine, when trained upon a tree, is generally a year later in bearing fruit than when grown on the cross-piece. There are some persons, again, who altogether forbid that a vine should be pruned until such time as it equals the tree in height. At the first pruning it may be cut to within six feet from the ground, below which a shoot must be left, and encouraged to run out by bending the young wood. Upon this shoot, when pruned, there should not be more than three buds left. The branches that take their rise from these buds should be trained in the following year upon the lowermost stages of the tree, and so in each successive year taught to climb to the higher ones. Care, too, should always be taken to leave one hard, woody branch at each stage, as well as one breeding shoot, at liberty to mount as high as it pleases. In addition to these precautions, in all pruning, those shoots should be cut off which have borne fruit the last year, and after the ten-
59 Rasilis.
61 Columella, B. v. c. 6.

so Columella, B. v. c. 6 . 
drils ${ }^{62}$ have been crit away on every side fresh branches should be trained to run along the stages. In Italy the pruning is so managed that the shoots and tendrils of the vines are arranged so as to cover the branches of the tree, while the shoots of the vine in their turn are surrounded with clusters of grapes. In Gallia, on the other hand, the vine is trained to pass from tree to tree. On the Amilian Way, again, the vine is seen embracing the trunks of the Atinian elms that line the road, while at the same time it carefully aroids their foliage. ${ }^{63}$

It is a mark of ignorance in some persons to' suspend the vine with a cord beneath the branches of the tree, to the great risk of stifling it ; for it ought to be merely kept up with a withe of osier, and not tightly laced. Indeed, in those places where the willow abounds, the withes that it affords are preferred, on account of their superior suppleness, while the Sicilians employ for the purpose a grass, which they call " ampelodesmos:" ${ }_{64}$ throughout the whole of Greece, rushes, cyperus, and sedge ${ }^{e 5}$ are similarly employed. When at any time the vine has been liberated from its bonds, it should be allowed to range uncontrolled for some days, and to spread abroad at pleasure, as well as to recline upon the ground which it has been looking down upon the whole year through. For in the same manner that beasts of burden when released from the yoke, and dogs when they have returned from the chase, love to roll themselves on the ground, just so does the vine delight to stretch its loins. The tree itself, too, seems to rejoice, and, thus relieved from the continuous weight which has burdened it, to have all the appearance of now enjoying a free respiration. Indeed, there is no object in all the economy of Nature that does not desire certain alternations for the enjoyment of rest, witness the succession of night and day, for instance. It is for this reason that it is forbidden to prune the vine directly the vintage is over, and while it is still exhausted by the process of reproduction.

Directly the vine has been pruned, it ought to be fastened. again to the tree, but in another place; for there is no doubt that it feels very acutely the indentations that are made in it

${ }^{62}$ Capreolis.

${ }^{63}$ As being too dense and shady.

${ }^{64}$ From the Greek, meaning the "vine-band." It was, probabiy, a kind of rush.

${ }^{65}$ Fée thinks that he may mean the Festuca fluitans more particulariy, by the name $u l v a$. 
by the holdfasts. In the Gallic method of cultivation they train out two branches at either side, if the trees are forty feet apart, and four if only twenty; where they meet, these branches are fastened together and made to grow in unison; if, too, they are anywhere deficient in number or strength, care is taken to fortify them by the aid of small rods. In a case, however, where the branches are not sufficiently long to meet, they are artificially prolonged by means of a hook, and so united to the tree that desires their company. The branches thus trained to unite they used to prune at the end of the second year. But where the vine is aged, it is a better plan to give them a longer time to reach the adjoining tree, in case they should not have gained the requisive thickness; besides which, it is always good to encourage the growth of the hard wood in the dragon branches.

There is yet another method, ${ }^{66}$ which occupies a middle piace between this mode of propagation and that by layers. It consists of laying the entire vine in the earth, and then splitting the stock asunder by means of wedges; the fibrous portions are then trained out in as many furrows, care being taken to support each of the slender plants by fastening it to a stake, and not to cut away the branches that shoot from the sides. The growers of Novara, not content with the multitude of shoots that run from tree to tree, nor yet with an abundance of branches, encourage the stock-branches to entwine around forks planted in the ground for the purpose ; a method, however, which, in addition to the internal defects arising from the soil, imparts a harshness to the wine.

There is another fault, too, that is committed by the people of Varracina, ${ }^{67}$ near Rome-they only prune their vines every other year ; not, indeed, because it is advantageous to the tree, but from a fear lest, from the low prices fetched by their wines, the expense might exceed the profits. At Carseoli they adopt a middle course, by pruning away only the rotten parts of the vine, as well as those which are beginning to wither, and leaving the rest to bear fruit, after thus clearing away all superfluous incumbrances. The only nutriment they give it is this exemption from frequent pruning; but unless the soil should happen to be a very rich one, the vine, under such

${ }^{96} \mathrm{It}$ is no longer used, and Fée doubts its utility.

67 Hardouin suggests "Tarracifa." 
a method of cultivation, will very soon degenerate to a wild state.

The vine that is thus trained requires the ground to be ploughed very deep, though such is not the case for the sowing there of grain. It is not customary to cut away the leaves in this case, which, of course, is so much labour spared. The trees themselves require pruning at the same period as the vine, and are thinned by clearing away all useless branches, and such parts as would only absorb the nutriment. We have already ${ }^{68}$ stated that the parts that are lopped should never look north or south : and it will be better still, if they have not a western aspect. The wounds thus made are very susceptible for a considerable time, and heal with the greatest difficulty, if exposed to excesses of cold or heat. The vine when trained on a tree enjoys advantages that are not possessed by the others; for the latter have certain fixed aspects, while in the former, it is easy to cover up the wounds made in pruning, or to turn them whichever way you please. When trees are pruned at the top, cup-like cavities should be formed ${ }^{69}$ there, to prevent the water from lodging.

\section{CHAP. 36. - HOW GRAPES ARE PROTECTED FROM THE RAVAGES OF INSECTS.}

Stays, too, should be given to the vine for it to take hold of and climb upwards, if they are taller than it. (24.) Espaliers ${ }^{70}$ for vines of a high quality should be cut, it is said, at the Quinquatria, ${ }^{71}$ and when it is intended to keep the grapes, while the moon is on the wane. We are assured, moreover, that those which are cut at the change of the moon, are exempt from the attacks of all insects. ${ }^{72}$ According to another system, it is said that vines should be pruned by night at full moon, and while it is in Leo, Scorpio, Sagittarius, or Taurus : and that, in general, they ought to be planted either when the moon is at full or on the increase. In Italy, ten workmen will suffice for one hundred jugera of vineyard.

\section{CHAP. 37.-THE DISEASES OF TREES.}

Having now treated sufficiently at length of the planting 68 In c. 16 of this Book.

${ }^{70}$ Pergulas. See B. xiv. c. 3.

is See B. xviii. c. 56. These, of course, are mere superstitions.

is Animalium. 
and cultivation of trees--(for we have already said enough of the palm ${ }^{73}$ and the cytisus, ${ }^{74}$ when speaking of the exotic trees) - we shall proceed, in order that nothing may be omitted, to describe other details relative to their nature, which are of considerable importance, when taken in connection with all that precedes. Trees, we find, are attacked by maladies; and, indeed, what created thing is there that is exempt from these evils? Still however, the affections of the forest trees, it is said, are not attended ${ }^{75}$ with danger to them, and the only damage they receive is from hail-storms while they are budding and blossoming; with the exception, indeed, of being nipped either by heat or cold blasts in unseasonable weather; for frost, when it comes at the proper times, as we have already stated, ${ }^{76}$ is serviceable to them. "Well but," it will be said, " is not the vine sometimes killed with cold?" No doubt it is, and this it is through which we detect inherent faults in the soils, for it is only in a cold soil that the vine will die. Just in the same way, too, in winter we approve of cold, so long as it is the cold of the weather, and not of the ground. It is not the weakest trees, too, that are endangered in winter by frost, but the larger ones. When they are thus attacked, it is the summit that dries away the first, from the circumstance that the sap becomes frozen before it is able to arrive there.

- Some diseases of trees are common to them all, while others, again, are peculiar to individual kinds, Worms ${ }^{77}$ are common to them all, and so, too, is sideration, ${ }^{78}$ with pains in the limbs ${ }^{79}$ which are productive of debility in the various parts. Thus do we apply the names of the maladies that prerail among mankind to those with which the plants are afflicted. In the same way, too, we speak of their bodies being mutilated, the eyes of the buds being burnt up, with many other expressions of a similar nature. It is in accordance with the same phraseology that we say that trees are aflicted with hunger or indigestion, both of which result from the

73 In B. xiii. c. 6.

74 In B. xiii. c. 47.

75 This is the opinion of Theophrastus, Hist. Plant. B. iv. c. 16.

76 In c. 2 of this Book.

77 "Vermiculatio." Fée understands this to apply to the attacks of insects in general, the Dermestes typographus more particularly.

$78 \mathrm{Or}$, in other words, the evil influences of the heavenly bodies: this, of course, is not believed in at the present day.

${ }_{79}$ Necrosis, in particular portions of the plant. 
comparative amount of sap that they contain; while some, again, are troubled with obesity, as in the case of all the resinous trees, which, when suffering from excessive fatness, ars changed into a torch-tree. ${ }^{80}$ When the roots, too, begin to wax fat, trees, like animals, are apt to perish from excess of fatness. Sometimes, too, a pestilence ${ }^{81}$ will prevail in certain classes of trees, just as among men, we see maladies attack, at one time the slave class, and at another the common people, in cities or in the country, as the case may be.

Trees are more or less attacked by worms; but still, nearly all are subject to them in some degree, and this the birds ${ }^{82}$ are able to detect by the hollow sound produced on tapping at the bark. These worms even have now begun to be looked upon as delicacies ${ }^{83}$ by epicures, and the large ones found in the robur are held in high esteem ; they are known to us by the name of "cossis ;" and are even fed with meal, in order to fatten them! But it is the pear, the apple, and the fig ${ }^{84}$ that are most subject to their attacks, the trees that are bitter and odoriferous enjoying a comparative exemption from them. Of those which infest the fig, some breed in the tree itself, while others, again, are produced by the worm known as the cerastes ; they all, however, equally assume the form of the cerastes, ${ }^{85}$ and emit a small shrill noise. The service-tree is infested, too, with a red hairy worm, which kills it; and the medlar, when old, is subject to a similar malady.

The disease known as sideration entirely depends upon the heavens; and hence we may class under this head, the ill

${ }^{80}$ See B. xvi. c. 19. He alludes to an exuberant secretion of resin, in which case the tree becomes charged with it like a torch.

81 $\mathrm{He}$ alludes to the epidemic and contagious maladies by which trees are attacked. The causes of these attacks are often unknown, but they may probably proceed, in many instances, from springs of hot water, or gaseous emanations secreted in the earth.

82 The woodpecker more particularly. See B. x. c. 20.

83 It is not known, with certainty, what these worms or caterpillars were. The larva of the capricorn beetle, or of the stag-beetle, has been suggested. Geoffroi thinks that it may have been the larva of the palmweevil. This taste for caterpillars, probably, no longer prevails in any part of Europe.

81 This passage, which is quite conformable to truth, is from Theophrastus, Hist. Plant. B. iv. c. 16 , and B. iii. c. 12 .

s5 See B. xvi. c. 80 . 
effects produced by hail-storms, carbunculation, ${ }^{86}$ and the damage caused by hoar-frosts. When the approach of spring tempts the still tender shoots to make their appearance, and they venture to burst forth, the malady attacks them, and scorches up the eyes of the buds, filled as they are with their milky juices : this is what upon flowers they call "charcoal "87 blight. The consequences of hoar-frost to plants are even more dangerous still, for when it has once settled, it remains there in a frozen form, and there is never any wind to remove it, seeing that it never prevails except in weather that is perfectly calm and serene. Sideration, however, properly so called, is a certain heat and dryness that prevails at the rising of the ${ }^{88} \mathrm{Dog}$-star, and owing to which grafts and young trees pine away and die, the fig and the vine more particularly. The olive, also, besides the worm, to which it is equally subject with the fig, is attacked by the measles, ${ }^{89}$ or as some think fit to call it, the fungus or platter; it is a sort of blast produced by the heat of the sun. Cato ${ }^{90}$ says that the red moss $^{91}$ is also deleterious to the olive. An excessive fertility, too, is very often injurious to the vine and the olive. Scab is a maladycommon to all trees. Eruptions, ${ }^{92}$ too, and the attacks of a kind of snail that grows on the bark, are diseases peculiar to the fig, but not in all countries; for there are some maladies that are prevalent in certain localities only.

In the same way that man is subject to diseases of the sinews, so are the trees as well, and, like him, in two different ways. Either ${ }^{93}$ the virulence of the disease manifests itself in the feet, or, what is the same thing, the roots of the tree, or else in the joints of the fingers, or, in other words, the extremities of the branches that are most distant from the trunk. The parts that are thus affected become dry and shrivel up: the Greeks have appropriate names ${ }^{91}$ by which to distinguish

86 The effects produced upon young shoots by frost, are still so called.

87 Probably from the black colour which it turns.

88 In this case it would be very similar to what we call sun-stroke.

89 "Clavum," a nail. He appears to allude to a gall that appears on the bark of the olive, the eruption forming the shape of a nail, and, in some instances, a "patella," or platter. The Coccus adonideum is an insect that is very destructive to the olive.

91 A sort of Erineum, Fée suggests. See B. xv. c. 6.

92 "Impetigo." "Tetter," or " ringworm," literally.

93 From Theophrastus, Hist. Plant. B. iv. c. 16.

$94 \Sigma \phi u \kappa \varepsilon \lambda \iota \sigma \mu o ̀ s$ and кọáóos. 
each of these affections. In either case the first symptoms are that the tree is suffering from pain, and the parts affected become emaciated and brittle; then follows rapid consumption and ultimately death; the juices being no longer able to enter the diseased parts, or, at all events, not circulating in them. The fig is more particularly liable to this disease: but the wild fig is exempt from all that we have hitherto mentioned. $\mathrm{Scab}^{95}$ is produced by viscous dews which fall after the rising of the Vergiliæ; but if they happen to fall copiously, they drench the tree, without making the bark rough. When the fig is thus attacked, the fruit falls off while green; and so, too; if there is too much rain. The fig suffers also from a superfluity of moisture in the roots.

In addition to worms and sideration, the vine is subject to a peculiar disease of its own, which attacks it in the joints, and is produced from one of the three following causes:either the destruction of the buds by stormy weather, or else the fact, as remarked by Theophrastus, that the tree, when pruned, has been cut with the incisions upwards, ${ }^{96}$ or has been injured from want of skill in the cultivator. All the injury that is inflicted in these various ways is felt by the tree in the joints more particularly. It must be considered also as a species of sideration, when the cold dews make the blossoms fall off, and when the grapes harden ${ }^{97}$ before they have attained their proper size. Vines also become sickly when they are perished with cold, and the eyes are frost-bitten just after they have been pruned. Heat, too, out of season, is productive of similar results : for everything is regulated according to a fixed order and certain determinate movements. Some maladies, too, originate in errors committed by the vine-dresser; when they are tied too tight, for instance, as already mentioned, ${ }^{98}$ or when in trenching round them the digger has struck them an unlucky blow, or when in ploughing about them the roots have been strained through carelessness, or the bark has been stripped from off the trunk: sometimes, too, contusions are produced by the use of too blunt a pruning-knife. Through all the causes thus enumerated the tree is rendered more sen-

${ }_{95}$ From Theophrastus, Hist. Plant, B. iv. c. 16. Fée is at a loss to know what is meant by these viscous dews, and is unable to identify the disease here mentioned as "scabies." It is not improbable that it was caused by an insect.

97 See B. xviii. c. 69. 96. See cc. 35 and 50 of this Book.

98 In c. 35 . See also c. 45 of this Book. 
sicire to either cold or heat, as every injurious influence from without is apt to concentrate in the wounds thus made. The apple, however, is the most delicate of them all, and more particularly the one that bears the sweetest fruit. In some trees weakness induced by disease is productive of barrenness, and does not kill the tree; as in the pine ${ }^{99}$ for instance, or the palm, when the top of the tree has been removed; for in such case the tree becomes barren, but does not die. Sometimes, too, the fruit itself is sickly, independently of the tree; for example, when there is a deficiency of rain, or of warmth, or of wind, at the periods at which they usually prevail, or when, on the other hand, they have prevailed in excess; for in such cases the fruit will either drop off or else deteriorate. But the worst thing of all that can befall the vine or the olive, is to be pelted with heavy showers just when the tree is shedding its blossom, for then the fruit is sure to fall off ${ }^{1}$ as well.

Rain, too, is productive of the caterpillar, a noxious insect that eats away the leaves, and, some of them, the blossoms as well; and this in the olive even, as we find the case at Miletus; giving to the half-eaten tree a most loathsome appearance. This pest is produced by the prevalence of a damp, languid heat; and if the sun should happen to shine after this with a more intense heat and burn them up, this pest only gives place to another ${ }^{2}$ just as bad, the aspect only of the evil being changed.

There is still one other affection that is peculiar to the olive and the vine, known as the "cobweb," 3 the fruit being enveloped in a web, as it were, and so stifled. There are certain winds, too, that are particularly blighting to the olive and the vine, as also to other fruits as well : and then besides, the fruits themselves, independently of the tree, are very much wormeaten in some years, the apple, pear, medlar, and pomegranate for instance. In the olive the presence of the worm may be

99 From Theophrastus, Hist. Plant. B. iv. c. 16. If the terminal bud of the palm is taken off, it will mostly die.

1 "Decidunt." The French use a similar word-couler. In this case the pollen, being washed off by the showers, has not the opportunity of fecundating the ovary of the flower.

2 The insect Ichneumon or Pupivora, probably, which breeds in the larvæ or else in the body of the caterpillar. The passage is from Theophrastus, B. iv. c. 16.

3 Caused probably by a maggot or moth passing from one grape or olire to another, and spinning its web in vast quantities. See Theophrastus, 3 iv. c. 17 . 
productive of a twofold result: if it grows beneath the skin, it will destroy the fruit, but if it is in the stone, it will only gnaw it away, making the fruit all the larger. The prevalence of showers after the rising of Arcturus ${ }^{4}$ prevents them from breeding; but if the rains are accompanied with wind from the south, they will make their appearance in the ripe fruit even, which are then very apt to fall. This happens more particularly in moist, watery localities; and even if they do not fall, the olives that are so affected are good for nothing. There is a kind of fly also that is very troublesome to some fruit, acorns and figs for instance: it would appear that they breed from the juices ${ }^{5}$ secreted beneath the bark, which at this period are sweet. These trees, too, are generally in a diseased state when this happens.

There are certain temporary and local influences which cause instantaneous death to trees, but which cannot properly be termed diseases ; such, for example, as consumption, blast, or the noxious effects of some winds that are peculiar to certain localities; of this last nature are the Atabulus ${ }^{6}$ that prevails in Apulia, and the Olympias ${ }^{7}$ of Euboea. This wind, if it happens to blow about the winter solstice, nips the tree with cold, and shrivels it up to such a degree that no warmth of the sun can ever revive it. Trees that are planted in valleys, and are situate near the banks of rivers, are especially liable to these accidents, the vine more particularly, the olive, and the fig. When this has been the case, it may instantly be detected the moment the period for germination arrives, though, in the olive, somewhat later. With all of these trees, if the leaves fall off, it is a sign that they will recover; but if such is not the case, just when you would suppose that they have escaped uninjured, they die. Sometimes, however, the leaves will become green again, after being dry and shrivelled. Other trees, again, in the northern regions, Pontus and Phrygia, for example, suffer greatly from cold or frost, in case they should continue for forty days after the winter solstice. In these countries, too, as well as in other parts, if a sharp frost or copious rains should happen to come on immediately after fructification, the fruit is killed in a very few days even.

${ }^{4}$ See B. xviii. c. 74.

5 On the contrary, this sweet juice is secreted by the insect itself, an aphis or vine-fretter.

6 The north-west wind. See Horace, Sat. B, i. s. v. 1. 71.

7 See B. ii. c. 46. 
Injuries inflicted by the hand of man are productive also of bad effects. Thus, for instance, pitch, oil, and grease, ${ }^{8}$ if applied to trees, and young ones more particularly, are highly detrimental. They may be killed, also, by removing a circular piece of the bark from around them, with the exception, indeed, of the cork-tree, ${ }^{9}$ which is rather benefitted than otherwise by the operation; for the bark as it gradually thickens tends to stifle and suffocate the tree: the andrachle, ${ }^{10}$ too, receives no injury from it, if care is taken not to cut the body of the tree. In addition to this, the cherry, the lime, and the vine shed their bark ;11 not that portion of it, indeed, which is essential to life, and grows next the trunk, but the part that is thrown off, in proportion as the other grows beneath. In some trees the bark is naturally full of fissures, the plane for instance: in the linden it will all but grow again when removed. Hence, in those trees the bark of which admits of cicatrization, a mixture of clay and dung ${ }^{12}$ is employed by way of remedy; and sometimes with success, in case excessive cold or heat does not immediately supervene. In some trees, again, by the adoption of these methods death is only retarded, the robur and the quercus, ${ }^{13}$ for example. The season of the year has also its peculiar influences; thus, if the bark is removed from the fir and the pine, while the sun is passing through Taurus or Gemini, the period of their germination, they will instantly die, while in winter they are able to withstand the injurious effects of it much longer: the same is the case, too, with the holm-oak, the robur, and the quercus. In the trees above mentioned, if it is only a narrow circular strip of bark that is removed, no injurious effects will be perceptible; but in the case of the weaker trees, as well as those which grow in a thin soil, the same operation, if performed even on one side only, will be sure to kill them. The removal of the top ${ }^{14}$ in

${ }^{8}$ He probably means if applied to the bark of young trees.

9 The cork-tree forms no exception to the rule-if a complete ring of the bark that lies under the epidermis is removed, the death of the tree is the inevitable result. See B. xvi. c. 13.

10 Probably the Arbutus integrifolia. See B. xiii. c. 40.

11 This in reality is not the bark, but merely the epidermis, which is capable of reproduction in many trees.

12 See c. 16 of this Book.

${ }_{13}$ This method, however, is often found efficacious in preserving the life of the oak, as well as many other trees, by excluding the action of the air and water.

11 It prevents them from increasing in height, but does not cause their death. 
the pitch-tree, the cedar, and the cypress is productive of a similar result; for if it is either cut off or destroyed by fire, the tree will not survive : the same is the case, too, if they are bitten by the teeth of animals.

Varro ${ }^{15}$ informs us, too, as we have already stated, ${ }^{16}$ that the olive, if only licked by a she-goat, will be barren. ${ }^{37}$ When thus injured, some trees will die, while in others the fruit be. comes deteriorated, the almond, ${ }^{18}$ for instance, the fruit of which changes from sweet to bitter. In other cases, again, the tree is improved ${ }^{19}$ even - such, for instance, as the pear known in Chios as the Phocian pear. We have already mentioned ${ }^{20}$ certain trees, also, that are all the better for having the tops removed. Most trees perish when the trunk is split; but we must except the vine, the apple, the fig, and the pomegranate. Others, again, will die if only a wound is inflicted : the fig, however, as well as all the resinous trees, is proof against such injury. It is far from surprising that, when the roots of a tree are cut, death should be the result; most of them perish, however, when, not all the roots, but only the larger ones, and those which are more essential to life, have been severed.

Trees, too, will kill one another ${ }^{21}$ by their shade, or the density of their foliage, as also by the withdrawal of nourishment. Iry, ${ }^{22}$ by clinging to a tree, will strangle ${ }^{23}$ it. The mistletoe, too, is far from beneficial, and the cytisus is killed by the plant to which the Greeks have given the name of halimon. ${ }^{24} \mathrm{It}$ is the nature of some plants not to kill, but to injure, by the odour they emit, or by the admixture of their juices; such is the influence exercised by the radish and the laurel upon the vine. ${ }^{25}$ For the vine may reasonably be looked

15 De Re Rust. B. i. c. 2.

16 In B. viii. c. 76 , and B. xv. c. 8.

17 This statement is fabulous. Goats are apt to injure trees by biting the buds and young shoots. Fabulous as it is, however, Fée remarks that it still obtains credit among the peasantry in France.

18 This fabulous story is taken from Theophrastus, De Causis, B. v. c. 25.

19 Also from Theophrastus, Hist. Plant. B.iv. cc. 19-20, and De Causis, B. v. c. 22. It is just possible that on some of the branches being torn off by an animal, the tree may have grown with increased vigour.

20 In B. xiii. c. 9, and in c. 30 of this Book. 21 See B. xvi. c. 47.

22 It must be remembercd that ivy is not a parasite, and that it has no suckers to absorb the nutriment of another tree.

23 See B. xvi. c. 62 .

24 C. Bauhin gives this name to several species of Atriplex. Lacuna was of opinion that the Halimon of Dioscorides was the same as the Viburnum. ${ }^{25}$ A superstitious belief only, as Fée remarks. 
upon as possessed of the sense of smell, and affected by odours in a singular degree; hence, when it is near a noxious exhalation, it will turn away and withdraw from it. It was from his observation of this fact that Androcydes borrowed the radish ${ }^{26}$ as his antidote for drunkenness, recommending it to be eaten on such occasions. The vine, too, abhors all coleworts and garden herbs, and the hazel ${ }^{27}$ as well ; indeed it will become weak and ailing if they are not removed to a distance from it. Nitre, alum, warm sea-water, and the shells of beans ${ }^{28}$ and fitches act as poisons on the vine.

CHAP. 38. (25.) - PRODIGIES CONNECTED WITH TREES.

Among the maladies which affect the various trees, we may find room for portentous prodigies also. For we find some trees that have never had a leaf upon them ; a vine and a pomegranate bearing ${ }^{29}$ fruit adhering to the trunk, and not upon the shoots or branches; a vine, too, that bore grapes but had no leaves; and olives that have lost their leaves while the fruit remained upon the tree. There are some marvels also connected with trees that are owing to accident; an olive that was completely burnt, has been known to revive, and in Bœotia, some fig-trees that had been quite eaten away by locusts budded afresh. ${ }^{30}$ Trees, too, sometimes change their colour, and turn from black to white; this, however, must not always be looked upon as portentous, and more particularly in the case of those which are grown from seed; the white poplar, too, often becomes black. Some persons are of opinion also that the service-tree, if transplanted to a warmer locality, will become barren. But it is a prodigy, no doubt, when sweet fruits become sour, or sour fruits sweet; and when the wild fig becomes changed into the cultivated one, or vice versâ. It is sadly portentous, ${ }^{31}$ too, when the tree becomes deteriorated by the change, the cultivated olive changing into the wild, and the white grape or fig becoming black: such was the case, also, when upon the arrival of Xerxes there, a plane-tree at Laodicea was trans-

26 See B. xix. c. $26 . \quad 27$ Virgil shared this belief : see Georg. ii. 1. 299. 28 This may be true in some measure as to nitre, alum, and warm seawater; but not so as to the shells of beans and pigeon-pease, which would make an excellent manure for it.

29 This, as Fée remarks, is not by any means impossible, nor, indeed, are any other of the cases mentioned in this paragraph, owing to some accidental circumstance.

30 See B. xxix. c. 29.

31 These stories can, of course, be only regarded as fabulous. 
formed into an olive. In such narratives as these, the book written in Greek by Aristander abounds, not to enter any further on so extended a subject; and we have in Latin the Commentaries of $\mathrm{C}$. Epidius, in which we find it stated that trees hare even been known to speak. In the territory of Cumæ, a tree, and a very ominous presage it was, sank into the earth shortly before the civil wars of Pompeius Magnus began, leaving only a few of the branches protruding from the ground. The Sibylline Books were accordingly consulted, and it was found that a war of extermination was impending, which would be attended with greater carnage the nearer it should approach the city of Rome.

Another kind of prodigy, too, is the springing up of a tree in some extraordinary and unusual place, the head of a statue, for instance, or an altar, or upon another tree even. ${ }^{32} \mathrm{~A}$ figtree shot forth from a laurel at Cyzicus, just before the siege of that city; and so in like manner, at Tralles, a palm issued from the pedestal of the statue of the Dictator Cæsar, at the period of his civil wars. So, too, at Rome, in the Capitol there, in the time of the wars against Perseus, a palm-tree grew from the head of the statue of Jupiter, a presage of impending victory and triumphs. This palm, however, having been destroyed by a tempest, a fig-tree sprang up in the very same place, at the period of the lustration made by the censors M. Messala and C. Cassius, ${ }^{33}$ a time at which, according to Piso, an author of high authority, all sense of shame had been utterly banished. Above all the prodigies, however, that have ever been heard of, we ought to place the one that was seen in our own time, at the period of the fall of the Emperor Nero, in the territory of Marrucinum; a plantation of olives, belonging to Vectius Marcellus, one of the principal members of the Eques. trian order, bodily crossed the public highway, while the fields that lay on the opposite side of the road passed over to supply the place which had been thus vacated by the olive-yard. ${ }^{34}$

\section{CHAP. 39. (26.)-TREATMENT OF THE DISEASES OF TREES.}

Having set forth the various maladies by which trees are attacked, it seems only proper to mention the most appropriate 32 This may easily be accounted for, by the seed accidentally lodging in a crevice of the tree.

${ }_{31} \mathrm{An}$ exaggerated account merely of a land-slip. 
remedies as well. Şome of these remedies may be applied to all kinds of trees in common, while others, again, are peculiar to some only: The methods that are common to them all, are, baring the roots, or moulding them up, thus admitting the air or keeping it away, as the case may be; giving them water, or depriving them of it, refreshing them with the nutritious juices of manure, and lightening them of their burdens by pruning. The operation, too, of bleeding, ${ }^{35}$ as it were, is performed upon them ly withdrawing their juices, and the bark is scraped all round ${ }^{36}$ to improve them. In the vine, the stock branches are sometimes lengthened out, and at other times repressed; the buds too are smoothed, and in a measure polished up, in case the cold weather has made them rough and scaly. These remedies are better suited to some kinds of trees and less so to others: thus the cypress, for instance, has a dislike to water, and manifests an aversion to manure, spading round it, pruning, and, indeed, remedial operations of every kind; nay, what is more, it is killed by irrigation, while, on the other hand, the vine and the pomegranate receive their principal nutriment from it. In the fig, again, the tree is nourished by watering, while the very same thing will make the fruit pine and die: the almond, too, if the ground is spaded about it, will lose its blossom. In the same way, too, there must be no digging about the roots of trees when newly grafted, or indeed until such time as they are sufficiently strong to bear. Many trees require that all superfluous burdens should be pruned away from them, just as we ourselves cut the nails and hair. Old trees are often cut down to the ground, and then shoot up again from one of the suckers; this, however, is not the case with all of them, but only those, the nature of which, as we have already stated, ${ }^{37}$ will admit of it.

\section{CHAP. 40.-METHONS OF IRRIGATION.}

Watering is good for trees during the heats of summer, but injurious in winter; the effects of it are of a varied nature in autumn, and depend upon the peculiar nature of the soil. Thus, in Spain for instance, the vintager gathers the grapes while the ground beneath is under water; on the other hand, in most parts of the world, it is absolutely necessary to carry off the autumn rains by draining. It is about the rising of the

so See c. 43 of this Book.

36 See c. 45 of this Book.

37 In B. xvi. cc. 53, 56, 66, 67, and 90 . 
Dog-star that irrigation is so particularly beneficial ; but even then it ought not to be in excess, as the roots are apt to become inebriated, and to receive injury therefrom. Care should be taken, too, to proportion it to the age of the tree, joung trees being not so thirsty as older ones; those too which require the most water, are the ones that have been the most used to it. On the other hand, plants which grow in a dry soil, require no more moisture than is absolutely necessary to their existence.

\section{CHAP. 41.-REMARKABLE FACTS CONNECTED WITH IRRIGATION.}

In the Fabian district, which belongs to the territory of Sulmo ${ }^{33}$ in Italy, where they are in the habit, also, of irrigating the fields, the natural harshness of the wines makes it necessary to water the vineyards; it is a very singular thing, too, that the water there kills all the weeds, while at the same time it nourishes the corn, thus acting in place of the weedinghook. In the same district, too, at the winter solstice, and more particularly when the snow is on the ground or frosts prevail, they irrigate the land, a process which they call "warming" the soil. This peculiarity, however, exists in the water of one river ${ }^{39}$ only, the cold of which in summer is almost insupportable.

CHAP. 42. (27.)-INCISIONS MADE IN TREes.

The proper remedies for charcoal-blight and mildew ${ }^{40}$ will be pointed out in the succeeding Book.11 In the meantime, however, we may here observe that among the remedies may be placed that by scarification. ${ }^{42}$ When the bark becomes meagre and impoverished by disease, it is apt to shrink, and so compress the rital parts of the tree to an excessive degree : upon which, by means of a sharp pruning knife held with both hands, incisions are made perpendicularly down the tree, and a sort of looseness, as it were, imparted to the skin. It is a

38 This was the native place of Ovid, who alludes to its cold streams, Tristia, B. iv. El. x. ll. 3, $4:-$

"Sulmo mihi patria est, gelidis uberrimus undis, Millia qui novies distat ab urbe decem."

Irrigation of the vine is still practised in the east, in Italy, and in Spain; but it does not tend to improve the quality of the wine.

39 The Sagrus, now the Sangro.
40 "Uredo rubigo" and "uredo caries."
42 Still practised upon the cherry-tree.
41 Cc. 45 and 70.

voL. III. 
proof that the method has been adopted with success, when the fissures so made remain open and become filled with wood of the trunk growing between the lips.

CHAP. 43.-OTHER REMEDIES FOR THE DISEASES OF TREES.

The medical treatment of trees in a great degree resembles that of man, seeing that in certain cases the bones of them both are perforated even. ${ }^{43}$ The bitter almond will become sweet, if, after spading round the trunk and cleaning it, the lowermost part of it is pierced all round, so that the humours may have a passage for escape and ensure being removed. In the elm, too, the superfluous juices are drawn off, by piercing the tree above ground to the pith when it is old, or when it is found to suffer from an excess of nutriment. So, too, when the bark of the fig is turgid and swollen, the confined juices are discharged by means of light incisions made in a slanting direction; by the adoption of which method the fruit is prevented from falling off. When fruit-trees bud but bear no fruit, a fissure is made in the root, and a stone inserted; the result of which is, that they become productive. ${ }^{44}$ The same is done also with the almond, a wedge of robur being employed for the purpose. For the pear and the service tree a wedge of torch-wood is used, and then covered over with ashes and earth. It is even found of use, too, to make circular incisions around the roots of the vine and fig, when the vegetation is too luxuriant, and then to throw ashes over the roots. A late crop of figs is ensured, if the first fruit is taken off when green and little larger than a bean; for it is immediately succeeded by fresh, which ripens at a later period than usual. If the tops of each branch are removed from the fig, just as it is beginning to put forth leaves, its strength and productiveness are greatly increased. As to caprification, the effect of that is to ripen the fruit.

CHAP. 44.-CAPRIFICATION, AND PARTICULARS CONNECTED WrTH THE FIG.

It is beyond all doubt that in caprification the green fruit gives birth to a kind of gnat; ${ }^{45}$ for when they have taken

43 ire allucies to the medical operation for the removal of carious bones, described by Celsus, B. viii.c. 3 .

44 This is still done by some persons; but it can be productive of no beneficial result.

45 See B. $x v$, c. 21 : the Cynips psencs of Linn. It penetrates the fig 
flight, there are no seeds to be found within the fruit: from this it would appear that the seeds have been transformed into these gnats. Indeed, these insects are so eager to take their flight, that they mostly leave behind them either a leg or a part of a wing on their departure. There is another species of gnat, ${ }^{46}$ too, that grows in the fig, which in its indolence and malignity strongly resembles the drone of the beehive, and shows itself a deadly enemy to the one that is of real utility; it is called centrina, and in killing the others it meets its own death.

Moths, too, attack the seeds of the fig: the best plan of getting rid of them, is to bury a slip of mastich, ${ }^{47}$ turned unside down, in the same trench. The fig, too, is rendered extremely productive ${ }^{48}$ by soaking red earth in amurca, and laying it, with some manure, upon the roots of the tree, just as it is beginning to throw out leaves. Among the wild figs, the black ones, and those which grow in rocky places, are the most esteemed, from the fact of the fruit containing the most seed. Caprification takes place most advantageously just after rain.

\section{CHAP. 45.- - ERRORS THAT MAY BE COMMITTED IN PRUNING.}

But, before everything, especial care should be taken that intended remedies are not productive of ill results; as these may arise from either remedial measures being applied in excess or at unseasonable times. Clearing away the branches is of the greatest benefit to trees, but to slaughter ${ }^{49}$ them this way every year, is productive of the very worst results. The vine is the only tree that requires lopping every year, the myrtle, the pomegranate, and olive every other; the reason being that these trees shoot with great rapidity. The other trees are lopped less frequently, and none of them in autumn ; the trunk even is never scraped, ${ }^{50}$ except in spring. In pruning a tree, all that is removed beyond what is absolutely necessary, is so much withdrawn from its vitality.

CHAP. 46.-THE PROPER MODE OF MANURING TREES.

The same precautions, too, are to be regarded in manuring. at the base, and deposits an egg in each seed, which is ultimately eaten by the larva; hence the supposed transformation.

${ }_{46} \mathrm{~A}$ kind of wasp, probably.

47 A puerility borrowed from Columella, B. v. c. 10.

${ }^{48}$ From Columella, B. v. c. 10.

49 Trucidatio.

${ }^{50}$ For the removal of moss and lichens, which obstruct evaporation, and collect moisture to an inconvenient degree, besides harbouring insects. 
Though manure is grateful to the tree, still it is necessary to be careful not to apply it while the sun is hot, or while it is too new, or more stimulating than is absolutely necessary. The dung of swine will burn ${ }^{51}$ up the vine, if used at shorter intervals than those of five years; unless, indeed, it is mixed with water. The same is the case, too, with the refuse of the currier's workshop, unless it is well diluted with water : manure will scorch also, if laid on land too plentifully. It is generally considered the proper proportion, to use three modii to every ten feet square; this, however, the nature of the soil must decide.

\section{CHAP. 47.-MEDICAMENTS FOR TREES.}

Wounds and incisions of trees are treated also with pigeon dung and swine manure. If pomegranates are acid, the roots of the tree are cleared, and swine's dung is applied to them : the result is, that in the first year the fruit will have a vinous flavour, but in the succeeding one it will be sweet. Some persons are of opinion that the pomegranate should be watered four times a year with a mixture of human urine and water, at the rate of an amphora to each tree; or else that the extremities of the branches should be sprinkled with silphium ${ }^{52}$ steeped in wine. The stalk of the pomegranate should be twisted, if it is found to split while on the tree. The fig, too, should be drenched with the amurca of olives, and other trees when they are ailing, with lees of wine; or else lupines may be sown about the roots. The water, too, of a decoction of lupines is beneficial to the fruit, if poured upon the roots of the tree. When it thunders at the time of the Vulcanalia, ${ }^{53}$ the figs fall off ; the only remedy for which is to have the area beneath ready covered with barley-straw. Lime applied to the roots of the tree makes cherries come sooner to maturity, and ripen more rapidly. The best plan, too, with the cherry, as with all other kinds, is to thin the fruit, so that that which is left behind may grow all the larger.

(28.) There are some trees, again, which thrive all the better for being maltreated, ${ }^{54}$ or else are stimulated by pungent substances; the palm and the mastich for instance, which derive nutriment from salt water. ${ }^{55}$ Ashes have the same virtues as

${ }^{51}$ Agriculturists, Fée says, are not agreed upon this question.

52 Or laser. See B. xix. c. $15 . \quad 53$ See B. xviii. c. 35.

54 Pœnâ emendantur.

55 It is very doubtful whether this is not likely to prove very injurious to them. This passage is from Theophrastus, De Causis, B. iii. c. 23. 
salt, only in a more modified degree; for which reason it is, that fig-trees are sprinkled with them; as also with rue, ${ }^{56}$ to keep away worms, and to prevent the roots from rotting. What is still more even, it is recommended to throw salt ${ }^{57}$ water on the roots of vines, if they are too full of humours; and if the fruit falls off, to sprinkle them with ashes and vinegar, or with sandarach if the grapes are rotting. ${ }^{58}$ If, again, a vine is not productive, it should be sprinkled and rubbed with strong vinegar and ashes; and if the grapes, instead of ripening, dry and shrivel up, the vine should be lopped near the roots, ${ }^{59}$ and the wound and fibres drenched with strong vinegar and stale urine; after which, the roots should be covered up with mud annealed with these liquids, and the ground spaded repeatedly.

As to the olive, if it gives promise of but little fruit, the roots should be bared, and left exposed to the winter cold, ${ }^{60}$ a mode of treatment for which it is all the better.

All these operations depend each year upon the state of the weather, and require to be sometimes retarded, and at other times precipitated. The very element of fire even has its own utility, in the case of the reed for instance; which, after the reed-bed has been burnt, will spring up all the thicker and more pliable. ${ }^{61}$

Cato, ${ }^{62}$ too, gives receipts for certain medicaments, specifying the proportions as well; for the roots of the large trees he prescribes an amphora, and for those of the smaller ones, an urna, of amurca of olives, mixed with water in equal proportions, recommending the roots to be cleared, and the mixture to be gradually poured upon them. In addition to this, in the case of the olive and the fig, he recommends that a layer of straw should be first placed around them. In the fig, too, more particularly, he says that in spring the roots should be well moulded up; the result of which is, that the fruit will not fall off while green, and the tree will be all the more productive, and not affected with roughness of the bark.

56 Without any efficacy, beyond a doubt.

57 The action of salt upon vegetation is, at the best, very uncertain.

58 These recipes are worthless, and almost impracticable.

59 This method is still adopted, but with none of the accessories here mentioned by Pliny.

${ }_{60}$ A dangerous practice, Fée remarks, and certainly not to be adopted.

61 Mitior. 
In the same way, too, ${ }^{63}$ to prevent the vine-fretter ${ }^{64}$ from attacking the tree, he recommends that two congii of amurca of olives should be boiled down to the consistency of honey, after which it must be boiled again with one-third part of bitumen, and one-fourth of sulphur: and this should be done, he says, in the open air, for fear of its igniting if prepared in-doors; with this mixture, the vine is to be anointed at the ends of the branches and at the axils; after which, no more fretters will be seen. Some persons are content to make a fumigation with this mixture while the wind is blowing towards the vine, for three days in succession.

Many persons, again, attribute no less utility and nutritious virtue to urine than Cato does to amurca; only they add to it an equal proportion of water, it being injurious if employed by itself. Some give the name of "volucre" 66 to an insect which eats away the young grapes : to prevent this, they rub the pruning-knife, every time it is sharpened, upon a beaverskin, and then prune the tree with it: it is recommended also, that after the pruning, the knife should be well rubbed with the blood of a bear. ${ }^{67}$ Ants, too, are a great pest to trees; they are kept away, however, by smearing the trunk with red earth and tar: if a fish, too, is hung up in the vicinity of the tree, these insects will collect in that one spot. Another method, again, is to pound lupines in oil ${ }^{68}$ and anoint the roots with the mixture. Many people kill both ants as well as moles ${ }^{69}$ with amurca, and preserve apples from caterpillars as well as from rotting, by touching the top of the tree with the gall of a green lizard.

Another method, too, of preventing caterpillars, is to make a woman, ${ }^{70}$ with her monthly courses on her, go round each tree, barefooted and ungirt. Again, for the purpose of pre-

${ }^{63}$ At the present day, fumigations are preferred to any such mixtures as those here described. Caterpillars are killed by the fumes of sulphur, bitumen, or damp straw.

61 "Convolvulus." He alludes to the vine Pyralis, one of the Lepidoptera, the caterpillar of which rolls itself up in the leaves of the tree, after eating a way the foot-stalk.

66 The "fly," or " winged" insect. The grey weevil, Fée thinks, that eats the buds and the young grapes.

67 An absurd superstition.

is This may possibly be efficacious, but the other precepts here given are full of absurdity.

${ }^{69}$ It might possibly drive them to a distance, but would do no more.

70 An absurd notion, very similar to some connected with the same subject, which have prevailed even in recent times. 
venting animals from doing mischief by browsing upon the leaves, they should be sprinkled with cow-dung each time after rain, the showers having the effect of washing away the virtues of this application.

The industry of man has really made some very wonderful discoveries, and, indeed, has gone so far as to lead many persons to believe, that hail-storms may be averted by means of a certain charm, the words of which I really could not venture seriously to transcribe ; although we find that Cato ${ }^{71}$ has given those which are employed as a charm for sprained limbs, employing splints of reed in conjunction with it. The same author, ${ }^{72}$ too, has allowed of consecrated trees and groves being cut down, after a sacrifice has first been offered: the form of prayer, and the rest of the proceedings, will be found fully set forth in the same work of his.

Summari.-Remarkable facts, narratives, and observations, eight hundred and eighty.

Roman autHors QUoTed.-Cornelius Nepos, ${ }^{73}$ Cato $^{74}$ the Censor, M. Varro ${ }^{75}$ Celsus, ${ }^{76}$ Virgil,${ }^{77}$ Hyginus ${ }^{78}$ Saserna ${ }^{79}$ father and son, Scrofa, ${ }^{80}$ Calpurnius Bassus, ${ }^{81}$ Trogus, ${ }^{82}$ Amilius Macer, ${ }^{83}$ Græcinus ${ }^{84}$ Columella, ${ }^{85}$ Atticus Julius, ${ }^{86}$ Fabianus ${ }^{87}$ Mamilius Sura, ${ }^{88}$ Dossenus Mundus, ${ }^{89}$ C. Epidius, ${ }^{90}$ L. Piso. ${ }^{91}$

7 De Re Rust. 160. The words of this charm over the split reed while held near the injured limb, were as follow:- "Sanitas fracto-motas danata daries dardaries astataries"-mere gibberish.

${ }_{72}$ De Re Rust. 139. This prayer was offered to the deity of the sacred grove, after a pig had been first offered-" If thou art a god, or if thou art a goddess, to whom this grove is sacred, may it be allowed me, through the expiation made by this pig, and for the purpose of restraining the overgrowth of this grove, \&c." It must be remembered that it was considered a most heinous offence to cut down or lop a consecrated grove. See Ovid, Met. B. viii. c. 743.

73 See end of B. ii.

75 See end of B. ii.

77 See end of B. vii.

79 See end of B. $x$.

81 See end of B. xvi.

${ }_{83}$ See end of B. ix.

${ }^{85}$ See end of B. viii.

${ }^{87}$ Fabianus Papirius; see end of B. ii.

88 See end of $B$. $x$.

74 See end of B. iii.

76 See end of $B$. vii.

78 See end of B. iii.

80 See end of B. xi.

82 See end of B. vii.

81 See end of B. xiv.

86 See end of $B$. xiv.

${ }^{83}$ See end of B. xiv.

90 A Roman rhetorician, preceptor of Antony and Augustus. He is said to have claimed descent from Epidius, a deity worshipped on the banks of the Sarnus.

${ }_{91}$ See end of B. ii. 
Foreign aUthors QUoted.-Hesiod, ${ }^{92}$ Theophrastus, ${ }^{93}$ Aristotle, ${ }^{94}$ Democritus, ${ }^{95}$ Theopompus, ${ }^{96}$ King Hiero, ${ }^{97}$ King Attalus ${ }^{98}$ ' Philometor, King Archelaus, ${ }^{99}$ Archytas, ${ }^{1}$ Xenophon, ${ }^{2}$ Amphilochus $^{3}$ of Athens, Anaxipolis ${ }^{4}$ of Thasos, Apollodorus ${ }^{5}$ of Lemnos, Aristophanes ${ }^{6}$ of Miletus, Antigonus ${ }^{7}$ of Cymæ, Agathocles $^{8}$ of Chios, Apollonius ${ }^{9}$ of Pergamus, Bacchius ${ }^{10}$ of Miletus, Bion ${ }^{11}$ of Soli, Chæreas ${ }^{12}$ of Athens, Chæristus ${ }^{13}$ of Athens, Diodorus ${ }^{14}$ of Priene, Dion ${ }^{15}$ of Colophon, Epigenes ${ }^{16}$ of Rhodes, Euagon ${ }^{17}$ of Thasos, Euphronius ${ }^{18}$ of Athens, Androtion ${ }^{19}$ who wrote on Agriculture, Eschrion ${ }^{20}$ who wrote on Agriculture, Lysimachus ${ }^{21}$ who wrote on Agriculture, Dionysius $^{22}$ who translated Mago, Diophanes ${ }^{23}$ who made an Epitome of Dionysius, Aristander ${ }^{24}$ who wrote on Portents.

92 See end of $B$. vii.

93 See end of B. iii.

${ }_{95}$ See end of B. ii. .

97 See end of B. viii.

99 See end of $\mathrm{B}$. viii.

94 See end of B. ii.

96 See end of B. ii.

98 See end of B. viii.

1 See end of $\mathbf{B}$. viii.

2 For Xenophon of Athens, see end of B. iv. For Xenophon of Lampsacus, see end of $\mathrm{B}$. iii.
3 See end of B. viii.
5 See end of B. viii.
7 See end of B. viii.
9 See end of B. viii.
11 See end of B. vi.
13 See end of B. xiv.
15 See end of $B$. viii.
17 See end of B. $x$.
19 See end of B. viii.
21 See end of B. viii.
${ }_{23}$ See end of B. viii.
4 See end of B. viii.
${ }^{6}$ See end of B. viii.
${ }^{B}$ See end of B. viii.
10 See end of $B$. viii.
12 See end of B. viii.
14 See end of B. viii.
16 See end of B. ii.
18 See end of B. viii.
20 See end of B. viii.
22 See end of B. xii.
${ }^{24}$ See end of B. viii.

END OF VOL. III. 







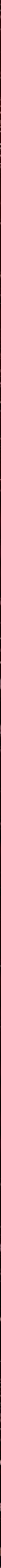




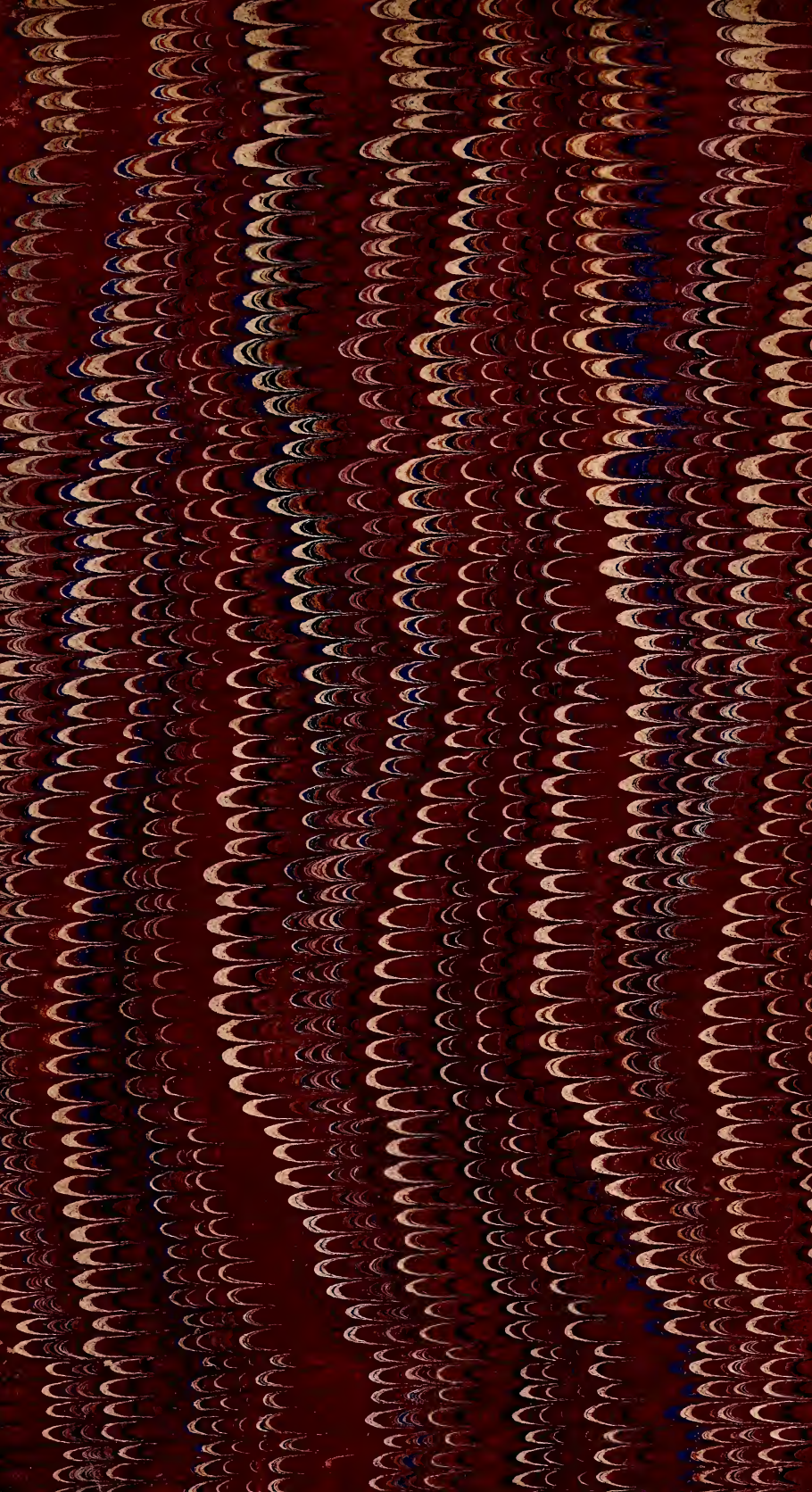




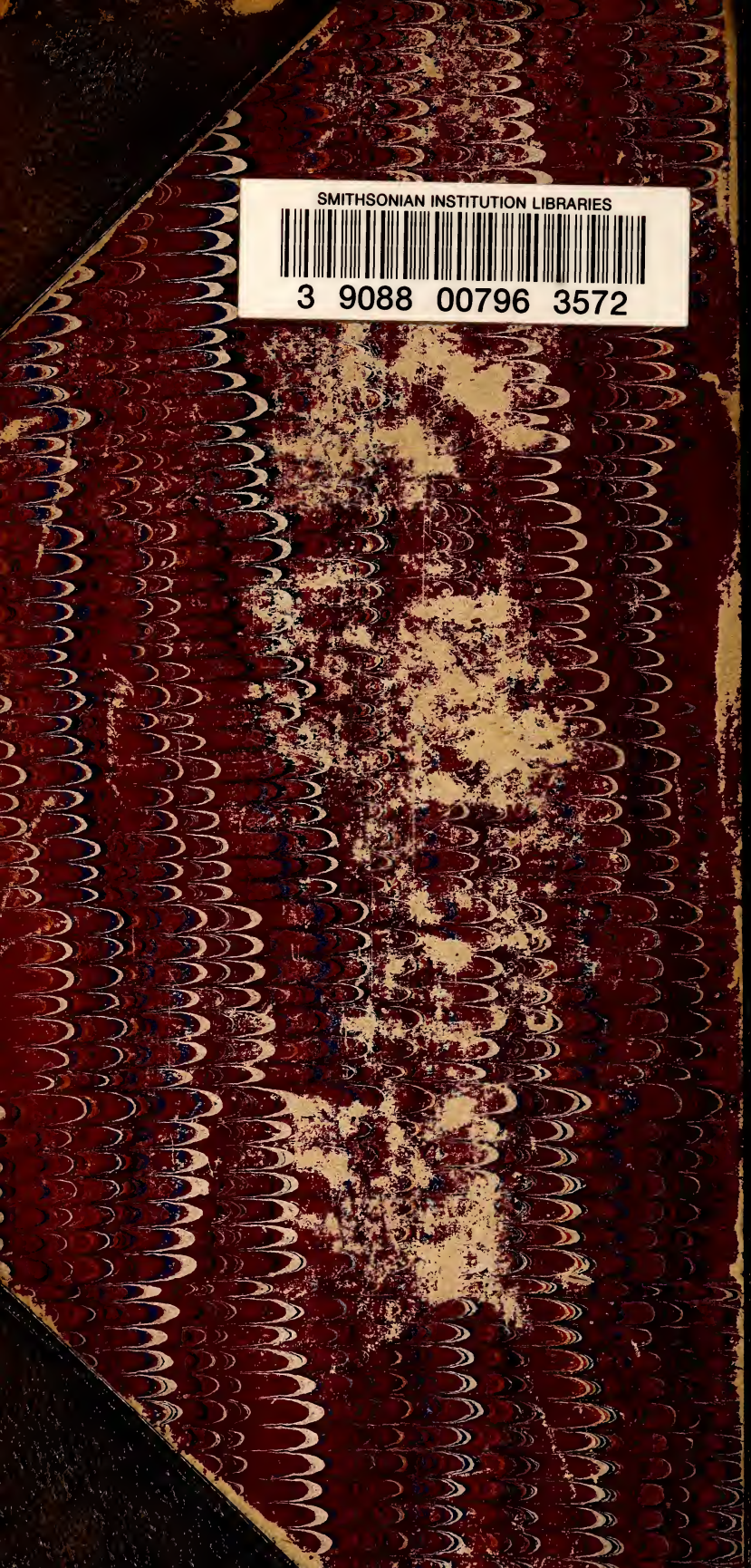

